\title{
WestVirginiaUniversity
}

THE RESEARCH REPOSITORY @ WVU

Graduate Theses, Dissertations, and Problem Reports

2009

\section{Design of reinforced concrete seals for underground coal mines}

\author{
Rajagopala Reddy Kallu \\ West Virginia University
}

Follow this and additional works at: https://researchrepository.wvu.edu/etd

\section{Recommended Citation}

Kallu, Rajagopala Reddy, "Design of reinforced concrete seals for underground coal mines" (2009).

Graduate Theses, Dissertations, and Problem Reports. 2900.

https://researchrepository.wvu.edu/etd/2900

This Dissertation is protected by copyright and/or related rights. It has been brought to you by the The Research Repository @ WVU with permission from the rights-holder(s). You are free to use this Dissertation in any way that is permitted by the copyright and related rights legislation that applies to your use. For other uses you must obtain permission from the rights-holder(s) directly, unless additional rights are indicated by a Creative Commons license in the record and/ or on the work itself. This Dissertation has been accepted for inclusion in WVU Graduate Theses, Dissertations, and Problem Reports collection by an authorized administrator of The Research Repository @ WVU.

For more information, please contact researchrepository@mail.wvu.edu. 


\title{
Design of Reinforced Concrete Seals for Underground Coal Mines
}

\author{
RAJAGOPALA REDDY KALLU
}

\author{
Dissertation Submitted to the \\ College of Engineering and Mineral Resources \\ at West Virginia University \\ in partial fulfillment of the requirements for the degree of
}

\section{Doctor of Philosophy \\ in \\ Mining Engineering}

\author{
Syd S. Peng, Ph.D., Chair \\ Keith A. Heasley, Ph.D. \\ R. Karl Zipf, Jr., Ph.D. \\ Christopher J. Bise, Ph.D. \\ Felicia F. Peng, Ph.D.
}

Department of Mining Engineering

\section{Morgantown, West Virginia \\ 2009}

Keywords: Roof-to-floor Convergence, Explosion Pressure, Concrete Constitutive Behavior, Concrete Damage, Numerical modeling. 


\section{ABSTRACT \\ Design of Reinforced Concrete Seals for Underground Coal Mines \\ RAJAGOPALA REDDY KALLU}

The conventional 'full-scale' explosion test for seal evaluation is expensive and time consuming. Therefore, alternative methodologies must be developed for the design of mine seals to meet the new MSHA design standards. This dissertation employed advanced explicit finite element code, ABAQUS, to develop reinforced concrete (RC) seal models for addressing various design parameters related to the RC seal design.

Firstly, using back analysis of structural data available from NIOSH full-scale explosion tests on RC seals, a suitable RC seal model was developed with a proper concrete constitutive material. Secondly, the optimum rebar parameters such as rebar diameter, and vertical and horizontal spacing for reinforcing the concrete seal were determined. Thirdly, parametric analysis using the model with the optimum rebar parameters was performed. The parameters analyzed included entry height, entry width, surrounding rock strength, seal-rock/coal interface strength. A total of about 280 computer models were run. And finally, a RC seal design chart was developed for typical entry dimensions by analyzing the results of the numerical models.

Entry height is the dominating factor in RC seal design, whereas entry width has little effect. The tensile failure of concrete material on the outby surface of the seal dominates the seal failure mechanism. The reinforced steel rebars resist the high tensile stresses that may develop near the surface of the seal and prevent further tensile failure in the concrete material. It was also observed that simple tensile cracks in the concrete material on the surface of the seal do not significantly influence the overall stability of the seal. Various factors, such as, weighted average damage factor (WADF), tensile failure in the concrete, maximum lateral displacements, and axial forces in the steel rebars have been used to quantitatively assess the adequacy of the seal design.

This work also showed that various factors such as concrete constitutive behavior, roof-tofloor convergence, surrounding rock constitutive behavior, and explosion loading nature significantly influence the seal design. A very small amount of convergence on the seal could actually double the capacity of the seal, and this positive influence of convergence is valid only within certain limits. A weak surrounding rock deforms significantly under the rebar loading and could not provide sufficient anchorage for the seal, causing the concrete to fail extensively. It was shown in this dissertation that explosion pressures with instantaneous rise time and maintained for longer durations at peak values significantly influence the seal stability. 


\section{ACKNOWLEDGEMENT}

I would like to thank all my committee members Dr. Syd S. Peng, Dr. Keith A. Heasley, Dr. R. Karl Zipf, Dr. Christopher J. Bise and Dr. Felicia F. Peng for spending their precious time in going through this dissertation, and for giving their valuable suggestions throughout my dissertation work.

I take this opportunity to express my sincere gratitude to my advisor Dr. Syd S. Peng for giving me a wonderful opportunity to work with him. He is been a constant source of inspiration, encouragement and support throughout my graduate study. During my association with Dr. Peng, I learned a great deal from his astounding qualities, vast pool of knowledge and hard work that made him a unique personality in the mining industry.

It was always been a great pleasure working with Dr. R. Karl Zipf, NIOSH. He is always been a continuous source of information and great help. Regular meetings and discussions with him always helped me to enhance my knowledge and technical thinking.

I am grateful to Dr. Khaled M. Morsy and Dr. Asmaa Yassien for their constant help, encouragement and valuable suggestions in completing this dissertation successfully.

I would also like to acknowledge the kind cooperation, encouragement and support that I received from my friends and fellow students during my stay at WVU. Special thanks are due to Murali Gadde for his constant encouragement, valuable suggestions and support ever since I know him.

I also like to thank Karen Centofanti and Karla Vaughan for providing outstanding administrative support throughout my association with the Mining Engineering Department at WVU.

Last but not the least, I am grateful to all my family members for their love, support, encouragement and sacrifice. Especially, I would like to thank my wife Ragini, who joined me about a year ago in my journey, for her love, support and patience all these days. 


\section{TABLE OF CONTENTS}

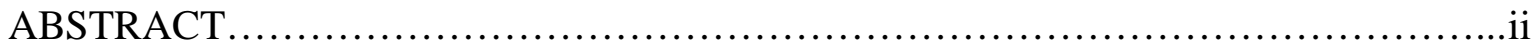

ACKNOWLEDGEMENT.............................................................. ii

ACRONYMS \& ABBREVIATIONS ........................................ vii

LIST OF FIGURES..................................................................... vii

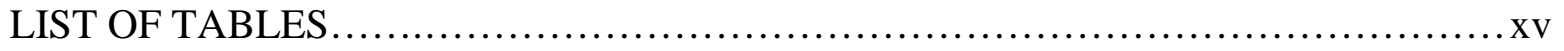

Chapter 1 INTRODUCTION..............................................................01

1.1 State-of-the-Art Review..............................................01

1.1.1 Recent Developments in Seal Design Regulations.............. 01

1.1.2 Seal Design Standards under Final Rule........................ 03

1.1.3 Mine Seal Applications........................................ 05

1.1.4 Seal Design Practices............................................. 09

A. Seal Design Technology................................... 10

B. Seals Constructed for 20 psi Design Standard............. 11

C. Seal Design and Approval process........................ 17

D. Seal Evaluation Techniques .............................. 17

E. Post PIB-P06-16 Seal Design..................................20

1.1.5 Principles of Dynamic Analysis............................... 22

A. Analytical Solution......................................... 23

B. Numerical Solution............................................ 26

1.2 Scope and Objectives.............................................. 28

Chapter 2 DESIGN METHODOLOGY .................................................... 30

2.1 Selection of Appropriate Numerical Code........................... 30

2.2 Factors Considered in RC Seal Design............................... 30

2.3 Verification Cases................................................. 31

2.4 Parametric Analysis............................................. 32

2.5 Development of Design Guidelines............................... 32

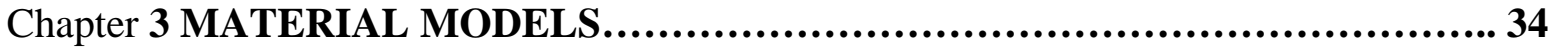

3.1 Surrounding Rock Strata................................................................. 34 
3.2 Concrete Constitutive Behavior.............................. 35

3.3 Steel Rebars................................................... 35

3.4 Seal-Rock/Coal Rib Interfaces................................. 36

3.5 General ABAQUS Model Description............................. 36

Chapter 4 CONCRETE CONSTITUTIVE BEHAVIOR.............................40

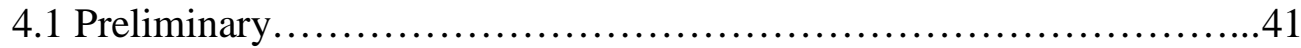

4.2 Concrete Model I: Empirical Model............................. 45

4.3 Concrete Model II CEB \& Barth and Wu Model..................... 49

4.4 Chapter Summary............................................... 54

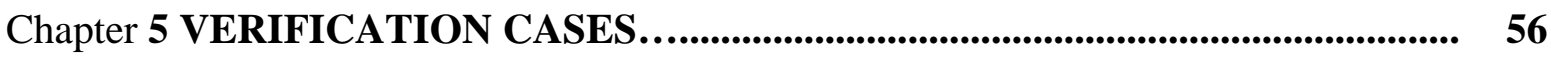

5.1 Case I: Insteel 3-D Seal.................................... 56

5.2 Case II: Insteel 3-D Seal....................................... 63

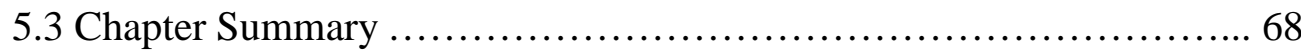

Chapter 6 DESIGN OF REINFORCED CONCRETE SEAL.........................69

6.1 Effect of Rebars Size and Spacing on Seal Response............... 69

6.1.1 Effect of vertical rebars spacing......................... 69

6.1.2 Effect of vertical rebars size........................... 73

6.1.3 Effect of horizontal rebar size and spacing................ 78

6.2 Effect of Seal/Rock Interface Strength........................... 79

6.3 Effect of Rock Strength on Seal Stability......................... 83

6.4 RC Seal Mechanical Response.................................. 87

6.5 RC Seal Design Guidelines........................................99

6.5 RC Seal Design Table......................................... 100

Chapter 7 ROOF-TO-FLOOR CONVERGENCE.....................................111

7.1 Capacity of RC Seal Vs Convergence........................... 113

7.2 Maximum Allowable Convergence............................. 122

Chapter 8 EXPLOSION LOADING NATURE..................................... 125

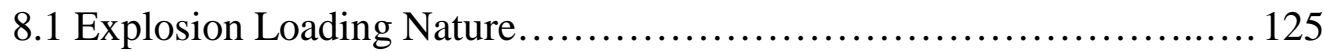


8.2 Multiple Explosions .......................................... 129

8.3 Explosion Loading Duration.................................. 138

Chapter 9 CONCLUSIONS AND FUTURE WORK...................................... 140

REFERENCES.............................................................. 143

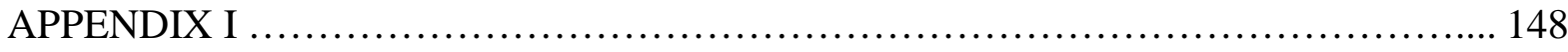

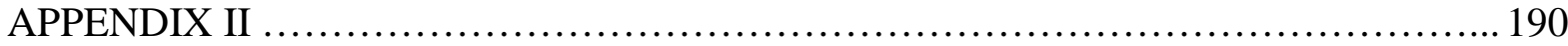

APPENDIX III ............................................................ 202

APPENDIX IV ............................................................. 208 


\section{ACRONYMS AND ABBREVIATIONS}

$\begin{array}{ll}\text { ACI } & \text { American Concrete Institute } \\ \text { BOM } & \text { Bureau of Mines } \\ \text { CEB } & \text { Comite European Du Beton } \\ \text { CFR } & \text { Code of Federal Regulation } \\ \text { ISD } & \text { Industrial Safety Division } \\ \text { LLEM } & \text { Lake Lynn Experimental Mine } \\ \text { LVDT } & \text { Linear Variable Displacement Transducer } \\ \text { MINER } & \text { Mine Improvement and New Emergency Response } \\ \text { MSHA } & \text { Mine Safety and Health Administration } \\ \text { NIOSH } & \text { National Institute for Occupational Safety and Health } \\ \text { PRL } & \text { Pittsburgh Research Laboratory } \\ \text { SRCM } & \text { Safety Research Coal Mine } \\ \text { USACE } & \text { United States Army Corps of Engineers } \\ \text { ERDC } & \text { USACE Engineer Research and Development Center }\end{array}$




\section{LIST OF FIGURES}

Figure 1.1 50 psi design pressure-time curves for monitored sealed areas that are maintained inert ................................................... 4

Figure 1.2120 psi design pressure-time curves for unmonitored sealed areas that are not maintained inert ............................................. 5

Figure 1.3 Typical layout of room-and-pillar mine: Typical locations for district and panel seals, (Zipf et al., 2007).................................. 7

Figure 1.4 Typical layout of longwall mining with immediate panel sealing: Typical locations for district, panel, and crosscut seals, (Zipf et al., 2007)......... 8

Figure 1.5 Meshblock seal under construction (Zipf at al., 2008).................. 12

Figure 1.6 Insteel 3D seal under construction showing the rear insteel panel with stayfoam backing (Zipf et al., 2008)................................ 12

Figure 1.7 Schematic diagram of pumpable cementitious seals with no steel reinforcement and no hitching (Zipf et al., 2008)....................... 13

Figure 1.8 HeiTech pumpable bag seal design and construction (Sapko et al, 2003).................................................... 14

Figure 1.9 Standard solid-concrete-block seal design (Greninger et al., 1991)......... 14

Figure 1.10 Packsetter bag seal under construction with pressurized bag in place...... 15

Figure 1.11 Conceptual drawing of the composite polymer seal design

(Weiss et al., 1996)................................................... 15

Figure 1.12 Wood crib seal design with packsetter bags (Sapko et al., 2003).......... 16

Figure 1.13 Omega block seal design and construction (Sapko et al., 2003).......... 16

Figure 1.14 Plan view of LLEM.............................................. 18

Figure 1.15 Mine seal test area in the LLEM..................................... 18

Figure 1.16 Test chamber for pressure loading of seals with water, compressed air and with methane-air mixture ignition (Sapko et al, 2005)............ 19

Figure 1.17 Typical single-degree-of-freedom system............................ 25

Figure $2.1 \quad$ Schematic showing the seal rotation angle............................... 33

Figure 3.1 Modified Drucker-Prager yield surface in the p-q plane.................... 34 
Figure 3.2 Bilinear stress-strain model for Grade 60 steel........................ 35

Figure 3.3 Coulomb friction model with critical shear stress limit................. 36

Figure 3.4 General layout of ABAQUS model................................... 37

Figure 3.5 Construction of reinforced concrete seal.............................. 38

Figure 3.6 Location of lateral displacement monitoring points on the outby face of the seal................................................... 38

Figure 3.7 Location of lateral pressure monitoring points on the both faces of the seal........................................................... 39

Figure 3.8 Location of axial force monitoring points on the outby and inby

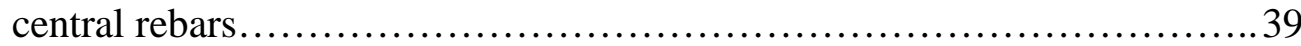

Figure 4.1 Concrete stress-strain relationship in compression and tension........... 42

Figure 4.2 Concrete damage index in compression and tension.................... 42

Figure 4.3 Damage contours for different concrete models (mid-vertical

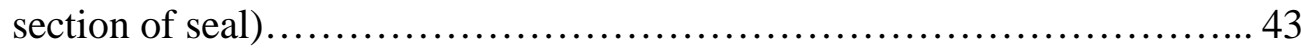

Figure 4.4 Lateral displacements in the seal for different concrete models............ 43

Figure 4.5 The history of axial forces in the central rebar on outby side at various locations.......................................................... 44

Figure 4.6 Plastic strain in the outby steel rebars for different concrete models....... 44

Figure 4.7 Model I: Stress-strain behavior of concrete in compression and tension.... 46

Figure 4.8 Model I: Tensile damage contours of 18 in. thick RC seal................47

Figure 4.9 Model I: Tensile damage contours of 24 in. thick RC seal................47

Figure 4.10 Model I: Tensile damage contours of 30 in. thick RC seal................47

Figure 4.11 Model I: Volume weighted average damage factor...................... 48

Figure 4.12 Model I: The history of axial forces in the center vertical rebar ........... 49

Figure 4.13 Model I: The history of lateral displacements for different seal thickness... 49

Figure 4.14 Model II: Stress-strain behavior of concrete in compression and tension... 51

Figure 4.15 Model II: Relationship between concrete damage and plastic strain......... 52 
Figure 4.16 Model II: Tensile damage contours of 30 in. thick RC seal............... 53

Figure 4.17 Model II: The history of axial forces in the center vertical rebar for $30 \mathrm{in}$. thick seal ......................................................... 53

Figure 4.18 Model II: Plastic strain in the steel rebars for 30 in. thick seal............. 54

Figure 4.19 Model II: The history of lateral displacements for 30 in. thick seal ........54

Figure 5.1 Schematic drawing of Insteel 3-D seal, Precision Main Repair (Zipf et al., 2008)................................................... 57

Figure 5.2 Detailed plan view of Insteel 3-D seal (Zipf et al., 2008)................ 58

Figure 5.3 Insteel 3-D seal under construction (Zipf et al., 2008)................... 58

Figure 5.4 Model of Insteel 3-D seal with stayform backing (Zipf et al., 2008)........ 59

Figure 5.5 Recorded history of explosion overpressure and seal displacement....... 60

Figure 5.6 Case I: Predicted and measured lateral displacement-time curves........... 61

Figure 5.7 Case I: Lateral displacement contour (in both seal and rebars)

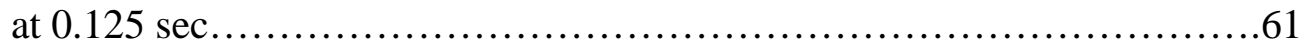

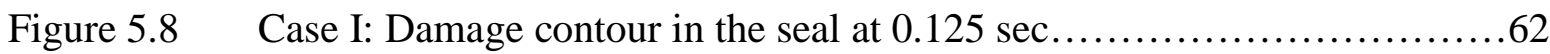

Figure 5.9 Case I: Plastic strain in the steel rebars at 0.125 sec..................... 62

Figure 5.10 Case II: Recorded history of explosion overpressure and seal ............6 63 displacement

Figure 5.11 Case II: Predicted and measured lateral displacement-time curves......... 64

Figure 5.12 Case II: Lateral displacement contour (in both seal and rebars)

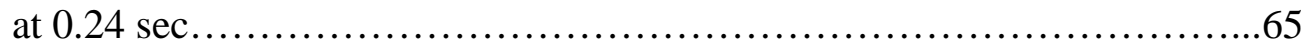

Figure 5.13 Case II: Damage contour in the seal at 0.24 sec....................... 65

Figure 5.14 Modified concrete stress-strain behavior in compression and tension...... 66

Figure 5.15 Modified concrete damage and plastic strain relationship............... 67

Figure 5.16 The history of predicted and measured lateral displacements (modifed concrete model).........................................66 67

Figure 5.17 Damage contour in the seal with modified concrete behavior............ 68

Figure 6.1 Tensile damage contour for seals with different vertical rebar spacing..... 70 
Figure 6.2 Weighted average damage factor vs vertical rebar spacing. 71

Figure 6.3 Axial forces in the rebars for seals with different vertical rebar spacing... 72

Figure 6.4 Maximum lateral displacements developed in the seal (Outby_M)........ 73

Figure 6.5 Tensile damage contour for seals with different vertical rebar sizes....... 74

Figure 6.6 Weighted average damage factor vs vertical rebar size..................75

Figure 6.7 Axial forces in the rebars for seals with different vertical rebar sizes....... 76

Figure 6.8 Maximum lateral displacements developed in the seal (Outby_M)......... 77

Figure 6.9 Weighted average damage factor for seals constructed with different

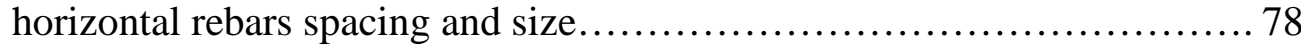

Figure 6.10 Maximum lateral displacements developed in the seals constructed with different horizontal rebars spacing and size....................... 79

Figure 6.11 Damage contours in seals with different interface strengths............... 81

Figure 6.12 Weighted average damage factor with different interface strengths....... 82

Figure 6.13 Max. lateral displacements (Outby_M) in seals with different interface strengths......................................................... 82

Figure 6.14 Max. axial forces developed in rebars (Inby_T/B) for seals with different interface strengths........................................ 83

Figure 6.15 Damage contours in seal with different surrounding rock strengths....... 85

Figure 6.16 WADF for seals with different surrounding rock strengths.............. 86

Figure 6.17 Max. lateral displacements (outby_M) and axial forces (Inby_T/B) for seals with different surrounding rock strengths.................... 86

Figure 6.18 Axial forces in the rebars for seals with different thickness............. 89

Figure 6.19 Schematic diagrams for axial forces (shown in thousand lbs) in the rebars....................................................... 90

Figure 6.20 The history of axial forces in the central vertical inby rebar (Inby_M)..... 91

Figure 6.21 The history of axial forces in the central vertical outby rebar (Outby_M).. 91

Figure 6.22 The history of lateral displacements for different seals at outby_M....... 92

Figure 6.23 Contour of lateral displacements in the seal (plot is magnified 40 times)... 93 
Figure 6.24 Maximum lateral displacement Vs seal thickness......................... 94

Figure 6.25 Damage contours in seals with different thickness...................... 95

Figure 6.26 Damage contours in 18 in. thick seal (Mid-vertical section)................ 96

Figure 6.27 Damage contours in seal with different thickness (Mid-half vertical

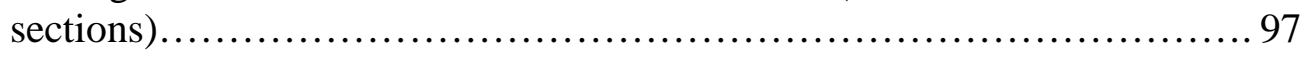

Figure 6.28 Weighted average damage factor (WADF) for different seal thicknesses... 98

Figure 6.29 Seal loading concept (not to scale)................................. 100

Figure 6.30 Reinforced concrete seal design chart................................ 102

Figure 6.31 Plot of WADF and maximum lateral displacements for $4 \mathrm{ft}$ high seal...... 103

Figure 6.32 Plot of WADF and maximum lateral displacements for $5 \mathrm{ft}$ high seal...... 104

Figure 6.33 Plot of WADF and maximum lateral displacements for $6 \mathrm{ft}$ high seal...... 105

Figure 6.34 Plot of WADF and maximum lateral displacements for $7 \mathrm{ft}$ high seal...... 106

Figure 6.35 Plot of WADF and maximum lateral displacements for $8 \mathrm{ft}$ high seal...... 107

Figure 6.36 Plot of WADF and maximum lateral displacements for $9 \mathrm{ft}$ high seal...... 108

Figure 6.37 Plot of WADF and maximum lateral displacements for $10 \mathrm{ft}$ high seal...... 109

Figure 6.38 Plot of WADF and maximum lateral displacements for $12 \mathrm{ft}$ high seal......110

Figure 7.1 Measured rate of convergence for different entry ages.................... 111

Figure 7.2 Location of convergence station near an experimental seal................. 112

Figure 7.3 Effect of roof-to-floor convergence: 120 psi explosion pressure........... 116

Figure 7.4 Effect of roof-to-floor convergence: 140 psi explosion pressure........... 117

Figure 7.5 Effect of roof-to-floor convergence: $160 \mathrm{psi}$ explosion pressure........... 118

Figure 7.6 Effect of roof-to-floor convergence: 180 psi explosion pressure........... 119

Figure 7.7 Effect of roof-to-floor convergence: 200 psi explosion pressure........... 120

Figure 7.8 Effect of roof-to-floor convergence.................................. 121

Figure 7.9 Contours of plastic strain in the seal (half section) and in rebars at 0.1 in. convergence................................................. 115 
Figure 7.10 The history of lateral displacements for $6 \mathrm{ft}$ high seal (Outby_M).......... 123

Figure 7.11 Maximum allowable convergence for various seal heights............... 124

Figure 8.1 120 psi pressure-time curves with different rise and down times.......... 125

Figure 8.2 The history of axial forces developed in the vertical rebar (Inby_B/T)..... 126

Figure 8.3 The history of Lateral displacements in the seal (Outby_M)................ 127

Figure 8.4 Max. lateral displacements and axial forces observed with different p-t curves.................................................... 127

Figure 8.5 Damage contours in seal subjected to different $\mathrm{p}$-t curves................ 128

Figure 8.6 Weighted average damage factor for seals subjected to different p-t curves......................................................... 129

Figure 8.7 Different pressure-time (p-t) curves for multiple explosions............. 130

Figure 8.8 Damage contours in seals subjected to p-t curves as shown in

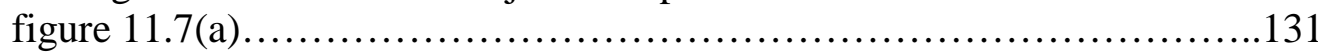

Figure 8.9 The history of lateral displacements (Outby_M) in seals subjected to multiple explosions with p-t curves as shown in figure $11.7(a) \ldots \ldots \ldots \ldots . . .132$

Figure 8.10 The history of axial forces (Inby_B/T) in vertical rebars in seals subjected to multiple explosions with p-t curves as shown in figure 11.7(a)

Figure 8.11 Damage contours in seals subjected to multiple explosions with p-t curves as shown in figure 11.7(b)

Figure 8.12 The history of lateral displacements (Outby_M) in seals subjected to multiple explosions with p-t curves as shown in figure 11.7(b).

Figure 8.13 The history of axial forces (Inby_B/T) in vertical rebars in seals subjected to multiple explosions with p-t curves as shown in figure $11.7(\mathrm{~b}) \ldots \ldots \ldots . .134$

Figure 8.14 Damage contours in seals subjected to multiple explosions with p-t curves as shown in figure 11.7(c).

Figure 8.15 The history of lateral displacements (Outby_M) in seals subjected to multiple explosions with p-t curves as shown in figure $11.7(\mathrm{c}) \ldots \ldots \ldots \ldots . . .136$

Figure 8.16 The history of axial forces (Inby_B/T) in vertical rebars in seals subjected to multiple explosions with p-t curves as shown in figure $11.7(\mathrm{c}) \ldots \ldots \ldots \ldots 136$ 
Figure 8.17 Maximum axial forces developed in steel rebars (Inby_T/B) in seals subjected to multiple explosions with p-t curves shown in figure $11.7 \ldots \ldots 137$

Figure 8.18 Maximum lateral displacements developed in seals (Outby_M) subjected to multiple explosions with p-t curves shown in figure $11.7 \ldots \ldots \ldots \ldots . . . . .137$

Figure 8.19 Weighted average factor for seals subjected to multiple explosions

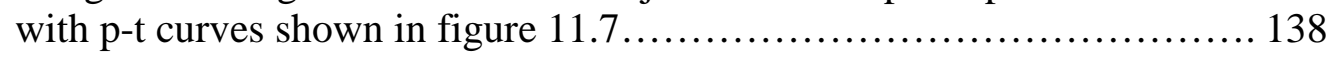

Figure 8.20 Change of WADF over the duration of explosion loading (instantaneous rise time) ........................................ 139

Figure 8.21 Change of WADF over the duration of explosion loading

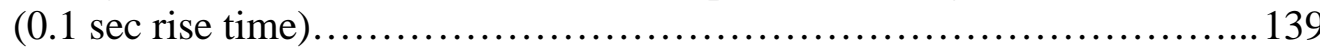




\section{LIST OF TABLES}

Table 3.1 Geo-mechanical properties of rock, coal and steel........................ 34

Table 4.1 Geo-mechanical properties of concrete models........................... 41

Table 5.1 Seal construction details: Case I....................................... 59

Table 6.1 Seal model combinations for size and spacing of steel rebars.................69

Table 6.2 Rock strength properties.......................................... 84

Table 6.3 Minimum required RC Seal thickness in inches for typical entry dimensions... 101

Table 7.1 Convergence table (6'x20'x24'” seal)................................ 114 


\section{Chapter 1 INTRODUCTION}

eals are constructed in underground coal mines to isolate the abandoned mining areas
from active mining areas. The primary purpose of these seals is to prevent an explosion which may occur in the atmosphere on one side of the seal from propagating to the other side of the seal. It should also be able to prevent potentially explosive or toxic gases from leaking, or migrating to the active mining areas, or the ventilating air from leaking into the sealed areas. The Federal Coal Mine Health and Safety Act of 1969 (Coal Act), the predecessor to the existing MINER Act, first recognized that mine operators must seal abandoned and isolated areas of underground coal mines with "explosion proof bulkheads" that are to be constructed with "solid, substantial and incombustible materials" for the protection of miners' safety.

\subsection{STATE-OF-THE-ART REVIEW}

\subsubsection{Recent Developments in Seal Design Regulations}

The recent explosions that occurred in the U.S. coal mining industry, and resulted in many fatalities, have changed the seal construction requirement in underground coal mines in the U.S. The Sago mine accident which occurred on January $2^{\text {nd }} 2006$ in Upshur County, West Virginia caused twelve fatalities. Later in the same year on May $20^{\text {th }}$ another explosion happened at Darby No. 1 mine which resulted in five fatalities. The subsequent detailed accident investigations into these incidents by the Mine Safety and Health Administration (MSHA) revealed that, in both cases, the failure of the seals to withstand the explosion pressures generated in the sealed off area due to a methane air explosion was the main cause of the catastrophes. MSHA also reported that the explosion pressures generated in these accidents were much higher than the designed capacity of the mine seals. The failed seals in both mines were constructed with the same approved alternative (other than the standard solid concrete block seals) seal material for a 20 psi seal, but none of these seals were constructed in the same manner as they were constructed for testing at the Lake Lynn experimental mine (30 CFR Part 75). 
Immediately following these underground coal mine disasters, in June 2006, MSHA issued a moratorium on the use of alternative methods and materials for new seal construction and restricted new seal construction to the standard Mitchell-Barrett solid concrete block design, Program Information Bulletin (PIB) No. P06-11 to 14. MSHA also recognized the fact that, from accident investigations and previous experience, the magnitude of the explosion pressures that can develop in sealed areas due to methane or coal dust explosions is much higher than the 20 psi design standard. Subsequently, on July $19^{\text {th }}$, 2006, MSHA issued another Program Information bulletin (PIB), No. P06-16, in which it increased the design standard for mine seals to 50 psi from the previous 20 psi standard. These new guidelines also required new alternative seal designs to be designed and certified by a professional engineer who has knowledge in structural engineering. MSHA also addressed a number of other issues related to the construction and effectiveness of the existing alternative and solid concrete block seals. Further, MSHA closely reviewed the history of seals in the U.S. and abroad and concluded that currently most coal producing countries have coal mine seal requirements that are in excess of 20 psi.

To ensure the safety of miners working underground, the U.S. Congress passed the Mine Improvement and New Emergency Response Act (the MINER Act) in 2006. Section 10 under this act requires MSHA to increase the seal design standard by the end of 2007. In response to the MINER Act, National Institute for Occupational Safety and Health (NIOSH) engineers recommended a three-tiered explosion design criteria for new seals in coal mines in a draft report, "Explosion Pressure Design Criteria for New Seals in U.S. Coal Mines", published on February $8^{\text {th }}$, 2007 (Zipf et al., 2007). The report provides a sound scientific and engineering justification for the proposed new design standards. The report also states that "successful implementation of the seal design criteria and recommendations in this report should reduce the risk of seal failure due to explosions in abandoned areas of underground coal mines”.

In their work, NIOSH engineers examined seal design criteria and practices used in the U.S., Europe and Australia. They also considered various kinds of explosive atmospheres that can accumulate within the sealed areas and used simple gas explosion models, AutoReaGas and FLACS, to estimate worse case explosion pressures that could develop in the sealed areas. 
AutoReaGas, available from Century-Dynamics (2007) in the U.K. and FLACS, available from GexCon (2007) of the Christian Michelson Research Institute in Norway, are specialized computational fluid dynamics (CFD) models used extensively in the oil, gas and chemical industries to assess risks, consequences and mitigation measures for various gas explosion scenarios (Zipf et al., 2007).

Based on the investigations of the recent mine explosions, the recommendations from the NIOSH draft report, MSHA's in-mine seal evaluations, and other reports, MSHA issued an Emergency Temporary Standard (ETS) on sealing of abandoned areas on May 22 ${ }^{\text {nd }}, 2007$, under 101(b) of Federal Mine Safety and Health Act of 1977 to comply with the requirements of the MINER Act. Similar to the NIOSH report recommendations, the ETS established a three-tiered approach for explosion overpressure loading criteria applicable to new seals: (i) 50 psi overpressure (ii) 120 psi overpressure and, (iii) an overpressure greater than 120 psi.

On April $18^{\text {th }}$, 2008, MSHA published the Final Rule on sealing of abandoned areas which is similar to the ETS but with revision. In developing this final rule, MSHA considered the investigation reports of the Sago and Darby mine explosions, implementation and enforcement experience under the ETS, MSHA's in-mine seal evaluations and review of technical literature, the 2007 NIOSH draft and final Reports on 'Explosion Pressure Design Criteria for Seals', the U.S. Army Corps of Engineer's (USACE) draft report, accident reports, research studies, public comments, hearing transcripts and supporting documentation from all segments of the mining community. The final rule includes requirements for seal strength, design, construction, maintenance and repair of seals, and monitoring and control of atmospheres behind seals in order to reduce the risk of seal failure and the risk of explosions in abandoned areas of underground coal mines (30 CFR Part 75).

\subsubsection{Seal Design Standards under the Final Rule (30 CFR Part 75.335(a))}

The final rule requires that the seals constructed in underground coal mines after October $20^{\text {th }}$ 2008 be designed, constructed and maintained in accordance with the provisions of the final rule. The final rule, like the ETS, follows a three-tiered approach with the additional requirements that the seal designs must resist explosions of specific duration and intensity. 
The explosion pressure duration and intensity is characterized in the given pressure-time curves.

The final rule requires that seals withstand at least 50 psi overpressure when the atmosphere in the sealed area is monitored and maintained inert and should be designed using a pressuretime curve with an instantaneous rise time and that the minimum pressure must be maintained for at least four seconds and then released instantaneously (Figure 1.1 (a)). Monitored seals, constructed to separate the active longwall panel from the previously mined longwall panel must be designed using a pressure-time curve with overpressure rising to at least 50 psi in 0.1 second and that the minimum pressure be maintained (Figure 1.1 (b)).

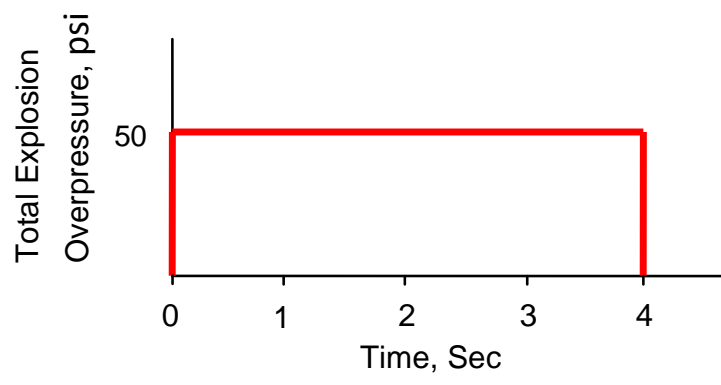

(a) For general sealed areas

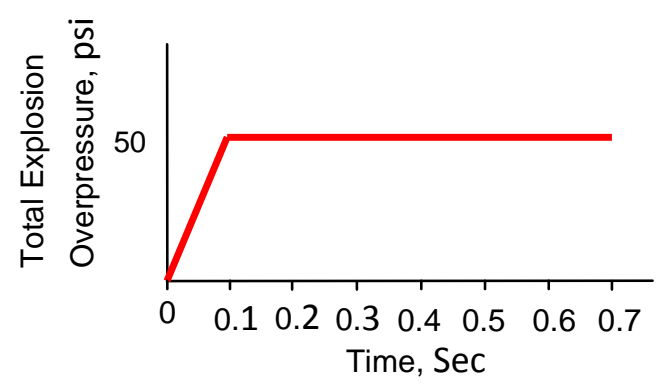

(b) For longwall gob isolator seals

Figure 1.150 psi design pressure-time curves for monitored sealed areas that are maintained inert

Seals should withstand overpressures of at least 120 psi if the atmosphere in the sealed area is not monitored and is not maintained inert and should be designed using a pressure-time curve with an instantaneous rise time and that the minimum pressure must be maintained for at least four seconds and then released instantaneously (Figure 1.2 (a)). Unmonitored seals constructed to separate the active longwall panel from the previously mined longwall panel must be designed using a pressure-time curve with overpressure rising to at least 120 psi in 0.25 second and that the minimum pressure be maintained (Figure 1.2 (b)).

Seals should withstand more than 120 psi overpressure if the atmosphere in the sealed area is not monitored and is not maintained inert, and either (i) the atmosphere in the sealed area is likely to contain homogeneous mixtures of methane between 4.5 percent and 17.0 percent and oxygen exceeding 17.0 percent throughout the entire area; or (ii) pressure piling could 
result in overpressures greater than 120 psi in the sealed area; or (iii) other conditions such as the likelihood of a detonation in the sealed area are encountered.

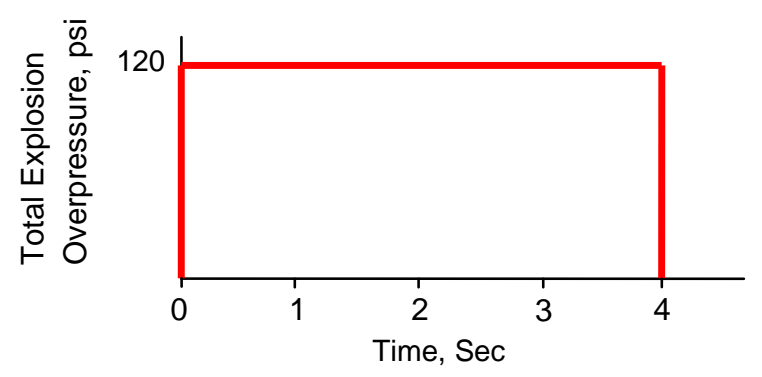

(a) For general sealed areas

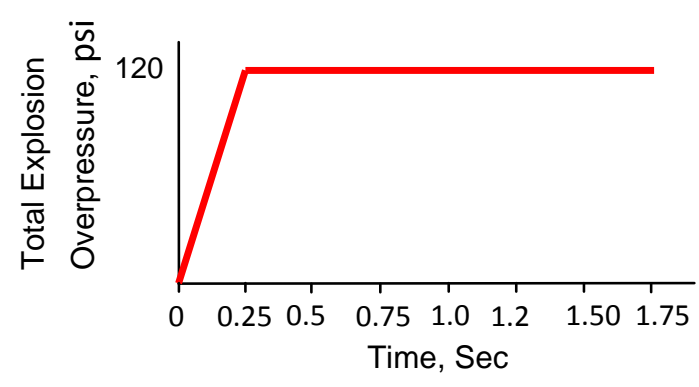

(b) For longwall gob isolator seals

Figure 1.2120 psi design pressure-time curves for unmonitored sealed areas that are not maintained inert

MSHA also considered NIOSH's 640 psi seal design standard, but due to the absence of empirical and other related data supporting the existence of conditions in underground coal mines that necessitates use of seals that can withstand more than 120 psi explosion pressure, MSHA could not specifically recommend a 640 psi strength requirements for seals. According to the final rule, mine operators must evaluate the atmosphere of the area to be sealed and determine when higher pressure seals should be used and at what strength.

\subsubsection{Mine Seal Applications (Zipf, et al., 2007)}

When an area of an underground coal mine is mined out, mine operators usually choose to isolate the abandoned area by constructing seals. Seals, when constructed appropriately, can withstand potential explosion pressures generated from ignition of methane or coal dust, and can also prevent leakage of potential explosive or toxic gases into the active mine workings. They also help control the methane in the mined-out areas, and thus reduce the risk of a methane explosion. Continued ventilation of the abandoned areas in most cases proves costly and diverts the fresh ventilating air from reaching the productive areas. Large mined-out areas, if not sealed, are required to be properly ventilated, inspected, and maintained. According to MSHA there are over 13,000 seals installed in the active coal mines in the U.S. 
Mine seals have various applications depending on the situations in which they are constructed. Based on the location of the seals with reference to mining layout, they are divided into three different categories: panel seals, district seals and cross-cut seals. In each application, seal design engineers should consider all the factors that influence the performance of the seals such as explosion loading potential, roof-to-floor convergence, and air leakage potential. Explosion loading potential depends mainly on the volume and geometry of the sealed-out area. Large sealed volumes with longer propagation distances can lead to higher gas and dust explosion pressures. The roof-to-floor convergence potential depends mainly on the proximity of the seals to the mined-out areas and time. Seals constructed close to the fully extracted longwall or room and pillar panels would experience more damage from the excessive convergence. The air leakage potential depends mainly on the ventilation system pressure differential as well as on the damage to the seal and surrounding rock caused by the convergence loading.

Panel seals are usually the primary application of seals in room-and-pillar mining or in longwall mining. These seals are constructed to isolate the fully extracted individual room and pillar panels or longwall panels. In room-and-pillar mining, panel seals are constructed in every entry leading to or exiting the panel (Figure 1.3). In the case of longwall panels, panel seals are usually constructed on both ends of the tailgate side (Figure 1.4). Panel seals usually experience high explosion pressures because of the long open entries left behind the seals which may lead to large accumulations of methane gas. Panel seals experience moderate levels of convergence and leakage.

District seals are the most common application of seals in room-and-pillar or longwall mining. These seals are constructed to isolate a group of fully extracted panels from the ventilation system (Figures 1.3 and 1.4). These seals can be subjected to very large explosion pressures due to the large volume of open entries left behind the seals and the long run up distances. These seals experience low roof-to-floor convergence and moderate leakage owing to high ventilation pressure differential.

Finally, cross-cut seals are usually constructed in the crosscuts of longwall gateroads for immediate sealing of the panel (Figure 1.4). In the present regulations, cross-cut seals are called 'gob isolation' seals. Coal seams highly prone to spontaneous heating require the 
immediate construction of cross-cut seals, soon after the longwall face passes the cross-cut, for limiting the oxygen supply to the mined-out area. The open area behind these seals is small, making the potential volume of explosive mix and the explosion loading potential also small. The cross-cut seals are subjected to high convergence because of their close proximity to the mined-out area and experience high leakage potential due to the damage from high convergence.

While designing mine seals for application in various situations, every design engineer should identify all potential influential parameters and select the seal materials and design methods accordingly.

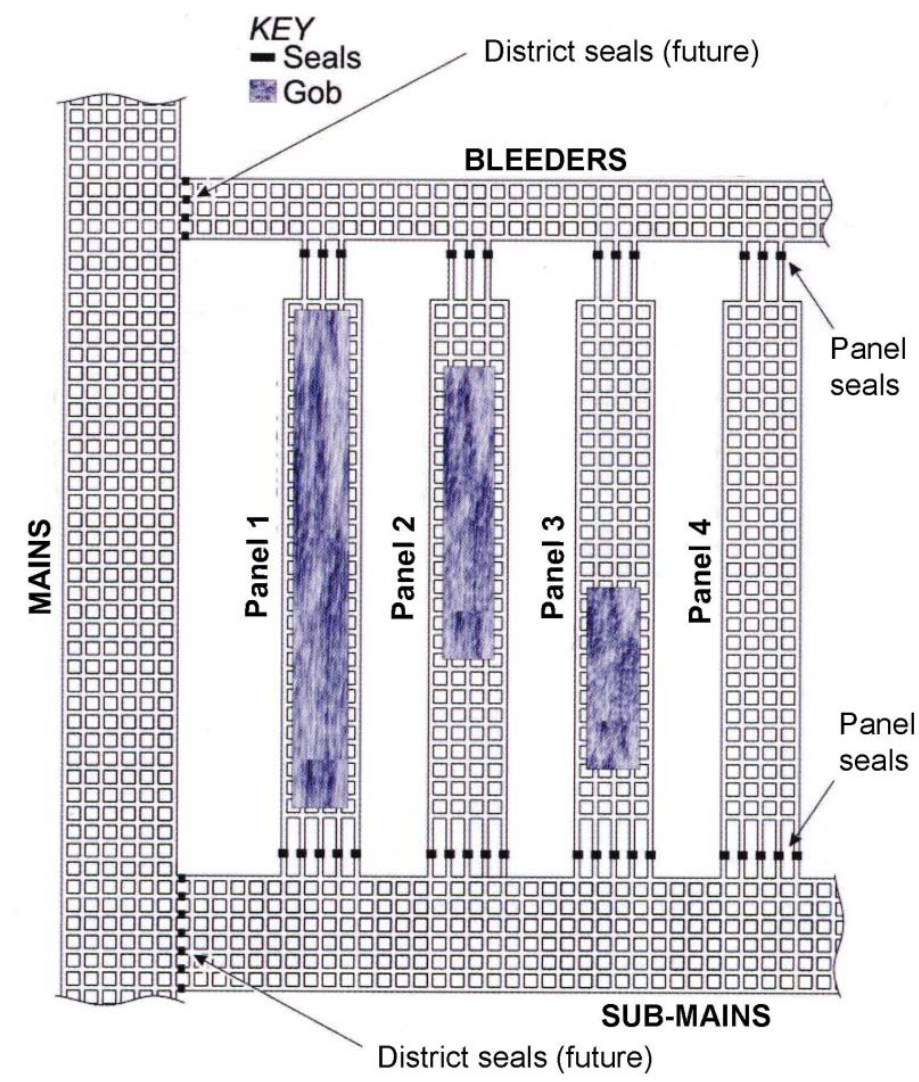

Figure 1.3 Typical layout of room-and-pillar mine: Typical locations for district and panel seals, (Zipf et al., 2007) 


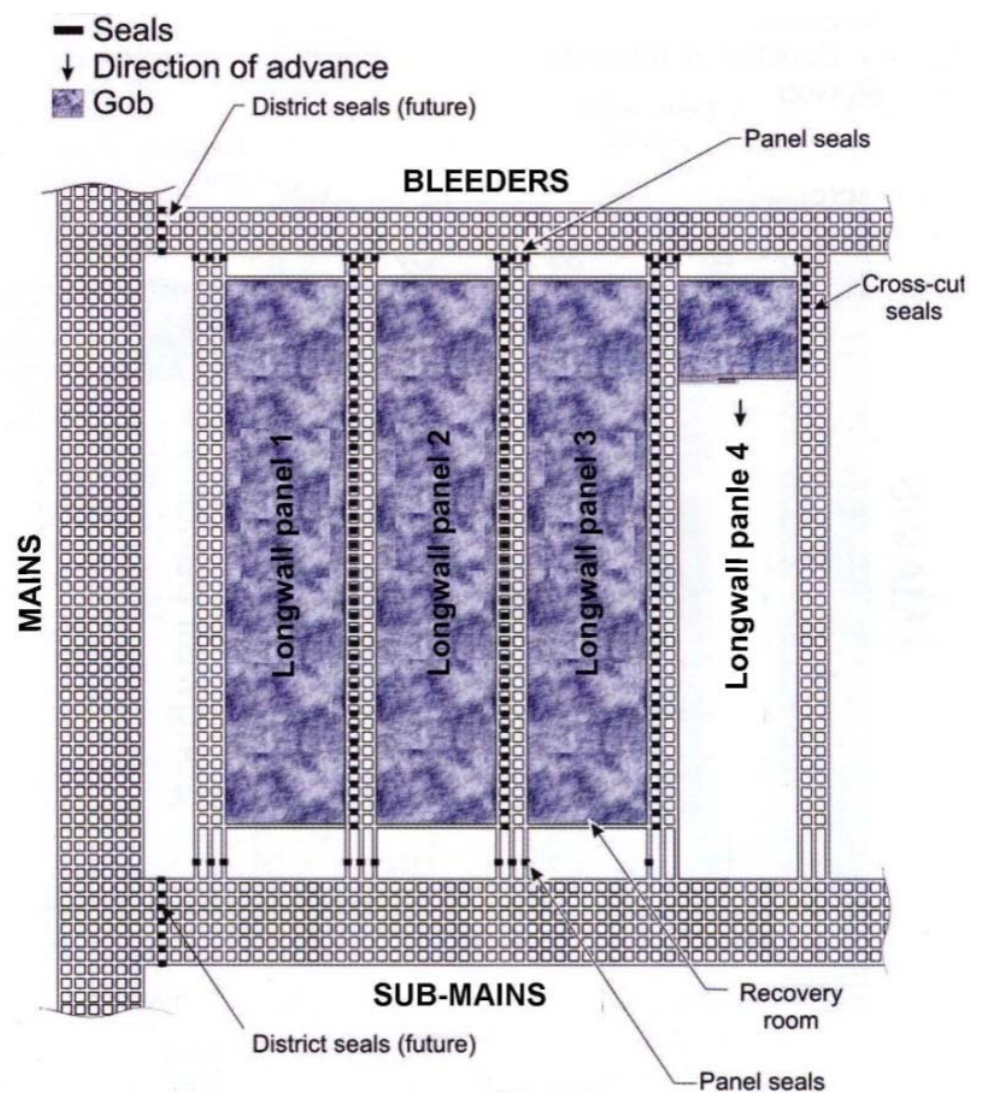

Figure 1.4 Typical layout of longwall mining with immediate panel sealing: Typical locations for district, panel, and crosscut seals, (Zipf et al., 2007) 


\subsubsection{Seal Design Practices}

rior to the issue of Program Information Bulletin P06-16 in July 2006, Federal coal
mine safety regulations ( 30 CFR 75.335) required mine operators to construct seals underground that can withstand explosion overpressures of at least 20 psi. The 20 psi seal design standard first came into effect from a 1992 rule change to CFR 30 Part 75.335(a) (2). The seals were required to be constructed of solid, substantial and incombustible material so that an explosion occurring on one side will be prevented from propagating to the other side.

The 1921 regulation for sealing connections between coal mines on U.S. Government-owned land requires that stoppings withstand a pressure of 50 psi. This regulation was based on the general assumption of men experienced in mine-explosion investigations (Rice et al., 1931). In the U.K. commissions investigating disasters that occurred in 1933 and 1960 reported that “... it is desirable in designing explosion proof bulkheads to assure that the pressures of 20 to 50 psi may develop ... and that the figure of 50 psig gives a good margin of safety in practice”. In Poland and Germany, authorities decided that bulkheads should withstand at least 72 psi explosion pressure (Zipf et al., 2007).

In 1971, Mitchell reported in his work titled "Explosion-proof bulkheads - Present practices" that researchers conducted studies for the first time in 1914 in the Bureau's experimental coal mine on how to protect sealed areas from explosions originating in the active mining areas. In these studies, rock-dust barriers on both faces of a weak stopping effectively limited the propagation of flame into the sealed area even though the stoppings were destroyed (Rice et al., 1922). Further studies, reported in 1930, resulted in the design of concrete bulkheads for sealing abandoned areas. These concrete bulkheads were constructed from cement, sand and aggregate (1:2:4 mix), water, and six reinforcement bars per cubic foot of bulkhead. Researchers, in 1968, in the U.K. and Germany developed gypsum bulkheads which withstood 215 psi explosion pressure and failed at 260 psi pressure in explosion trials (Genthe, 1968). The word 'seal' was referred as bulkhead in those days.

Mitchell (1971) reported that “in the Bureau's experimental mine, propagating explosions have developed from 1 to 120 psi pressure, and in a few trials pressure piling caused higher, unrecordable pressures and considerable damage”. He also noted that explosion pressures 
seldom exceeded 20 psi $60 \mathrm{~m}$ ( $200 \mathrm{ft}$ ) from the origin of the explosion. Mitchell concluded that a seal may be considered "explosion proof" when its construction is adequate to withstand a static load of $20 \mathrm{psi}$, provided that the area to be sealed contains sufficient incombustible material to abate the explosion hazard in that area and that adequate incombustible material is maintained in the adjoining open passageways. This 20 psi explosion pressure later became the design standard in the Federal Coal Mine Health and Safety Act of 1969.

Mitchell also indicated from his research that a seal designed to withstand a given static load will have a considerable margin for safety should it be subjected to a greater dynamic load. An explosion pressure pulse of high pressure and short duration would be less destructive than one in which pressure is lower and continuously rising.

Prior to 1992, the Code of Federal Regulations (CFR) lacked a definitive engineering design specification for explosion-proof bulkheads or seals. In response to the requirement in the CFR, Stephan (1990) provided technical justification based on investigations of underground coal mine explosions between 1977 and 1990. His conclusion, that the explosion pressures on mine seals generally do not exceed 20 psi, later became the design standard in the CFR in 1992.

\section{A. Seal Design Technology}

Prior to 1990, seals were extensively constructed in underground coal mines with solid concrete blocks and mortar. These seals have been shown to withstand explosion pressures exceeding 40 psi and meet the requirements of seals construction laid out in 30 CFR Part 75.329-2 (Stephan, 1990). However, other types of seal materials such as: cementitious foam, wood, innovative light weight blocks, or rock are also available for use in underground coal mines, but their use was very much limited.

MSHA's Industrial safety division (ISD) worked with the former Bureau of Mines (BOM) to determine suitable characteristics for the design and performance of underground coal mine seals. The former Bureau of Mines has performed full-scale explosion testing of a number of seals at its Lake Lynn Experimental Mine (LLEM). Prior to 1990, the Bureau of Mines conducted many full-scale explosion tests on solid-concrete block seals of various 
construction and design. Most concrete block seals tested were proven to be inadequate to serve the intended purpose except for the standard 16 inch thick concrete block seal with mortared joints and with a center pilaster hitched to the ribs and floor (Stephen, 1990) (At that point in time, full-scale tests on other types of seal construction materials were under way or planned for the future).

Beginning in 1992, seals constructed from alternative materials were permitted in underground coal mines provided they could withstand an explosion overpressure of at least 20 psi. These alternative seals are constructed from a variety of materials such as: cementitious foam, Omega blocks, wood, HeiTech pumpable bags, etc.

\section{B. Seals Constructed for 20 psi Design Standard}

A variety of seals were approved and constructed in underground coal mines in the U.S. Zipf et al. (2008) organized the seal structures into six categories, based on the materials used for construction, in an effort to document all available structural data relevant to full-scale explosion tests conducted by NIOSH at Lake Lynn experimental mine during the period 1997 through 2008.

1. Concrete like materials with steel reinforcement

2. Pumpable cementitious materials

3. Solid concrete block seals

4. Polymer and aggregate materials

5. Wood crib block seals

6. Light weight blocks

Concrete like materials with steel reinforcement: These seals are usually constructed with concrete or concrete-like material such as shotcrete or gunite with internal steel reinforcement. A skeleton of steel bars laid out vertically and horizontally and tied to the rebars grouted into the roof, floor and/or ribs. Reinforcement wire mesh is also used to strengthen the seal. Concrete or concrete like materials are pumped to fill the steel structure. There are essentially two varieties of concrete seals available, the 3D seal marketed by 
Precision Mine Repair and the Meshblock seal marketed by R.G. Johnson Company (Figures 1.5 and 1.6)
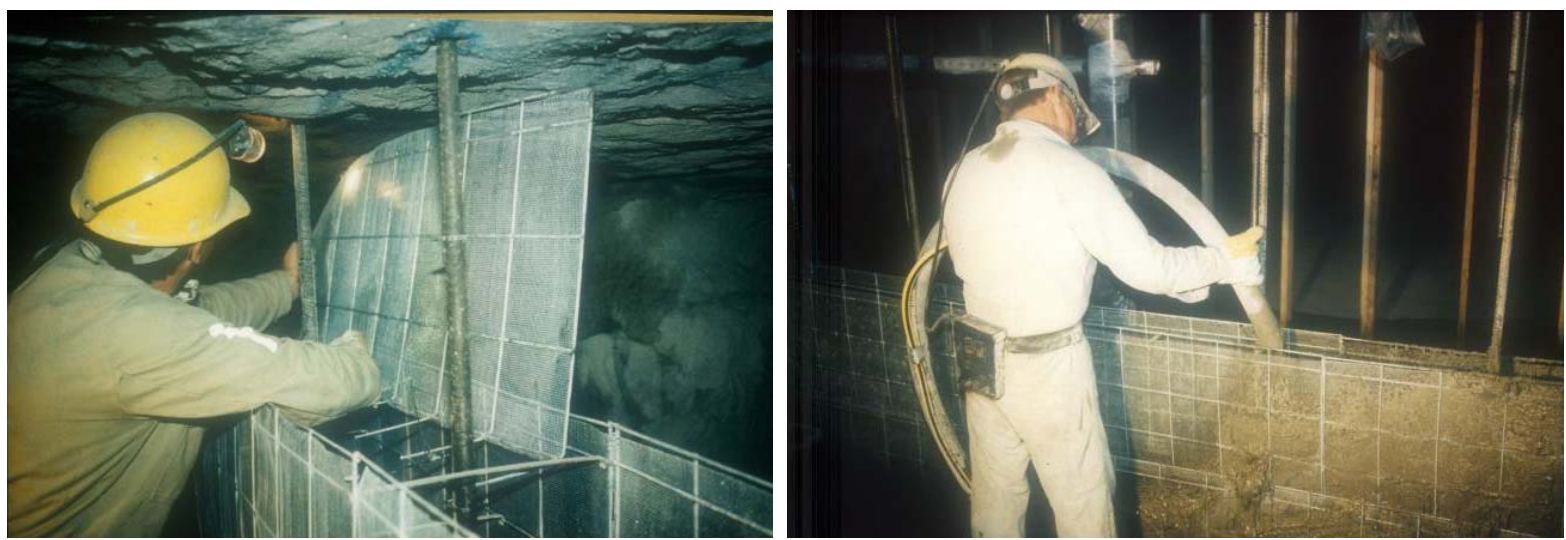

Figure 1.5 Meshblock seal under construction (Zipf at al., 2008)

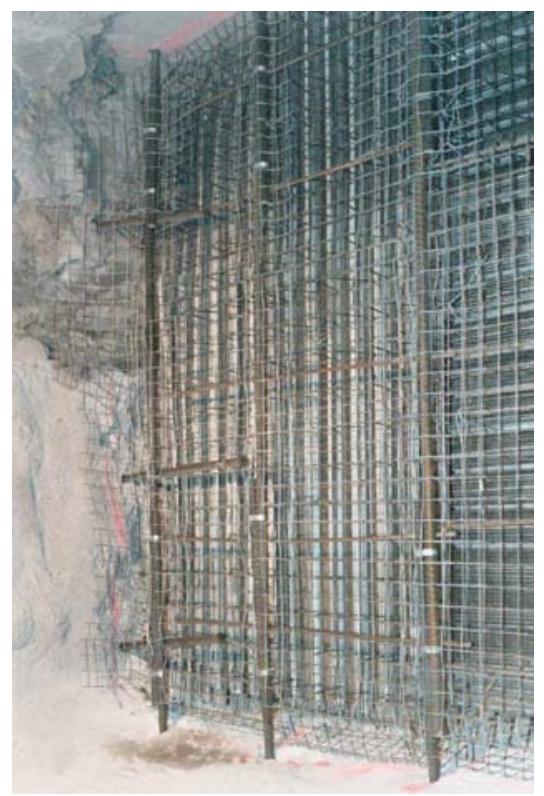

Figure 1.6 Insteel 3D seal under construction showing the rear insteel panel with stayfoam backing (Zipf et al., 2008)

Pumpable cementitious materials: These seals are constructed using cementitious materials without any steel reinforcement and without the need for hitching into the floor or ribs. Friction between the seal and the surrounding rock plays a major role in holding the seal in place. These seals can take a significant amount of roof-to-floor convergence without losing much of their strength. These seals include the Tekseal manufactured by Minova, Inc. and 
the Celuseal manufactured by R.G. Johnson Company. Tekseal and Celuseal are both lightweight and non combustible cement-based products and can produce different compressive strengths with different formulations. Construction of these seals is very simple, and only requires continuous mixing of cementitious powder, water and air and then pumping between the form walls. NIOSH reports by Greninger et al. (1991), Weiss et al. (1993, 1996, and 2008) and Sapko et al. (2005) provide more details on the construction of these seals. Refer to Figure 1.7 for illustration of the design.

Other variation of cementitious material seal are Ribfill seal, Rockfast seal and HeiTech column Bag Pumpable seal made by HeiTech Corporation. Refer to NIOSH reports by Weiss et al. (2002) and Sapko et al. (2003) for more details. Refer to Figure 1.8 for illustration.
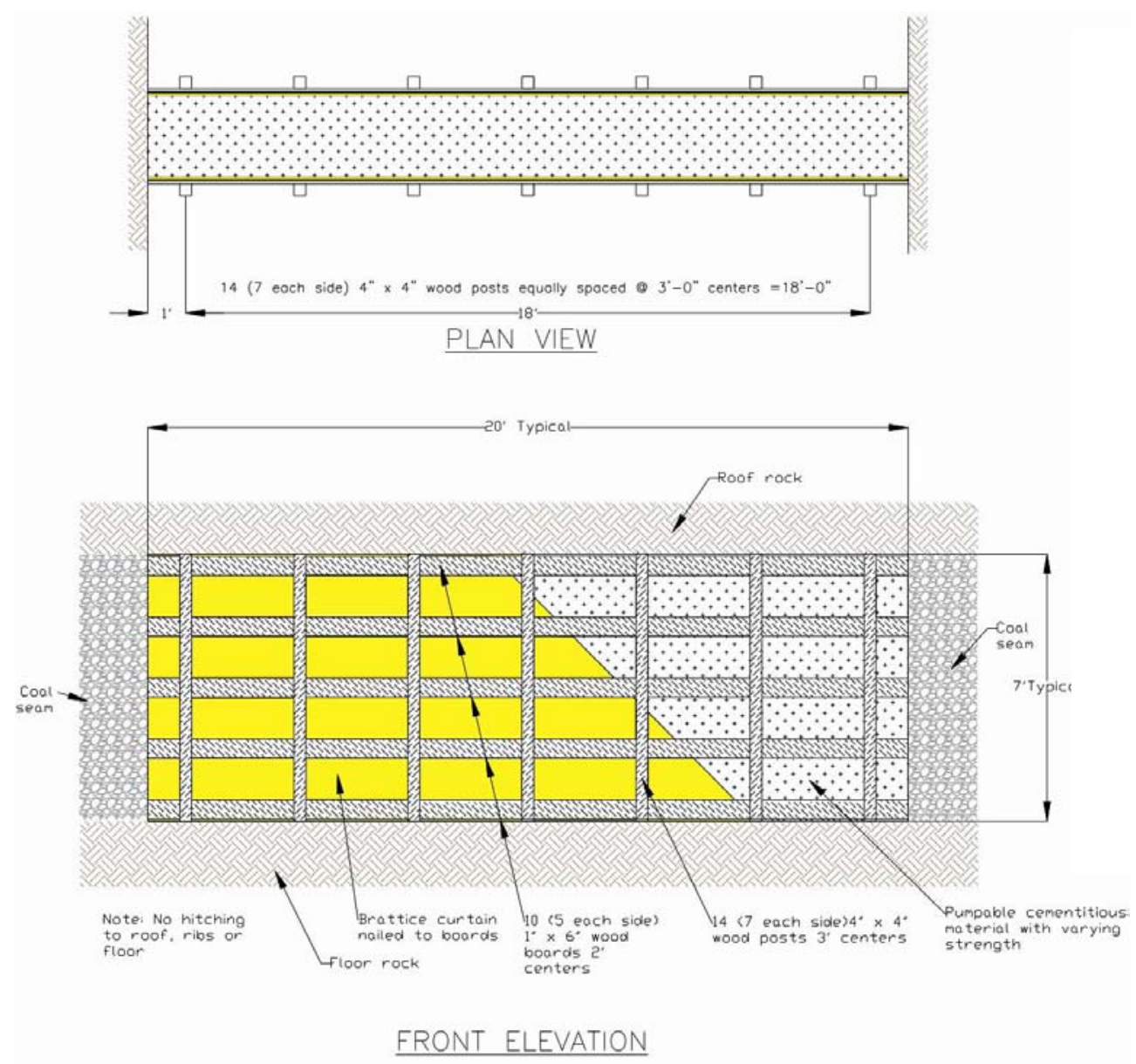

Figure 1.7 Schematic diagram of pumpable cementitious seals with no steel reinforcement and no hitching (Zipf et al., 2008) 

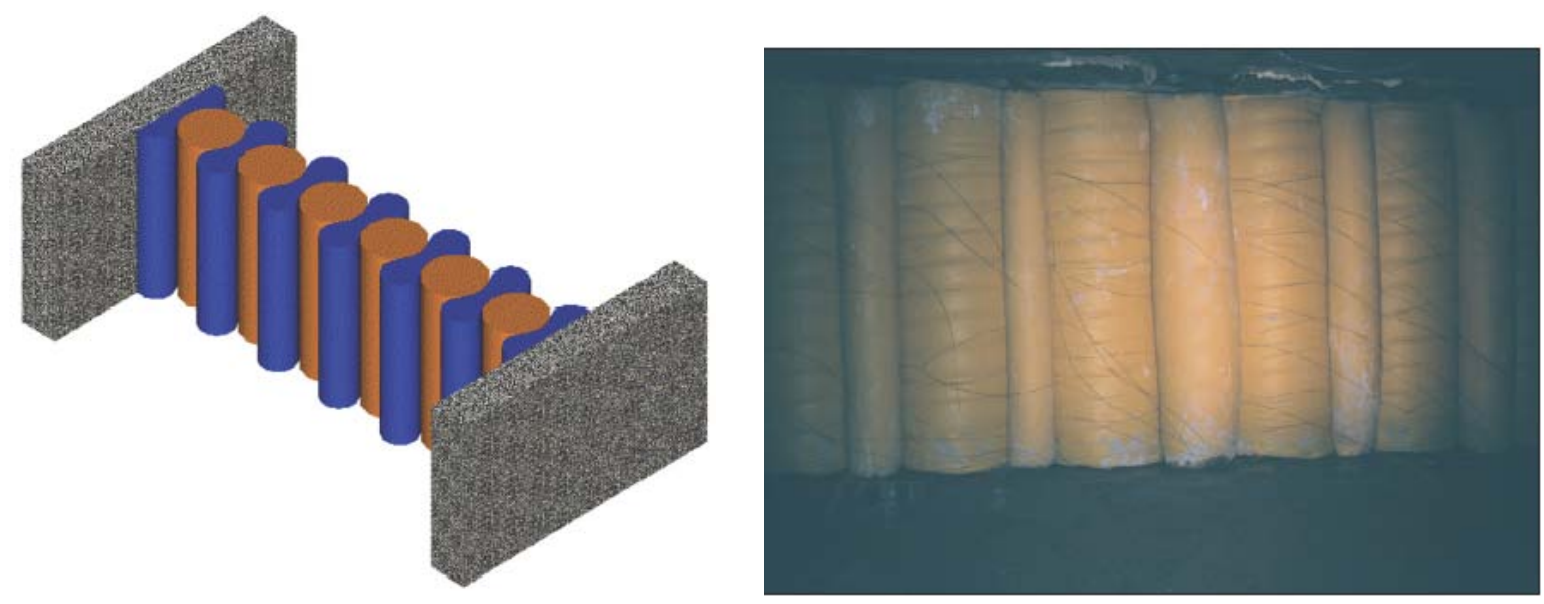

Figure 1.8 HeiTech pumpable bag seal design and construction (Sapko et al., 2003)

Solid concrete block seals: These seals are articulated structures made from concrete blocks bonded together with mortar, or dry stacked, with or without hitching into the floor or ribs, with or without a center pilaster. Most important of these seals are the standard concrete block seals or the Mitchell-Barrett seals and the Packsetter bag seals. Standard concrete block seals are constructed from concrete blocks measuring 6 in. by 8 in. by 16 in. stacked with mortar between the joints, with a center pilaster and hitched into the floor and ribs to a depth of approximately 6 in. (Figure 1.9). Packsetter bag seals are similar to the standard concrete blocks seals except that pressurized packsetter bags supplied by Strata Products (USA) are used in place of conventional hitching into the floor and ribs (Figure 1.10). NIOSH reports by Greninger et al. (1989, 1991), Weiss et al. $(1993,1996)$, and Sapko et al. (2005) provide additional details on the construction of the standard solid-concrete block seals.

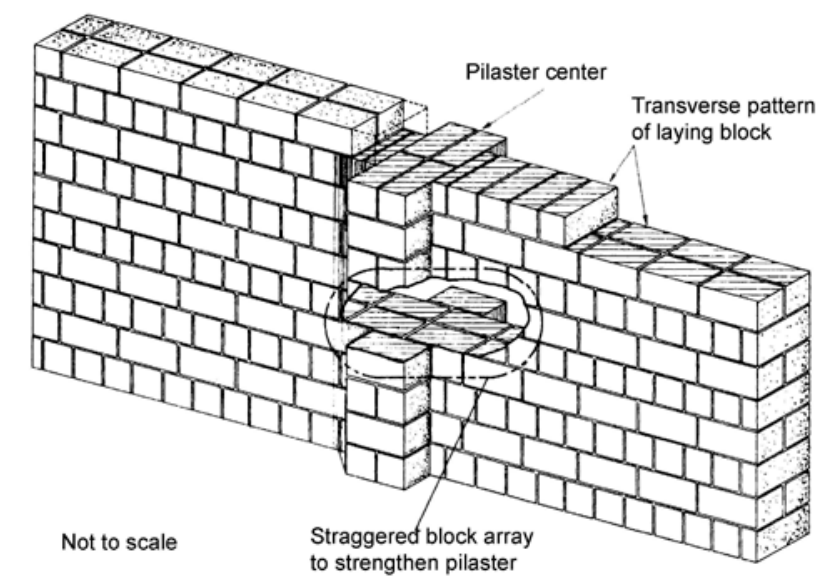

Figure 1.9 Standard solid-concrete-block seal design (Greninger et al., 1991) 


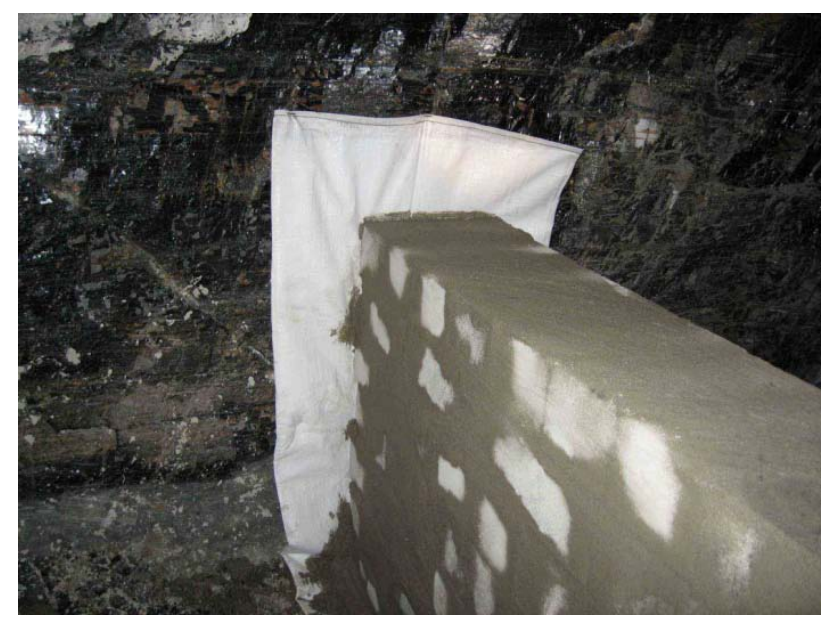

Figure 1.10 Packsetter bag seal under construction with pressurized bag in place

Polymer and aggregate materials: These seals are constructed using a mixture of twocomponent polyurethane foam and crushed limestone aggregate. This mixture is used to fill the space between two stoppings constructed from hollow concrete blocks separated by about 18 inches. The MICON 550 is the only seal of this type available, manufactured by MICON. The NIOSH report by Weiss et al. (1996) provides more details on the construction of these seals (Figure 1.11).

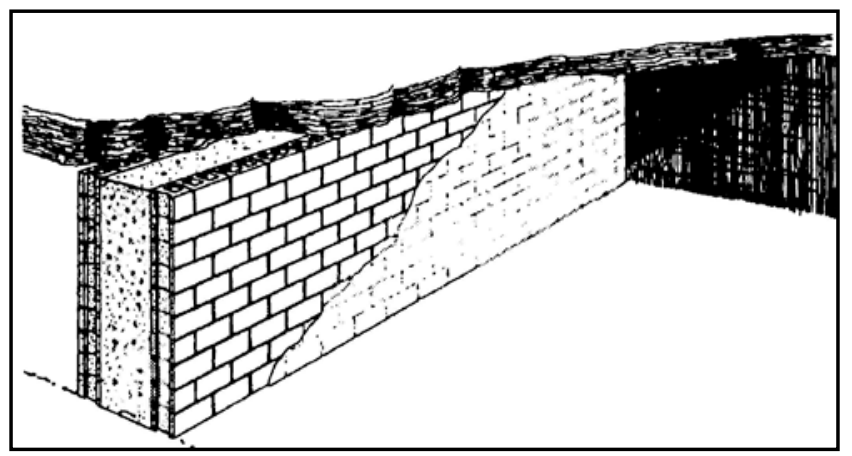

Figure 1.11 Conceptual drawing of the composite polymer seal design (Weiss et al., 1996)

Wood crib block seals: Wood crib type seals are generally used in deeper coal mines that experience excessive high roof and/or floor convergence, which results in premature, and at times catastrophic failure of more conventional type seal designs (Sapko et al., 2003). These seals are usually constructed from wood crib blocks of at least 36 in. long and measuring either 5 in. by 5 in. or 6 in. by 6 in. in cross-section, stacked horizontally with their length parallel to the ribs, with about 6 in. of hitching into the floor and ribs or the pressurized 
packsetter bags are used in lieu of hitching (Figure 1.12). These wood cribs are nailed together if hitching into the floor and ribs is made, or glued if pressurized packsetter bags are used instead of hitching. Wood cribs require very little installation time compared to conventional concrete block seals.
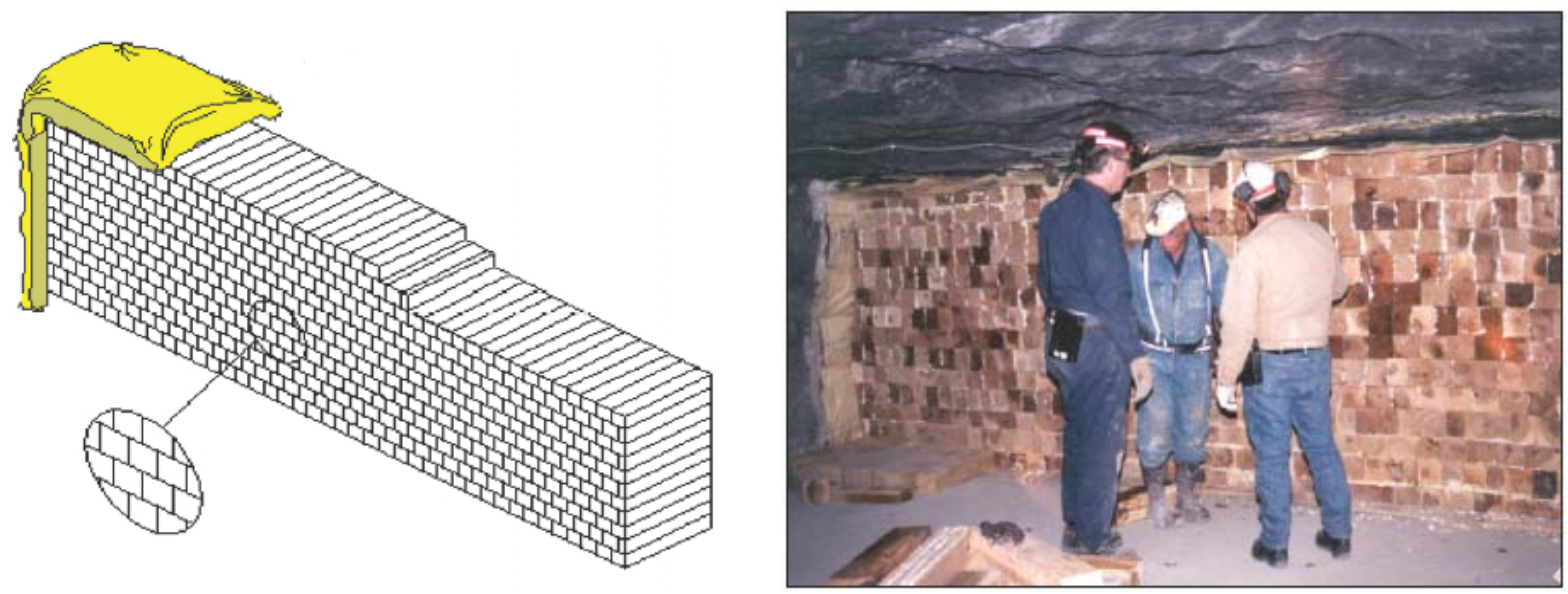

Figure 1.12 Wood crib seal design with packsetter bags (Sapko et al., 2003)

Light weight blocks: These seals are constructed from light weight blocks called Omega blocks manufactured by Burrell Mining Products International. Omega blocks are noncombustible, glass-fiber reinforced blocks measuring $8 \mathrm{in}$. by 16 in. by 24 in. having a compressive strength ranging from 70 to 110 psi. A layer of BlocBond mortar manufactured by Quikrete Company is applied along the horizontal and vertical joints. Omega block seals are constructed with and without hitching (Figure 1.13).
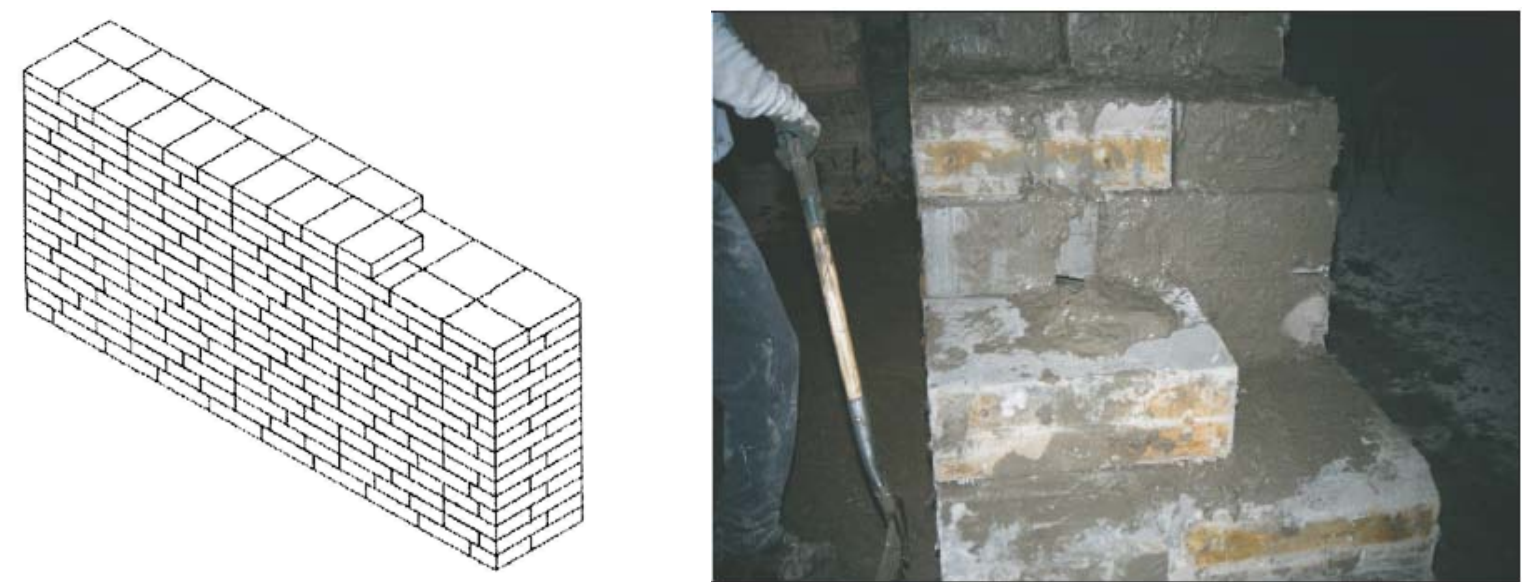

Figure 1.13 Omega block seal design and construction (Sapko et al., 2003) 


\section{Seal Design and Approval Process}

Prior to the issuance of PIB P06-16 mine seals were built to withstand explosion overpressure of 20 psi. A mine seal was considered adequate and approved for use in underground coal mines if it could sustain an explosion overpressure of at least 20 psi in a full-scale explosion test conducted at NIOSH Lake Lynn experimental mine. This "buildand-test” (Gadde et al., 2006) approach did not necessitate the development of engineering methodologies or design procedures.

\section{Seal Evaluation Techniques}

Prior to July 2007, the only method accepted by MSHA for evaluating seal design and performance was a full-scale explosion tests conducted within the multiple entries of Pittsburgh Research Laboratory's (PRL) Lake Lynn Experimental Mine (LLEM), for deeming a seal design suitable for use in U.S. coal mines (Triebsch and Sapko, 1990). Starting in 1990, MSHA's Industrial Safety Division worked with the former BOM to determine suitable characteristics for the design and performance of underground coal mine seals by conducting a large number of full-scale methane gas explosions in the entries of LLEM (Stephen, 1990).

Figures 1.14 and 1.15 show the layout of LLEM used for evaluating the design and performance of mine seals for compliance with 30 CFR. The LLEM is an abandoned limestone mine with entry size of about $7 \mathrm{ft}$ high and about $20 \mathrm{ft}$ wide. A wide range of seal designs constructed from a variety of materials mentioned in the previous section were tested at this facility. Most of the seals were constructed between B and C drifts. About a nine to ten percent methane-air mixture was ignited in a chamber at the closed end of the $\mathrm{C}$ drift to generate the explosion pressure. Each drift was installed with environmentally controlled data-gathering stations (Figure 1.14). Each data-gathering station houses a strain gauge pressure transducer for measuring the static pressure generated by the explosion and an optical sensor to detect flame arrival. Every tested seal was monitored with a Linear Variable Displacement Transducers (LVDT) for measuring the seal displacement at the center on the outby side. Many seal designs have withstood the required 20 psi explosion pressure, with little visual damage, but failed to comply with the subsequent post-explosion leakage criteria 
(Sapko et al., 2005). NIOSH research reports by Greninger et al. $(1989,1991)$ and Weiss et al. (1993, 1996, and 1999) discuss the details of LLEM explosion tests and results.

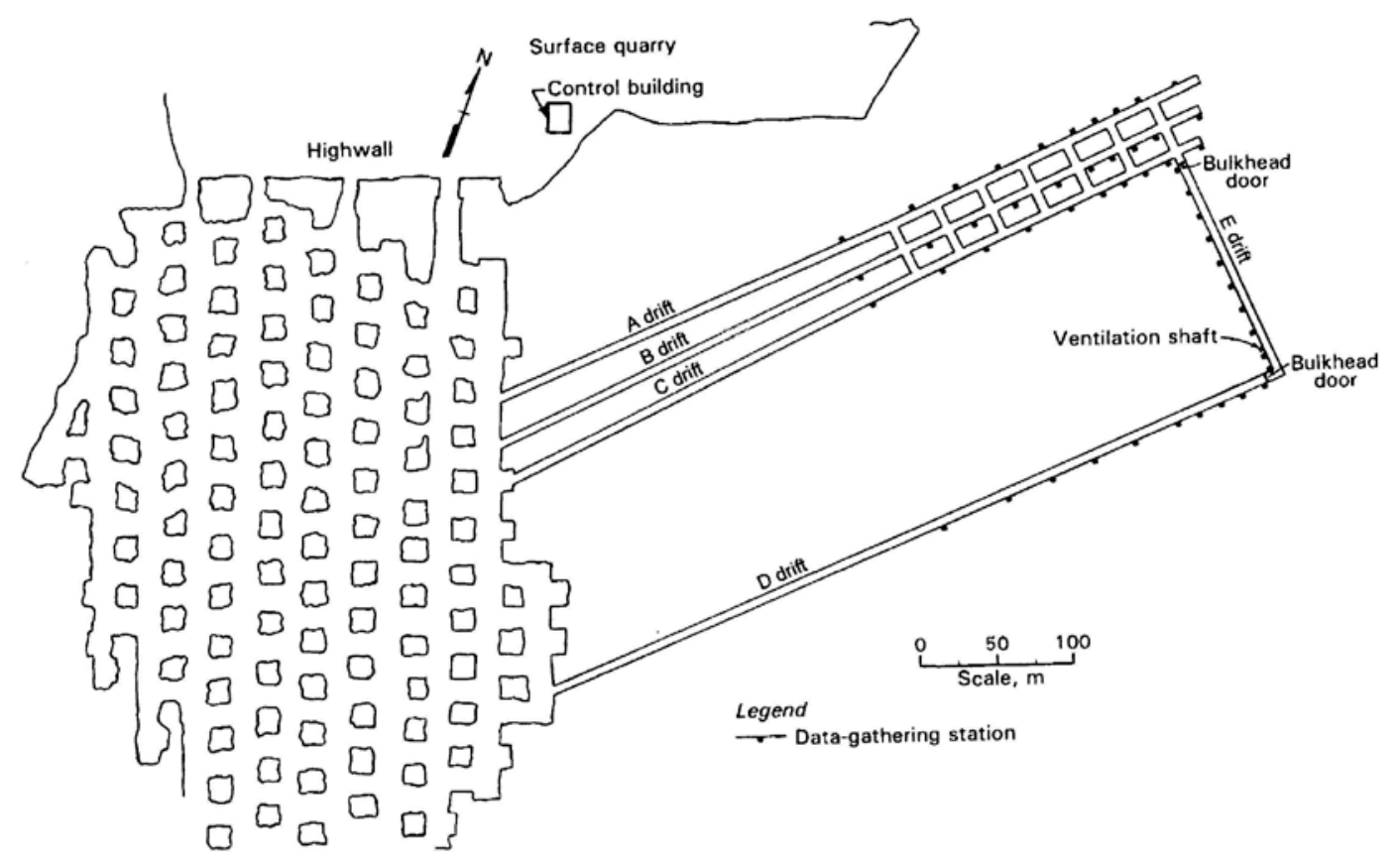

Figure 1.14 Plan view of LLEM (Weiss et al., 1999)

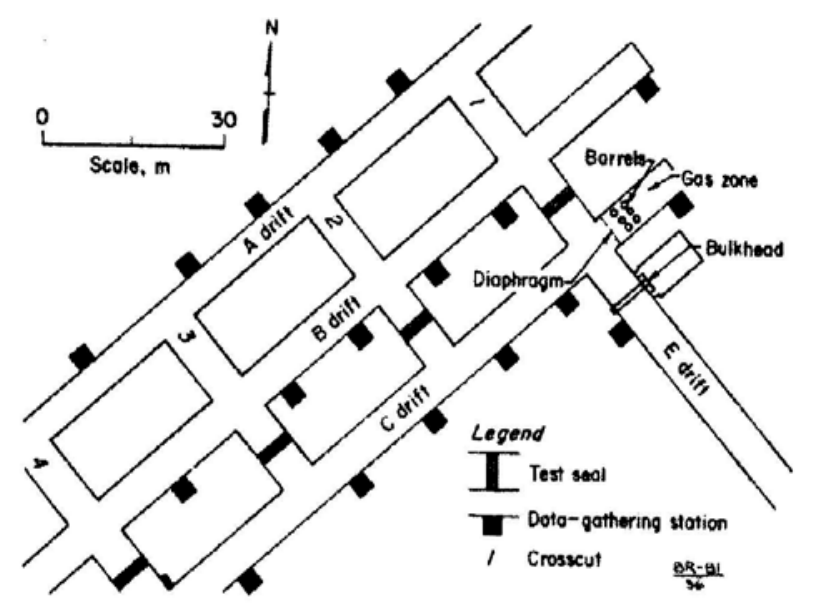

Figure 1.15 Mine seal test area in the LLEM (Weiss et al., 1999)

As this full-scale explosion testing for evaluation of mine seals is very elaborate, timeconsuming and expensive, NIOSH researchers developed an alternative 'Test Chamber Approach' to better characterize the strength properties of mine seals and facilitate the in-situ testing of seals in an operating mine (Sapko et al., 2005). With the "Test Chamber 
Approach”, NIOSH constructed two test chambers within the LLEM and one within the Safety Research Coal Mine (SRCM) with pneumatic, hydrostatic and methane-air explosion loading capabilities to study the static and dynamic responses of various mine seals. Figure 1.16 shows the schematic diagram of the test chamber design.

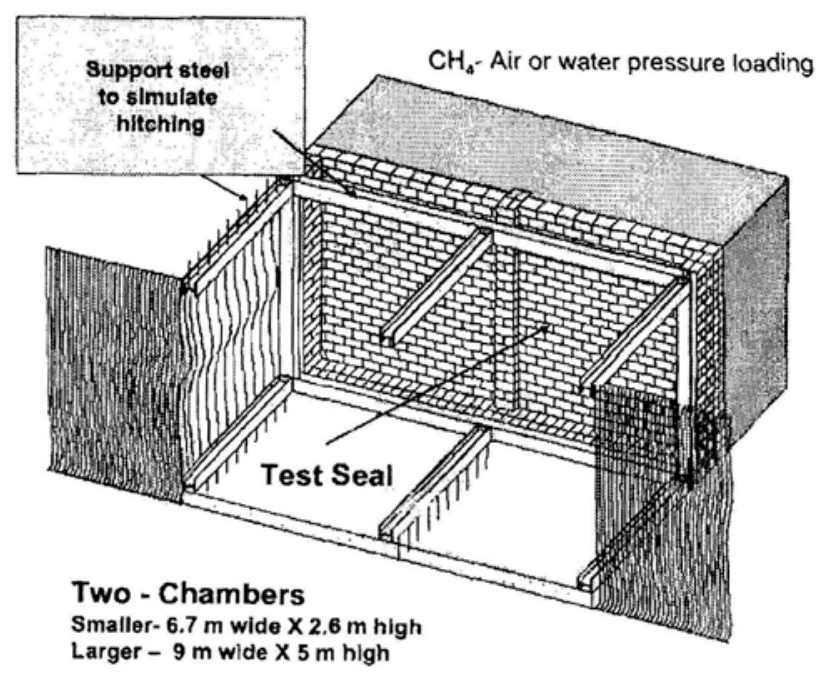

Figure 1.16 Test chamber for pressure loading of seals with water, compressed air, and methane-air mixture ignition (Sapko et al., 2005)

Test results from these chamber tests were used to compare the strength characteristics of the same type of seals tested under full-scale explosion tests at LLEM. Although many standard seal designs appeared to be mostly intact after the confined explosion within the chamber, some seals were later shown to be unable to properly limit the exchange of air from one side to the other (Sapko et al., 2005). The test chambers helped determine the leakage characteristics of seals after they were subjected to 20 psi pressure loading.

NIOSH also conducted test chamber explosion tests to determine the ultimate failure pressure of various seal designs. According to Sapko et al., (2005) this type of evaluation test using methane is intended only for controlled experimental research and not intended for use in coal mines.

Zipf et al., (2008) recently tried to document all the structural data available from the explosion tests conducted at this facility from 1997 through 2008 in a report titled "Compendium of Structural Testing Data for 20 psi Coal Mine Seals". 


\section{E. Post PIB-P06-16 Seal Design}

Recently developed regulations require the use of pressure-time curves stipulated in the 30 CFR for design of mine seals for 50 psi and 120 psi. Use of conventional full-scale explosion tests for evaluating mine seals for these new design standards may not be feasible. Generation of such high explosion pressures in experimental mines is dangerous and may cause permanent damage to the mine entries or testing facilities. Further, evaluation of seals constructed from different types of materials, for various mining conditions like entry size, roof convergence, and surrounding rock types, etc, may not be very practical with conventional methods discussed in Section 1.1.4(D), p. 17. Moreover, conditions that might exist in one site are likely to vary within a mine and between mines. It follows that design by full-scale testing in an experimental mine is not a practical way of ensuring the adequacy of structural seal design.

Considering these factors, there is a need for adopting new scientific methods and the use of engineering practices or structural dynamics principles for evaluation of new seal designs and for understanding the dynamic seal response. New design methodologies should be convenient, cheaper, faster, and more economical as compared to the full-scale explosion tests, and should also provide reliable designs.

In the U.S., some designers recently tried using various analytical and numerical methods for the design of mine seals. The application of analytical methods for the design of mine seals has been questioned by some designers (Gadde et al., 2007) because of the extremely simplifying assumptions made in the design process. In mid-2007, MSHA proposed 120 psi reinforced concrete (RC) seal designs based on analytical solutions but could not provide a detailed understanding on how the seal structure responds to the explosion loading.

Numerical methods have been successfully used by some researchers (Burke, 2003; Gadde et al., 2007; Kallu et al., 2007; Westman, 2007) for addressing various seal/stopping design issues. Numerical methods provide not only reliable seal designs but also provide a detailed understanding into the structural response of the seals to the explosion loading. In the recent past, numerical methods have gained much popularity and acceptance in their application to various structural designs across the world. The application of analytical and numerical 
methods, for design of mine seals, and their limitations are discussed in detail in the following sections. 


\subsubsection{Principles of Dynamic Analysis}

7 wo different methods are generally used either separately or concurrently in static 1 analysis: one is based on the principle of equilibrium, and the other is based on principle of conservation of energy, i.e., based on work done and internal energy stored.

For the analysis of structures under dynamic loading, the same two methods are basically used with little changes. In dynamic loading, load changes rapidly with time and the acceleration velocity and the mass of the structure induces inertial forces in the structure. So 'inertia' (resistance) and 'damping' terms should also be considered in the equation of the equilibrium in dynamic analysis.

According to the principles of equilibrium, the dynamic analysis of any structure involves solution of the following second order differential equation for the entire structure:

$$
M y^{\prime \prime}(t)+C_{d} y^{\prime}(t)+R(y(t))=F(t)
$$

where,

$M$ - equivalent or 'lumped' mass of the system,

$C_{d}$ - damping coefficient taken as 5 percent of the critical value, i.e., very lightly damped,

$y(t)$ - displacement of the mass as a function of time $t$,

$y^{\prime}(t)$ - velocity of the mass or first derivative displacement,

$y$ ”' $(t)$ - acceleration of the mass or second derivative of displacement,

$R$ - structural resistance as a function of displacement $y$,

$F(t)$ - structural load as a function of time, i.e., expected blast pressure history

The major differences between static and dynamic analysis are 'inertia' and 'damping' (Biggs, 1964). In a dynamic model, the loads change so fast that the mass of the structure induces inertial forces in the structures in addition to the normal static forces. In a static analysis the first two terms in the equation (1.1) are ignored. The term $C_{d}$ in the equation 
(1.1) represent damping of the structure. Every real structure has some internal natural mechanism in it to dissipate mechanical vibrations and eventually bring them down to zero. This energy dissipation effect is called damping and is generally represented in dynamic models by a viscous dashpot characterized by a parameter called the ‘damping ratio’ (Biggs, 1964).

As for the principles of conservation of energy, the work done must be equal to the sum of the kinetic energy and the strain energy in the structure.

$$
\mathrm{WD}=\mathrm{KE}+\mathrm{SE}
$$

where,

$$
\begin{aligned}
& \text { WD - work done } \\
& \text { KE - kinetic energy } \\
& \text { SE - strain energy }
\end{aligned}
$$

The strain energy in the above equation include both reversible elastic energy and irreversible plastic strain energy.

Thus, the difference between static and dynamic analysis of structures is the presence of inertial force in the equation of dynamic equilibrium, and kinetic energy in the equation of energy conservation. As both terms involve the mass of the structure, the mass of the structure becomes an important consideration in the dynamic analysis.

\section{Methods for solving dynamic equations of equilibrium}

In structural dynamics, there are several approaches available that can be successfully used for solving the dynamic equations of equilibrium. These approaches can be broadly classified into two different categories namely analytical solutions and numerical solutions.

\section{A. Analytical Solution}

An analytical solution is an exact mathematical expression for the solution to some differential equations and the boundary conditions that describe a system. Analytical solutions are intended for quick analysis of structures. For many partial differential equations 
and ordinary differential equations, finding an analytical solution is difficult or impossible. In the case when an analytical solution cannot be obtained, numerical methods are typically applied to get an approximate solution.

For a given structure under dynamic load, solving the complete dynamic equations of motion analytically would be difficult, often times impossible. However, for most practical problems, this can be accomplished by simple appropriate assumptions.

\section{Dynamic equivalent system}

In most cases, a structure can be replaced by an idealized (or dynamically equivalent) system which behaves in nearly the same manner as the actual structure. A structure under analysis is divided into a number of concentrated masses joined together by weightless springs and subjected to concentrated loads which vary with time. This concentrated mass-spring-load system is defined as an equivalent dynamic system.

Although all structures possess many degree of freedom, one mode usually predominates in the response to short duration loads; thus, for all practical purposes, this one mode may be considered to define the behavior of the structure and the problem can be simplified by considering a single-degree-of-freedom system whose properties are those of the fundamental mode of the structures.

\section{Single-degree-of-freedom system (SDOF)}

A single-degree-of-freedom system is defined as one in which only one type of motion is possible. Typical example for such a system is shown in Figure 1.17

In reality, all structures possess more than one degree of freedom regardless of how simple their construction. However, many structures can be adequately represented by a singledegree-of-freedom (SDOF) system for the purpose of a simple and quick analysis. Once the structure is divided into an equivalent SDOF model, the equations of dynamic equilibrium are written down and solved for the unknown parameters. The SDOF models typically provide the response of the structure at one point only, the center. 


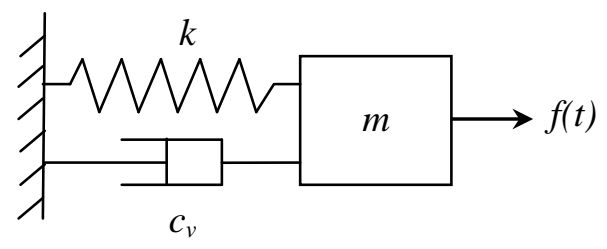

Figure 1.17 Typical single-degree-of-freedom system

The accuracy of the computed deformation of the SDOF approximation depends on the assumed deflected shape and the resistance of the structure over time. The equivalent SDOF system is usually selected such that the deformation of the concentrated mass is the same as that for a significant point of the actual structure. The assumption of deflected shape establishes an equation relating the relative deflection of all points of the structure.

The procedure for determining an equivalent dynamic system is outlined in Chapter 3 of the U.S. Department of Army, the Navy and the Air Force design manual TM 5-1300 (1990). This manual contains the tabulated design or transformation factors used to convert the real system to an equivalent SDOF system.

\section{Wall Analysis Code (WAC) (Slawson, 1995)}

The WAC is an SDOF model developed for the U.S. Army Corps of Engineers (USACE) Engineer Research and Development (ERDC), Structures Laboratory (Slawson, 1995). WAC was developed to provide an easy and quick solution for the response of typical walls subjected to blast loads. The WAC transforms the wall model to an equivalent SDOF model, calculates the actual and SDOF equivalent loads and solves the equation of motion, given in equation 4.1, to determine the response time history of a central point on the wall. Given the details of construction, including dimensions, material properties and support conditions, it can calculate the resistance function $(\mathrm{R}(y)$, pressure-deflection) of a wall or, it can accept a user defined resistance functions based on experimental data.

Researchers at NIOSH (Zipf et al., 2007) recently used WAC for the design of mine seals. Also, engineers at MSHA Tech support used a SDOF model for evaluation of mine seal designs submitted by various suppliers and mine operators for approval for use in underground coal mines. 
Despite the fact that SDOF models are extremely simple and relatively easy to use and have been validated for some common structures, many designers doubt the application of these models, in particular, for design of mine seals because of the following simple assumptions or limitations involved in the design process.

- Analytical solutions cannot provide an understanding of the basic seal response and failure mechanism

- Analytical solutions usually simplify the problem to a beam analysis, with simply supported or fully constrained

- Many factors, such as roof-to-floor convergence, interfaces or discontinuities, surrounding rock behavior, etc., that play an important role in the design of the actual structure are ignored by simple analytic solutions, or else the method uses very conservative assumptions.

- Analytical solutions usually provide only the central deflection of the structure, which alone is not sufficient for evaluating the structures

Design engineers should carefully consider the underlying simplified assumptions and limitations involved in the analytical solutions before applying these methods for the design of mine seals.

\section{B. Numerical Solution}

For many partial differential equations and ordinary differential equations, finding an analytical solution is difficult. In the case when an analytical solution cannot be obtained, numerical methods are applied to get an approximate but acceptable solution. In numerical solutions, partial differential equations are converted to simple linear forms that are much easier to solve.

Numerical solutions have gained much popularity for their application in the field of structural dynamics throughout the world. There are many numerical simulation codes based on continuum and discontinuum mechanics available for solving problems related to structural dynamics. Specific numerical codes are selected depending on the specific 
requirements of the design analysis. In particular reference to mine seal design, numerical solutions offer numerous advantages which include:

- Numerical solutions provide a better understanding of seal response to the explosion loading and seal failure mechanism

- Complicated seal geometries can be modeled

- Interfaces or discontinuities can be represented explicitly in the models

- The effect of roof-to-floor convergence, surrounding rock behavior, mining induced loading, etc., can be considered in the seal design process

- Can accommodate any type of explosion loading history

- Provides cost-effective means for parametric analysis in identifying the key parameters in the seal design

- Convenient, economic, provides reliable designs and saves a lot of time compared to full-scale explosion tests

Besides offering numerous advantages, numerical solutions also have some limitations. Numerical models require a lot of input data which may not be readily available in many instances, forcing designers to make some assumptions that may influence the reliability of the designs. Further, numerical codes require expertise in their application to structural design problems and also take significant amount of computer resources and time. They are not intended for use by untrained novices. 


\subsection{SCOPE AND OBJECTIVES}

7 The current 120 psi seal design and evaluation practices are mostly based on simple 1 analytical solutions. Applicability of these analytical solutions is very much limited because of the simple assumptions or limitations involved in the design process (refer to section 1.1.5(A), p. 23). So there is a need for developing a reliable methodology and design criteria for addressing the seal design issues.

\section{Scope}

This dissertation mainly focuses on the design of reinforced concrete seals for 120 psi explosion pressure with instantaneous rise time, for sealing abandoned areas of coal mines. The three dimensional finite-element based program, ABAQUS, is used as a tool for design of the 120 psi reinforced concrete seals. This work also provides an in-depth analysis of how the reinforced concrete structures respond to the dynamic explosion pressure loading, and discusses the failure mechanism of the seal structures under these loading conditions. Fullscale explosion test results obtained from NIOSH's Lake Lynn Experimental Mine tests on reinforced structures are used for validation of the numerical models. Finally various other factors, such as explosion loading nature, roof-to-floor convergence etc., that affect the performance of the reinforced concrete seals are also addressed in this dissertation.

\section{Objective}

Using 3-D finite element numerical analysis, this dissertation is to develop design criteria in the form of a design chart for the reinforced concrete seals subjected to 120 psi overpressure. The design criteria will consider the following factors:

1. Effect of concrete constitutive behavior, seal interaction with the surrounding rocks, and strength of the surrounding rocks.

2. Effect of rebar sizes and their vertical and horizontal spacing in reinforcing the concrete seal.

3. Effect of entry/crosscut dimensions. 
Other factors such as roof-to-floor convergence, nature of explosion loadings, and multiple explosions on seal behavior will also be investigated. 


\section{Chapter 2 DESIGN METHODOLOGY}

7 his dissertation employs a numerical simulation technique, because of the reasons

stated in section 1.1.5(B), p. 26, for the design of reinforced concrete seals by solving the dynamic equations of equilibrium. Although, finding the exact solution to the equations of motion is extremely difficult, the numerical methods provide approximate but practically acceptable results.

\subsection{Selection of appropriate numerical code}

The most popular numerical simulation methods are the finite element and finite difference methods. There are numerous numerical codes based on these methods available for solving structural dynamics problems. One such finite element based explicit code, ABAQUS, is used in this research because of various inherent capabilities it offers for simulating reinforced concrete structures. ABAQUS has a plasticity-based constitutive model for effectively simulating the non-linear behavior of concrete material. This plasticity-based model can simulate concrete cracking, tension stiffening, shear capacity of cracked concrete, and concrete crushing in compression. ABAQUS also offers the unique capability of describing the constitutive behavior of the reinforcement steel bars independent of the concrete material. These special capabilities of ABAQUS make it a good choice for the design of reinforced concrete structures.

\subsection{Factors Considered in RC Seal Design}

A number of factors that affect the performance of the reinforced concrete seals are considered in this research. Numerical models can be effectively used for evaluating these factors and help identifying the key influential parameters in the mine seal design. Factors considered in the current study include:

- Nature of the explosion loading - The pressure-time curves prescribed in the 30 CFR are used for design of reinforced concrete seals to comply with the regulatory requirements. Further, a detailed study on the influence of the nature of the explosion loading i.e., static or dynamic and single or multiple explosions, is conducted separately to evaluate the response of the reinforced concrete seal. 
- Roof-to-floor convergence - A high roof-to-floor convergence may induce heavy stresses in the seal structures and in some instances lead to failure of the seals. Previous research (Kallu et al., 2007) clearly indicated this phenomenon. The effect of convergence on RC seals for various entry dimensions will be investigated in detail in this work.

- Interaction of the roof, floor and coal interfaces with the seal structure - Shear strength along the seal-rock interfaces plays an important role in the stability of a mine seal. Higher shear strength along the interfaces provides an effective transfer of explosion loading pressure to the surrounding rock.

- Concrete constitutive behavior - A detailed study on the effect of the constitutive behavior of concrete on RC seal behavior is undertaken to establish an appropriate concrete model for use in the design of RC seals.

- Surrounding rock constitutive behavior - The strength and behavior of the surrounding rock also influences the design of RC seal in some instances.

\subsection{Verification Cases}

In every numerical simulation it is necessary to validate the results of the numerical models with standard physical test data or case studies, in order to have confidence in the results from future numerical models. Structural data available from NIOSH's LLEM full-scale explosion tests on two reinforced concrete structures were used as validation data in this work. Recently, NIOSH published a report (Zipf et al., 2008), 'Compendium of structural testing data for 20 psi coal mine seals', which presented all of the structural data available from explosion tests of 20 psi mine seals or ventilation stoppings that were conducted during the period 1997 through 2008 at LLEM. This report presents data on 52 different structures. However, only two structures meet the reinforced concrete seal criteria. Further, no other full-scale explosion test data are available in the U.S. except the above mentioned explosion tests data by NIOSH.

These explosion tests provide details on seal construction and material types, explosion loading history, lateral displacement-time history at the center of the seal, and 'pass' or 'fail' 
condition of the seals after the explosion tests. The complete details on the full-scale explosion tests on reinforced concrete seals, the verification cases, and the modeling results are presented in Chapter 5.

\subsection{Parametric Analysis}

Before attempting to do the actual reinforced concrete seal design, various other parameters involved in the design process are needed to be optimized first. For this purpose, a detailed parametric analysis was conducted on the following parameters. While conducting parametric analysis on one particular parameter, appropriate values were assumed carefully for other parameters. The parameters considered were:

- Vertical rebar spacing

- Vertical rebar size

- Horizontal rebar spacing

- Horizontal rebar size

- Seal-rock/coal interface strength

- Concrete constitutive model

\subsection{Development of Design Guidelines}

There are no engineering guidelines developed so far for judging the stability of the seal structures other than that the seal should be sufficient to handle the prescribed explosion loading. In the past, most of the seal designs were approved by MSHA based on the full-scale explosion test results that were conducted at LLEM of NIOSH. In structural dynamics, where analytical solutions are used, designers consider $1^{\circ}$ maximum allowable rotation angle (figure 2.1) for judging the stability of reinforced concrete structures subjected to blast loads. Guidelines for the use of WAC also suggest a $1^{\circ}$ rotation angle $(\theta)$ to provide a 'medium level of protection'.

This work will develop appropriate design guidelines for judging the stability of the reinforced concrete seals subjected to explosion pressure loading. Further, findings from the verification models are compared with the observations made during the full-scale explosion tests on mine seals to develop more realistic design criteria. 


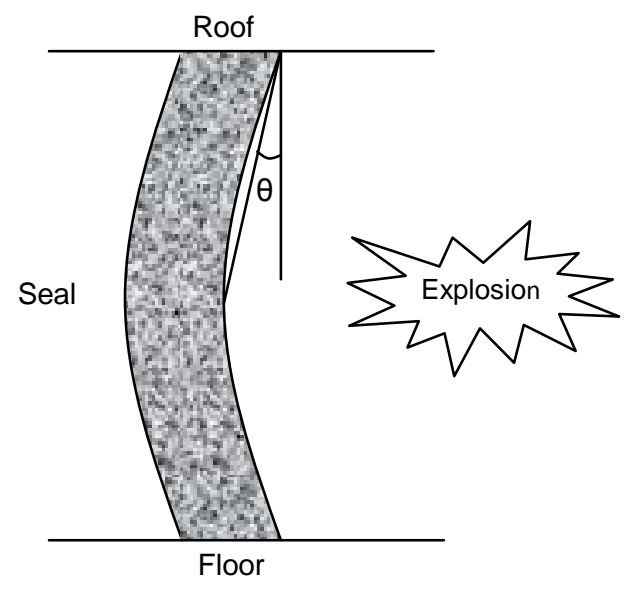

Figure 2.1 Schematic showing the seal rotation angle 


\section{Chapter 3 MATERIAL MODELS}

\subsection{Surrounding Rock Strata}

7 The immediate roof and floor rocks and coal are modeled using the Drucker-Prager 1 model. Deformation prior to yielding is assumed to be linear elastic governed by the elastic parameters $\mathrm{E}$ and $\nu$. The modified Drucker-Prager plasticity model in ABAQUS is intended for geological materials that exhibit pressure-dependent yield. The model uses nonassociated flow in the shear failure region. Figure 3.1 shows the modified Drucker-Prager yield surface in the shear failure region in the meridonial plane $(p-q)$, where ' $p$ ' indicates the hydrostatic stress and ' $q$ ' indicates the equivalent Von Mises stress.

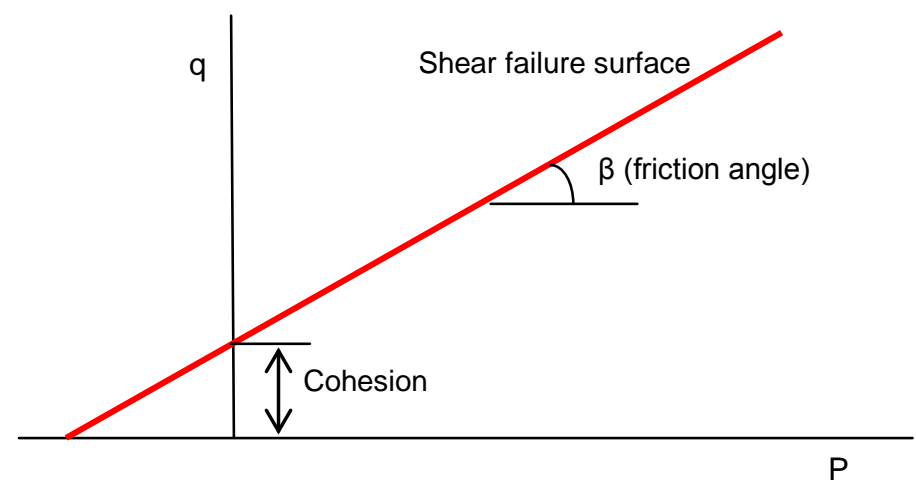

Figure 3.1 Modified Drucker-Prager yield surface in the p-q plane

The geo-mechanical properties of the coal, immediate roof and floor rocks, and steel reinforcement bars (rebars) used in the models are given in Table 3.1.

Table 3.1 Geo-mechanical properties of rocks, coal and steel

\begin{tabular}{|l|c|c|c|}
\hline \multicolumn{1}{|c|}{ Property } & Rock & Coal & Steel \\
\hline Young's Modulus (E), psi & $3 \mathrm{e}+06$ & $3 \mathrm{e}+05$ & $2.9 \mathrm{e}+07$ \\
\hline Poisson's ratio (v) & 0.19 & 0.35 & 0.28 \\
\hline Density, lbs/ft ${ }^{3}$ & 162.3 & 86.5 & 486 \\
\hline Friction angle & 35 & 29 & - \\
\hline Dilation angle & 0 & 0 & - \\
\hline Cohesion (psi) & 370 psi & 163 psi & - \\
\hline Yield strength (psi) & - & - & 60,000 psi \\
\hline
\end{tabular}




\subsection{Concrete Constitutive Behavior}

Non-linear behavior of concrete is simulated with a uniaxial stress-strain curve with strain softening and tension stiffening (capacity of the intact concrete between neighboring cracks to carry a limited amount of tensile forces). The Plasticity-based concrete damage model available in ABAQUS is used to define the yield function and flow potential. This plasticity based constitutive model can simulate concrete cracking, tension stiffening, shear capacity of the cracked concrete, and concrete crushing in compression. The complete non-linear behavior of concrete material models in compression and tension are discussed in detail in Chapter 4.

\subsection{Steel Rebars}

The steel rebar is assumed to behave as a bi-linear elastic-perfectly plastic material. A classical Von-Mises yield criterion with associated plastic flow is used in the modeling. Figure 3.2 shows the bi-linear elastic-perfectly plastic model for Grade 60 steel. The only reason to ignore the strain hardening behavior of steel is to make the models simple and more conservative. The steel rebars are modeled as beam elements embedded in the host concrete/rock elements. These rebars are embedded into the roof and floor to a distance of 2 $\mathrm{ft}$ in the simulation models.

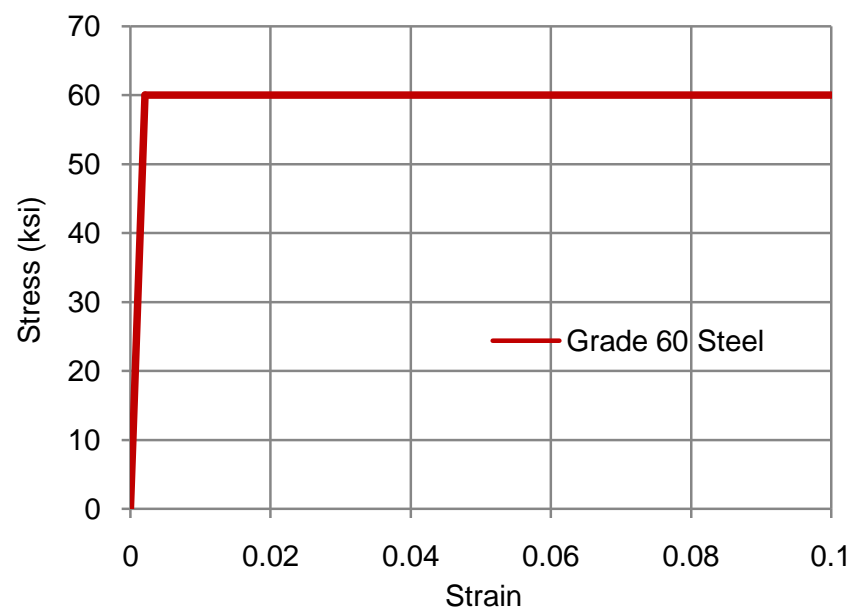

Figure 3.2 Bilinear stress-strain model for Grade 60 steel

In order to avoid complex interaction of the rebars with the surrounding rock, rebars are assumed to be fixed to the surrounding strata. In other words, no slip/shear along the rebar- 
rock interface is allowed. For all practical design purposes, the grouting length of the rebars should be determined based on the pull-out strength test results. It is believed that a $2 \mathrm{ft}$ grout length is sufficient to ensure that the pull-out strength will be larger than the steel yield strength. The concrete and the internal steel rebar interaction is approximately considered in the modeling by tension stiffening of the concrete material model. Refer to Chapter 4 for complete details. Mechanical properties of the steel rebars are given in Table 3.1.

\subsection{Seal-Rock/Coal Rib Interfaces}

The interface between the reinforced concrete seal and the surrounding rock is modeled using the bi-linear Coulomb friction model with zero cohesion. Figure 3.3 shows the graphical representation of the Coulomb friction model with critical shear stress limit. According to this model, sliding will occur if the magnitude of the shear stress along the interface reaches a critical value, $\tau_{\max }$, regardless of the magnitude of the contact pressure. The interface friction angle is selected the same as for the cement mortar interface $\left(58^{\circ}\right)$.

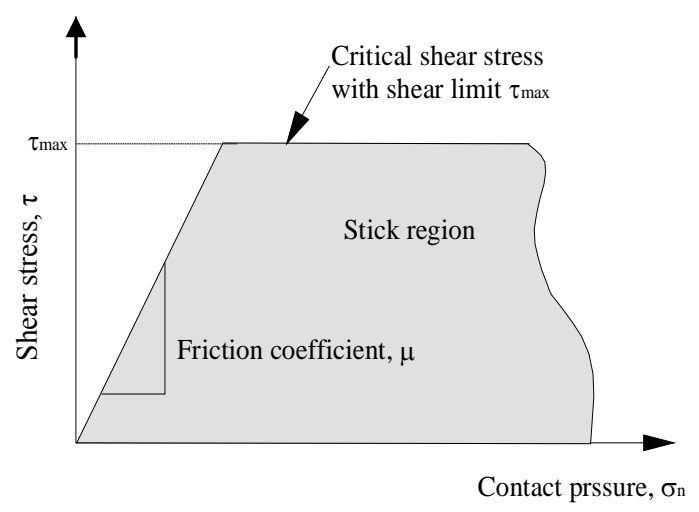

Figure 3.3 Coulomb friction model with critical shear stress limit

\subsection{General ABAQUS Model Description}

Figure 3.4 shows the general construction details of the seal, rebars and the surrounding rock. Model geometry includes about $10 \mathrm{ft}$ of roof, $10 \mathrm{ft}$ of floor and about $10 \mathrm{ft}$ of ribs as shown in the figure 3.4. Two sets of vertical and horizontal rebars (Grade 60 steel) are laid about 2.5 in. (cover distance) inside from both faces of the seal, in accordance with the guidelines suggested by the ACI (American Concrete Institute) for design of reinforced concrete structures. 
The seal regulations require the seals to withstand explosions that may happen on either sides of the seal. Two sets of steel rebar on both faces of the seal enable the seal to withstand the high tensile forces that may develop in the seal from the possible explosion pressures on either side of the seal. These steel rebar are hosted in the concrete and are embedded into the roof and floor to a distance of $2 \mathrm{ft}$. To reduce the complexity associated with the embedded rebar simulation in the models, the rebars are assumed to be simply fixed to the roof and floor, i.e., no relative displacements are allowed between rebars and the rock.

After applying the appropriate initial and boundary conditions, interface properties, and constitutive behavior of materials the model is solved dynamically in two steps. In the first step, a very small amount of velocity (0.0004 in/sec) is applied for about 0.1 sec on the top face of the model to allow initialization of self weight of the structure. In the second step, explosion loading is applied on the inby face of the seal using the MSHA specified pressuretime curve and the model is solved for the prescribed amount of time. A number of predefined monitoring points are selected in the model to record the history of seal's lateral displacements, seal response pressures, and axial forces in the rebars.

Figure 3.5 shows the reinforced concrete seal (designed for 120 psi explosion pressure) under construction in one of the western U.S. coal mines.

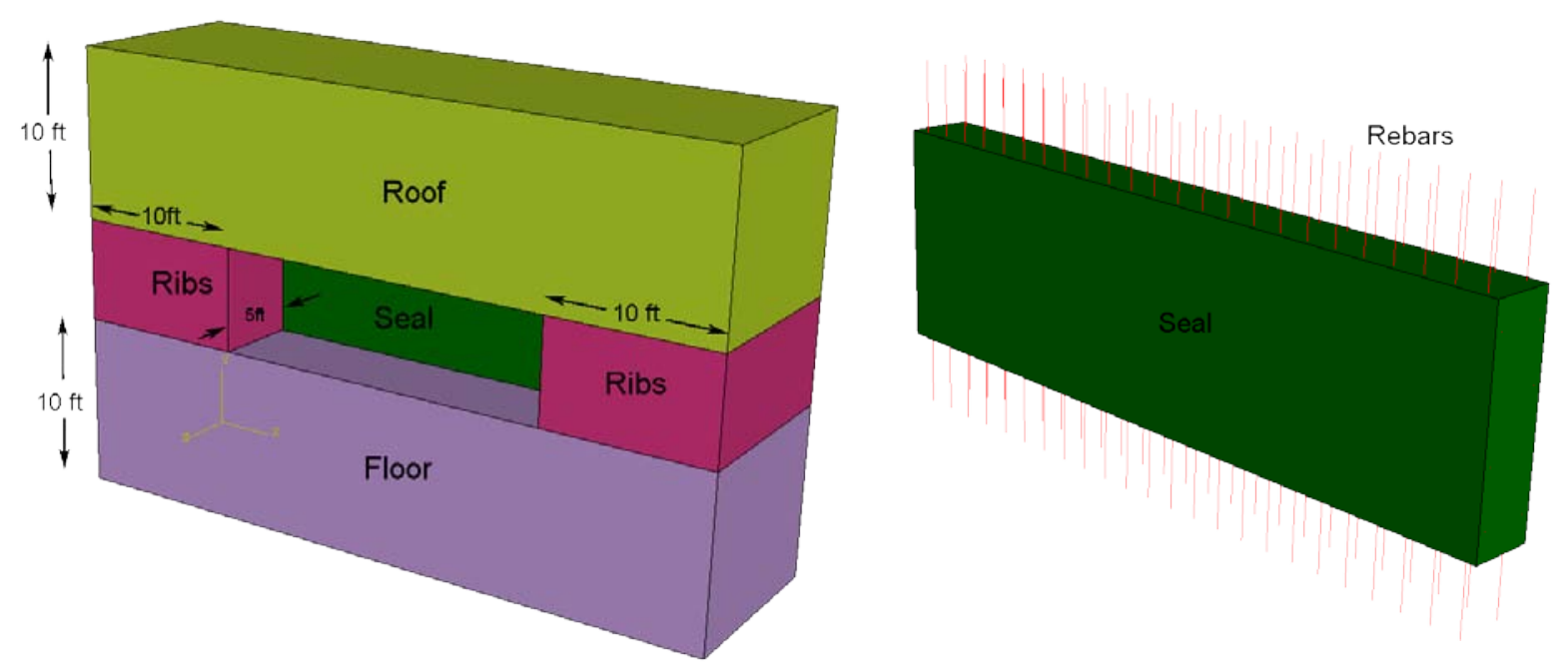

Figure 3.4 General layout of ABAQUS model 

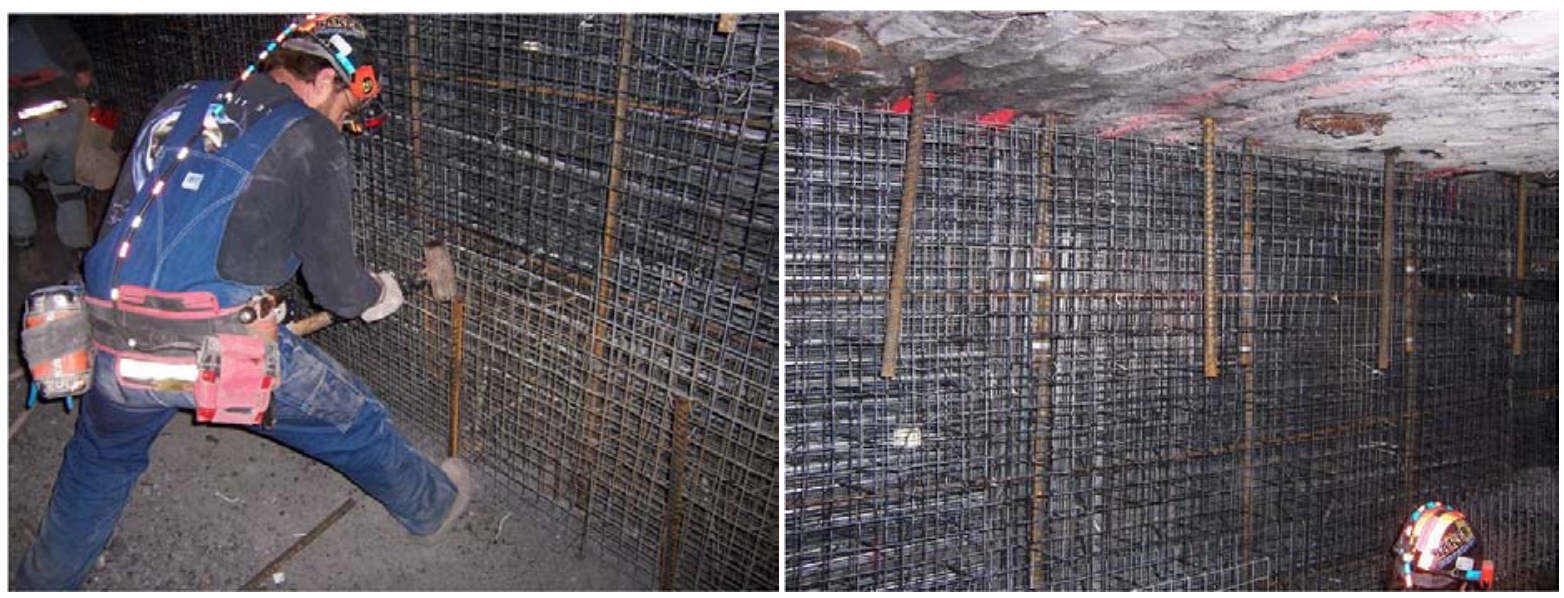

Figure 3.5 Construction of reinforced concrete seal

\section{Monitoring points in the models}

A number of monitoring points on the outby and inby faces of the seal were selected to record the history of lateral displacements, lateral seal response pressure, and axial forces in the rebars. These monitoring points selected such that they cover the most critical locations on the seal as shown in the figures 3.6 to 3.8. The legends used in the figures read as $\mathrm{T}-$ Top, M - Middle, B - Bottom, MT - Mid Top, MB - Mid Bottom.

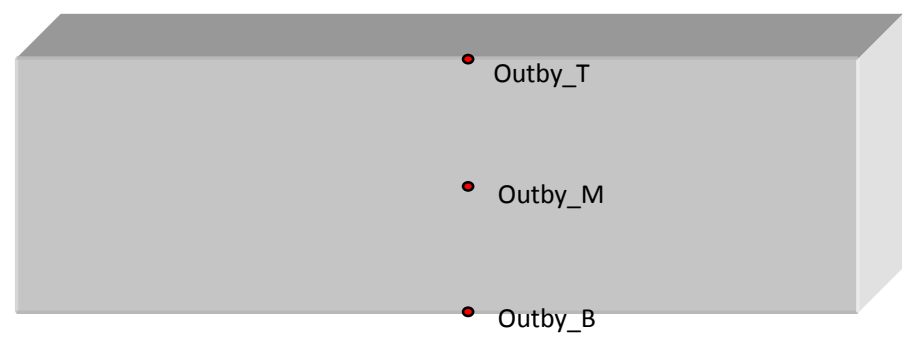

Figure 3.6 Location of lateral displacement monitoring points on the outby face of the seal 


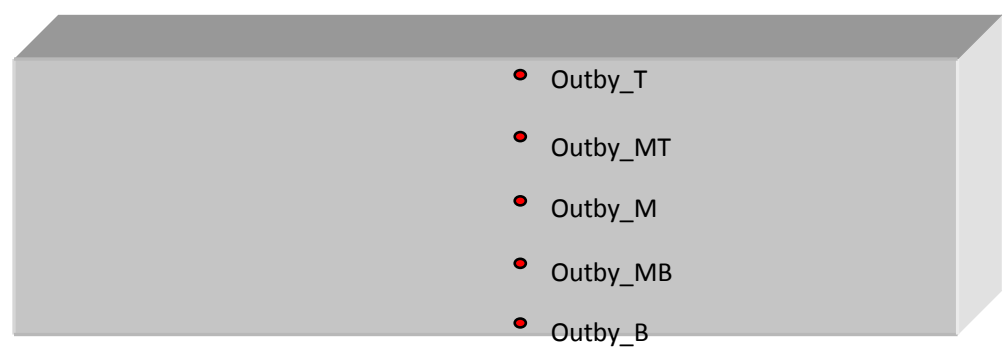

(a) Front view

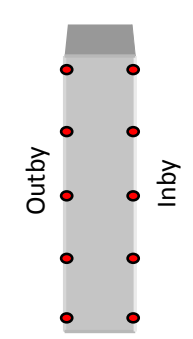

(b) Side view

Figure 3.7 Location of lateral pressure monitoring points on the both faces of the seal

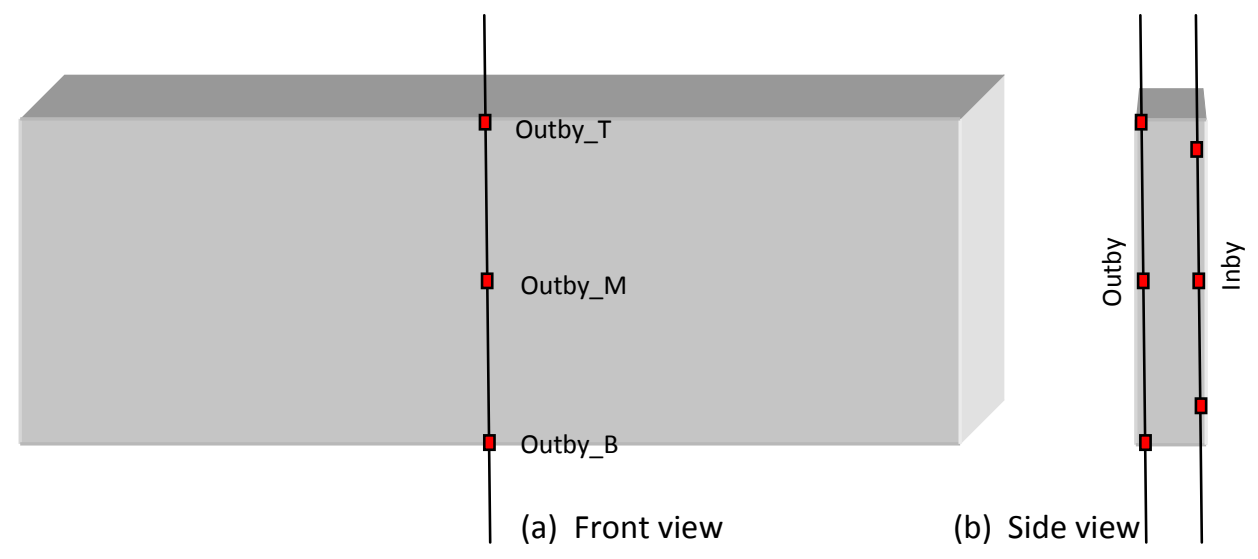

Figure 3.8 Location of axial force monitoring points on the outby and inby central rebars 


\title{
Chapter 4 CONCRETE CONSTITUTIVE BEHAVIOR
}

\author{
Concrete is a heterogeneous, cohesion-frictional material that exhibits complex non- \\ linear behavior under aa multi-axial state of stress. So, knowledge of the complete \\ stress-strain behavior is essential to understand the mode of failure of the concrete structures. \\ The phenomenon of redistribution of the stresses in certain localized regions of a complex \\ structure is closely associated with the ability of the concrete to undergo large deformation \\ without total failure ( $\mathrm{Li}$ et al., 2002). So, more realistic data on the stress-strain behavior of \\ reinforced concrete in compression and in tension is essential for predicting meaningful \\ results from the modeling.
}

Except for the stress-strain data for concrete in compression, to date, only very limited experimental data have been made available in terms of the complete stress-strain response of the normal concrete subjected to uniaxial tension (Evans and Marathe, 1968). This limitation is because of the considerable experimental difficulties involved in conducting an experiment that produces the true tensile properties of concrete in direct tension.

In the past, some researchers (Evans and Marathe, 1968; Gopalaratnam and Shah, 1985; Guo and Zhang, 1987; and Li et al., 2002) tried to obtain the stress-strain behavior of concrete in tension using specially designed testing machines. These researchers concluded that normal concrete materials exhibit some softening behavior in uniaxial compression and tension. Though the size and composition of the concrete specimens used by these researchers are different, for the same strength material, they exhibit similar behavior.

During the initial phases of this work, three different concrete material models, available in ABAQUS manual, were considered in the modeling to investigate the influence of concrete behavior in compression and tension on seal response. The results from these models suggested that seal response is highly sensitive to the behavior of the concrete in compression as well as in tension. A summary of the results on these studies is provided in Section 4.1.

Further in this dissertation, two other typical concrete models were investigated for use in the modeling. The first model is based on the empirical formulae that estimate both tensile and compression behavior of normal concrete (Bangash, 2001). The second concrete model is 
developed and verified by various researchers based on laboratory and experimental work. Part of the work described in this chapter has been done by Morsy et al. (2008).

\subsection{Preliminary Work}

This work was initially carried out to understand the influence of the post-failure behavior of the concrete in both compression and tension. For this purpose, three different concrete models provided in the ABAQUS manuals are considered. Table 4.1 provides the mechanical properties of the concrete material models. The complete behavior of concrete models in compression and tension is shown in the stress-strain graphs in figure 4.1. Figure 4.2 shows the concrete damage variables in compression and in tension for different models. Model 1 \& 3 are elastic-plastic models with no damage in compression. Model 2 exhibits significant strain softening behavior in compression and tension, and also consider damage in both compression and tension. These models are subjected to 120 psi instantaneous explosion loading lasting for about 1 second (work carried-out before the final rules came into effect).

Table 4.1 Geo-mechanical properties of concrete models

\begin{tabular}{|c|c|c|c|c|}
\hline \multicolumn{2}{|r|}{ Properties } & Model 1 & Model 2 & Model 3 \\
\hline \multirow{2}{*}{ Elastic } & Young's modulus, x $10^{6} \mathrm{psi}$ & 4.35 & 3.84 & 4.5 \\
\hline & Poisson's ratio & 0.2 & 0.167 & 0.2 \\
\hline Flow & Dilation angle, deg & 38 & 15 & 36 \\
\hline \multirow{7}{*}{ Compression } & Material model & Elastic-Plastic & Strain Softening & Elastic-Plastic \\
\hline & Yield strength, psi & 2900 & 3483 & $1885 *$ \\
\hline & Ultimate strength, psi & 4350 & 4692 & $3495 *$ \\
\hline & Plastic strain at ultimate strength & 0.0015 & 0.0012 & $.001 *$ \\
\hline & Residual strength, psi & - & 428 & - \\
\hline & Plastic strain at residual strength & - & .01 & - \\
\hline & Compression damage & No & Yes & No \\
\hline \multirow{6}{*}{ Tensile } & Material Model & Strain Softening & Strain Softening & Strain Softening \\
\hline & Ultimate Strength, psi & 483 & 258 & 421 \\
\hline & Residual strength, psi & 4.83 & 5.8 & 7.7 \\
\hline & $\begin{array}{l}\text { Crack width at residual strength } \\
\text { (maximum damage), in }\end{array}$ & 0.0029321 & 0.19685 & 0.018983 \\
\hline & Tensile damage & Yes & Yes & Yes \\
\hline & $\begin{array}{l}\text { Crack width-strength (damage) } \\
\text { relation ship }\end{array}$ & linear & Non-linear & Non-linear \\
\hline
\end{tabular}

(*) The corresponding constants of model 1 are used instead. 

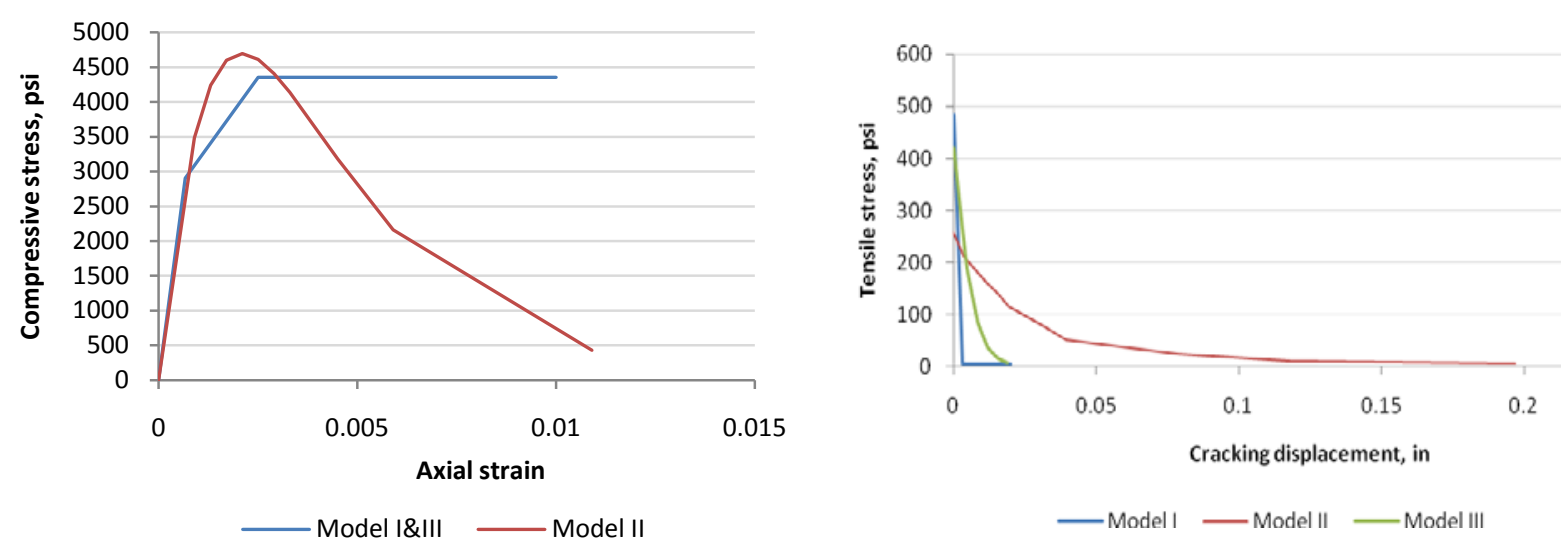

Figure 4.1 Concrete stress-strain relationship in compression and tension
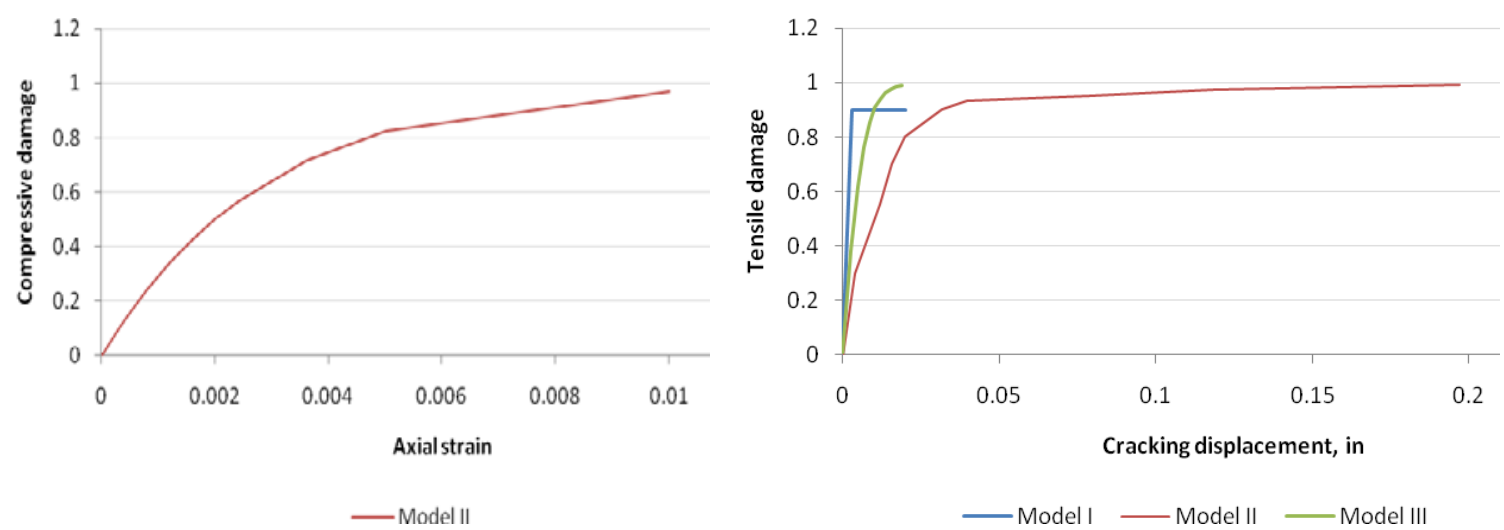

Figure 4.2 Concrete damage index in compression and tension

\section{Results and discussion}

Figure 4.3 shows the damage contours for different concrete models. Model 2 exhibits extensive damage in the seal which is caused by the significant strain-softening behavior of the concrete model in compression and tension. Figure 4.4 shows the lateral displacements in the seal at various locations on the outby face of the seal for the different concrete models. The lateral displacements in models 1 \& 3 are stabilized and are very much similar, but model 2 is under continuous deformation. Figure 4.5 shows the history of the axial forces in the central vertical rebar for different models. The high strain softening behavior of the concrete in model 2 caused the explosion pressure to transfer to the internal reinforced steel rebars. The axial forces in the rebars gradually built up over time and reached the yield strength of the steel. Figure 4.6 shows the amount of plastic strain developed in the rebars 
for different models. The complete description of this work is provided in quarterly reports on "Design of underground mine seals under explosion loading" submitted to NIOSH.

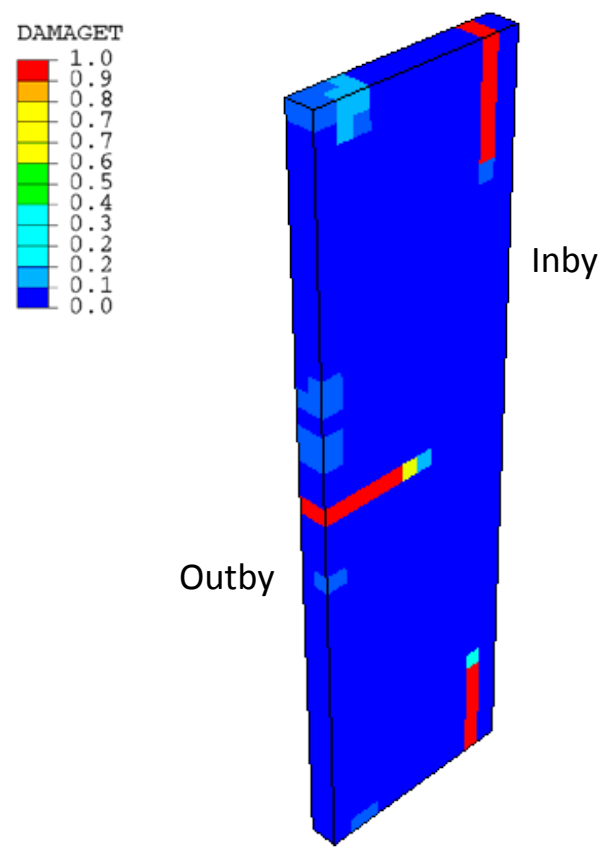

(a) Model 1

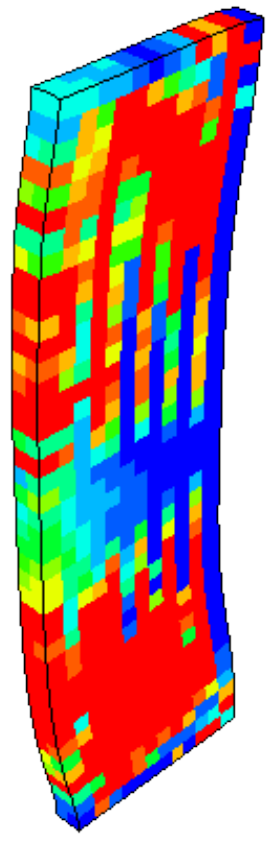

(b) Model 2

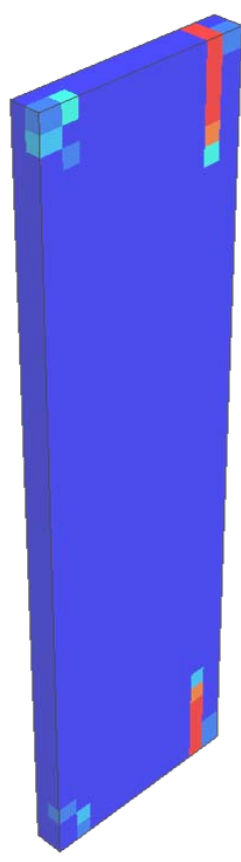

(c) Model 3

Figure 4.3 Damage contours for different concrete models (mid-vertical section of seal)

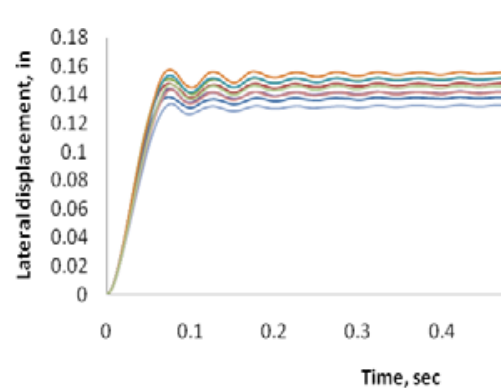

(a) Model 1

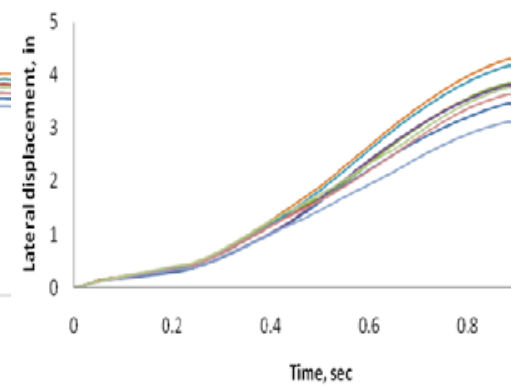

(b) Model 2

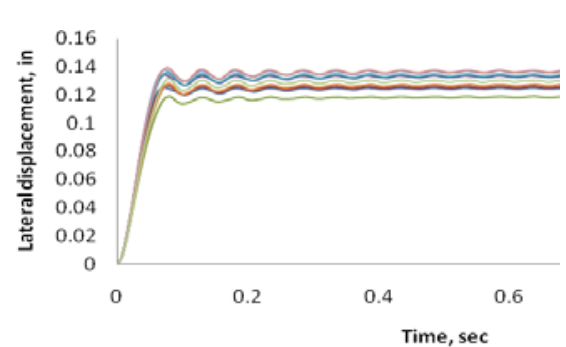

(c) Model 3

Figure 4.4 Lateral displacements in the seal for different concrete models 

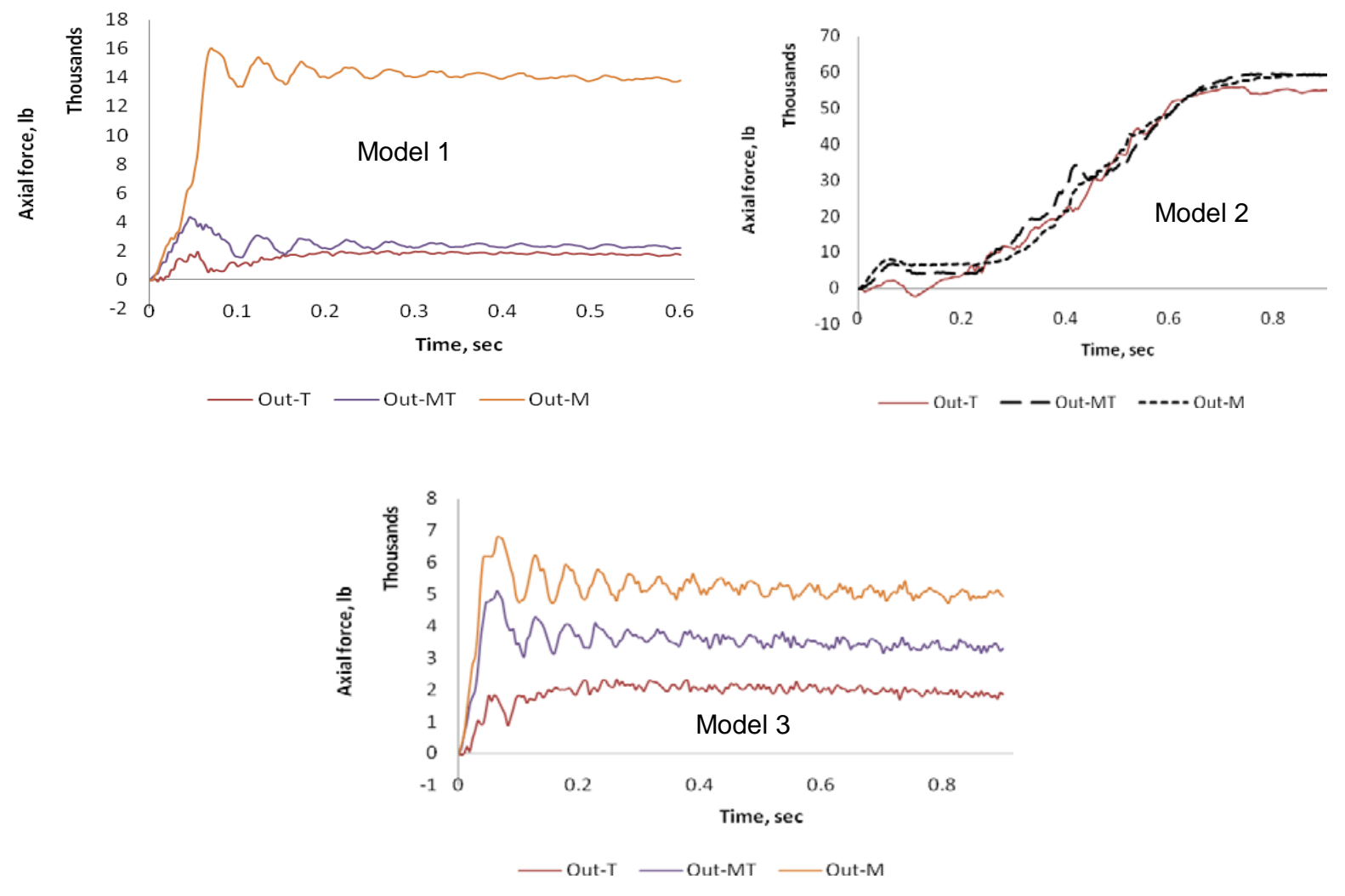

Figure 4.5 The history of axial forces in the central rebar on outby side at various locations

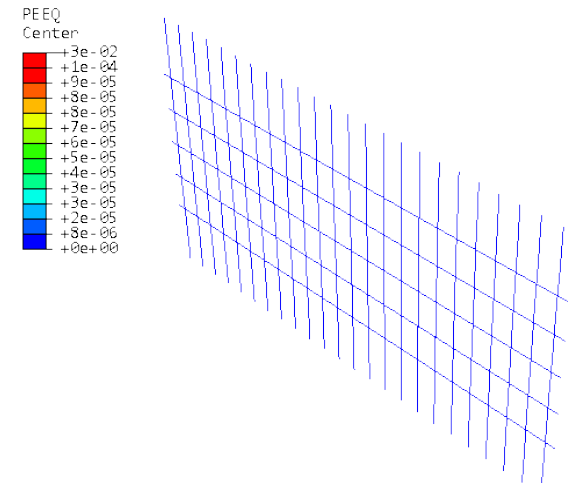

(a) Model 1

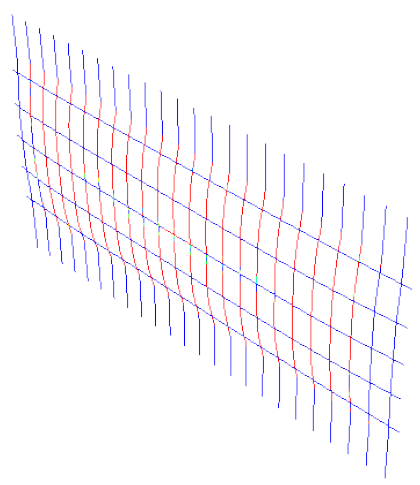

(b) Model 2

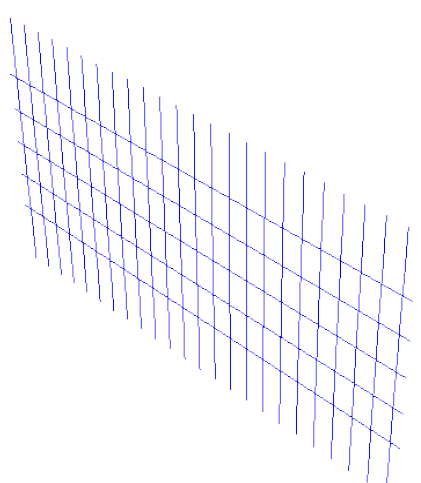

(c) Model 3

Figure 4.6 Plastic strain in the outby steel rebars for different concrete models

\section{Summary}

This work was primarily carried out to understand the degree-of-influence of the strain softening behavior of the concrete in compression and tension on the seal response. These 
concrete models predict significantly different results. The concrete model 2, with significant strain softening behavior in compression and tension, produces results that offset significantly from that of model $1 \& 3$, indicating the significance of the complete strainstrain behavior of concrete in compression and tension, especially the post-peak strain softening and tension stiffening behavior.

Two other typical concrete models are investigated further to arrive at a more reliable concrete constitutive model for use in this dissertation. The first model is based on empirical formulae that estimate both tensile and compression behavior of normal concrete (Bangash, 2001). The second concrete model is developed and verified by various researchers based on laboratory and experimental work. The complete details of these models are provided in the following sections.

For this purpose, the reinforced concrete seal models were prepared for entry dimensions of 8 $\mathrm{ft}$ high and $20 \mathrm{ft}$ wide. Seal thicknesses of 18 in., 24 in., and $30 \mathrm{in.}$ were considered in this study. Interface shear strength of 200 psi was used in all these models. No. 9 vertical rebars were placed at 10 in. spacing and No. 6 horizontal rebars were placed at 18 in. spacing. Other construction details of the models were similar to those described in Section 3.5. As this work was completed before the final rule came into effect, all these models were subjected to 120 psi instantaneous explosion pressure loading lasting for only 0.7 second.

\subsection{Concrete Model I: Empirical Model}

This concrete model is based on empirical formulae that estimate both tensile and compression behavior of normal concrete (Bangash, 2001). Figure 4.7 shows the stress-strain relationship for this concrete in compression and tension. Concrete material model I consist of three different regions in compression; elastic, strain hardening and strain softening. Crushing in the concrete material occurs at an ultimate strain $\left(\varepsilon_{c u}\right)$ of 0.0035 . The strain $\left(\varepsilon_{0}\right)$ at the peak stress is estimated by $2.4 \times 10^{-5} \sqrt{\sigma_{c u}}$. The hardening part of the stress-strain behavior of concrete material in compression is calculated using equation (4.1).

$$
0<\varepsilon<\varepsilon_{0} \quad \frac{\sigma}{\sigma_{c u}}=2 \frac{\varepsilon}{\varepsilon_{0}}\left(1-\frac{\varepsilon}{2 \varepsilon_{0}}\right)
$$


The strain softening part of the stress-strain behavior of concrete material in compression is calculated using equation (4.2).

$$
\varepsilon_{0}<\varepsilon<\varepsilon_{c u} \quad \frac{\sigma}{\sigma_{c u}}=1-0.15\left(\frac{\varepsilon-\varepsilon_{0}}{\varepsilon_{c u}-\varepsilon_{0}}\right)
$$

where, $\sigma_{c u}$ is the ultimate compressive strength, $\varepsilon_{\text {си }}$ is the ultimate strain, and $\sigma$ is stress.

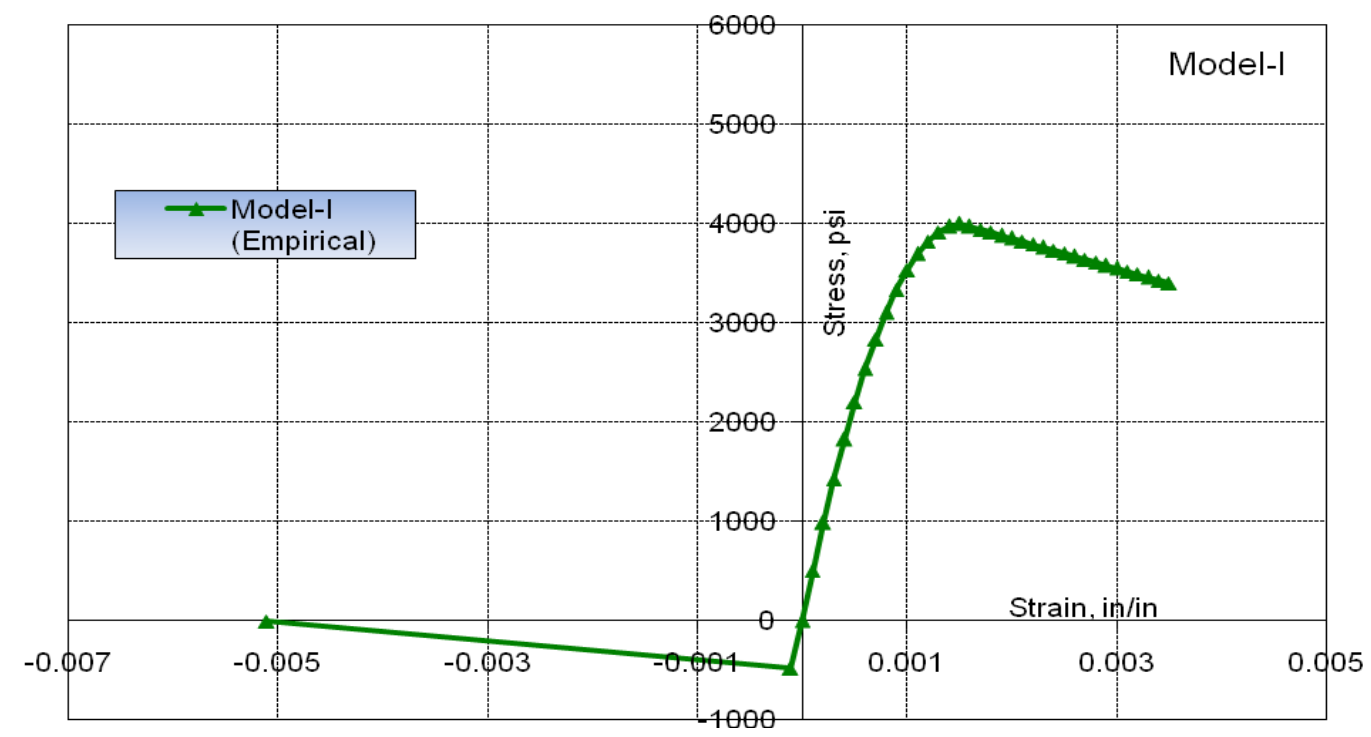

Figure 4.7 Model I: Stress-strain behavior of concrete in compression and tension

\section{Results and discussion}

Figures 4.8 to 4.10 show the damage contours in the seals for different thickness. With an 18 in. thick seal, simple vertical cracks are developed in the seal on the outby side. These cracks extend approximately 6 in. deep into the seal (Figure 4.8). Tensile damage is also observed near the top and bottom of the seal along the vertical rebar lines. This localized damage is due to the punching effect of the tensioned steel rebars on the thin cover of concrete. This localized damage do not have significant affect on the overall stability of the seal. It can also be observed from these figures that with the increase in seal thickness the extent of damage in the seal is reduced significantly. 

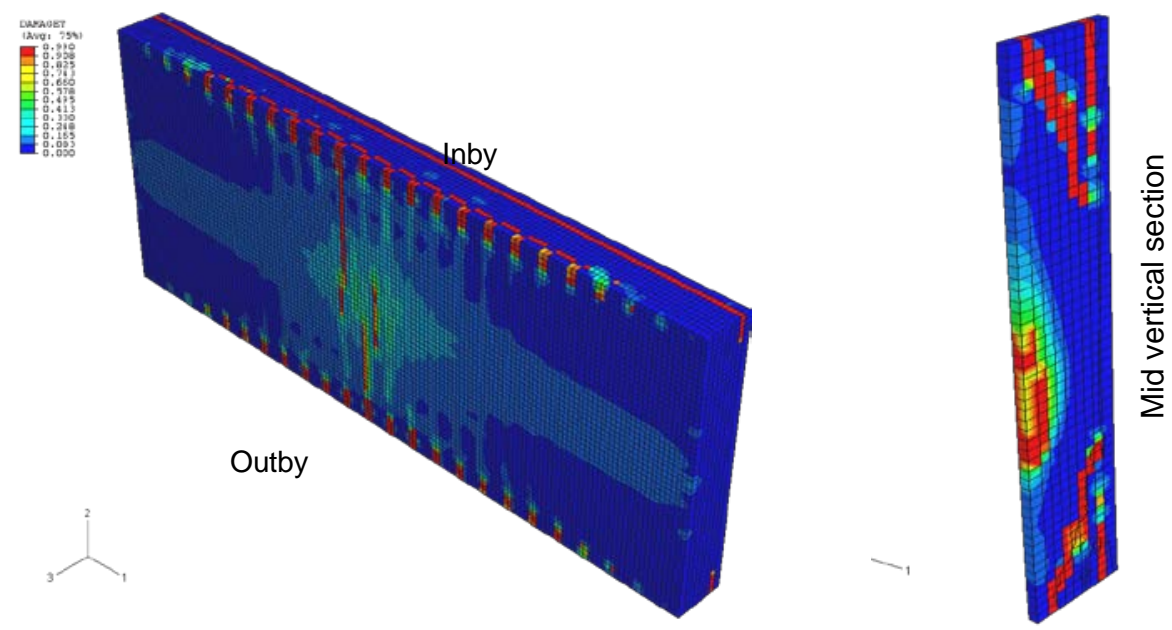

Figure 4.8 Model I: Tensile damage contours of 18 in. thick RC seal
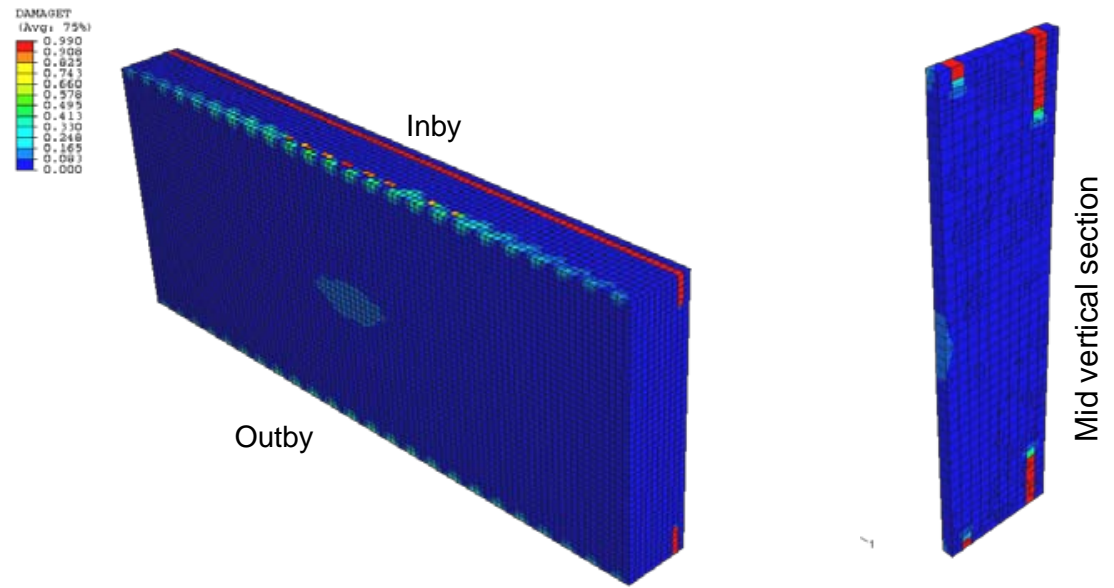

Figure 4.9 Model I: Tensile damage contours of 24 in. thick RC seal
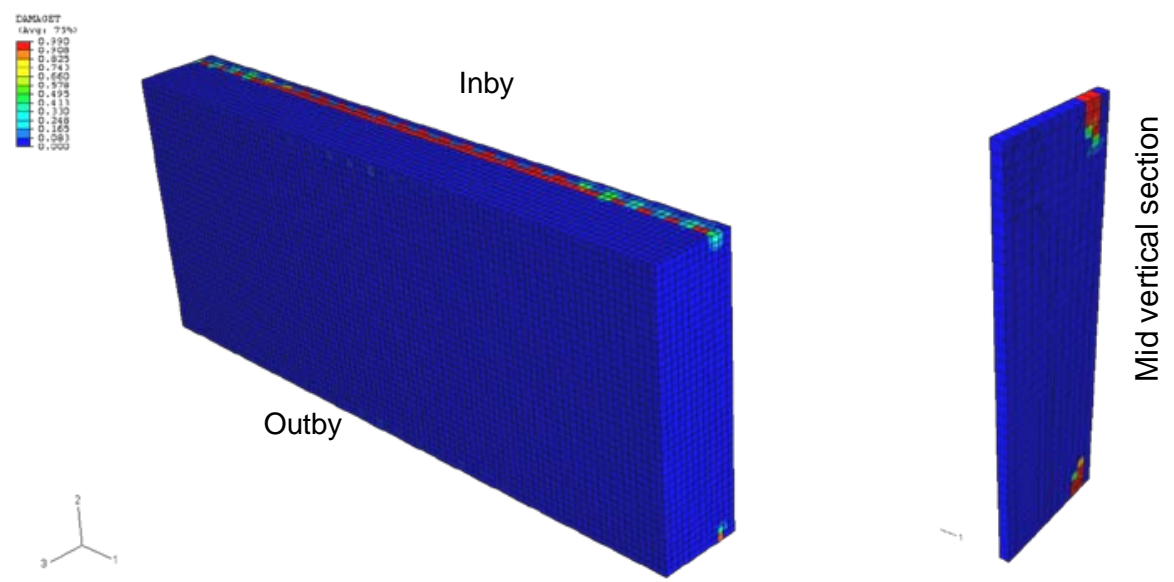

Figure 4.10 Model I: Tensile damage contours of 30 in. thick RC seal 
In order to arrive at a single value for the damage for the entire seal a volume weighted average damage factor (WADF) is calculated as:

$$
W A D F=\frac{\sum V_{e} \cdot D}{\sum V_{e}}
$$

where, $V_{e}$ is volume of element and $D$ is Damage factor of element

The weighted average damage factor decreased exponentially with an increase in seal thickness and is reaching a near constant value (Figure 4.11) when the seal thickness is around 30 in.

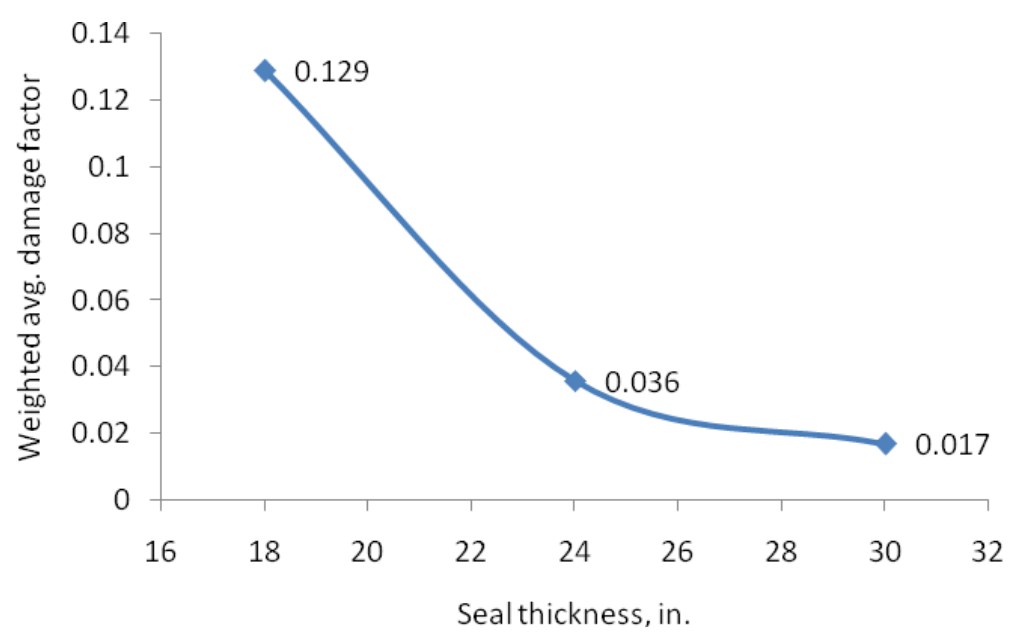

Figure 4.11 Model I: Volume weighted average damage factor

Figure 4.12 shows the history of axial forces developed in the rebars. The reinforcement rebars on the outby side experienced high tensile stress while the rebars on the inby side experienced high compressive stresses. The magnitude of these stresses is reduced significantly with an increase in seal thickness. Further, it can be observed from these results that the maximum amount of axial force developed in all these cases is well below the yield strength of steel. Figure 4.13 shows the lateral displacement history in the seal at mid point on the outby side. 

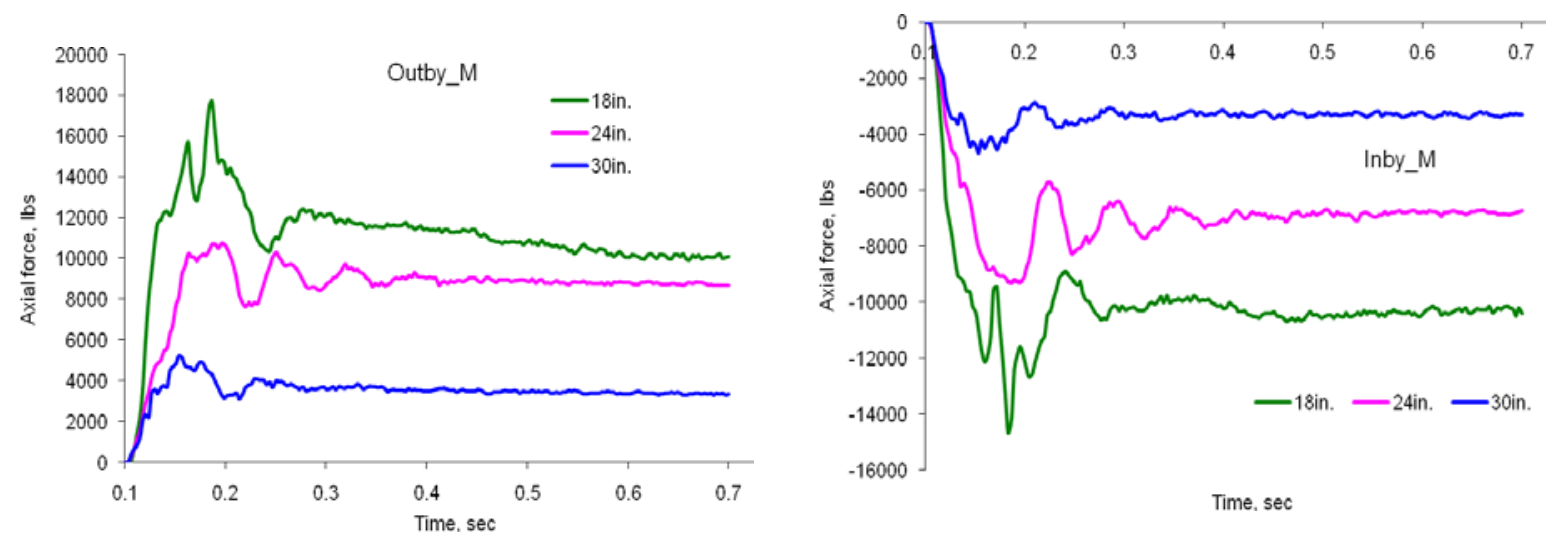

Figure 4.12 Model I: The history of axial forces in the center vertical rebar

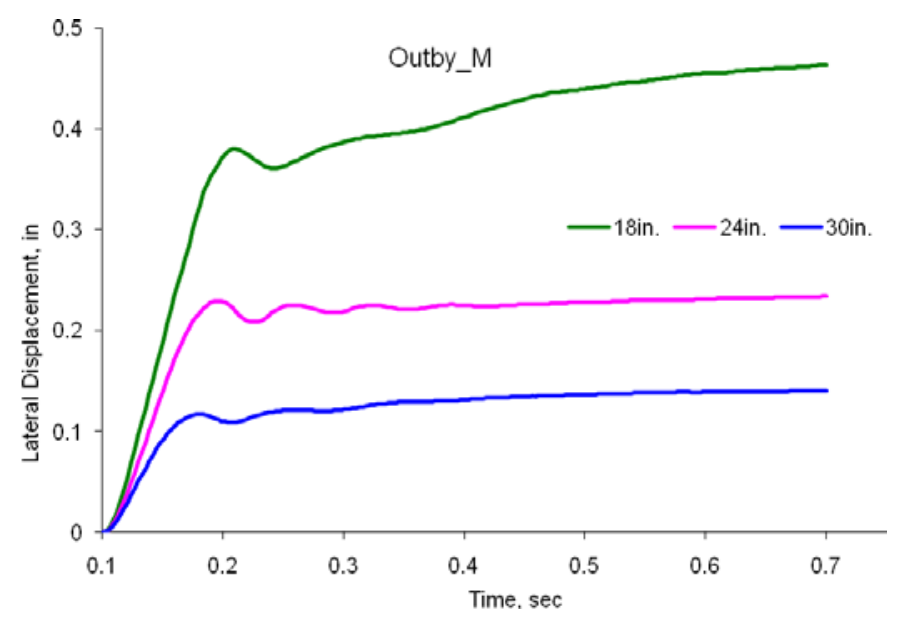

Figure 4.13 Model I: The history of lateral displacements different seal thickness

\subsection{Concrete Model II: CEB \& Barth and Wu Model}

The compressive part of this concrete material model was initially developed by Comite European Du Beton (CEB, 1970) and has been verified by Barth and Wu (2006) by comparing the complete load-deflection relationships and ultimate capacities resulting from the finite element analysis of two simply supported composite girders and a 4-span continuous composite steel bridge with experimental data. Simply supported composite girder experimental tests were conducted by Mans (2001) at the University of Nebraska and 
the 4-span continuous composite steel bridge experimental test was reported by Burdette and Goodpasture (1971). Barth and Wu (2001) used the finite element based software ABAQUS in their analysis.

The CEB compressive concrete model relates the stress-strain by the following equation which is a function of only one parameter $\left(f^{\prime}{ }_{c}\right)$, yet it can accurately reflect the variation in response due to different strengths that are observed in practice (Hognestad et al., 1955). However, it is noted that the compressive concrete constitutive law appears to have only minor effects on the overall results (ASCE, 1993; Cope and Rao, 1981).

$$
f_{c}=\frac{0.85 f_{c}^{\prime}\left(a-206,000 \varepsilon_{C}\right) \varepsilon_{C}}{1+b \varepsilon_{C}}
$$

where, $\quad a=6193.6\left(0.85 f_{c}+1.015\right)^{-0.953}$

$b=8074.1\left(0.85 f_{c}+1.450\right)^{-1.085}-850$

$f_{c}=28$-day concrete compressive strength, ksi

$\varepsilon_{C}=$ compressive strain in concrete

ABAQUS requires the inelastic material properties to be input in the form of true (Cauchy) stress $\left(\sigma_{\text {true }}\right)$ and true (logarithmic) strain $\left(\varepsilon_{\text {true }}\right)$, which can be calculated from the engineering stress $\left(\sigma_{e n g}\right)$ and engineering strain $\left(\varepsilon_{e n g}\right)$ using equations (4.5) and (4.6).

$$
\begin{aligned}
& \sigma_{\text {true }}=\sigma_{\text {eng }}\left(1+\varepsilon_{\text {eng }}\right) \\
& \varepsilon_{\text {true }}=\ln \left(1+\varepsilon_{\text {eng }}\right)
\end{aligned}
$$

Using the above equations, the stress-strain relationship in compression is plotted in figure 4.14. Based on data available in the literature (Wittry, 1993), a value of 0.0038 is assumed for the maximum compressive strain $\left(\varepsilon_{c \operatorname{cmax}}\right)$. This value is typical American Concrete Institute (ACI) maximum compressive strain value and is thought to be conservative since higher values of crushing strain have been reported in physical tests (Wittry, 1993). 


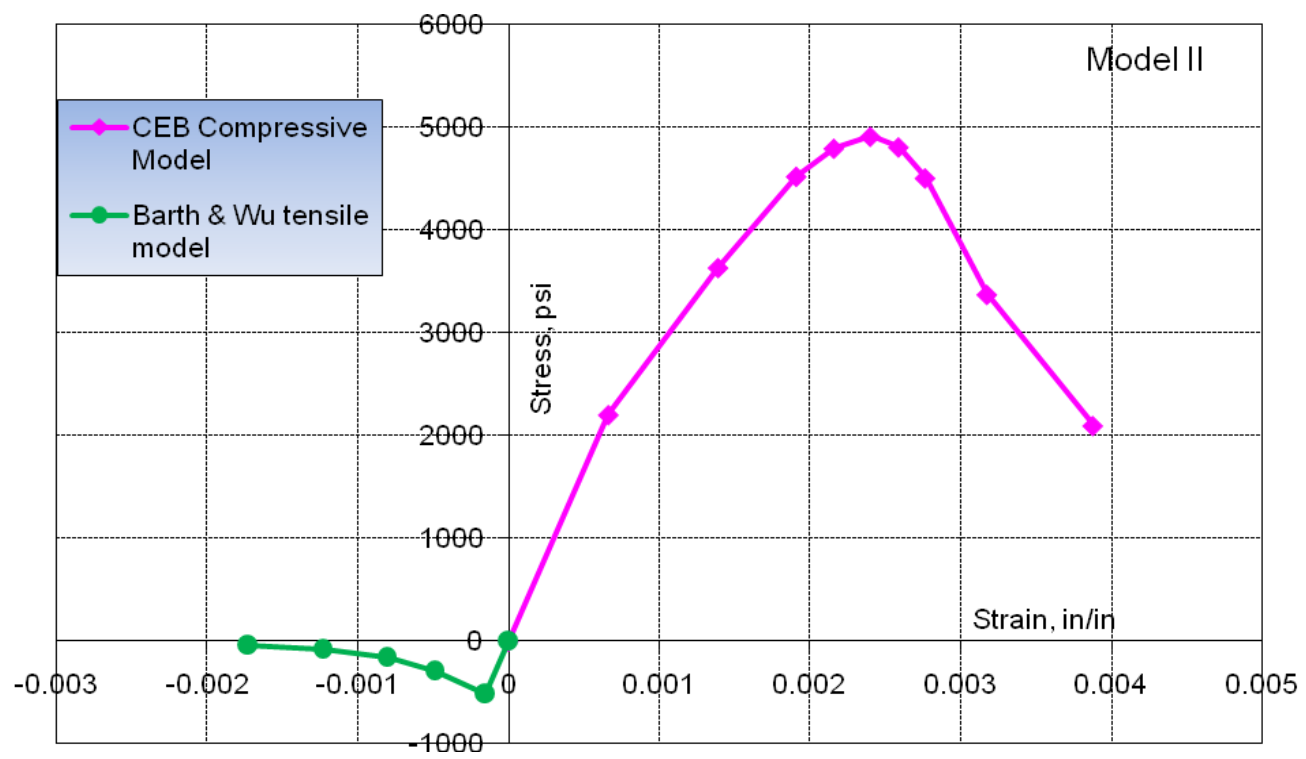

Figure 4.14 Model II: Stress-strain behavior of concrete in compression and tension

Barth and Wu (2006) used a non-linear concrete tension model in their analysis, according to which the tensile stress increases linearly up to concrete cracking stress $\left(f_{t}\right)$ and then unloads gradually (Figure 4.14). A parabolic curve passing through the concrete cracking point $\left(f_{t}, \varepsilon_{t}\right)$ and concrete maximum strain point $\left(\varepsilon_{t u}\right)$ is suggested for the gradual unloading portion by Barth and Wu (2006). Beyond the cracking stress, concrete exhibits a significant tension stiffening behavior and the tensile load carrying capacity of the concrete decreases exponentially. The concrete and the internal steel reinforcement interaction is approximately considered by the tension stiffening behavior of the concrete.

According to Barth and Wu (2006) a numerically stable solution can be achieved by introducing the tension stiffening in the concrete model; however, this may cause a large deviation in the results if too large tension stiffening is included in the analysis.

\section{Concrete Damaged Plasticity}

The Concrete Damage Plasticity option in ABAQUS is used to define the yield function and flow potential. An isotropic damaged elasticity in combination with isotropic tensile and compressive plasticity is used in the Concrete Damage Plasticity model to better represent the inelastic behavior of concrete. 
This concrete damaged plasticity model uses the yield function proposed by Lubliner et al. (1989) with the modifications suggested by Lee and Fenves (1998) to consider different evolution of strength characteristics under tension and compression. The evolution of the yield surface is defined by the hardening variables (equivalent tensile and compressive plastic strains).

The equivalent tensile and compressive plastic strain can be automatically calculated by ABAQUS using the Concrete Tension Stiffening and Concrete Compression Hardening options, and the tensile and compressive damages by using the Concrete Tension Damage and Concrete Compression Damage options, respectively.

Figure 4.15 shows the relationship between concrete damage and plastic strain for compression and tension (Barth et al., 2006). A damage variable close to 1.0 indicates complete failure of the material and, close to 0.0 indicates no-damage in the material.

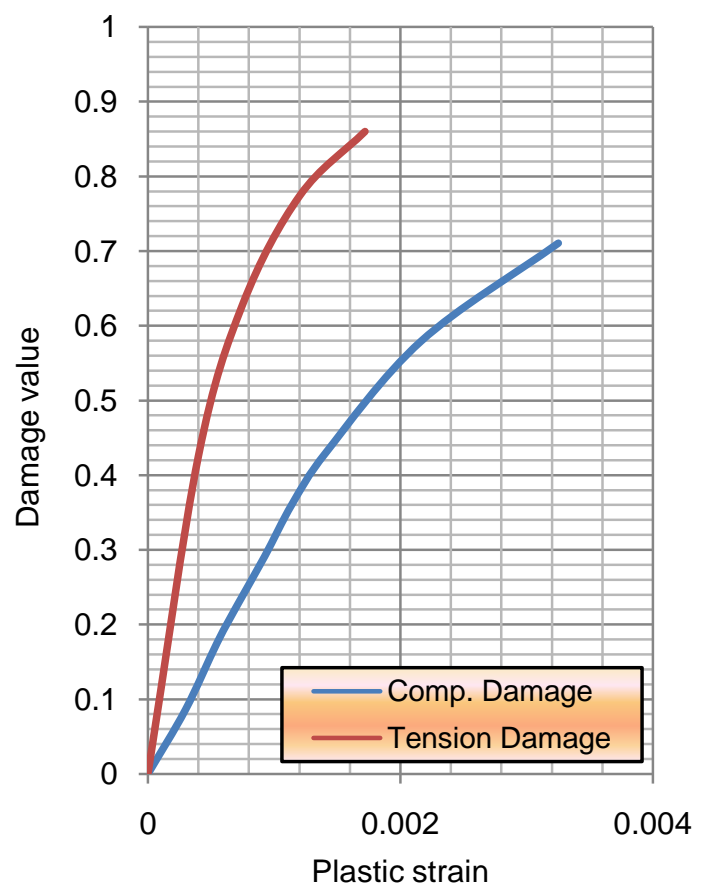

Figure 4.15 Model II: Relationship between concrete damage and plastic strain

\section{Results and Discussion}

The CEB \& Barth and Wu model predicts similar results when compared to the empirical concrete model, but is more conservative. The empirical model predicted no damage in the 
30 in. thick seal, but the CEB \& Barth and Wu model predicted some damage (horizontal crack at mid height of the seal) as shown in the figure 4.16. This tensile cracking in the concrete resulted in transfer of the stresses to the steel rebars on the outby side. Figure 4.17 shows the history of tensile forces in the central rebar on the outby side. The tensile forces in the rebar increased sharply to about $13,000 \mathrm{lbs}$ compared to only 5,000 lbs with empirical model. In either model, the tensile stresses in the rebars are much lower than the yield strength of the steel. Figure 4.18 show the plastic strain in the steel rebars for 30 in thick seal. Figure 4.19 shows the history of the lateral displacements on the outby side of the seal. A weighted average damage factor of about 0.0321 is calculated for this 30 in. thick seal.
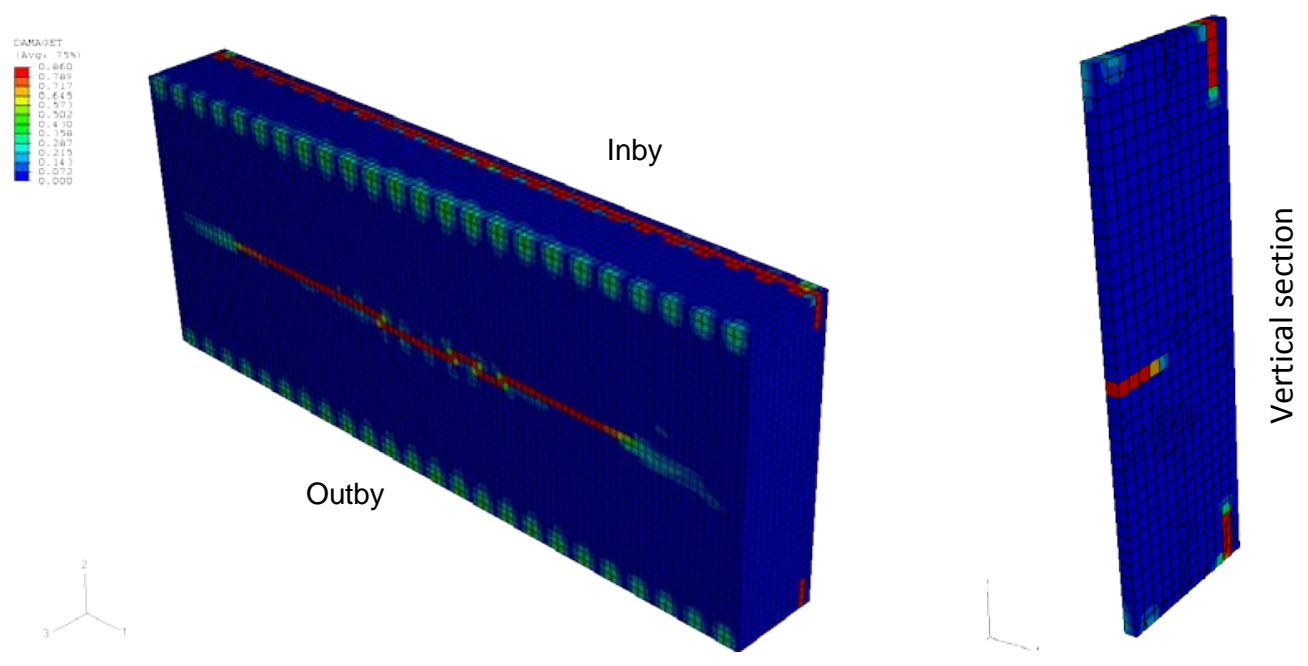

Figure 4.16 Model II: Tensile damage contours of 30 in. thick RC seal

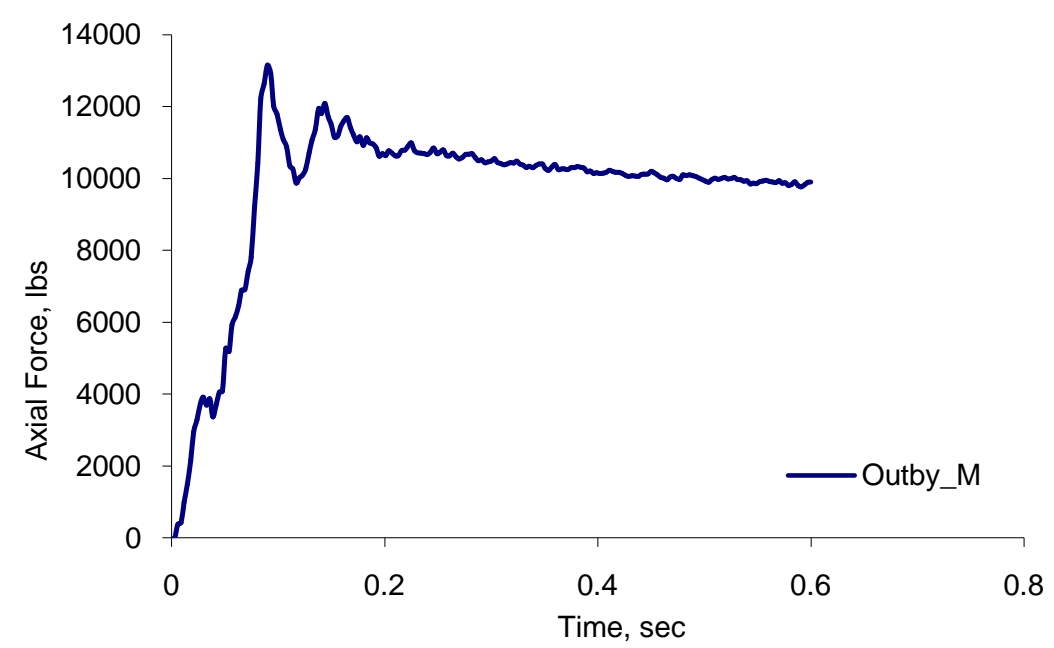

Figure 4.17 Model II: History of axial forces in the center vertical rebar for 30 in. thick seal 


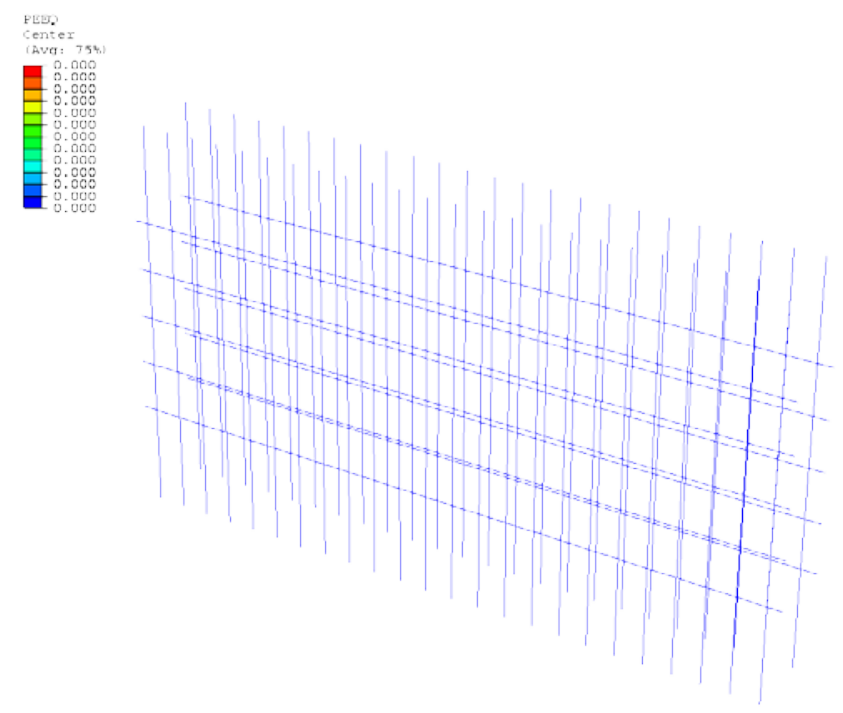

Figure 4.18 Model II: Plastic strain in the steel rebars for 30 in. thick seal

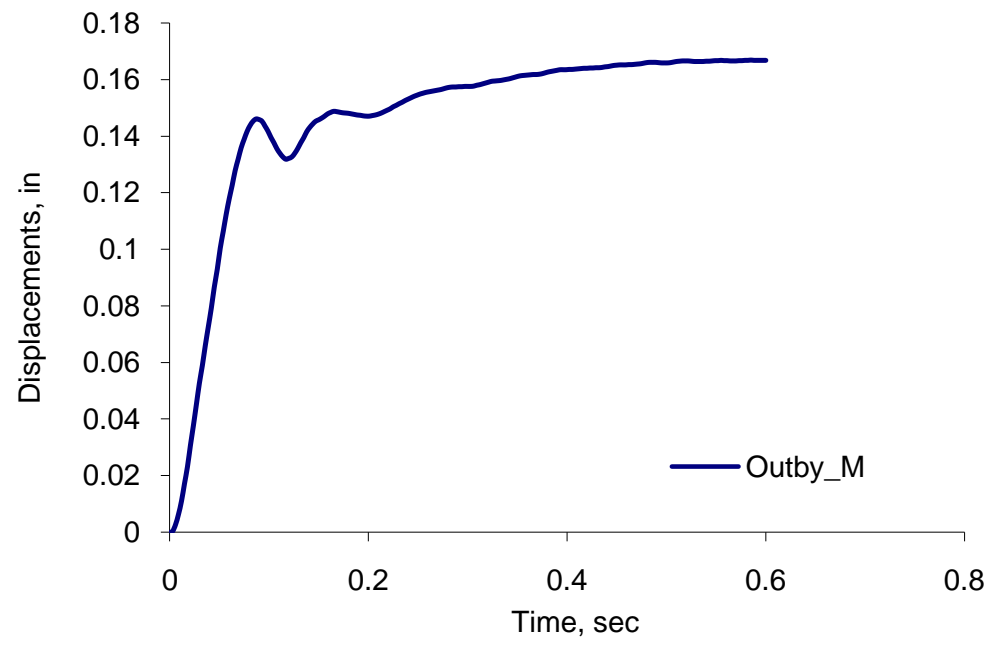

Figure 4.19 Model II: The history of lateral displacements for 30 in. thick seal

\subsection{Chapter Summary}

The preliminary work on the concrete behavior, described in Section 4.1, clearly suggests the importance of the complete stress-strain behavior of the concrete in compression and tension, especially the post peak behavior of the concrete in both compression and tension. 
Although the empirical concrete model described in Section 4.2 provides complete data on stress-strain behavior of the concrete in compression and tension, lacks data on the damage variables for use with ABAQUS. The damage data available with CEB \& Barth and $\mathrm{Wu}$ concrete model was used with this empirical concrete model. The empirical concrete model predicts acceptable results.

The CEB \& Barth and Wu concrete model described in Section 4.3 has been verified for use with finite element analysis, and provides complete data on stress-strain behavior of the concrete and the damage variables in both compression and tension. The CEB \& Barth and Wu concrete model predicts similar results compared to that of empirical concrete model, but is more conservative.

Since the CEB \& Barth and Wu concrete model has been verified and has complete data set available for use with ABAQUS, and predicts conservative results compared to empirical concrete model, it is decided to use CEB \& Barth and Wu concrete model for further use in this dissertation. 


\section{Chapter 5 VERIFICATION CASES}

lthough NIOSH engineers conducted extensive full-scale explosion tests in LLEM on
mine seals constructed from various types of construction materials, there were only two tests that were conducted on seals constructed from concrete like materials with internal steel reinforcement that meet the reinforced concrete seal criteria (Zipf et al., 2008). Further, because of the unavailability of the original records on these explosion tests, complete constitutive behavior of the concrete used in the construction of these seals was not available. These seals were tested for the old 20 psi design standard. In both these tests, explosion overpressure was created by igniting a methane-air mixture in a confined area. The explosion overpressure was monitored using pressure transducers and the lateral displacements on the outby side of the seal and at the center were monitored using LVDT's. The complete details on these full-scale explosion tests are provided in the following sections.

In this dissertation, the full-scale experimental test data available from these two cases were used for verification of the results predicted from the finite element models. Part of the work on simulating the verification cases has been done by Yassien (2008).

\subsection{Case I: Insteel 3-D Seal}

\section{Seal construction details}

The Insteel 3-D seal marketed by Precision Mine Repair, was constructed with concrete, steel rebars and wires. Figures 5.1 to 5.4 show the construction details of the seal. This seal survived the full-scale methane explosion test conducted in LLEM.

To construct the seal, vertical holes are drilled in two sets into the roof and floor to a depth of at least 12 in. and evenly-spaced across the entry on less than $2 \mathrm{ft}$ centers. The vertical holes in the front and rear rows offset from each other laterally as shown in the plan view of Figure 5.1. Three horizontal holes are also drilled into each rib to a depth of $12 \mathrm{in.}$ on $2 \mathrm{ft}$ centers, and, $3 \mathrm{ft}$ long \#8 steel rebar anchors are grouted into these vertical and horizontal holes. No hitching is made in the roof and floor. 
The \#8 reinforcement rebars are tied to the corresponding rebar anchors in the roof and the floor. Two sets of \#3 horizontal steel reinforcement rebars are also laid from rib to rib and spaced less than 16 in. apart as shown in the Figure 5.2. Insteel-3D panels shown in figure 5.3 are laid across the entry and tied to the front and rear rows of vertical rebars. Stayfoam backing was used on the inby side to hold the concrete in place while spraying (Figure 5.4). Shotcrete/concrete (362 bags of Pak Mix Pro Line concrete mix or 25,340 lbs of dry mix) was applied to the entire structure to a total thickness of about 11.5 in.

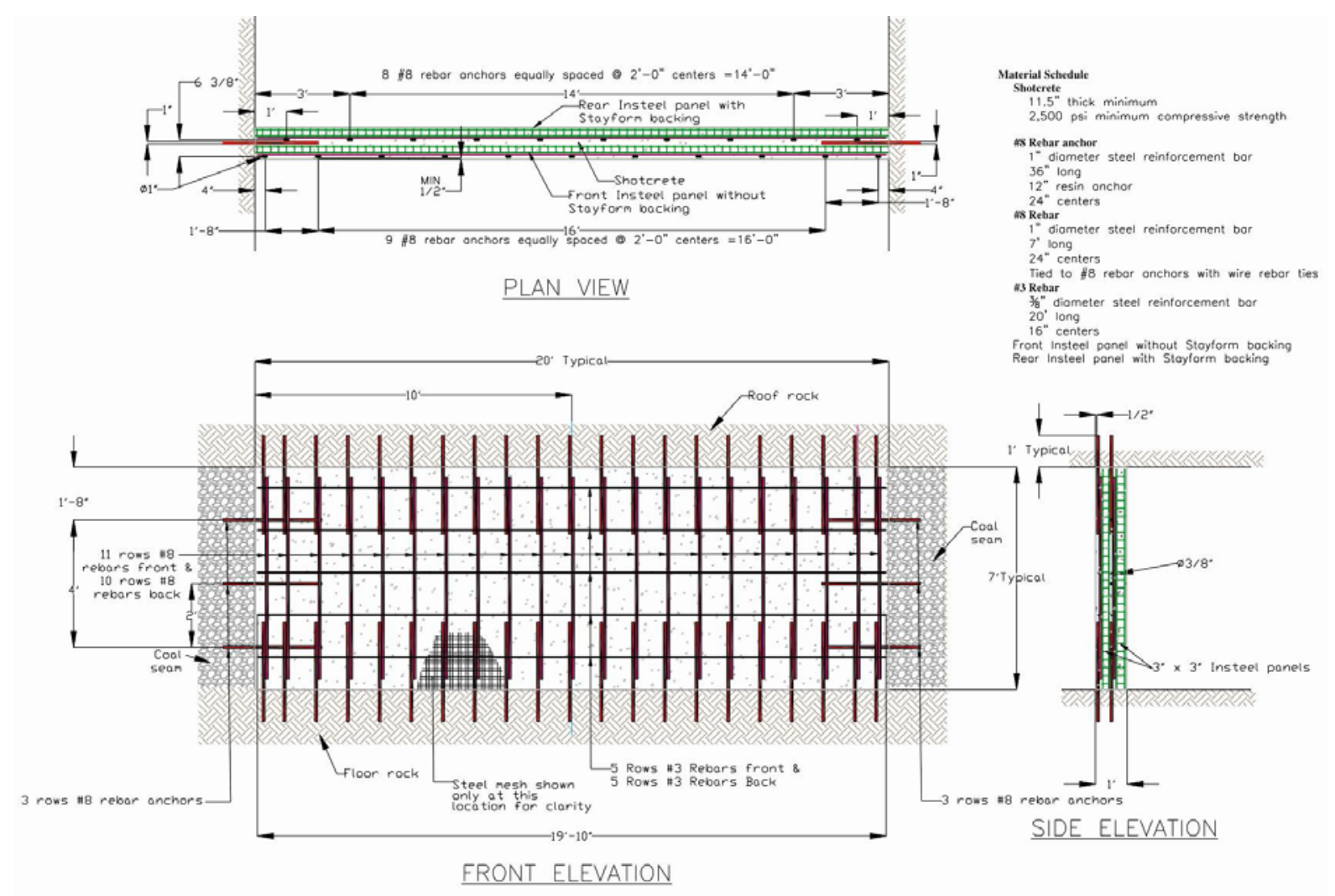

Figure 5.1 Schematic drawing of Insteel 3-D seal, Precision Main Repair (Zipf et al., 2008) 


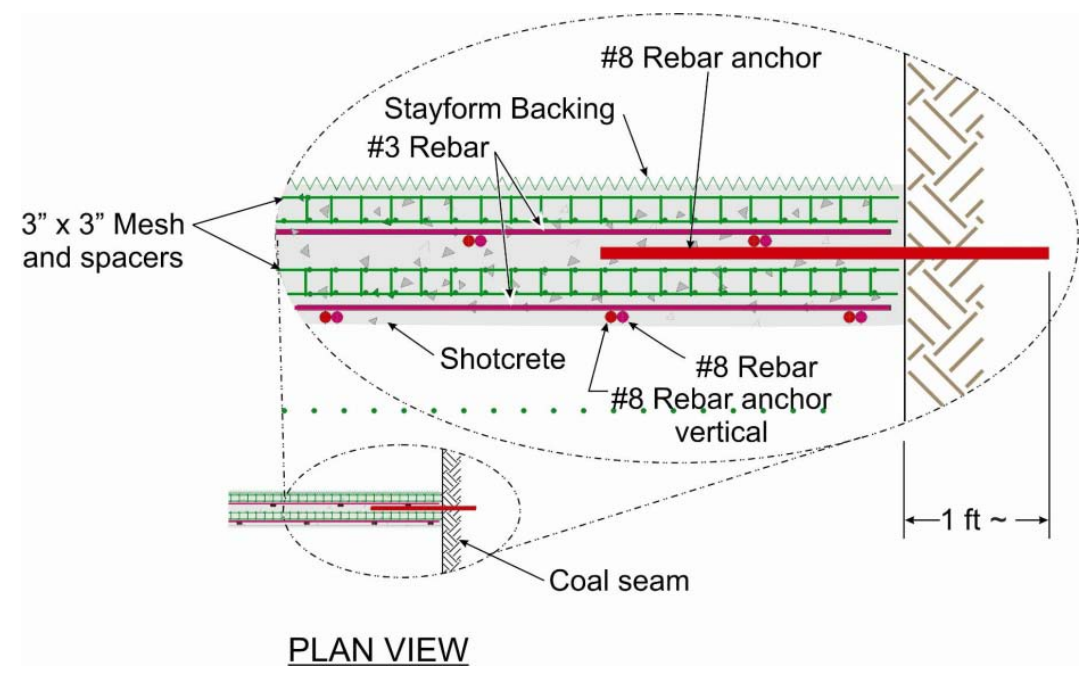

Figure 5.2 Detailed plan view of Insteel 3-D seal (Zipf et al., 2008)

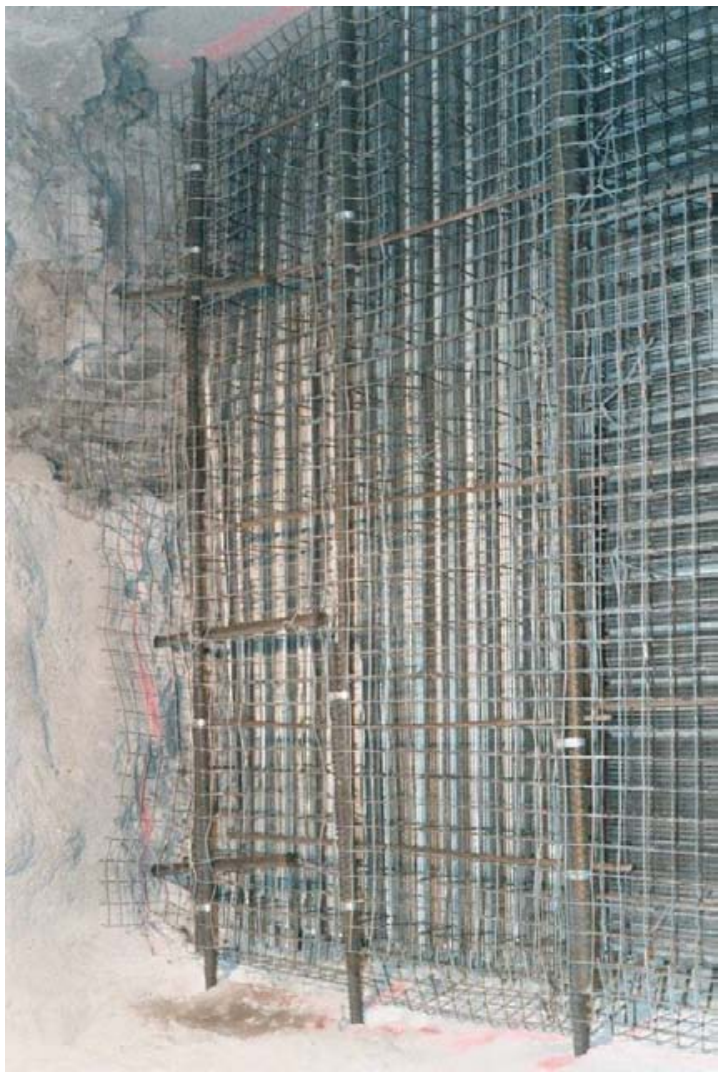

(a)

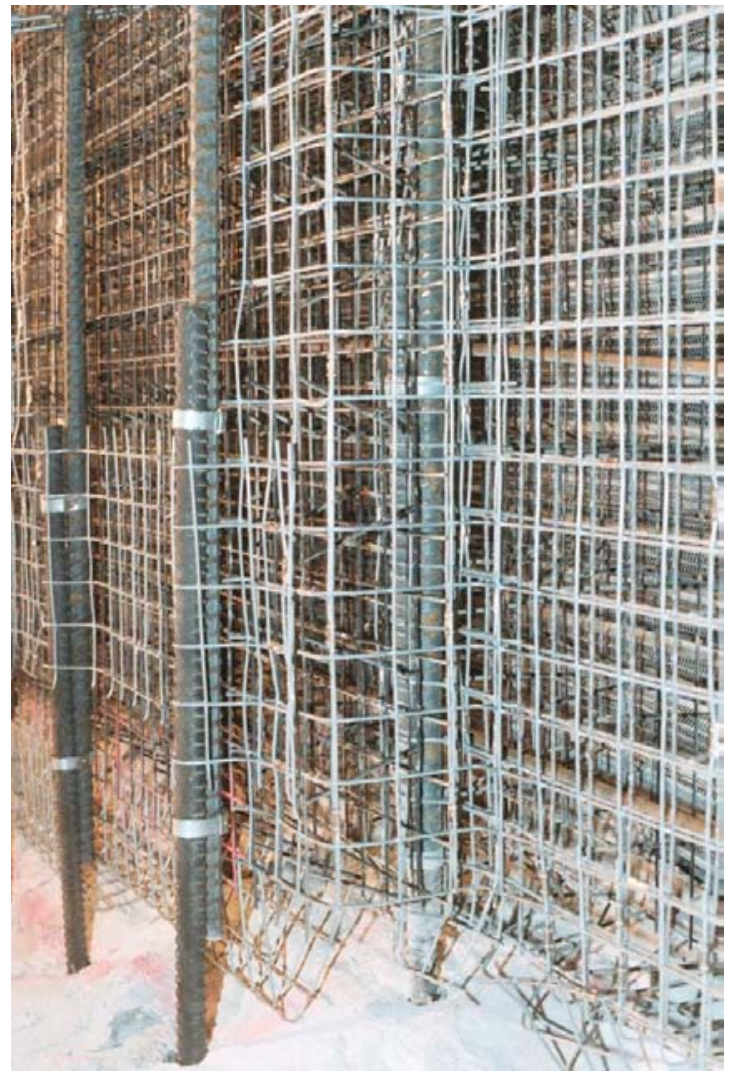

(b)

Figure 5.3 Insteel 3-D seal under construction (Zipf et al., 2008) 


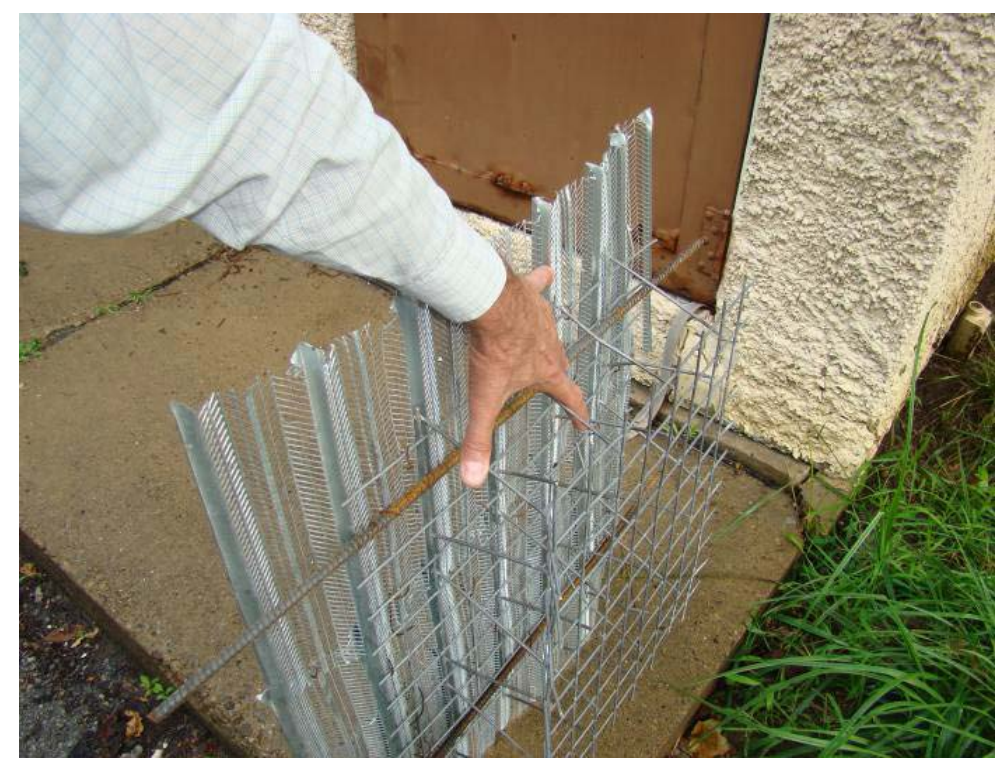

Figure 5.4 Model of Insteel 3-D seal with stayform backing (Zipf et al., 2008)

Summary of the seal construction details and remarks are presented in Table 5.1.

Table 5.1 Seal construction details: Case I

\begin{tabular}{l|l|l}
\hline Parameter & Dimension & Remarks \\
\hline Entry dimensions (height x width) & $7 \mathrm{ft}$ x $19 \mathrm{ft}$ & Survived the explosion. \\
Seal thickness & $11.5 \mathrm{in.}$ & Maximum recorded \\
Horizontal rebar size \& spacing & $\# 3$ and 19 in. & pressure is 57.5 psi and \\
Vertical rebar size \& spacing & $\# 8$ and 24 in. & max. displacement is \\
Anchor rebar size & $\# 8$ & 0.08 in. \\
Strength of concrete used & $>2,500 \mathrm{psi}$ & \\
Steel grade & Grade 60 & \\
\hline
\end{tabular}

\section{Instrumentation details}

LVDT's were installed on the outby side to record the lateral displacement history of the seal at the center. To record the explosion pressure loading on the seal, pressure transducers were installed in the entries on the inby side of the seal. The recorded explosion overpressure and the lateral displacements from the explosion test are presented in Figure 5.5. The explosion 
pressure reached a maximum value of 57 psi in just 0.1 sec and the lateral displacements reached about 0.075 in.

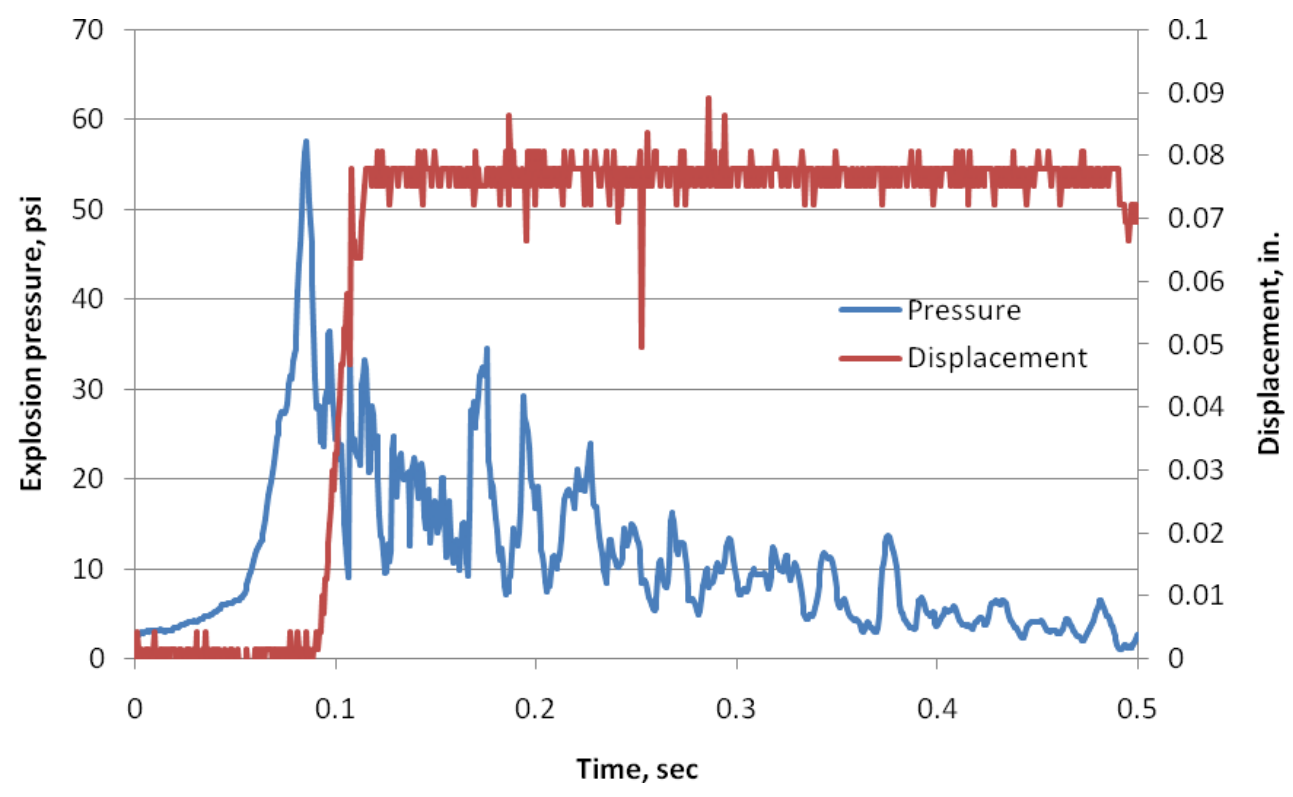

Figure 5.5 Recorded history of explosion overpressure and seal displacement

\section{Case I: ABAQUS model}

Using the seal construction details described in the previous section a finite element based ABAQUS model was constructed. The exact pressure-time curve (Figure 5.5) recorded in the full-scale explosion test was used for applying the explosion loading to the seal in the model. The CEB \& Barth and Wu concrete constitutive model discussed in Section 4.3 was used for simulating the non-linear behavior of the concrete.

\section{Case I: Results and discussion}

The history of lateral displacement at the center of the seal on the outby face predicted by the model and the measured displacements from LVDT are plotted in the figure 5.6. The predicted displacements from the model and the measured displacements match very well with some exceptions. The rise time of the lateral displacement matches very well with the measured rise time, but the magnitude of peak displacement predicted from the model is offset by about 0.02 in. from the measured value. Further, it can be observed from figure 5.6 that lateral displacements predicted by the model are fluctuating and dampening over time. 
The measured displacements are almost steady at about 0.08 in., because the LVDT used in the measurement was not spring-loaded and attached to the structure. The LVDT measurements are valid up to the peak displacement but the measurement system could not record the lateral oscillations of the structure. Figure 5.7 shows the contours of lateral displacements in the seal as well as in the steel rebars at $0.125 \mathrm{sec}$ time.

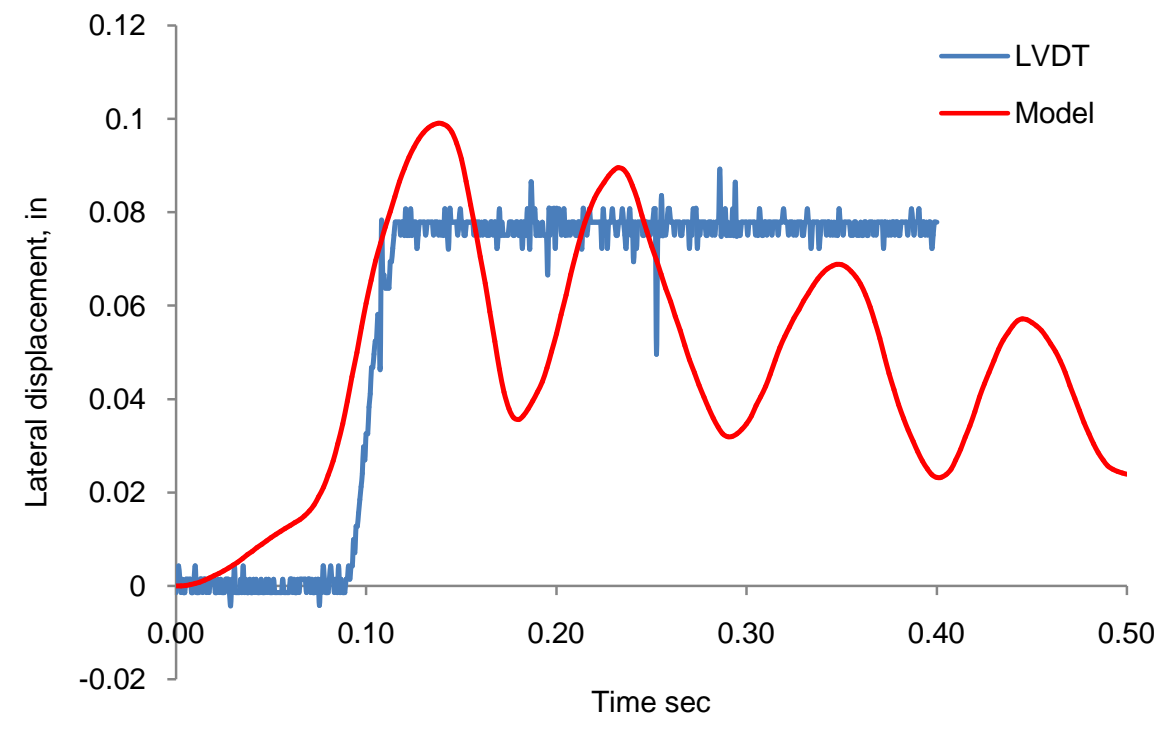

Figure 5.6 Case I: Predicted and measured lateral displacement-time curves

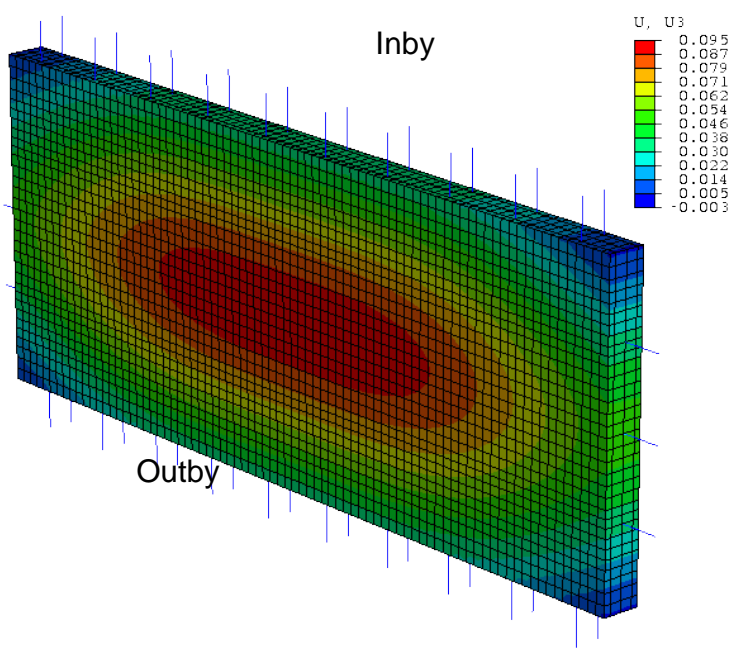

(a)

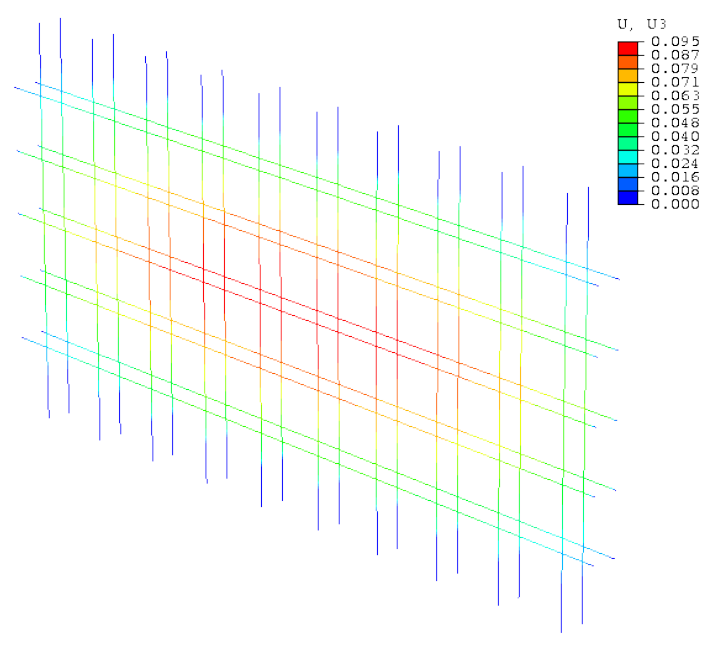

(b)

Figure 5.7 Case I: Lateral displacement contours (in both seal and rebars) at $0.125 \mathrm{sec}$ 
Field observations from the explosion test show that the seal survived the explosion with very little damage. The ABAQUS model also predicts similar results. Figure 5.8 shows the damage contours in the seal at $0.125 \mathrm{sec}$. A small horizontal tensile damage crack extending to about half the thickness of the seal is observed at mid height of the seal. The volume weighted average damage factor is calculated to be 0.01485 for this seal. The rebars in the seal show no signs of yielding (figure 5.9).
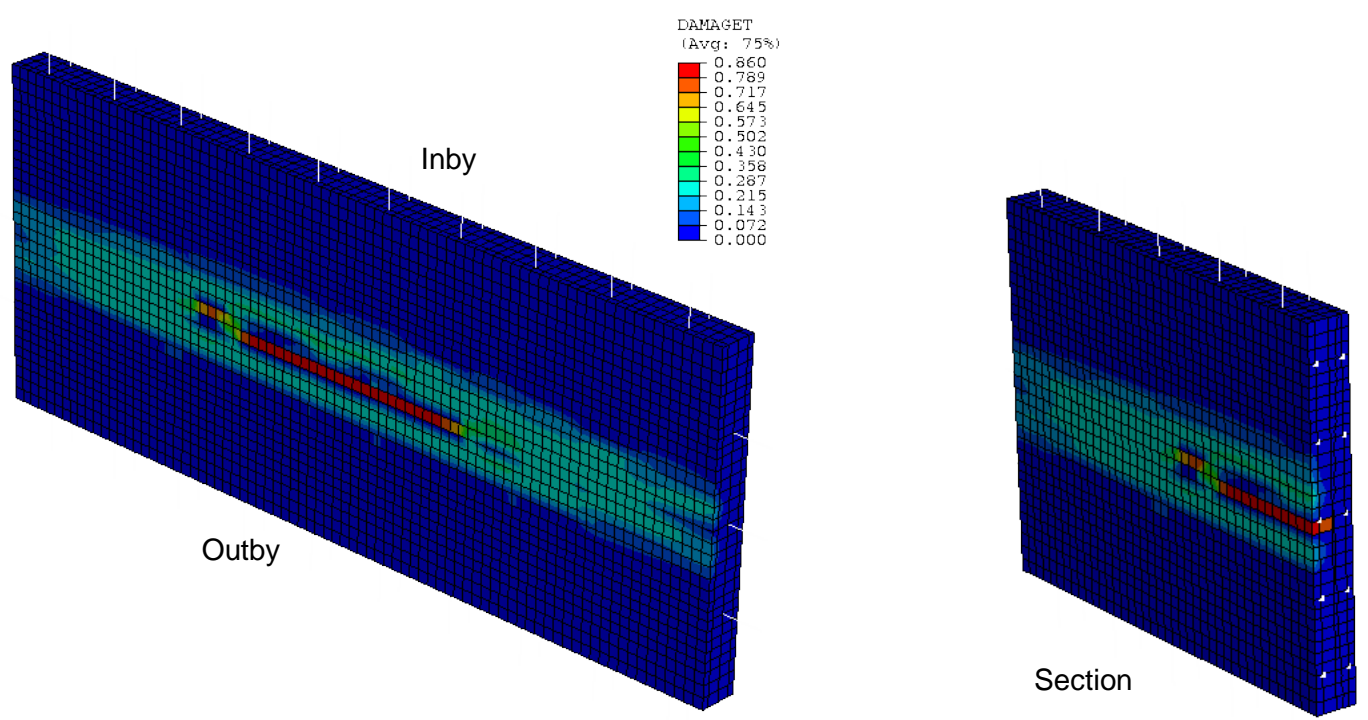

Figure 5.8 Case I: Damage contours in the seal at $0.125 \mathrm{sec}$

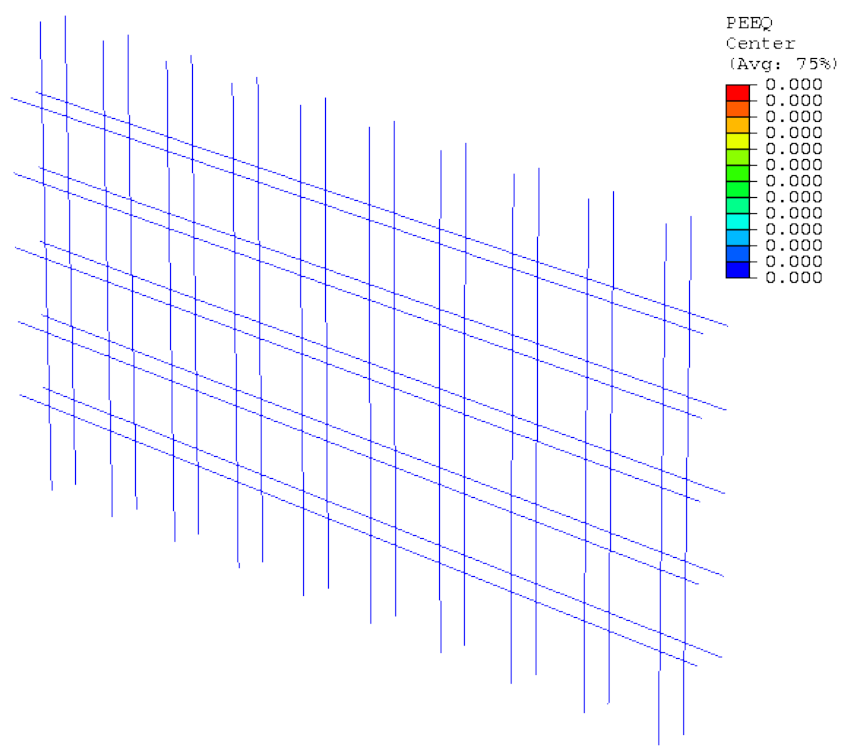

Figure 5.9 Case I: Plastic strain in the steel rebars at $0.125 \mathrm{sec}$ 


\section{Case I: Conclusion}

The CEB and Barth and $\mathrm{Wu}$ concrete model used in the ABAQUS verification model predicted very close results as compared to the measured experimental results. This verification case added some confidence to the modeling technique used in this dissertation.

\subsection{Case II: Insteel 3-D Seal}

Construction of this seal was very much similar to the one in the Case I with small differences. Unlike Case I, only one row of vertical reinforcement rebars were used in the seal construction to anchor the seal to the roof and floor. The specifications of reinforced rebars, anchors, and Insteel 3-D panels were the same as in Case I. The Shotcrete (203 bags of Pak Mix Pro Line concrete mix or 15,631 lbs of dry mix) was applied to the entire structure to only a total thickness of about 7 inches.

The recorded explosion overpressure and the lateral displacements from the explosion test are presented in figure 5.10.

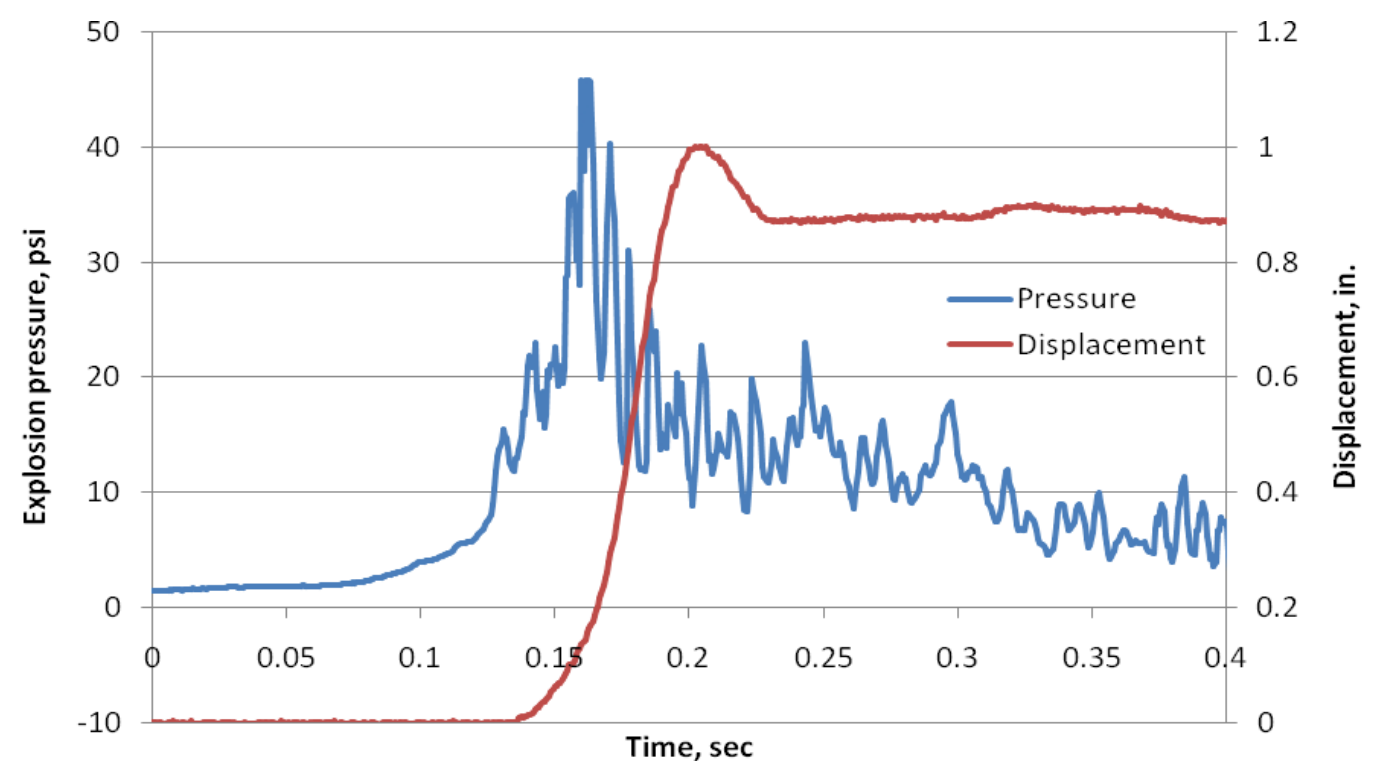

Figure 5.10 Case II: Recorded history of explosion overpressure and seal displacement 


\section{Case II: ABAQUS model}

A finite element based ABAQUS model was constructed using the available seal construction details. The exact pressure-time curve (figure 5.10) recorded in the full-scale explosion test was used for applying the explosion loading to the seal in the model. Initially the CEB \& Barth and Wu concrete constitutive model discussed in Section 4.3 was used without any modifications for simulating the non-linear behavior of the concrete.

\section{Case II: Results and discussion}

With the CEB \& Barth and Wu concrete material, the ABAQUS model could not predict results very close to the experimental results. In the explosion test, the seal showed about 1 in. of lateral displacements in the middle, but the ABAQUS model predicted only about 0.44 in. Figure 5.11 shows the history of lateral displacements recorded from the full-scale experimental test and from the ABAQUS model. Figure 5.12 shows the contours of lateral displacements in the seal and rebars at 0.24 sec.

Although the ABAQUS model predicted very small lateral displacements compared to the experimental results, it did predicted extensive tensile damage in the model on the outby face of the seal. But, the observations from the explosion tests concluded that the seal had survived the explosion test. Figure 5.13 shows the damage contours in the model.

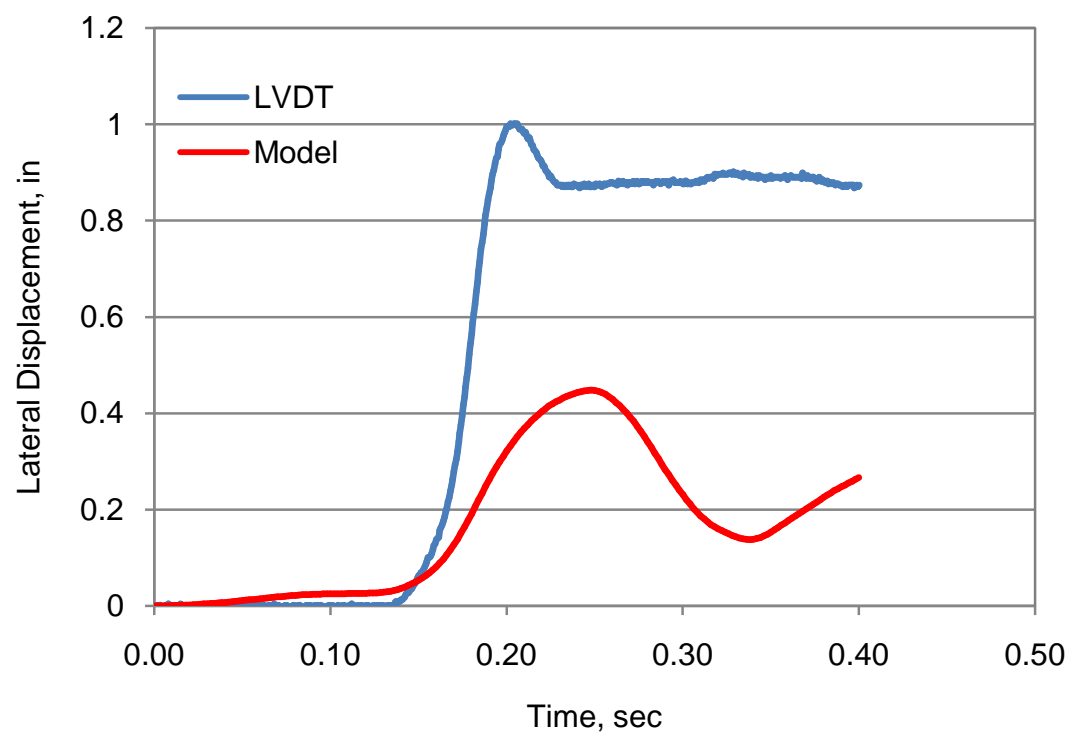

Figure 5.11 Case II: Predicted and measured lateral displacement-time curves 


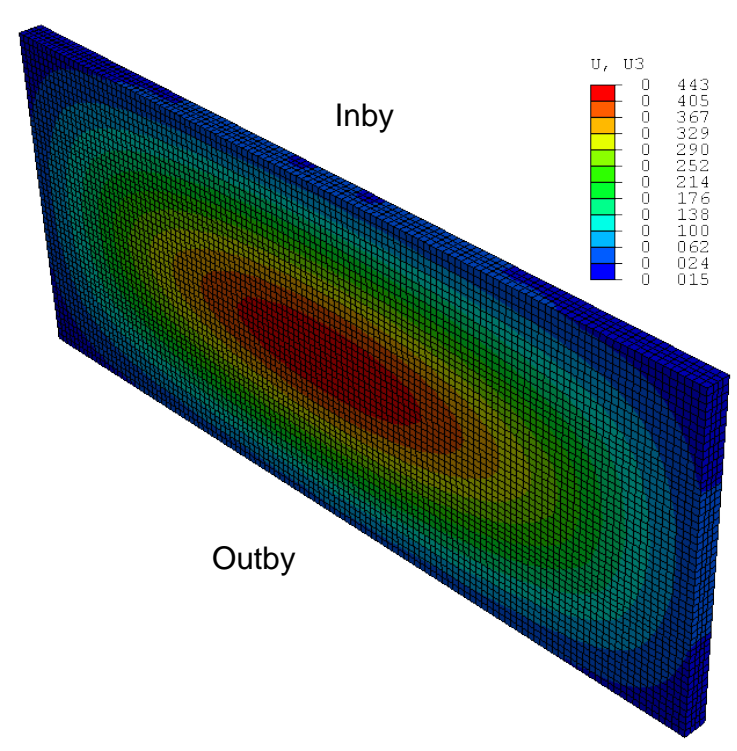

(a)

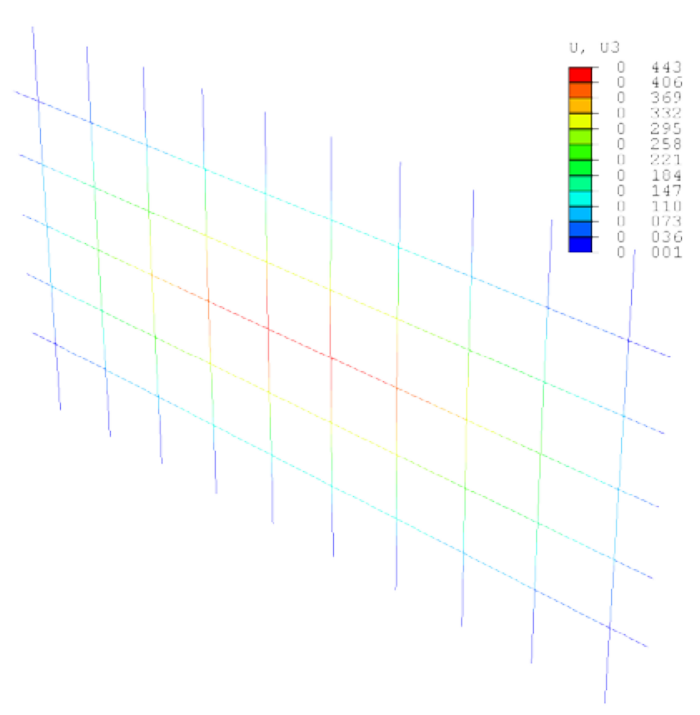

(b)

Figure 5.12 Case II: Lateral displacement contours (in both seal and rebars) at $0.24 \mathrm{sec}$
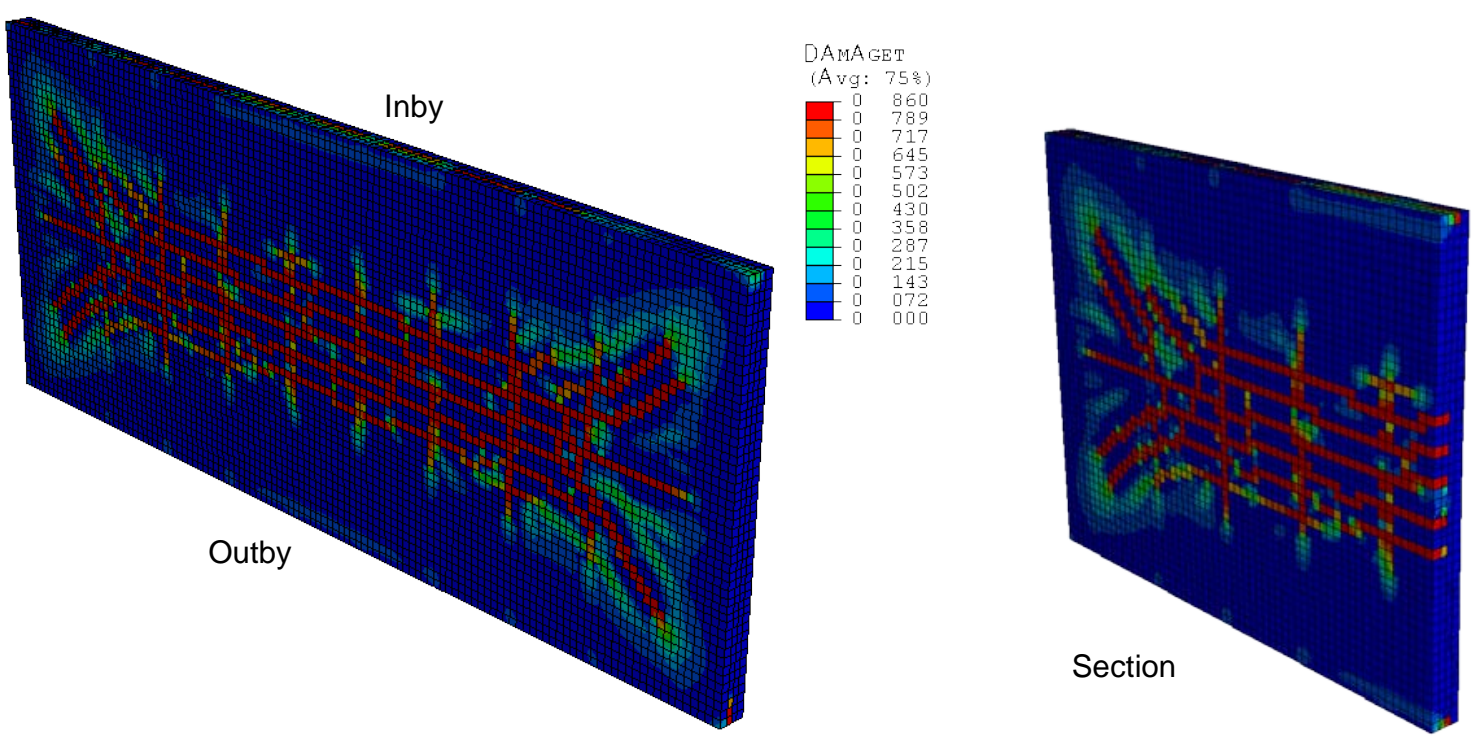

Figure 5.13 Case II: Damage contours in the seal at $0.24 \mathrm{sec}$

Although NIOSH reported that the minimum strength of the concrete used in the construction of the seal was 2500 psi, no other data pertaining to the concrete constitutive behavior is available. 
It was decided to change the characteristics of the concrete constitutive behavior in the model in order to produce model results close to the experimental results. Various combinations of ultimate strength of concrete in compression and tension, post peak behavior of the concrete in both compression and in tension, and damage variables of the concrete were tried to match the experimental results.

The concrete constitutive behavior shown in figure 5.14 predicted very close lateral displacements with the experimental results. This stress-strain curve was calculated using the empirical equations presented in Section 4.2. Figure 5.15 shows the relationship between concrete damage variables and plastic strain used in this model.

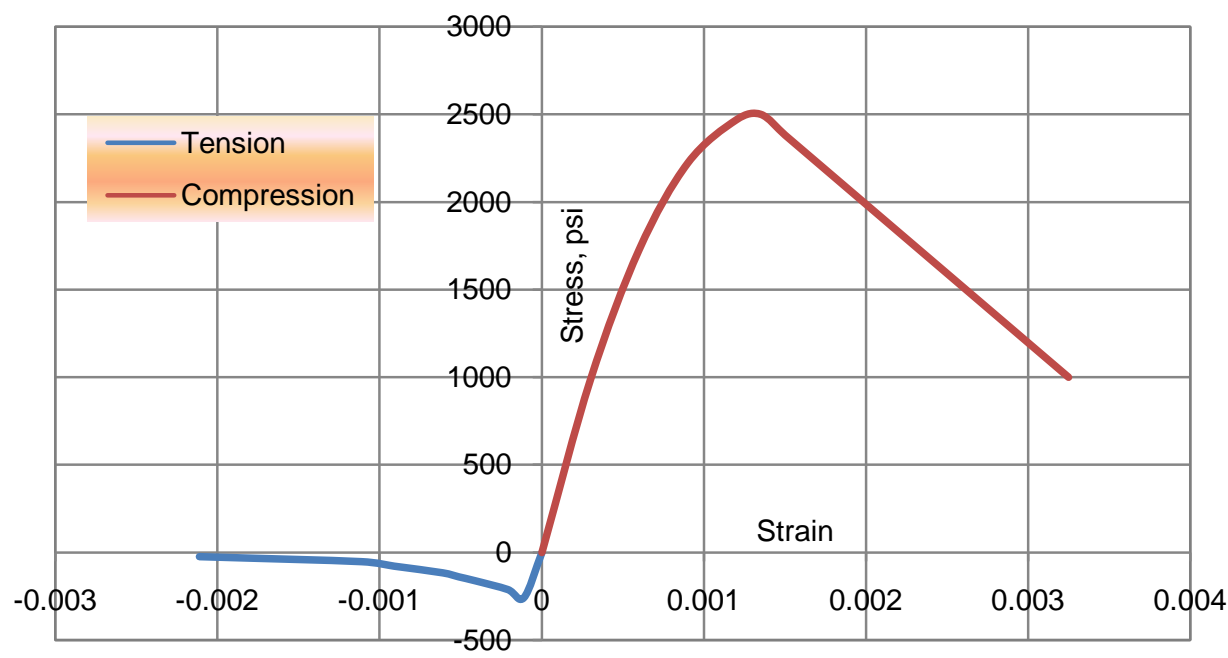

Figure 5.14 Modified concrete stress-strain behavior in compression and tension

Although the model predicted very close maximum lateral displacements compared to the experimental values, the displacements took a very long time to reach the peak value compared to the measured displacements (Figure 5.16). Further, the seal model showed extensive tensile damage (Figure 5.17) on the outby surface of the seal, but the observations from the full-scale explosion test concluded that the seal had survived the explosion loading. 


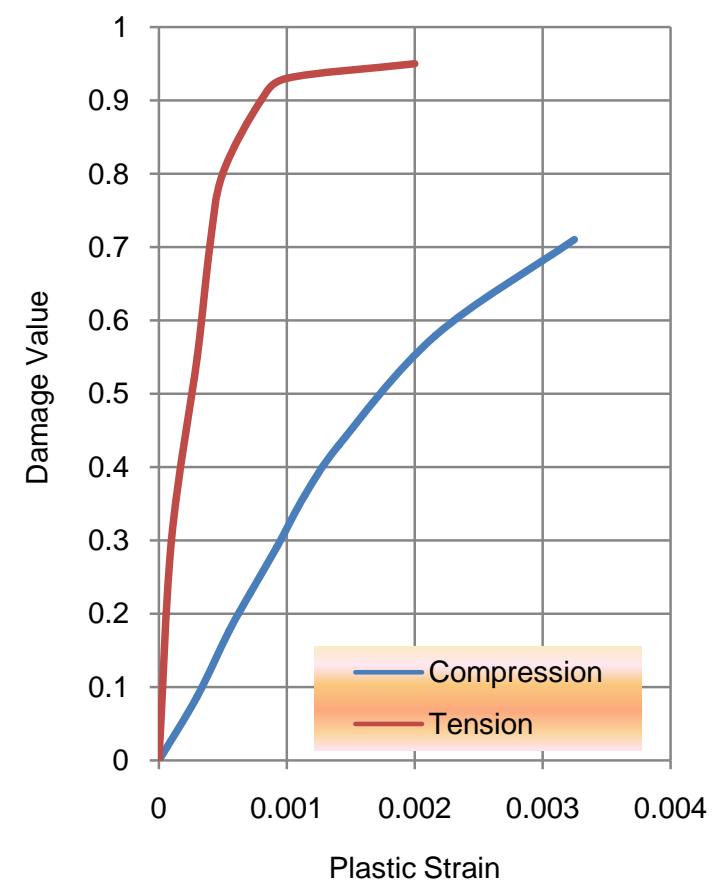

Figure 5.15 Modified concrete damage and plastic strain relationship

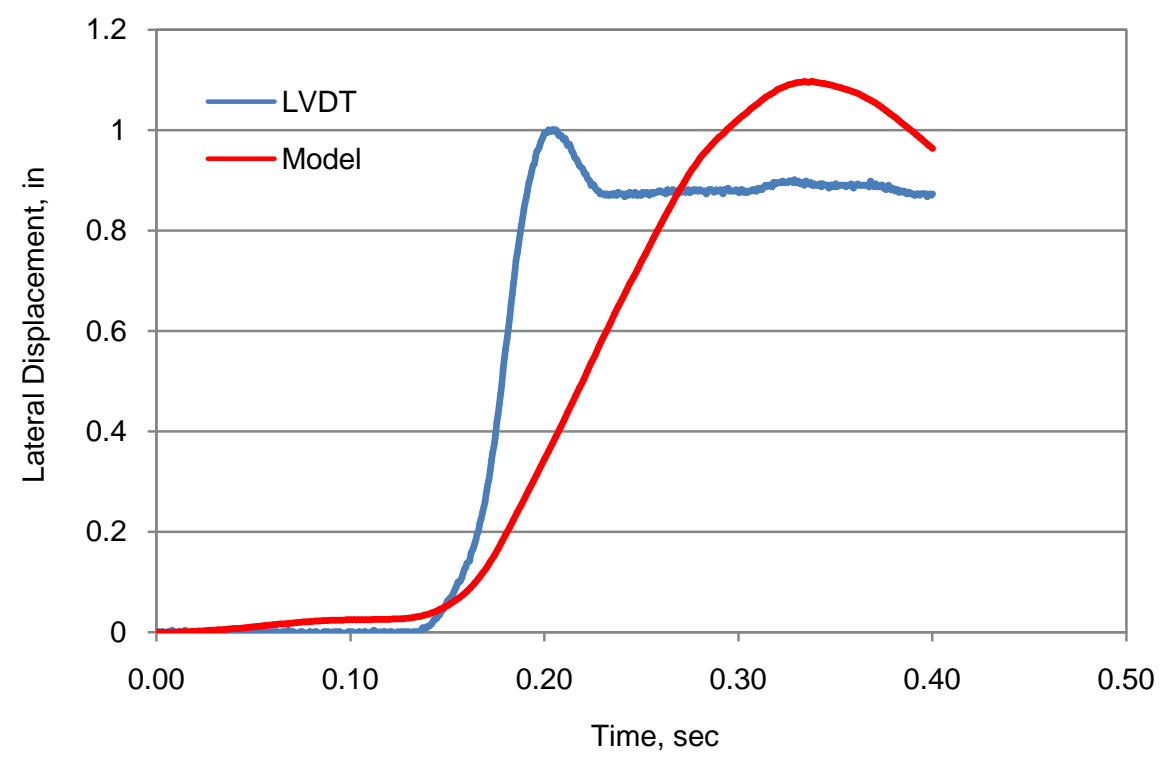

Figure 5.16 The history of predicted and measured lateral displacements (modifed concrete model) 


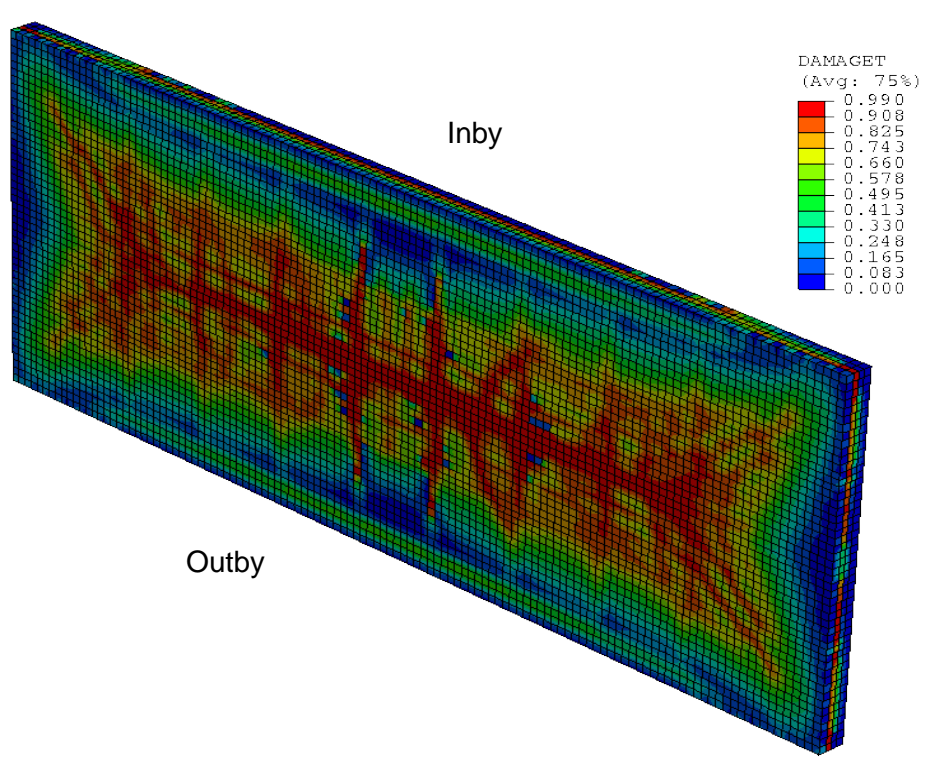

Figure 5.17 Damage contours in the seal with modified concrete behavior

\subsection{Chapter Summary}

The CEB \& Barth and Wu concrete model predicted very close results compared to the measured experimental data in Case I. The same concrete model cannot predict good results with Case II. Changing the concrete constitutive behavior in Case II resulted in modeling results predict somewhat close to the measured experimental results, but the significant difference in the rise times of the displacements remain unanswered. It is believed that unavailability of complete data pertaining to the concrete constitutive behavior may have caused the modeling results deviate from the measured experimental results.

The modeling results with Case I show that the seal has developed a tensile crack on the outby surface of the seal, but NIOSH declared the seal 'passed' the full-scale explosion test. Based on these observations, it is believed that development of simple/single tensile cracking on the outby surface of the seal may be allowed in the seal design. 


\section{Chapter 6 DESIGN OF REINFORCED CONCRETE SEAL}

7 The CEB \& Barth and Wu concrete model described in the Section 4.3 was used in the

1 actual design of reinforced concrete seals. Before attempting to do the actual RC seal design it is important to optimize some of the parameters used in the seal design such as, size and spacing of the vertical and horizontal reinforced rebars used in the construction of the seal, and the seal-rock/coal interface strength. The following sections provide complete details on the effect of these parameters on the seal response.

\subsection{Effect of Rebars Size and Spacing on Seal Response}

A number of numerical models were constructed with the parameters shown in Table 6.1 to determine the optimal size and spacing of the vertical and horizontal rebars. MSHA proposed parameters for the 120 psi seal designs based on the analytical solutions are identified as bold letters in the table. The optimized values found from this study will be used in the actual seal design process.

Table 6.1 Seal model combinations for size and spacing of steel rebars

\begin{tabular}{|c|c|c|c|c|}
\hline \multirow{2}{*}{$\begin{array}{c}\text { Entry size } \\
\text { (h x w), ft }\end{array}$} & \multicolumn{2}{|c|}{ Vertical rebar } & \multicolumn{2}{c|}{ Horizontal rebar } \\
\cline { 2 - 5 } & Spacing, in. & Size & Spacing, in. & Size \\
\hline \multirow{3}{*}{$6 \times 20$} & 8 & $\# 6$ & 10 & $\# \mathbf{6}$ \\
\cline { 2 - 5 } & $\mathbf{1 0}$ & $\# 7$ & 14 & $\# 7$ \\
\cline { 2 - 5 } & 12 & $\# 8$ & $\mathbf{1 8}$ & $\# 8$ \\
\cline { 2 - 5 } & 14 & $\# \mathbf{9}$ & & $\# 9$ \\
\hline
\end{tabular}

\subsubsection{Effect of vertical rebars spacing}

Four different ABAQUS models were built with vertical rebar spacing 8 in., 10 in., 12 in., and $14 \mathrm{in}$. In order to find out the influence of one particular parameter it is important to have other parameters constant. These parameters are interdependent, and require utmost care in choosing values for rest of the parameters while doing parametric analysis on one particular parameter. The values for the following parameters are assumed in this study: 
Entry dimensions (h x w)

Vertical rebar size

Horizontal rebar size \& spacing

Seal-rock/coal interface strength

Seal thickness

Concrete model
: $6 \mathrm{ft}$ x $20 \mathrm{ft}$

: \#9

: \#6 and 18 in.

: 200 psi

: 24 in.

: CEB \& Barth and Wu

\section{Results and discussion}

Figure 6.1 shows the tensile damage contours in the seals. The extent of the tensile cracks in the seals increased with the increase in the rebar spacing from 8 in. to 14 in. The volume weighted average damage increases linearly with vertical rebar spacing (Figure 6.2). Figure 6.3 shows the contours of axial forces developed in the rebars. The axial forces in the steel rebars also increased with increase in the rebar spacing, but are well below the yield strength of the steel in both horizontal and vertical rebars. Figure 6.4 shows the maximum lateral displacements developed in the seal on the outby side (Outby_M).

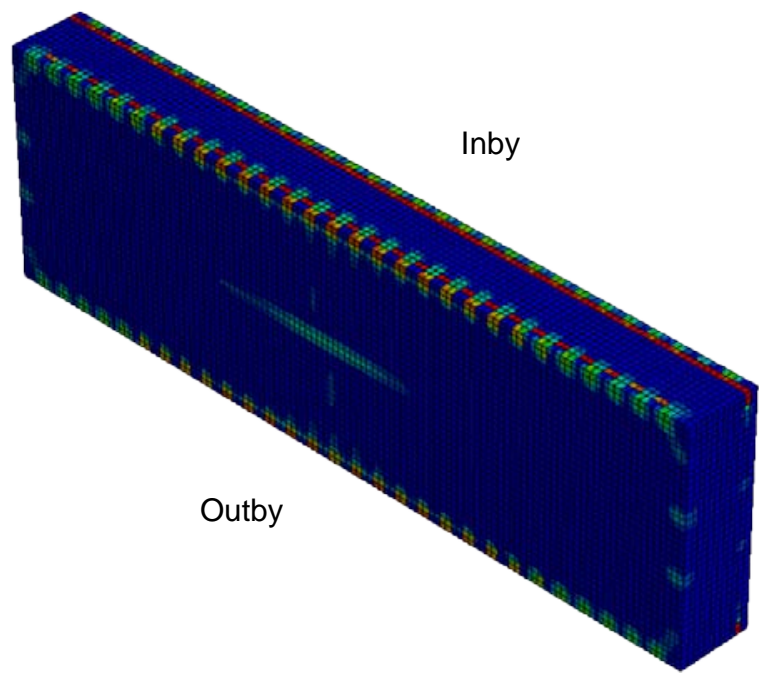

(a) 8 in. spacing

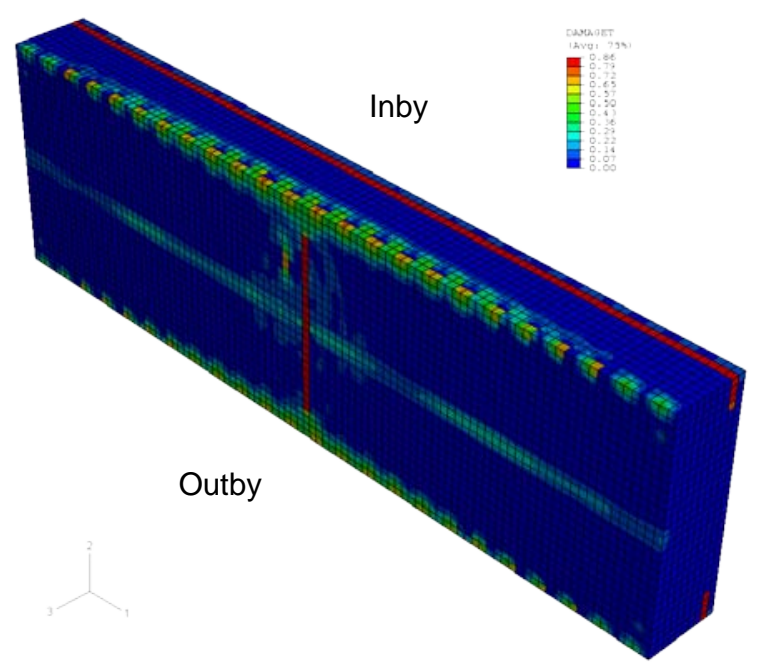

(b) 10 in. spacing

Figure 6.1 Tensile damage contours for seals with different vertical rebar spacing 


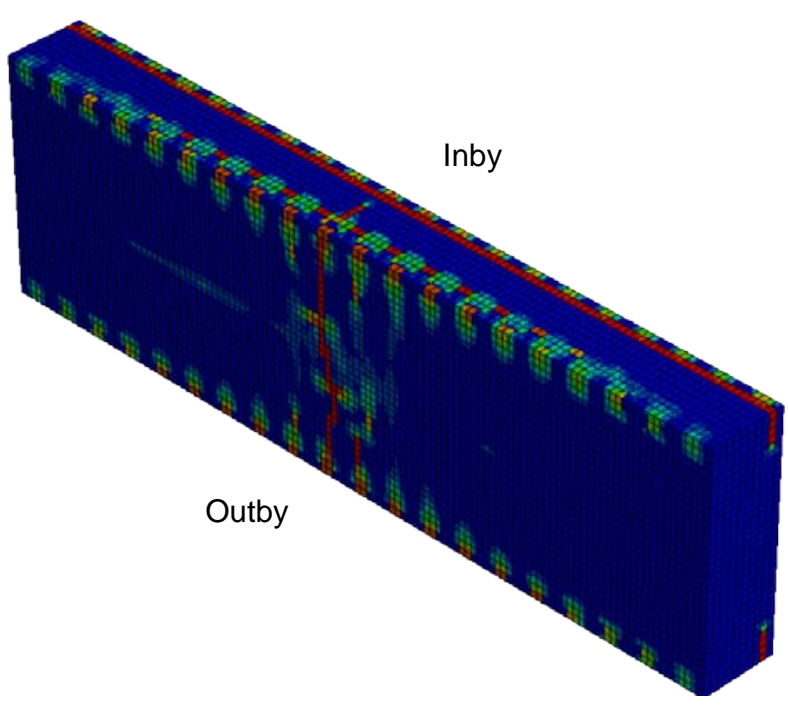

(c) 12 in. spacing

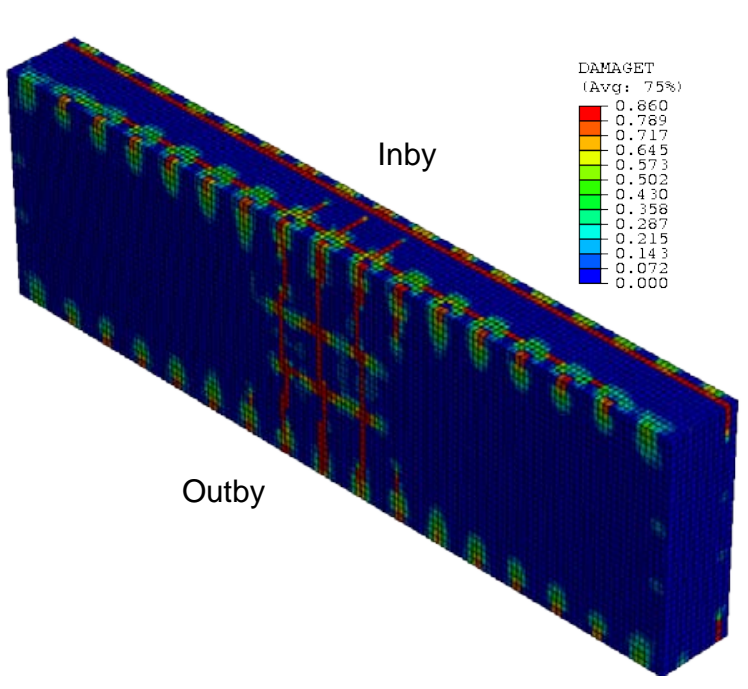

(d) 14 in. spacing

Figure 6.1 Tensile damage contours for seals with different vertical rebar spacing (continued)

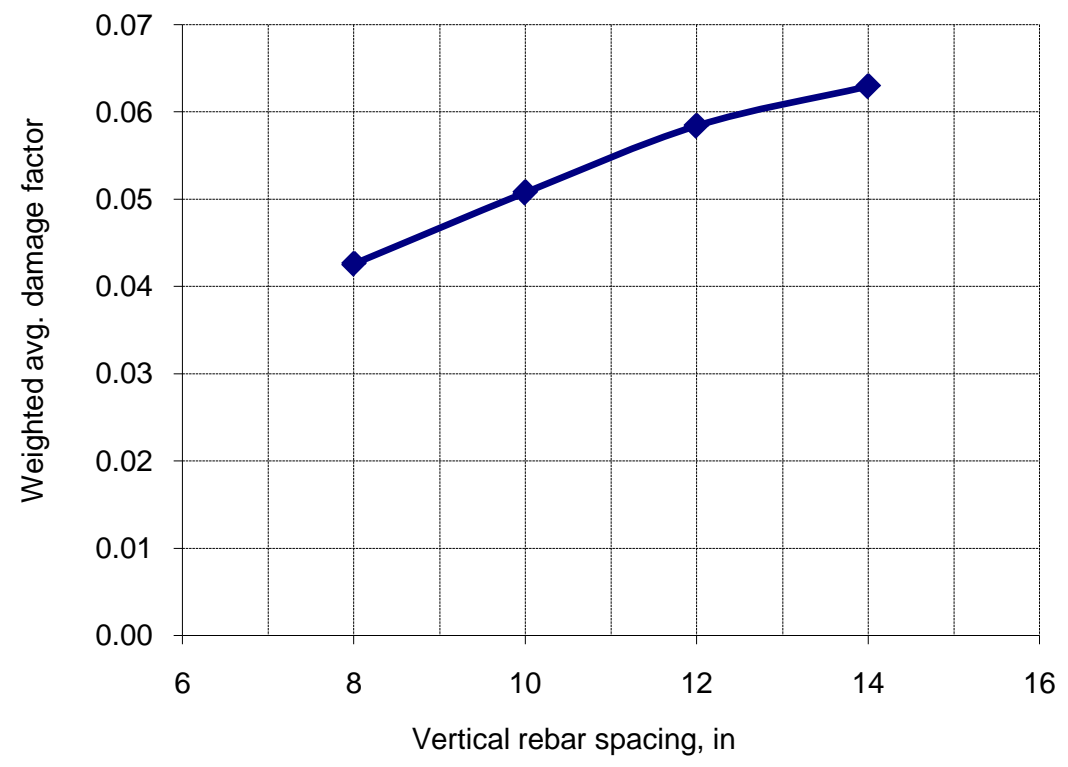

Figure 6.2 Weighted average damage factor vs vertical rebar spacing 


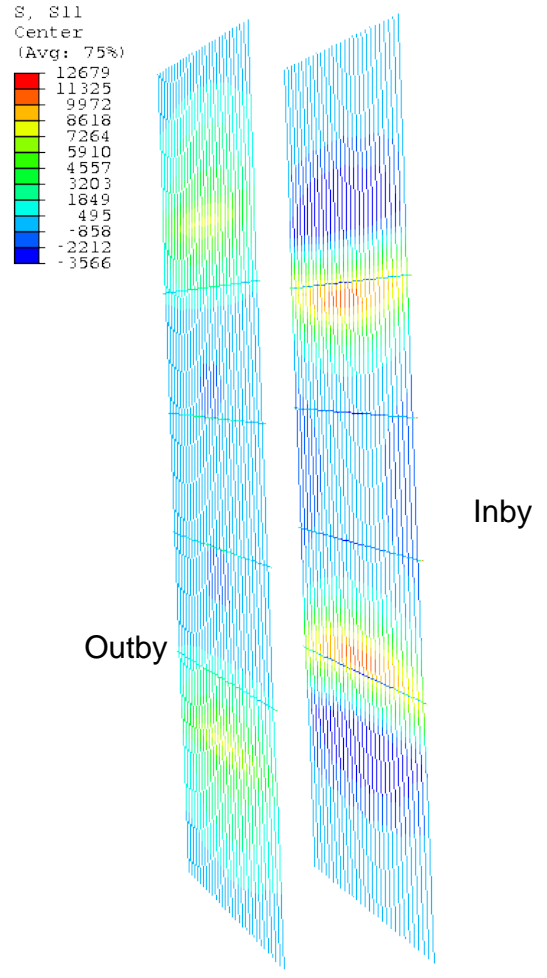

(a) 8 in. spacing

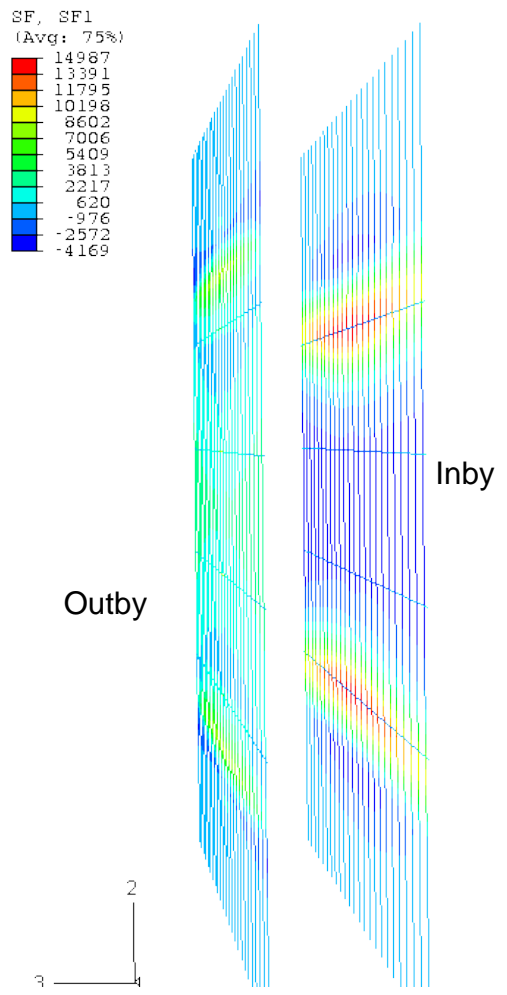

(b) 10 in. spacing
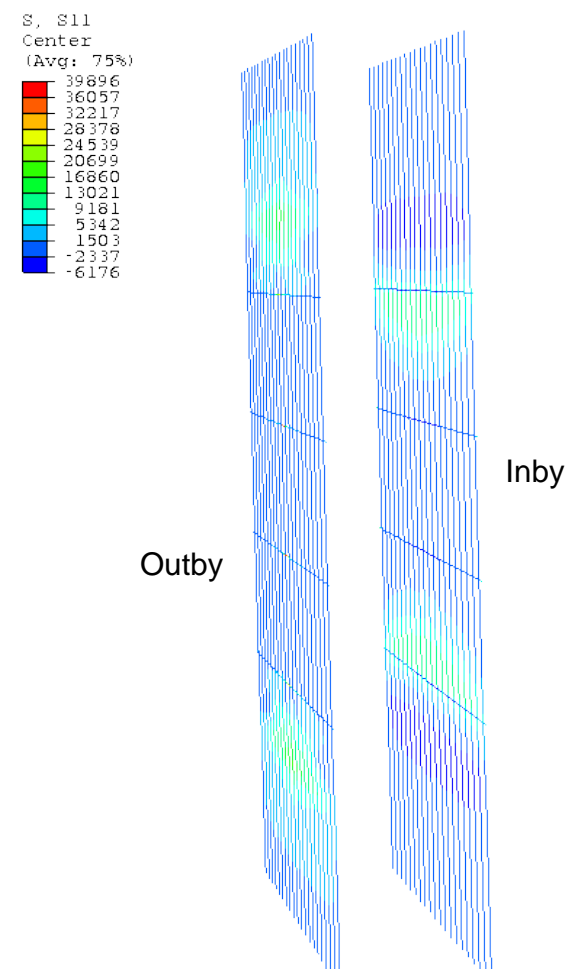

(c) 12 in. spacing

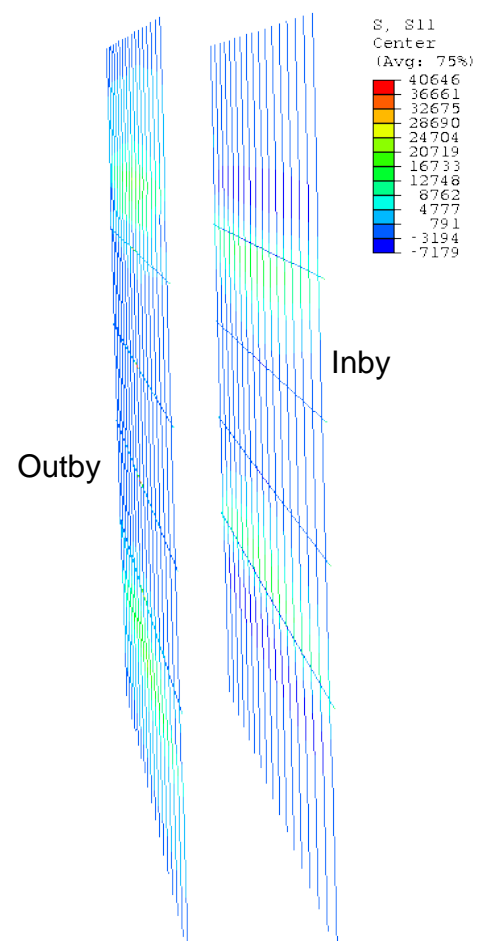

(d) 14 in. spacing

Figure 6.3 Axial forces in the rebars for seals with different vertical rebar spacing 


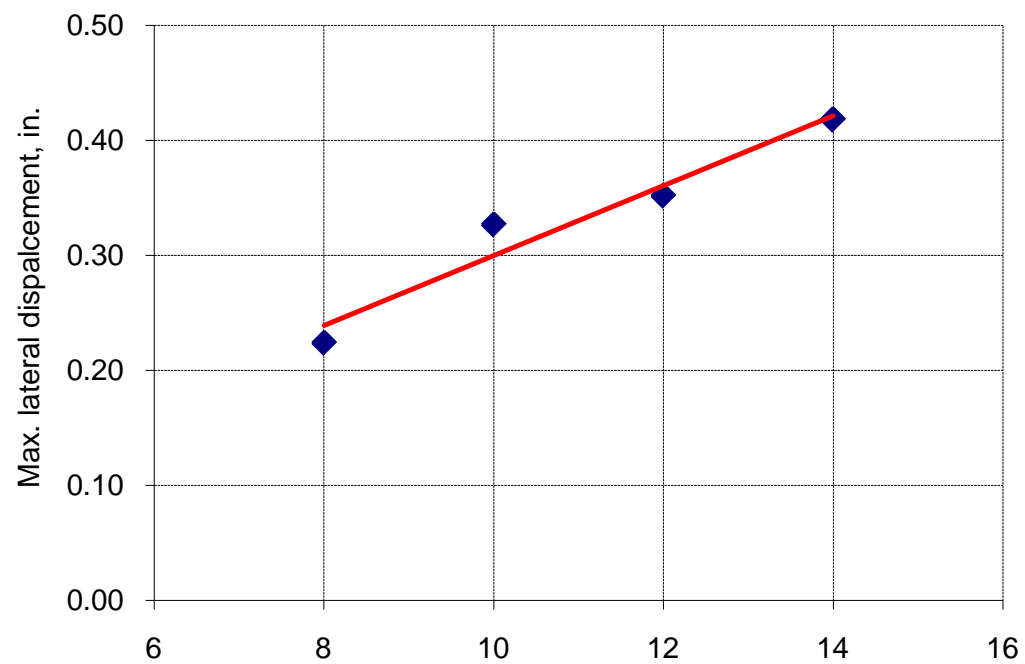

Figure 6.4 Maximum lateral displacements developed in the seal (Outby_M)

\section{Conclusion}

The spacing of the vertical rebars has significant influence on the stability of the seal. Rebars spaced at 8 in. apart showed no damage in the model. On the other hand, rebars spaced at 14 in. apart showed significant tensile cracks in the seal. In all of the above models, the tensile cracks extended to only half the distance of the seal thickness. Considering the results from the models and the practical difficulties involved in constructing the RC seal, vertical rebar spacing of about 10 in. can provide optimal design.

\subsubsection{Effect of vertical rebars size}

To investigate the influence of the vertical rebar size on the seal stability four different ABAQUS models were built with vertical rebar sizes \#6, \#7, \#8 and \#9. The following parameters were assumed for the models:

$\begin{array}{ll}\text { Entry dimensions (h x w) } & : 6 \mathrm{ft} \times 20 \mathrm{ft} \\ \text { Vertical rebar spacing } & : 10 \mathrm{in} . \\ \text { Horizontal rebar size \& spacing } & : \# 6 \text { and } 18 \mathrm{in} .\end{array}$


Seal-rock/coal interface strength

Seal thickness

Concrete model
: 200 psi

: 24 in.

: CEB \& Barth and Wu

\section{Results and discussion}

Figure 6.5 shows damage contours in the seals constructed with different rebars sizes. Seals constructed with larger size rebars produced less damage whereas the seals constructed with small size rebars produced more damage. Figure 6.6 shows the plot of weighted damage factor (WADF) with change in vertical rebar size. WADF drops sharply with increase in rebar size from \#6 to \#7 and changes little thereafter. Figure 6.7 shows the contours of axial forces in the rebars for seals constructed with different rebar sizes. Axial forces developed in the rebars are well within the yield strength of the steel in all cases. Maximum lateral displacements developed on the outby surface of the seal also fall sharply with increase in rebar size (Figure 6.8).

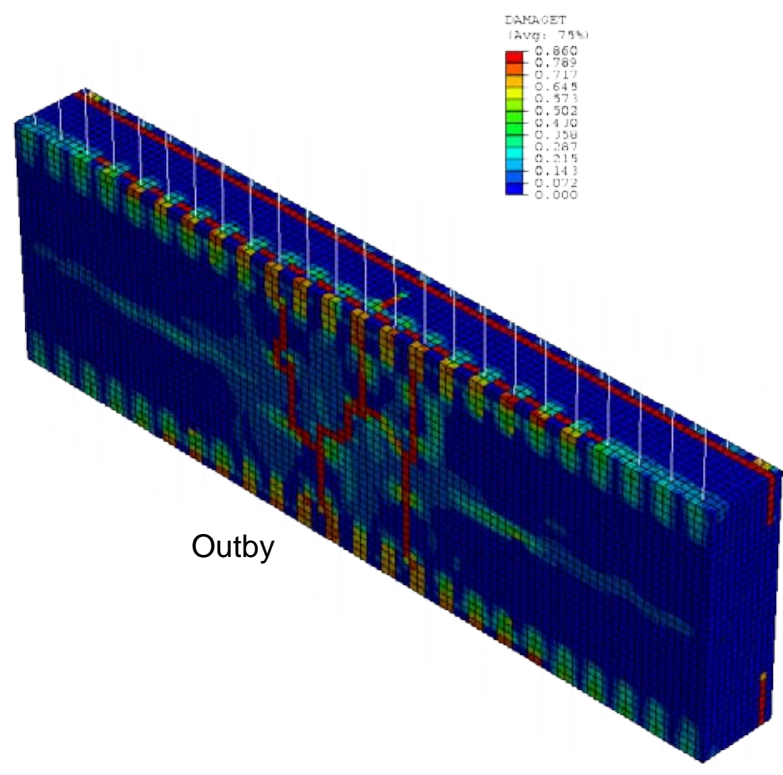

(a) \#6 rebars

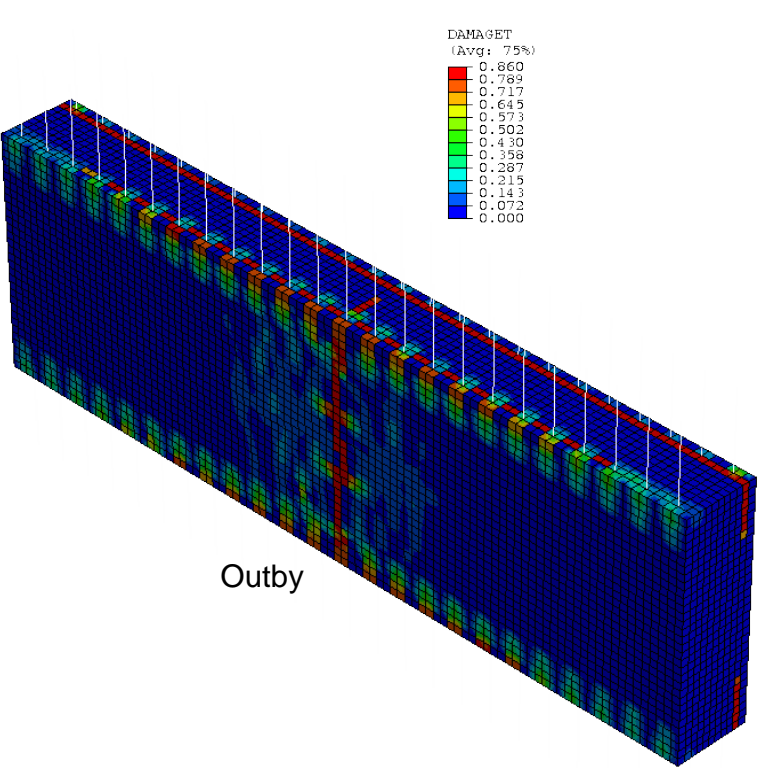

(b) \#7 rebars

Figure 6.5 Tensile damage contours for seals with different vertical rebar sizes 


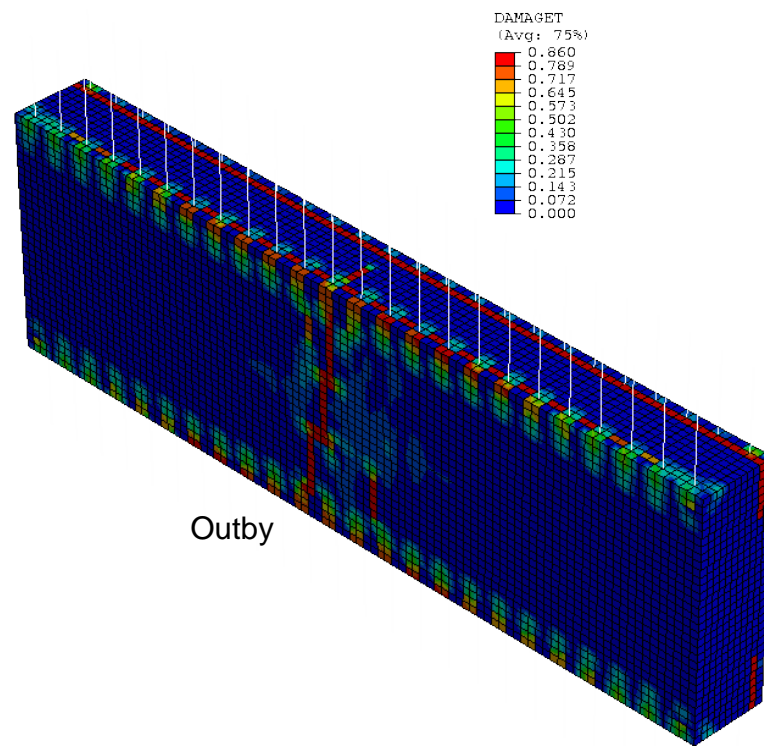

(c) \#8 rebars

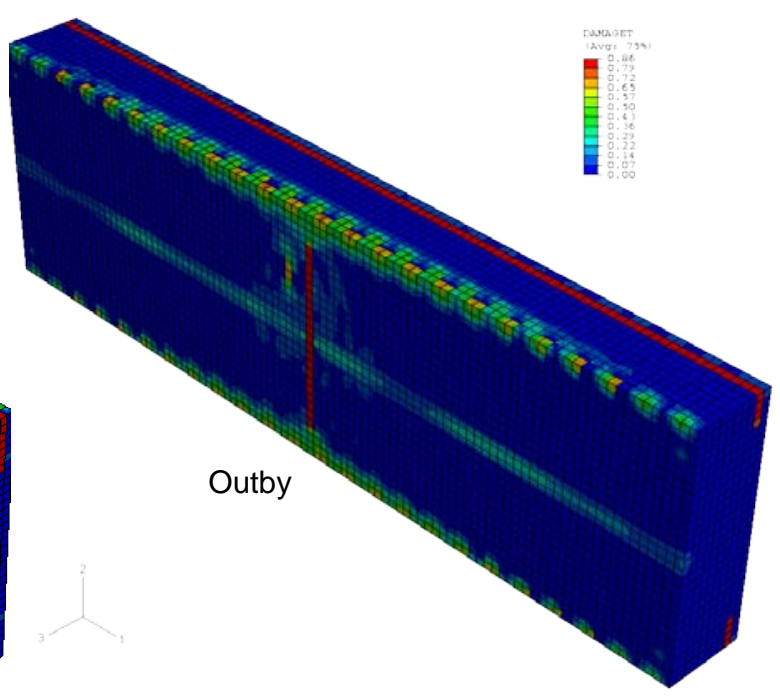

(d) \#9 rebars

Figure 6.5 Tensile damage contours for seals with different vertical rebar sizes (continued)

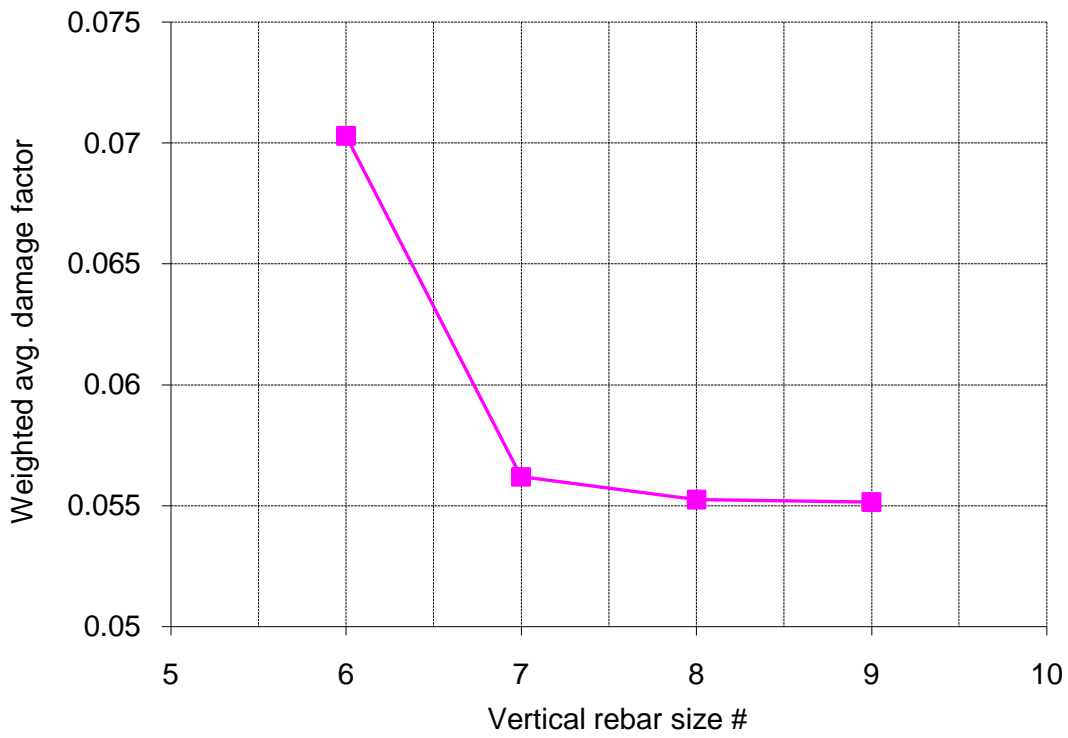

Figure 6.6 Weighted average damage factor vs vertical rebar size 


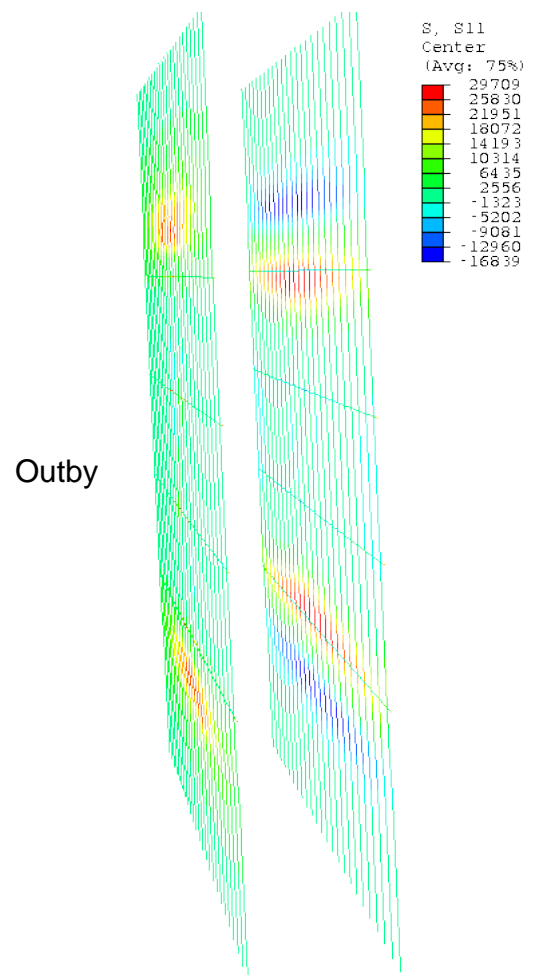

(a) \#6 rebars

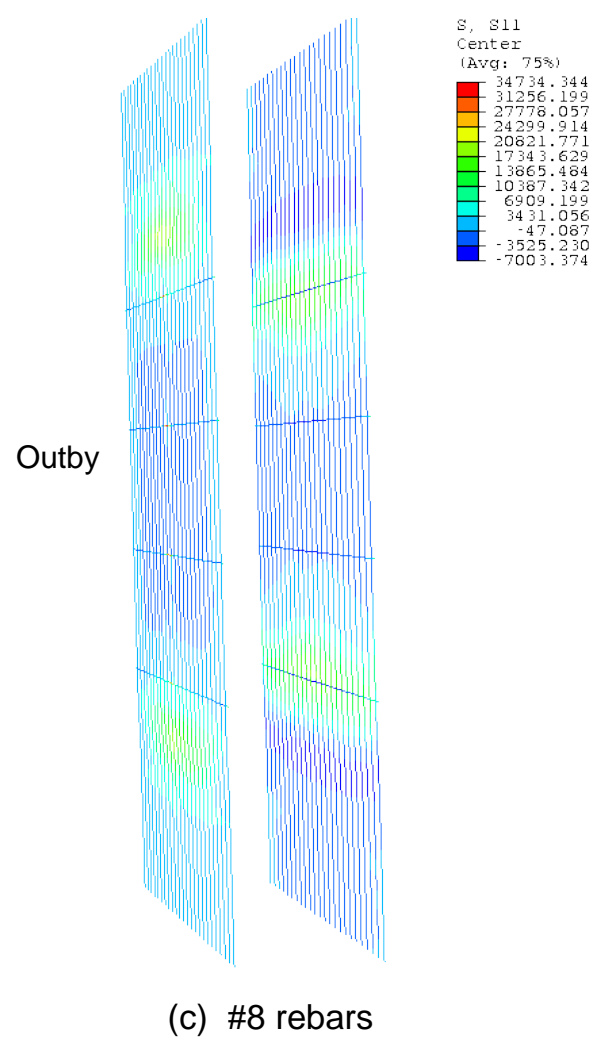

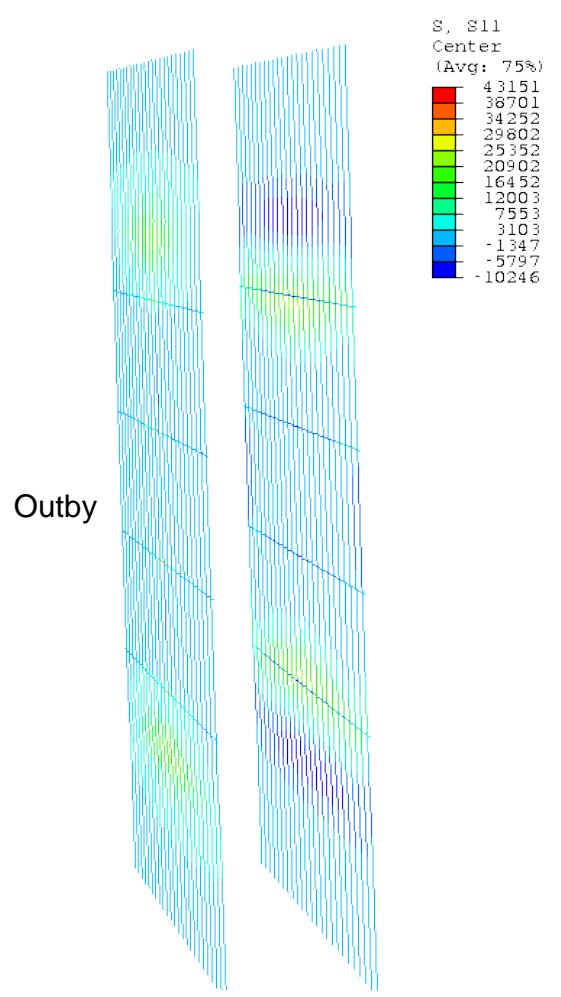

(b) \#7 rebars

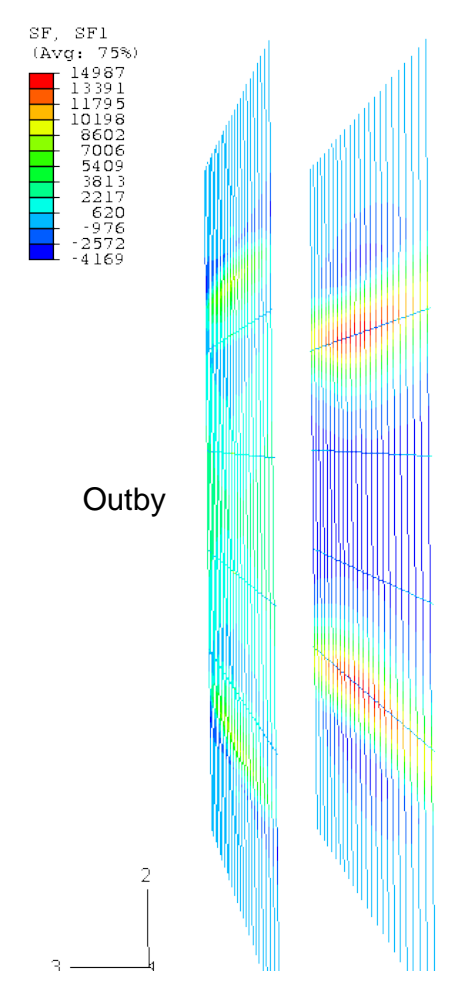

(d) \#9 rebars

Figure 6.7 Axial forces in the rebars for seals with different vertical rebar sizes 


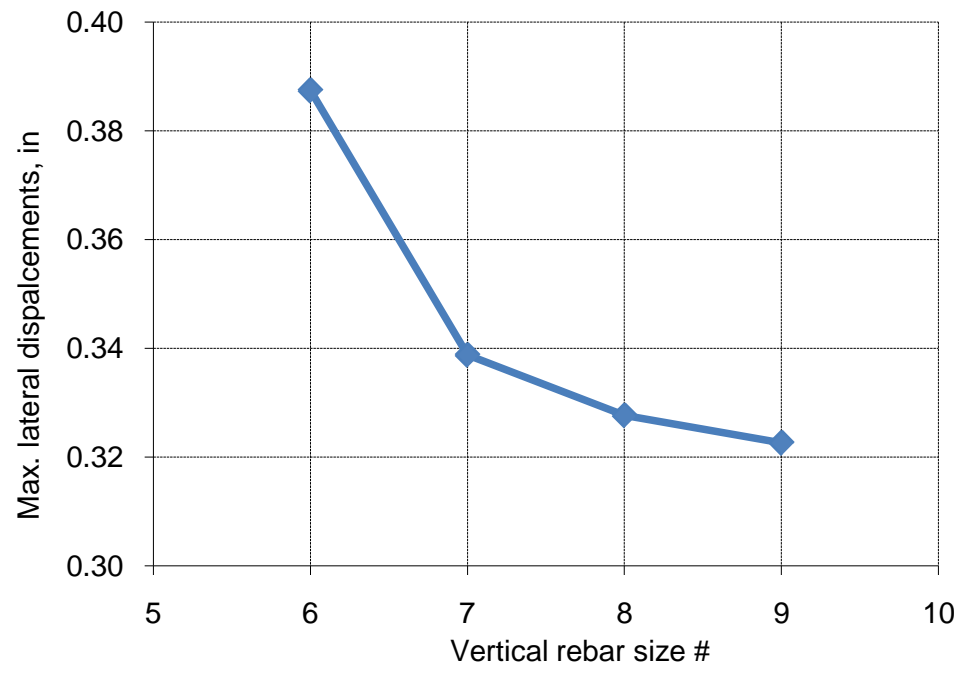

Figure 6.8 Maximum lateral displacements developed in the seal (Outby_M)

\section{Conclusion}

The size of the vertical rebars has some influence on the stability of the seal. The results presented above suggest that a rebar size of \#7 or \#8 would provide adequate design. Vertical rebars, unlike the horizontal rebars, are primarily used for anchoring the seal to the roof and floor strata. The use of larger diameter rebars offer more circumference area and hence provides higher grouting strength/pull-out strength per unit length of the rebar. Considering this fact it is believed that \#9 rebar would be an ideal choice for vertical rebars in the seal design. 


\subsubsection{Effect of horizontal rebars size and spacing}

Similarly a number of ABAQUS models were constructed with different combinations of horizontal rebar sizes (\#6 and \#9) and spacing (10, 14, and 18 in.) to understand their influence on the seal response. The following parameters are assumed for the models:

$\begin{array}{ll}\text { Entry dimensions (h x w) } & : 6 \mathrm{ft} \times 20 \mathrm{ft} \\ \text { Vertical rebar size \& spacing } & : \# 9 \text { and } 10 \mathrm{in} . \\ \text { Seal-rock/coal interface strength } & : 200 \mathrm{psi} \\ \text { Seal thickness } & : 24 \mathrm{in} . \\ \text { Concrete model } & : \text { CEB \& Barth and Wu }\end{array}$

Summary of the results obtained from these models are provided in the following figures. Figure 6.9 shows the weighted average damage factor for different combinations of horizontal rebar spacing and size. With the increase in rebar spacing, the weighted average damage factor gradually increased and at the same time increase in horizontal rebar size also caused the weighted average damage factor to go up. Unlike the small rebars, larger rebars distribute the bending stresses over its length and thus causing the concrete to develop multiple tensile cracks near the ceter of the seal, and hence high WADF. Similar behavior is observed with lateral displacements on the outby surface of the seal (Outby_M) (Figure 6.10).

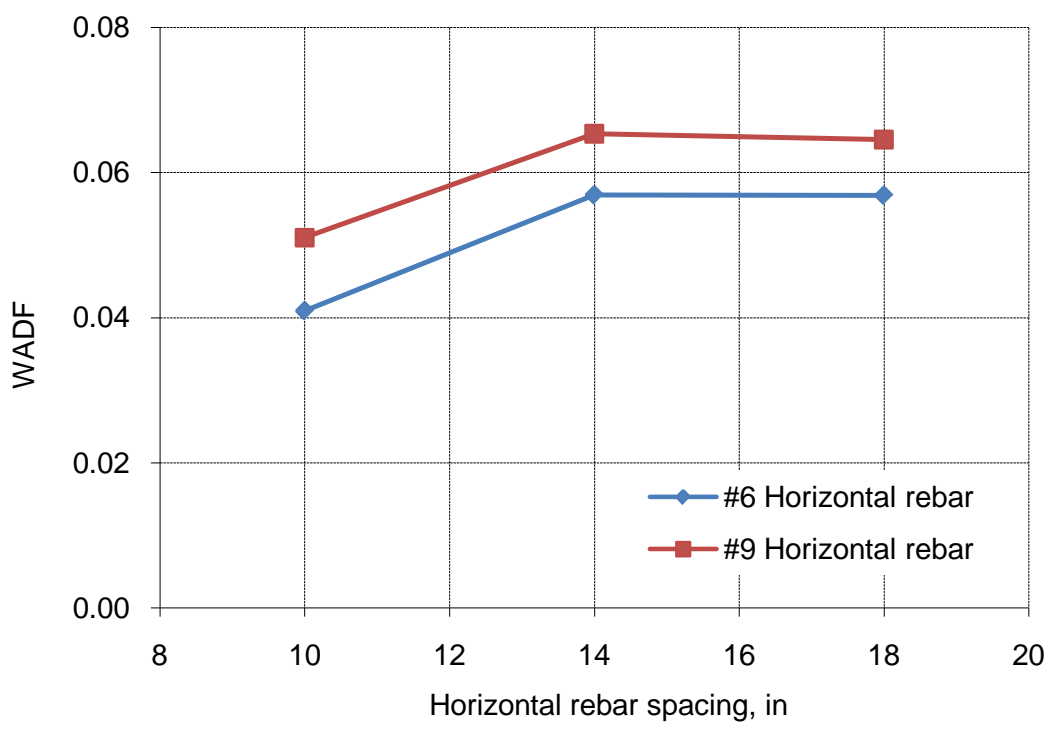

Figure 6.9 WADF for seals constructed with different horizontal rebars spacing and size 


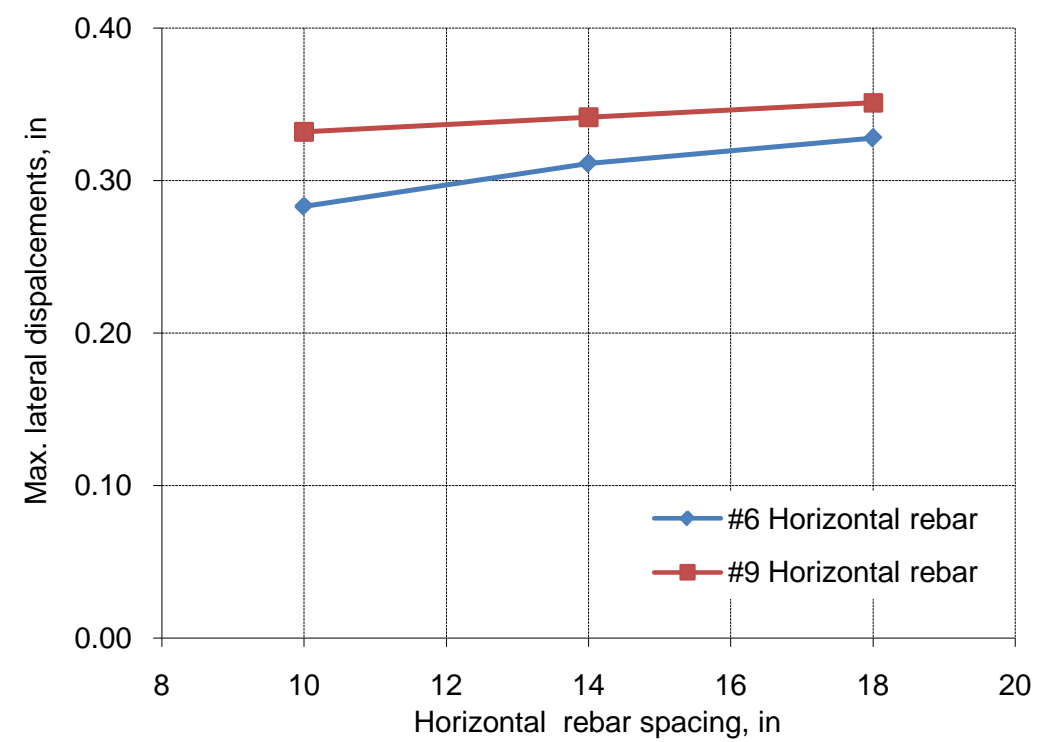

Figure 6.10 Maximum lateral displacements developed in the seals constructed with different horizontal rebars spacing and size

Since the horizontal rebars are not designed to anchor the seal to the ribs, \#6 rebars with 18 in. spacing can provide optimal design for the reinforced concrete seals.

\subsection{Effect of Seal/Rock Interface Strength}

The seal rock interface strength provides some constraint for the relative movement between seal and rock and helps transfer the explosion pressure from the seal to the surrounding rock. So it is important to understand the influene of the interface strength on the seal response. A number of ABAQUS models were solved with different seal/rock interface strengths ranging from 50 to 300 psi to understand the the seal behavior.

The following parameters were assumed for building the ABAQUS models. The other parameters or material models used are the same as those discussed in Chapter 3.

Entry dimensions (h x w)

Vertical rebar size \& spacing

Horizontal rebar size \& spacing

Seal thickness

Concrete model
: $6 \mathrm{ft} \times 20 \mathrm{ft}$

: \#9 and 10 in.

: \#6 and 18 in.

: 24 in.

: CEB \& Barth and Wu 


\section{Results and discussion}

Figure 6.11 shows the damage contours in seals with different seal/rock interface strength. For 50 to 200 psi interface strengths, the seals showed similar cracking pattern, single vertical crack at the center of the outby surface of the seal. Further increase in shear strength to beyond 200 psi actually caused the seal to develop a couple of vertical cracks on the outby surface. On the contrary, the weighted average damage factor gradually decreased with increase in interface shear strength (Figure 6.12). This is due to the reason that with lower interface shear strength the seal develops fairly high level of damage near the roof and floor lines on the outby surface. Lower interface strengths could not provide sufficient constraint to the cover concrete (from rebar line to the seal surface) to prevent it from cracking. This localized damage decreases significantly with increase in interface shear strength and predicted higher values for the weighted average damage factor at lower interface strengths in spite of less vertical tensile cracking on the outby surface.

Although the higher interface strengths predict more tensile cracks on the outby surface of the seal, the maximum axial forces in the rebars (Inby_T/B) and the maximum lateral displacements (Outby_M) decrease fairly linearly with increase in interface shear strength (Figures 6.13 and 6.14). A higher shear strength along the seal/rock interfaces provides higher lateral constraints for the seal movement and helps tranfer more stresses effectively across the interface from the concrete to the surrounding rock, and hence reduces the amount of axial force in the reinforced steel rebars. The higher the stress carried by the concrete the higher the tensile stresses on the outby surface of the seal and hense the higher tensile cracking.

The interface strength has a mixed influence on the seal behavior. To summarize, higher interface strengths helps reduce the localized damage along the roof and floor line on the outby surface of the seal but produces comparatively more tensile cracks in the seal. On the other hand, lower interface strengths reduce tensile cracking in the seal by transferring more stresses to the steel rebars but produce more localized damage near the roof and floor line. Considering the practical strength limits for concrete-rock interface from the available literature a value of 200 psi is assumed for use in this dissertation for the design of RC seals. 

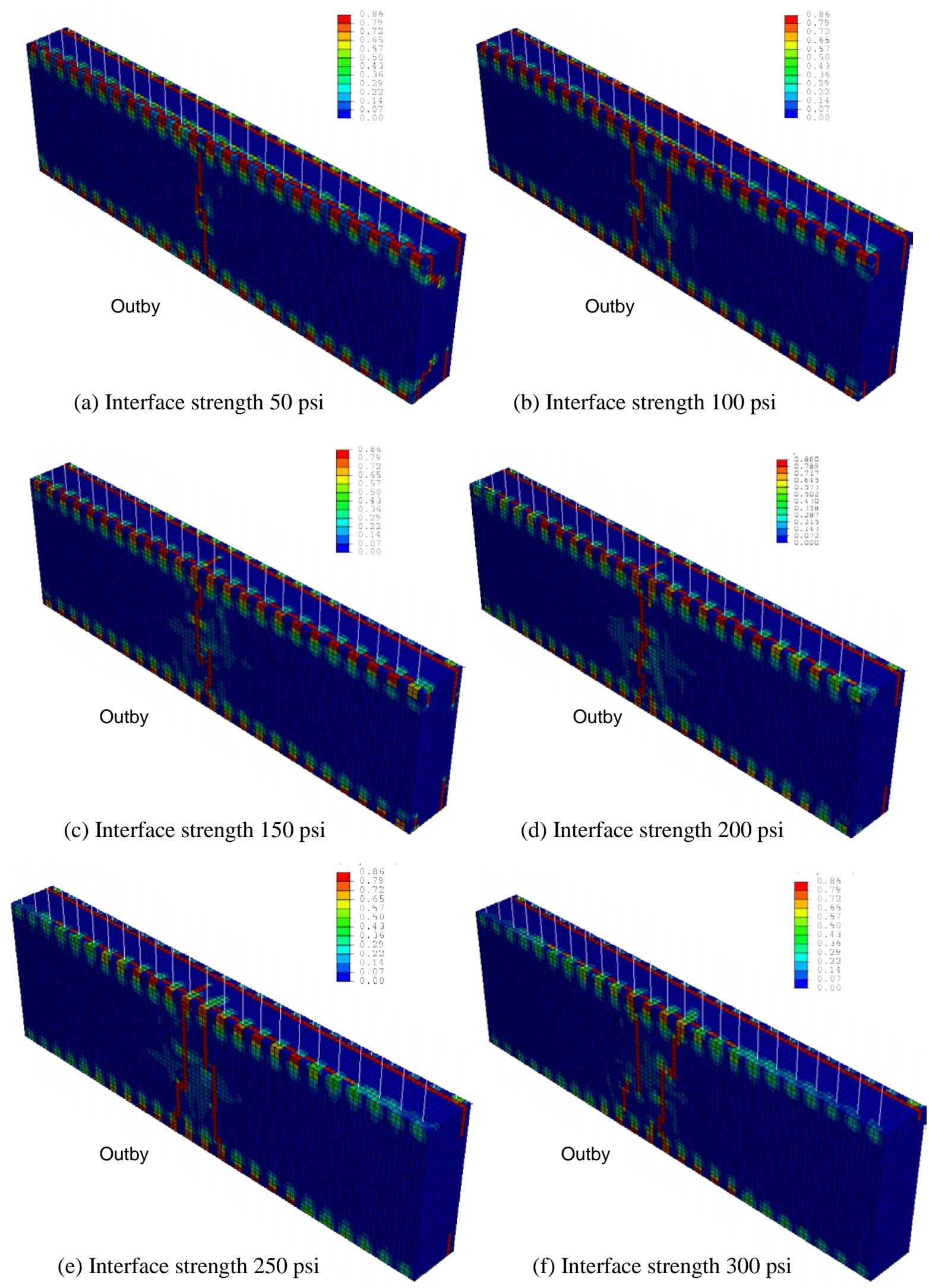

Figure 6.11 Damage contours in seals with different interface strengths 


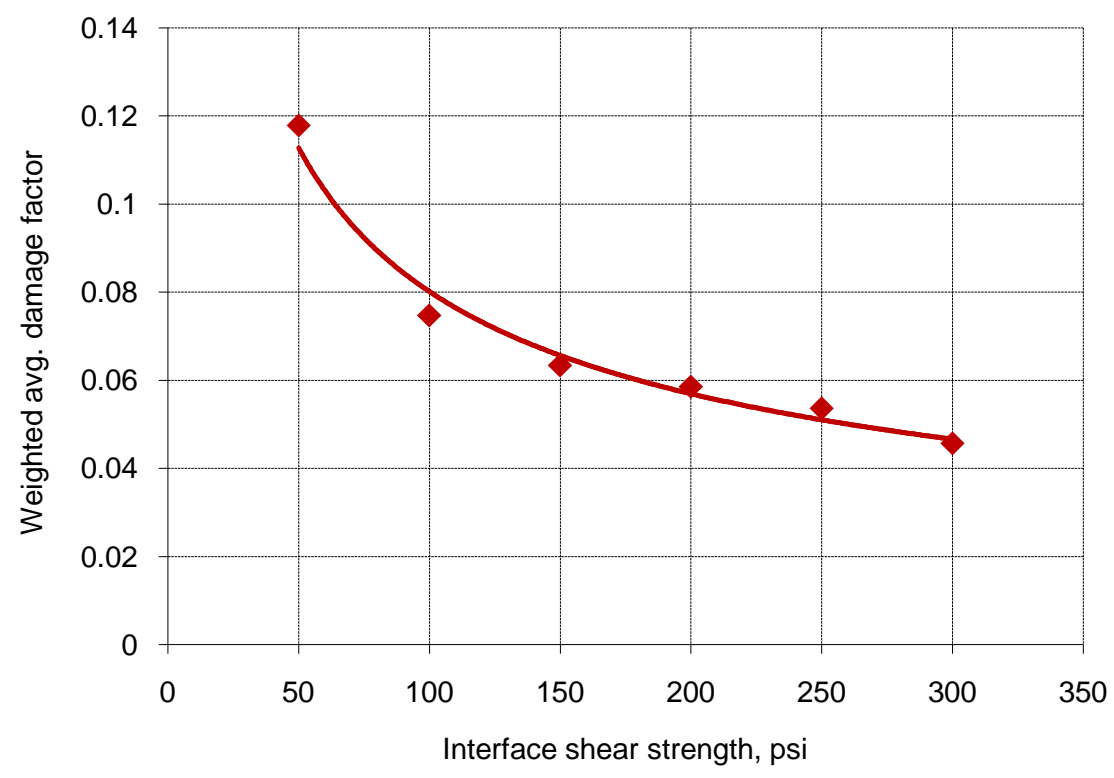

Figure 6.12 Weighted average damage factor with different interface strengths

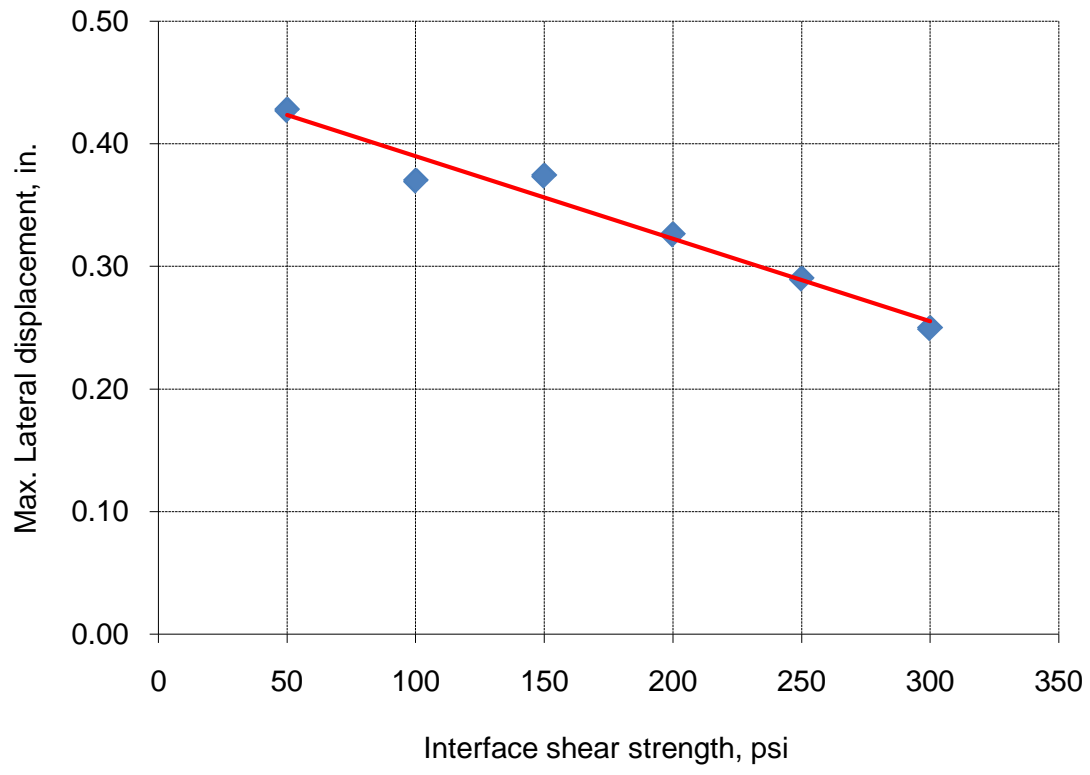

Figure 6.13 Max. lateral displacements (Outby_M) in seals with different interface strengths 


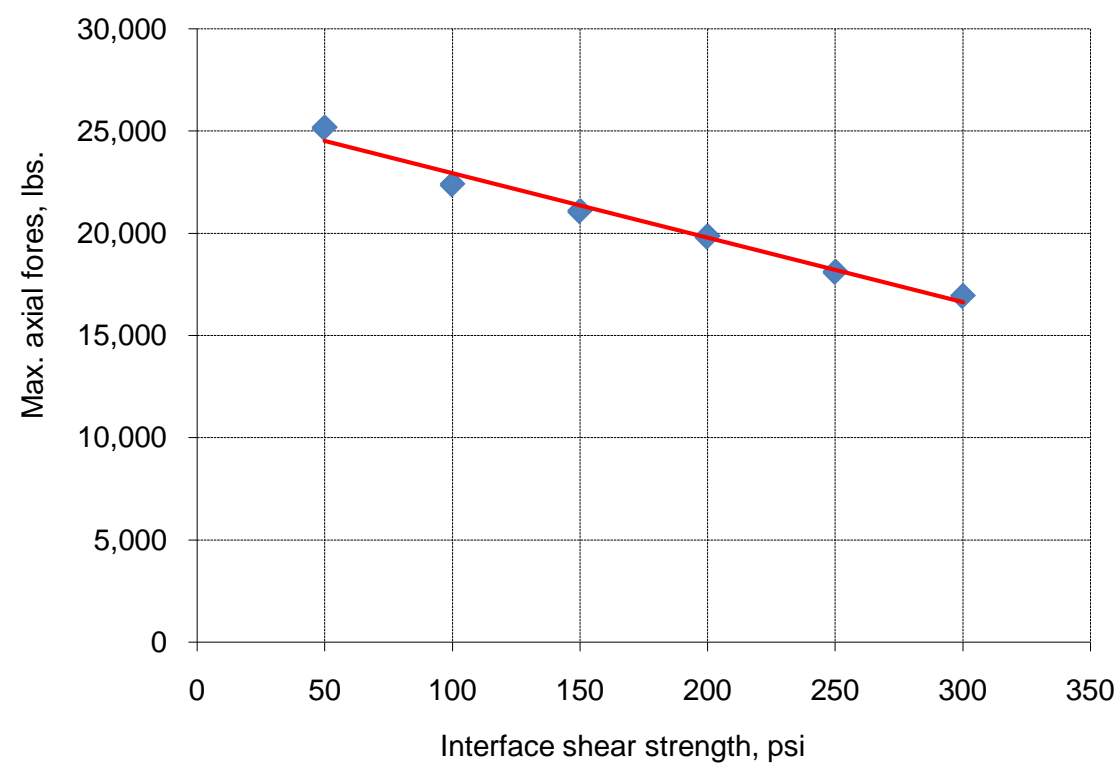

Figure 6.14 Max. axial forces developed in rebars (Inby_T/B) for seals with different interface strengths

\subsection{Effect of Rock Strength on Seal Stability}

The reinforced concrete seals primarily work because of positively anchoring the seal to the surrounding strata using the steel rebars. The reinforced concrete seal transfers the explosion pressure to the surrounding rock through the internal reinforced steel rebars. So it is important to recognize the importance of the rock strength in the design process. The ability of the surrounding rock to absorb the high tensile stresses, transferred from the steel rebars, without undergoing significant deformation also plays an important role in the effectiveness of the seal design. This part of the study considers different rock strengths for strong, intermediate and weak rock types in the design to understand the influence of the rock strength on the seal response. Table 6.2 shows the geo-mechanical properties for different rock strengths. RC seal designs proposed in this dissertation use the rock properties for the intermediate rock strength. 
Table 6.2 Rock strength properties

\begin{tabular}{|l|c|c|c|}
\hline \multirow{2}{*}{\multicolumn{1}{|c|}{ Property }} & \multicolumn{3}{c|}{ Rock (Roof/floor) } \\
\cline { 2 - 4 } & Strong & Intermediate & Weak \\
\hline Young's Modulus (E), psi & $3 \mathrm{e} 6$ & $3 \mathrm{e} 6$ & 3e5 \\
\hline Poisson ratio $(v)$ & 0.19 & 0.25 & 0.34 \\
\hline Insitu compressive strength $\left(\sigma_{\mathrm{c}}\right.$ ), psi & 3840 & 1280 & 900 \\
\hline Friction angle & 35 & 30 & 23 \\
\hline Density, lbs/ft & 35 & 162 & 145 \\
\hline
\end{tabular}

The CEB \& Barth and Wu concrete material model discussed in Section 4.3 was used for simulating the concrete constitutive behavior. The following parameters are assumed for building the ABAQUS models. All other parameters or material models used here were the same as those discussed in Chapter 3.

$\begin{array}{ll}\text { Entry dimensions (h x w) } & : 6 \mathrm{ft} \times 20 \mathrm{ft} \\ \text { Vertical rebar size \& spacing } & : \# 9 \text { and } 10 \mathrm{in} . \\ \text { Horizontal rebar size \& spacing } & : \# 6 \text { and } 18 \mathrm{in} . \\ \text { Seal-rock/coal interface strength } & : 200 \mathrm{psi} \\ \text { Seal thickness } & : 24 \mathrm{in} .\end{array}$

\section{Results and discussion}

Figure 6.15 shows the damage contours in the seals with different surrounding rock strengths. It is clear from the damage contours that the surrounding rock strength/stiffness has a significant influence on the seal stability. With a strong surrounding rock, the RC seal shows no damage/cracks on the outby surface whereas the seal with intermediate surrounding rock strength has developed a single vertical crack on the outby surface. With the weak surrounding rock, the seal has developed extensive tensile damage/multiple tensile cracks on the outby face. A weak rock deforms significantly under the rebar loading and cannot provide stiff support for the grouted rebars. Causing more stress transfer to the concrete material resulting in more tensile damage in the seal. Figure 6.16 shows the weighted average damage factor for seals with different rock strengths. For the seal with a weak surrounding rock, the WADF reaches as high as 0.15 . 
Figure 6.17 shows the maximum amount of axial forces and lateral displacements developed in the seals with different surrounding rock strengths. With a weak surrounding rock both the magnitudes of axial forces in the rebars and lateral displacements on the outby surface of the seal reach significantly higher values compared to the seals having an intermediate or a strong surrounding rock. As all the seal designs proposed in this dissertation are based on the intermediate rock strength, these designs can be effectively used for all other rock strengths except the weak rock.

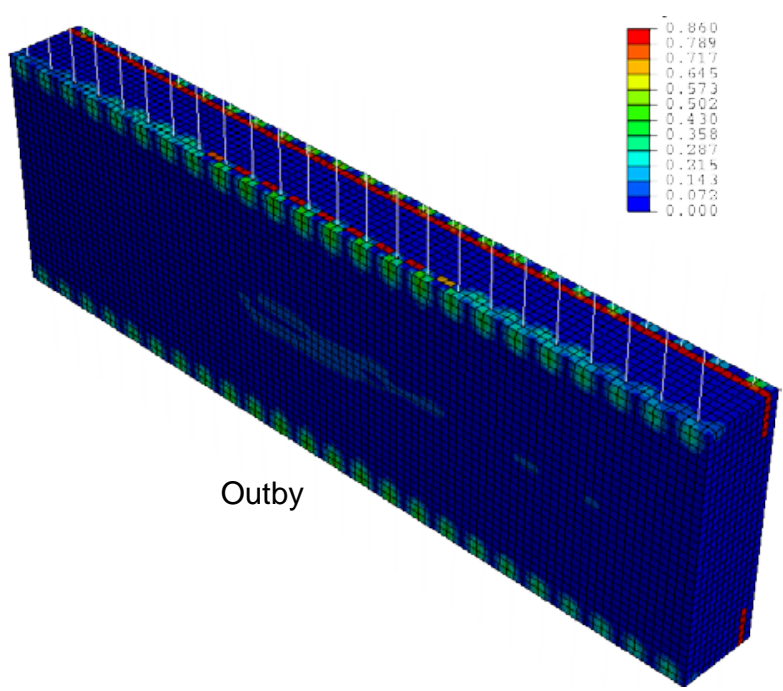

(a) Strong rock

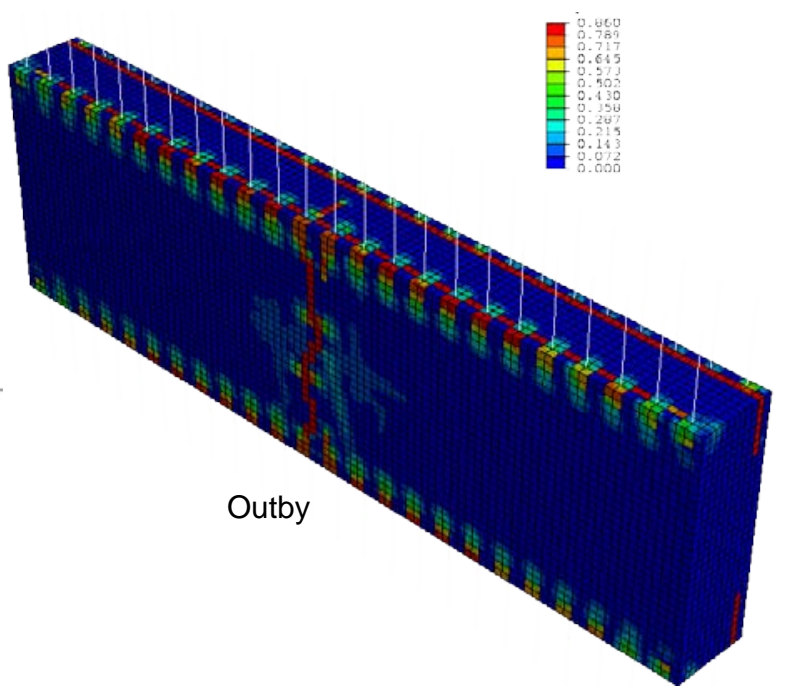

(b) Intermediate rock

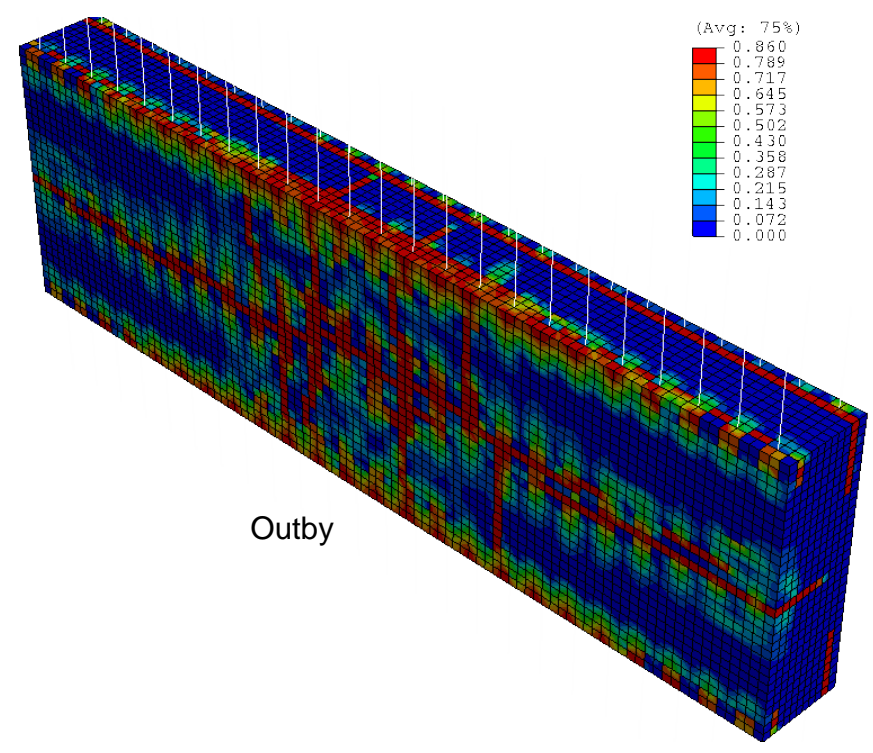

(c) Weak rock

Figure 6.15 Damage contours in seal with different surrounding rock strengths 


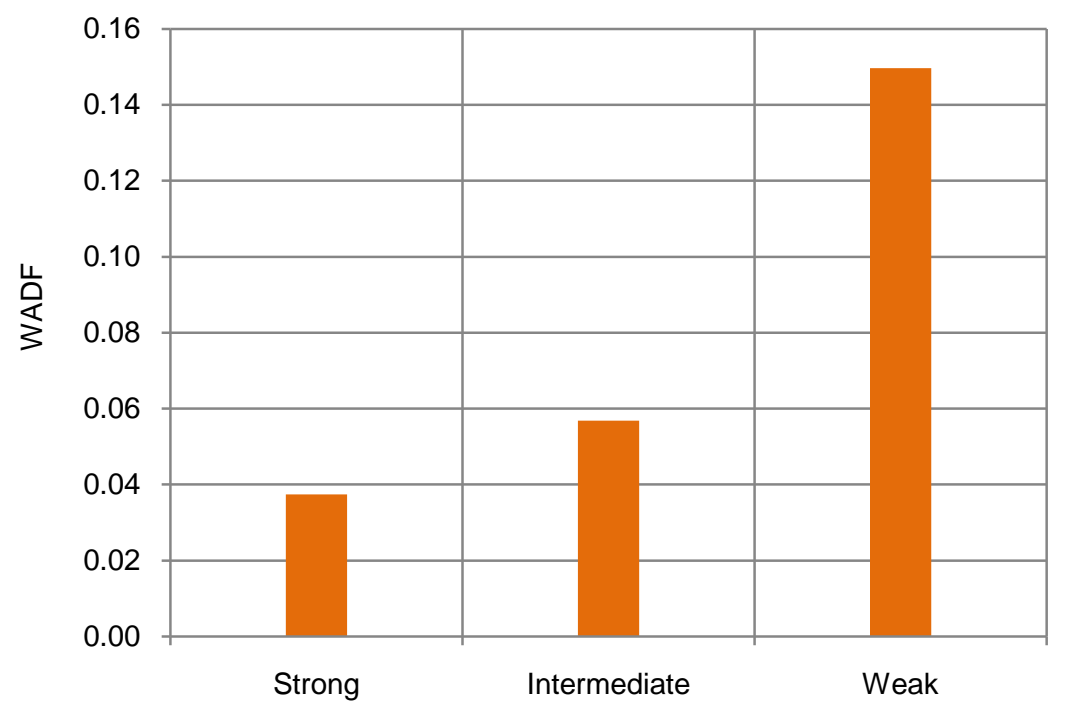

Figure 6.16 WADF for seals with different surrounding rock strengths

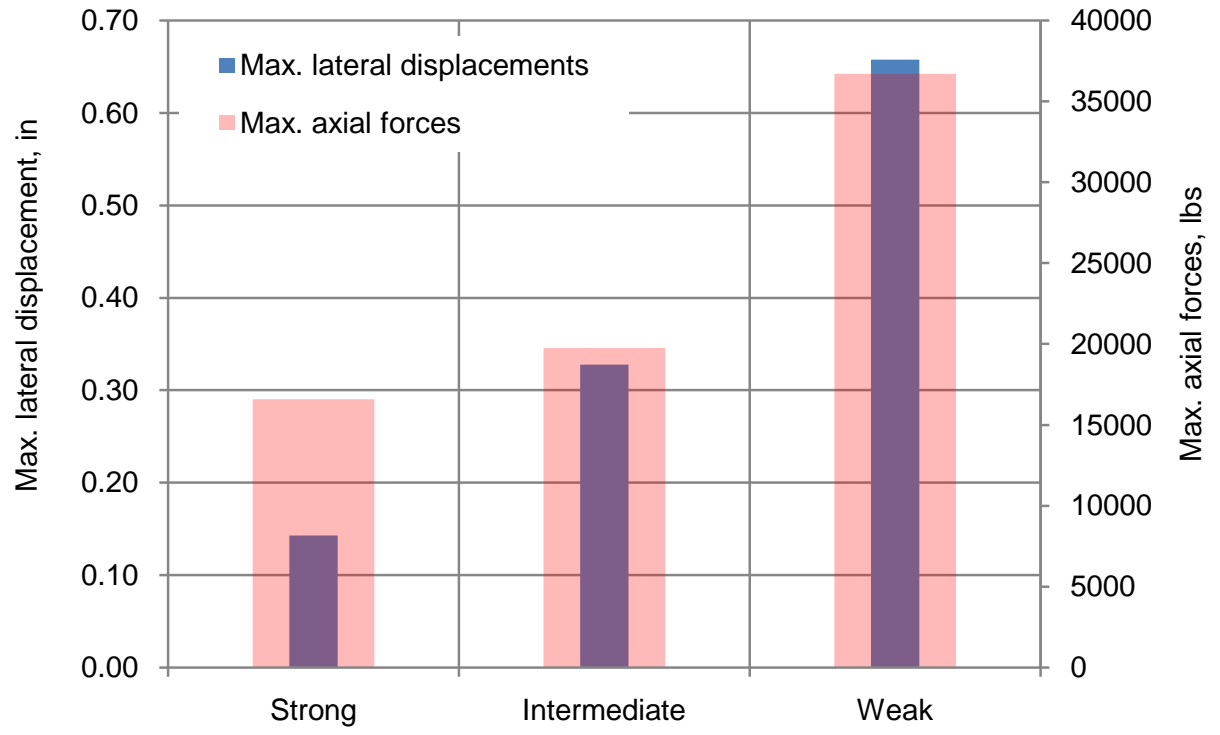

Figure 6.17 Max. lateral displacements (outby_M) and axial forces (Inby_T/B) for seals with different surrounding rock strengths 


\subsection{RC Seal Mechanical Response}

The primary aim of this study is to completely understand the RC seal response to the dynamic explosion loading and the seal failure mechanism under these loading conditions. Further, this study facilitates the development of appropriate design guidelines/criteria for judging the stability of the RC seals.

The optimum values for various structural parameters found from the previous models are used in this study. A number of finite element seal models are constructed with the following parameters and seal thickness is varying from 12 to $30 \mathrm{in}$. All these models were subjected to 120 psi instantaneous explosion loading pressure lasting for 4 sec and removed suddenly (Figure $1.2(\mathrm{a})$ ).

$\begin{array}{ll}\text { Entry dimensions (h x w) } & : 6 \mathrm{ft} \text { x } 20 \mathrm{ft} \\ \text { Vertical rebar size \& spacing } & : \# 9 \text { and } 10 \mathrm{in} . \\ \text { Horizontal rebar size \& spacing } & : \# 6 \text { and } 18 \mathrm{in} . \\ \text { Seal-rock/coal interface strength } & : 200 \mathrm{psi} \\ \text { Seal thickness } & : 12,15,18,21,24 \text { and } 30 \mathrm{in} .\end{array}$

Results and Discussion

The results provide a good insight into the basic seal response to the applied explosion loading. Figure 6.18 shows the contours of the axial forces in the vertical rebars for different seal thicknesses. In the 12 in. thick seal, a very high level of tensile axial forces are developed in the rebars on the inby as well as on the outby side. At this seal thickness, the reinforced concrete material shows complete failure in tension and offers no bending/shear resistance to absorb the explosion pressure. With the increase in seal thickness beyond 12 in. the axial forces in the inby rebars turn to compressive but the axial forces in the outby rebars still remain in tension. The structural integrity of the reinforced concrete improves significantly with the increase in seal thickness by offering high internal bending and shear resistance to absorb and transfer the explosion loading pressure effectively to the surrounding rock. 
The magnitude of the axial forces in the rebars at mid height i.e., tensile forces in the outby rebars and the compressive forces in the inby rebars, decreases significantly with increase in seal thickness from 15 to $30 \mathrm{in}$. At the same time, tensile forces in the outby and inby rebars near the roof and floor line increase significantly with increase in seal thickness from 15 to 30 in. Beyond 24 in. seal thickness, the axial forces are concentrated in the sections of the steel rebars near the roof and floor line, indicating that the seal has reached sufficient thickness to provide maximum internal bending resistance to the applied explosion loading and able to transfer the stresses to the steel rebars near the roof and floor lines, and eventually to the surrounding rock. At higher thickness, reinforced concrete seal behaves like a plug rather than just bending. The schematic diagrams shown in figure 6.19 explain this phenomenon clearly. The amount of axial forces (in thousand lbs) developed in the central vertical rebar at the monitoring locations as shown in figure 3.8 are shown in figure 6.19. The numbers shown in red indicate the magnitude of tensile forces and the numbers shown in blue/parenthesis indicate the magnitude of compressive forces.

Figure 6.20 and 6.21 shows the history of the axial forces in the vertical rebar at mid height on the inby and outby faces respectively. Except in the 12 in. thick seal the, inby rebars in all other cases are in compression (Figure 6.20). The history of the axial forces in the $12 \mathrm{in.}$ thick seal also indicates that the increase in tensile forces is gradual over time and not sudden, which means that the failure in the seal is gradual because of the ability of the steel to undergo significant deformation without losing its strength. The reinforced steel rebars used in the construction of the seals adds some softness to the seal designs. Further the maximum axial forces developed in the steel rebars in all models are well below the yield strength of the steel. 

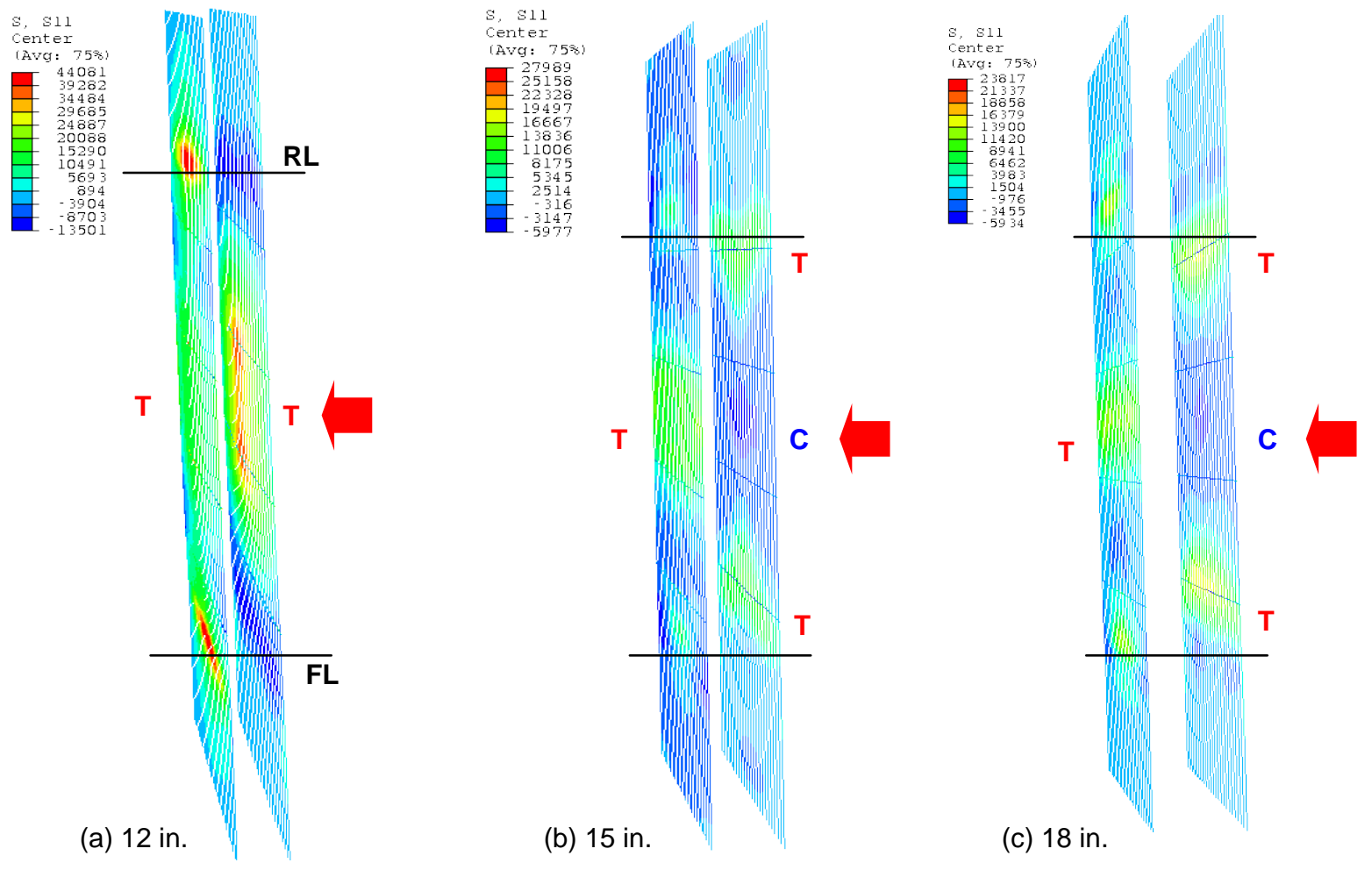

(c) 18 in.

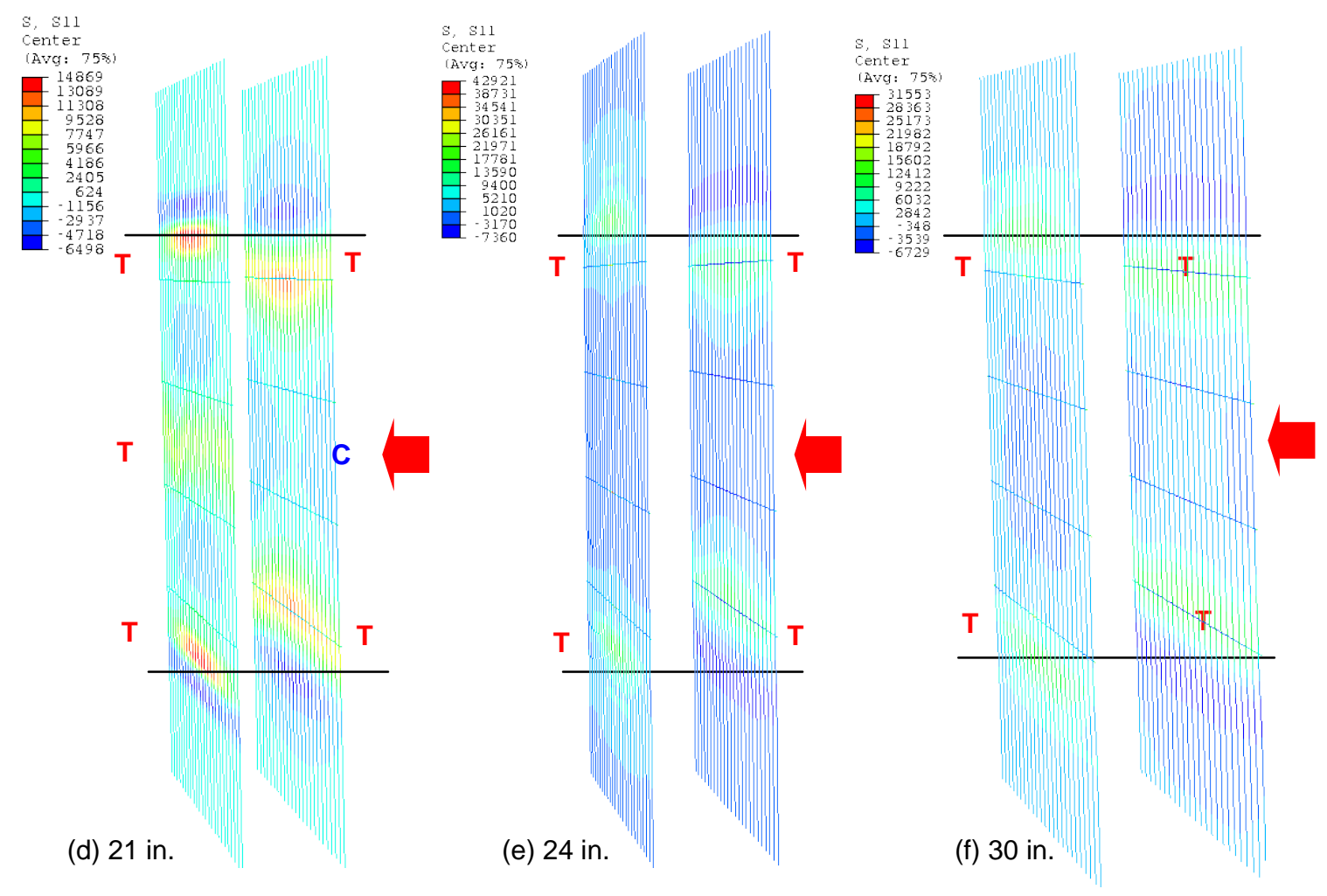

LEGEND: T - Tensile, C- Compressive, RL - Roof line, FL - Floor line

Figure 6.18 Axial forces in the rebars for seals with different thickness 


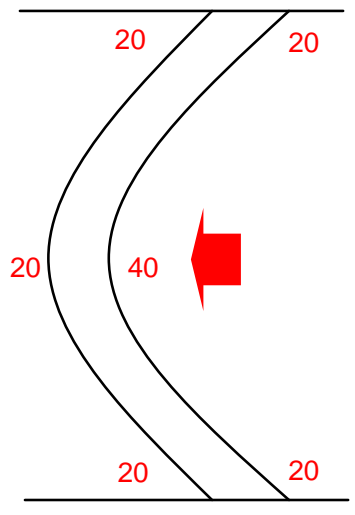

(a) 12 in. thick

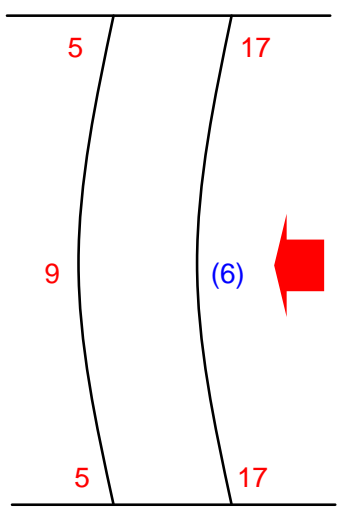

(d) 21 in. thick

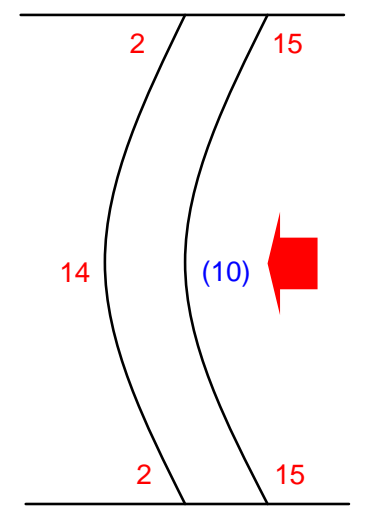

(b) 15 in. thick

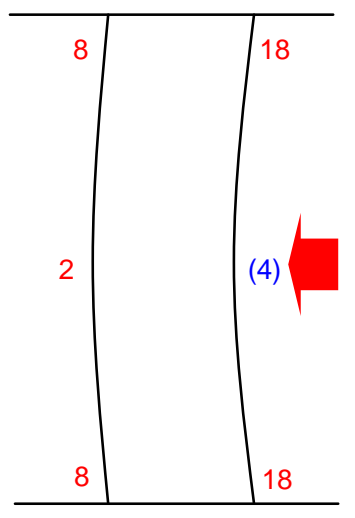

(e) 24 in. thick

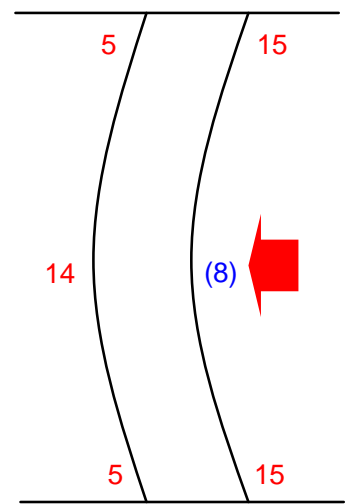

(c) 18 in. thick

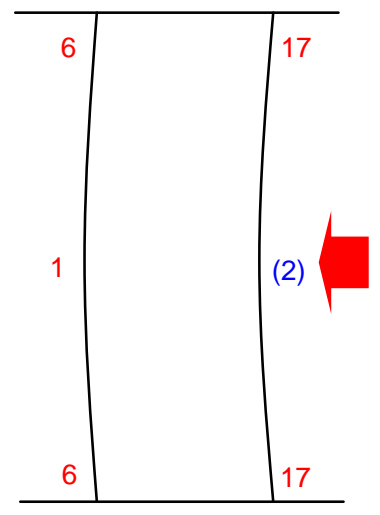

(f) 30 in. thick

LEGEND

Red numbers - Tension

Blue numbers / numbers in parentheses - Compression

Figure 6.19 Schematic diagrams for axial forces (shown in thousand lbs) in the rebars 


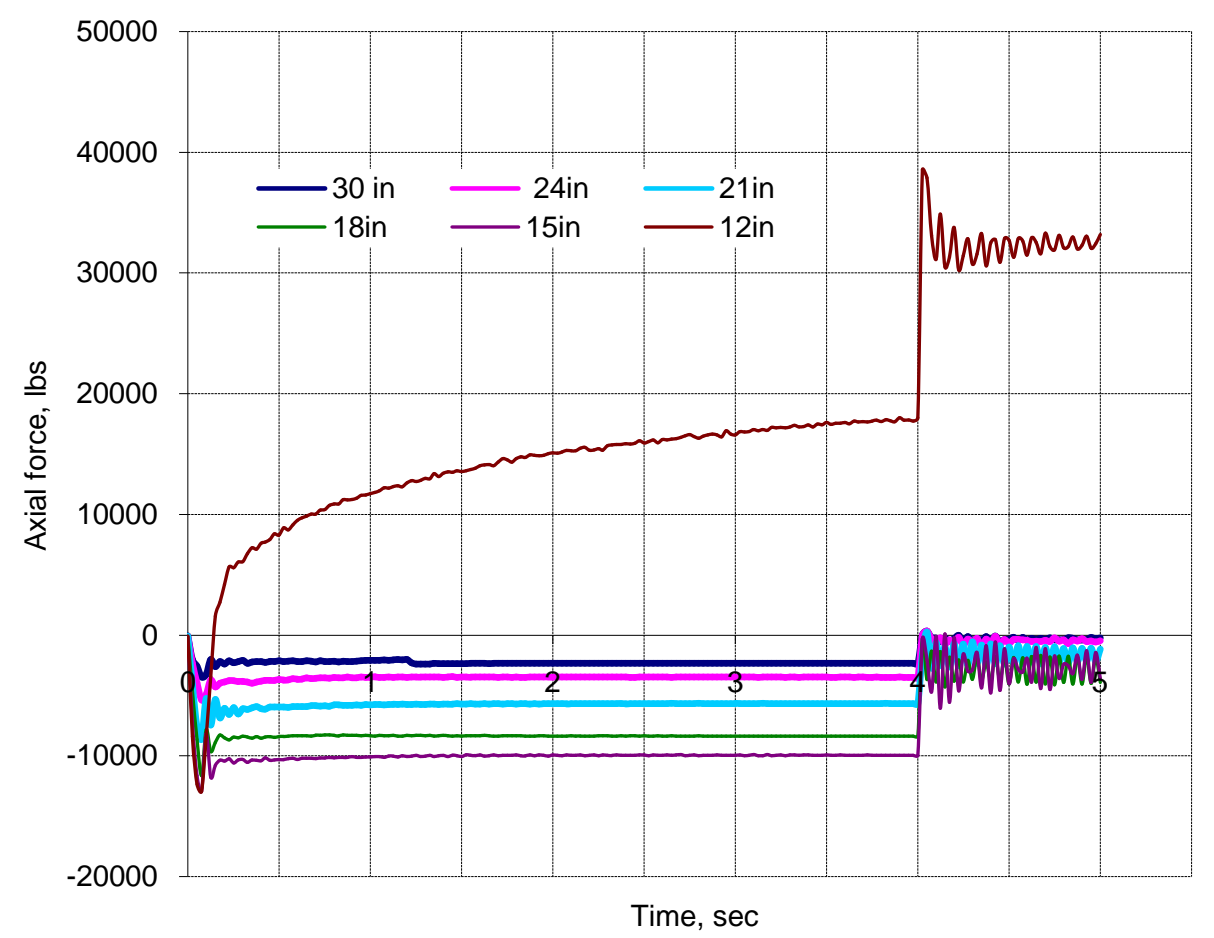

Figure 6.20 The history of axial forces in the central vertical inby rebar (Inby_M)

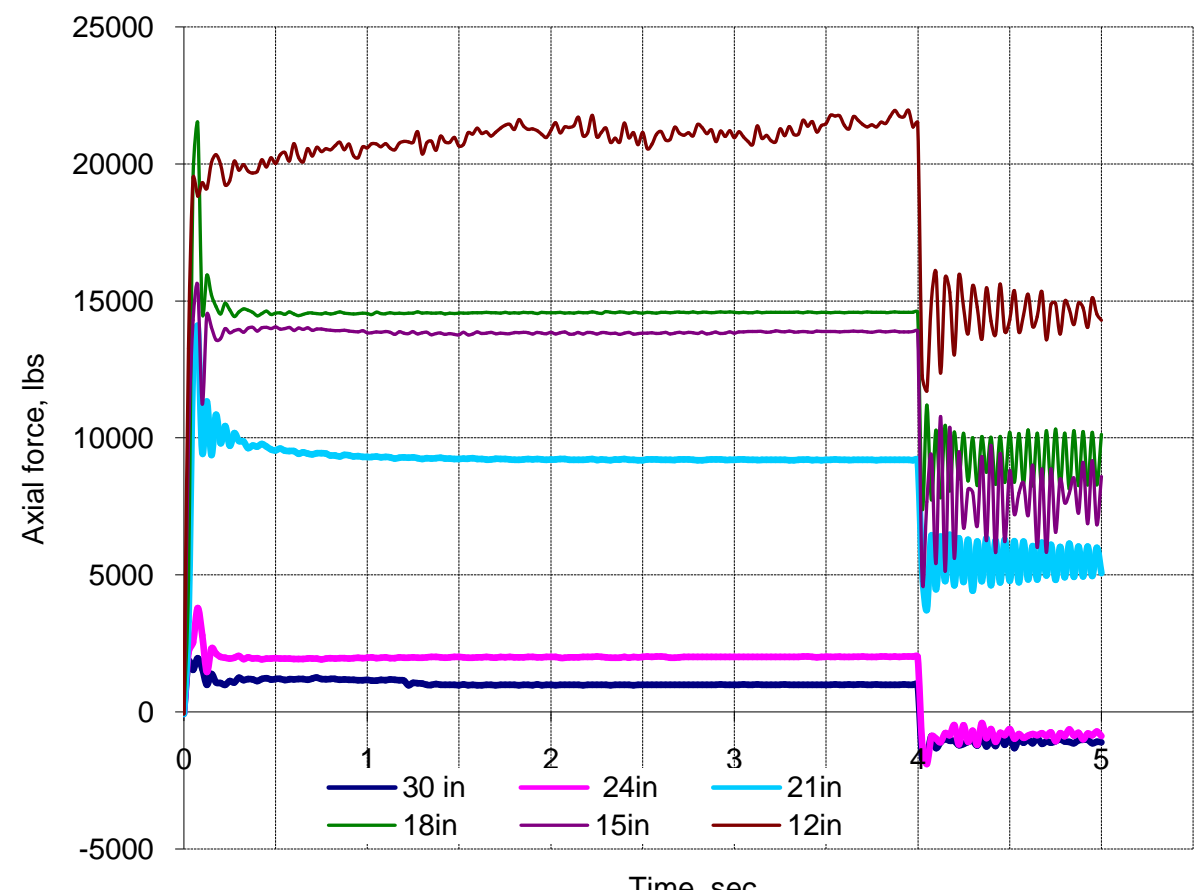

Figure 6.21 The history of axial forces in the central vertical outby rebar (Outby_M) 
Figure 6.22 shows the history of lateral displacements on the outby side of the seal at mid height for different seal thickness. The lateral displacement history in the 12 in. thick seal shows that the displacements are constantly increasing over time and reach a maximum value of about $1.2 \mathrm{in}$. over a period of $4 \mathrm{sec}$. This indicates the continuous deformation of the seal under the applied explosion loading pressure. The magnitude of the lateral displacements reduces significantly with the increase in seal thickness from 12 to 21 in. thick, and very much stabilizes over time. Further increase in seal thickness to 24 in. and beyond actually increases the magnitude of the lateral displacements, because of the change in the basic seal response to the explosion loading at higher seal thicknesses. Refer to the following paragraphs for further explanation on this particualr behavior of the seal. Lateral displacements to some extent also depend on the location of the monitoring node on the surface of the seal. Lateral displacement history may show some gradient, after the initial sharp rise, before reaching a steady value if the location of the node falls in the crack pattern.

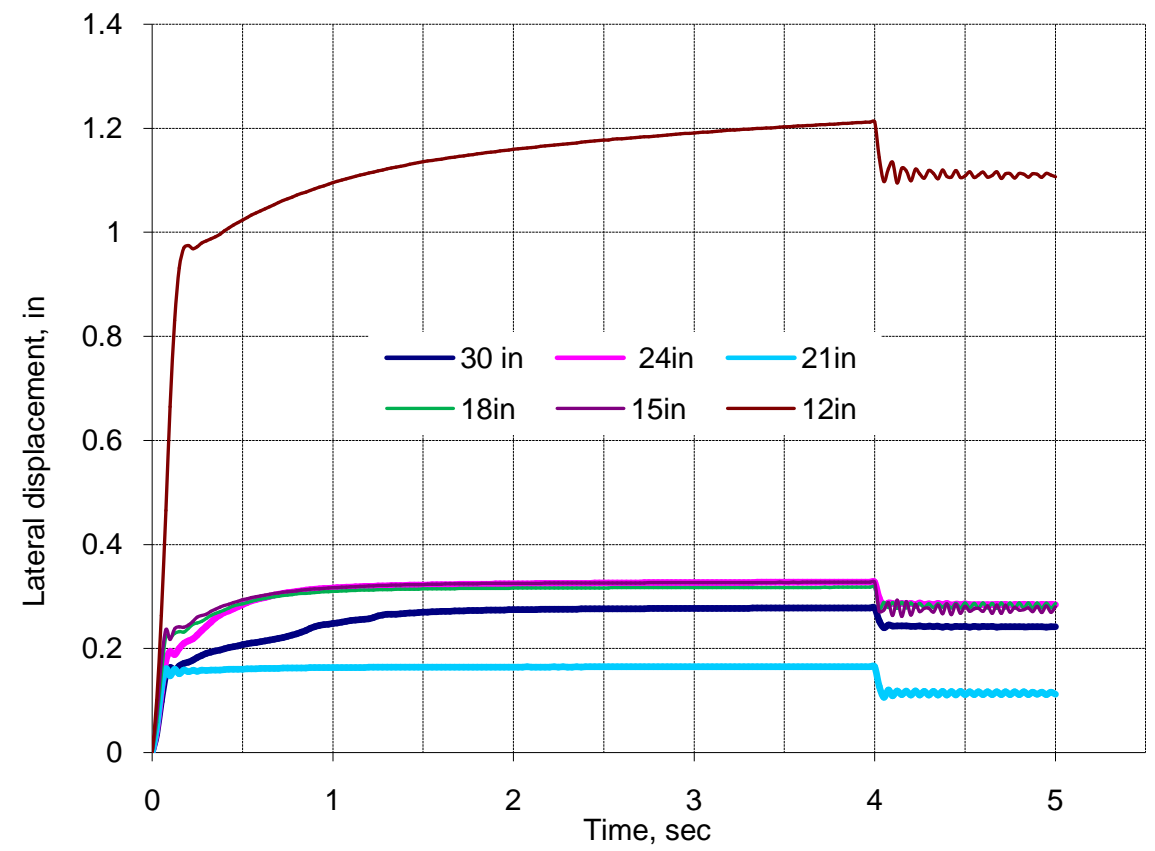

Figure 6.22 The history of lateral displacements for different seals at outby_M

Figure 6.23 shows the contours of the lateral displacements in the seals. The contour plot is magnified 40 times to show the shape of the deformation in the seals. 


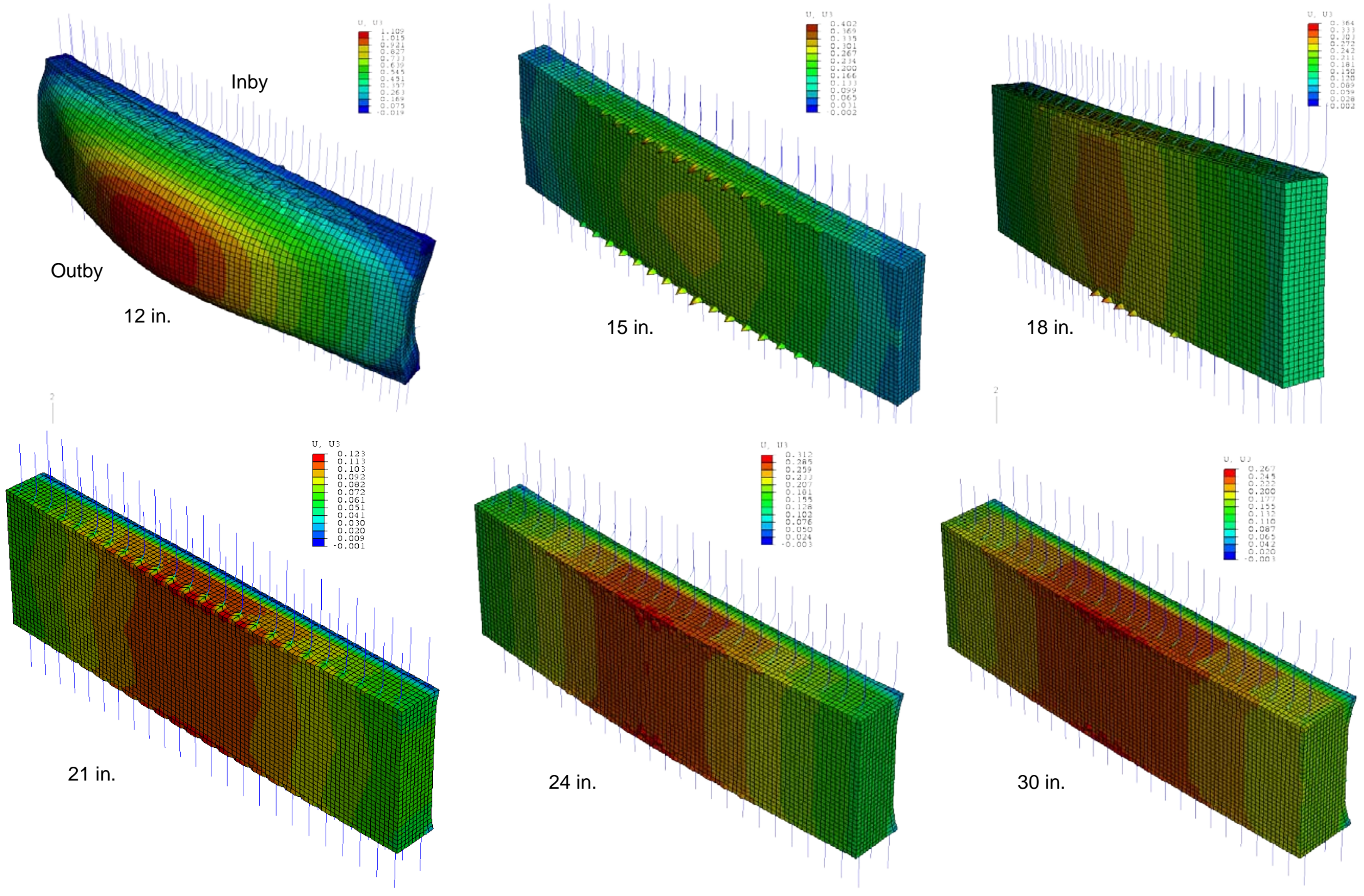

Figure 6.23 Contours of lateral displacements in the seal (plot is magnified 40 times) 
Figure 6.24 shows the plot of the maximum lateral displacements for different seal thickness measured at various locations in the seal. The displacements in the seal near the roof and the floor are very much the same at mid vertical cross section. The difference in the displacements at Outby_M and Outby_T/B decreases sharply with the increase in seal thickness but once the seal reaches sufficient thickness the difference approaches near zero and remains constant with further increase in the seal thickness, indicating that at higher thickness the seal behaves like a rigid body and tries to shear along the seal interfaces under the applied explosion loading. The seal in turn transfers the applied explosion loading to the surrounding rock through steel rebars and seal interfaces, causing the sections of the rebars near the roof and floor lines to be subject to high tensile stresses.

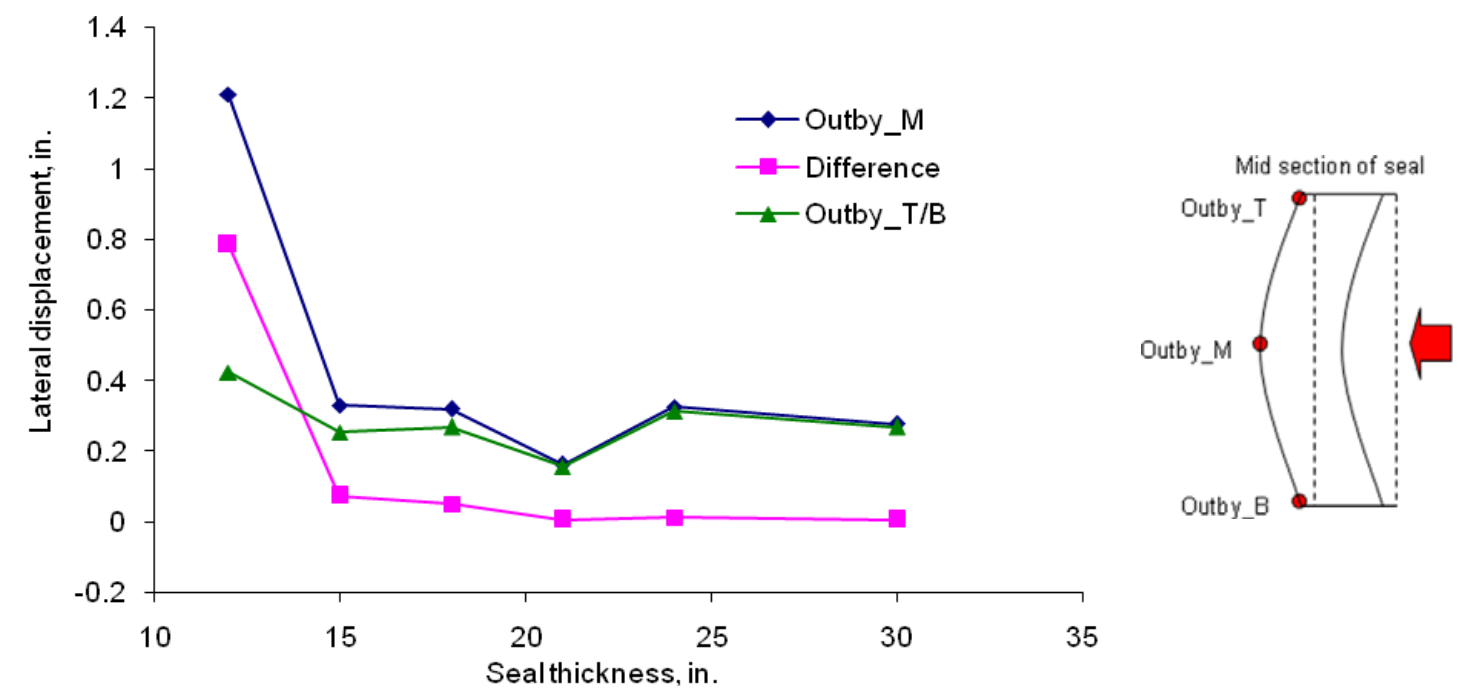

Figure 6.24 Maximum lateral displacement Vs. seal thickness

Figure 6.25 shows the damage contours in the concrete material on the outby face of the seals for different seal thicknesses. The red contour lines with damage values close to 1.0 indicate the tensile cracks on the outby surface of the seals. Under the applied explosion loading pressure, the 12 in. thick seal exhibits extensive damage with numerous horizontal and vertical tensile cracks on the outby surface of the seal. With an increase in seal thickness beyond 12 in. the extent of damage reduces significantly. There is some noticeable localized damage observed in the concrete along the rebar line near the roof and the floor. This localized damage is mainly because of the punching effect of the rebars on the concrete cover, which is about 2.5 in., and has a very little influence on the overall stability of the seal. 

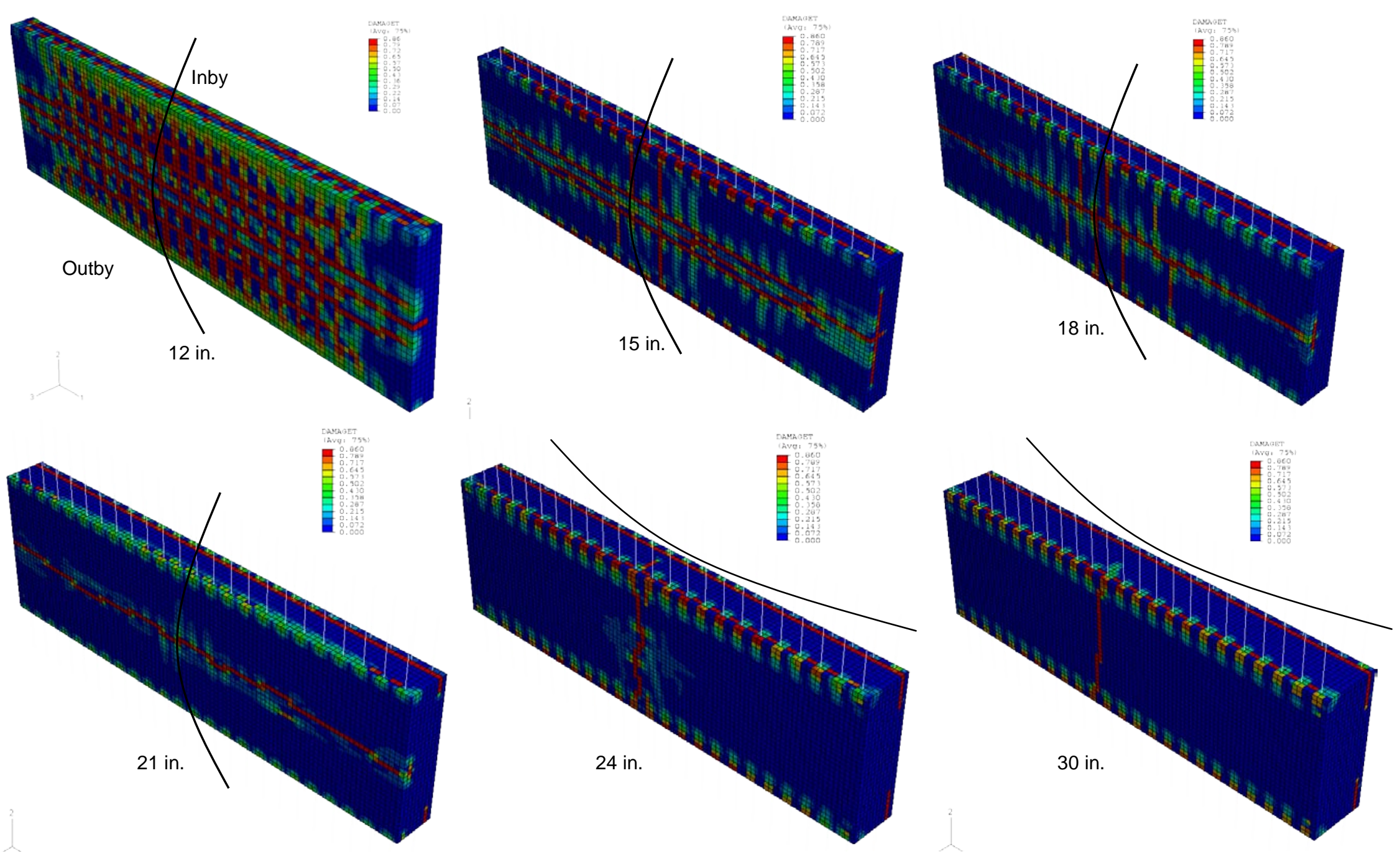

Figure 6.25 Damage contours in seals with different thickness 
The 15 in. thick seal shows some simple horizontal and vertical cracks on the outby face of the seal. An increase in seal thickness from 15 to 21 in. has reduced the concrete cracking from multiple cracks to a single horizontal crack running parallel to the seal on the outby face at mid height. Under the applied explosion loading the seal bends over its height, when it is sufficiently thin, and causes the horizontal tensile cracks develop on the surface of the seal. When the seal is sufficiently thick, 24 in. and beyond in this particular case, it bends over its length and develops vertical tensile cracks on the outby surface of the seal. The curves shown in figure 6.25 show how the seal bends in each case. This change in behavior of the seal with thickness causes the seal to develop more lateral displacements on the outby face (Figure 6.22).

In either case, bending of the seal under the explosion loading causes the inby section of the seal to be subject to compressive stresses and the outby section of the seal to be subject to tensile stresses. Concrete being weaker in tension develops tensile cracks on the outby surface of the seal, whereas the inby surface of the seal shows no signs of damage. These tensile cracks extend only half way deep into the seal (Figures 6.26 and 6.27). Also notice in figure 6.26 the development of shear failure surfaces originating from the top outby corner of the seal and extending deep into the seal. The extent of the shear failure is reduced significantly with increase in seal thickness to 21 in. and beyond (Figure 6.27).

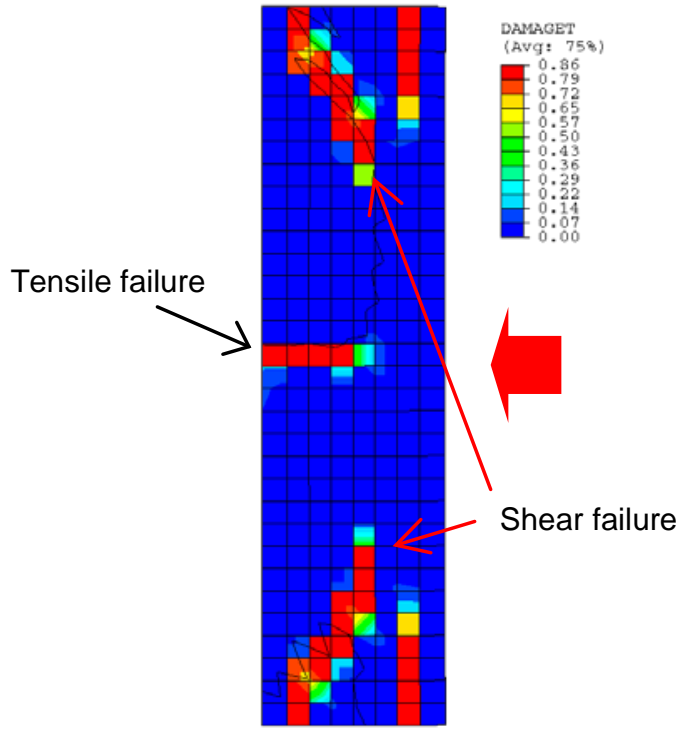

Figure 6.26 Damage contours in 18 in. thick seal (Mid-vertical section) 

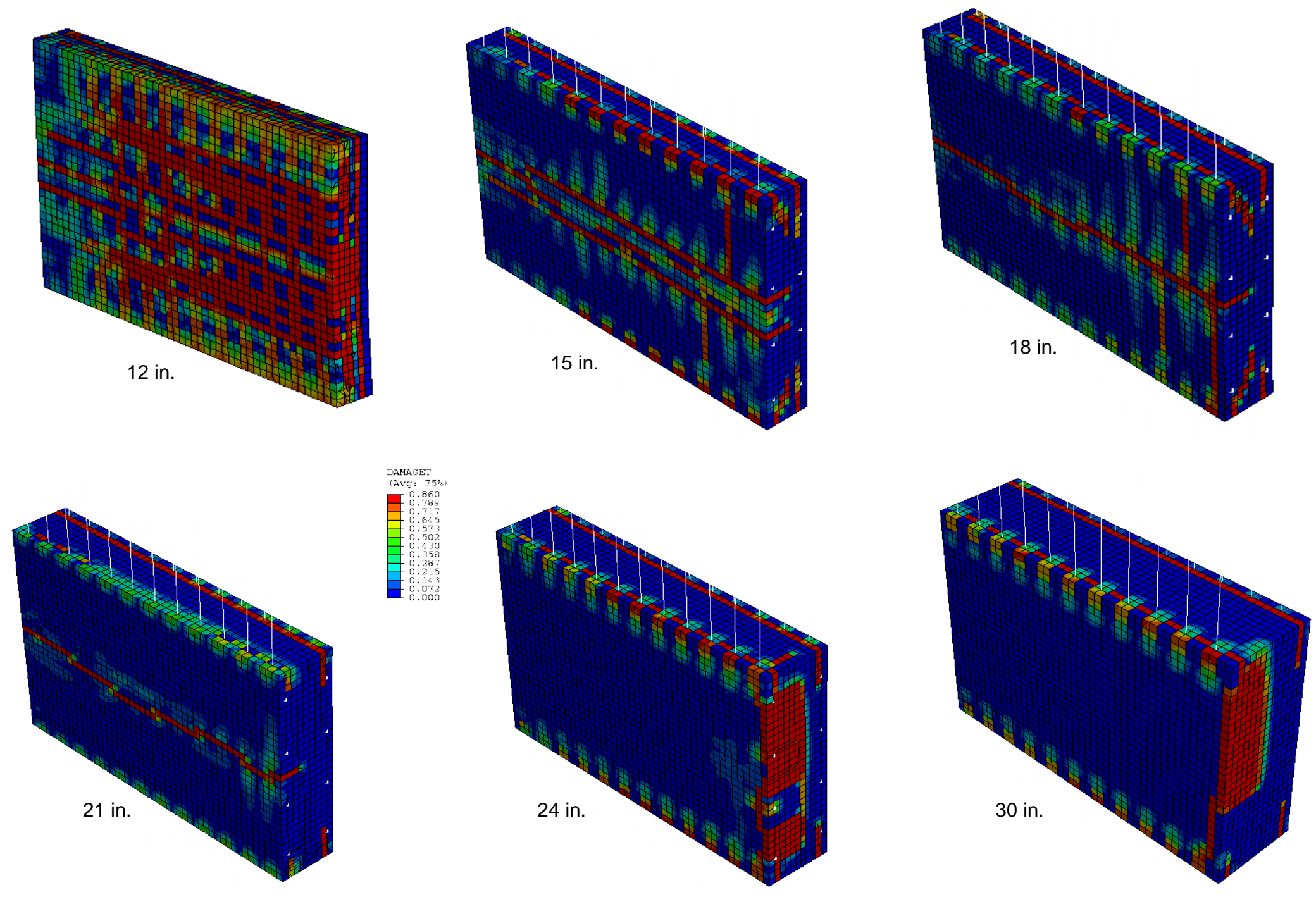

Figure 6.27 Damage contours in seal with different thickness (Mid vertical sections) 
It is important to recognize that the development of the cracks in concrete material cannot be avoided unless the seal is highly overdesigned or constructed using the fiber reinforced concrete material. Simple tensile cracking in the concrete does not necessarily indicate the complete failure of the seal. The primary purpose of installing the reinforced rebars close to the seal surface is to resist the high tensile stresses that may develop near the surface of the seal due to the explosion pressure loading.

Figure 6.28 shows the plot of weighted average damage factor (WADF) for different seal thicknesses. The WADF decreases sharply with increase in seal thickness to $21 \mathrm{in}$. and reaches a value of about 0.057 . Further increase in seal thickness beyond 21 in. showed very little change in WADF. This WADF plot can be effectively used for determining the optimal thickness of a reinforced concrete seal for a given entry dimension.

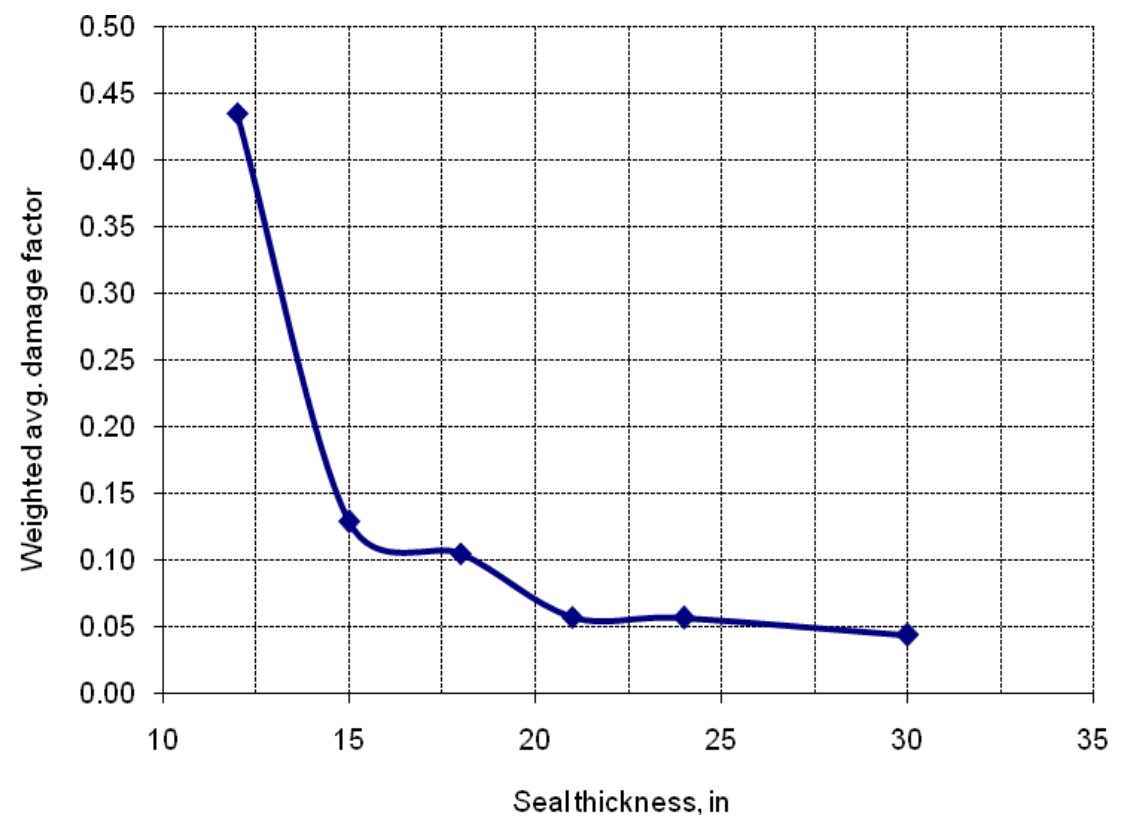

Figure 6.28 Weighted average damage factor (WADF) for different seal thicknesses

\section{Conclusion}

Concrete being weaker in tension develops tensile cracks on the outby surface of the seal. Simple tensile cracks on the outby surface of the seal do not necessarily indicate the complete failure of the seal. Modeling of the full-scale explosion test described in Section 5.1 
also showed a horizontal tensile crack developed on the outby surface of the seal Although NIOSH reported that the seal 'passed' the full-scale explosion test, because of unavailability of the original records, it was not clear whether the seal developed similar tensile damage.

The steel rebars used in the construction of the seal usually resist the high tensile stresses that may develop near the surface of the seal in the event of an explosion. Further, the maximum axial forces developed in the steel rebars are well within the yield strength of the steel. Modeling results also show that, when the seal is sufficiently thick, the tensile cracks developed on the surface of the seal extend only to half thickness of the seal and do not reach the inby surface of the seal, thus preventing the leakage of toxic gases through the cracks from the sealed off areas.

\subsection{RC SEAL DESIGN GUIDELINES}

Based on the results obtained from modeling of the verification cases, in-depth analysis of the seal response to the explosion loading, and the extensive modeling work carried-out in connection with this dissertation work, the following guidelines are proposed for the design of the reinforced concrete seals.

- Tensile cracking: The seal design is limited to a single or no tensile crack on the outby surface of the seal.

- WADF: The weighted average damage factor decreases exponentially with the increase in seal thickness and reaches a 'near-steady' value once the seal reaches sufficient thickness. 'Near-steady' value is used to identify the optimal seal design.

- Lateral displacements: Exhibits very much similar behavior compared to that of WADF.

- No shear failure in the seal (refer to Figure 6.26, p. 96) is allowed.

- No yielding in the steel rebars is allowed. 


\subsection{RC SEAL DESIGN TABLE}

A number of numerical models have been built to design the RC seals for typical coal mine entry sizes. Entries with width-to-height $(\mathrm{W} / \mathrm{H})$ ratio greater than or equal to 2.0 are modeled based on one-way slab loading concept i.e., only the vertical rebars are assumed to transfer the explosion loading and therefore keyed to the roof and floor. Entries with width-to-height ratio less than 2.0 are modeled based on two-way slab loading concept i.e., both vertical and horizontal rebars are keyed to the surrounding rock (Figure 6.29).

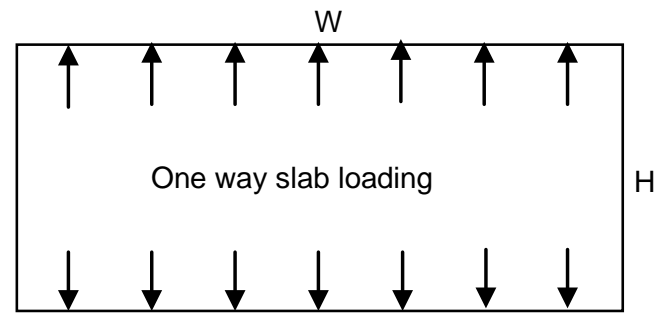

(a)

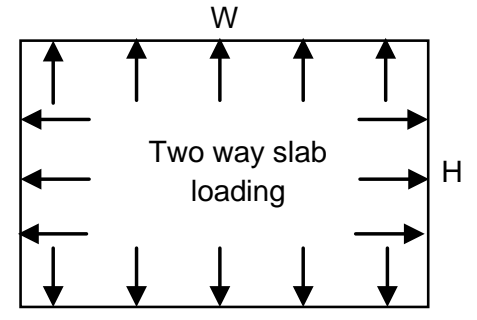

(b)

Figure 6.29 Seal loading concept

Material models discussed in Chapter 3 were used in this study. The CEB \& Barth and Wu concrete model described in Section 4.3 was used for simulating the behavior of the concrete. In almost all models, instantaneous 120 psi pressure-time curve with 4 sec duration was used for applying the explosion pressure loading to the seal except for $10 \mathrm{ft}$ and $12 \mathrm{ft}$ high seals. Numerical models with seal heights more than $10 \mathrm{ft}$ take a large amount of computer memory and computing time to solve the numerical models, so the explosion loading duration is reduced to $2 \mathrm{sec}$ instead of the normal 4 sec duration. Other parameters used in the construction of RC seal models were:
Vertical rebar size \& spacing
: \#9 and 10 in.
Horizontal rebar size \& spacing $\quad$ : \#6 and 18 in.
Seal-rock/coal interface strength $\quad$ : 200 psi
Surrounding rock strength
: Intermediate (refer to Table 6.2, p. 84)
Concrete strength
: 4800 psi (CEB \& Barth and Wu model)

\section{Results and discussion}


Results from the numerical models showed that the entry height has greater influence on the seal design than the entry width. At lower entry heights, width of the entry showed very little or no influence on the seal design. On the other hand, at higher entry heights, this width of the entry has some influence on the seal design (Figure 6.30). Considering this factor, entry widths $18 \mathrm{ft}$ and $22 \mathrm{ft}$ are excluded from the model combinations in order to reduce the modeling work. Following the guidelines described in Section 6.5, the reinforced concrete seals are designed for typical entry dimensions. Table 6.3 shows the required minimum thickness of reinforced concrete seal for typical entry dimensions to withstand 120 psi instantaneous explosion pressure loading. Figure 6.30 shows the graphical representation of required minimum seal thickness for typical coal mine entries.

Table 6.3 Minimum required RC seal thickness in inches for typical entry dimensions

\begin{tabular}{|c|c|c|c|c|c|c|c|c|c|}
\hline & \multicolumn{8}{|c|}{ Entry height, ft } \\
\hline & & $4 \mathrm{ft}$ & $5 \mathrm{ft}$ & $6 \mathrm{ft}$ & $7 \mathrm{ft}$ & $8 \mathrm{ft}$ & $9 \mathrm{ft}$ & $10 \mathrm{ft}$ & $12 \mathrm{ft}$ \\
\hline \multirow{3}{*}{ 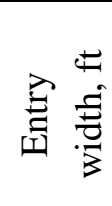 } & $16 \mathrm{ft}$ & 16 & 20 & 24 & 26 & 30 & 32 & 36 & - \\
\hline & $20 \mathrm{ft}$ & 16 & 22 & 24 & 28 & 30 & 34 & 38 & 44 \\
\hline & $24 \mathrm{ft}$ & 16 & 22 & 26 & 28 & 32 & 36 & 40 & 48 \\
\hline
\end{tabular}

* These seal designs are valid with the parameters shown above

Figures 6.31 to 6.38 show the plot of WADF and maximum lateral displacements (Outby_M) with seal thickness for various entry dimensions. Almost all models showed behavior similar to the one described in the previous section. The plot for weighted average damage factor took the exponentially decreasing path with increasing seal thickness (Figure 6.31(a)). ABAQUS models with other seal heights also show similar behavior but the seal thickness interval chosen is too close to show the complete exponential curve for WADF. On the other hand, the plot of maximum lateral displacements vs. seal thickness does not show a common trend for different seal heights. This trend is partly because of the location of the lateral displacement monitoring point on the outby side of the seal and partly because of the behavior of the seal as described in Section 6.4. Tensile damage contours of seals for various entry dimensions are provided in Appendix I. The history of the lateral displacements in the seal (Outby_M) for different entry dimensions are provided in Appendix II. 


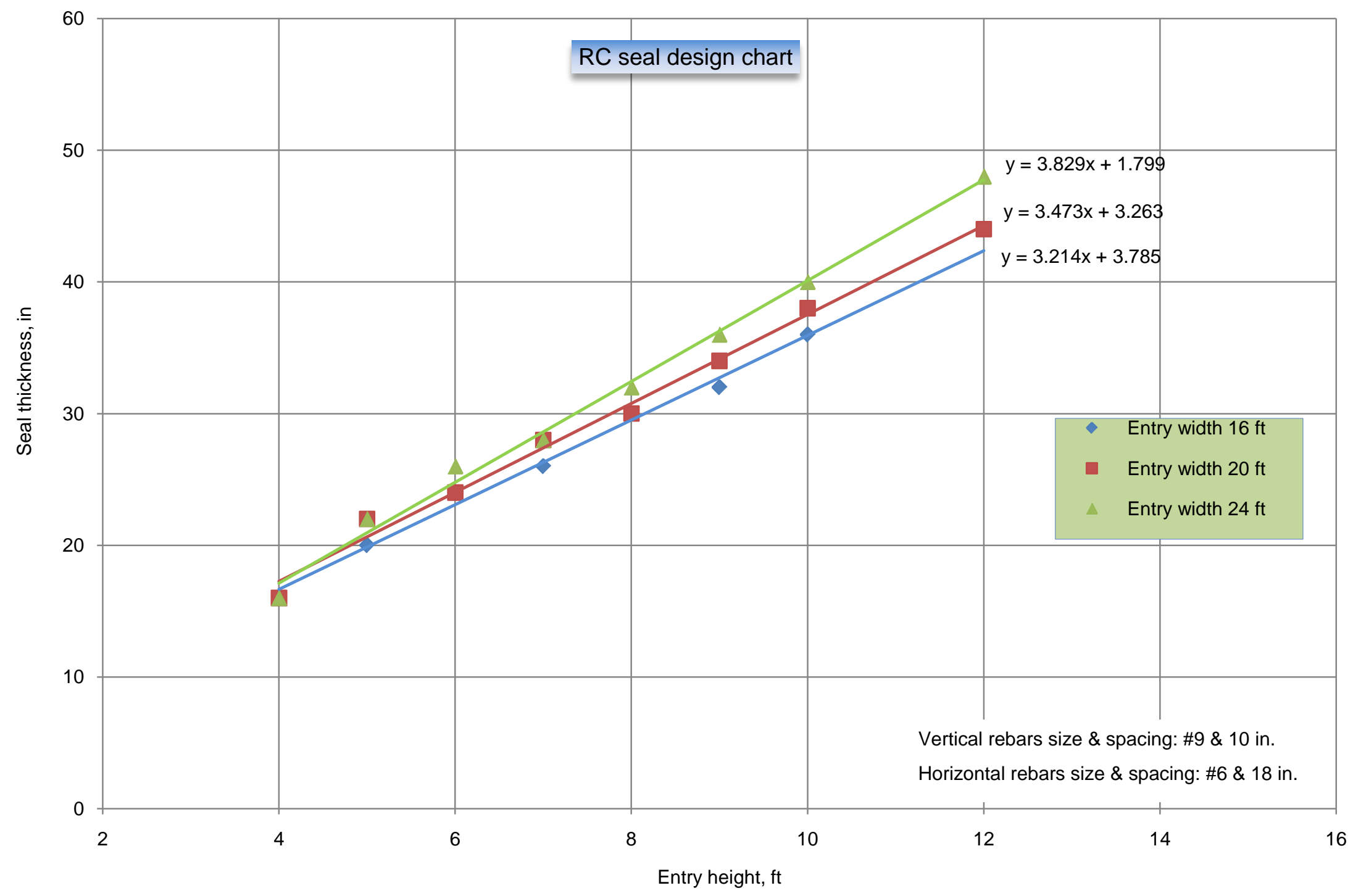

Figure 6.30 Reinforced concrete seal design chart 


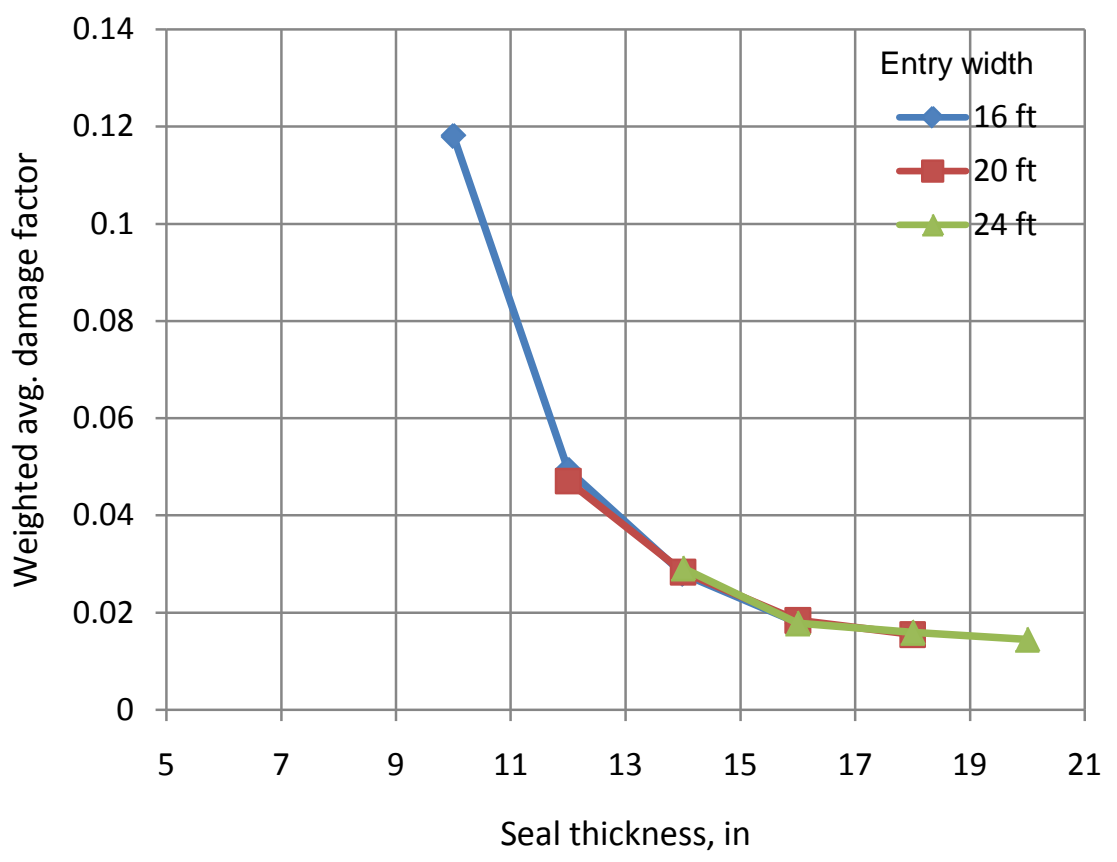

(a) WADF

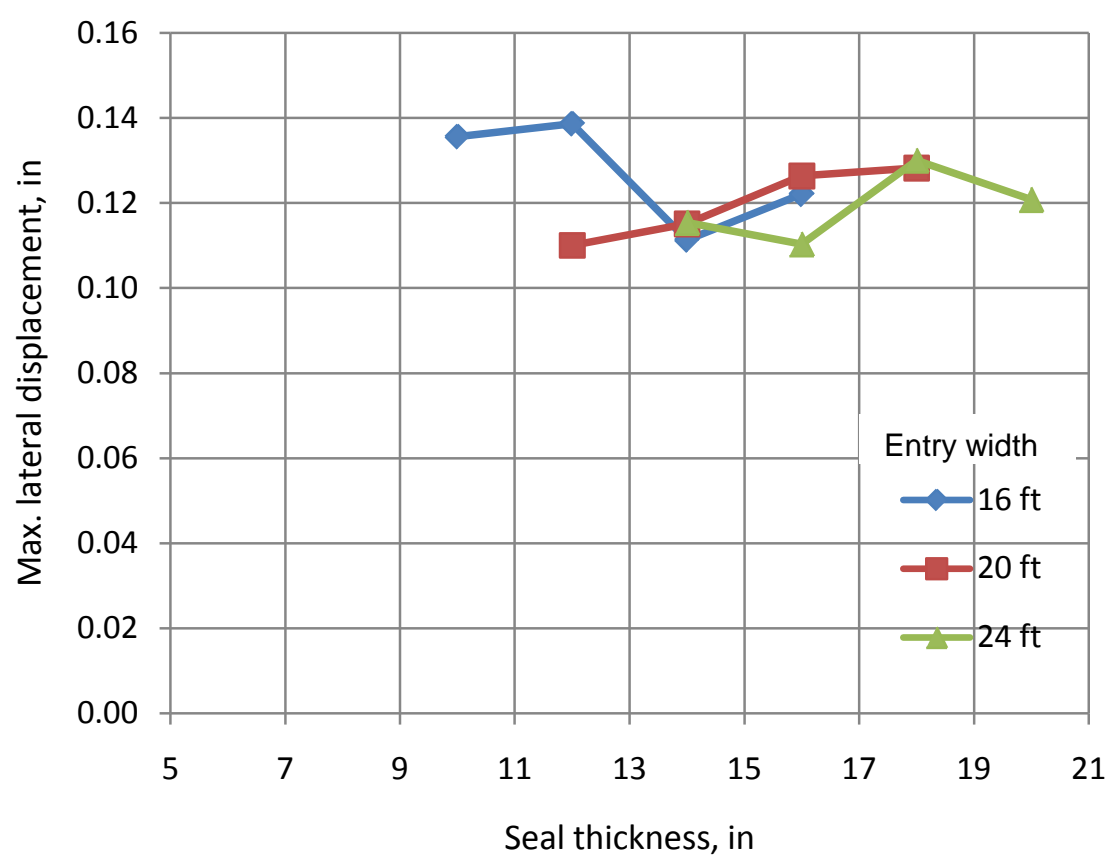

(b) Maximum lateral displacement

Figure 6.31 Plot of WADF and maximum lateral displacements for $4 \mathrm{ft}$ high seal 


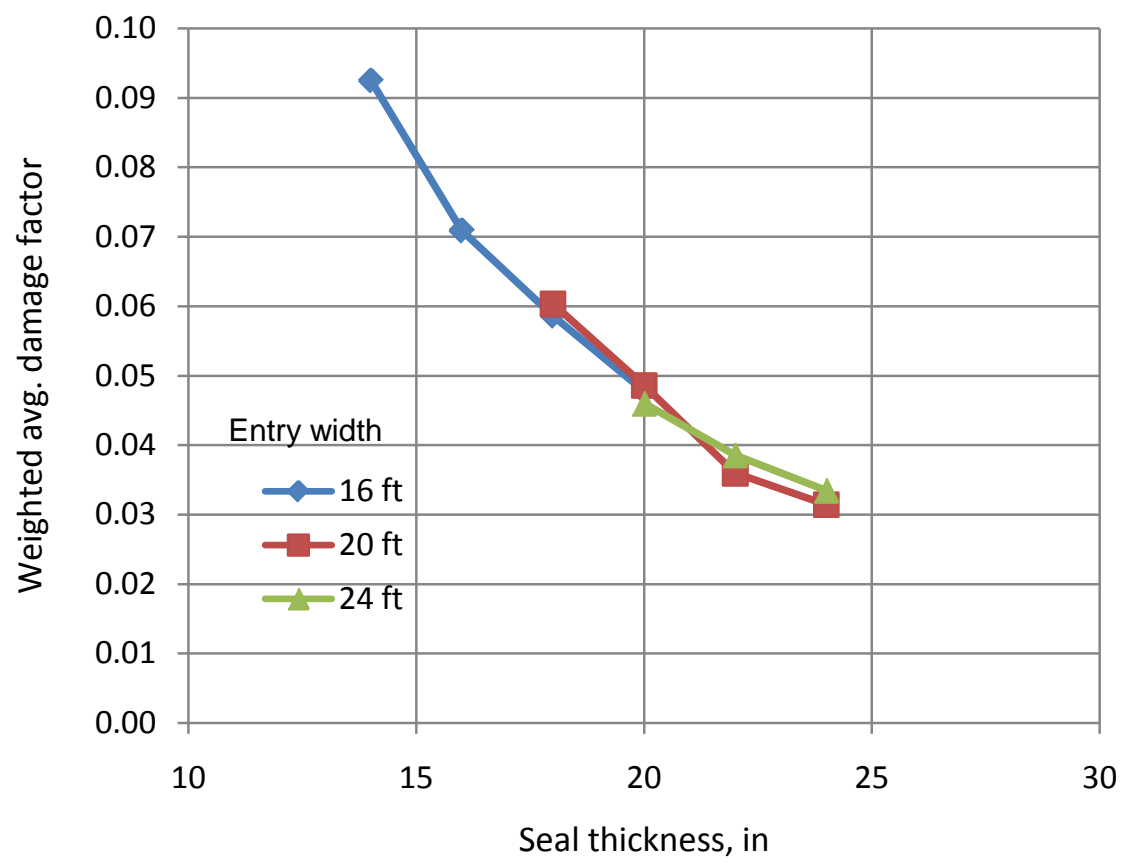

(a) WADF

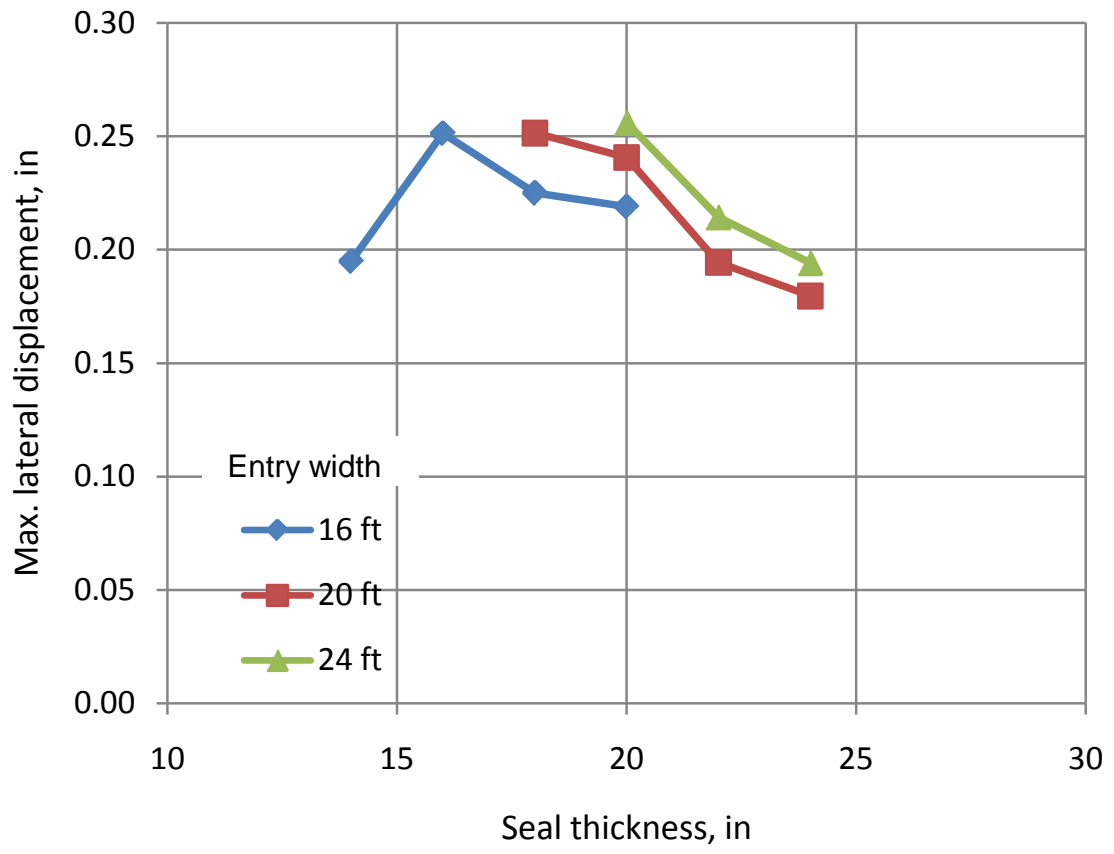

(b) Maximum lateral displacement

Figure 6.32 Plot of WADF and maximum lateral displacements for $5 \mathrm{ft}$ high seal 


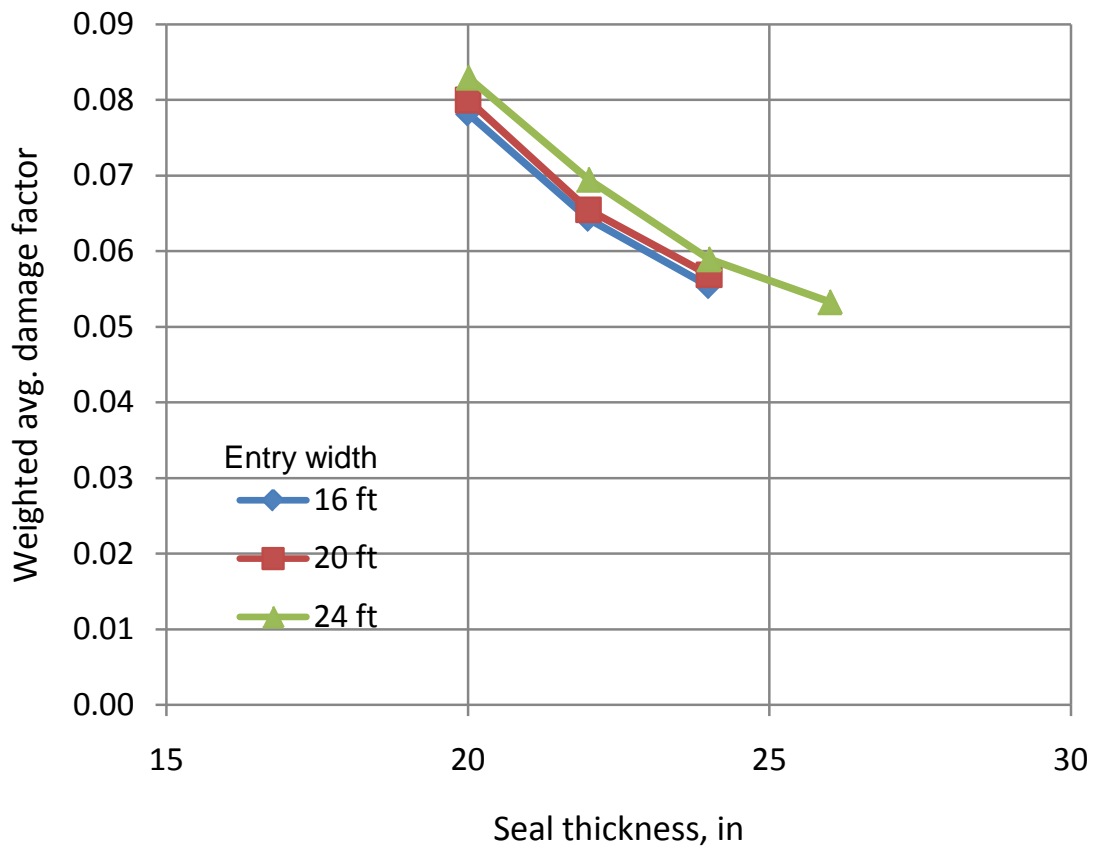

(a) WADF

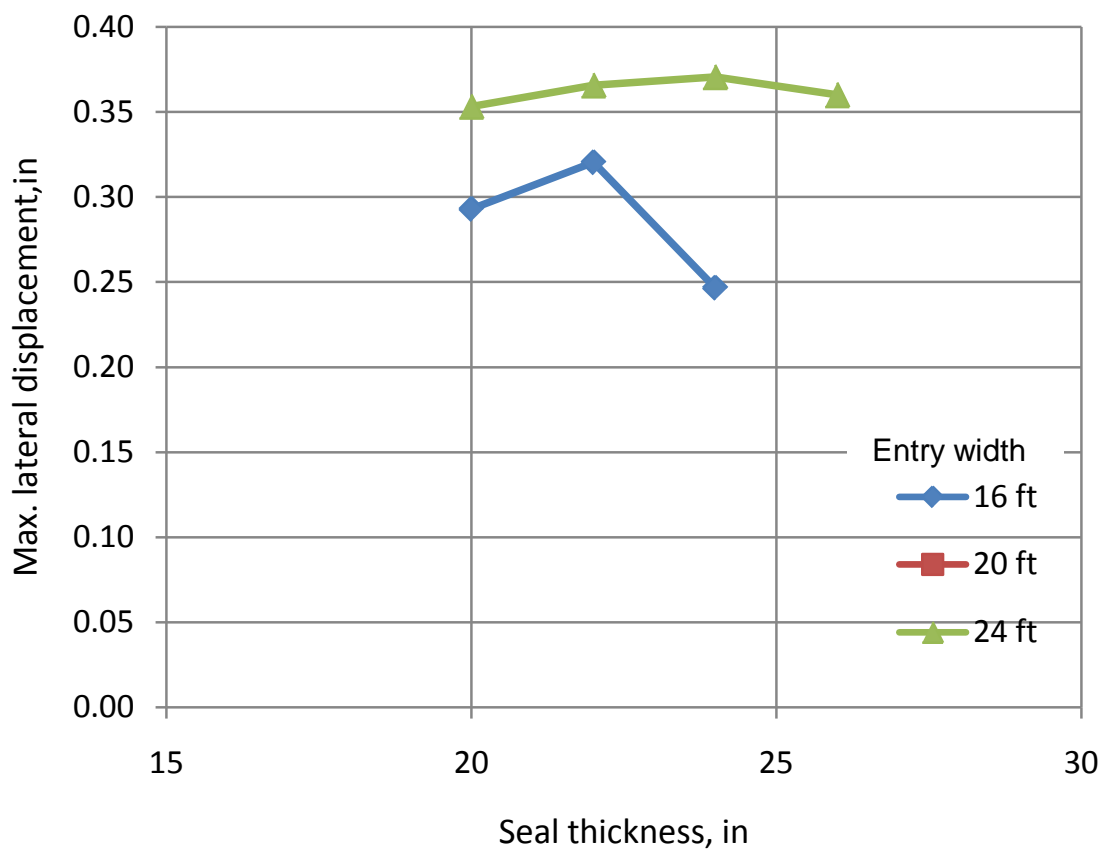

(b) Maximum lateral displacement

Figure 6.33 Plot of WADF and maximum lateral displacements for $6 \mathrm{ft}$ high seal 


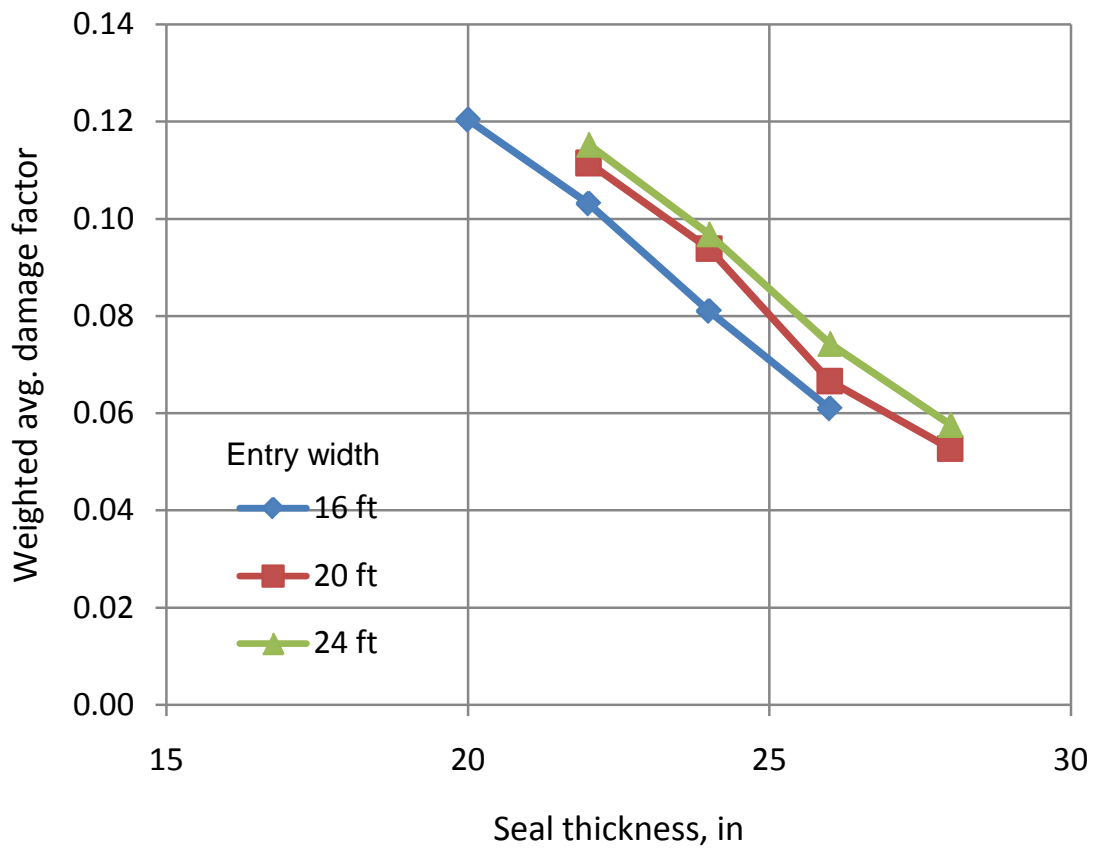

(a) WADF

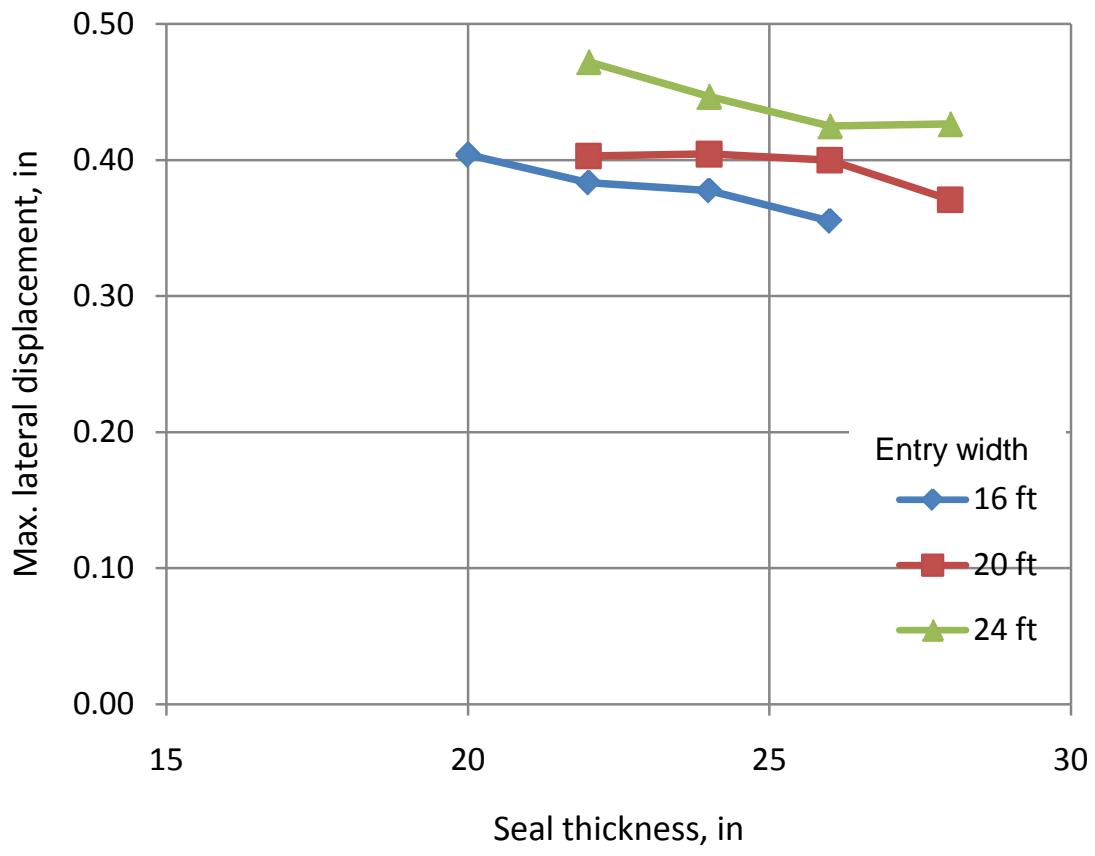

(b) Maximum lateral displacement

Figure 6.34 Plot of WADF and maximum lateral displacements for $7 \mathrm{ft}$ high seal 


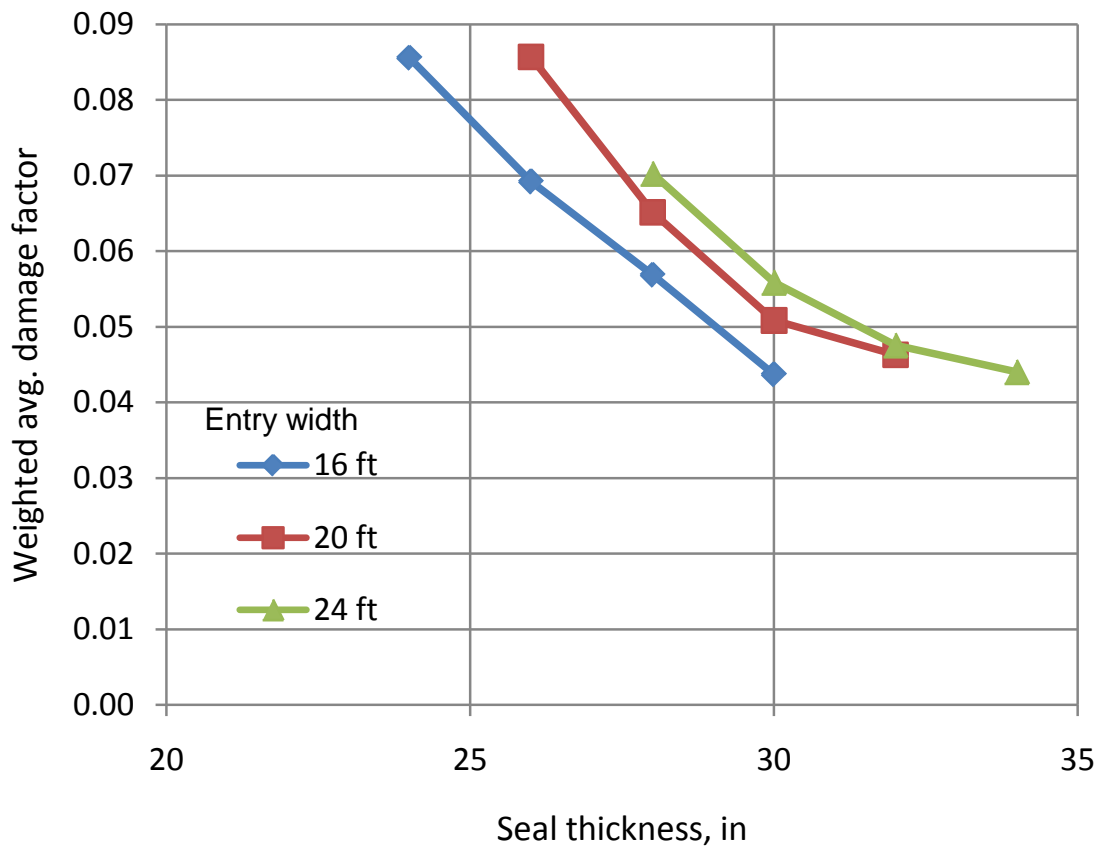

(a) WADF

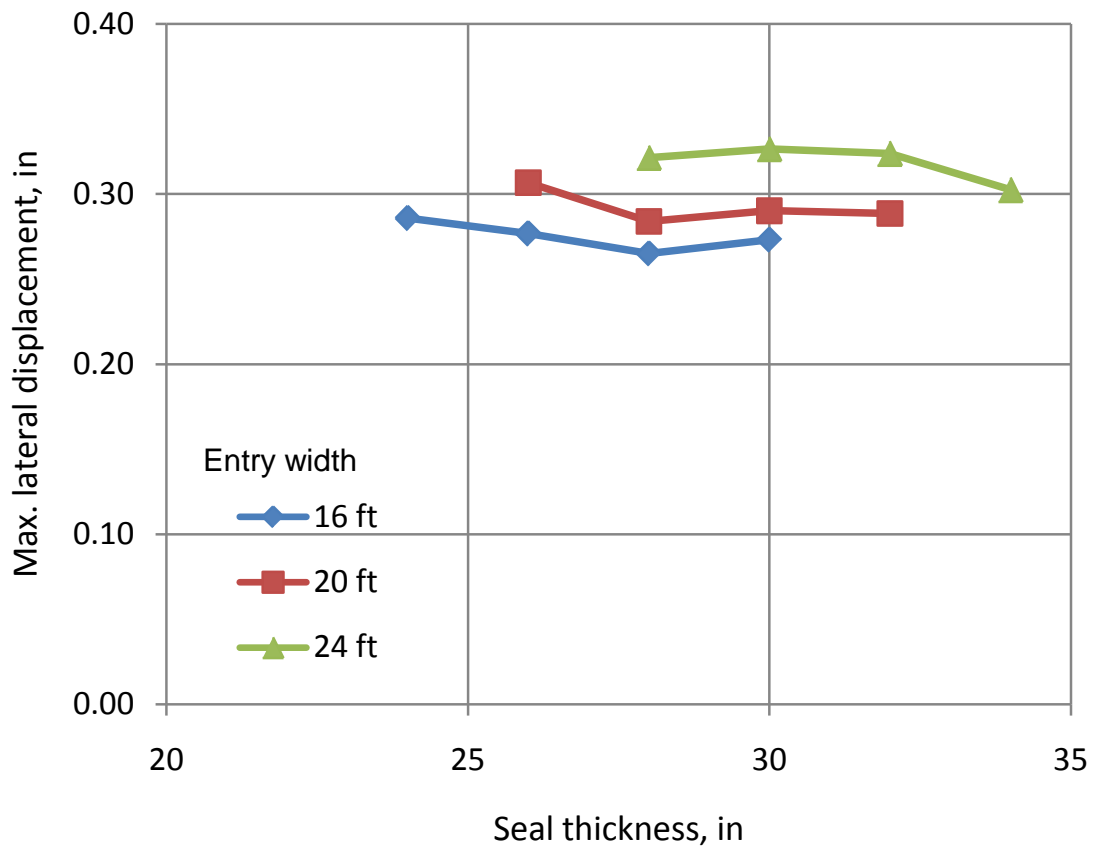

(b) Maximum lateral displacement

Figure 6.35 Plot of WADF and maximum lateral displacements for $8 \mathrm{ft}$ high seal 


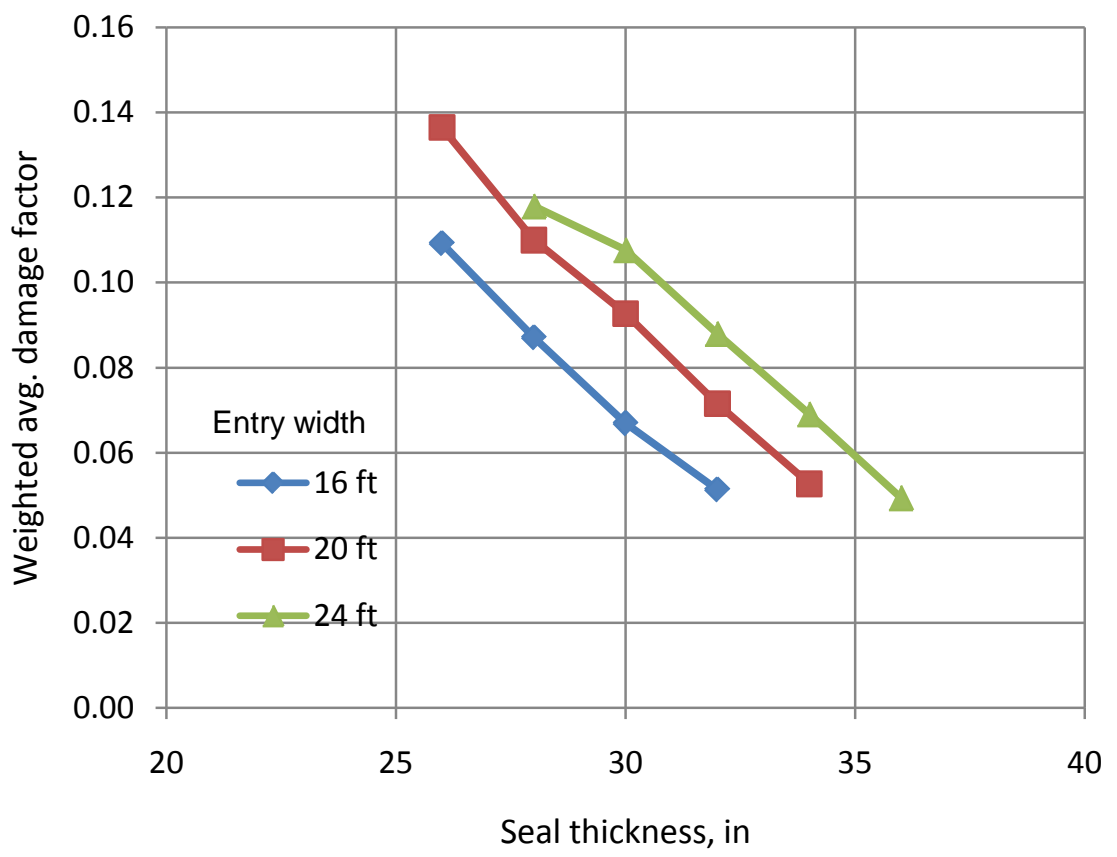

(a) WADF

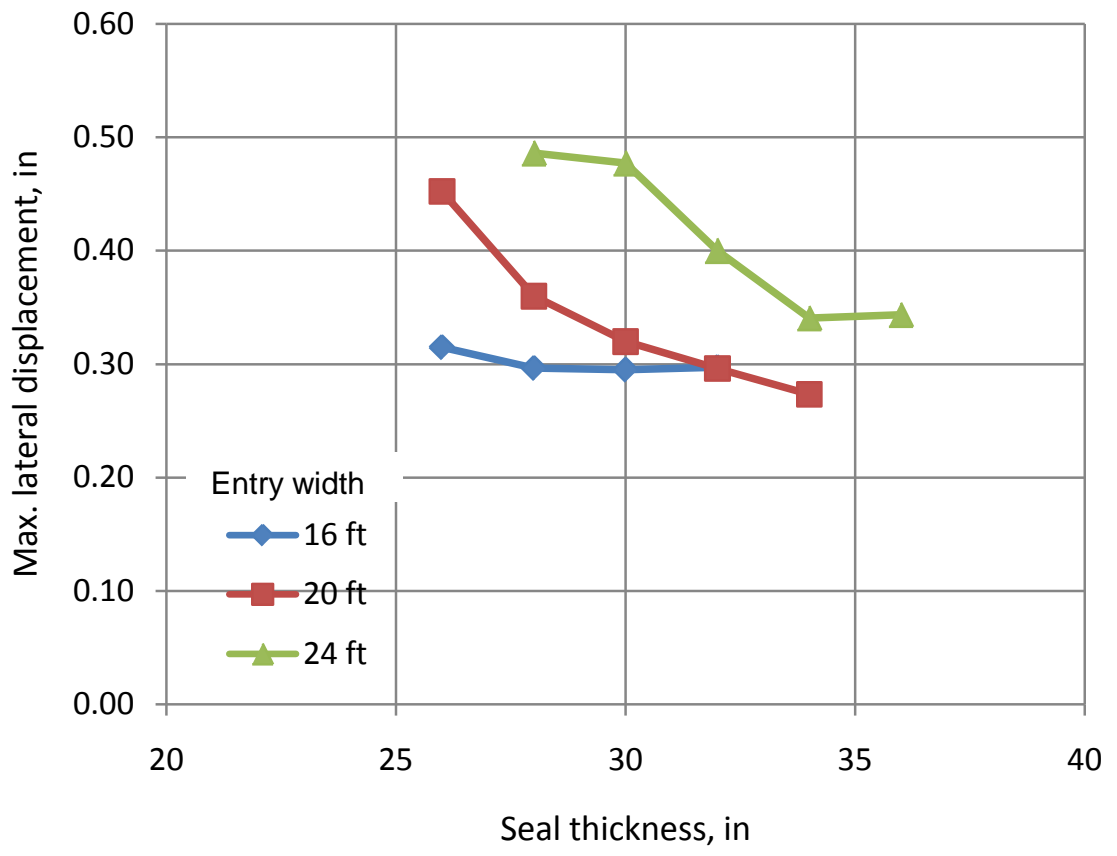

(b) Maximum lateral displacement

Figure 6.36 Plot of WADF and maximum lateral displacements for $9 \mathrm{ft}$ high seal 


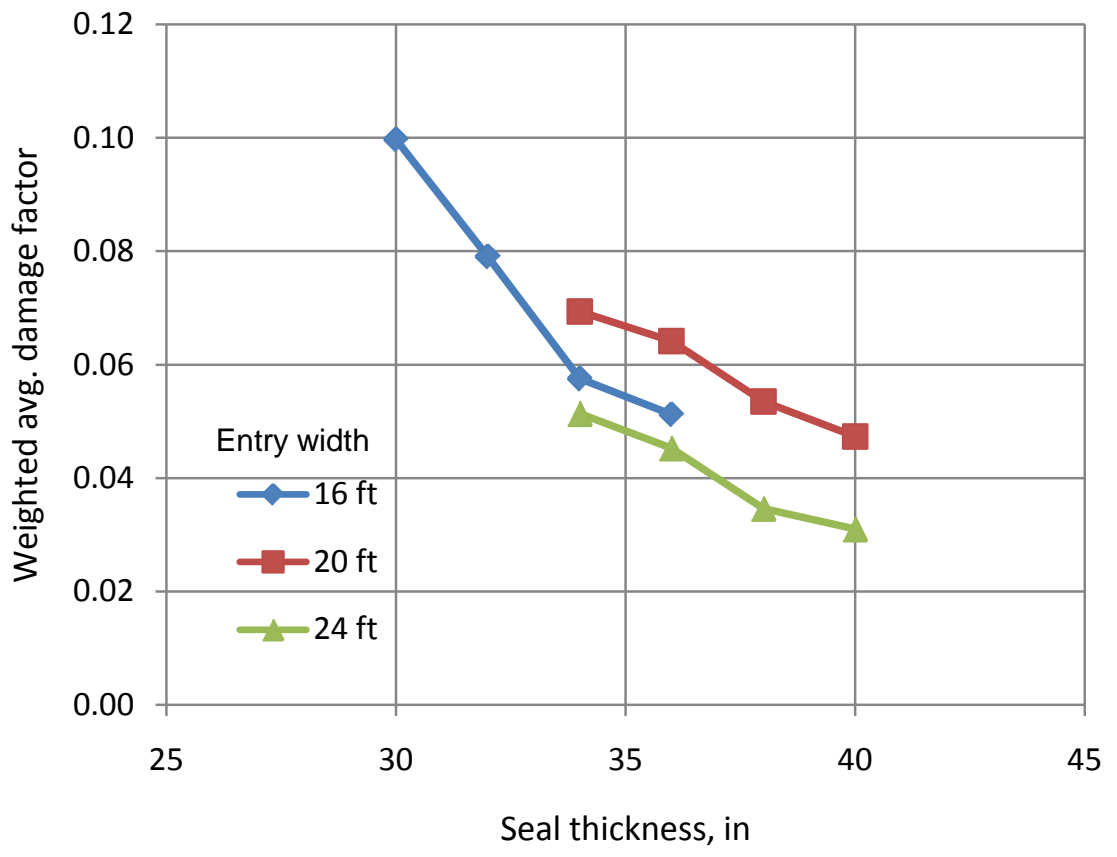

(a) WADF

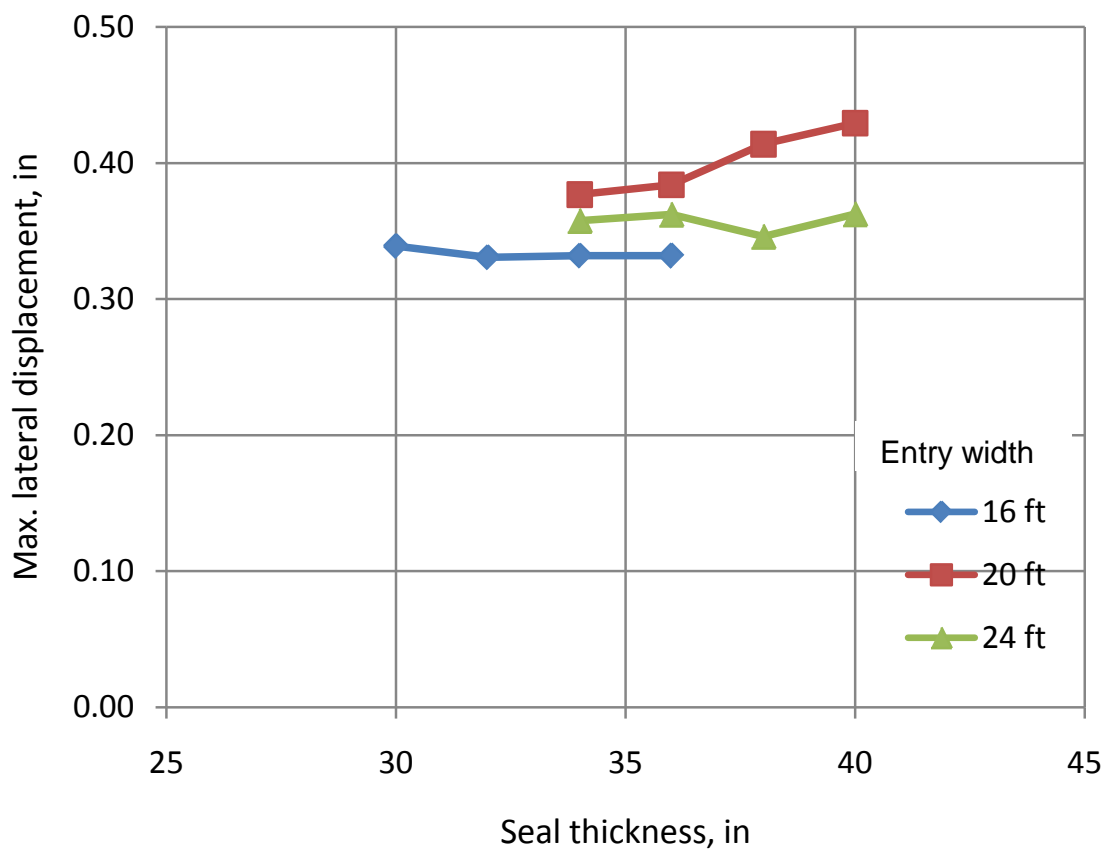

(b) Maximum lateral displacement

Figure 6.37 Plot of WADF and maximum lateral displacements for $10 \mathrm{ft} \mathrm{high} \mathrm{seal}$ 


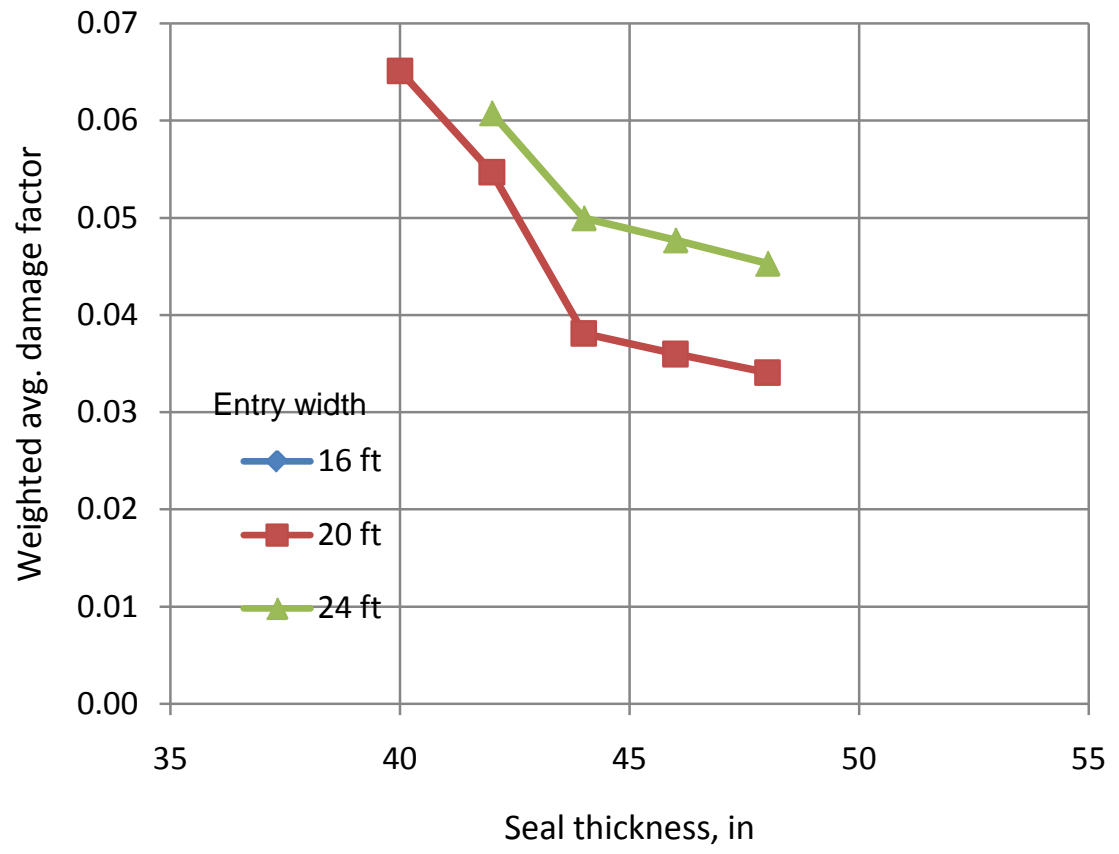

(a) WADF

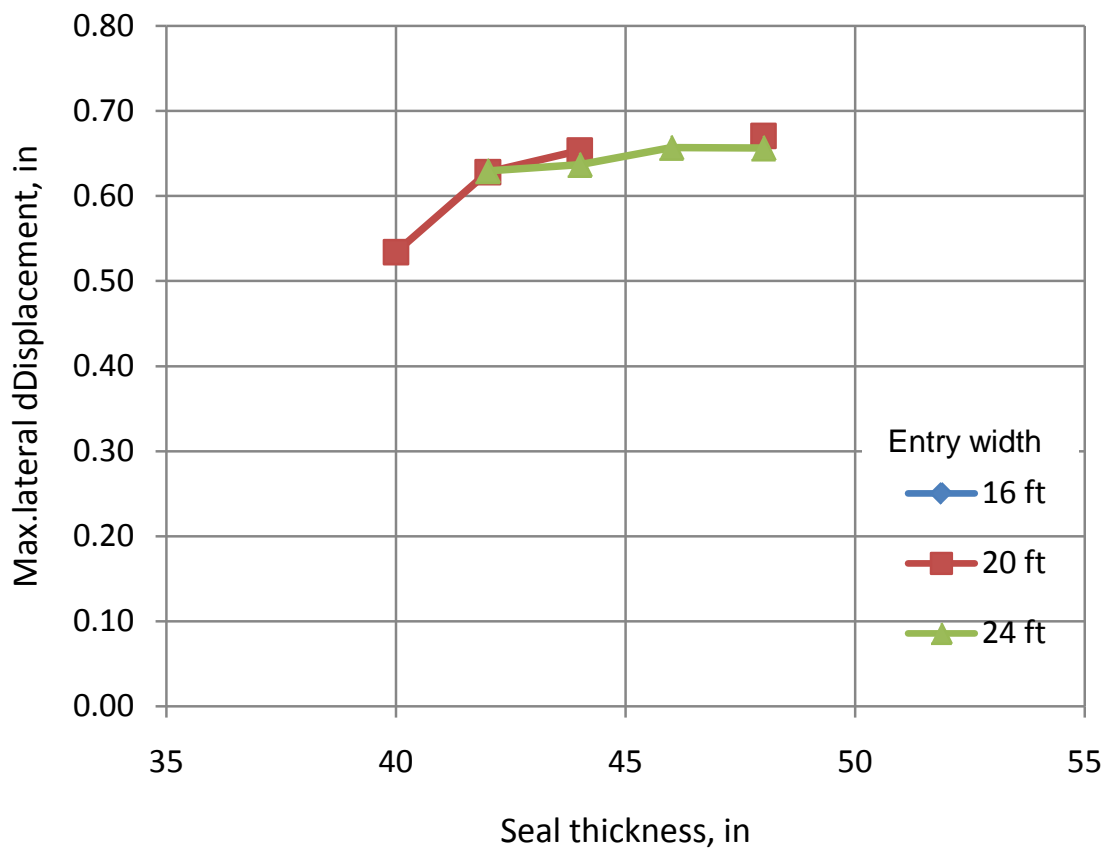

(b) Maximum lateral displacement

Figure 6.38 Plot of WADF and maximum lateral displacements for $12 \mathrm{ft} \mathrm{high} \mathrm{seal}$ 


\section{Chapter 7 ROOF-TO-FLOOR CONVERGENCE}

fter the initial development of coal mine entries they are subjected to different levels including but not limited to: the stress around the entry, the geological conditions, the age of mine entry, the mining method, the proximity of the entry to the mined out areas, etc. In general, it is observed in practice that the convergence rate is high during the initial phases of life of the mine entry and in due course of time the rate of convergence decreases exponentially and very much stabilizes after a certain period of time. Figure 7.1 shows the measured rate of convergence at one mine in Western Kentucky (Kallu et al., 2007). Roof-tofloor convergence was monitored by installing convergence stations in mine entries with different initial excavation ages and is plotted into one graph as shown below. Figure 7.2 shows the convergence station installed near an experimental seal.

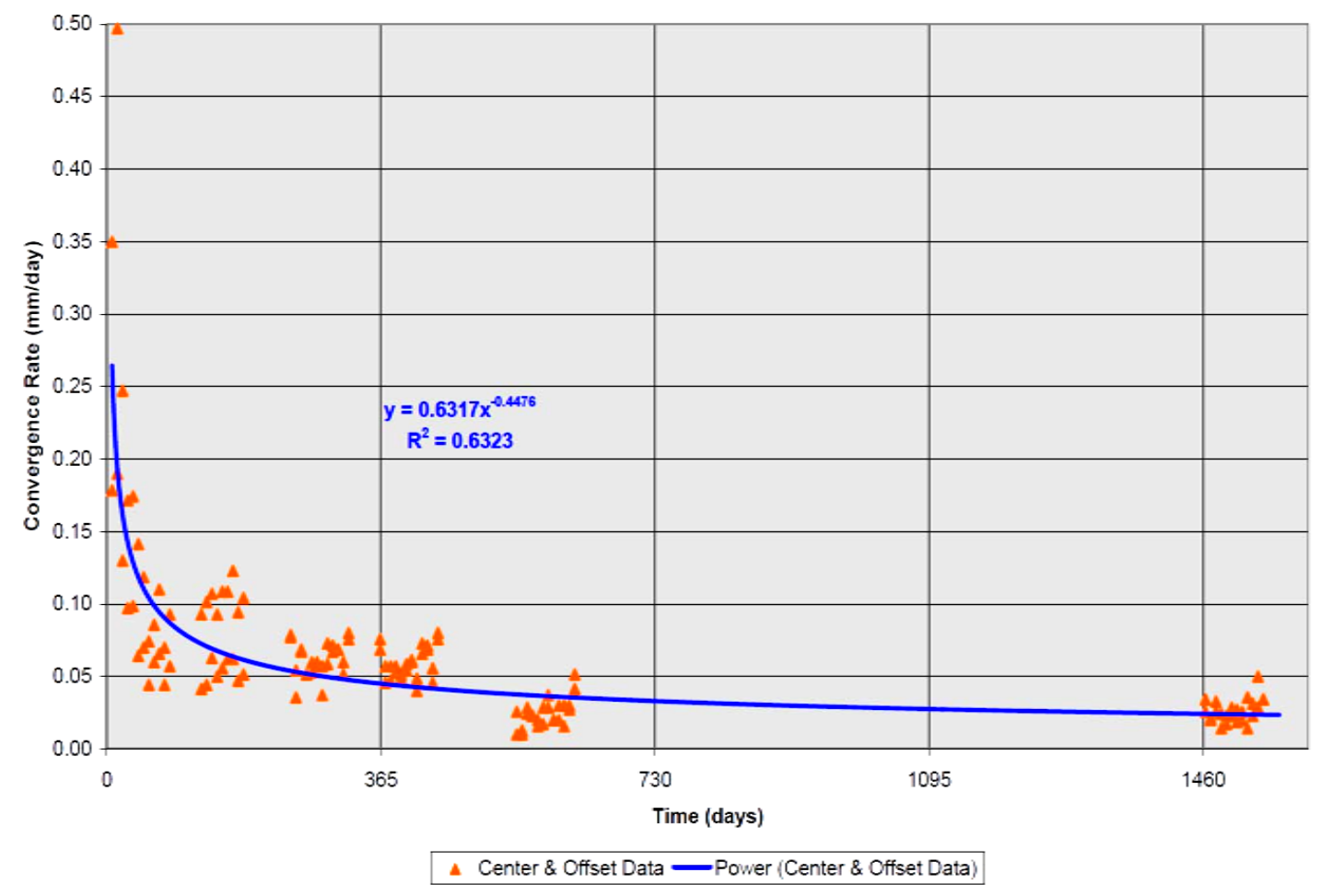

Figure 7.1 Measured rate of convergence for different entry ages (kallu et al., 2007) 


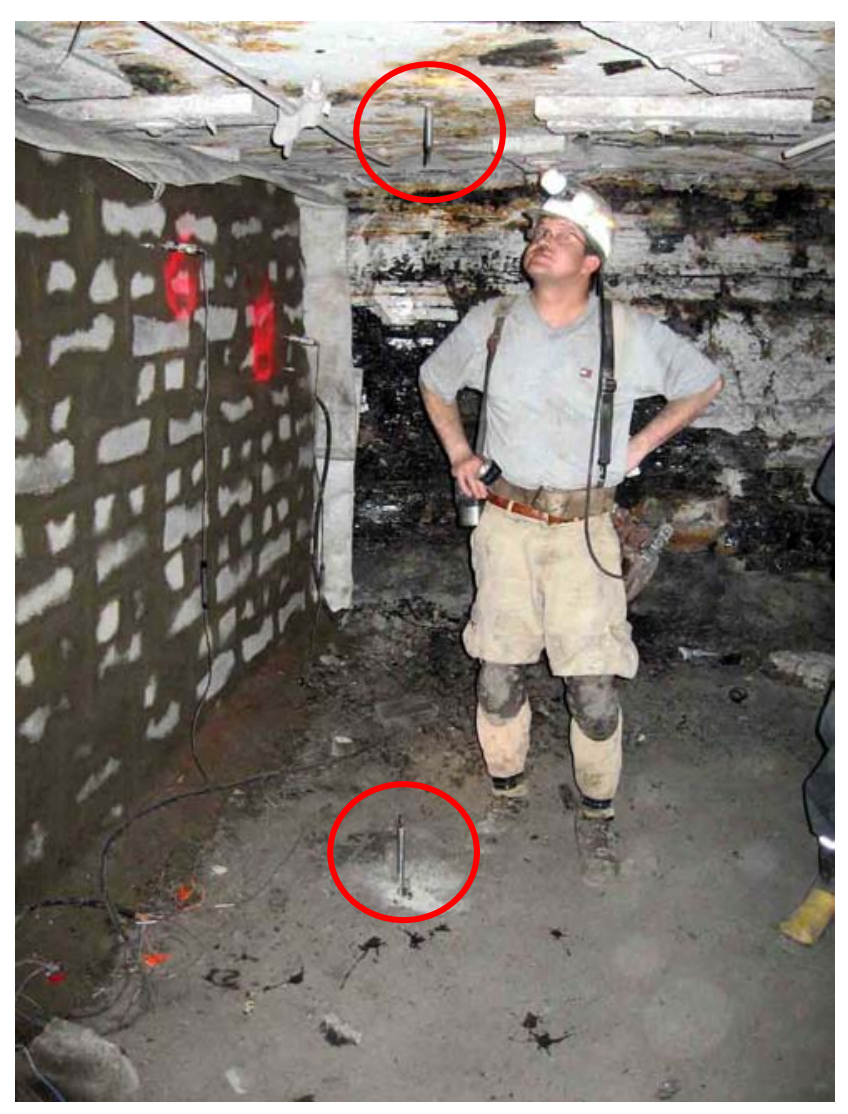

Figure 7.2 Location of convergence station near an experimental seal

While designing a particular type of seal it is important to understand how the seal responds to the roof-to-floor convergence. This is particularly significant with the reinforced concrete seals because they are stiffer than any other type of seals and cannot take a large amount of roof-to-floor convergence.

This chapter tries to address how the reinforced concrete seals respond to convergence loading and their ability to sustain higher explosion loading pressures when subjected to roof-to-floor convergence. Previous research by Kallu et al. (2007) on 'pre-stressed' seals showed that the capacity of the seal to sustain explosion pressure loading increases with an increase in roof-to-floor convergence, within certain limits. This work is divided into two different parts. The first part investigates the ability of the RC seal to sustain higher explosion loading pressures when subjected to roof-to-floor convergence. The second part of the study determines the maximum allowable convergence that a particular RC seal, designed for typical entry dimensions, can sustain before it is completely crushed by the convergence loading alone. 


\subsection{CAPACITY OF RC SEAL Vs CONVERGENCE}

The RC seal designed in Chapter 6 for $6 \mathrm{ft}$ high and $20 \mathrm{ft}$ wide entry was considered in this study. A large number of 3D ABAQUS models were built and subjected to different levels of roof-to-floor convergence. Instantaneous explosion loading pressure ranging from 120 to 300 psi was applied to the seal in 20 psi increments at each level of convergence as shown in Table 7.1. All these models were subjected to instantaneous explosion pressure loading lasting for 2 sec and then the explosion pressure removed suddenly. Seal designs proposed for typical entry dimensions in the previous chapter are designed for zero roof-to-floor convergence.

\section{Results and discussion}

Table 10.1 shows the summary of the stability condition of the seals at different levels of roof-to-floor convergence and explosion pressure. The convergence indicated in the table is calculated by averaging the relative displacements of the nodes at the top and bottom of the seal at mid vertical section. The letter ' $S$ ' indicates that the seal is stable and the letter ' $F$ ' indicates that the seal is 'not suitable' under the given loading conditions. From the table it can be observed that the explosion resistant capacity of the seal increases with increase in convergence on the seal. At zero convergence, the seal is only able to withstand 120 psi explosion pressure but the same seal can withstand about 280 psi explosion pressure at 0.073 in. of convergence. This positive influence of roof-to-floor convergence is only valid as long as the stresses induced in the seal due to the convergence loading are well within the strength limits of the concrete material. Once these induced stresses exceed the strength of the concrete the seal fails under the convergence loading alone. At about 0.085 in. of convergence the seal fails completely under the convergence loading.

Figures 7.3 to 7.8 shows the variation of the maximum lateral displacements and weighted average damage factor with roof-to-floor convergence at different levels of explosion pressure. At zero roof-to-floor convergence the RC seal developed a maximum lateral displacement of about 0.342 in. when subjected to 120 psi explosion pressure (Figure 7.3(a)). The magnitude of lateral dispalcements decrease sharply for a very small increase in convergence and at the same time increase the capacity of the seal to sustain explosion 
pressure loading. Further increase in convergence caused the lateral displacements to increase gradually with a mild steady slope. This increase in lateral displacements is primarily because of the increasing convergence load on the seal. The capacity of the seal to sustain explosion pressure loading also improved significantly during this stage, refer to Table 7.1. After the convergence on the seal has reached a certain amount, the lateral displacements started suddenly increasing. Observing the plastic strain and damage contours in the seal at this stage indicate the onset of shear failure in the seal due to the excessive convergence loading on the seal. Figure 7.9 shows the contours of plastic strain in the seal and rebars at $0.1 \mathrm{in}$. of convergence on the seal.

Table 7.1 Convergence table (6’x20’x24’’ seal)

\begin{tabular}{|c|c|c|c|c|c|c|c|c|c|c|}
\hline $\begin{array}{c}\text { Actual } \\
\text { Convergence } \\
\text { on seal, in. }\end{array}$ & \multicolumn{7}{|c|}{ Explosion pressure, psi } \\
\hline & 120 & 140 & 160 & 180 & 200 & 220 & 240 & 260 & 280 & 300 \\
\hline 0.0000 & S & F & F & F & & & & & & \\
\hline 0.0023 & S & S & F & F & & & & & & \\
\hline 0.0047 & S & S & S & F & & & & & & \\
\hline 0.0093 & S & S & S & S & F & F & & & & \\
\hline 0.0140 & S & S & S & S & S & F & & & & \\
\hline 0.0235 & S & S & S & S & S & F & F & F & & \\
\hline 0.0345 & S & S & S & S & S & S & F & F & & \\
\hline 0.0440 & S & S & S & S & S & S & F & F & & \\
\hline 0.0528 & S & S & S & S & S & S & S & F & & \\
\hline 0.0629 & S & S & S & S & S & S & S & S & F & \\
\hline 0.0728 & S & S & S & S & S & S & S & S & S & F \\
\hline 0.0827 & S & S & S & F & F & F & F & F & F & F \\
\hline 0.0929 & F & F & F & F & F & F & F & F & F & F \\
\hline 0.1040 & F & F & F & F & F & F & F & F & F & F \\
\hline 0.1825 & F & F & F & F & F & F & F & F & F & F \\
\hline
\end{tabular}

*S - Stable and F - Not suitable 
The plot of weighted average damage factor (WADF) also showed similar behavior with increase in roof-to-floor convergence as compared to the lateral displacemets behavior. Due to the differential magnitude of WADF, the graphs are plotted in both logarithmic (green) as well as in normal scale (Figure 7.3(b)). The graph plotted on logarithmic scale closely shows the trend of the WADF with increase in roof-to-floor convergence. Damage contours and history of lateral displacements of seals subjected to different levels of roof-to-floor covnergence and 120 psi instantaneous explosion pressure are given in Appendix III.

Similar trends of results are obtained with seals subjected to explosion pressures higher than 120 psi (Figures 7.4 to 7.7), except that the magnitude of lateral dispalcements and weighted average damage factor are moving higher with increase in explosion loading pressure (Figure 7.8).
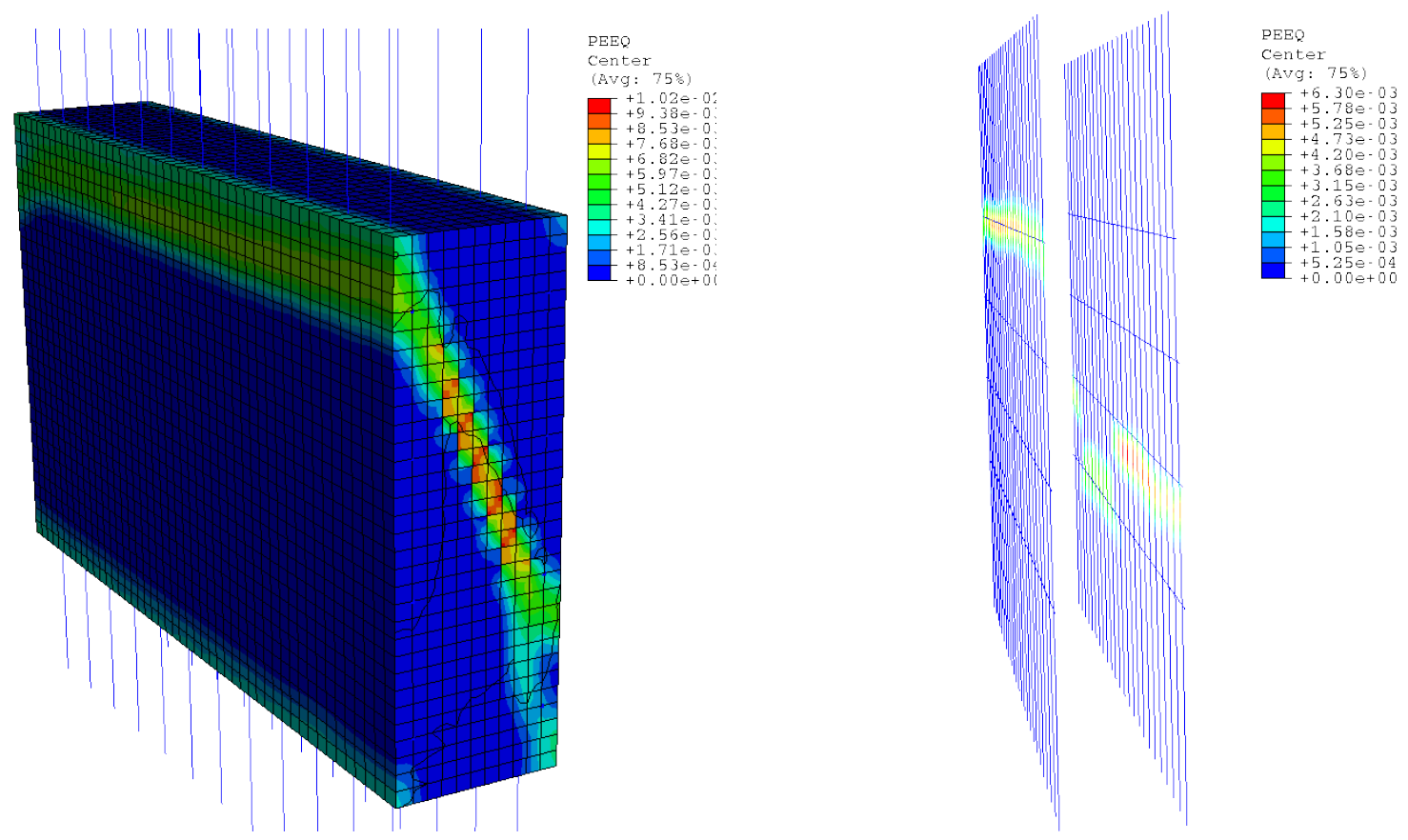

Figure 7.9 Contours of plastic strain in the seal (half section) and in rebars at 0.1 in. convergence. 


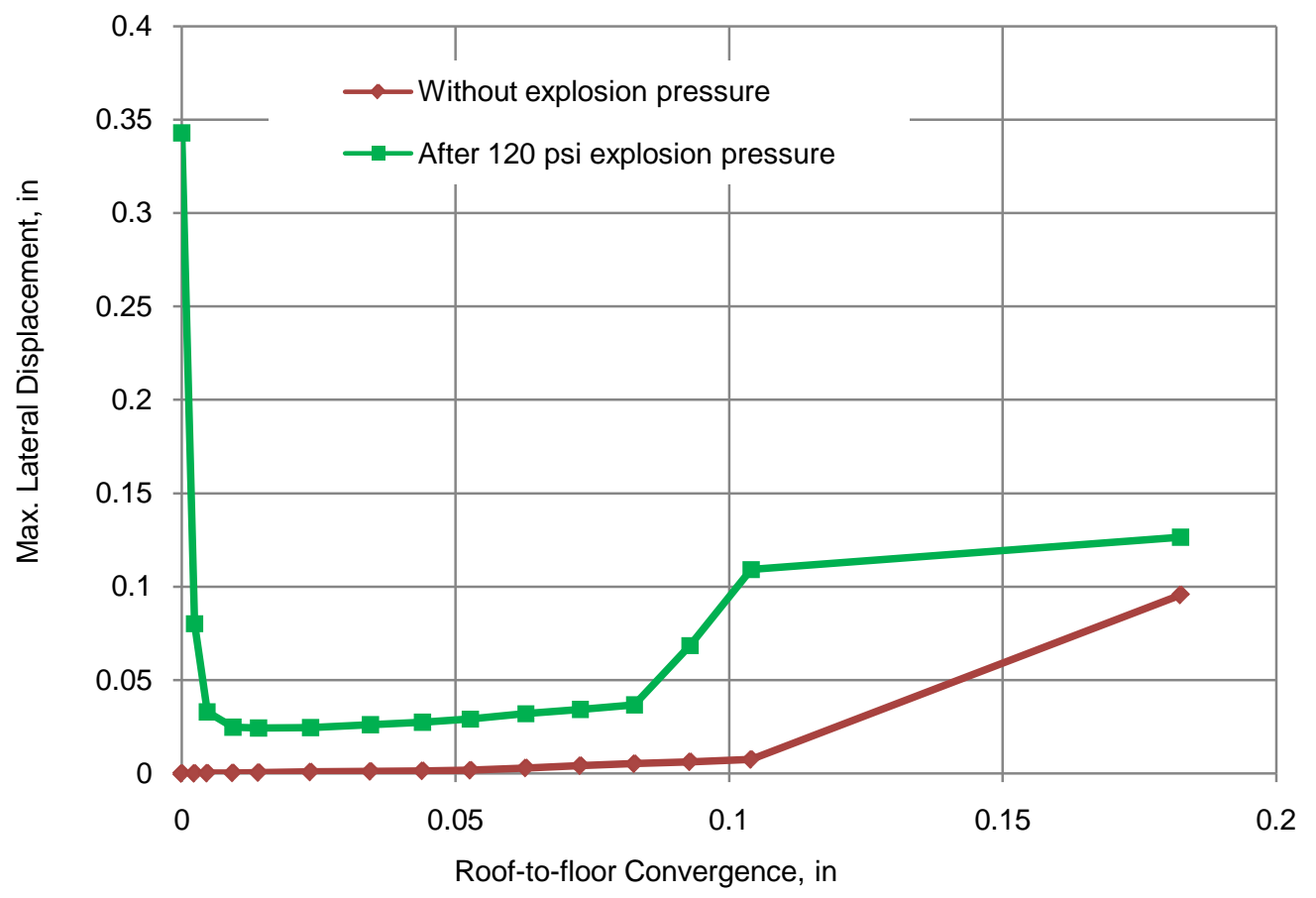

(a) Max. lateral displacements

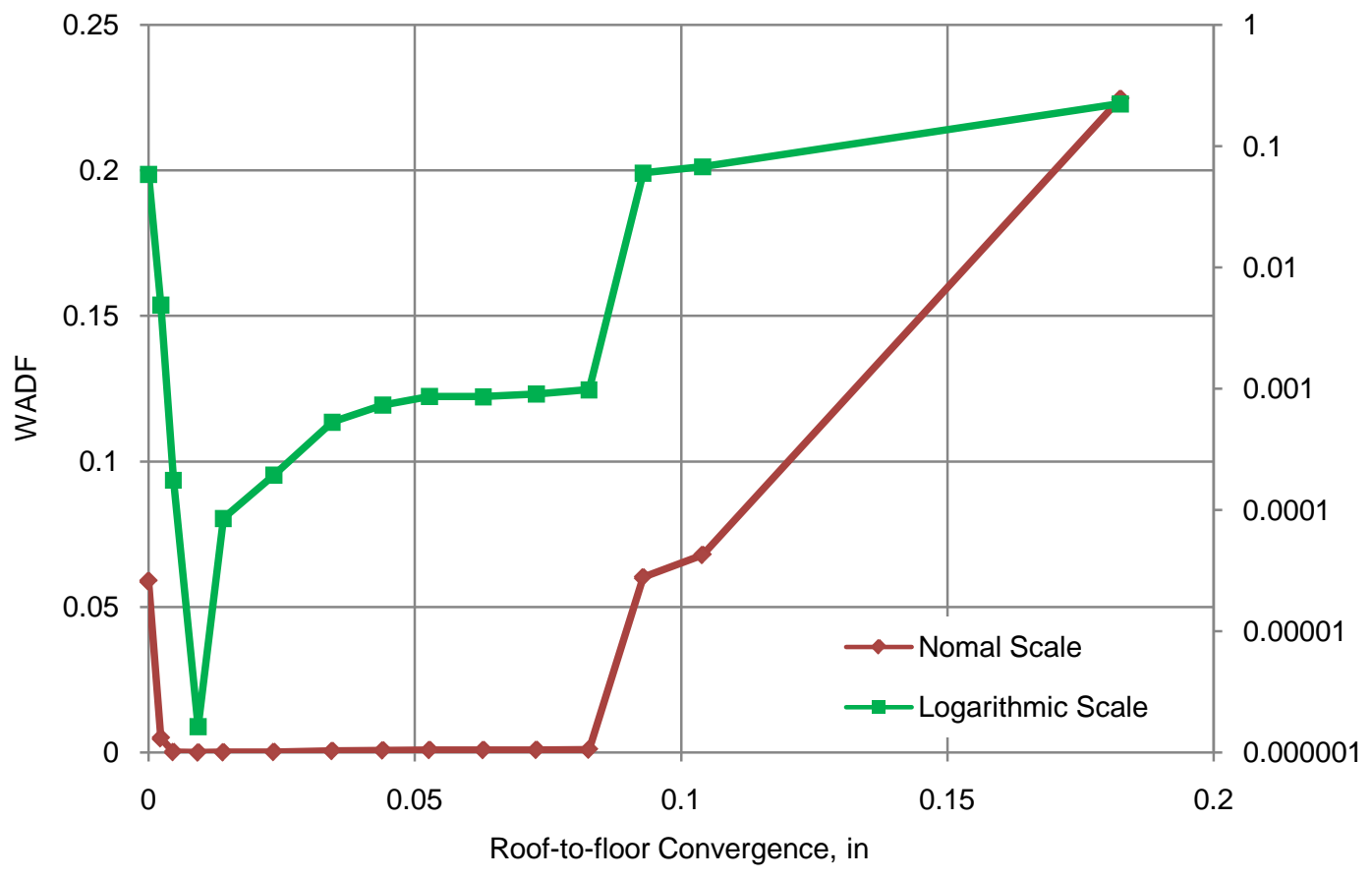

(b) Weighted average damage factor

Figure 7.3 Effect of roof-to-floor convergence: 120 psi explosion pressure 


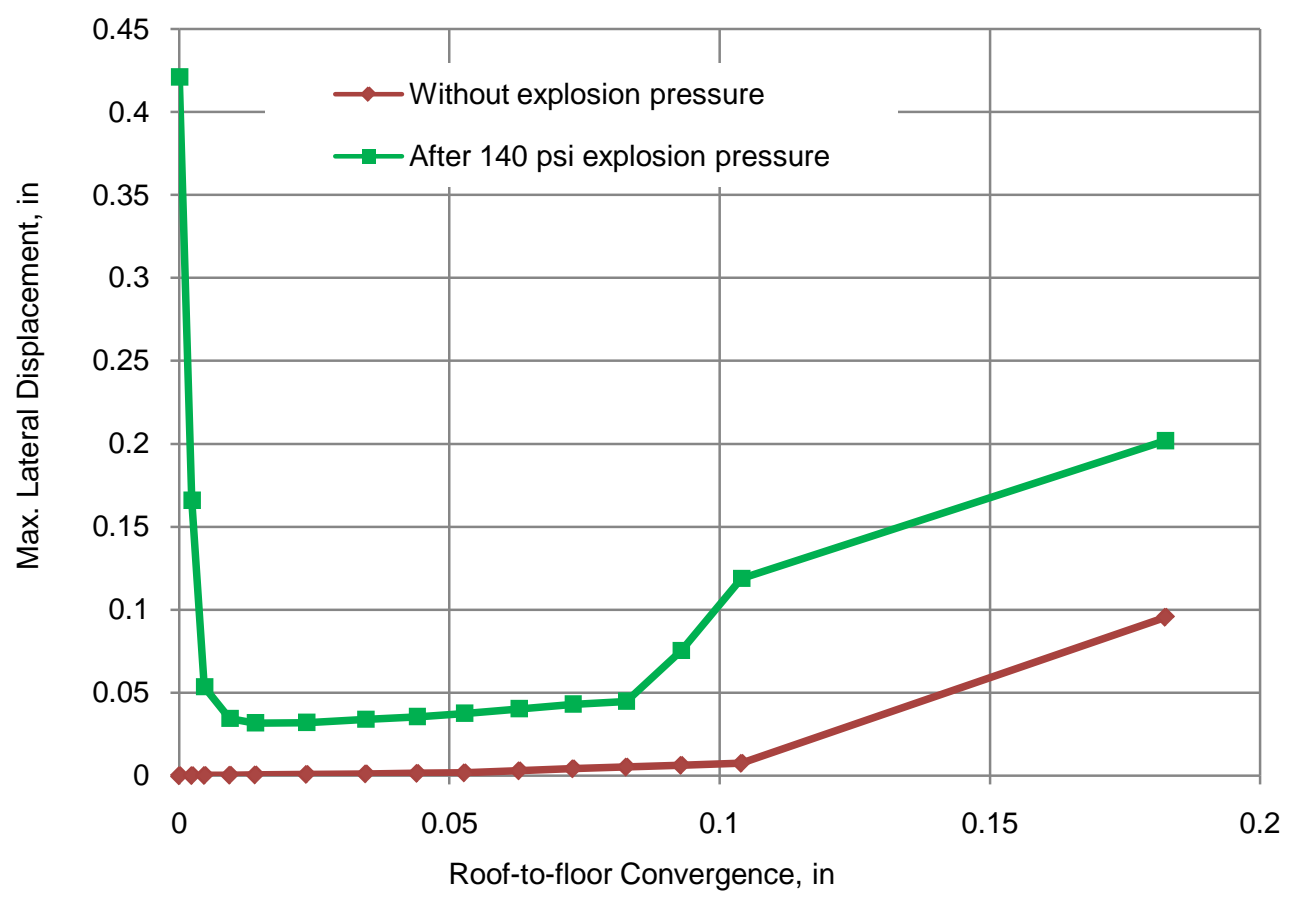

(a) Max. lateral displacements

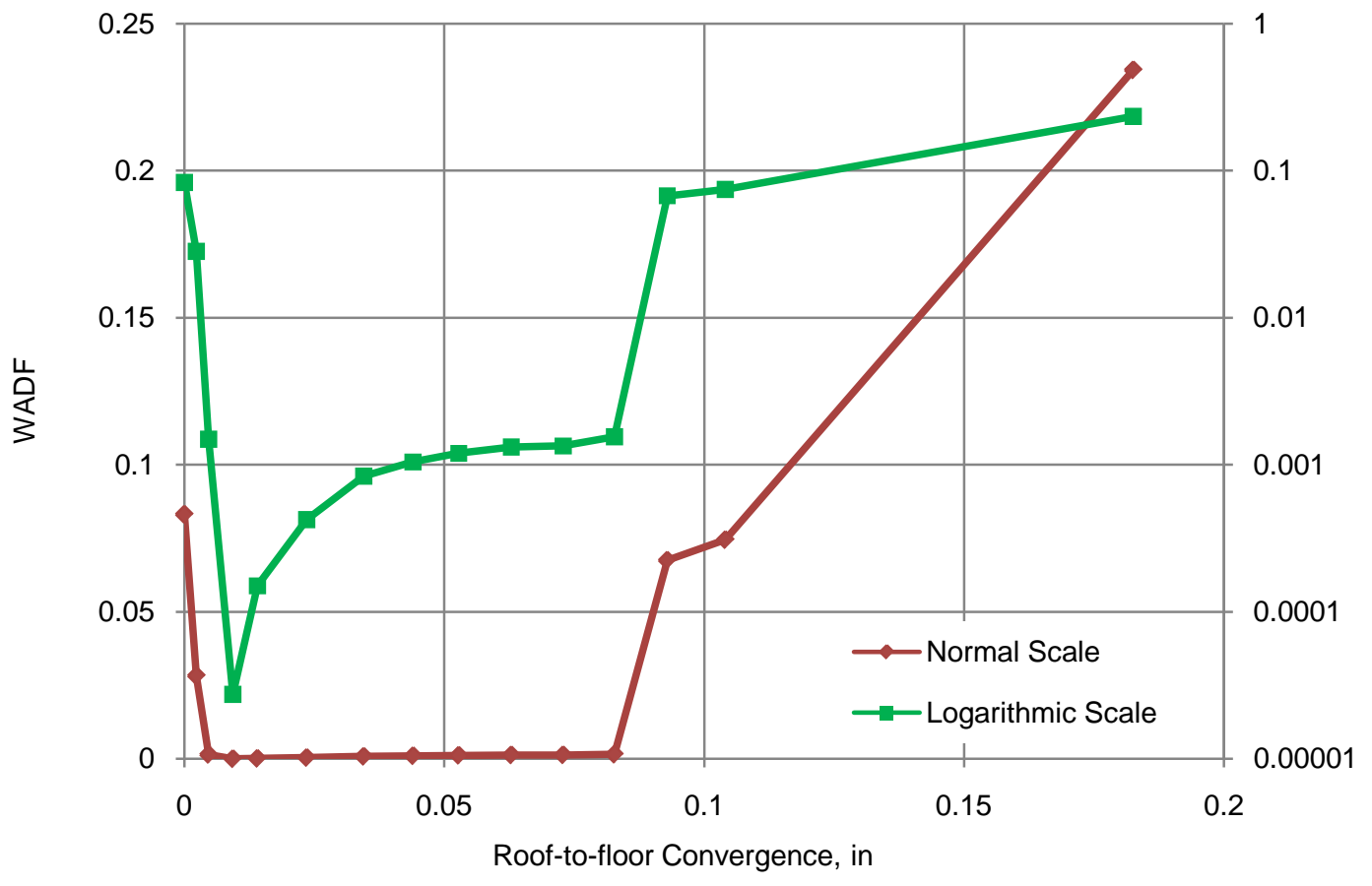

(b) Weighted average damage factor

Figure 7.4 Effect of roof-to-floor convergence: 140 psi explosion pressure 


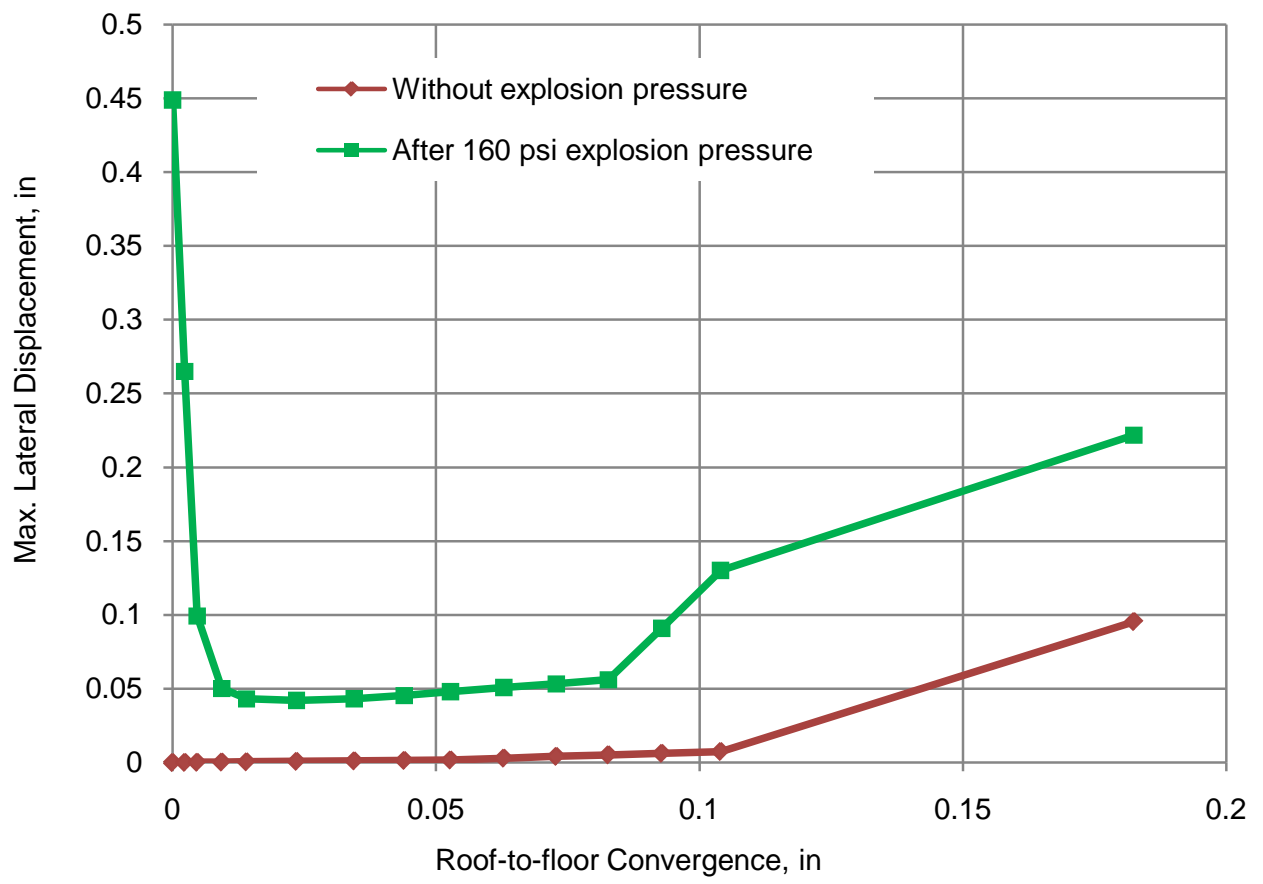

(a) Max. lateral displacements

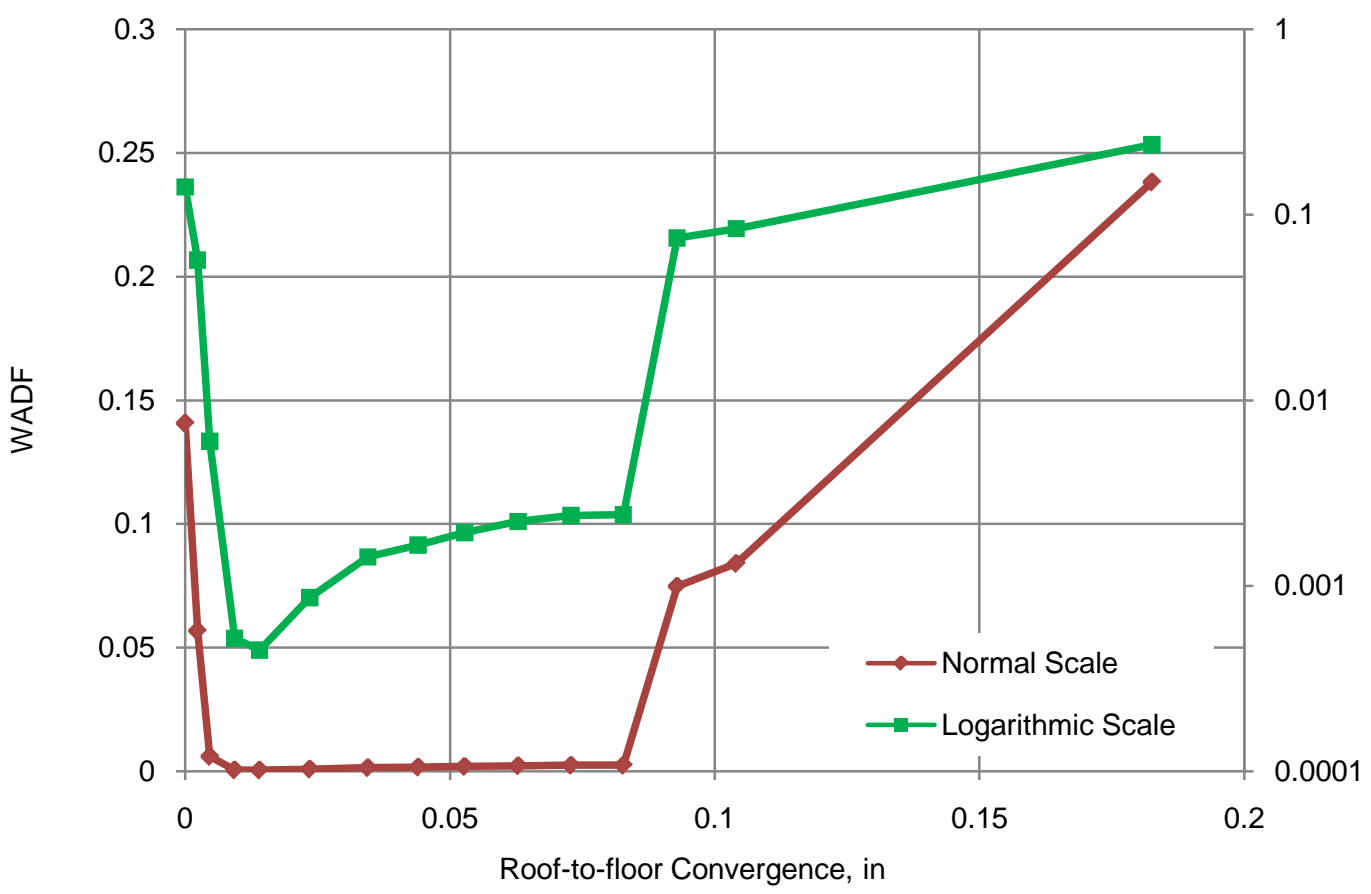

(b) Weighted average damage factor

Figure 7.5 Effect of roof-to-floor convergence: 160 psi explosion pressure 


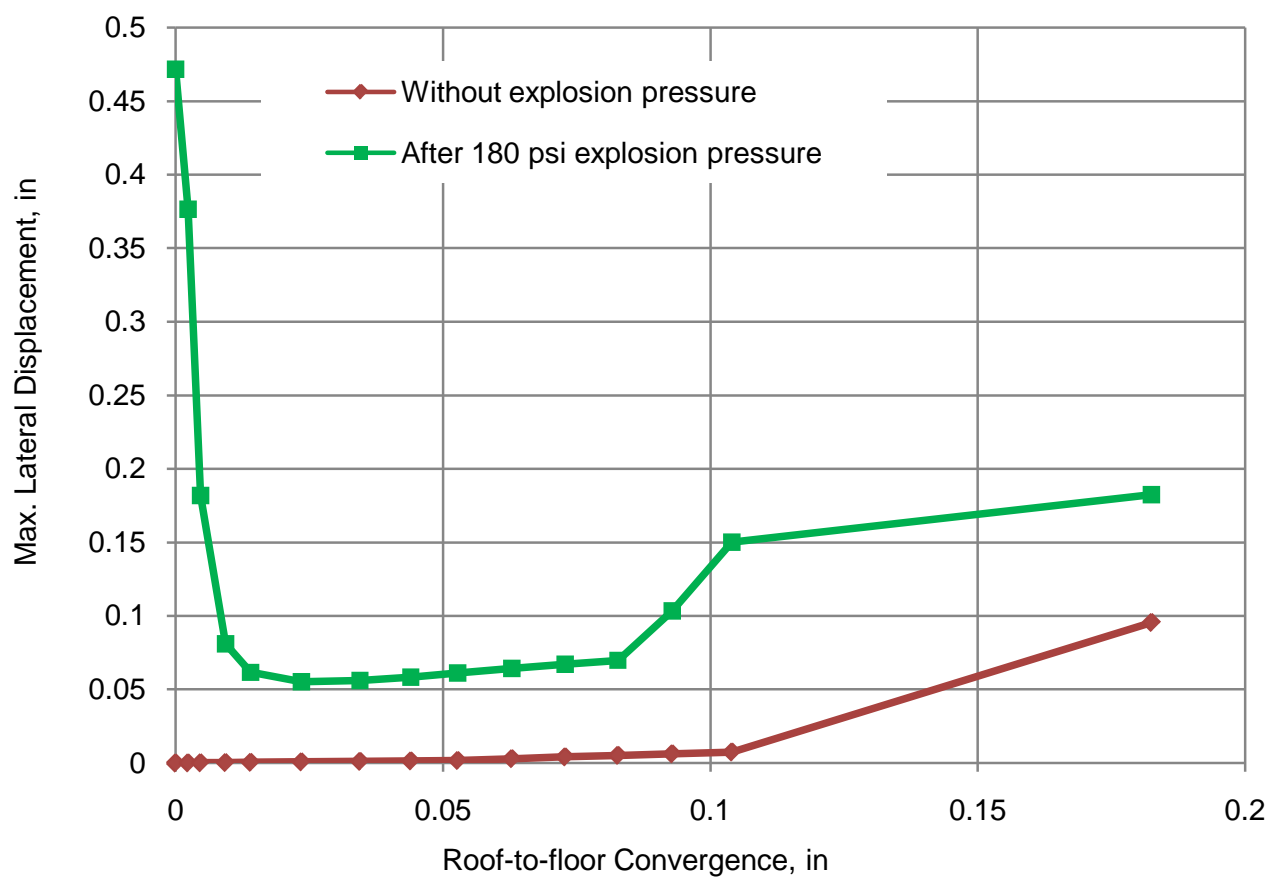

(a) Max. lateral displacements

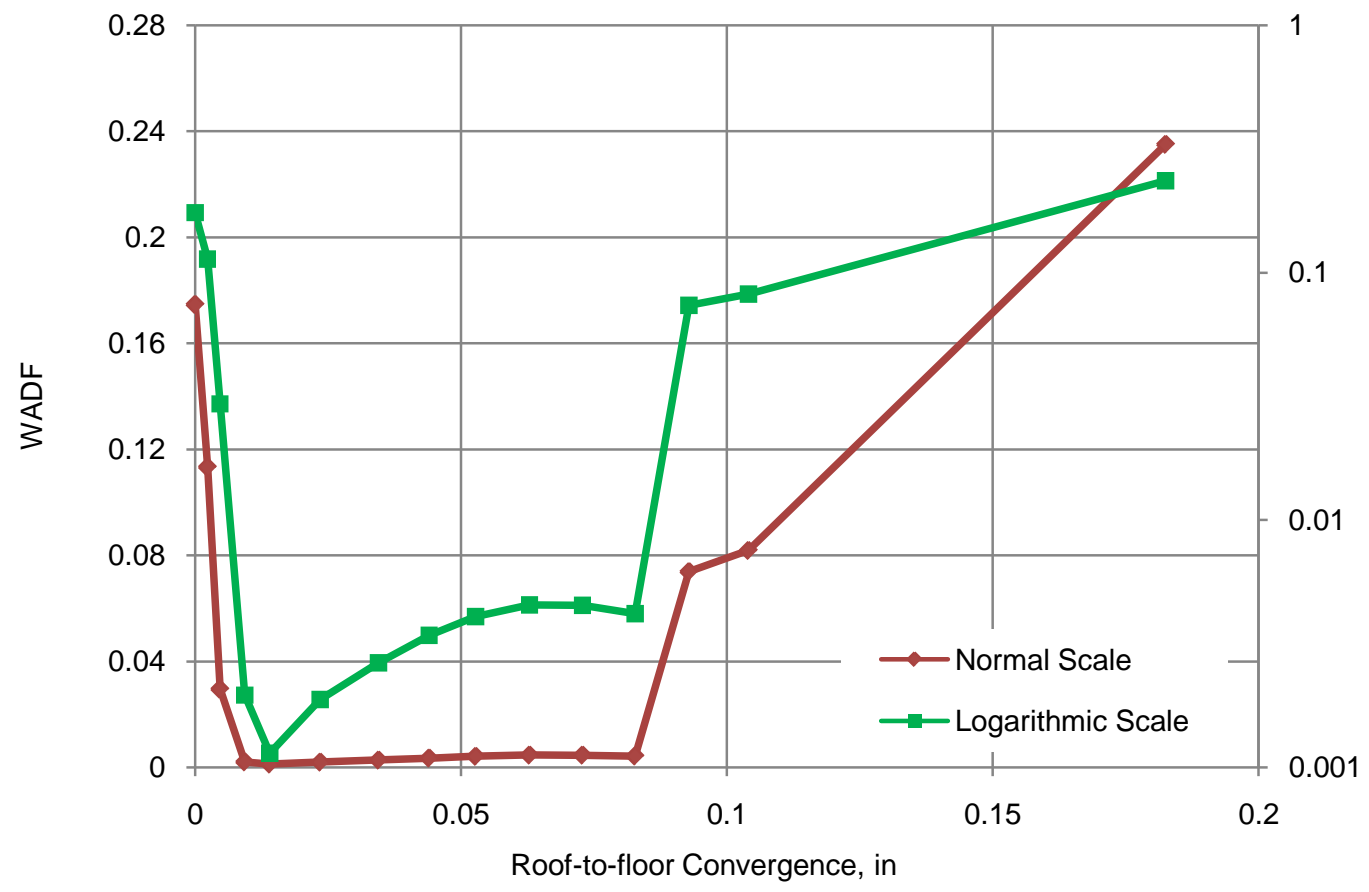

(b) Weighted average damage factor

Figure 7.6 Effect of roof-to-floor convergence: 180 psi explosion pressure 


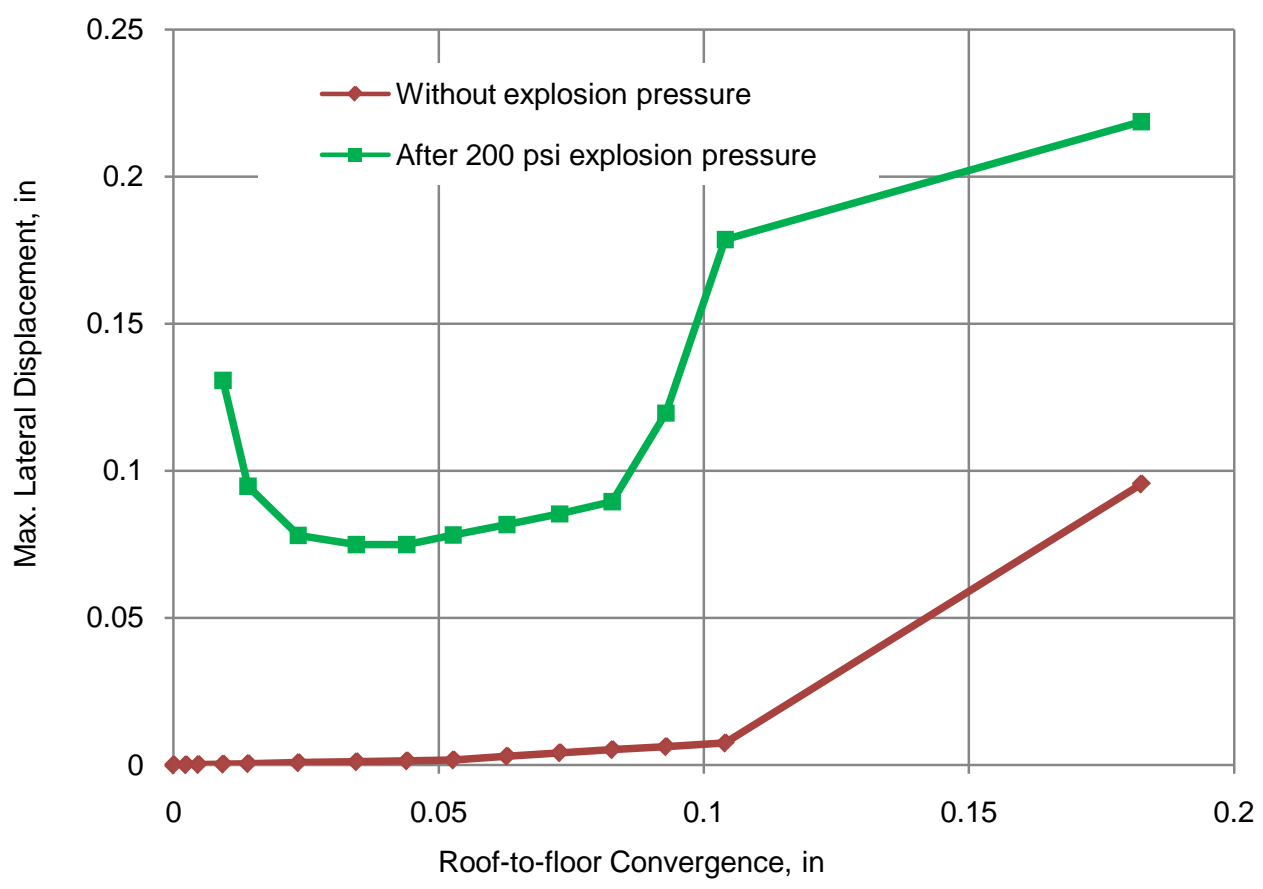

(a) Max. lateral displacements

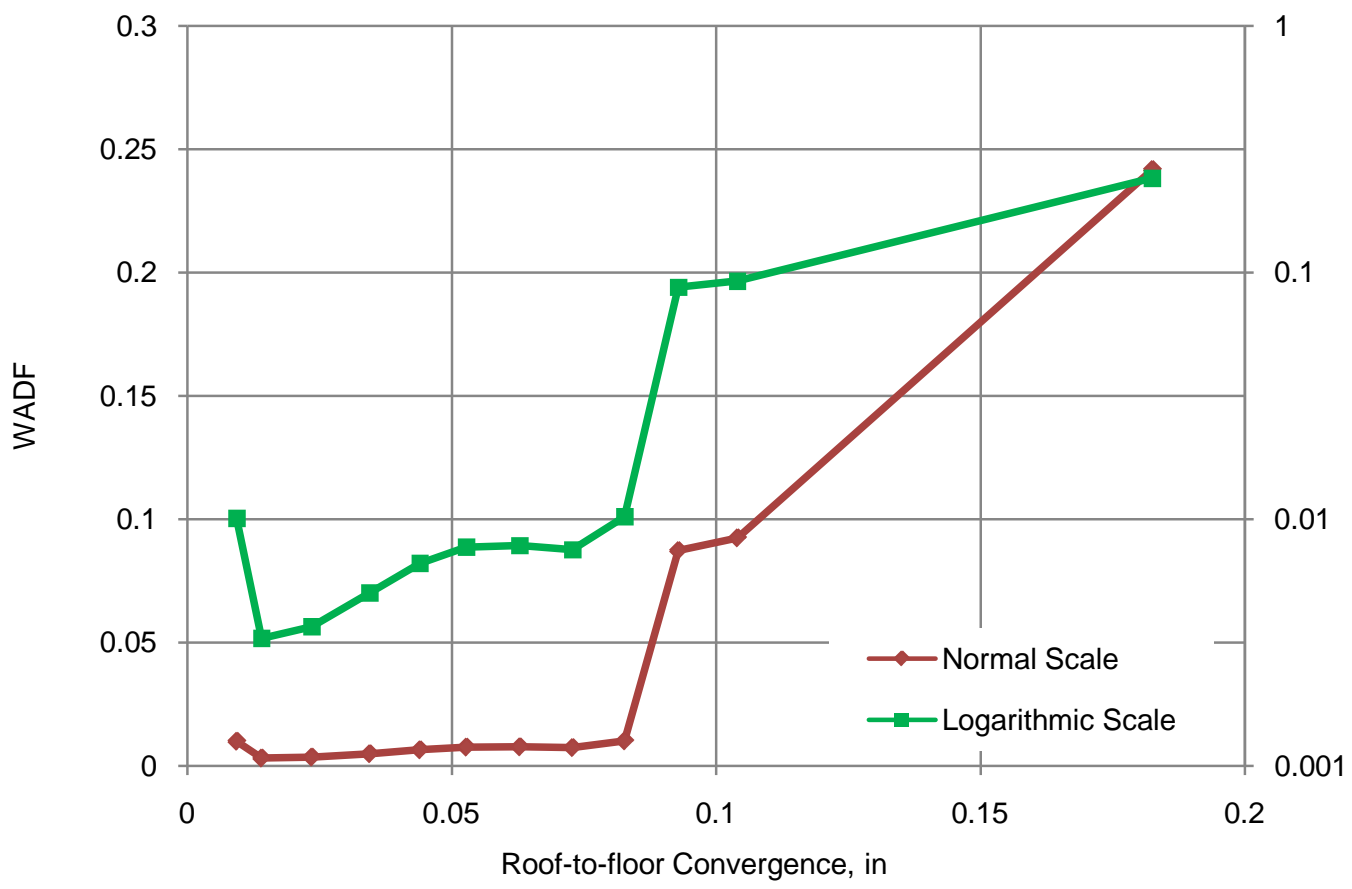

(b) Weighted average damage factor

Figure 7.7 Effect of roof-to-floor convergence: 200 psi explosion pressure 


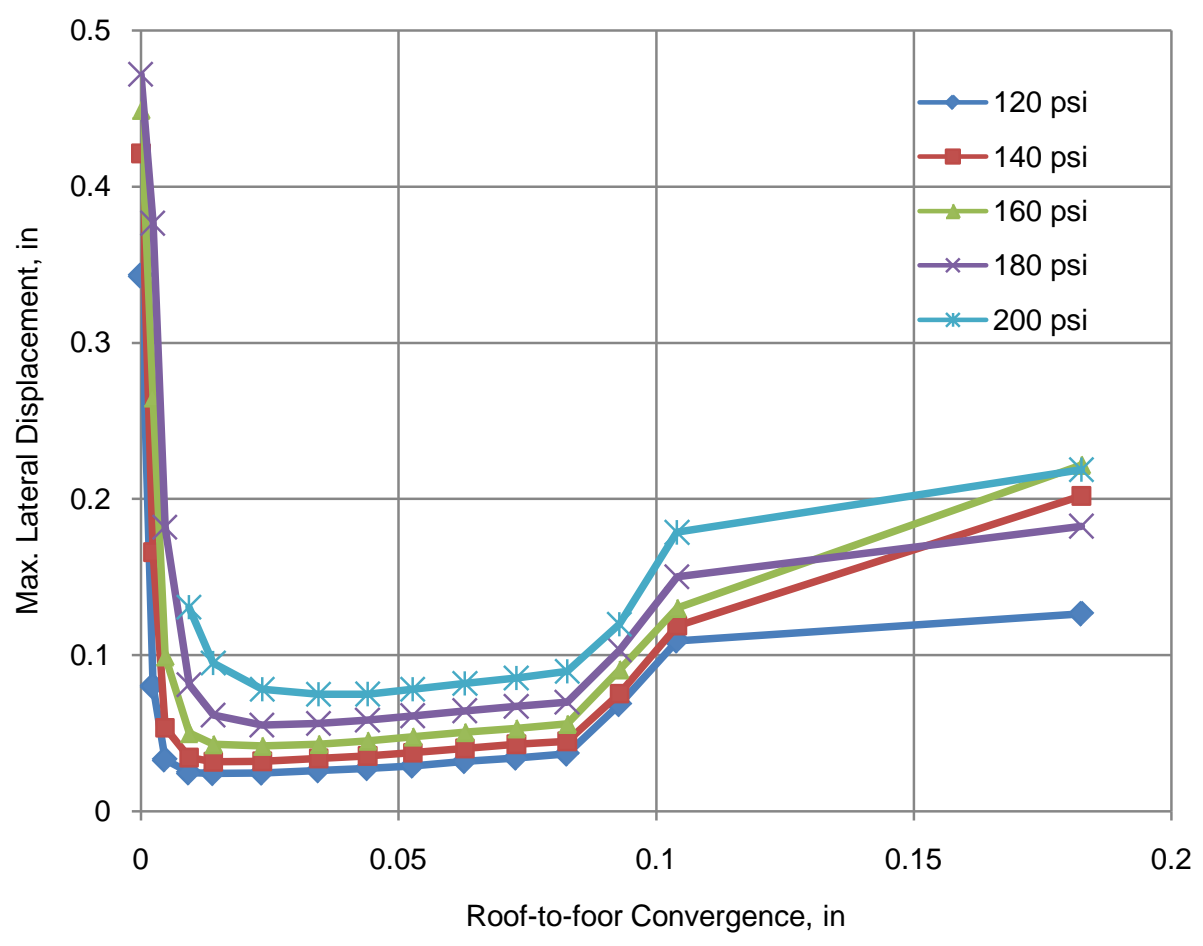

(a) Max. lateral displacements

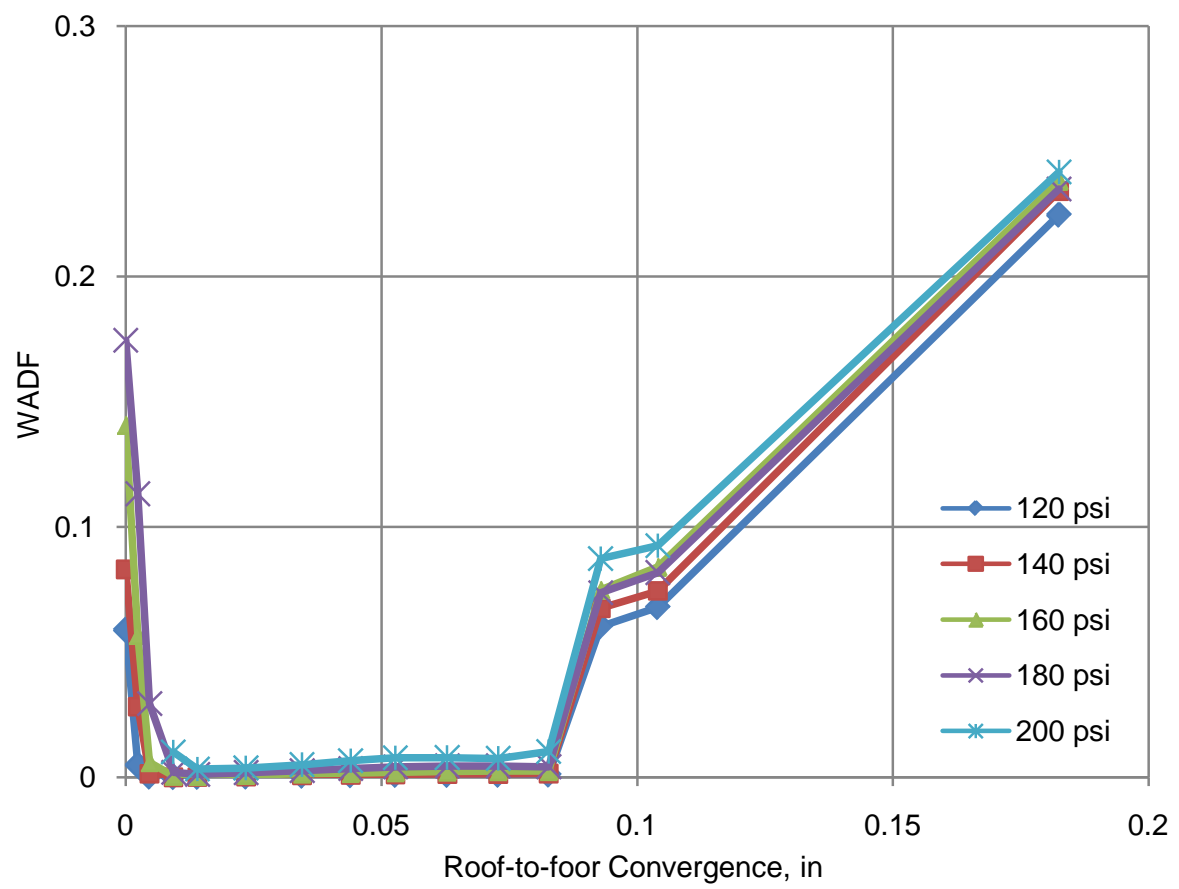

(b) Weighted average damage factor

Figure 7.8 Effect of roof-to-floor convergence 


\subsection{MAXIMUM ALLOWABLE CONVERGENCE}

This section tries to determine the maximum amount of roof-to-floor convergence that a particular RC seal, designed for various entry dimensions, can sustain without losing its ability to withstand the explosion pressure loading. A number of ABAQUS models were constructed for the entry dimensions and seal thicknesses as shown in Table 6.3. A very small amount of velocity is applied on top of the model (not on the seal directly) to gradually load the model and induce convergence on the seal.

Only the results for the $6 \mathrm{ft}$ high seals are discussed here and the results for the other seal heights are provided in Appendix IV. Figure 7.10 shows the plot of lateral displacements measured at the center of the seal on the outby side vs. time and convergence for the $6 \mathrm{ft}$ high and 16, 20, and $24 \mathrm{ft}$ wide seals. The lateral displacements plotted here are a result of the convergence load alone. Lateral displacements plotted on a time scale shows an instantaneous rise as compared to those plotted on a convergence scale. These graphs clearly show that the lateral displacements exhibit similar behavior for all entry widths, except in the post-failure region, indicating that the entry width has a very little or no influence on the seal's ability to sustain roof-to-floor convergence.

Although the results show that $6 \mathrm{ft}$ high seal can sustain $0.1 \mathrm{in}$. of convergence, under the 120 psi explosion loading pressure, the seal shows signs of yielding at around 0.085 in. of convergence (Figure 7.3). Based on the comprehensive modeling work, the maximum allowable convergence for different seal heights are plotted in figure 7.11. The slope of the line shown in figure 7.11 represents the maximum amount of strain (0.0012) that can be allowed on the RC seal. Refer to Appendix IV for complete results on different seal heights.

The legends in the following figures read as 'Seal height x Seal width x Seal thickness', eg., 6’x20’x24’’. 


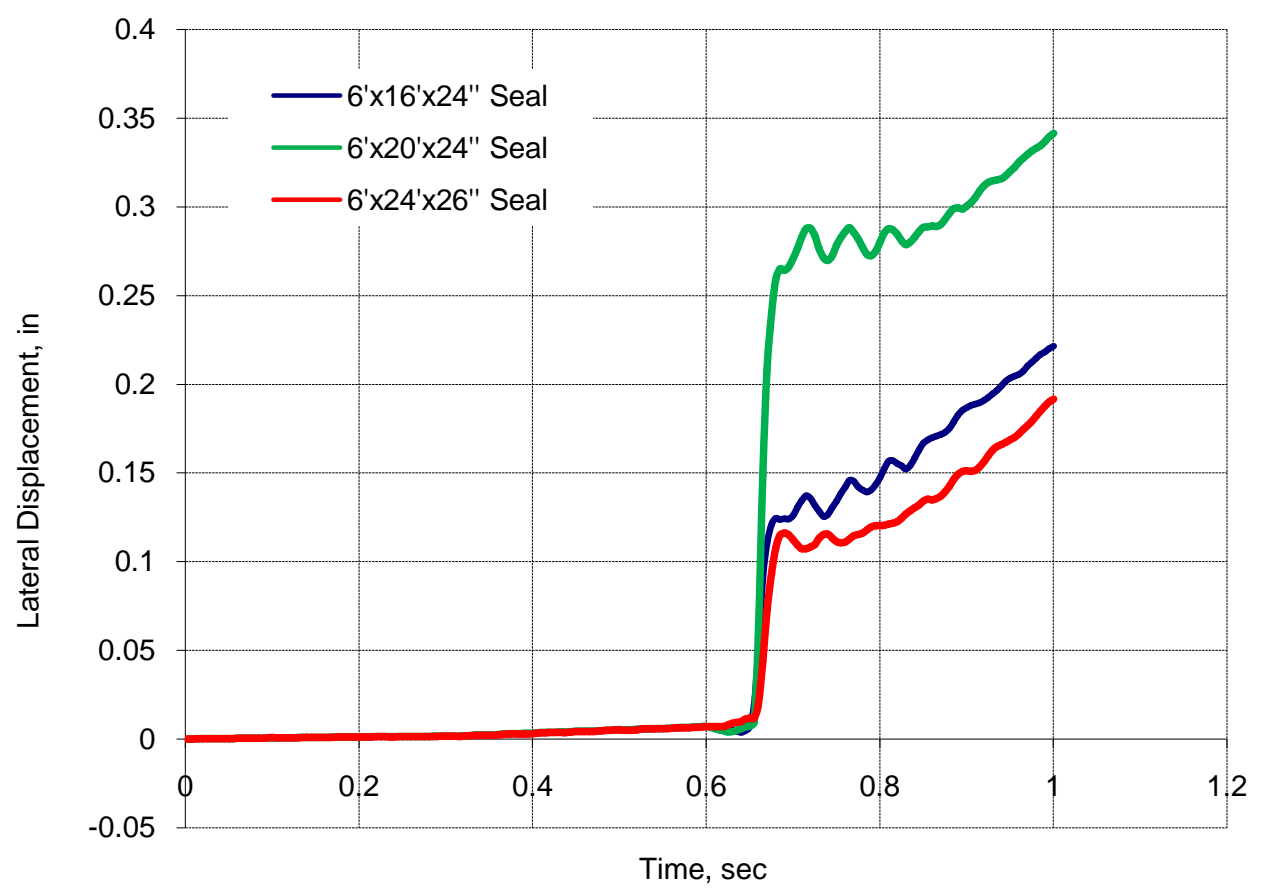

(a) Lateral displacements vs. time

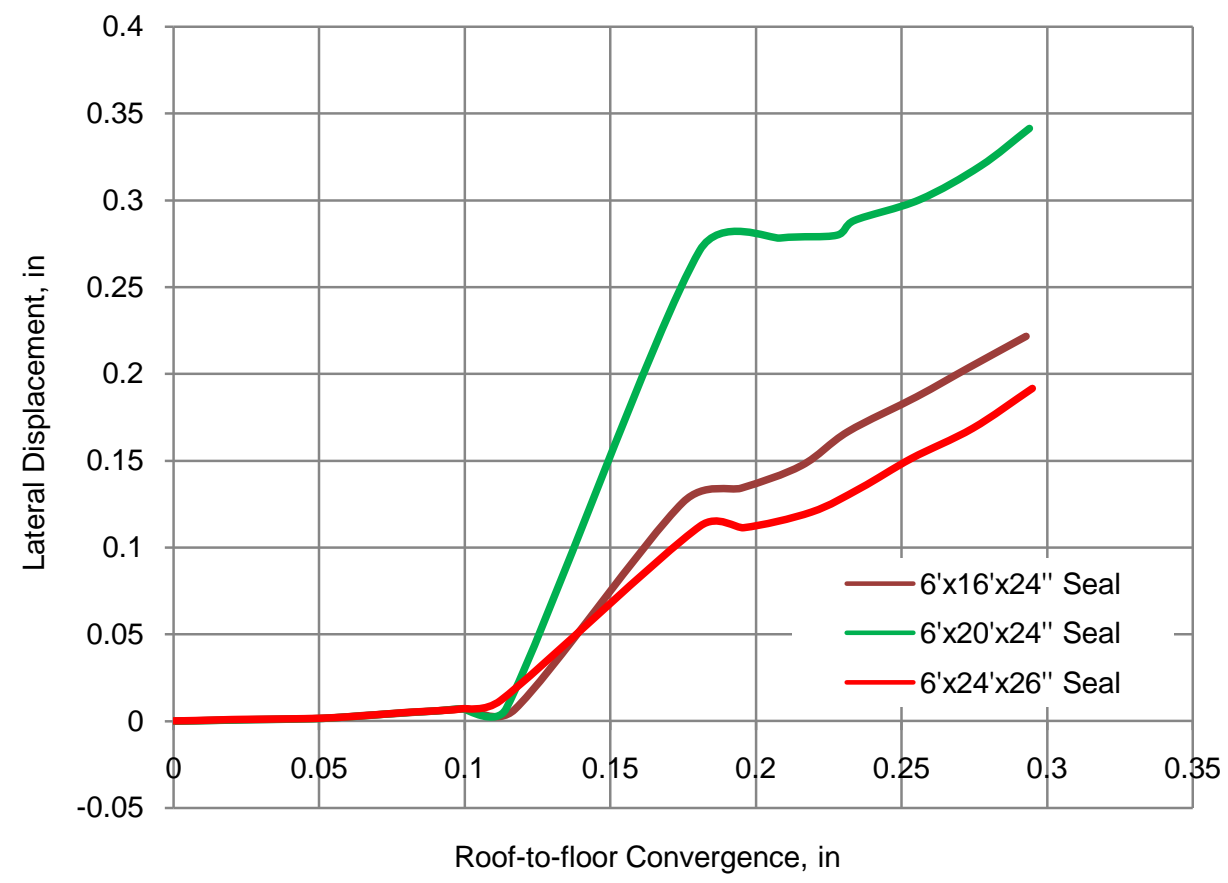

(b) Lateral displacemetns vs. convergence

Figure 7.10 The history of lateral displacements for $6 \mathrm{ft}$ high seal (Outby_M) 


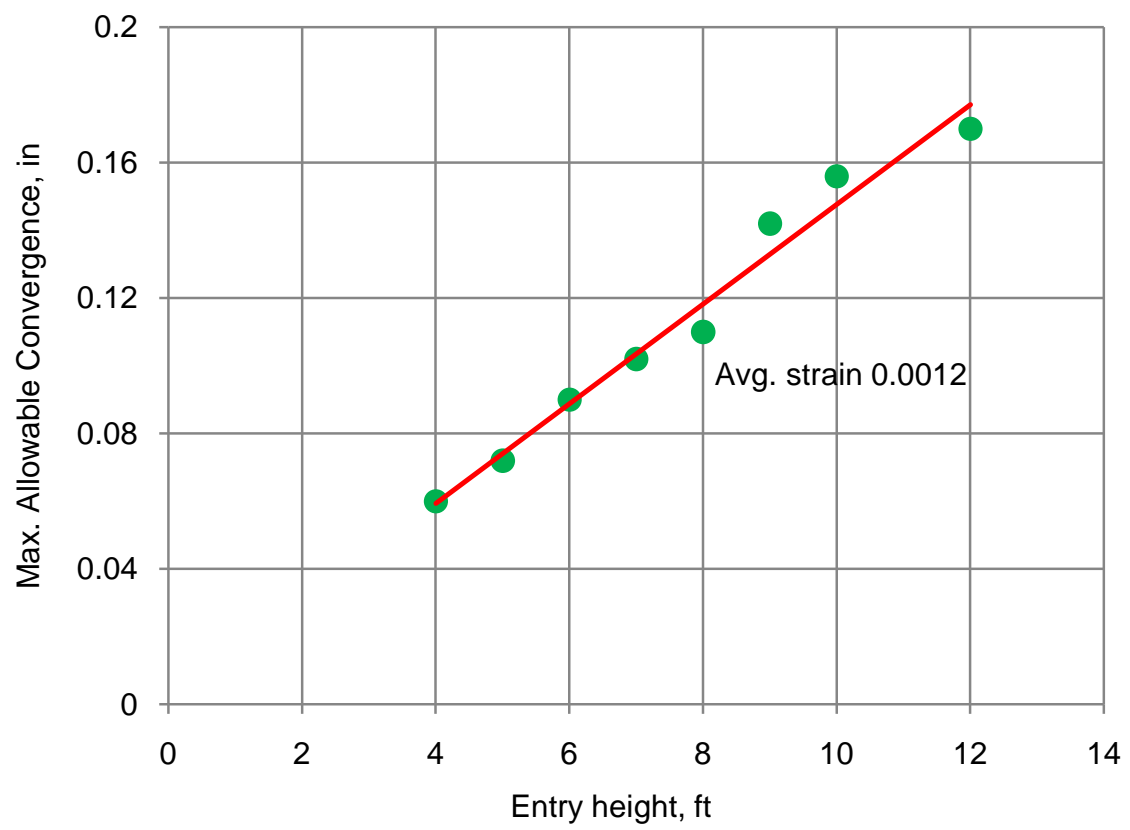

Figure 7.11 Maximum allowable convergence for various seal heights 


\section{Chapter 8 EXPLOSION LOADING NATURE}

7 his chapter investigates the effect of explosion loading nature on the seal stability. It is 1 divided into two different sections. The first section deals with the type of explosion loading i.e., explosion pressure with instantaneous or with different rise and down times etc., and the second section deals with multiple explosions of different nature. For this purpose, the seal designed for a $6 \mathrm{ft}$ high by $20 \mathrm{ft}$ wide entry, for 120 psi instantaneous pressure, is selected to understand its response. Refer to Chapter 6 for complete construction details of this seal.

\subsection{EXPLOSION LOADING NATURE}

Four different pressure-time (p-t) curves with a maximum of 120 psi explosion pressure shown in figure 8.1 are considered for investigating the seal response. In the first two p-t curves, the explosion pressure is applied for 4 seconds and then released instantaneously. On the other hand, in the later two p-t curves the explosion pressure is gradually reduced from 120 psi to zero over a period of 0.1 sec.

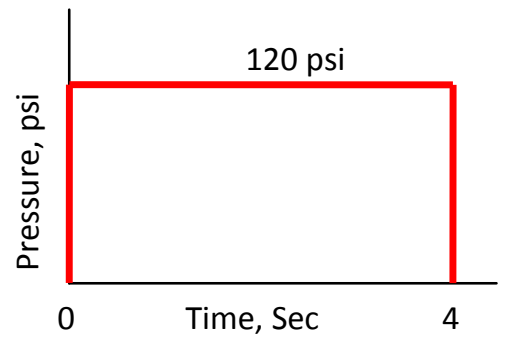

(a) Instantaneous rise time

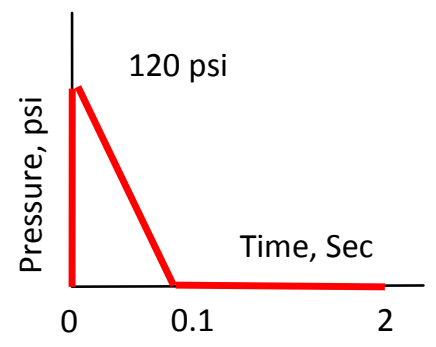

(c) Inst. rise time $+0.1 \mathrm{sec}$ down time

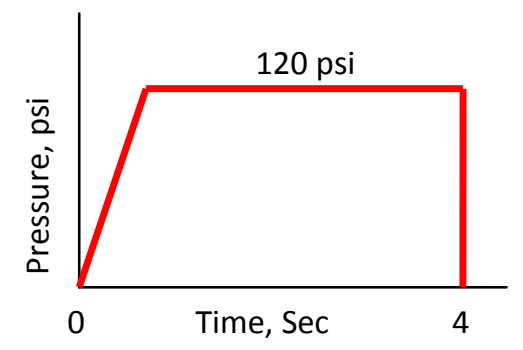

(b) $0.1 \mathrm{sec}$ rise time

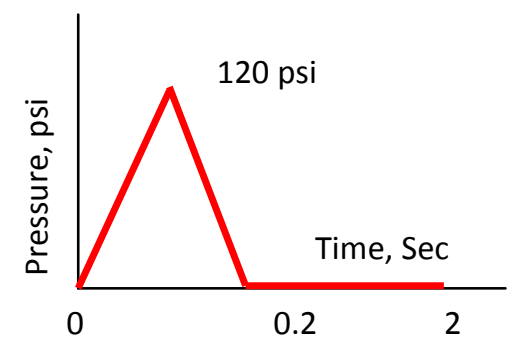

(d) 0.1 sec rise +0.1 down time

Figure 8.1120 psi pressure-time curves with different rise and down times 


\section{Results and discussion}

Figure 8.2 shows the history of axial forces developed in the rebars for seals subjected to the four different pressure-time loadings. Axial forces reach peak values in about $0.09 \mathrm{sec}$ for the p-t curves with instantaneous rise time and for the p-t curves with a 0.1 sec rise time, the axial forces reach the peak value in about $0.17 \mathrm{sec}$. Comparing the results for the p-t curves shown in figure 8.1 (a) and (b), where 120 psi pressure is maintained for about 4 sec, both axial forces and lateral displacements reach higher values for the p-t curve with the instantaneous rise time compared to the p-t curve with a $0.1 \mathrm{sec}$ rise time. In both cases, the lateral displacements take about the same time ( 1 to $2 \mathrm{sec}$ ) to reach close to the peak value (Figure 8.3).

The seals subjected to the p-t curves shown in figure 8.1(c) and 11.1(d) show a very close response except that the peak values for axial forces and lateral displacements offset by about $0.08 \mathrm{sec}$, which is mainly because of different explosion pressure rise times involved. With gradual unloading over a period of $0.1 \mathrm{sec}$, both the axial forces and the lateral displacements fall off the cliff and stabilized at some lower values over time. Figure 8.4 shows the maximum value of lateral displacements and axial forces developed in the seals that are subjected to different p-t loadings.

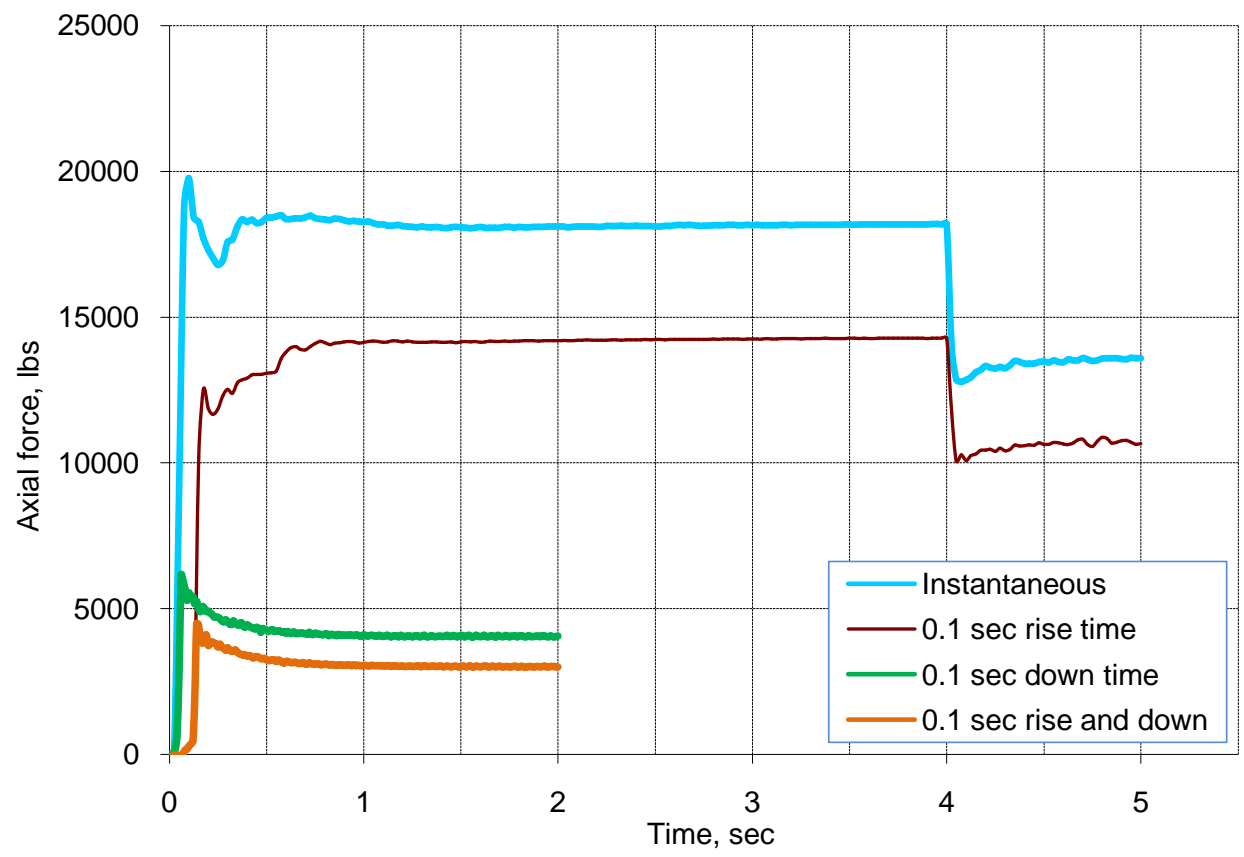

Figure 8.2 The history of axial forces developed in the vertical rebar (Inby_B/T) 


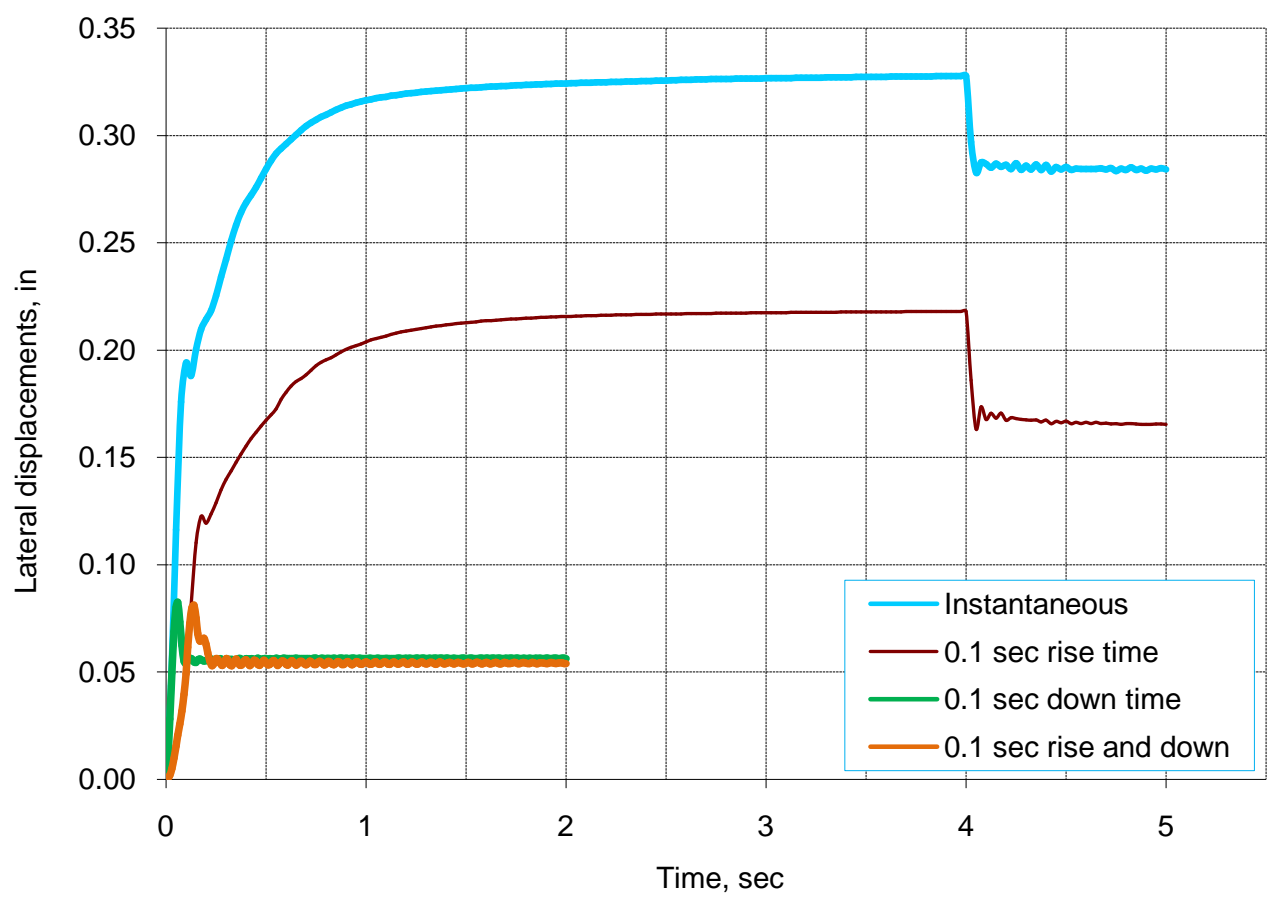

Figure 8.3 The history of lateral displacements in the seal (Outby_M)

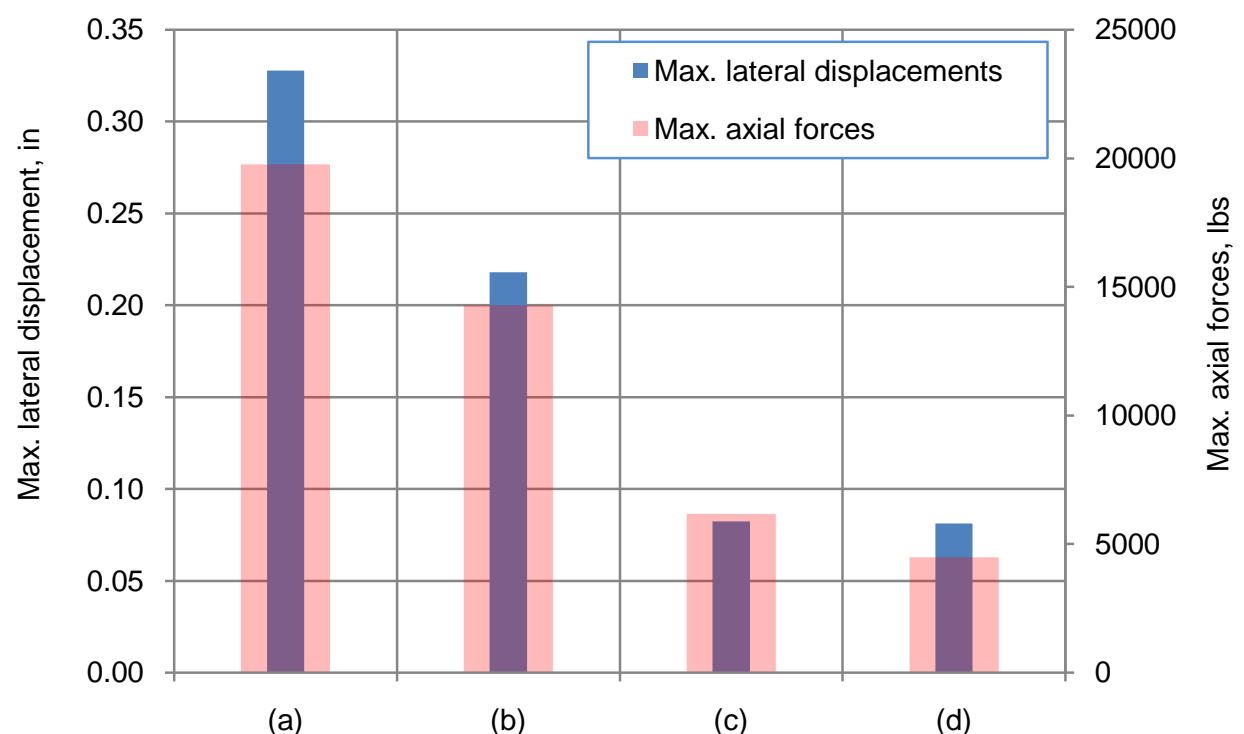

Figure 8.4 Max. lateral displacements and axial forces observed with different p-t curves

Figure 8.5 shows the damage contours in seals subjected to different p-t curve loadings. It is clear that the seal subjected to instantaneous pressure loading lasting for 4 seconds sustains 
higher damage compared to all other cases. The seal subjected to explosion pressure with 0.1 sec rise time and lasting for 4 sec showed similar but lower damage compared to the previous case discussed above (Figure 8.5(b)). The seals subjected to explosion pressure with different rise times and $0.1 \mathrm{sec}$ down showed no damage (cracks) on the outby surface of the seal (Figure 8.5(c) \& (d)). Figure 8.6 shows the weighted average damage factor for seals subjected to different p-t curves.

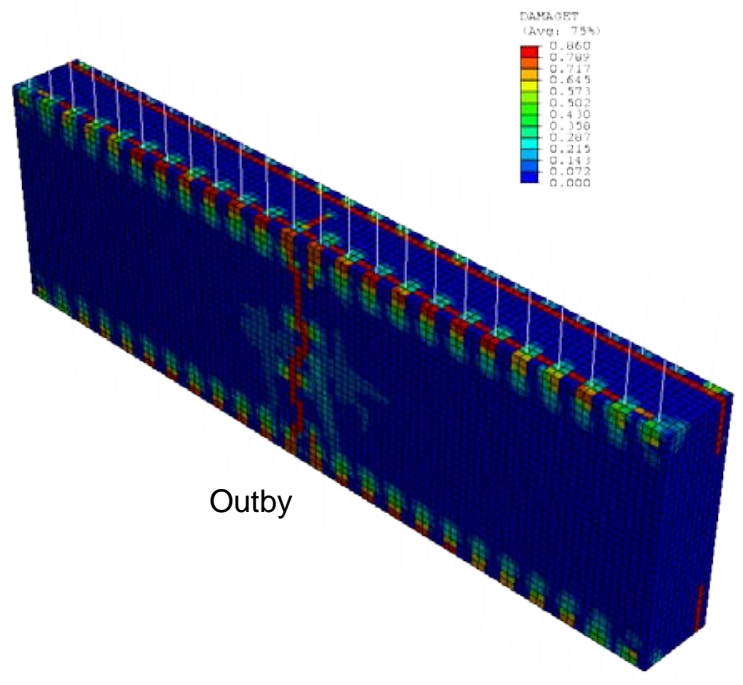

(a) Instantaneous rise time

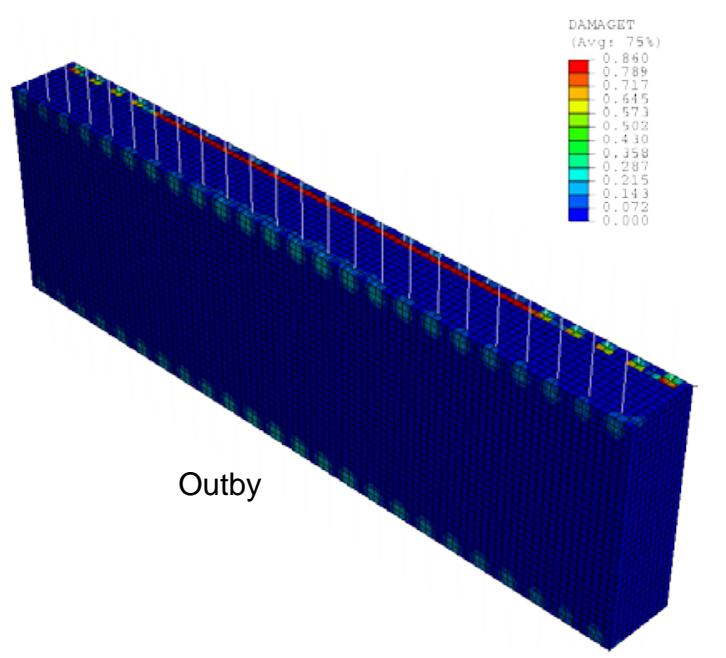

(c) Inst. rise time +0.1 sec down time

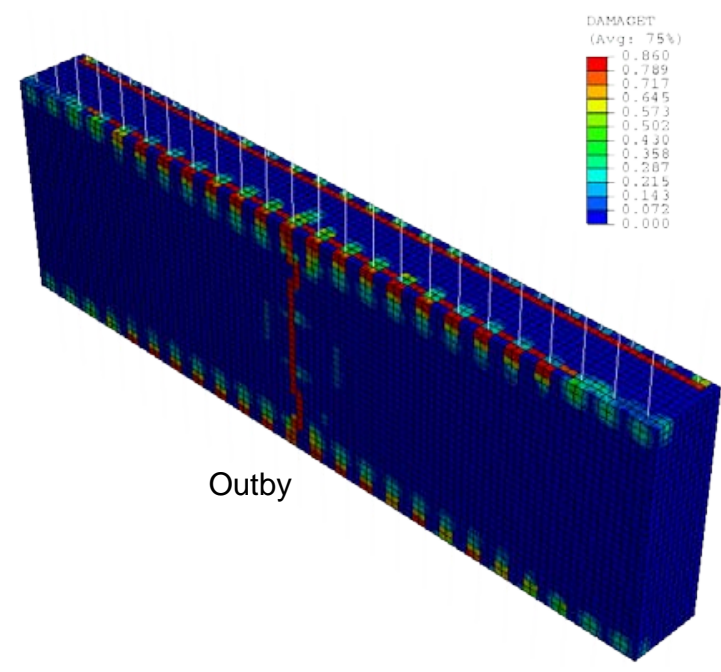

(b) $0.1 \mathrm{sec}$ rise time

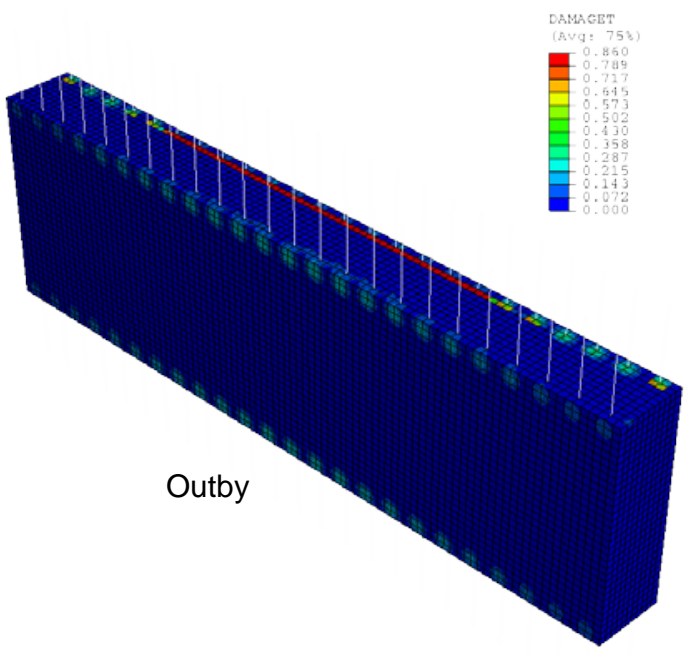

(d) 0.1 sec rise +0.1 down time

Figure 8.5 Damage contours in seal subjected to different p-t curves 


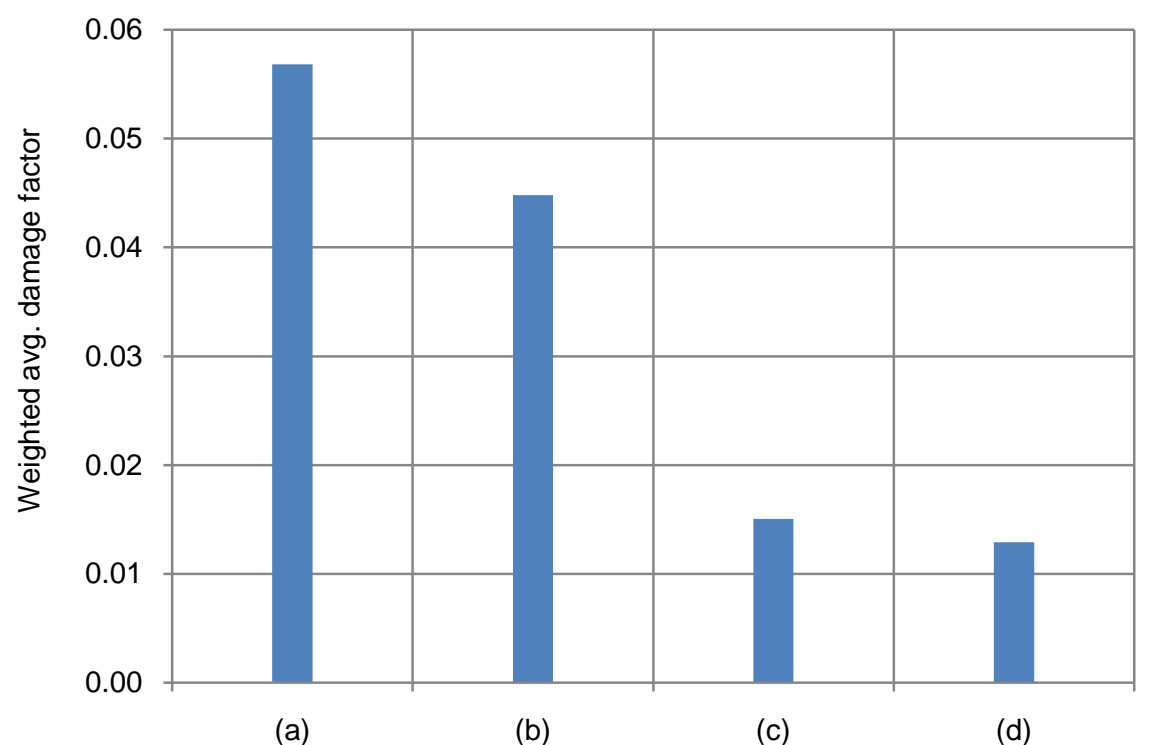

Figure 8.6 Weighted average damage factor for seals subjected to different p-t curves

\section{Conclusion}

Explosion pressures maintained for longer durations at peak values significantly influence the seal stability compared to any other parameter. Explosion pressures applied using p-t curve having instantaneous rise time produces comparatively more damage in the seal compared to the p-t curve with $0.1 \mathrm{sec}$ rise time; this influence is more significant when the peak explosion pressure is maintained for longer durations.

\subsection{MULTIPLE EXPLOSIONS}

In some instances in underground coal mines there is a possibility that mine seals may be subjected to multiple explosions. Different pressure-time (p-t) curves with multiple explosion pressures as shown in figure 8.7 are selected to study the reinforced concrete seal response. The duration of the peak explosion pressure for two and three explosions shown in figure 8.7(a) is reduced in order to cut down the model solving times. Refer to Section 8.3 (p. 138) for complete explanation on the effect of the duration of the peak explosion pressure loading on the seal response. 

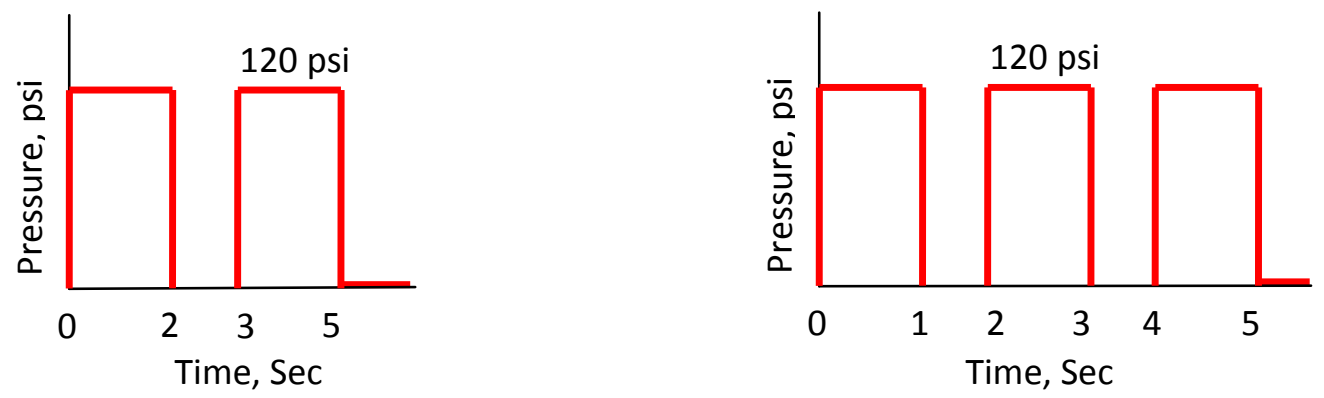

(a) Instantaneous
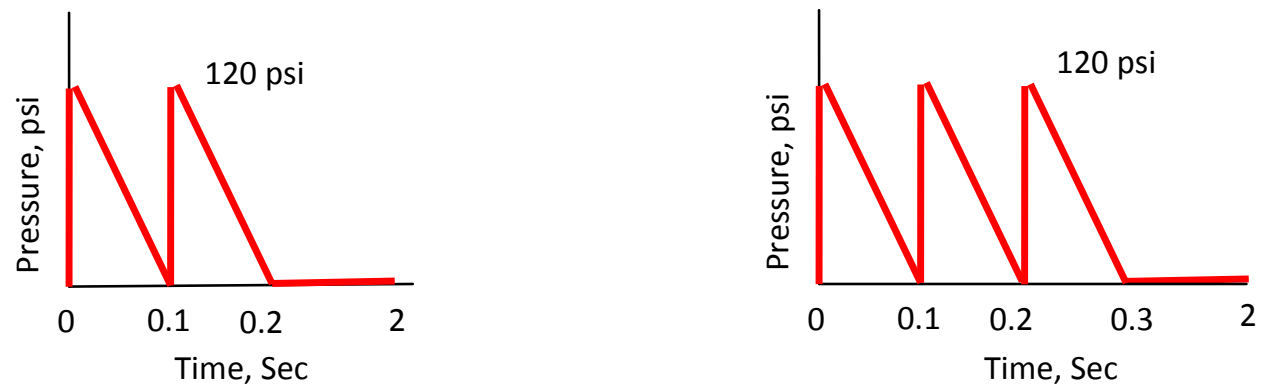

(b) Instantaneous rise and 0.1 sec down time
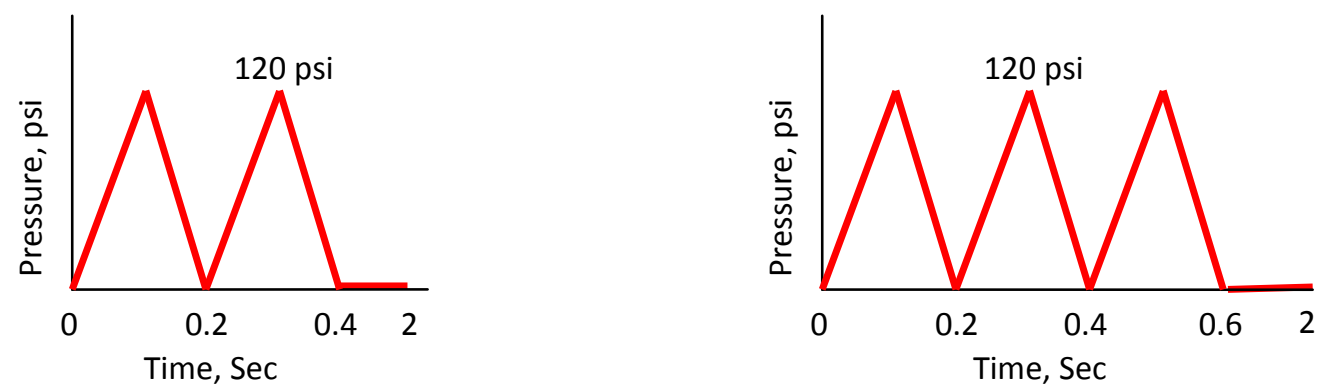

(b) $0.1 \mathrm{sec}$ rise and down time

Figure 8.7 Different pressure-time (p-t) curves for multiple explosions

\section{Results and discussion}

Figure 8.8 shows the damage contours in seals subjected to multiple explosions with instantaneous pressure loading as shown in figure 8.7 (a). The extent of the damage in the seals increases with an increase in number of explosions but is very much limited to a couple of tensile cracks on the outby surface of the seals. These cracks only extend to the half thickness of the seal and do not show up on the inby face of the seal. Figure 8.9 shows the history of the lateral displacements on the outby face of the seals that are subjected to 
multiple explosions. It can be clearly observed that with each explosion loading pulse, the lateral displacements reach higher levels and remain steady over time. This is a good indication that the seal is in a steady state condition and is not continuously deforming under the applied explosion pressure. Figure 8.10 shows the history of the axial forces in the vertical rebars (Inby_B/T) for seals subjected to multiple instantaneous explosions. The maximum axial forces developed in the steel rebars are well within the yield strength of the steel even after the seal is subjected to three instantaneous explosion pulses. Refer to figures 8.17 to 8.19 for comparison of the results obtained with different p-t curves shown in figure 8.7 .

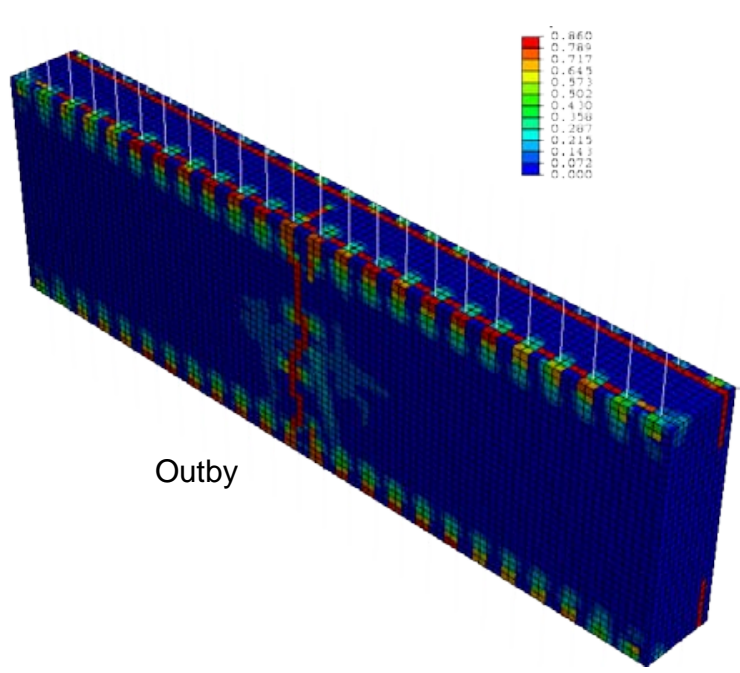

(a) Single explosion

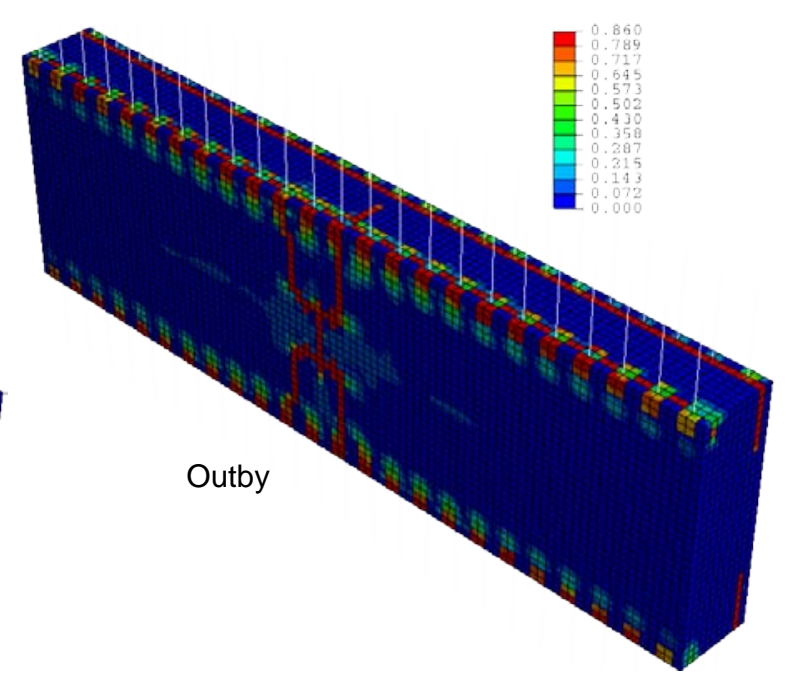

(b) Two explosions

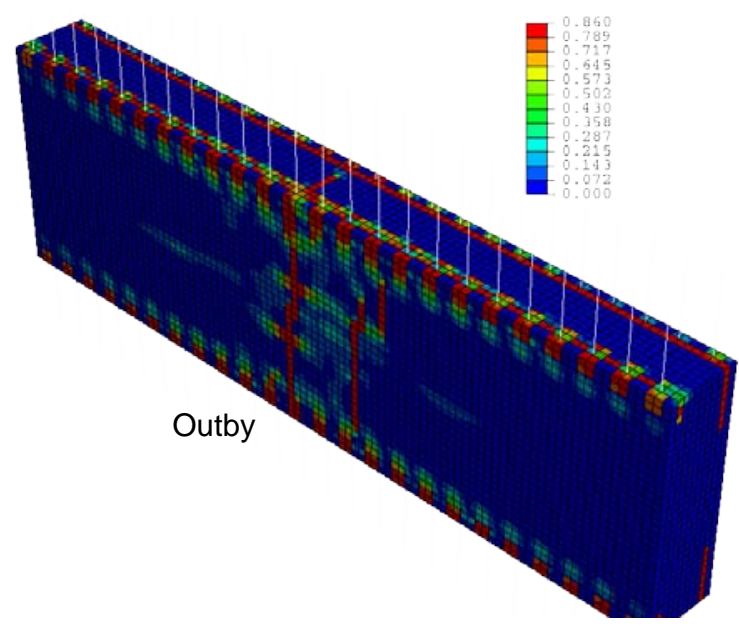

(c) Three explosions

Figure 8.8 Damage contours in seals subjected to p-t curves as shown in figure 8.7(a) 


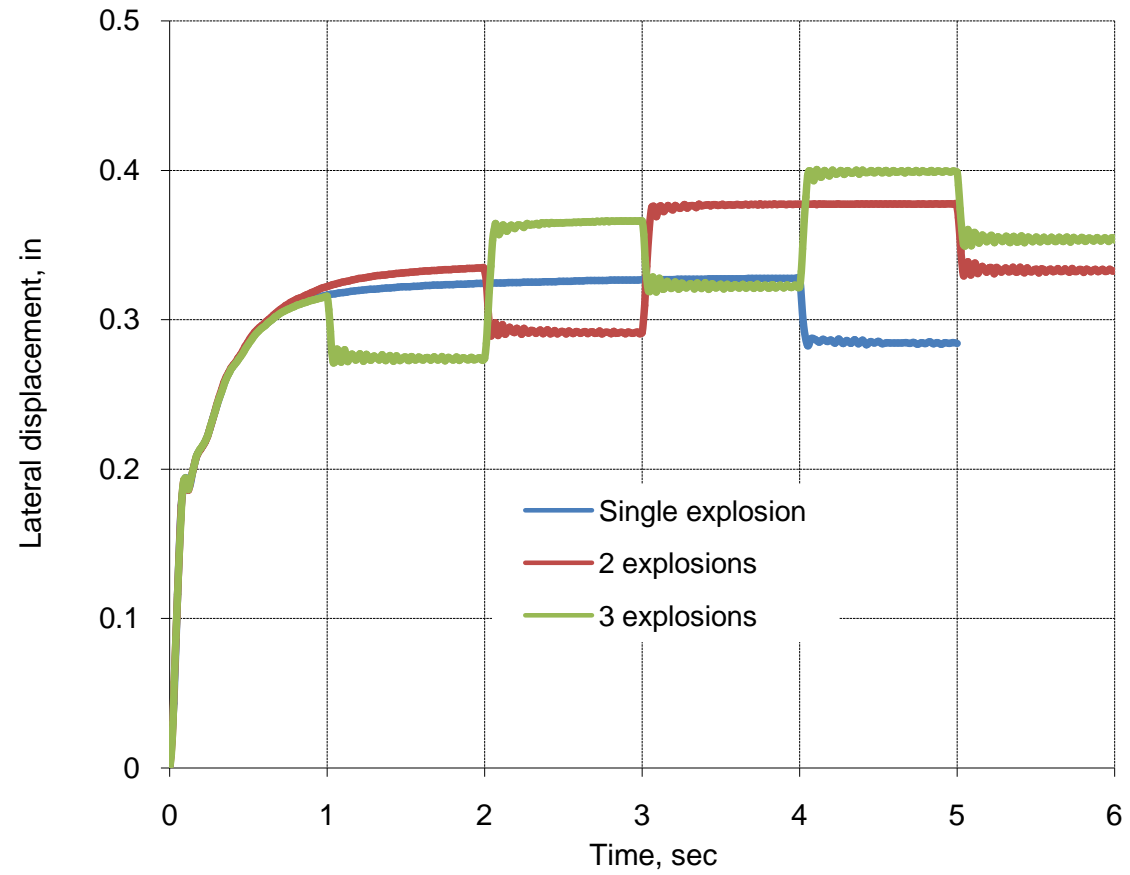

Figure 8.9 The history of lateral displacements (Outby_M) in seals subjected to multiple explosions with p-t curves as shown in figure 8.7(a)

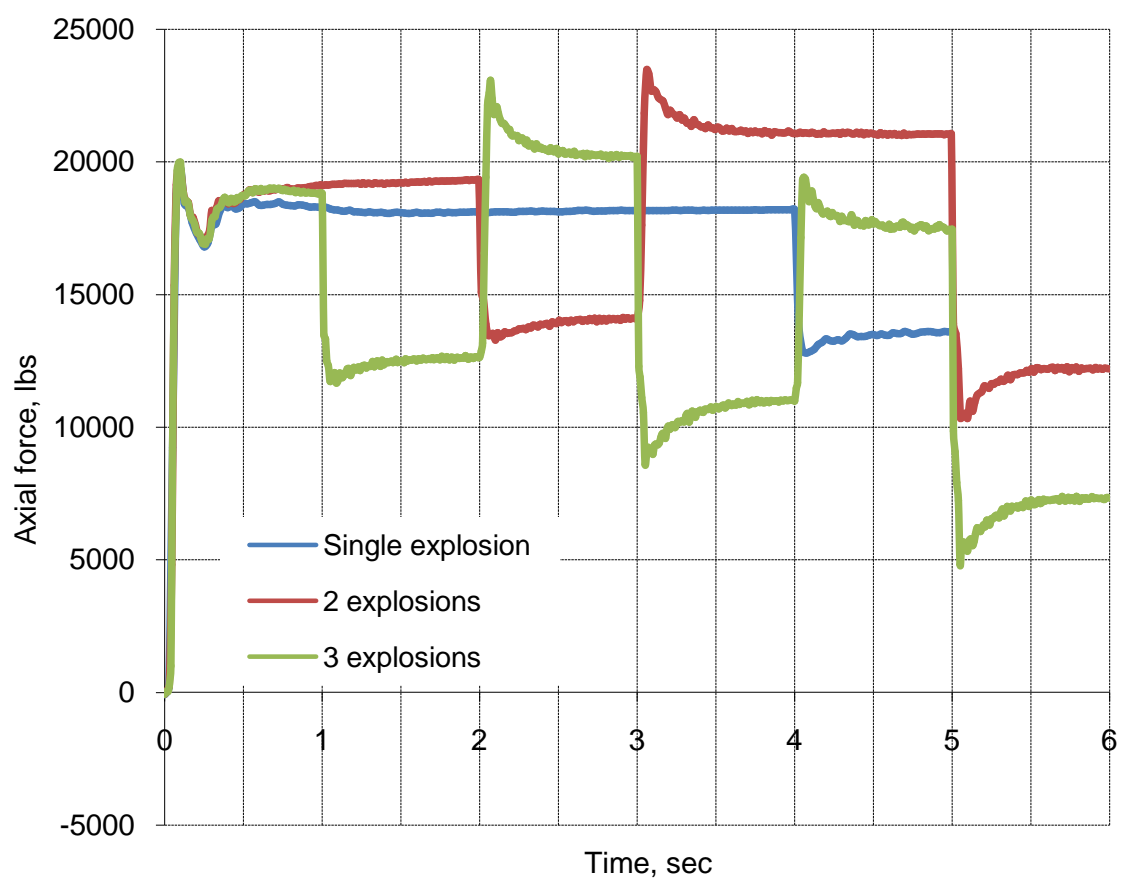

Figure 8.10 The history of axial forces (Inby_B/T) in vertical rebars in seals subjected to multiple explosions with p-t curves as shown in figure 8.7(a) 
Figure 8.11 shows the damage contours in seals subjected to multiple explosions with instantaneous rise time and $0.1 \mathrm{sec}$ down time as shown in figure 8.7(b). The seal shows no damage on the outby surface with one explosion, but after the second explosion of similar nature hit the seal it develops a vertical tensile crack on the outby surface of the seal. The extent of the damage increases very slightly with the third explosion of similar nature. Figures 8.12 and 8.13 show the history of the axial forces and the lateral displacements for the seals that are subjected to multiple explosions with instantaneous rise time and 0.1 sec down time, respectively. Refer to figures 8.17 to 8.19 for comparison.

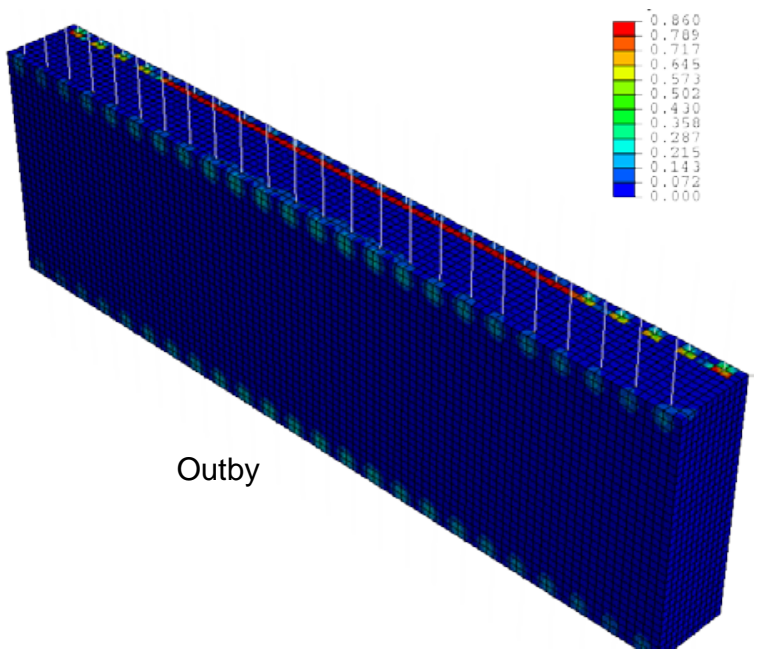

(a) Single explosion

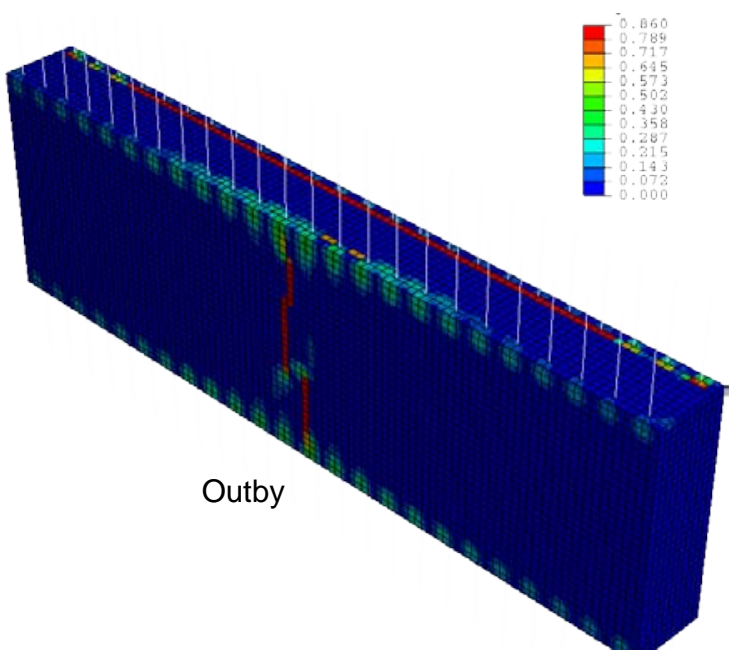

(b) Two explosions

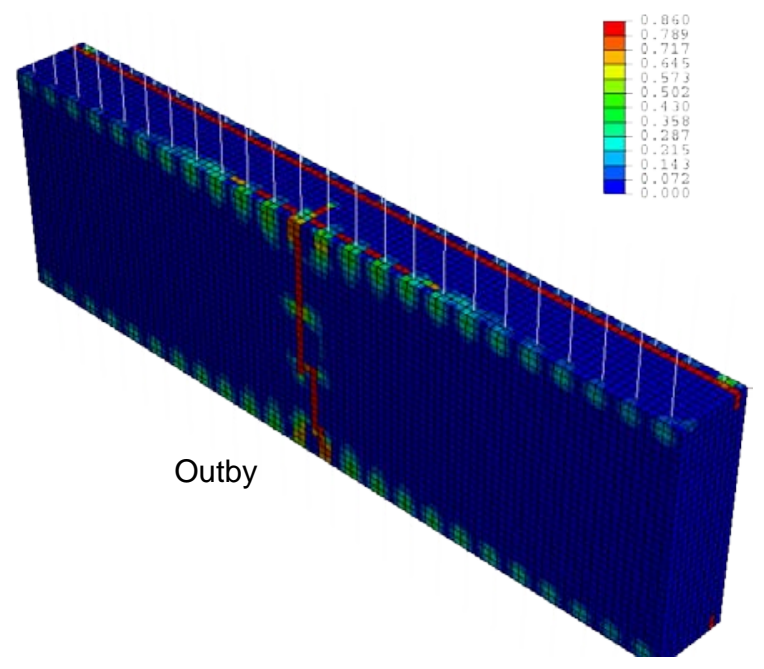

(c) Three explosions

Figure 8.11 Damage contours in seals subjected to multiple explosions with p-t curves as shown in figure 8.7(b) 


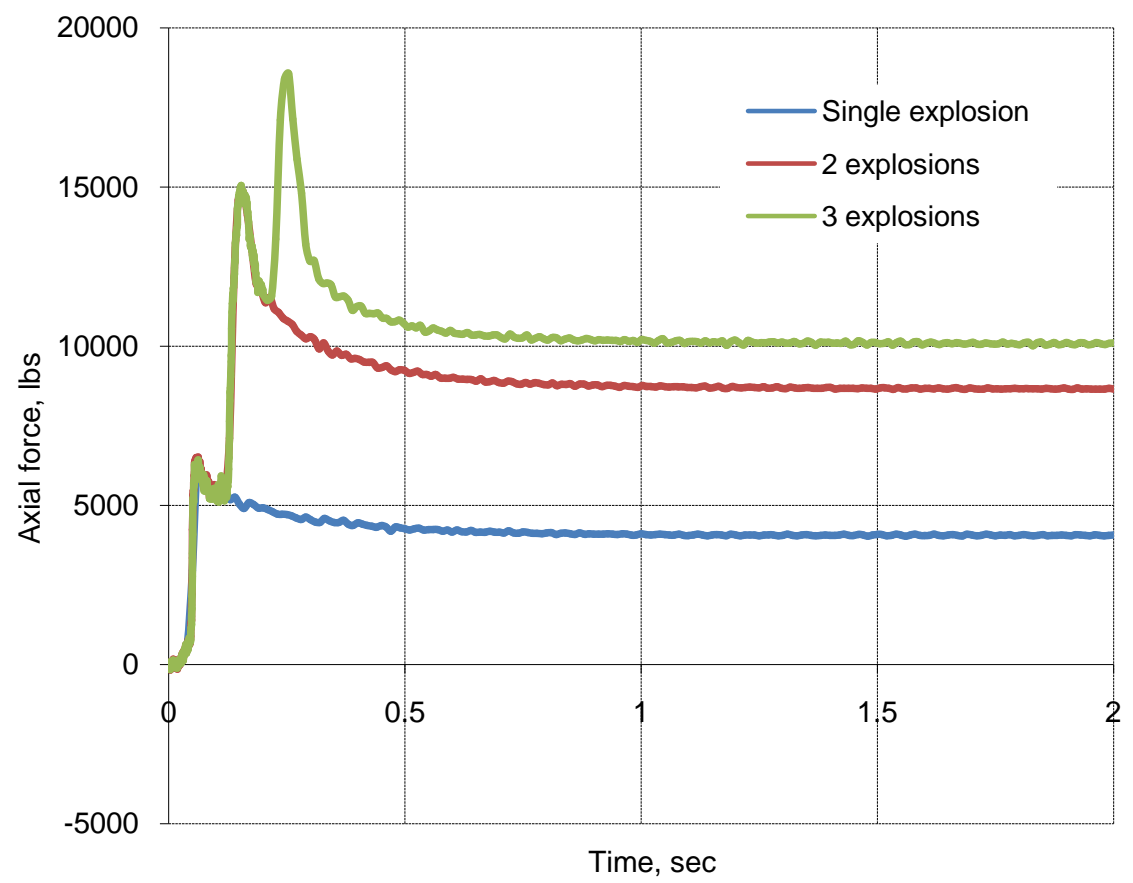

Figure 8.12 The history of lateral displacements (Outby_M) in seals subjected to multiple explosions with p-t curves as shown in figure 8.7(b)

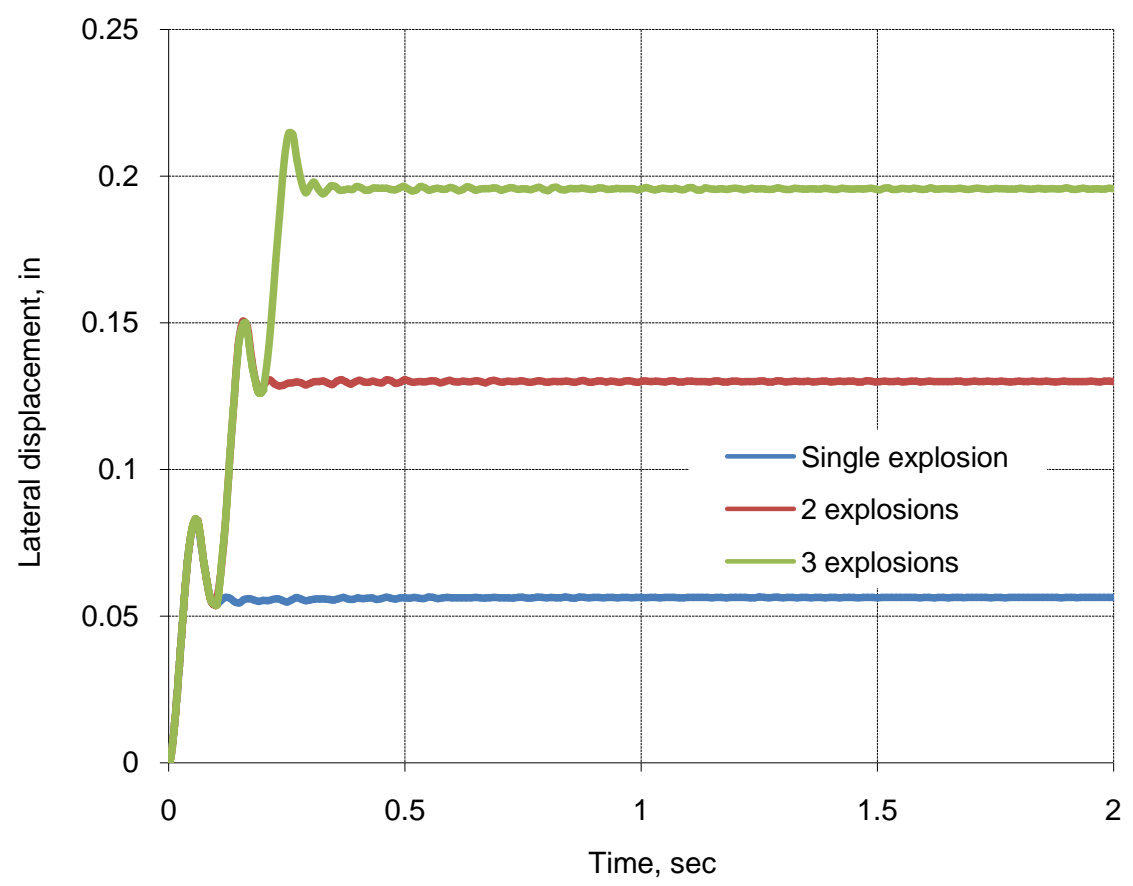

Figure 8.13 The history of axial forces (Inby_B/T) in vertical rebars in seals subjected to multiple explosions with p-t curves as shown in figure 8.7(b) 
Figure 8.14 shows the damage contours in seals subjected to multiple explosions with $0.1 \mathrm{sec}$ rise and down time as shown in figure 8.7(c). Similar results were predicted compared to the previous case except that there is no damage observed on the outby surface of the seal after it is subjected to two explosion pulses. Figures 8.15 and 8.16 show the history of the axial forces and lateral displacements for the seals that are subjected to multiple explosions with $0.1 \mathrm{sec}$ rise and down time respectively. Refer to figures 8.17 to 8.19 for comparison of results obtained with different p-t curves shown in figure 8.7.

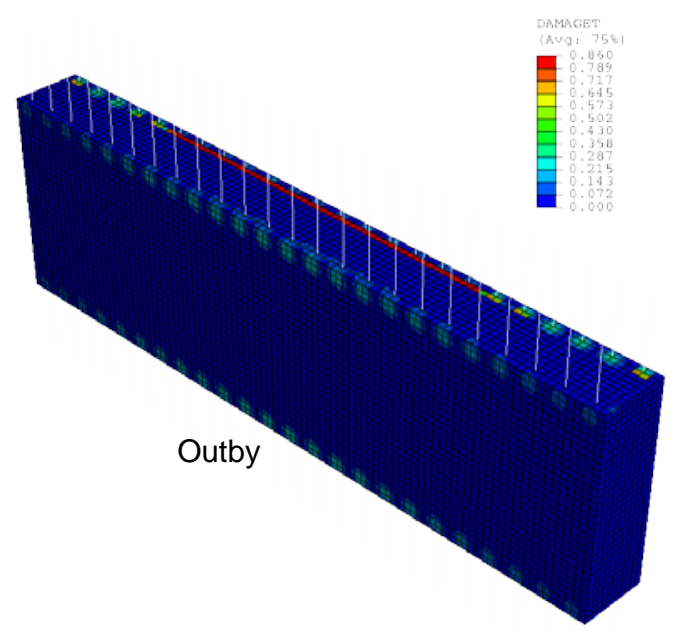

(a) Single explosion

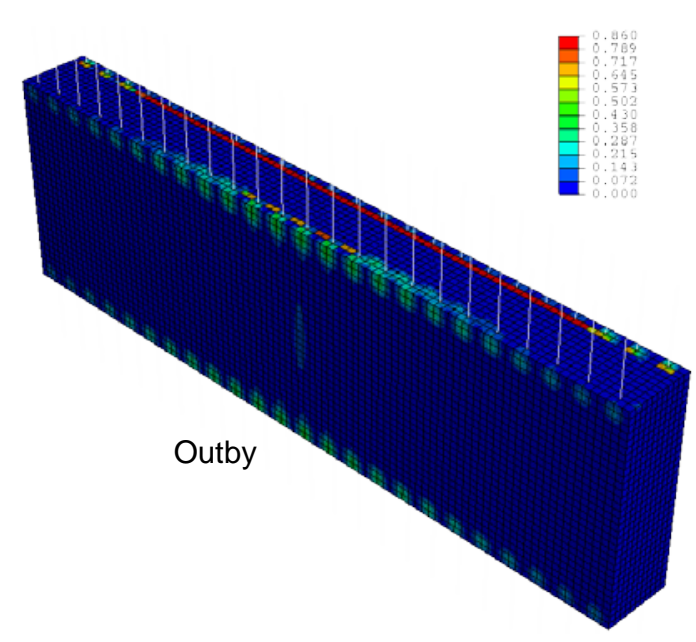

(b) Two explosions

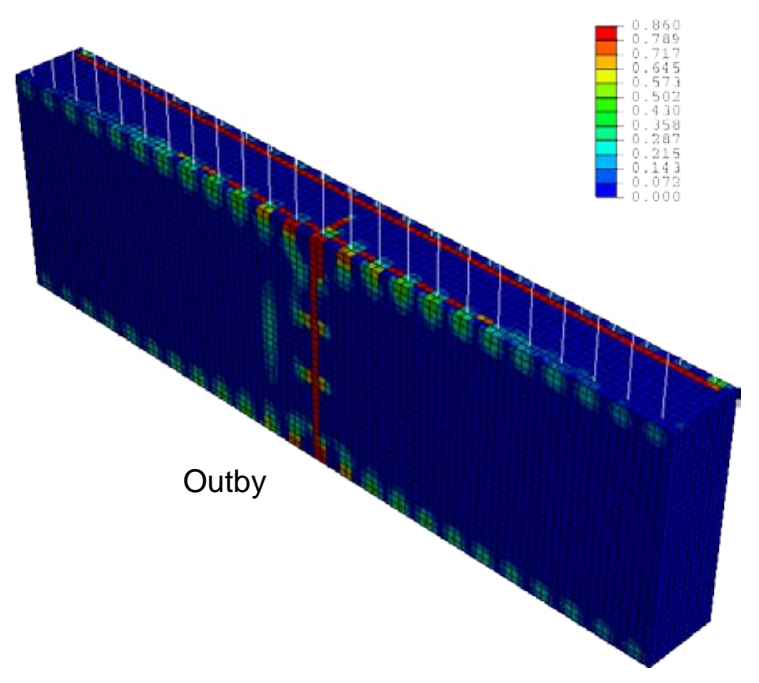

(c) Three explosions

Figure 8.14 Damage contours in seals subjected to multiple explosions with p-t curves as shown in figure 8.7(c) 


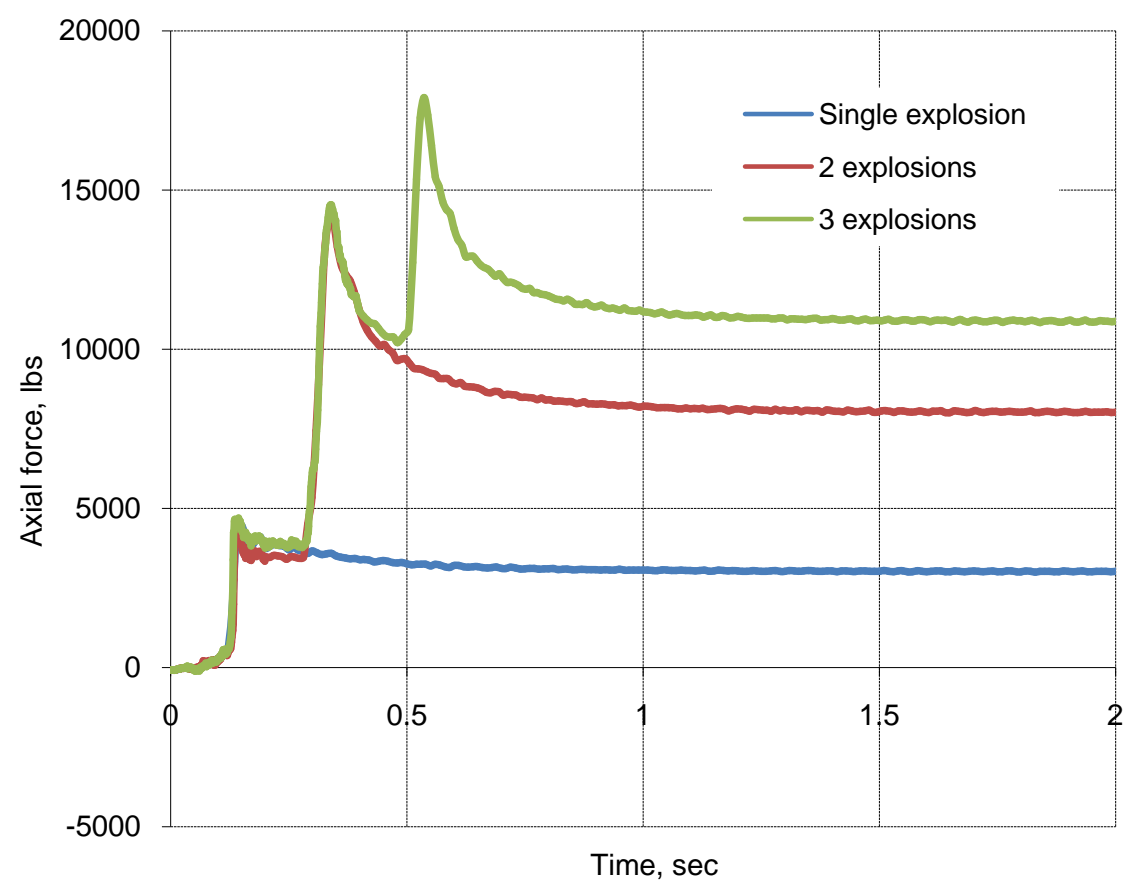

Figure 8.15 The history of lateral displacements (Outby_M) in seals subjected to multiple explosions with p-t curves as shown in figure 8.7(c)

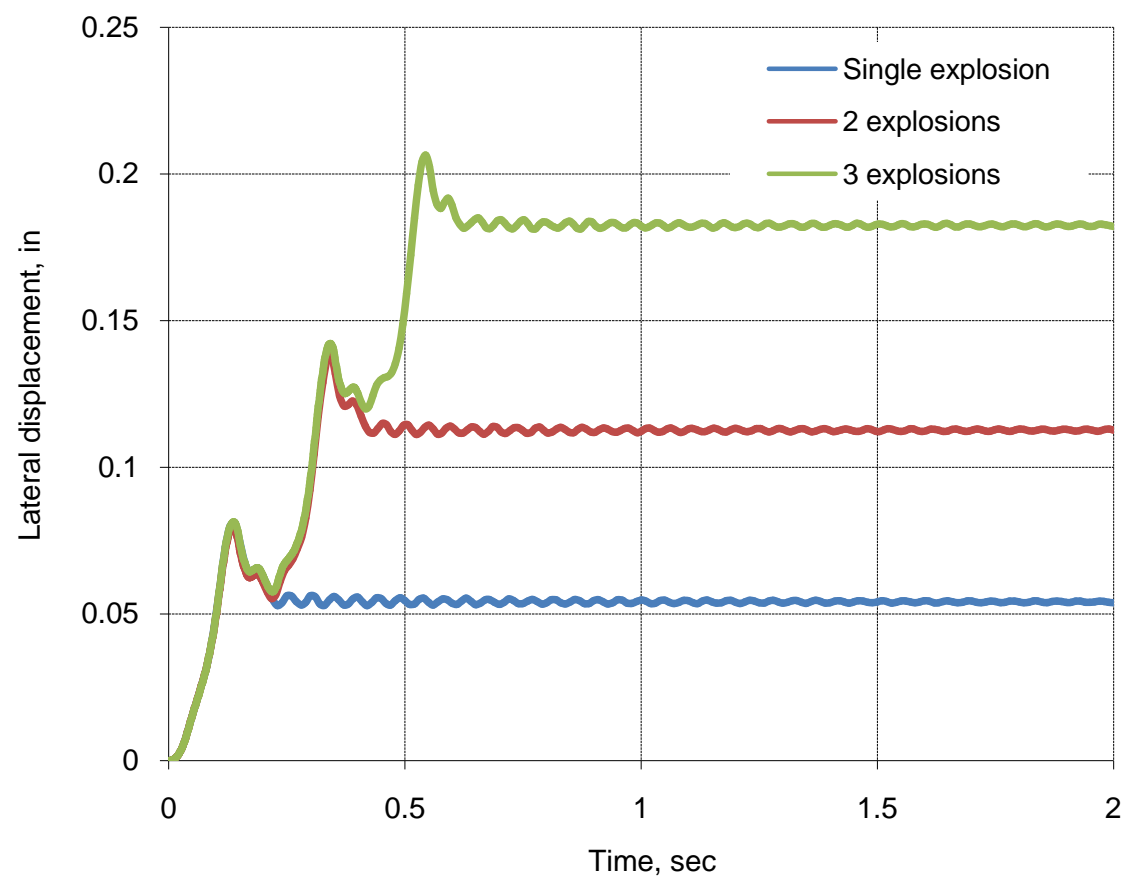

Figure 8.16 The history of axial forces (Inby_B/T) in vertical rebars in seals subjected to multiple explosions with p-t curves as shown in figure 8.7(c) 


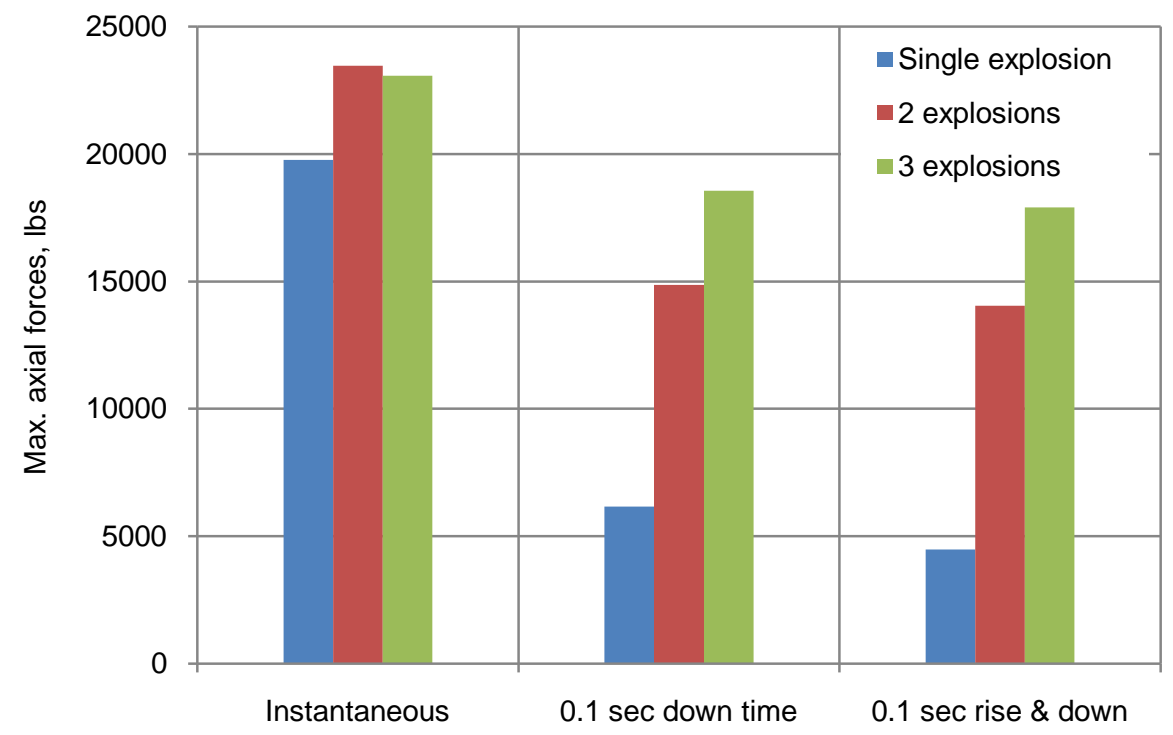

Figure 8.17 Maximum axial forces developed in steel rebars (Inby_T/B) in seals subjected to multiple explosions with p-t curves shown in figure 8.7

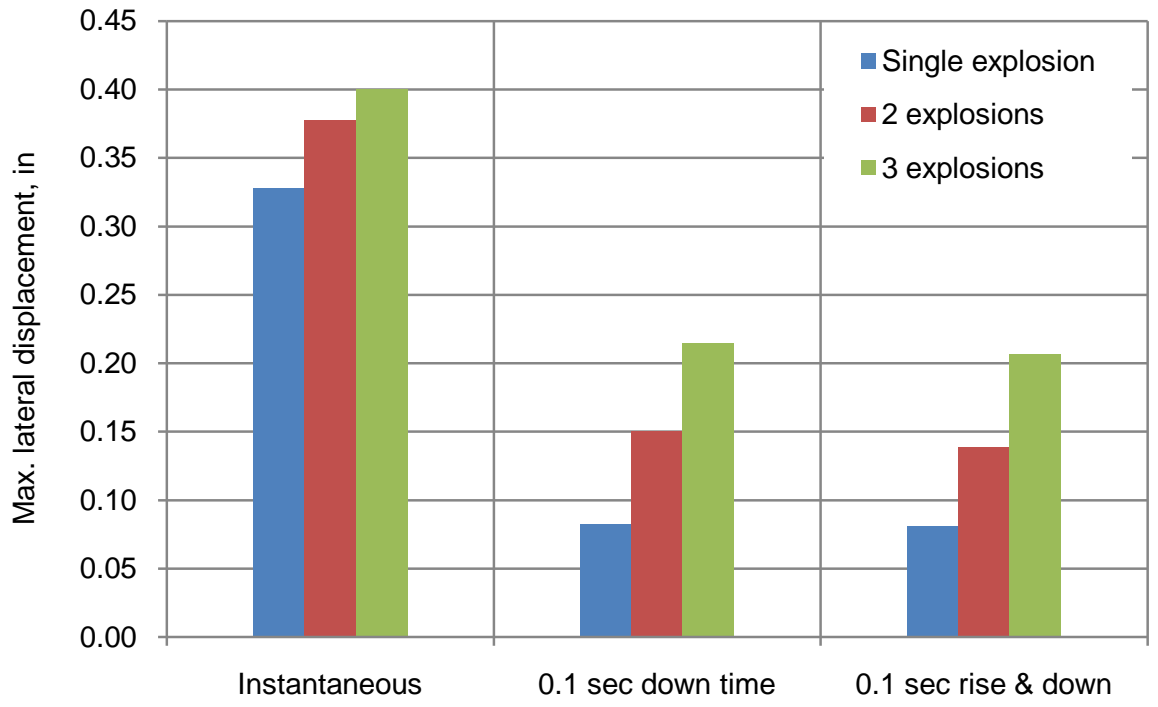

Figure 8.18 Maximum lateral displacements developed in seals (Outby_M) subjected to multiple explosions with p-t curves shown in figure 8.7 


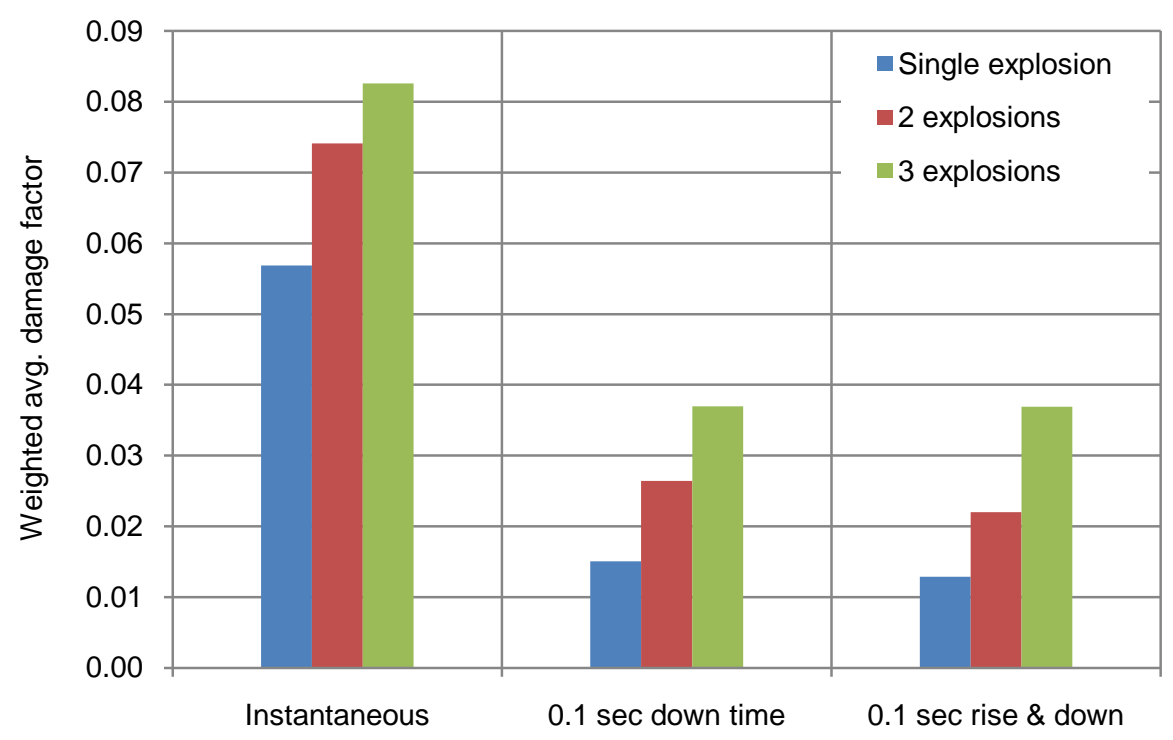

Figure 8.19 Weighted average factor for seals subjected to multiple explosions with p-t curves shown in figure 8.7

\subsection{EXPLOSION LOADING DURATION}

For seal design purposes MSHA requires the use of pressure-time (p-t) curve with instantaneous rise time and the explosion pressure maintained for $4 \mathrm{sec}$ and then dropped suddenly. While attempting to use the numerical simulation programs for design of seals in dynamic mode, the duration of the explosion loading has a great influence on the model running times. At the same time it is evident from the results discussed in Section 8.1 that the explosion pressures maintained for longer durations at peak values significantly influences the seal stability. This section tries to optimize the duration of the peak explosion pressure that must be applied using the p-t curve to help reduce the model running times without compromising on the seal response. The results obtained for the seal designed for $6 \mathrm{ft}$ high and $20 \mathrm{ft}$ wide entry is used for explanation.

Figures 8.20 and 8.21 show the change of weighted average damage factor of the seal subjected to different pressure-time curves as shown in the same figures. With the explosion pressure applied using the pressure-time curve having an instantaneous rise time the WADF increases very sharply initially and later gradually reaches a steady value in about 1.5 sec. With the pressure-time curve having $0.1 \mathrm{sec}$ rise time WADF takes a little longer time (about 
$2 \mathrm{sec}$ ) to reach a steady value. Similarly, in both cases the lateral displacements also reach the peak values in about 1.5 to 2 sec (Figures 6.22 and 8.3). Based on these results it is concluded that the explosion pressure maintained for about 1.5 to 2 seconds can sufficiently represent the longer duration loadings.

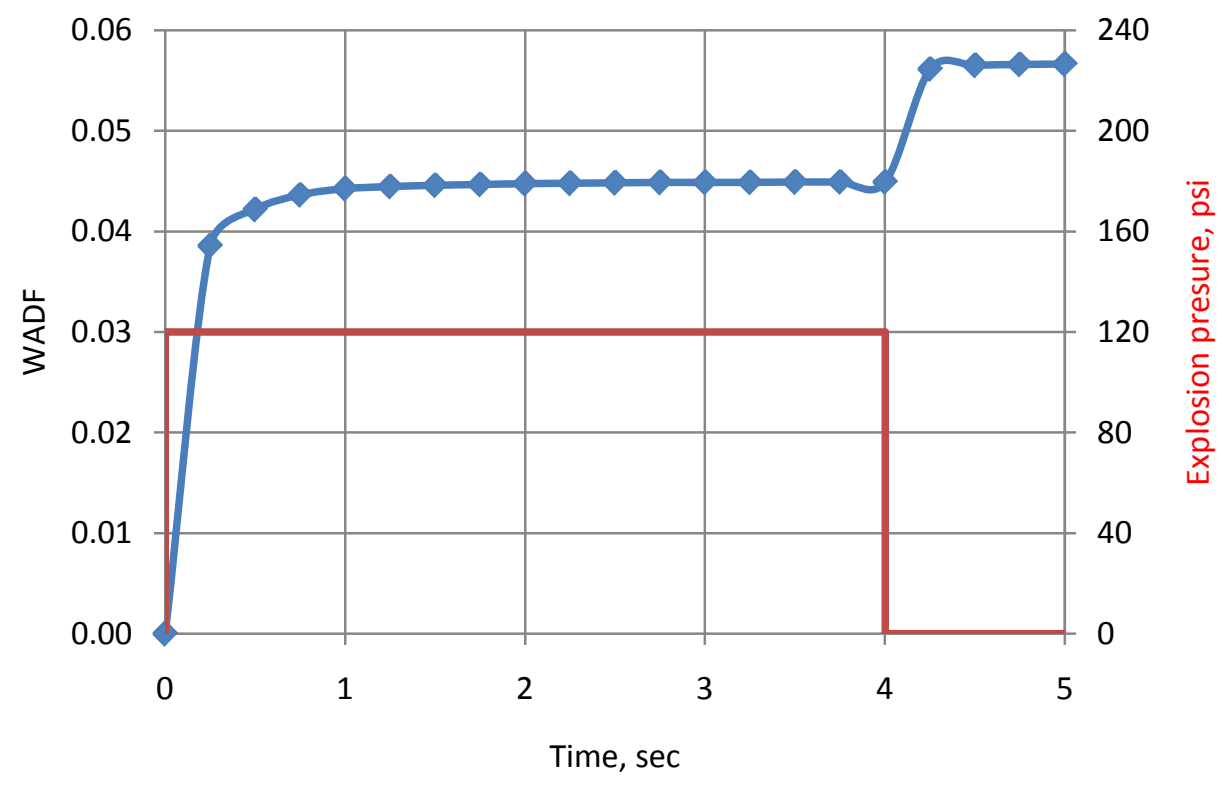

Figure 8.20 Change of WADF over the duration of explosion loading (instantaneous rise time)

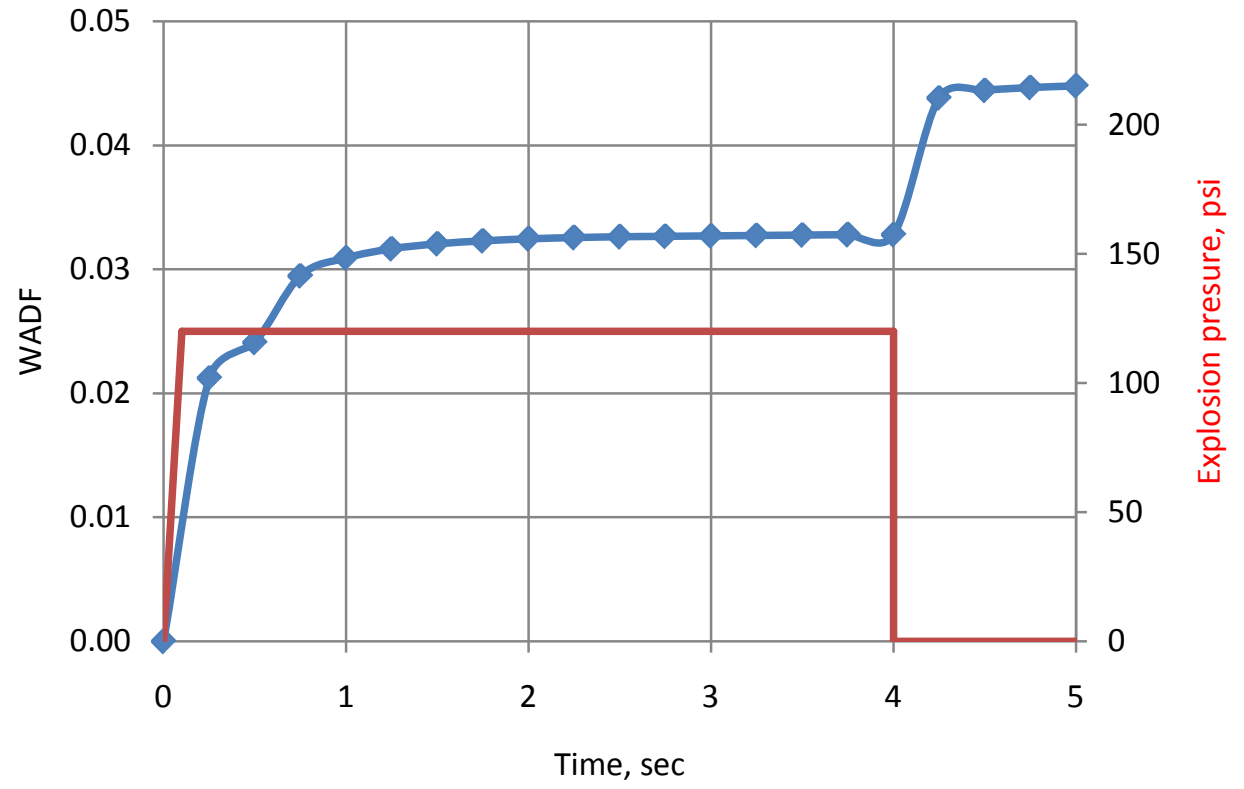

Figure 8.21 Change of WADF over the duration of explosion loading ( $0.1 \mathrm{sec}$ rise time) 


\section{Chapter 9 CONCLUSIONS \& FUTURE WORK}

ased on the numerical simulation and the in-mine experimental work carried out in connection with this dissertation the following conclusions are drawn:

The following guidelines are devised to quantitatively assess the adequacy of the reinforced concrete seal design:

- Tensile cracking: The seal design is limited to a single or no tensile crack on the outby surface of the seal.

- WADF: The weighted average damage factor decreases exponentially with the increase in seal thickness and reaches a 'near-steady' value once the seal reaches sufficient thickness. 'Near-steady' value is used to identify the optimal seal design.

- Lateral displacements: Exhibits very much similar behavior compared to that of WADF.

- No shear failure in the seal (refer to Figure 6.26, p. 96) is allowed.

- No yielding in the steel rebars is allowed.

Appropriate RC seal designs are proposed in the table (Table 6.3, p. 101) and graphical (Figure 6.30, p. 102) formats for typical coal mine entry dimensions.

Table 6.3 Minimum required seal thickness (in inches) for typical coal mine entries

\begin{tabular}{|c|c|c|c|c|c|c|c|c|c|}
\hline & \multicolumn{8}{|c|}{ Entry height, ft } \\
\hline & & $4 \mathrm{ft}$ & $5 \mathrm{ft}$ & $6 \mathrm{ft}$ & $7 \mathrm{ft}$ & $8 \mathrm{ft}$ & $9 \mathrm{ft}$ & $10 \mathrm{ft}$ & $12 \mathrm{ft}$ \\
\hline \multirow{3}{*}{ 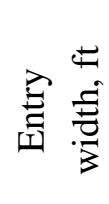 } & $16 \mathrm{ft}$ & 16 & 20 & 24 & 26 & 30 & 32 & 36 & - \\
\hline & $20 \mathrm{ft}$ & 16 & 22 & 24 & 28 & 30 & 34 & 38 & 44 \\
\hline & $24 \mathrm{ft}$ & 16 & 22 & 26 & 28 & 32 & 36 & 40 & 48 \\
\hline
\end{tabular}

These designs are valid with the following parameters:

Concrete strength

Vertical rebar size \& spacing

Horizontal rebar size \& spacing
: 4800 psi (CEB \& Barth and Wu model)

:\#9 and 10 in.

:\#6 and 18 in. 
Seal-rock/coal interface strength $\quad: 200$ psi

Surrounding rock strength $\quad$ : Strong \& Intermediate (Table 6.2, p. 84)

Two sets of rebars with 2.5 in. cover distance

Based on extensive modeling work it was found out that the reinforced concrete seal designs proposed in this dissertation can sustain a maximum strain value of 0.0012 (convergence).

Within certain limits, roof-to-floor convergence has a very positive influence on the ability of the RC seal to sustain higher explosion pressures. For example, a very small amount of convergence (0.073 in.) could actually increase the seal (6'x20'x24') capacity to almost 280 psi (Table 7.1, p. 114). The positive influence of convergence is only valid as long as the stresses induced in the seal due to the convergence loading are well within the compressive strength of the concrete material.

Complete knowledge of stress-strain behavior of the concrete is very much essential for the design of reinforced concrete seals. The CEB \& Barth and Wu concrete model discussed in this dissertation appears to provide acceptable results with numerical simulations.

Optimal seal designs cannot completely avoid the development of tensile cracks in the concrete material. Simple tensile cracking that appears on the surface of the seal does not necessarily indicate the complete failure of the seal. In most instances these tensile cracks do not reach the inby face of the seal and extend only to the half thickness of the seal. The reinforced steel rebars embedded in the concrete close to the seal surface actually take care of the high tensile stresses and tensile cracking that may develop near the surface of the seal under the explosion loading.

Although the \#7 or \#8 vertical rebars can provide adequate design, \#9 rebars are suggested for vertical bars because of the reason that larger diameter rebars offer more circumference area and hence provide higher grouting strength/pull-out strength per unit length of the rebar.

Entry height plays a greater role than entry width in the design of a RC seal. 
The Strength of the surrounding rock has a significant influence on the stability of the seal. A weak surrounding rock deforms significantly under the rebar loading and could not provide sufficient anchorage for the seal, causing the concrete to fail extensively. To be on the conservative side, the RC seal designs provided in this dissertation are based on intermediate rock strength (Table 6.2, p. 84) and are not suitable for 'weak' rock conditions.

Explosion pressure applied using a pressure-time (p-t) curve having an instantaneous rise time produces comparatively more damage in the seal compared to a p-t curve with a 0.1 sec rise time; this influence is more significant when the peak explosion pressure is maintained for a longer durations.

Explosion pressures maintained for longer durations at peak values significantly influence the seal stability, more than any other parameter. Based on the modeling results it is believed that explosion pressures maintained for 1.5 to 2 sec duration can sufficiently represent the longer duration explosion loadings.

The results showed that the seal designs proposed in this dissertation can sustain multiple explosions without undergoing catastrophic failure, and showed some degree of elasticity in their design.

\section{THOUGHTS FOR FUTURE WORK}

An alternative full-scale physical testing of a RC seal for 120 psi explosion pressure would help better validate the numerical modeling results, and thus help better use of numerical tools for more reliable seal designs.

A correlation between the actual roof-to-floor convergence and the convergence (or stress level) on the RC seals for different surrounding rock types, would actually allow better design of RC seals for long-term.

Simulation of full rebar-rock grout interfaces in the models would provide better insight into the $\mathrm{RC}$ seal response to the explosion loading. 


\section{REFERENCES}

ABAQUS/Explicit User’s Manuals, 2006, Version 6.5, Hibbitt, Karlsson \& Sorensen, Inc., USA.

ACI 318-95, Building code requirements for structural concrete and commentary, American Concrete Institute.

ASCE (1993). State-of-the-Art Report on Finite Element Analysis of Reinforced Concrete., ASCE, New York, NY.

Bangash, M. Y. H., 2001, Manual of numerical methods in concrete- modeling and applications validated by experimental and site monitoring data, Thomas Telford Ltd, pp. 35.

Barth, K. E., and H. Wu, 2006, Efficient nonlinear finite element modeling of slab on steel stinger bridges, Finite elements in analysis and design, Volume 42, No. 14, pp. 1304-1313

Biggs, J. M., 1964, Introduction to Structural Dynamics. New York: McGraw-Hill, 341 pp.

Burdette, E.G., and Goodpasture, D. W., 1971, Final report on full-scale bridge testing: an evaluation of bridge design criteria, Department of Civil Engineering, the University of Tennessee, USA.

Burke, L. M., 2003, Numerical Modeling for increased Understanding of the Behavior and Performance of Coal Mine Stoppings, M.S. Thesis, Virginia Poly. Institute and State Univ., $120 \mathrm{pp}$.

CEB, 1970, International recommendations for the design and construction of concrete structures, Comite Europeen Du Beton-Federation International De La Precontrainte.

Century Dynamics - AutoReaGas - U.K., www.century-dynamics.com

CFR Code of Federal Regulations, U.S. Government printing Office, Office of the Federal Register, Washington D.C. 
Cope, R. J., and Rao, P. V., 1981, “Non-Linear finite element strategies for bridge slabs.” IABSE Colloquium, Delft University, Netherlands, pp. 273-288.

Evans, R. H., and M. S. Marathe, 1968, Microcracking and stress-strain curves for concrete in tension, Materials and Structures, Vol. 1, No. 1, pp. 61-64.

Gadde, M. M., D. Beerbower, J. A. Rusnak, J. Honse, and P. Worley, 2007, Post PIB P06-16: How to Design Alternative Mine Seals?, Preprint No. 07-138, Paper presented at the SME annual meeting, Denver, CO, Feb 25-28, 12 pp.

Genthe, M., 1968, Research on explosion-proof bulkheads for mine fire control, GmBH, Essen, 188 pp.

GexCon - FLACS - Norway, www.gexcon.com

Gopalaratnam, V. S., and S. P. Shah, 1985, Softening response of plain concrete in direct tension, ACI Materials Journal, Vol. 82, No. 3, pp. 310-323.

Greninger, N. B., E. S. Weiss, S. J. Luzik, and C. R. Stephan, 1989, 'Performance Evaluation of Solid Cementitious Seals', USBM IR 4809, 9 pp.

Greninger, N. B., E. S. Weiss, S. J. Luzik, and C. R. Stephan, 1991, “Evaluation of SolidBlock and Cementitious Foam Seals,” USBM RI 9382, pp. 13 pp.

Guo Z., and G. X. Zhang, 1987, Investigation of complete stress-deformation curves for concrete in tension, ACI Materials Journal, Vol. 84, No. 4, pp. 278-285.

Hognestad, E., Hanson, N. W., and McHenry, D. (1955). “Concrete stress distribution in ultimate strength design.” J. Am. Concr. Inst., 27(4), pp. 454-479.

Http://www.msha.gov

Kallu, R. R, S. S. Peng, K. Morsy, D. Turner, and A. Zingano, 2007, "Effect of Roof Convergence on Stability of Underground Mine Seal Subjected to Explosion Loading Numerical Approach”, Proceedings $26^{\text {th }}$ International Conference on Ground Control in Mining, Morgantown, WV, July 31 - August 02, pp. 370-378. 
Li, Q., Y. Duan, and G. Wang, 2002, Behavior of large concrete specimens in uniaxial tension, Magazine of Concrete Research, October 2002, Vol. 54, No. 5, pp. 385-391.

Lee, J., and Fenves, G. L., 1998, "Plastic-damage model for cyclic loading of concrete structures.” Journal of Engineering Mechanics, 124(8), pp. 892-900.

Lubliner, J., J. Oliver, S. Oller, and E. Oňate, 1989, “A plastic-damage model for concrete.” International Journal of Solids and Structures, 25, pp. 299-329.

Mans, P.H., 2001, Full scale testing of composite plate girder constructed using 70-ksi high performance steel, M.S. Thesis, University of Nebraska-Lincholn, USA.

Morsy, K. M., Yassien, A., Kallu, R. R., Peng, S. S., 2008, Design of Reinforced Concrete Seals in Underground Coal Mines, $27^{\text {th }}$ International Conference on Ground Control in Mining, Morgantown, WV, July, pp. 180-188.

MSHA Program Information Bulletin No. P06-11 to 16, June to July 2006.

MSHA, 120 psi reinforced concrete seal, MSHA seal approval number 120-75.336.1.07.01.0, http://www.msha.gov/seals/approved120psiseal.pdf, accessed October 2007.

NIOSH Contract no. 200-2007-22541, 'Design of underground mine seals under explosion events', Sep.-Dec., 2007.

Rice, G. S., H. P. Greenwald, H. C. Howarth, and S. Arins, 1931, Concrete stopping in coal mines for resisting explosions: Detailed tests of typical stoppings and strength of coal as a buttress. BuMines Bull. 345, pp. 55-57.

Rice, G. S., L. M. Jones, W. L. Egy, and H. P., 1922, Greenwald, Coal-dust explosion tests in the experimental mine, 1913 to 1918. Inclusive. BuMines Bull. 167, 639 pp.

Sapko M. J., E. S. Weiss, J. D. Trackemas, and C. R. Stephan, 2003, “Designs for Rapid InSitu Sealing,” Paper presented at SME Annual Meeting, Cincinnati, OH, February 24-28, 2003, 8 pp.

Sapko M. J., E. S. Weiss, and S. P. Harteis, 2005, "Methods for Evaluating Explosion Resistant Ventilation Structures,” Proceedings 8th International Mine Ventilation Congress, 
published by Australasian Institute of Mining and Metallurgy, Victoria, Australia, pp. 211219.

Slawson, T. R., 1995, Wall Response to Airblast Loads: The Wall Analysis Code (WAC), Structures Laboratory, U.S. Army Engineers Waterways Experiment Station, Vicksburg, MS, ATTN CEWES-SS.

Stephen C. R, 1990, Construction of Seals in Underground Coal Mines. Industrial Safety Division. Report No. 06-213-90. Mine Safety and Health Administration, Pittsburgh, P.A, August 1, 1990, pp. 1-34.

Triebsch, G., and M. J. Sapko, 1990, Lake Lynn Laboratory: a state-of-the-art mining research facility, in Proceedings of International Symposium on Unique Underground Structures, Denver, CO, June, Vol 2, pp. 75-1-75-21 (CSM Press).

Weiss, E. S., N. B. Greninger, C. R. Stephan, and J.R. Lipscomb, 1993, “Strength Characteristics and Air-Leakage Determinations for Alternative Mine Seal Designs,” USBM RI 9477, 21 pp.

Weiss, E. S., W. A. Slivensky, M. J. Schultz, C., Stephan, and K. W. Jackson., 1996, “Evaluation of Polymer Construction Material and Water Trap Designs for Underground Coal Mine Seals,” USBM RI 9634, 16 pp.

Weiss, E. S., K. L. Cashdollar, I. V. S. Mutton, D. R. Kohli, and W. A. Slivensky, 1999, Evaluation of Reinforced Cementitious Seals, Pittsburgh, PA: US Department of Health and Human Services, National Institute for Occupational Safety and Health, RI 9647, 43 pp.

Weiss E. S., K. L. Cashdollar, and M. J. Sapko, 2002, “Evaluation of Explosion Resistant Seals, Stoppings, and Overcasts for Ventilation Control in Underground Coal Mining,” U.S. Department of Health and Human Services, National Institute for Occupational Safety and Health, Pittsburgh Research Laboratory, RI 9659, 48 pp.

Weiss, E. S., and S. P. Harteis, 2008, “Strengthening Existing 20-psi Mine Ventilation Seals with Carbon Fiber-Reinforced Polymer Reinforcement,” U.S. Department of Health and 
Human Services, National Institute for Occupational Safety and Health, Pittsburgh Research Laboratory, RI 9673, 38 pp.

Westman, E., 2007, Comparision of Arched Flat Seal Designs using Finite Element Analysis, SME Annual Meeting, Denver, CO. Feb. 25-28, 2007, Preprint 07-106, 4 pp.

Wittry, D. M., 1993, “An analytical study of the ductility of steel-concrete composite sections.” M.S Thesis, The University of Texas at Austin, USA.

Yassien A., 2008, Personal communication

Zipf, R. K., M. J. Sapko, and J. F. Brune, 2007, Explosion Pressure Design Criteria for New Seals in U.S. Coal Mines. Pittsburgh, PA: U.S. Department of Health and Human Services, National Institute for Occupational Safety and Health, IC 9500, 76 pp.

Zipf, R. K., E. S. Weiss, S. P. Harties, and M. J. Sapko, 2009, Compendium of Structural Testing Data of 20 psi Coal Mine Seals. Pittsburgh, PA: U.S. Department of Health and Human Services, National Institute for Occupational Safety and Health, IC in press. 


\section{APPENDIX I}

Damage contours in seals for various entry dimensions. 

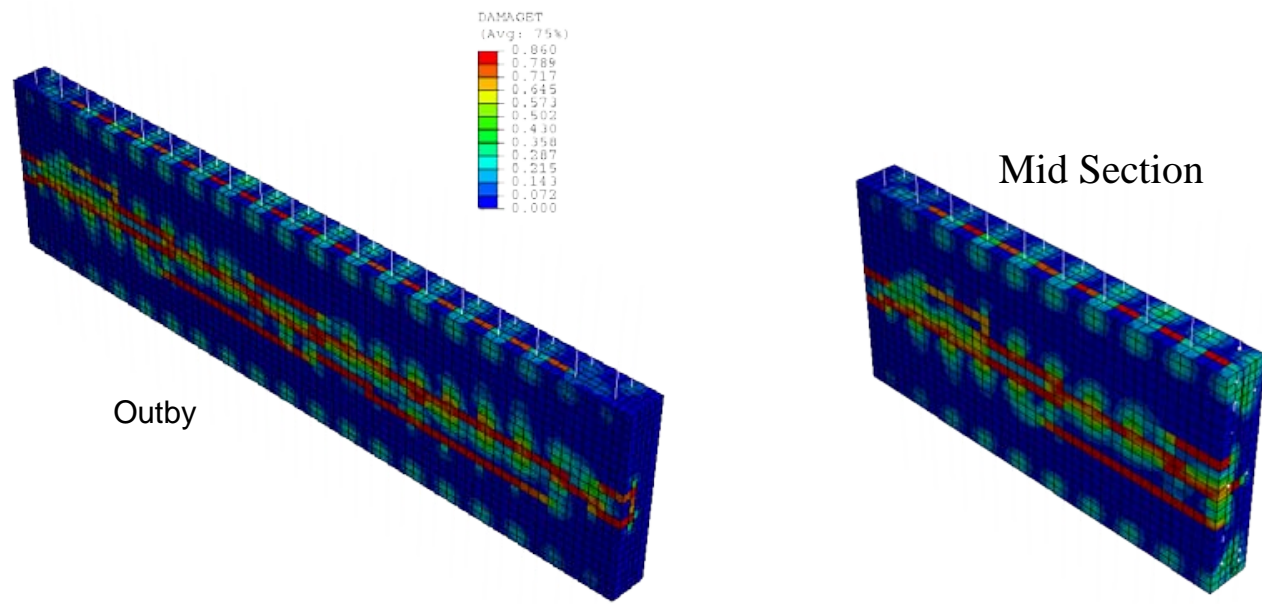

Entry dimension: $4 \mathrm{ft}$ x $16 \mathrm{ft}$, Seal thickness 10 in.
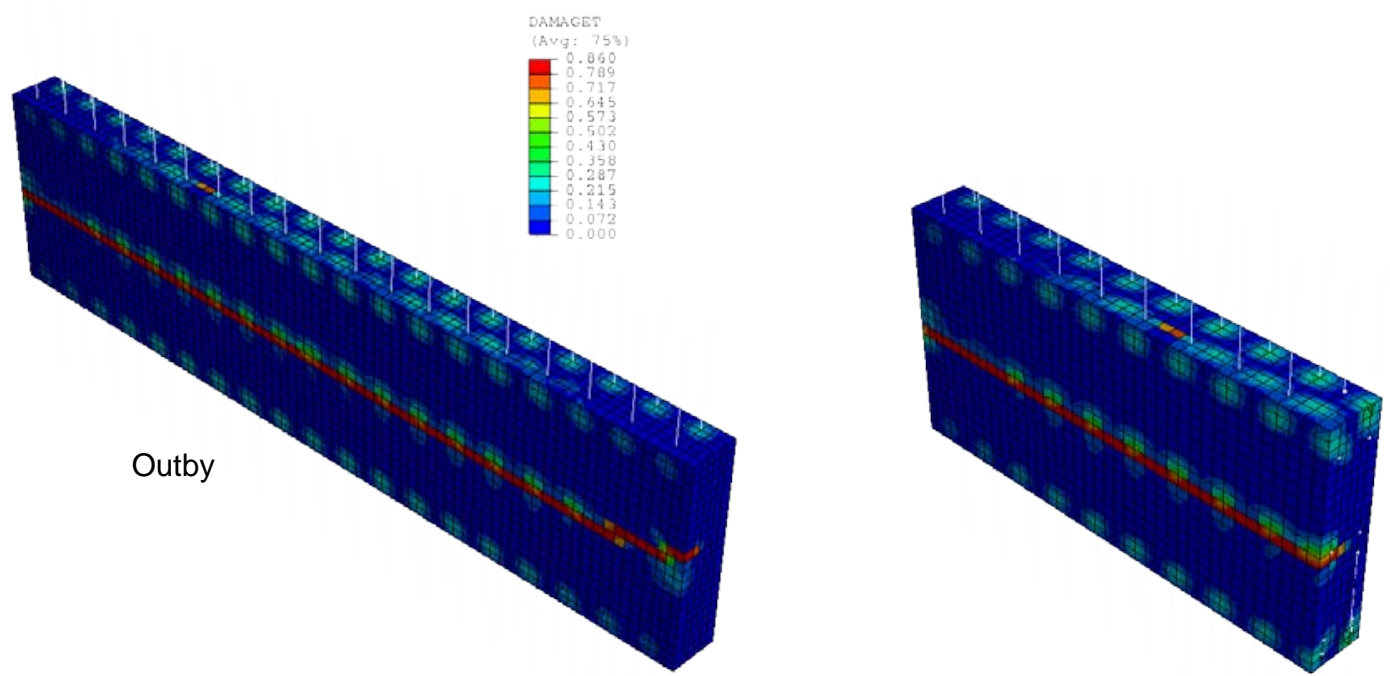

Entry dimension: $4 \mathrm{ft}$ x $16 \mathrm{ft}$, Seal thickness 12 in.
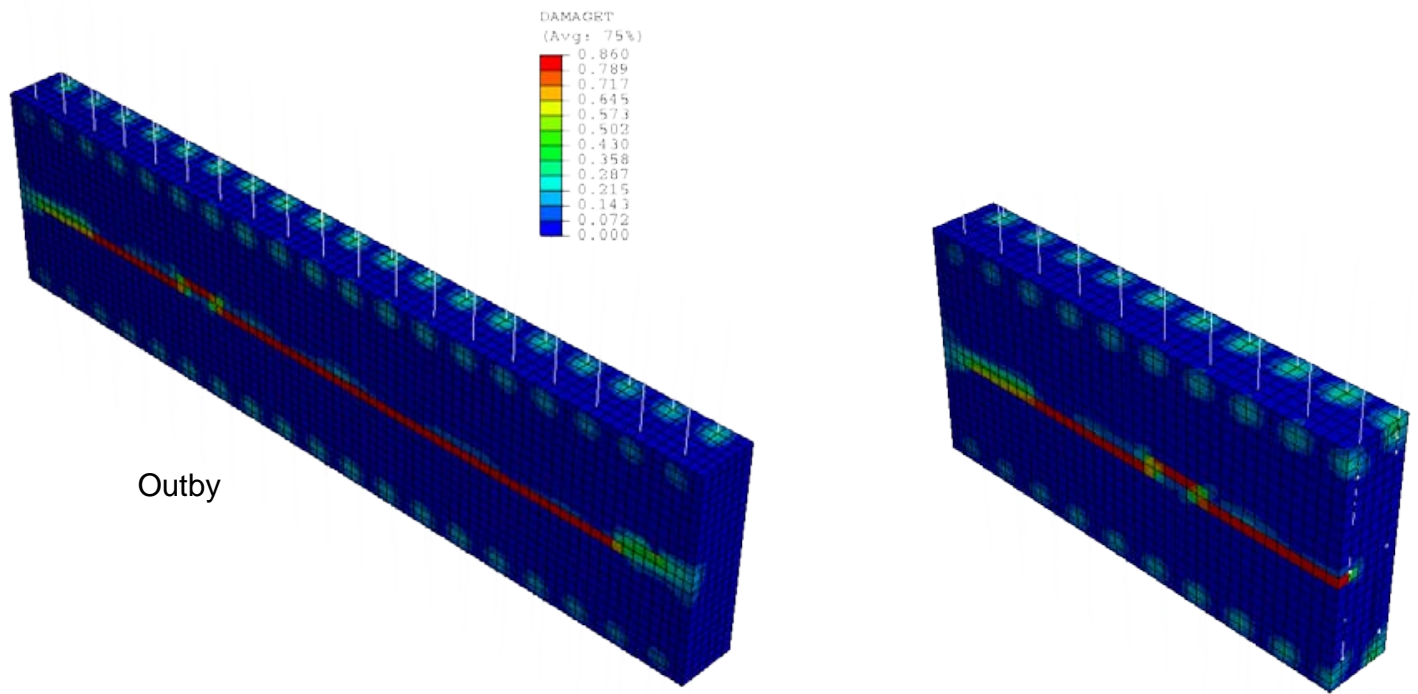

Entry dimension: $4 \mathrm{ft}$ x $16 \mathrm{ft}$, Seal thickness $14 \mathrm{in}$. 

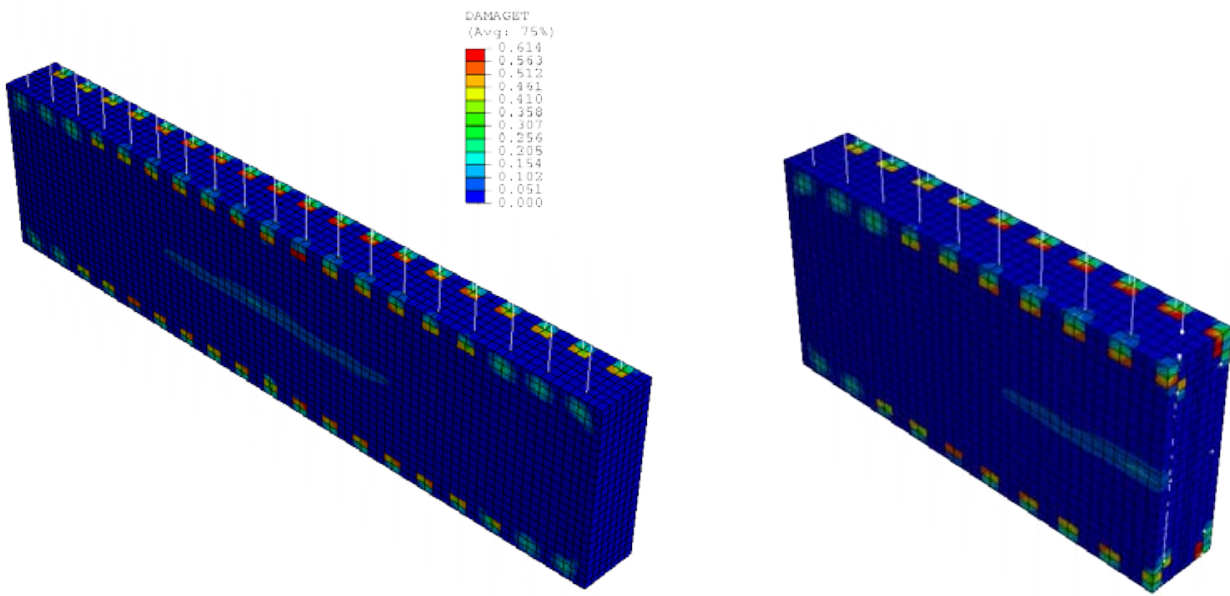

Entry dimension: $4 \mathrm{ft}$ x $16 \mathrm{ft}$, Seal thickness 16 in.
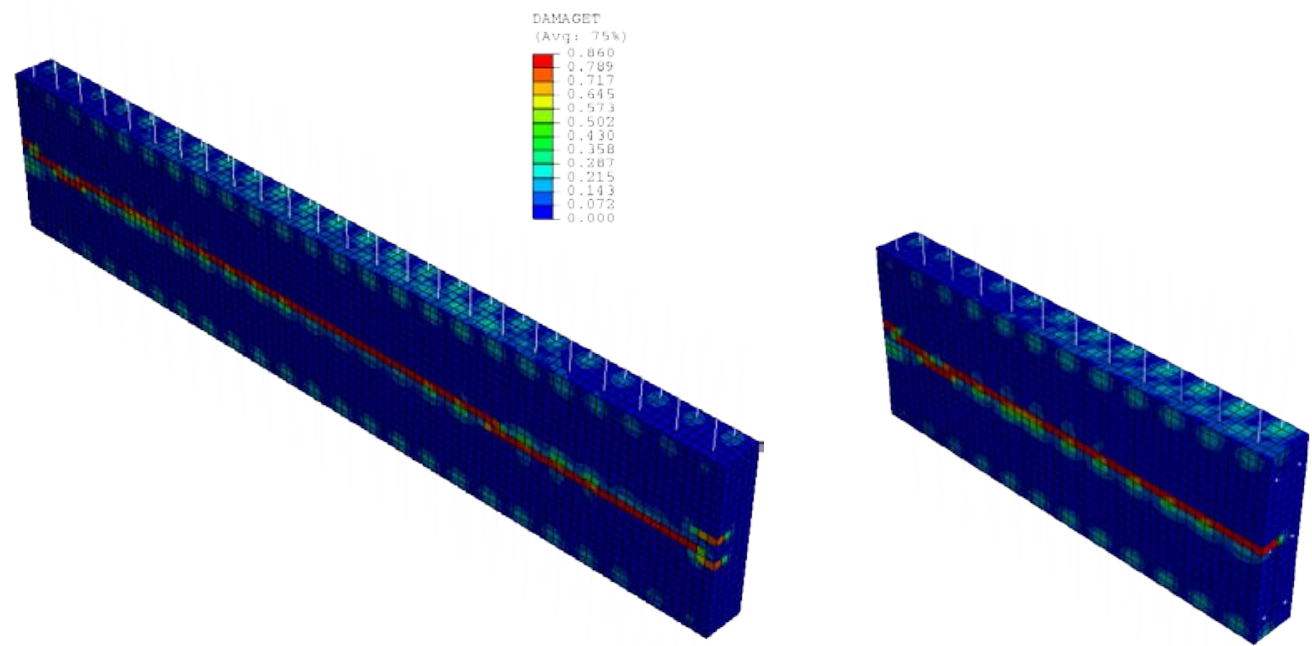

Entry dimension: $4 \mathrm{ft}$ x $20 \mathrm{ft}$, Seal thickness 12 in.

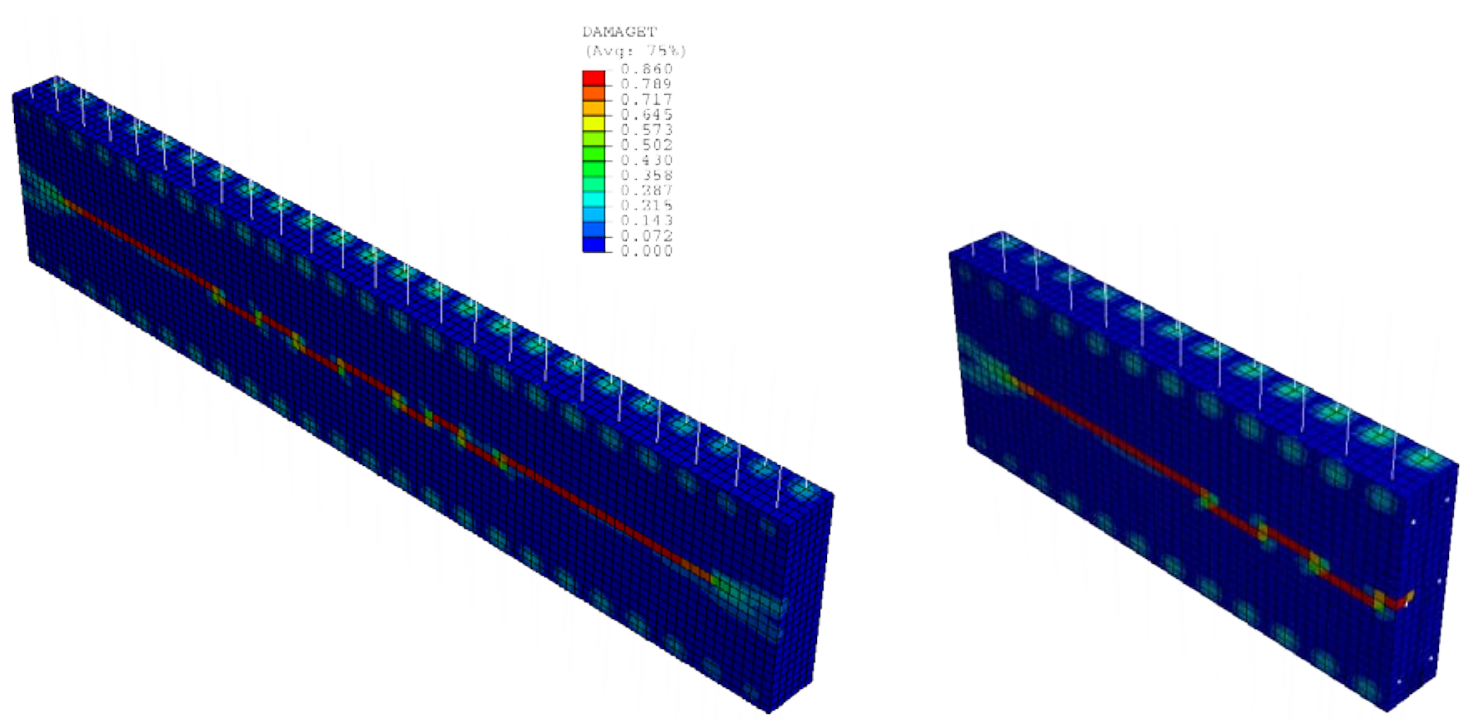

Entry dimension: $4 \mathrm{ft}$ x $20 \mathrm{ft}$, Seal thickness 14 in. 


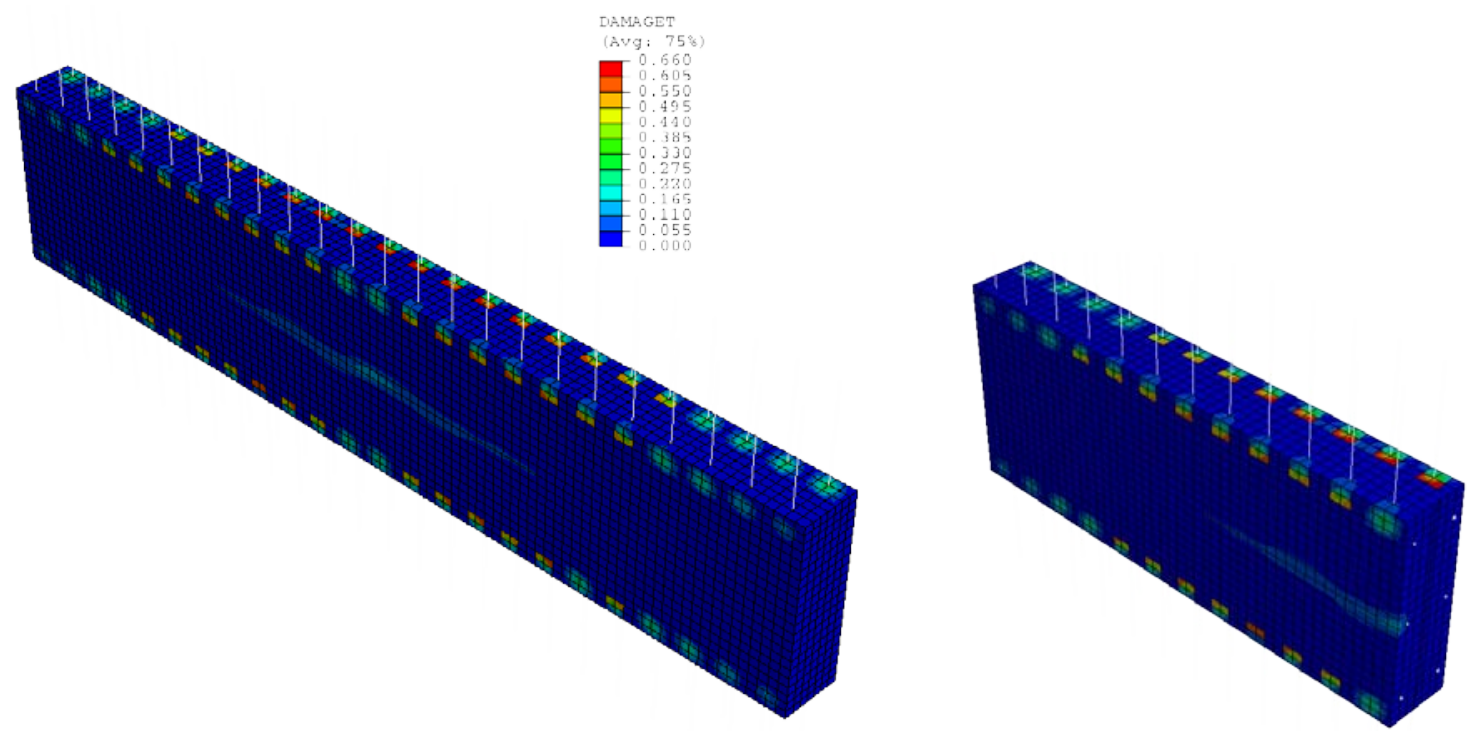

Entry dimension: $4 \mathrm{ft}$ x $20 \mathrm{ft}$, Seal thickness 16 in.

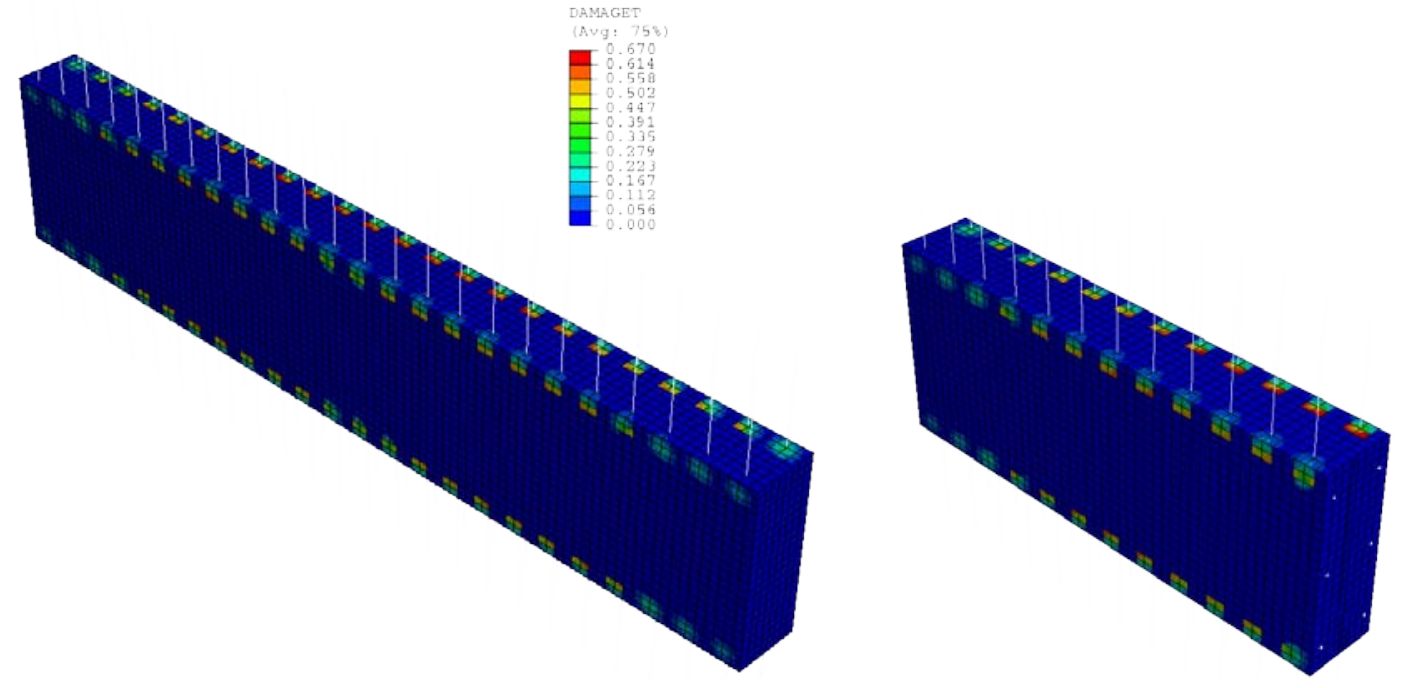

Entry dimension: $4 \mathrm{ft}$ x $20 \mathrm{ft}$, Seal thickness 18 in.

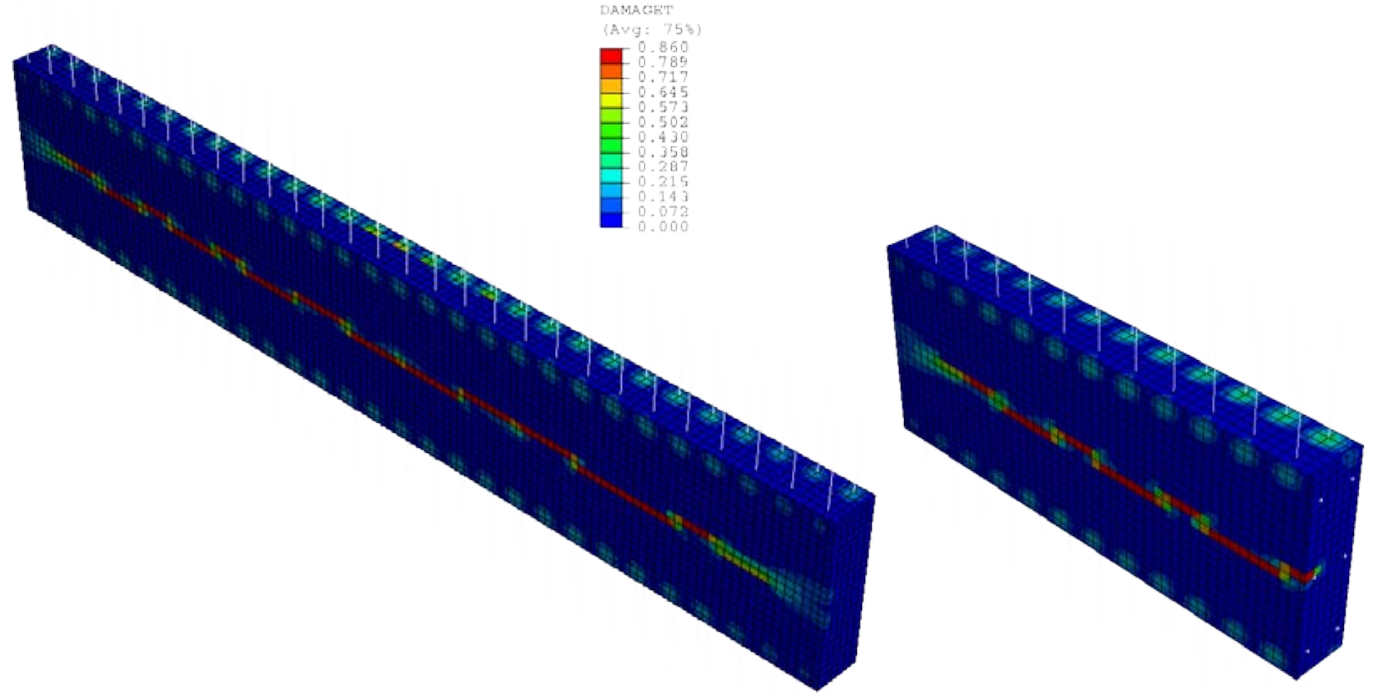

Entry dimension: $4 \mathrm{ft}$ x $24 \mathrm{ft}$, Seal thickness 14 in. 


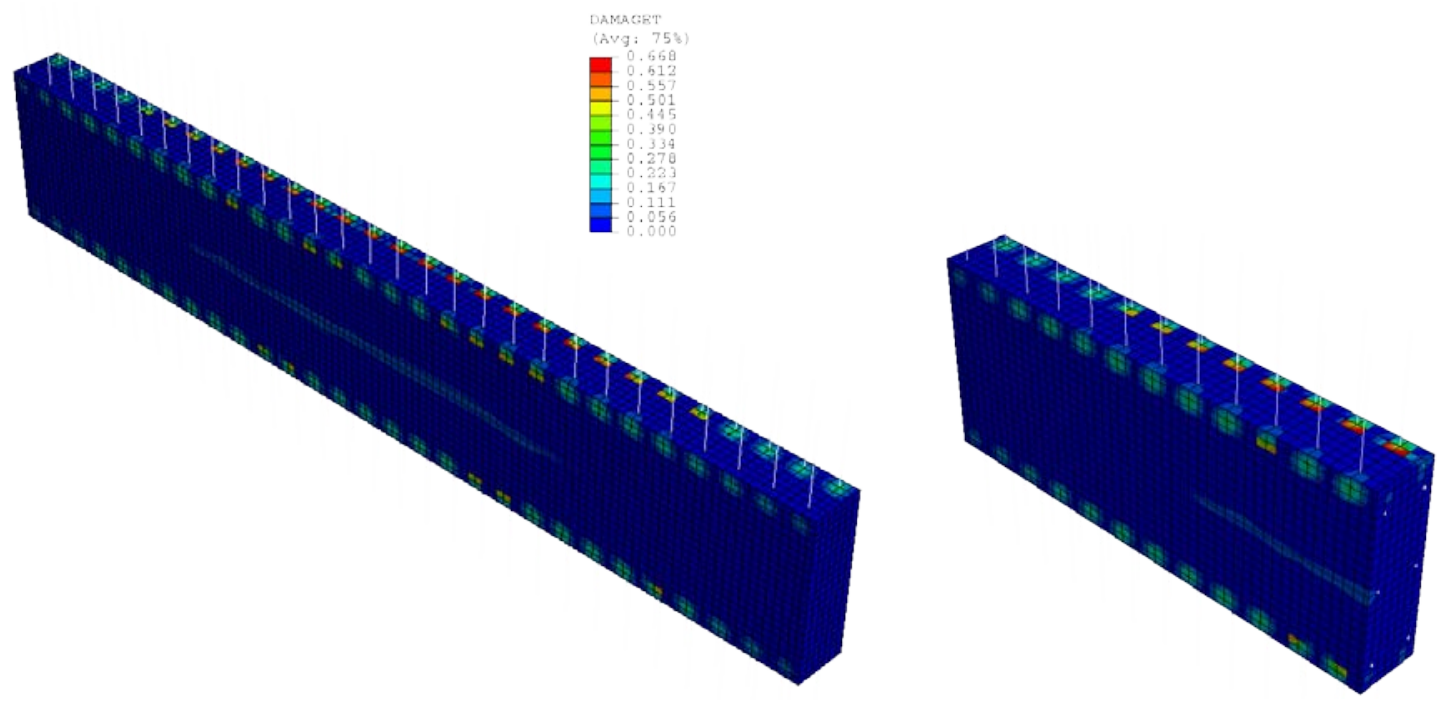

Entry dimension: $4 \mathrm{ft}$ x $24 \mathrm{ft}$, Seal thickness 16 in.
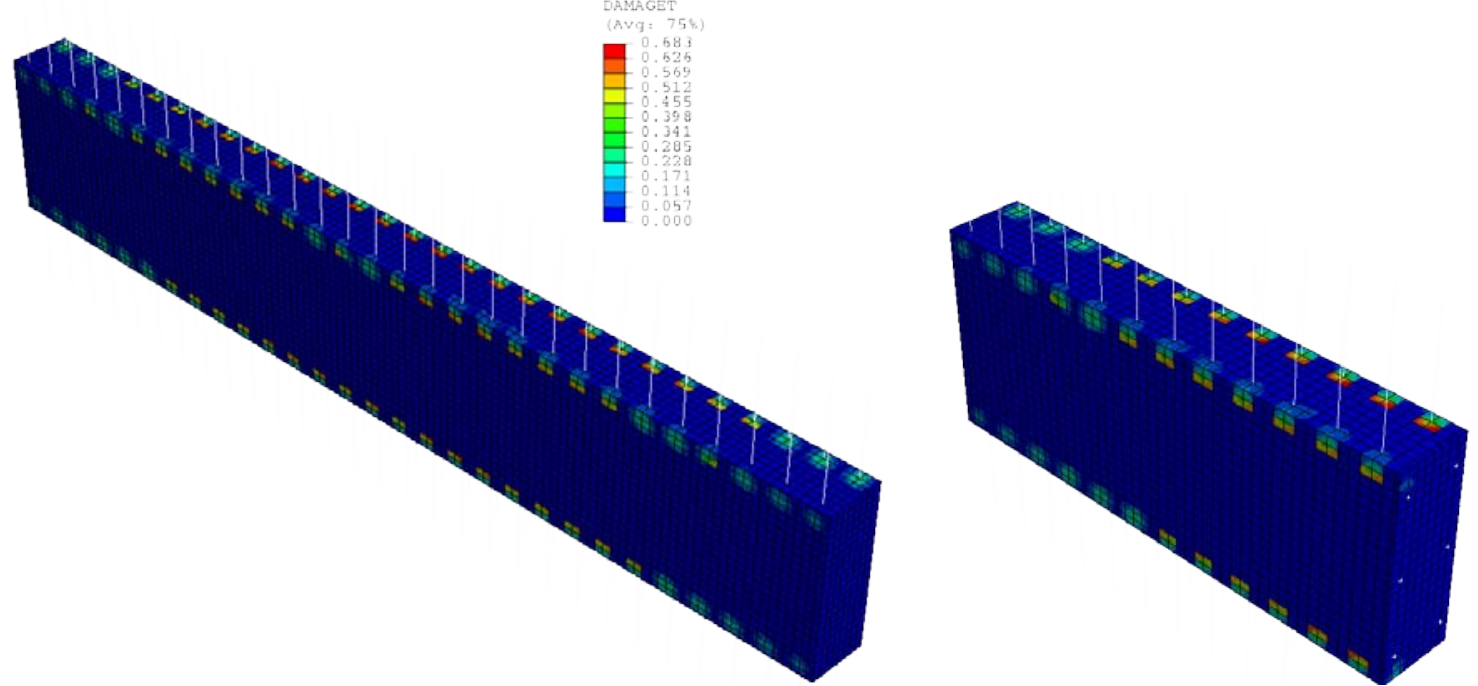

Entry dimension: $4 \mathrm{ft}$ x $24 \mathrm{ft}$, Seal thickness 18 in.

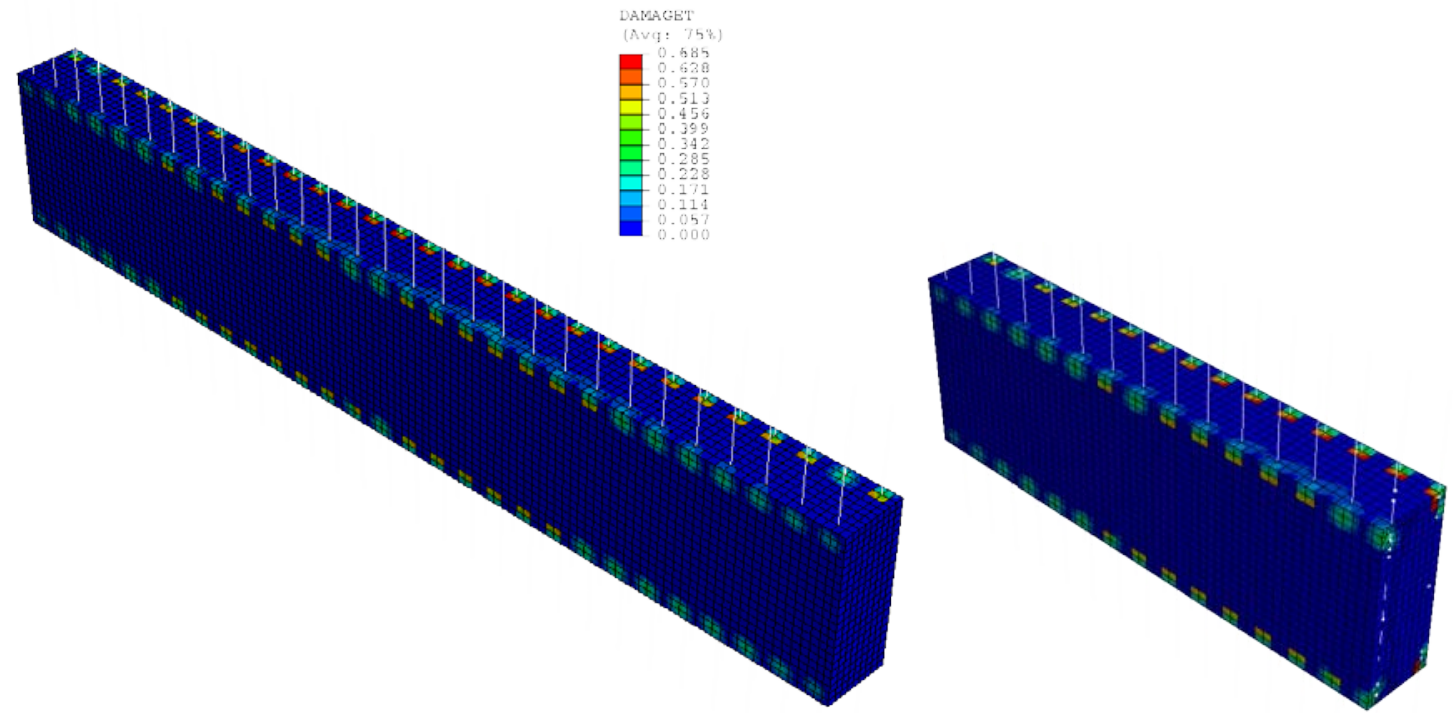

Entry dimension: $4 \mathrm{ft}$ x $24 \mathrm{ft}$, Seal thickness 20 in. 


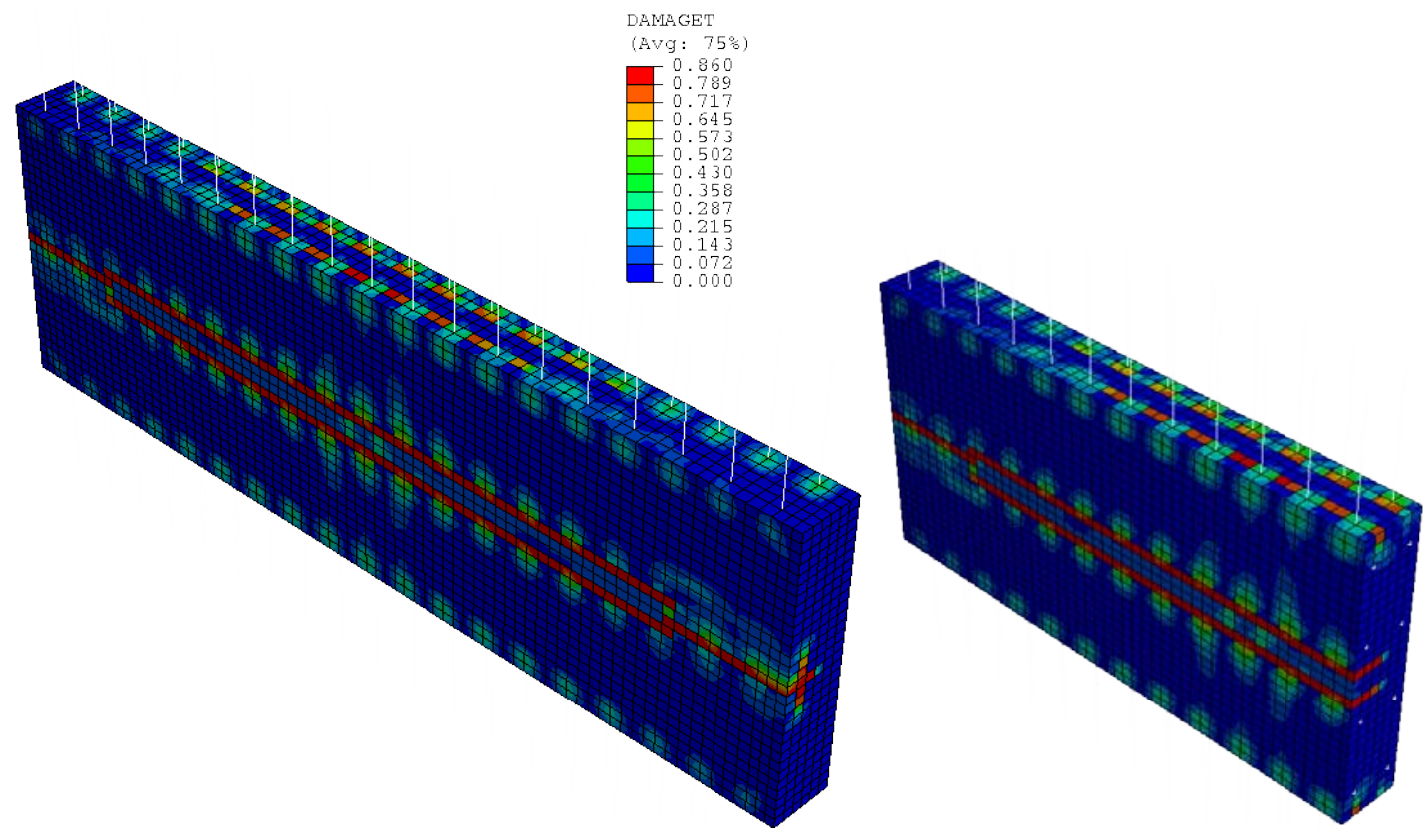

Entry dimension: $5 \mathrm{ft}$ x $16 \mathrm{ft}$, Seal thickness 14 in.
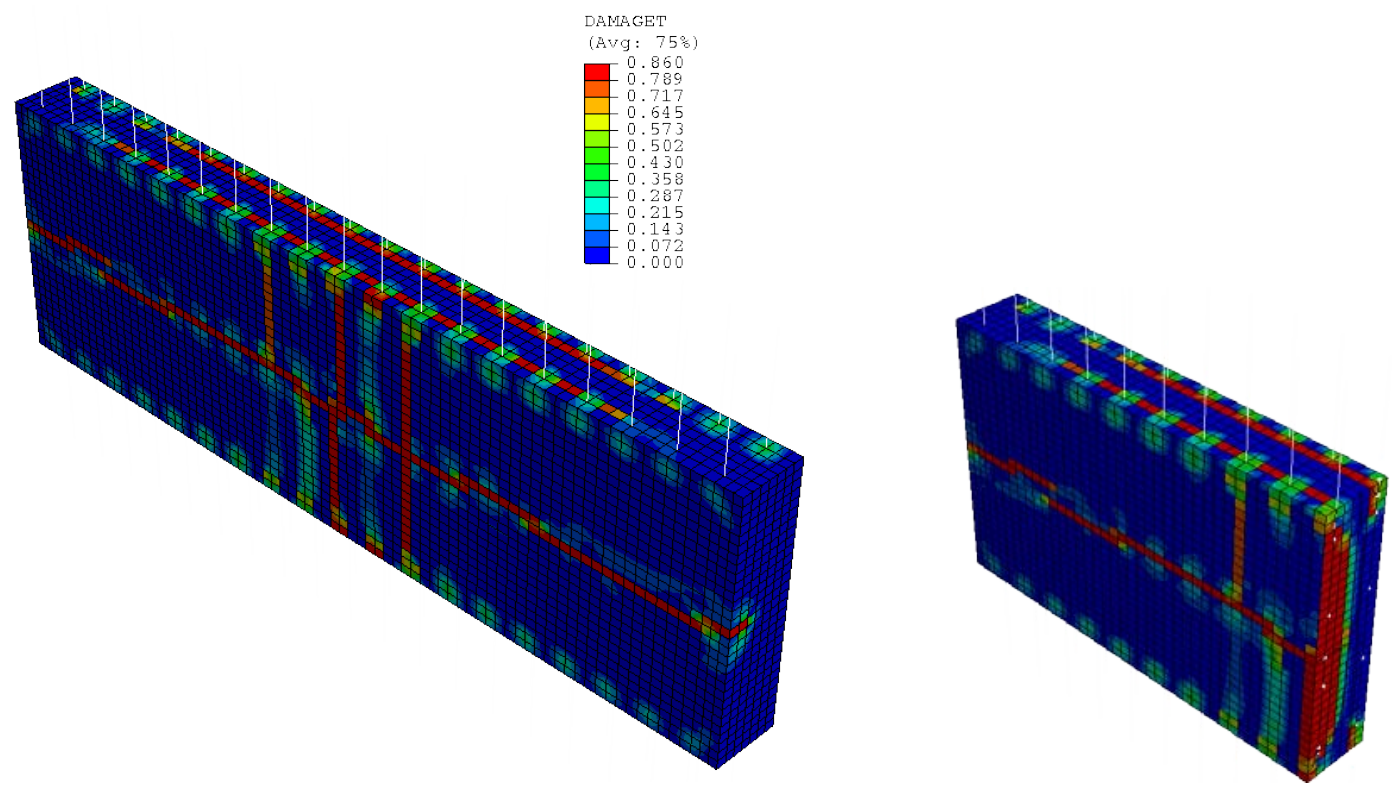

Entry dimension: $5 \mathrm{ft}$ x $16 \mathrm{ft}$, Seal thickness 16 in. 

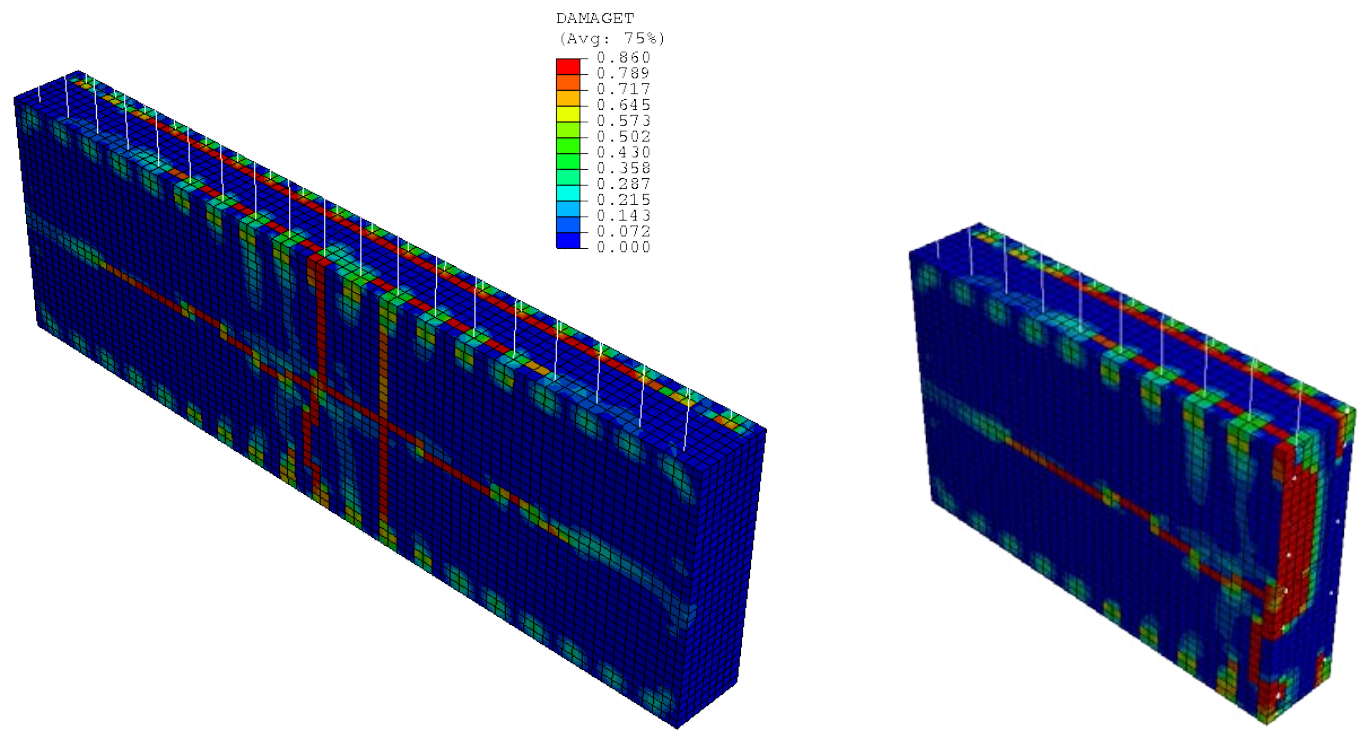

Entry dimension: $5 \mathrm{ft}$ x $16 \mathrm{ft}$, Seal thickness 18 in.
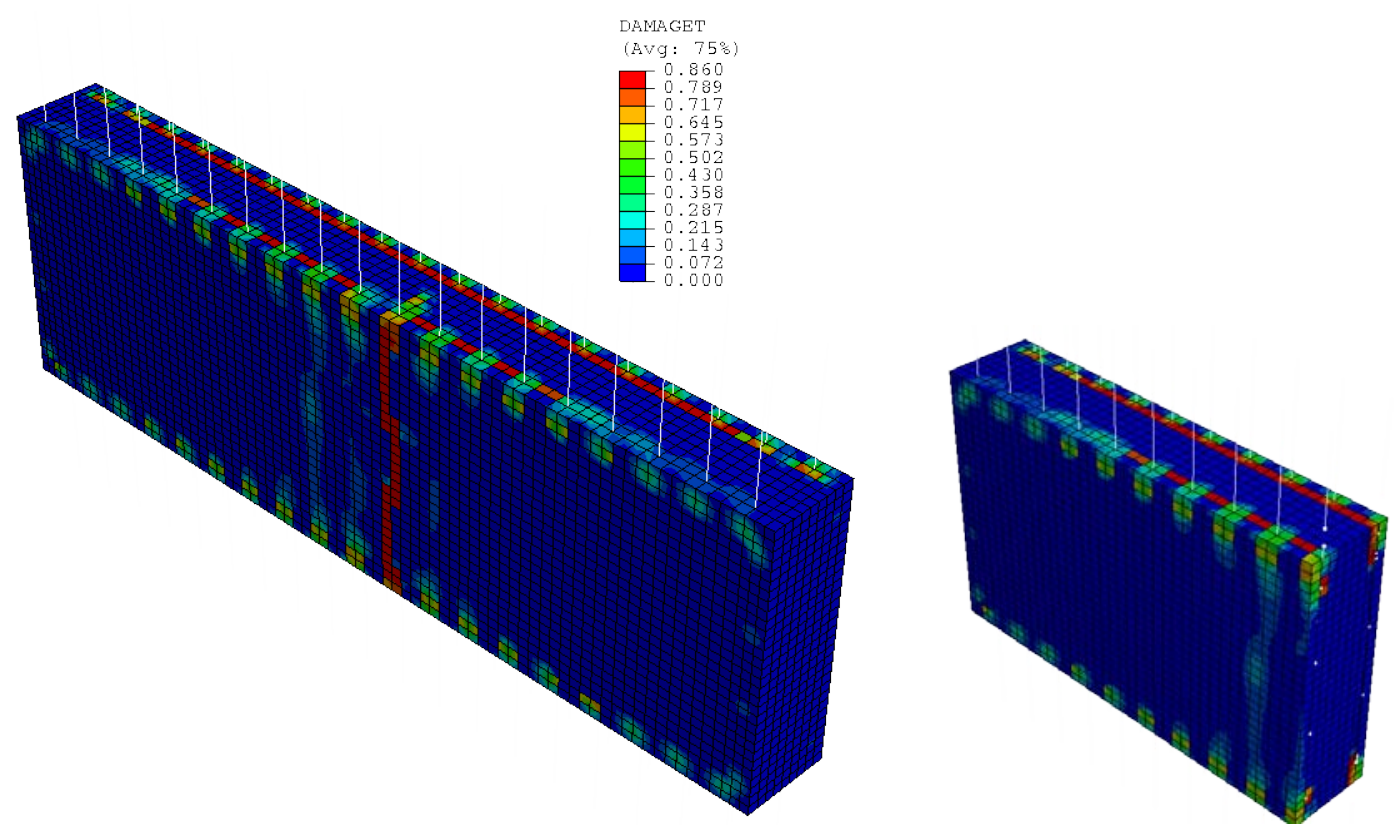

Entry dimension: $5 \mathrm{ft}$ x $16 \mathrm{ft}$, Seal thickness 20 in. 


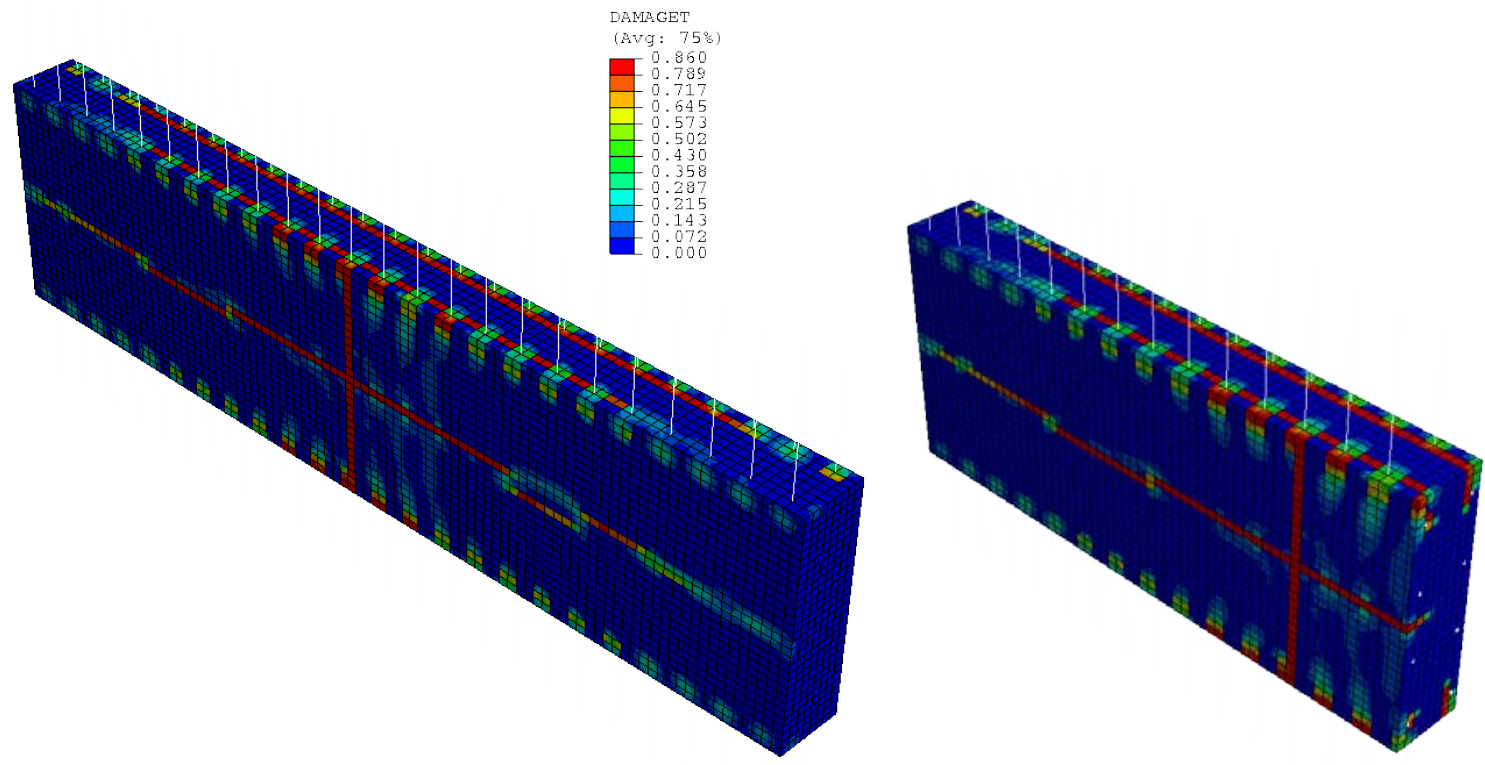

Entry dimension: $5 \mathrm{ft}$ x $20 \mathrm{ft}$, Seal thickness 18 in.

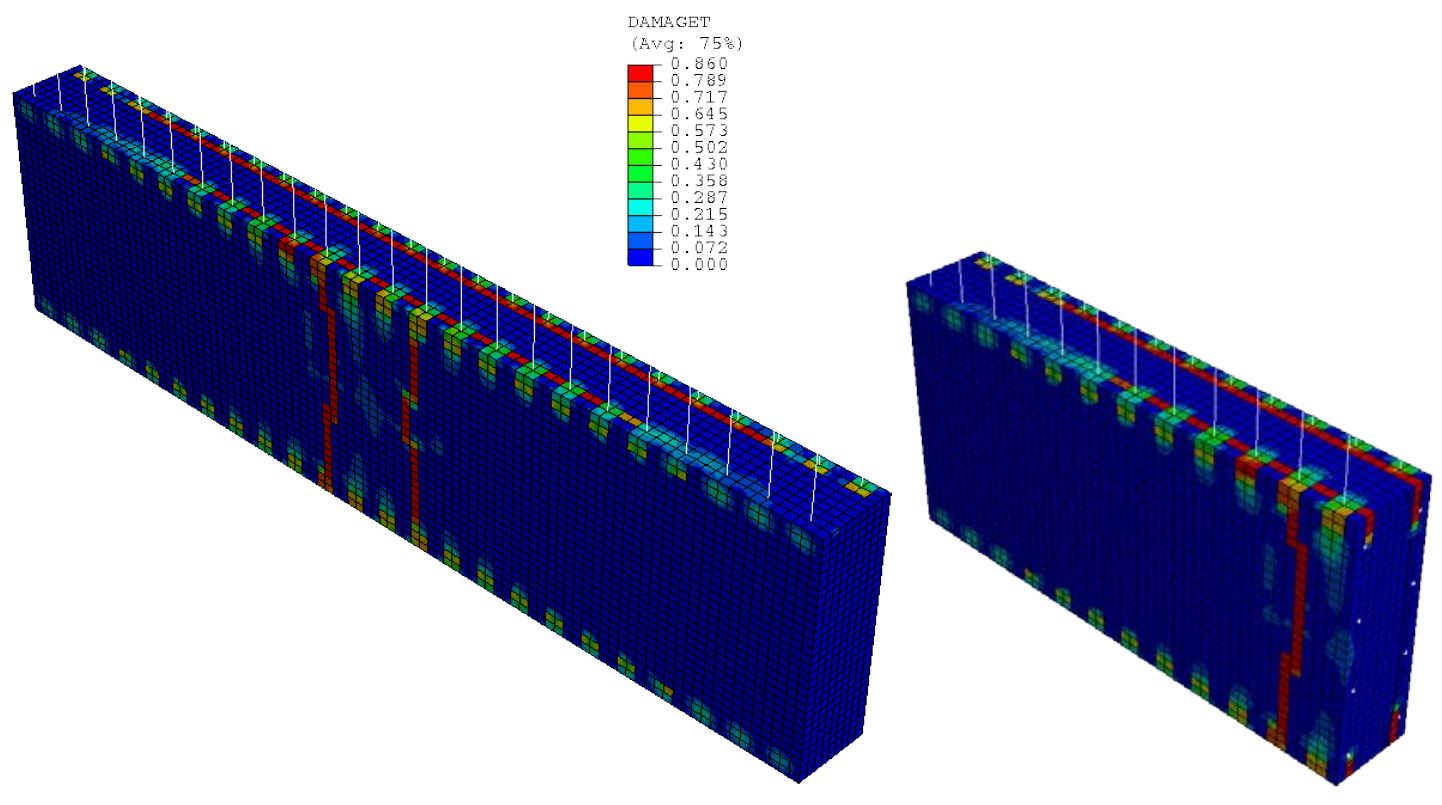

Entry dimension: $5 \mathrm{ft}$ x $20 \mathrm{ft}$, Seal thickness 20 in. 


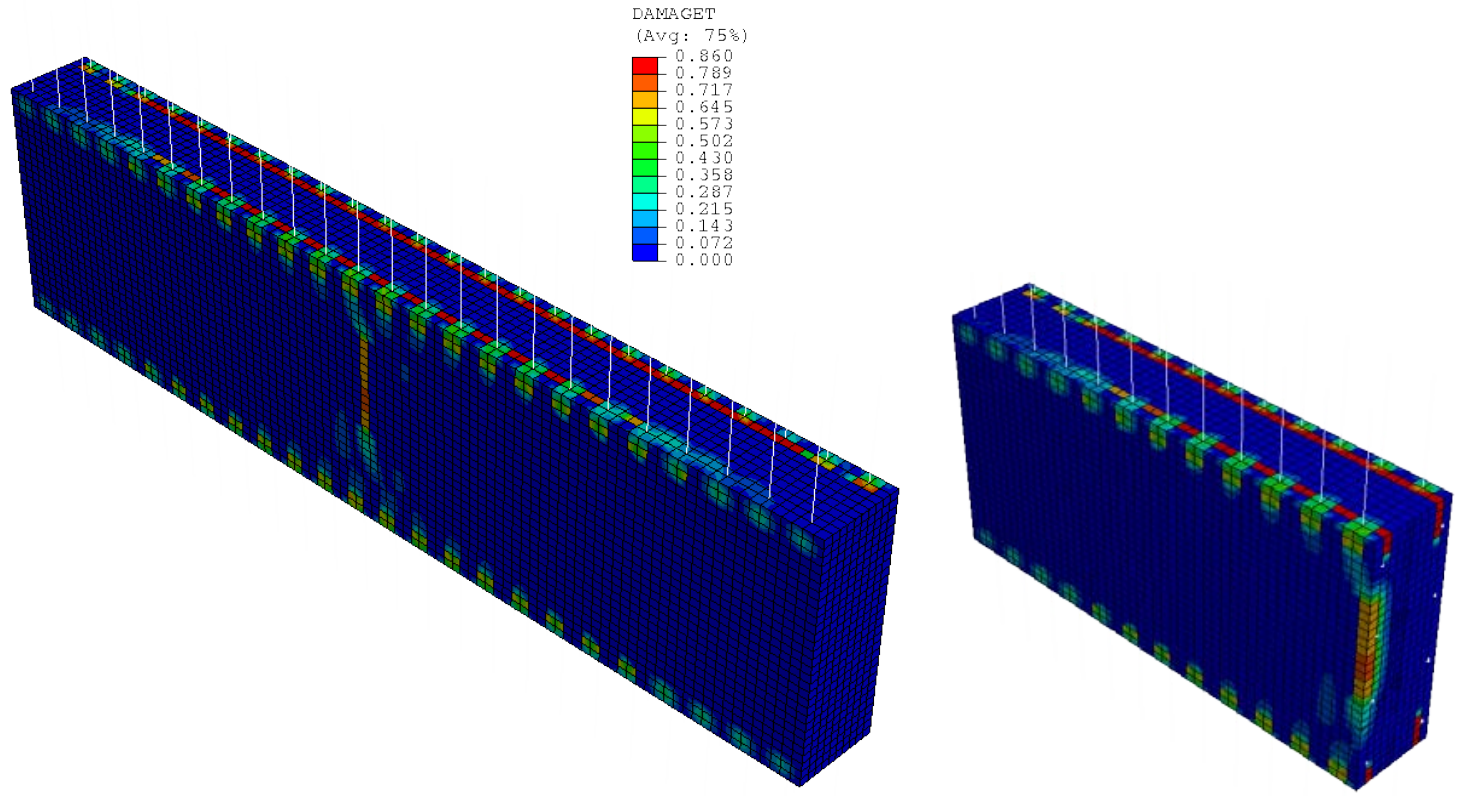

Entry dimension: $5 \mathrm{ft}$ x $20 \mathrm{ft}$, Seal thickness 22 in.
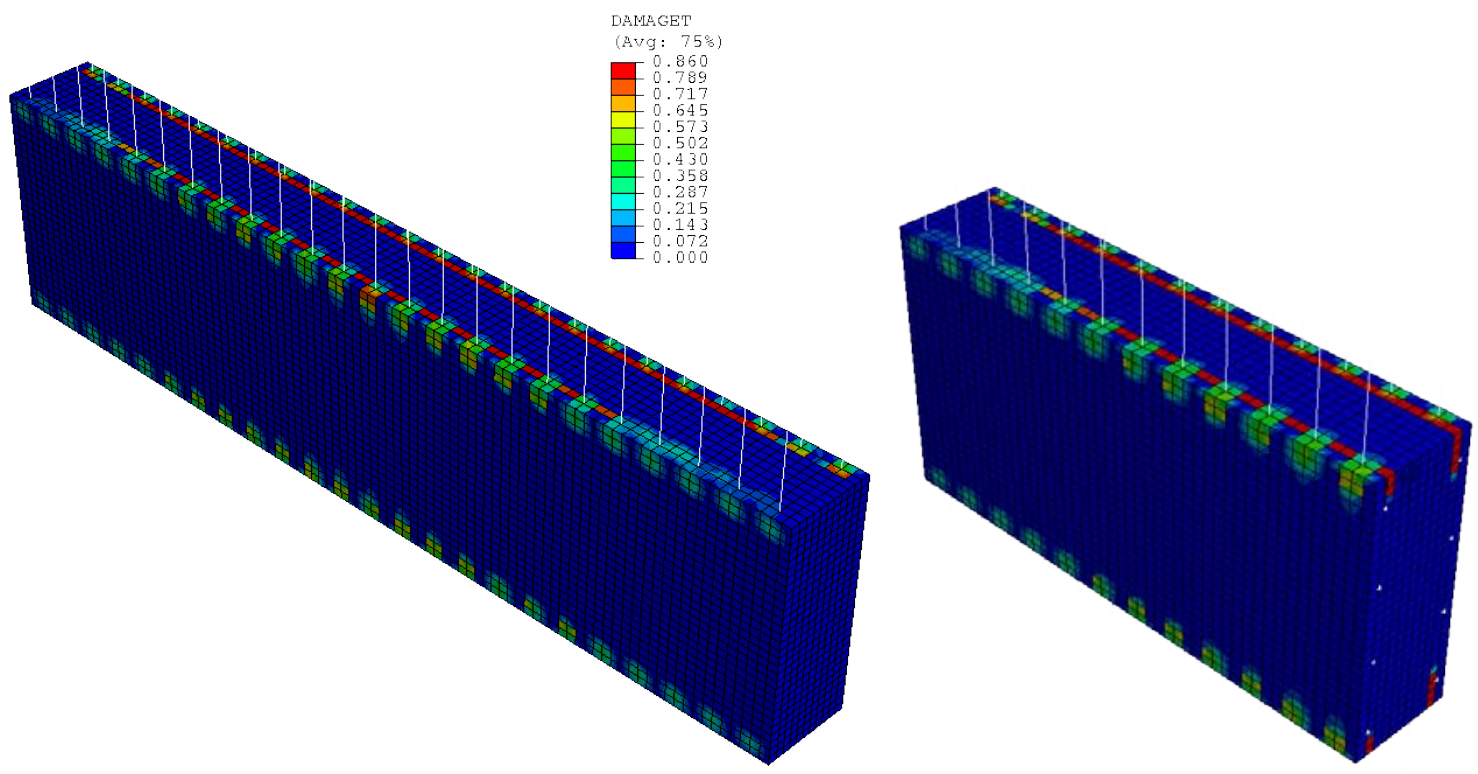

Entry dimension: $5 \mathrm{ft}$ x $20 \mathrm{ft}$, Seal thickness 24 in. 


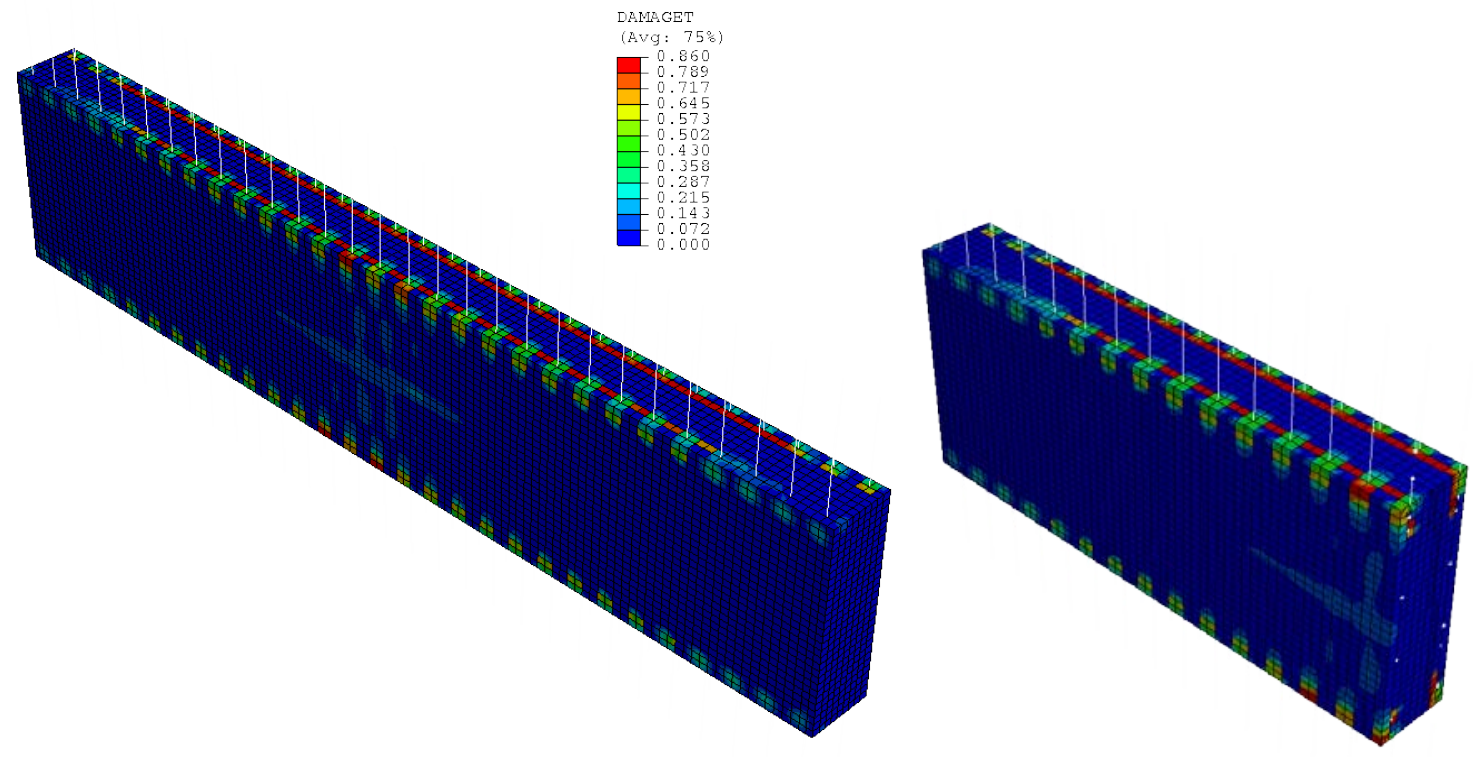

Entry dimension: $5 \mathrm{ft}$ x $24 \mathrm{ft}$, Seal thickness 20 in.

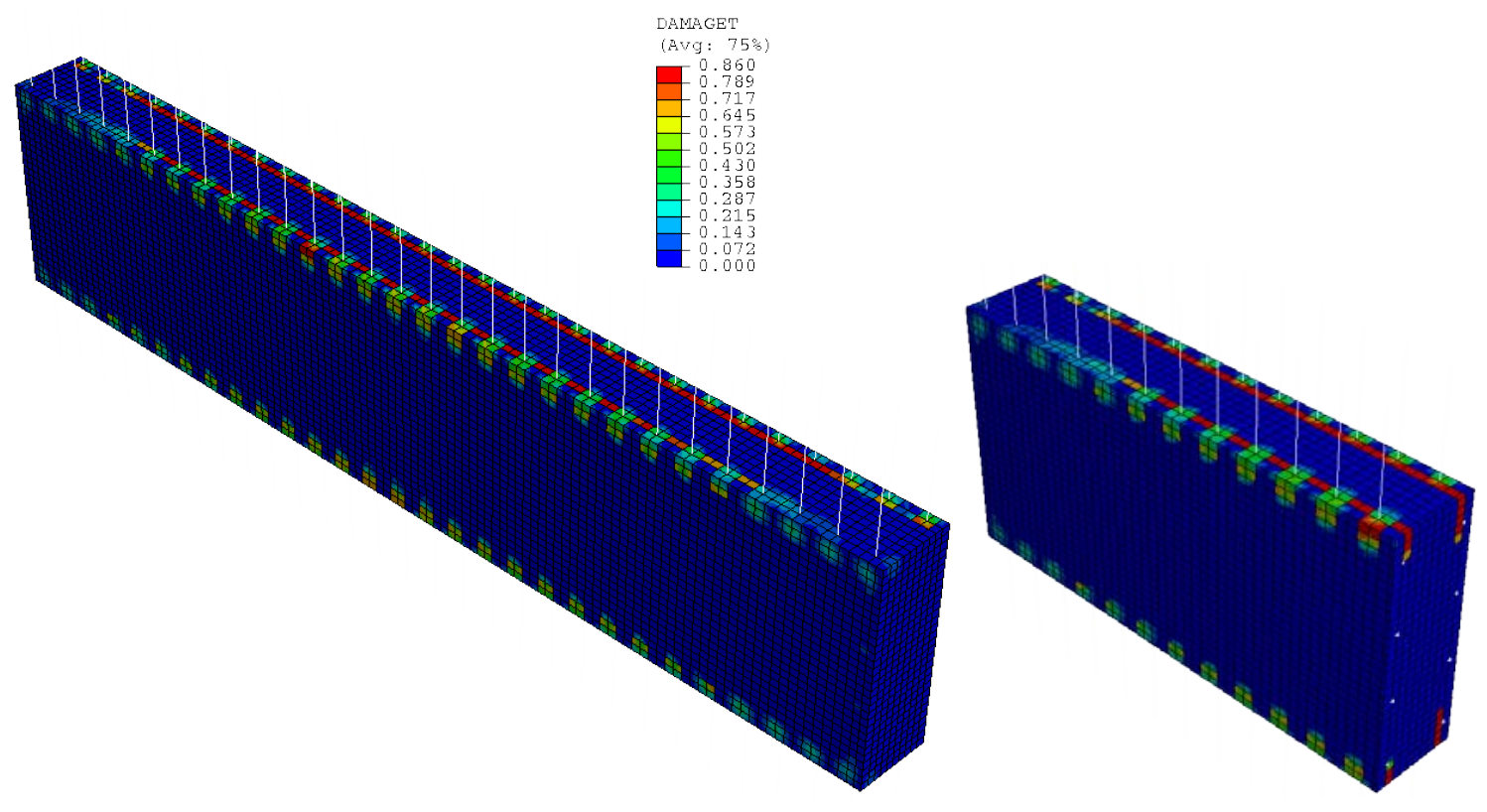

Entry dimension: $5 \mathrm{ft}$ x $24 \mathrm{ft}$, Seal thickness 22 in. 


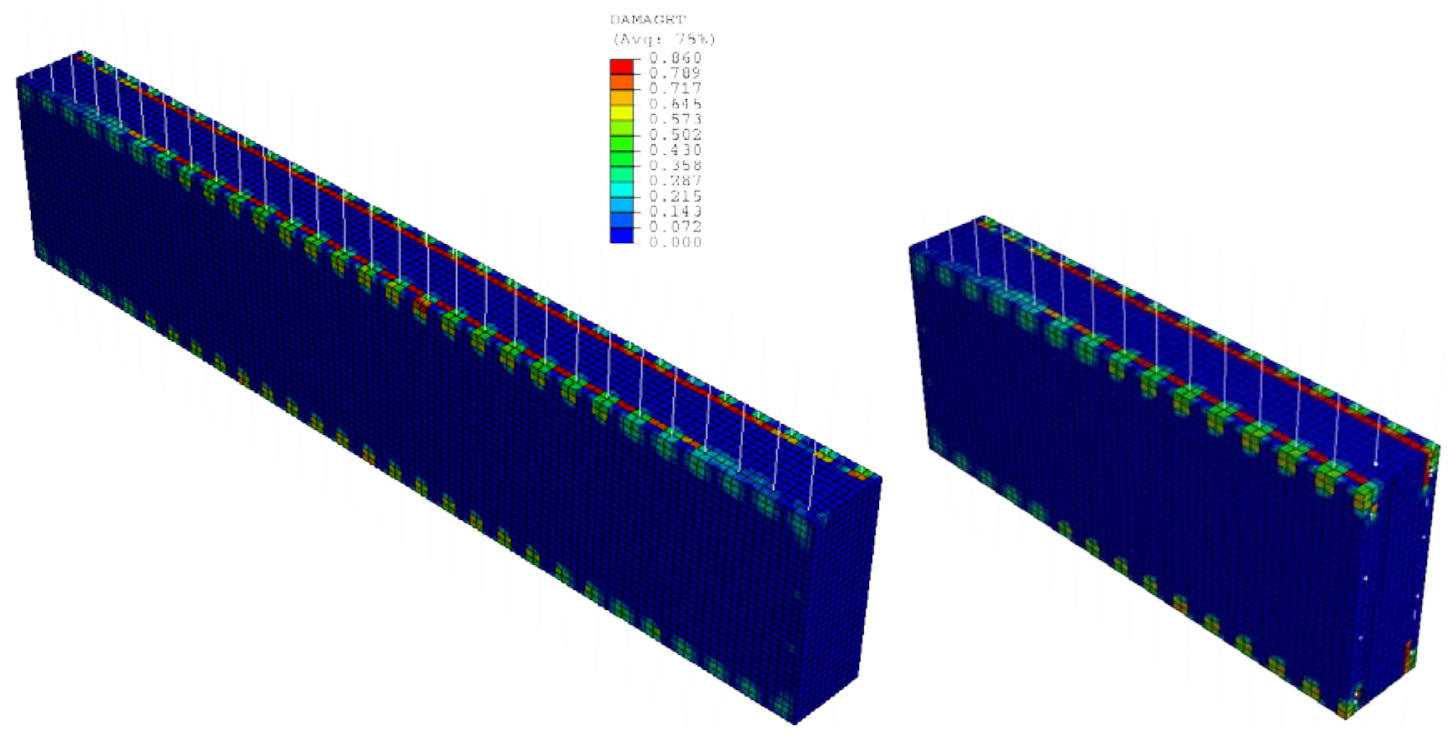

Entry dimension: $5 \mathrm{ft}$ x $24 \mathrm{ft}$, Seal thickness 24 in.
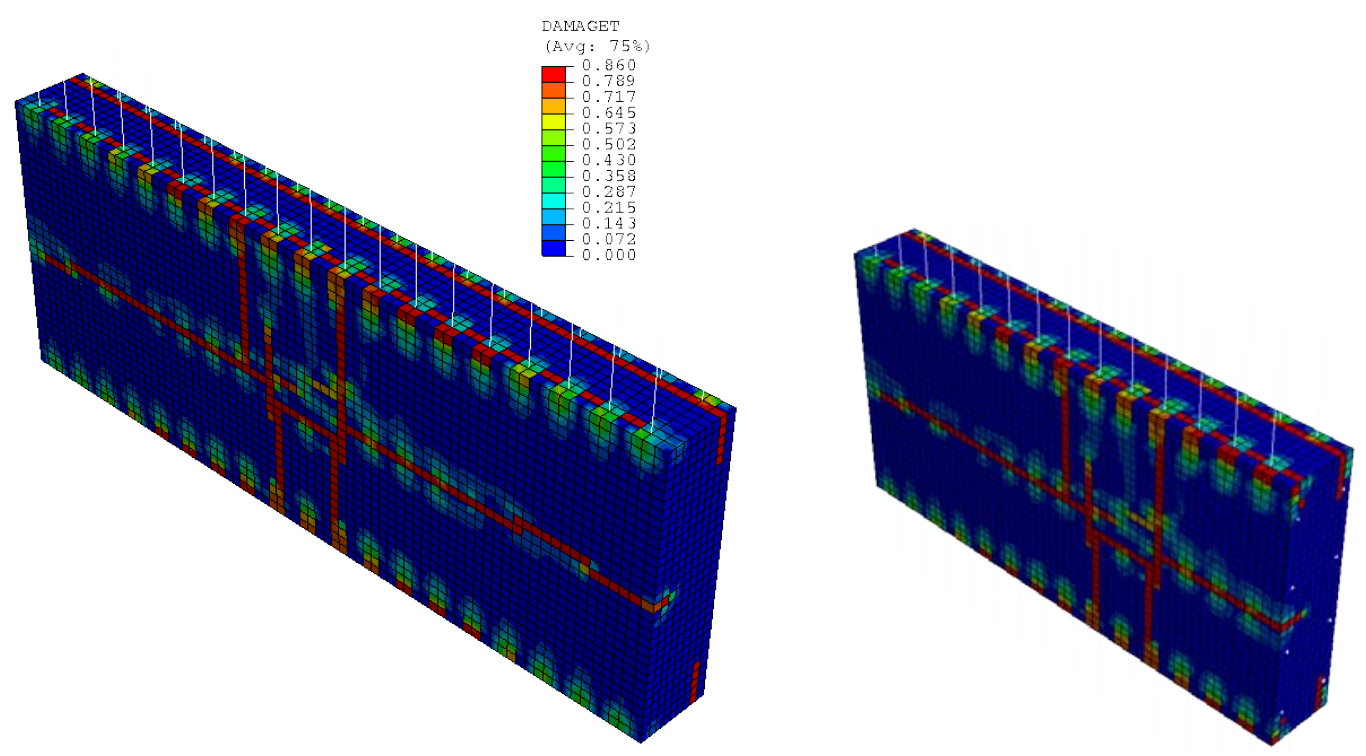

Entry dimension: $6 \mathrm{ft}$ x $16 \mathrm{ft}$, Seal thickness 20 in. 

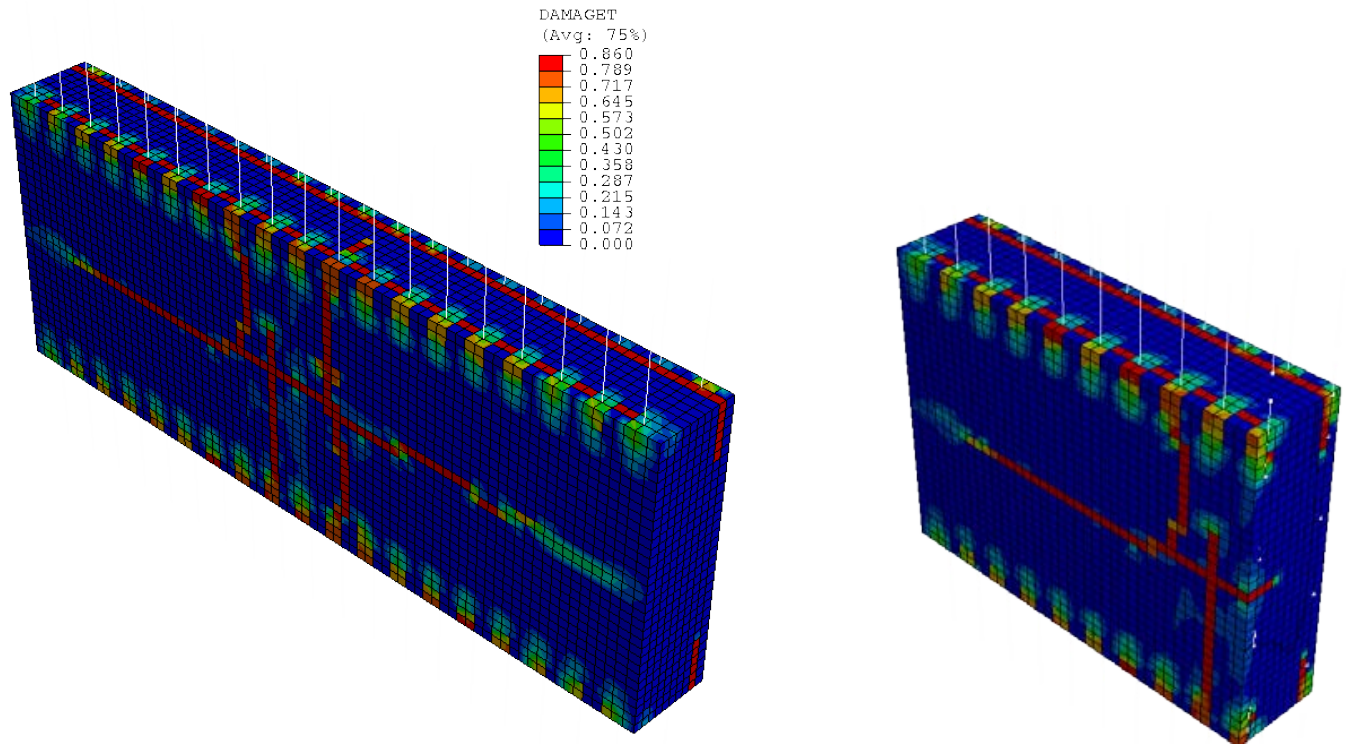

Entry dimension: $6 \mathrm{ft}$ x $16 \mathrm{ft}$, Seal thickness 22 in.
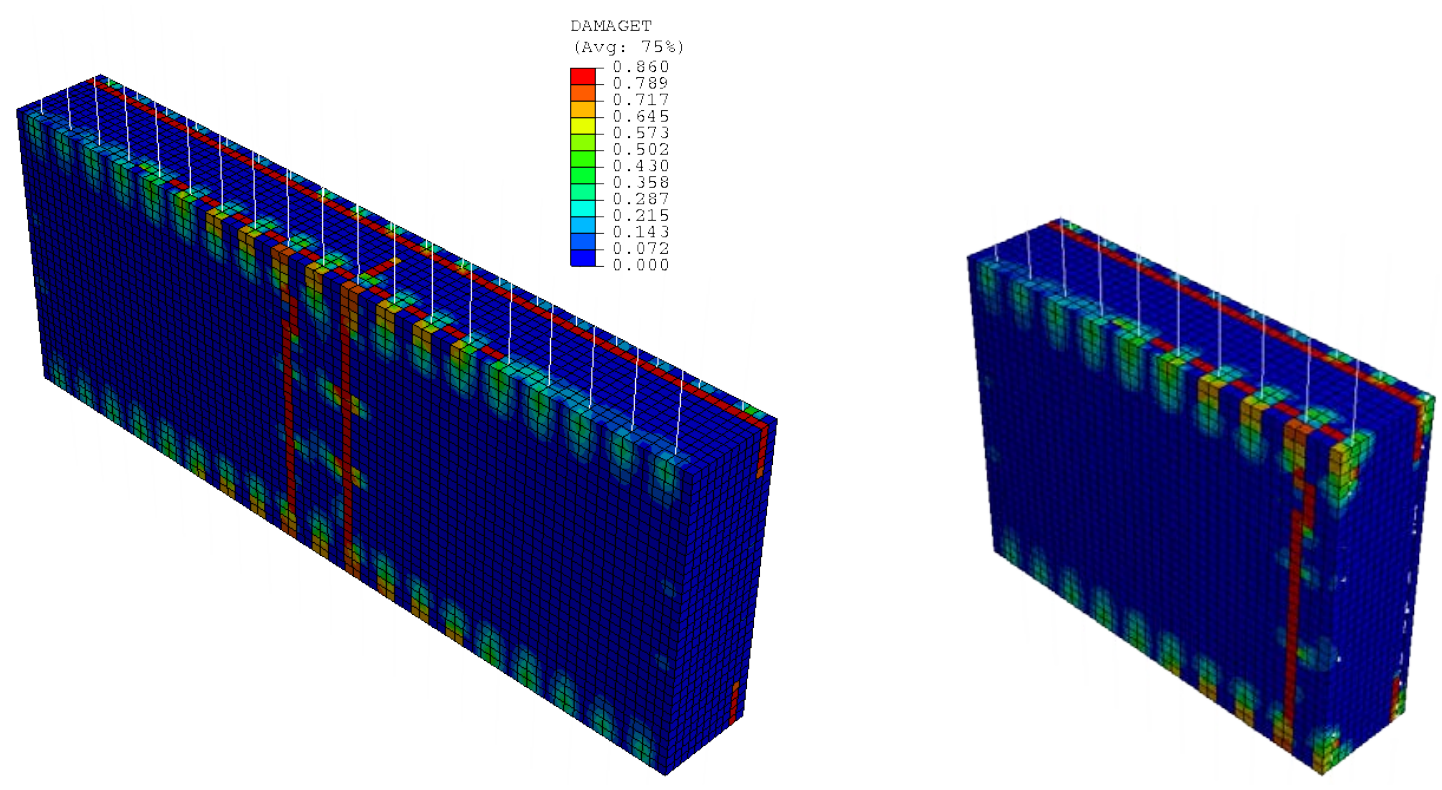

Entry dimension: $6 \mathrm{ft}$ x $16 \mathrm{ft}$, Seal thickness 24 in. 

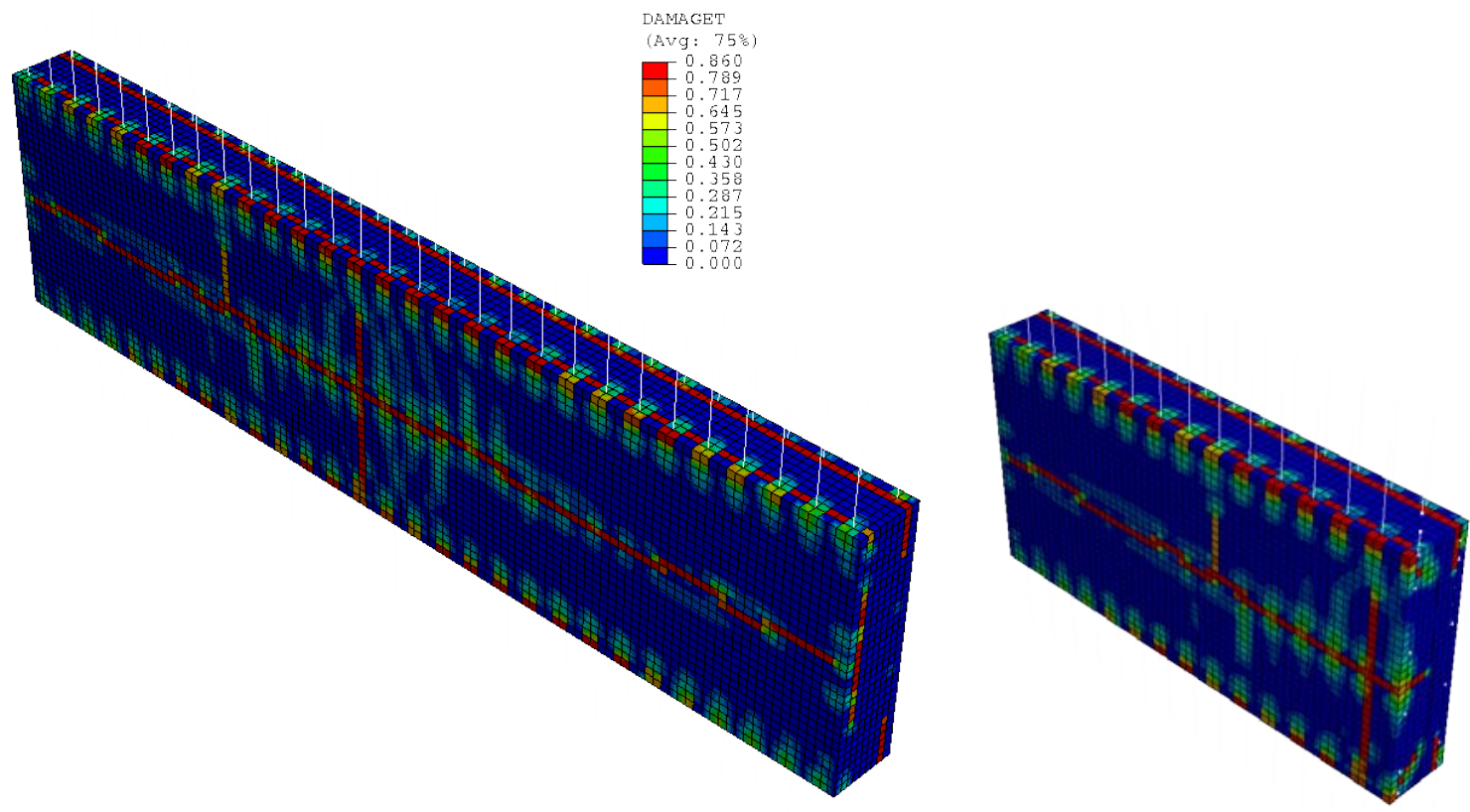

Entry dimension: $6 \mathrm{ft}$ x $24 \mathrm{ft}$, Seal thickness 20 in.

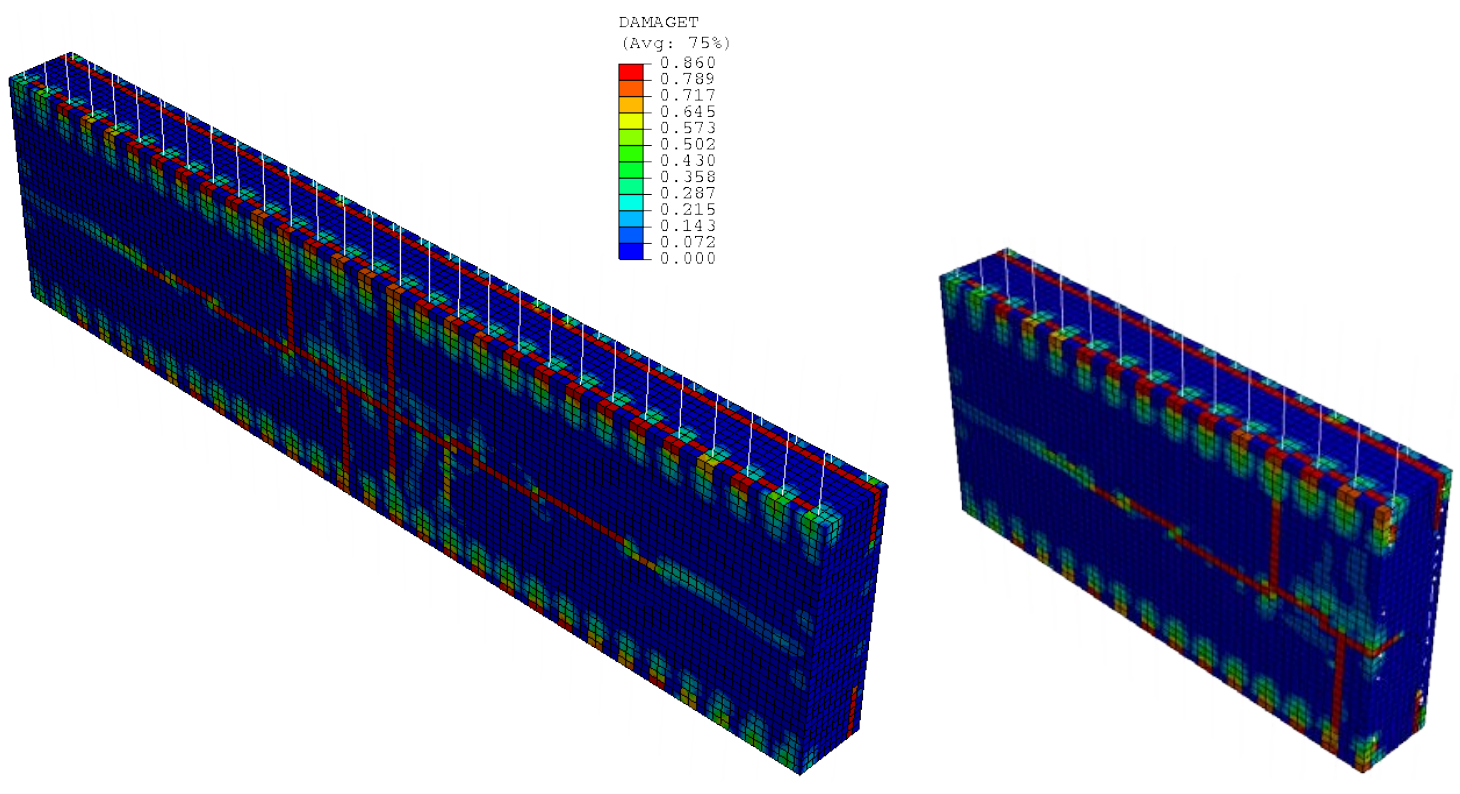

Entry dimension: $6 \mathrm{ft}$ x $24 \mathrm{ft}$, Seal thickness $22 \mathrm{in}$. 

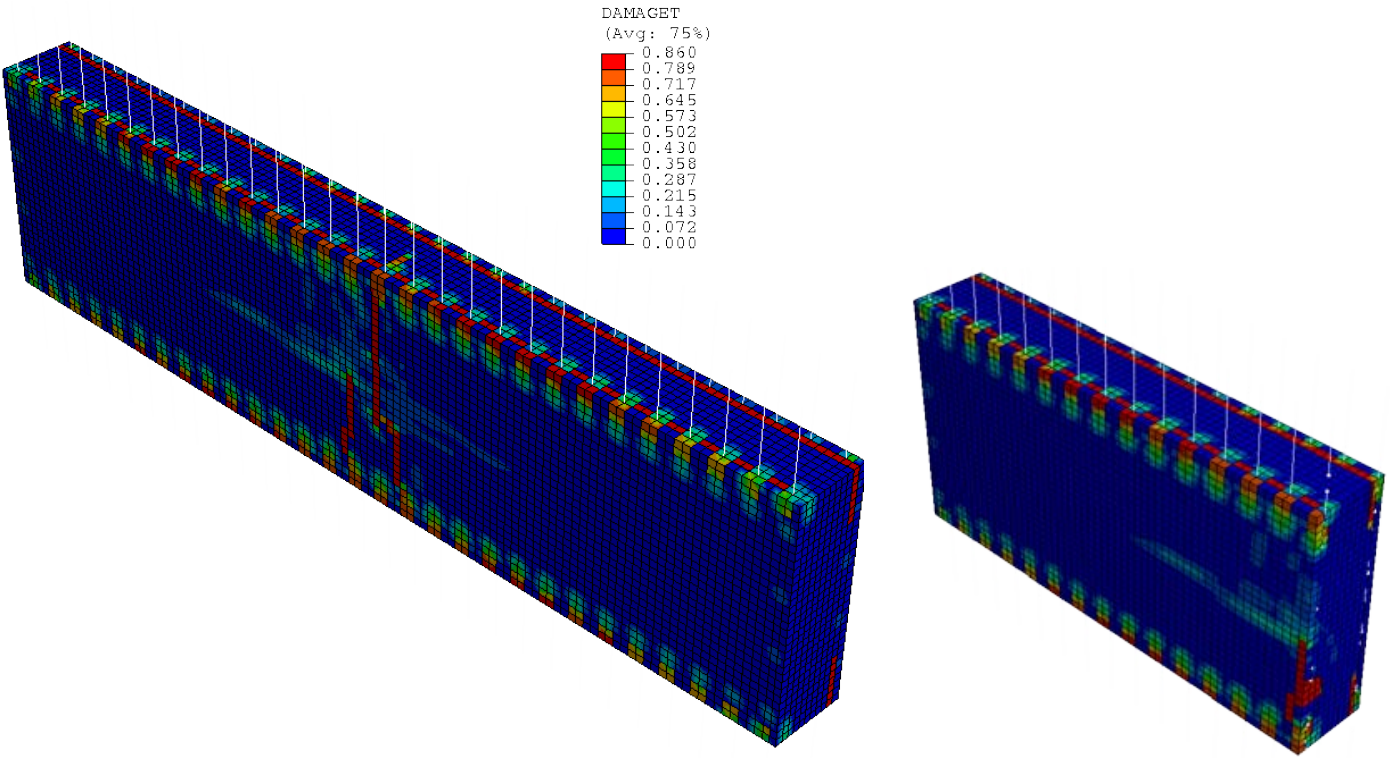

Entry dimension: $6 \mathrm{ft}$ x $24 \mathrm{ft}$, Seal thickness 24 in.
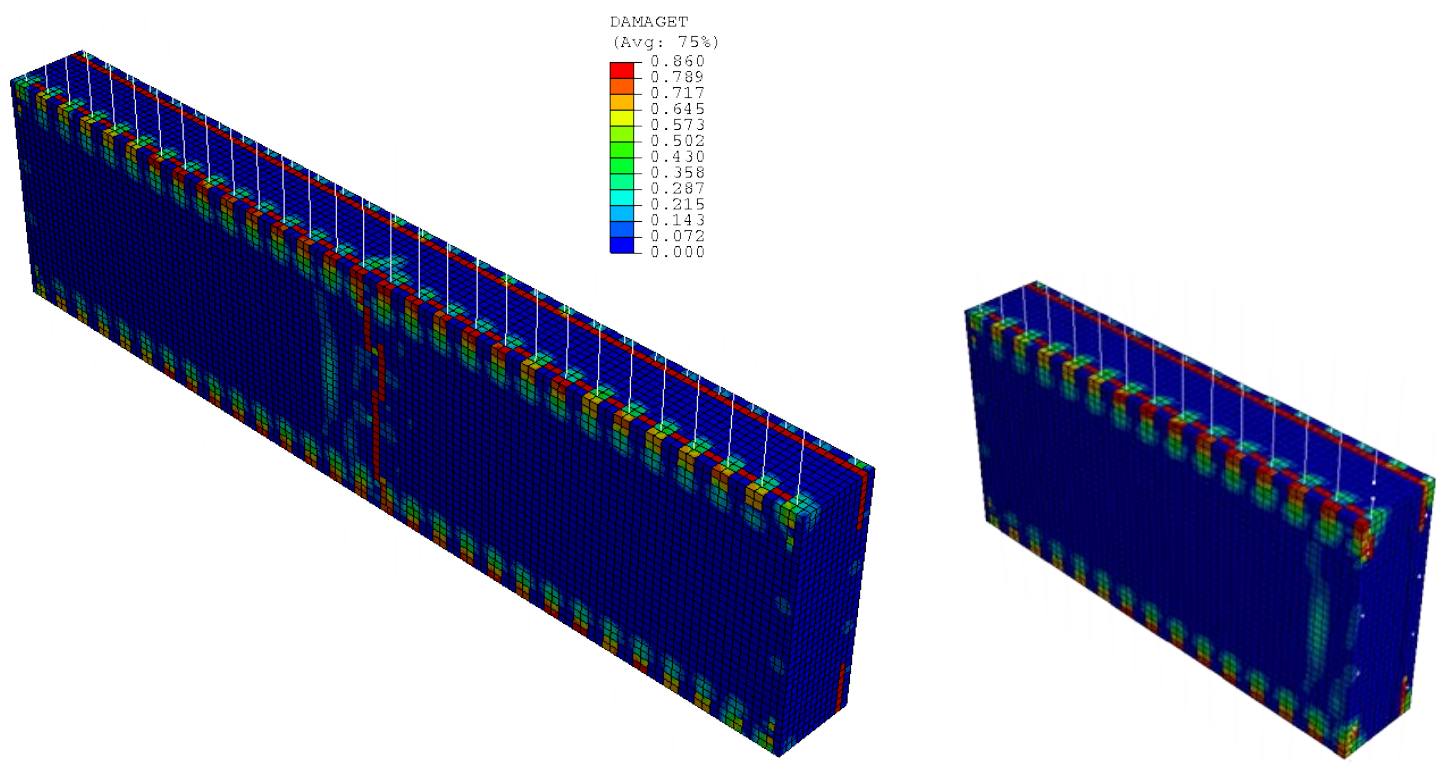

Entry dimension: $6 \mathrm{ft}$ x $24 \mathrm{ft}$, Seal thickness 26 in. 

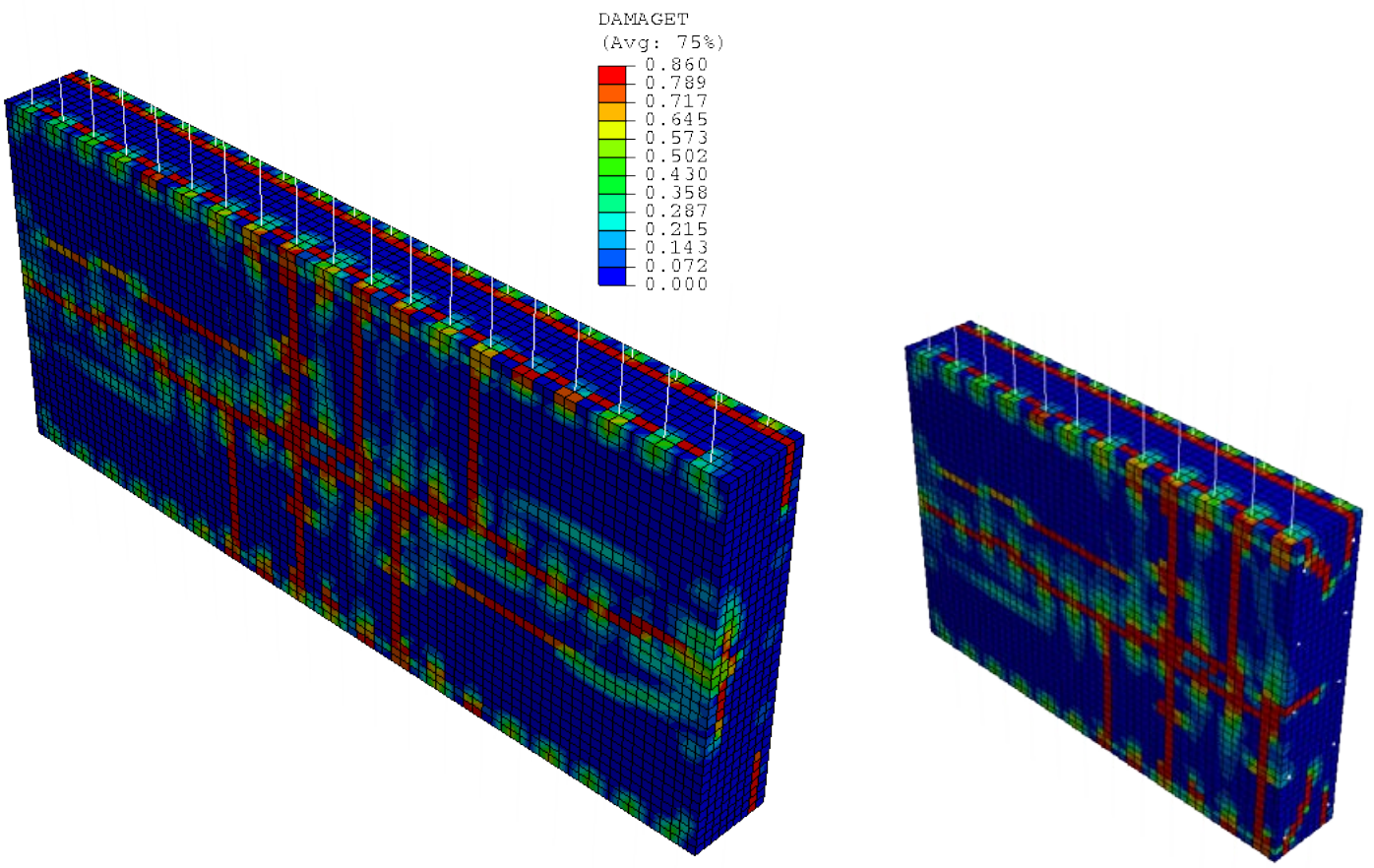

Entry dimension: $7 \mathrm{ft}$ x $16 \mathrm{ft}$, Seal thickness 20 in.
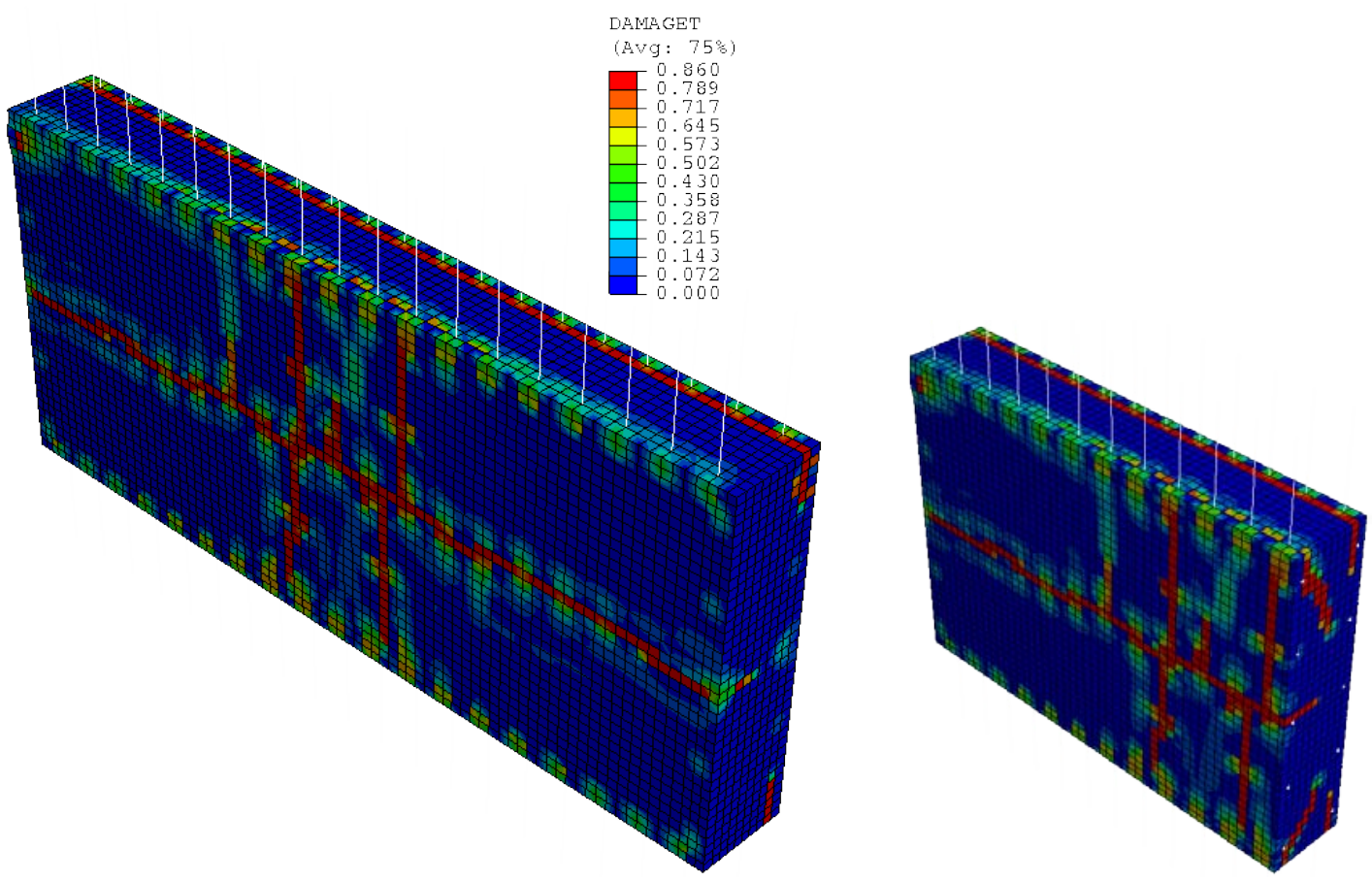

Entry dimension: $7 \mathrm{ft}$ x $16 \mathrm{ft}$, Seal thickness 22 in. 


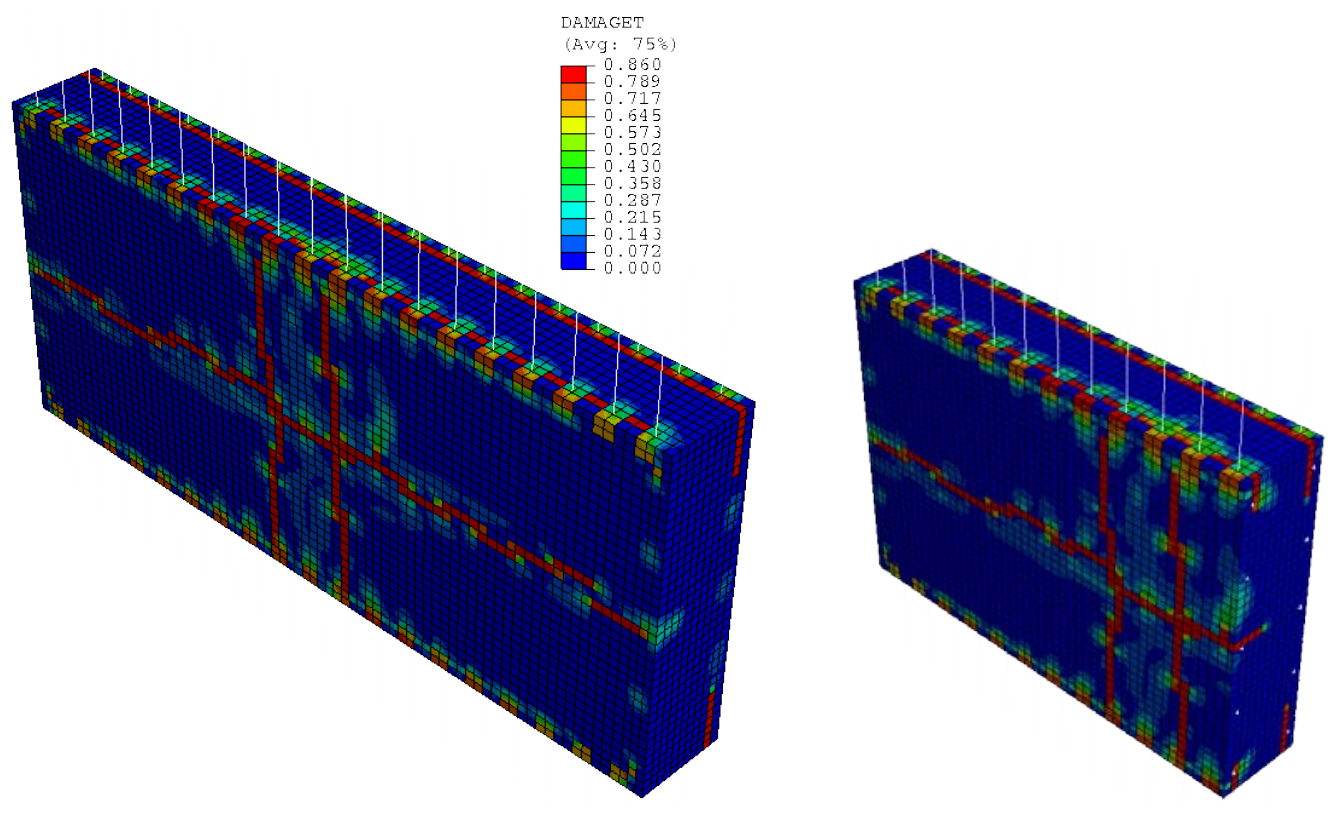

Entry dimension: $7 \mathrm{ft}$ x $16 \mathrm{ft}$, Seal thickness 24 in.
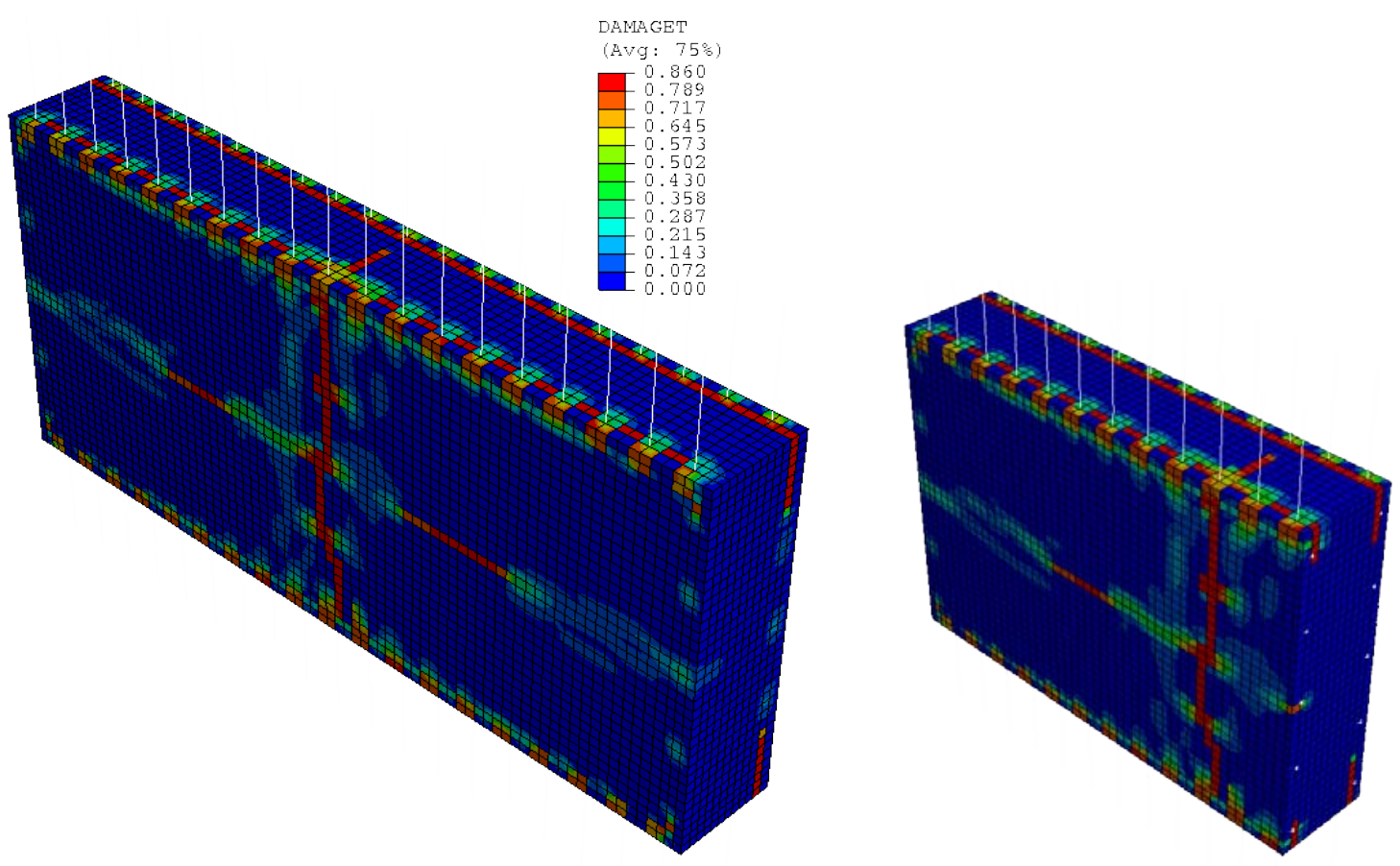

Entry dimension: $7 \mathrm{ft}$ x $16 \mathrm{ft}$, Seal thickness 26 in. 


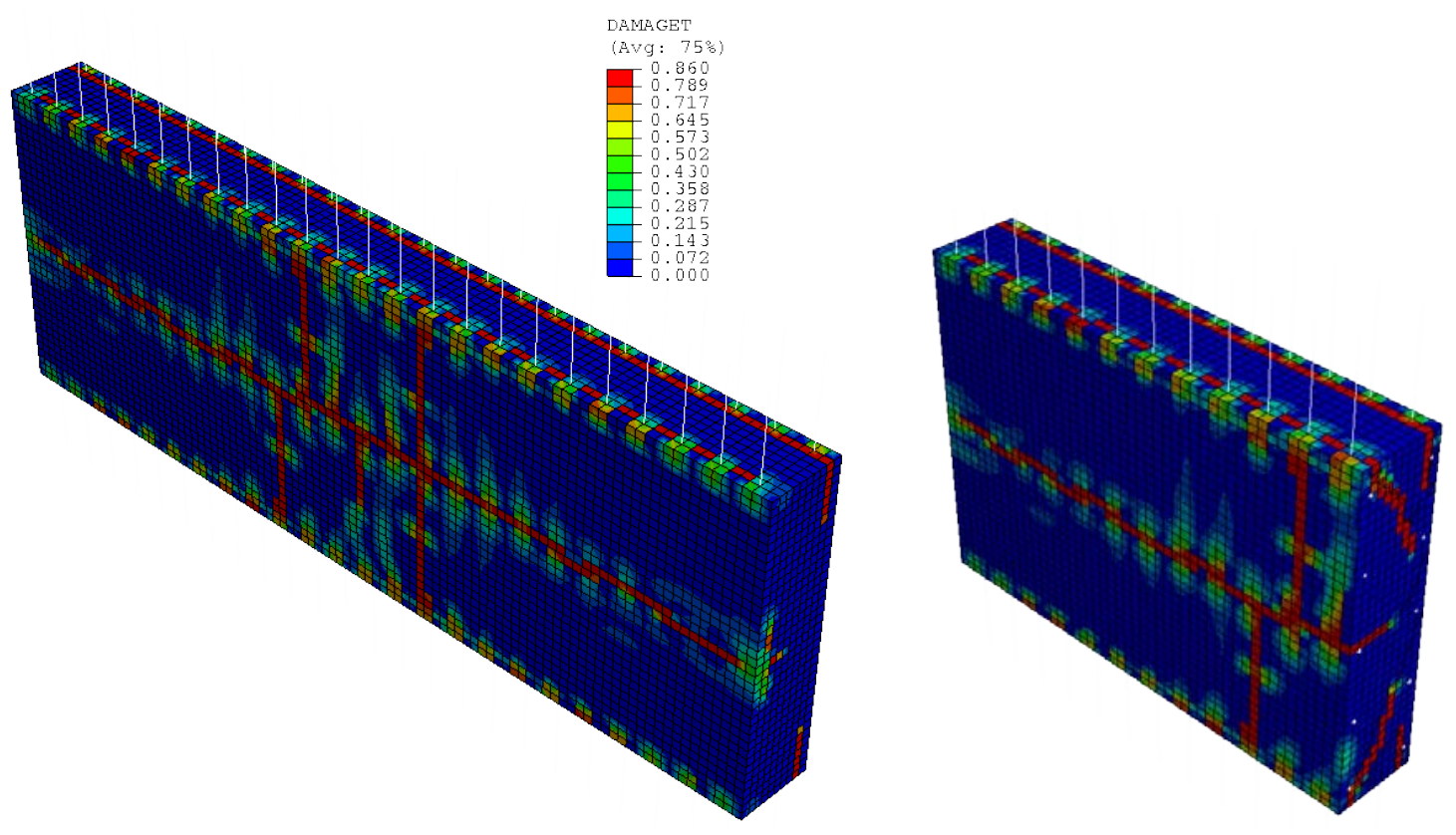

Entry dimension: $7 \mathrm{ft}$ x $20 \mathrm{ft}$, Seal thickness 22 in.
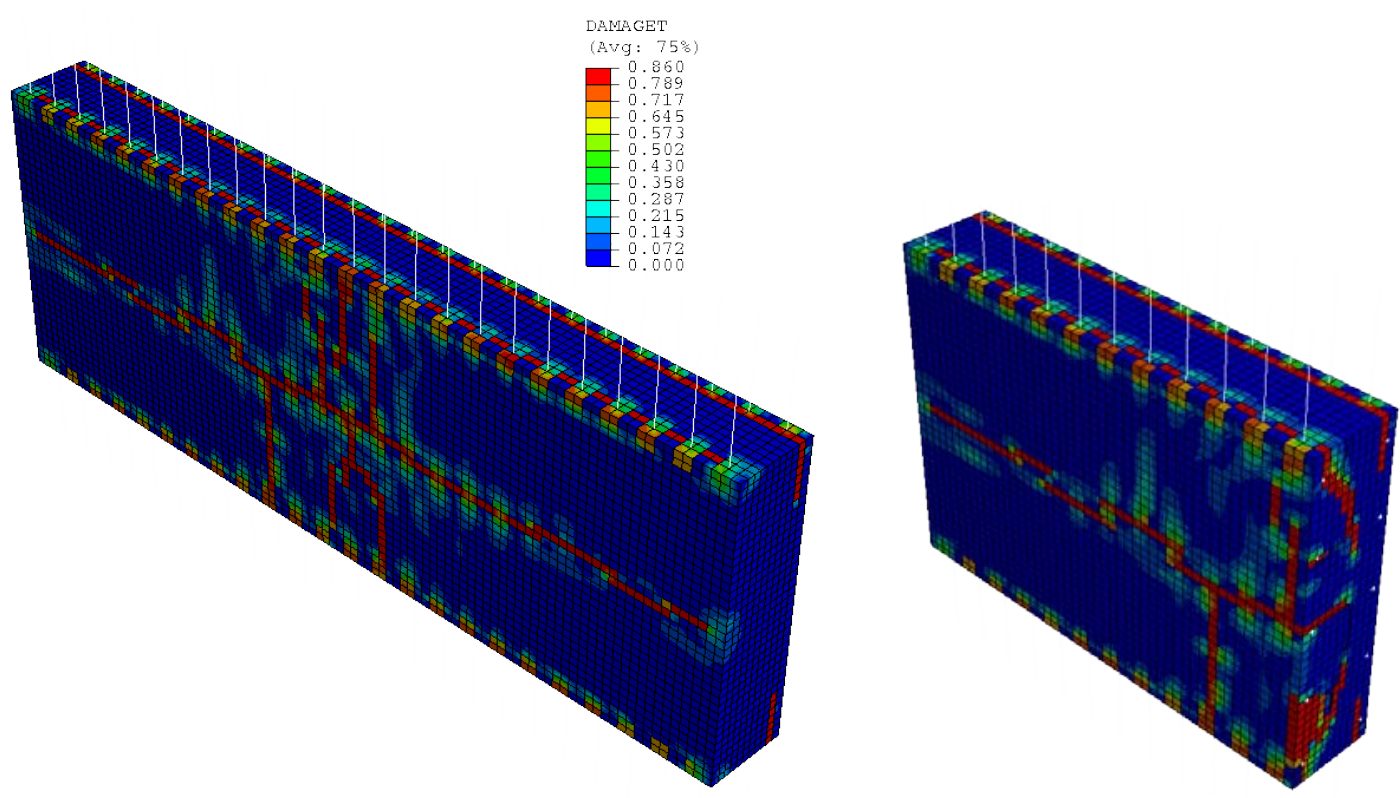

Entry dimension: $7 \mathrm{ft}$ x $20 \mathrm{ft}$, Seal thickness 24 in. 

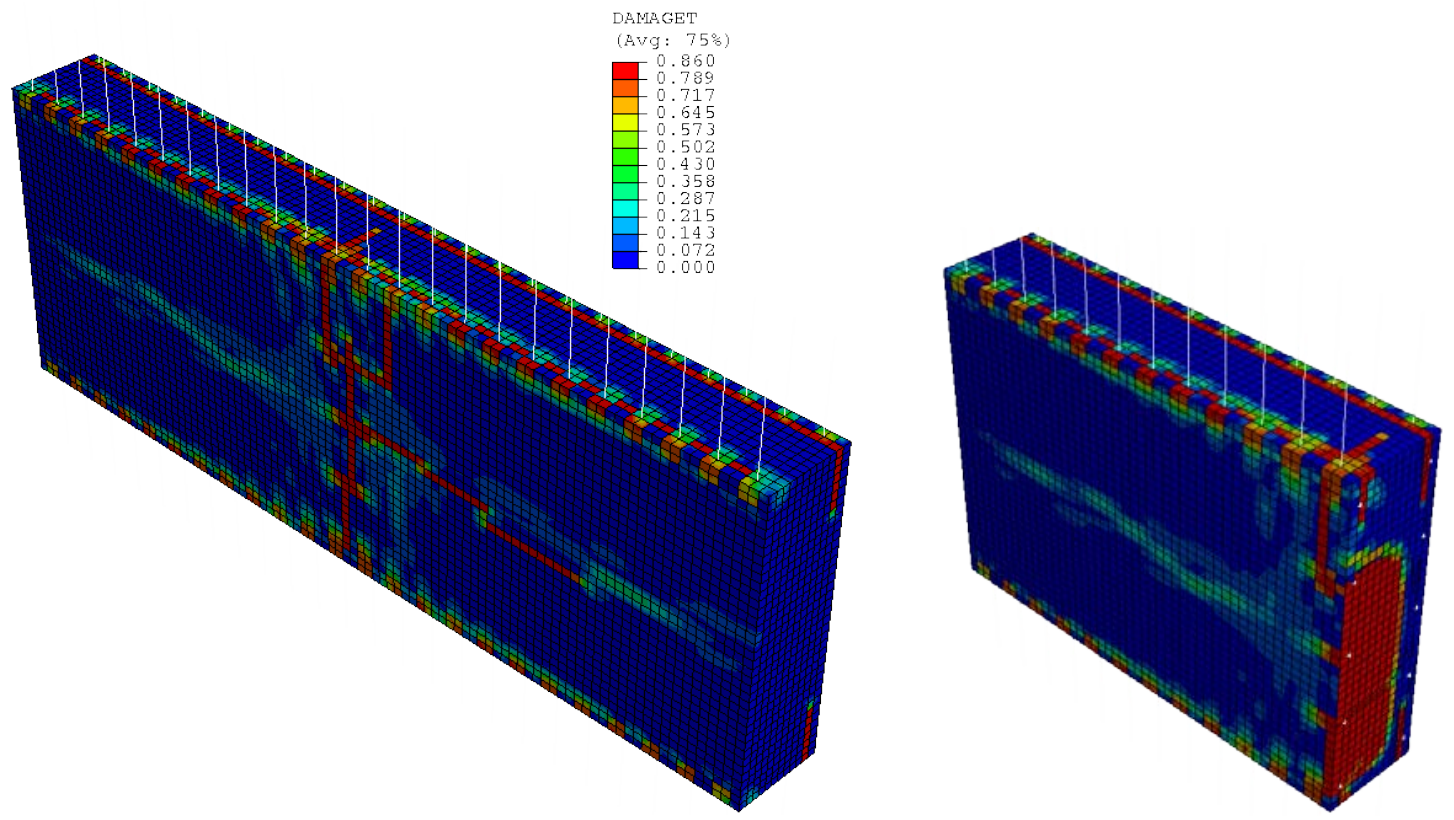

Entry dimension: $7 \mathrm{ft}$ x $20 \mathrm{ft}$, Seal thickness 26 in.
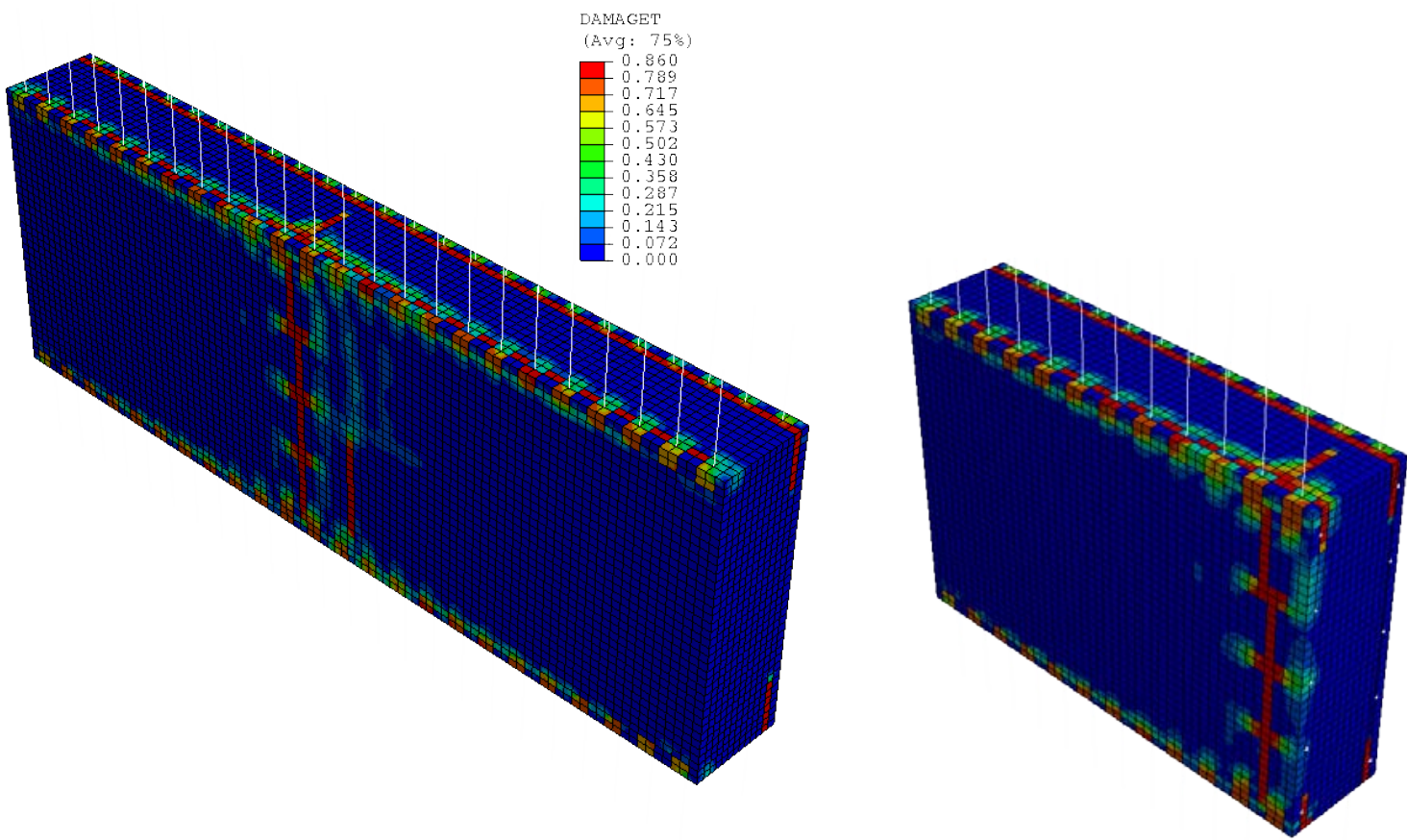

Entry dimension: $7 \mathrm{ft}$ x $20 \mathrm{ft}$, Seal thickness 28 in. 

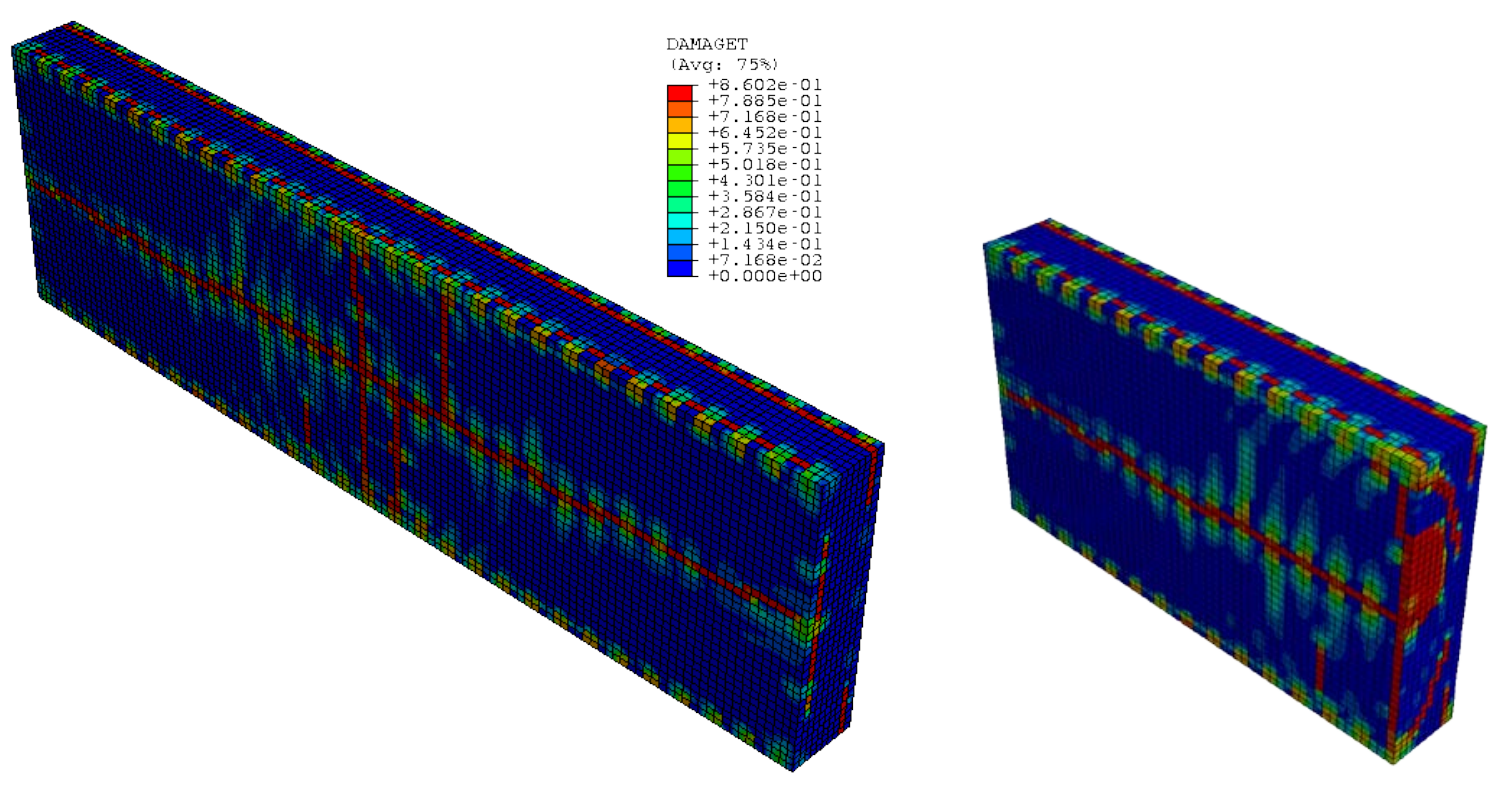

Entry dimension: $7 \mathrm{ft}$ x $24 \mathrm{ft}$, Seal thickness 22 in.
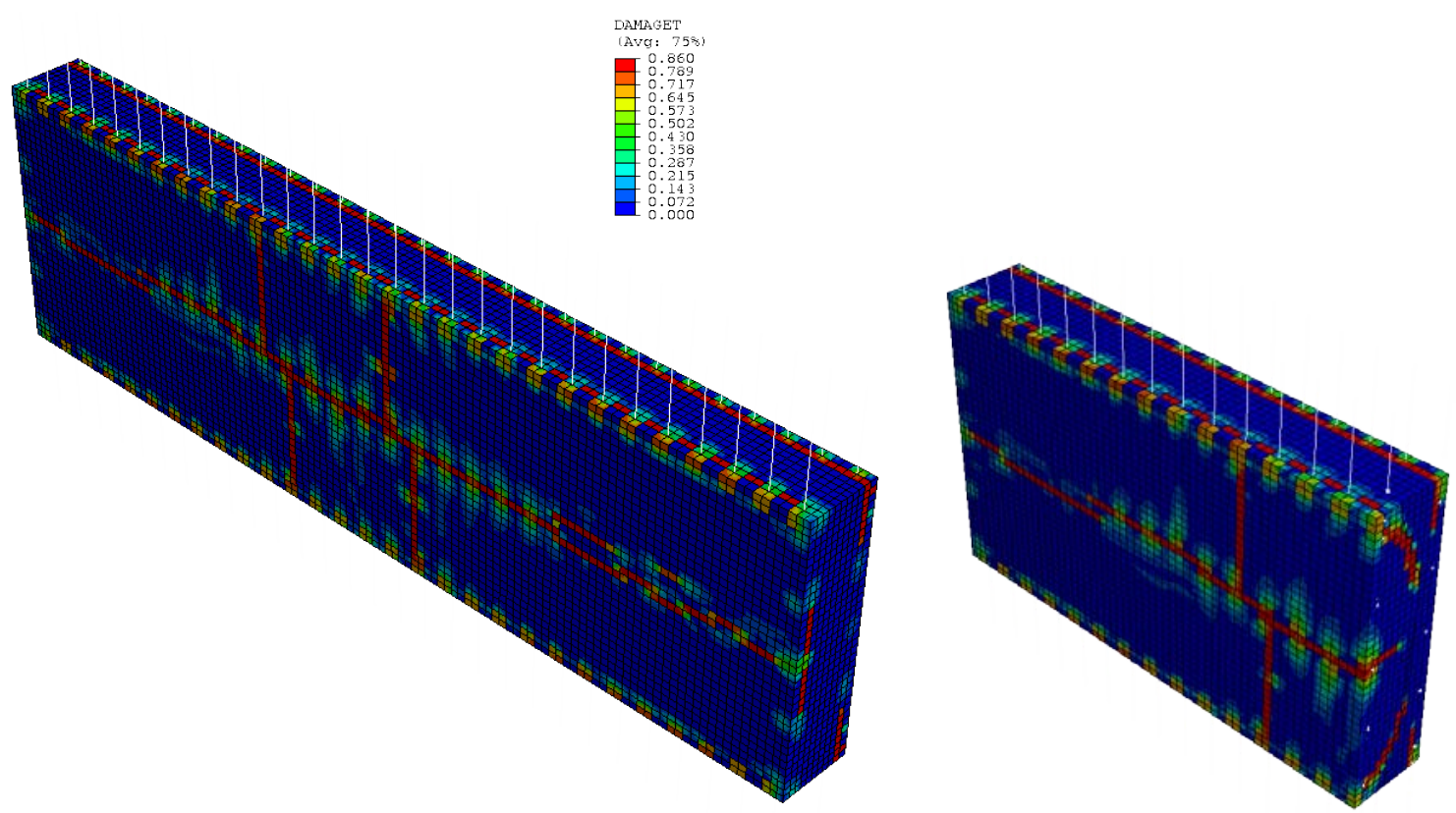

Entry dimension: $7 \mathrm{ft}$ x $24 \mathrm{ft}$, Seal thickness 24 in. 

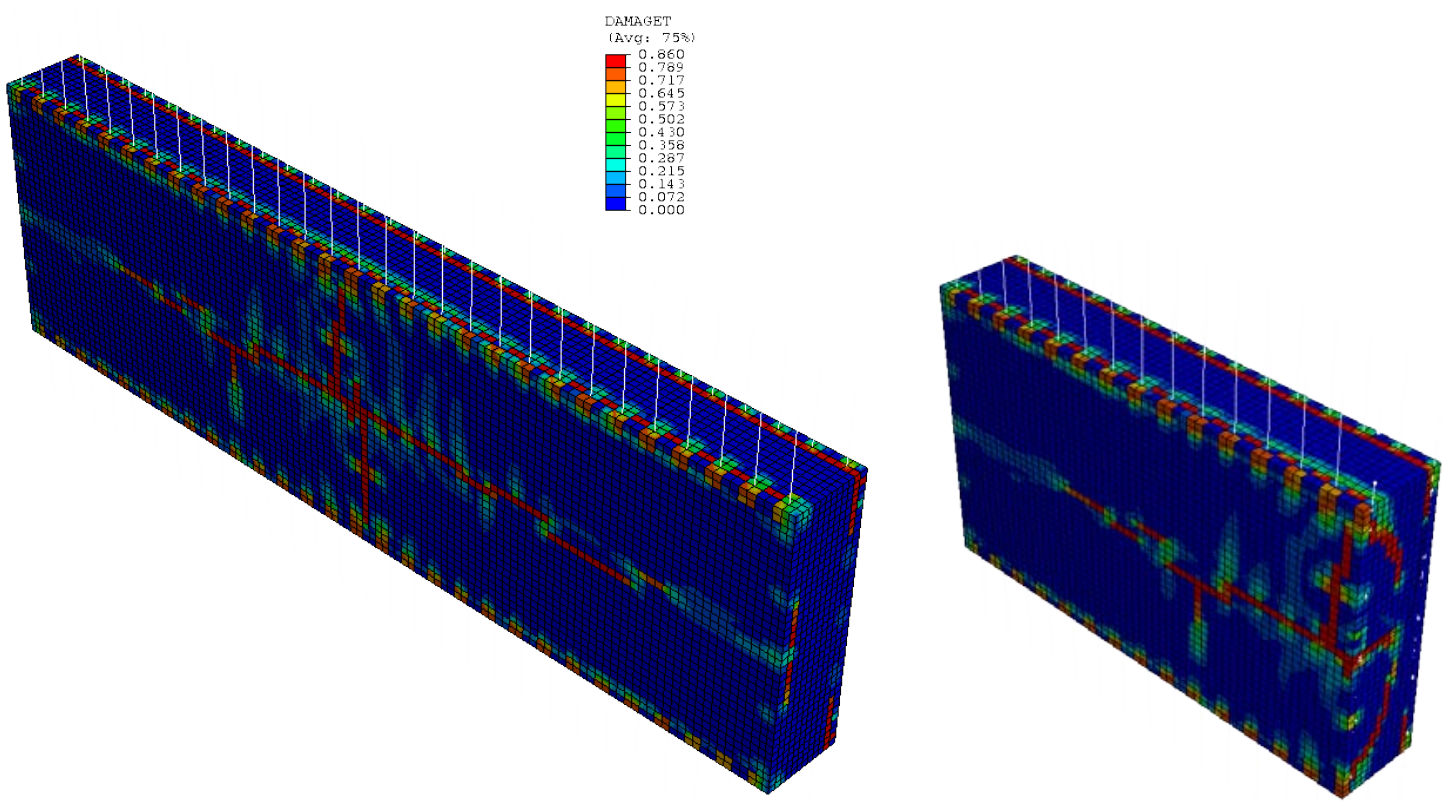

Entry dimension: $7 \mathrm{ft}$ x $24 \mathrm{ft}$, Seal thickness 26 in.
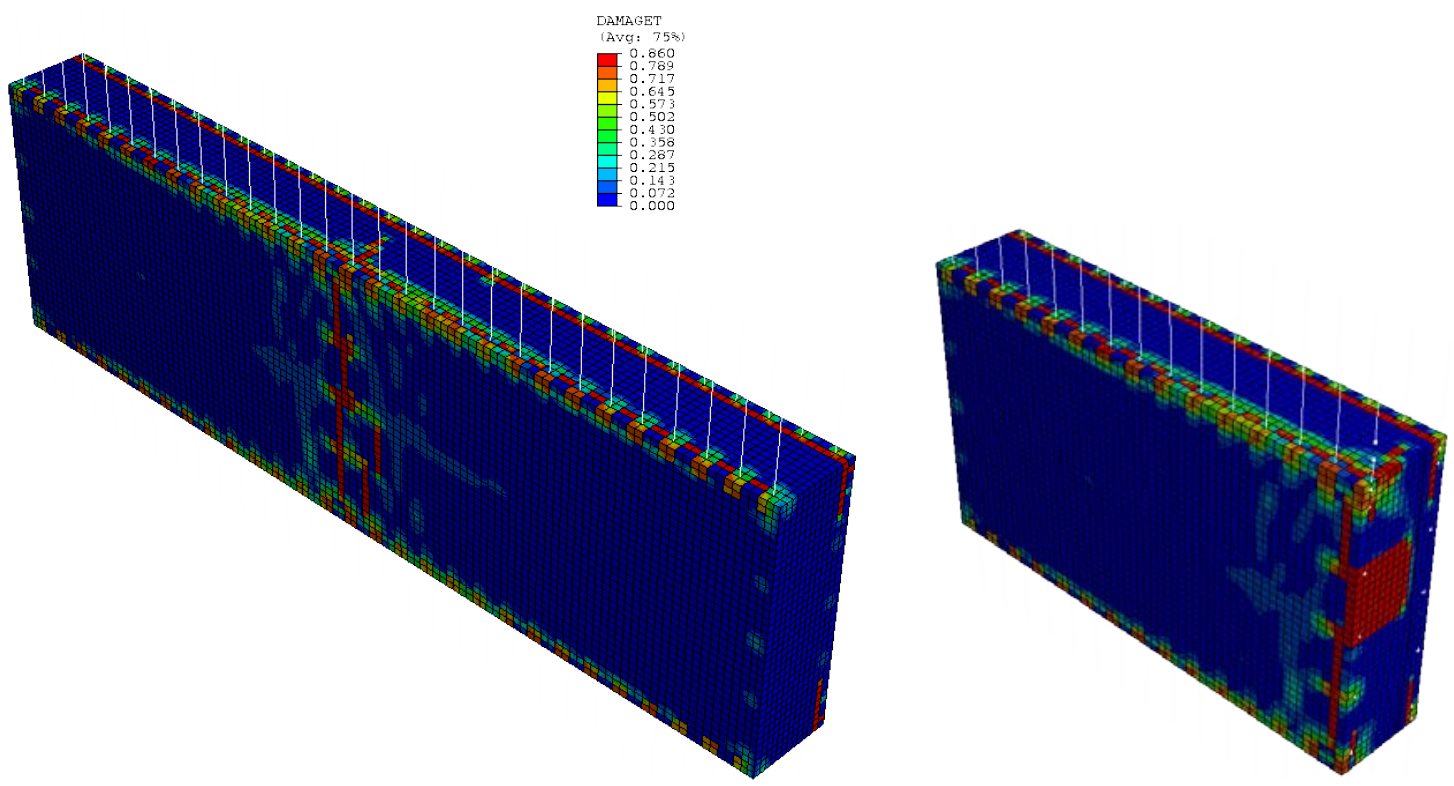

Entry dimension: $7 \mathrm{ft}$ x $24 \mathrm{ft}$, Seal thickness 28 in. 

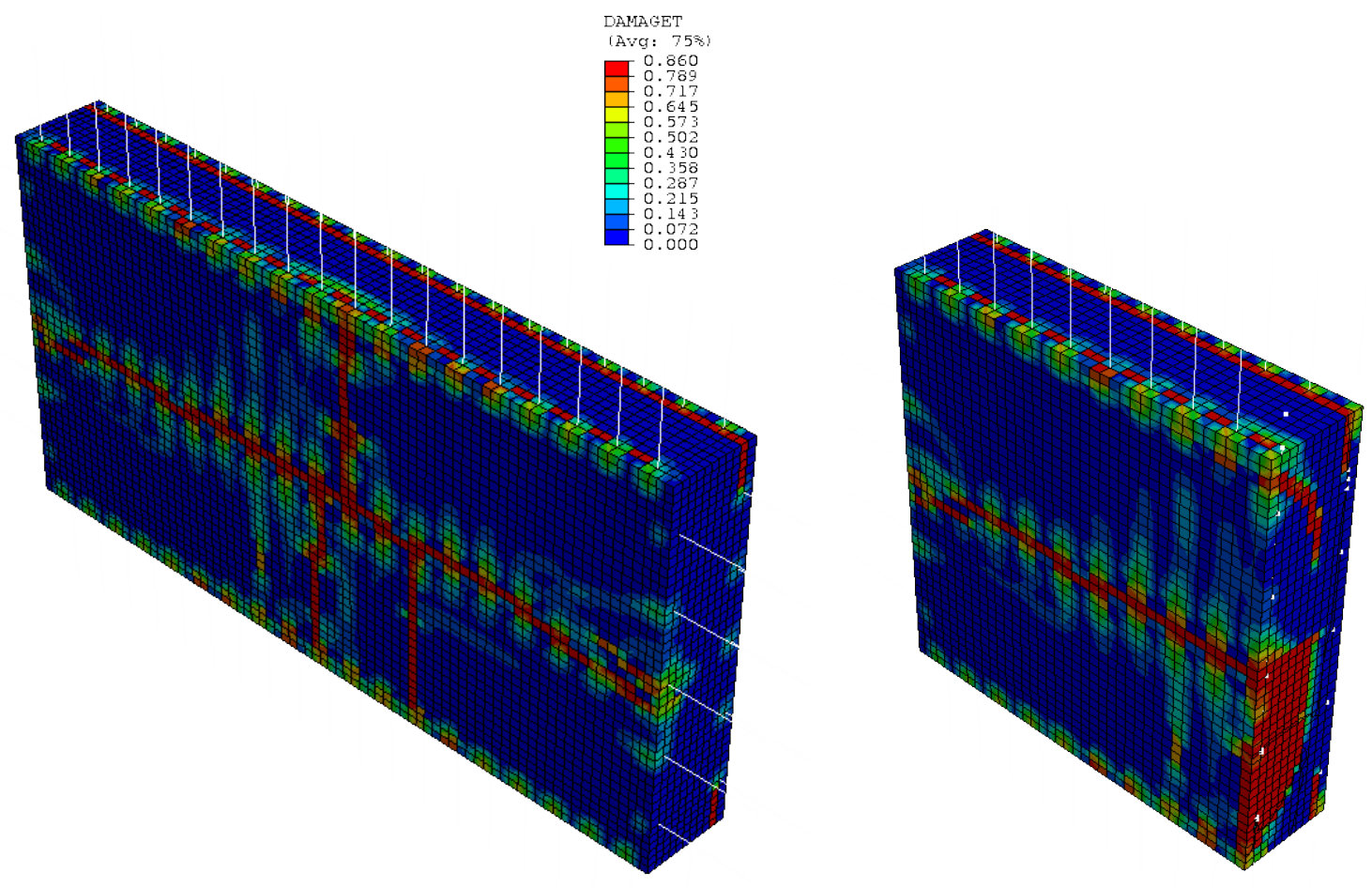

Entry dimension: $8 \mathrm{ft}$ x $16 \mathrm{ft}$, Seal thickness 24 in.
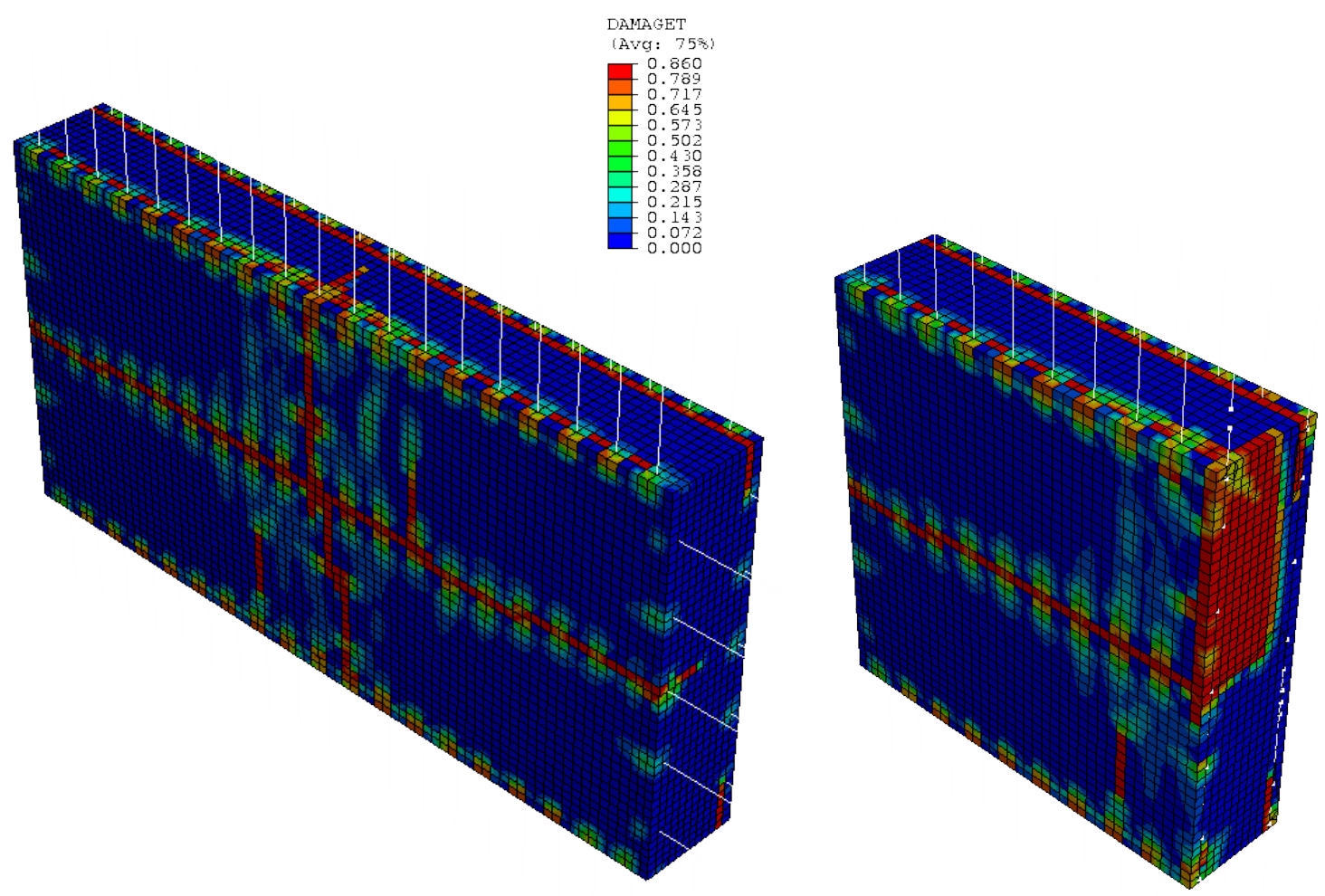

Entry dimension: $8 \mathrm{ft}$ x $16 \mathrm{ft}$, Seal thickness 26 in. 

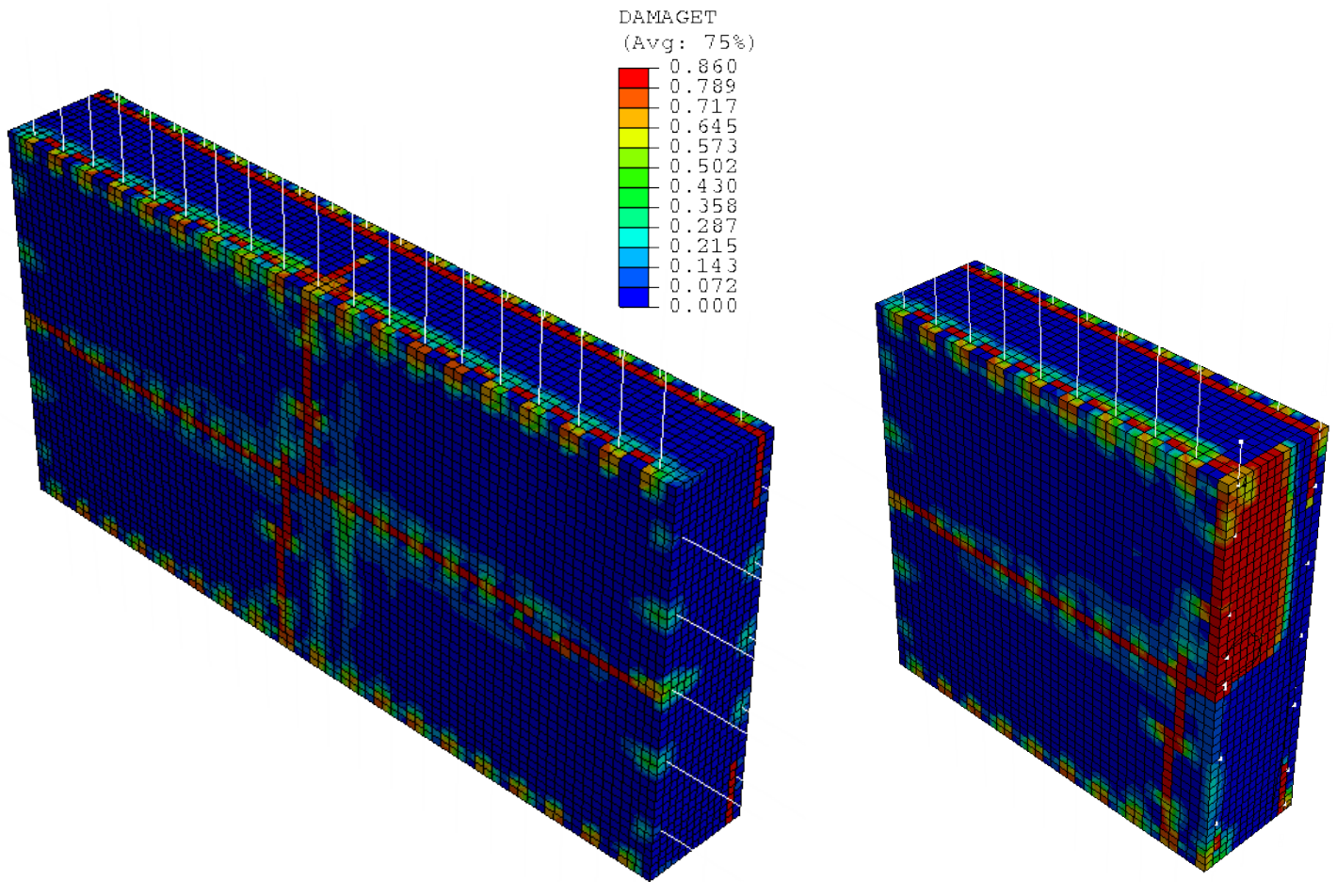

Entry dimension: $8 \mathrm{ft}$ x $16 \mathrm{ft}$, Seal thickness 28 in.

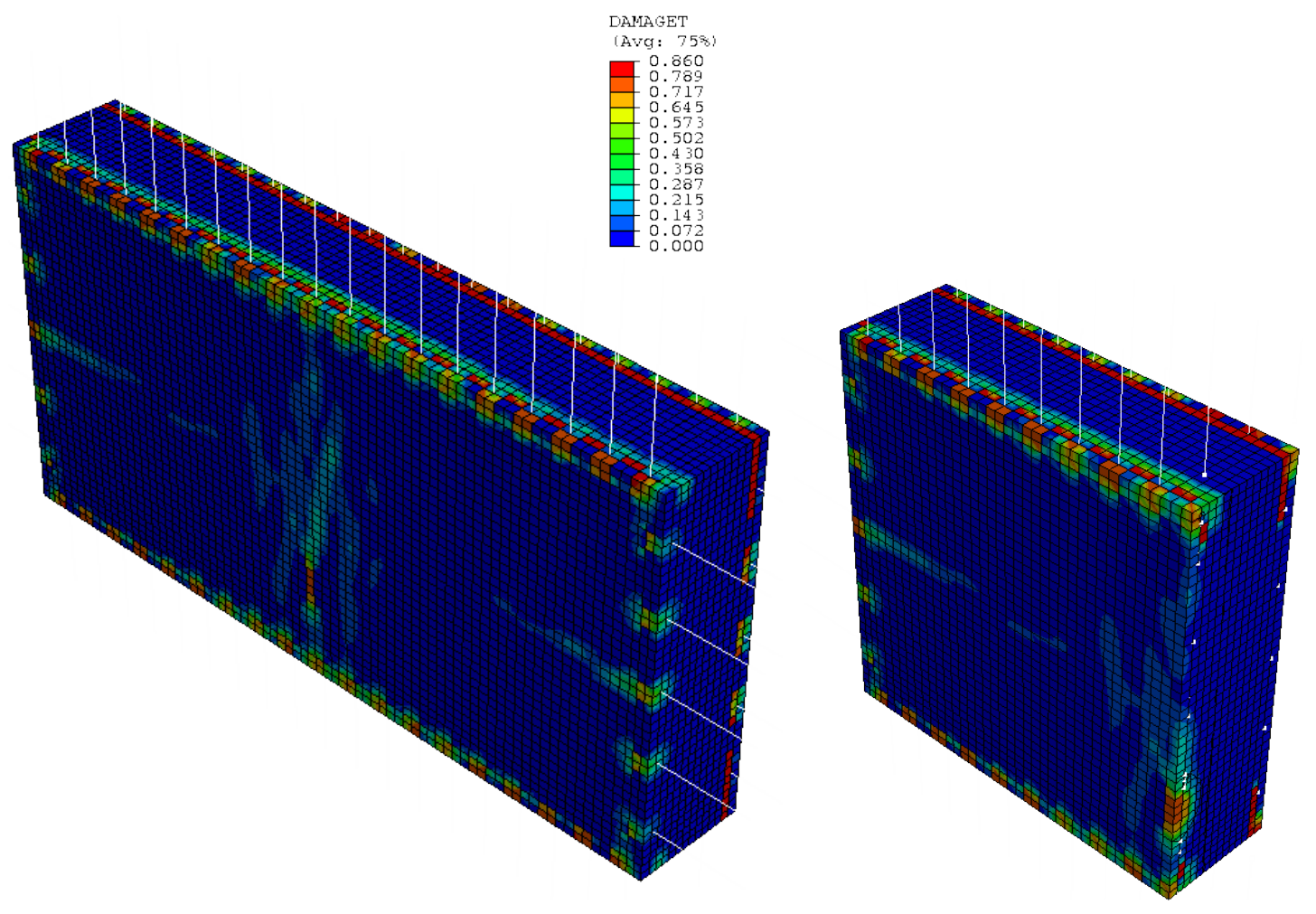

Entry dimension: $8 \mathrm{ft}$ x $16 \mathrm{ft}$, Seal thickness 30 in. 


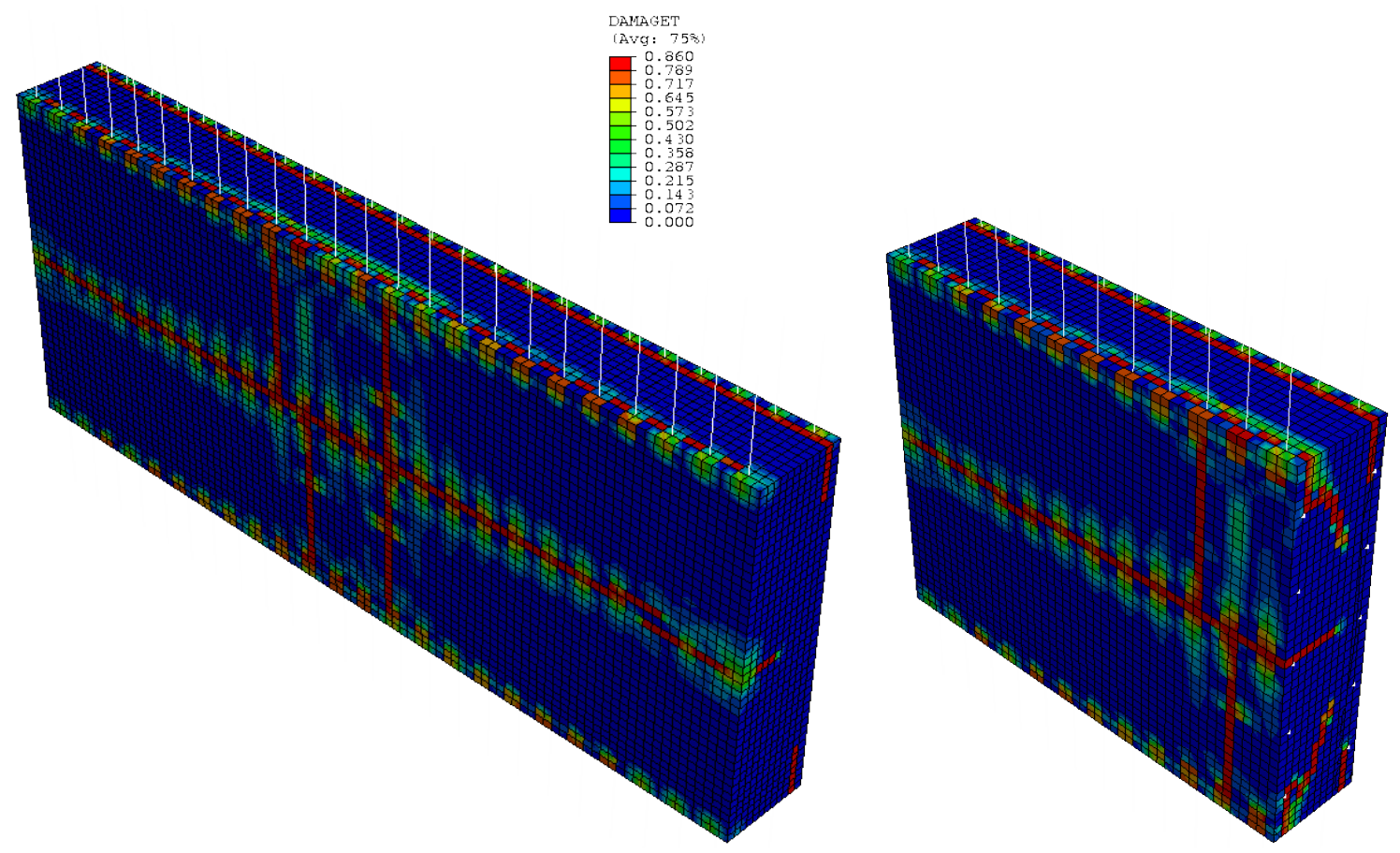

Entry dimension: $8 \mathrm{ft}$ x $20 \mathrm{ft}$, Seal thickness 26 in.
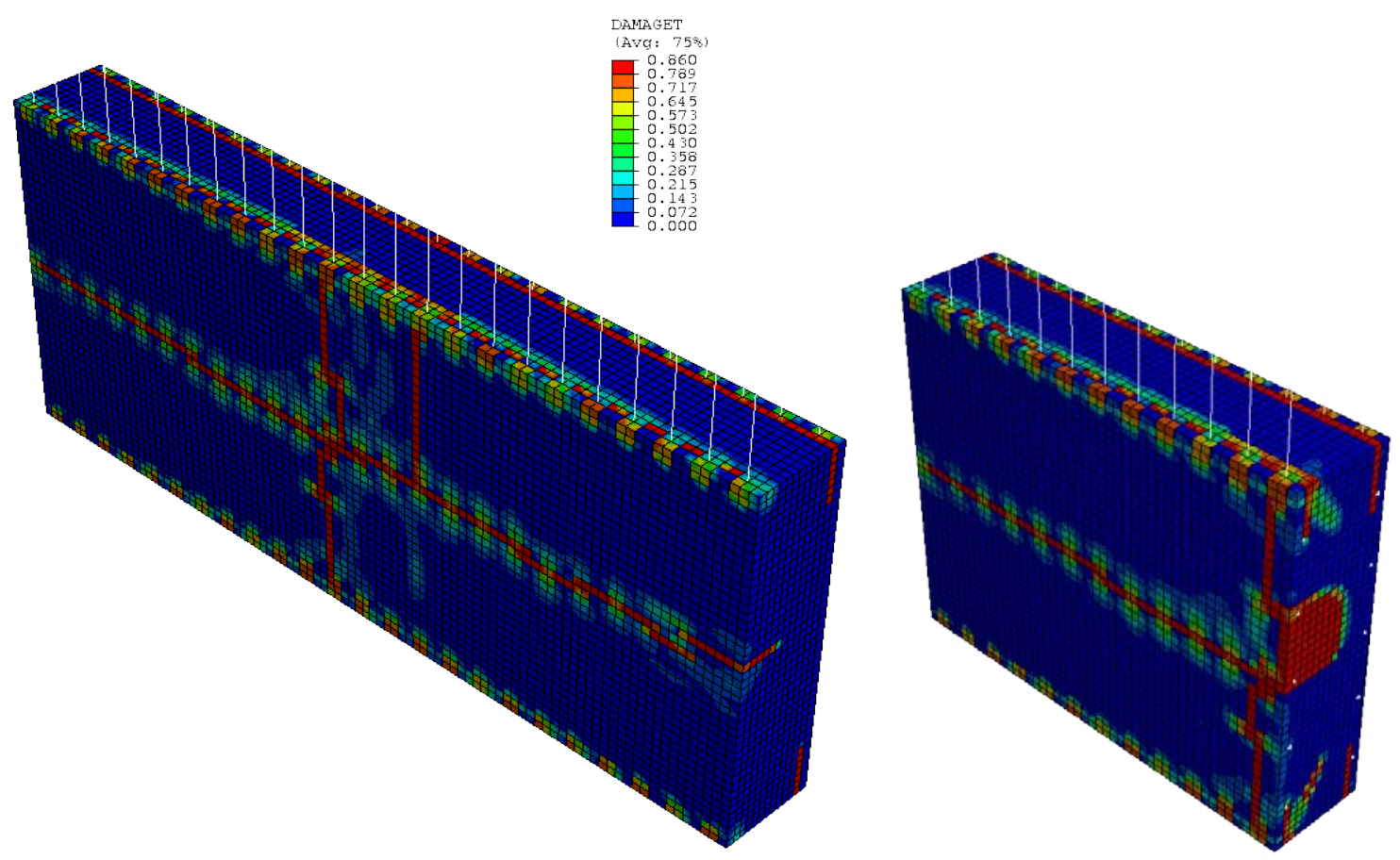

Entry dimension: $8 \mathrm{ft}$ x $20 \mathrm{ft}$, Seal thickness 28 in. 


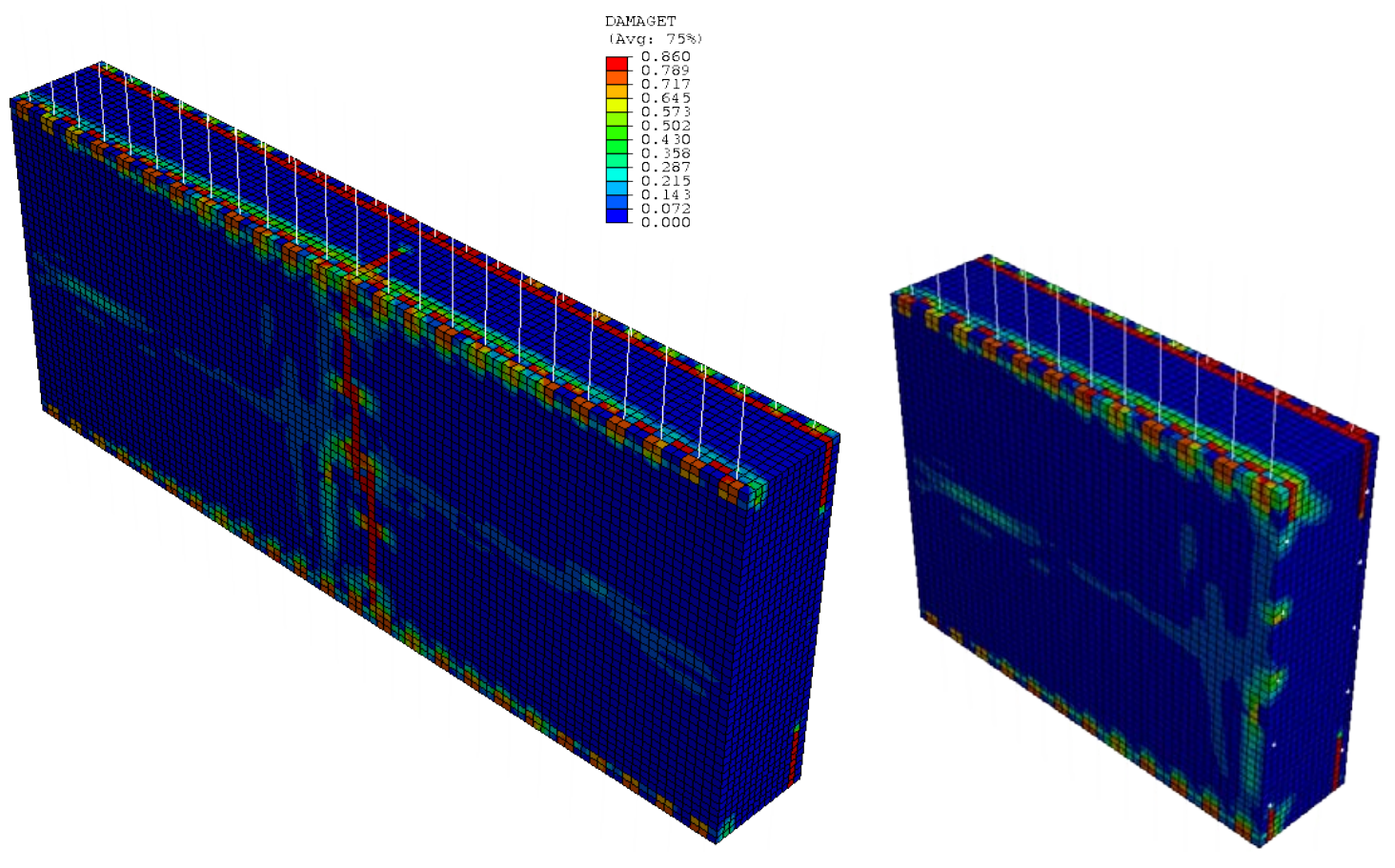

Entry dimension: $8 \mathrm{ft}$ x $20 \mathrm{ft}$, Seal thickness 30 in.
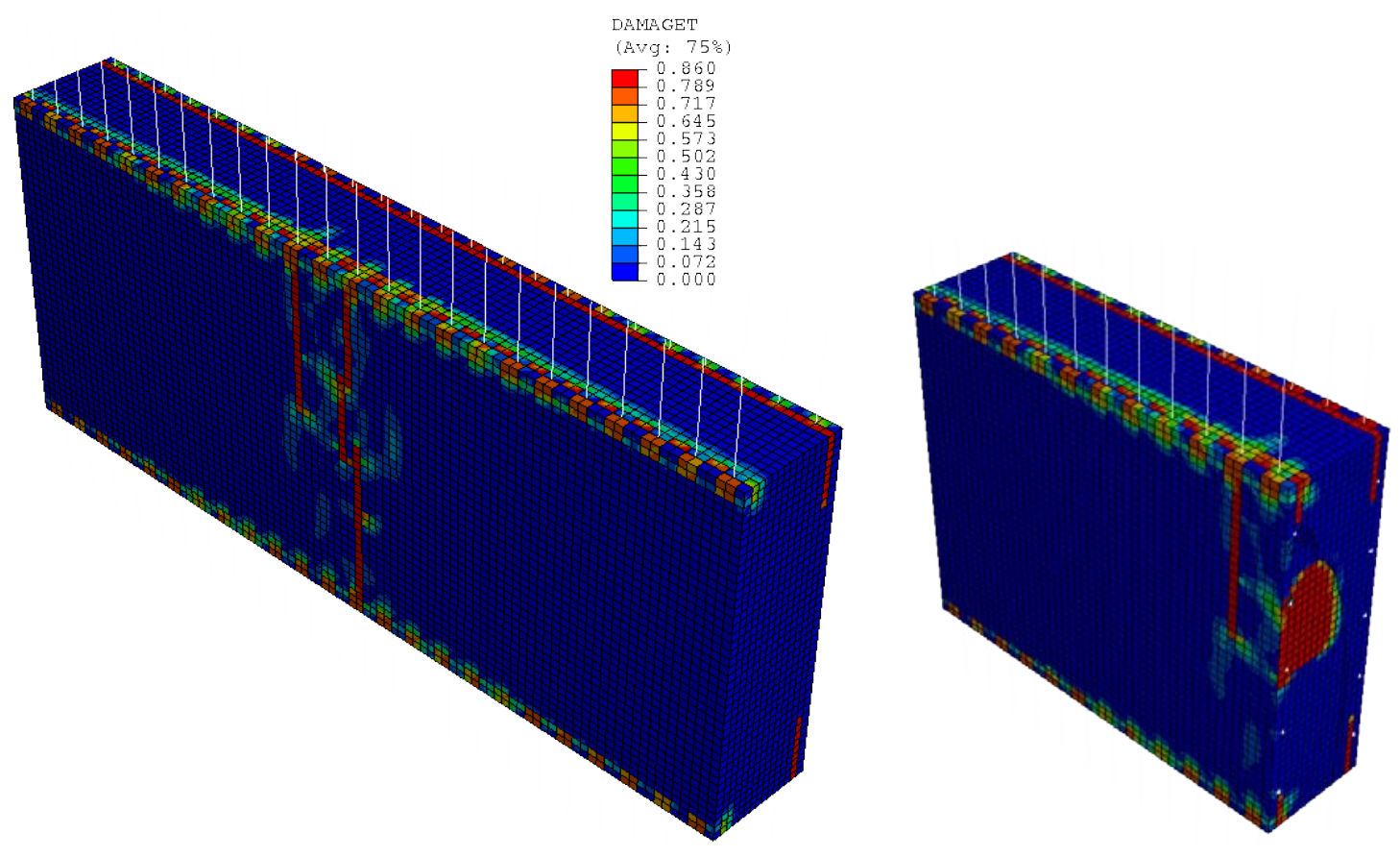

Entry dimension: $8 \mathrm{ft}$ x $20 \mathrm{ft}$, Seal thickness 32 in. 


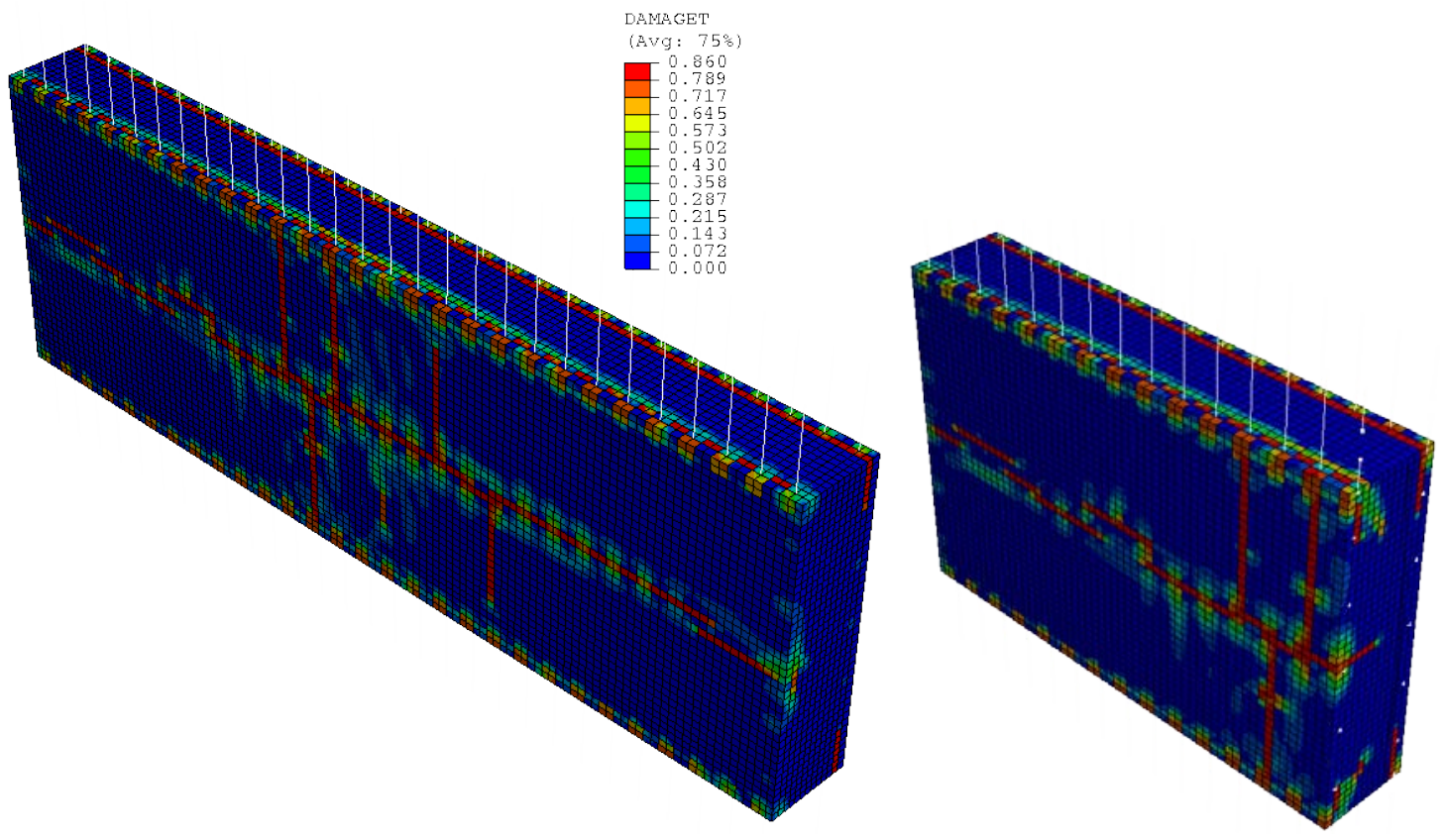

Entry dimension: $8 \mathrm{ft}$ x $24 \mathrm{ft}$, Seal thickness 28 in.

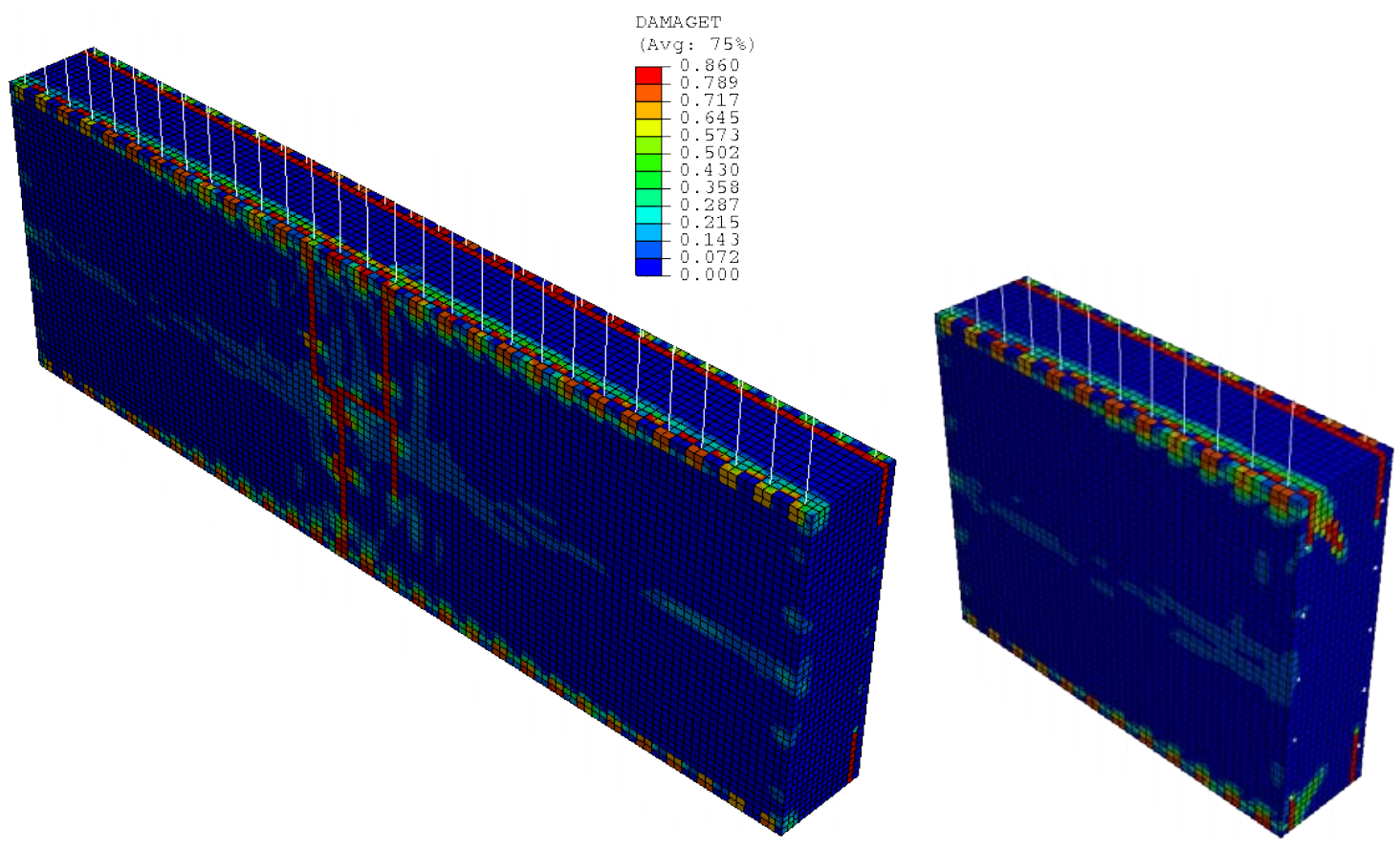

Entry dimension: $8 \mathrm{ft}$ x $24 \mathrm{ft}$, Seal thickness 30 in. 


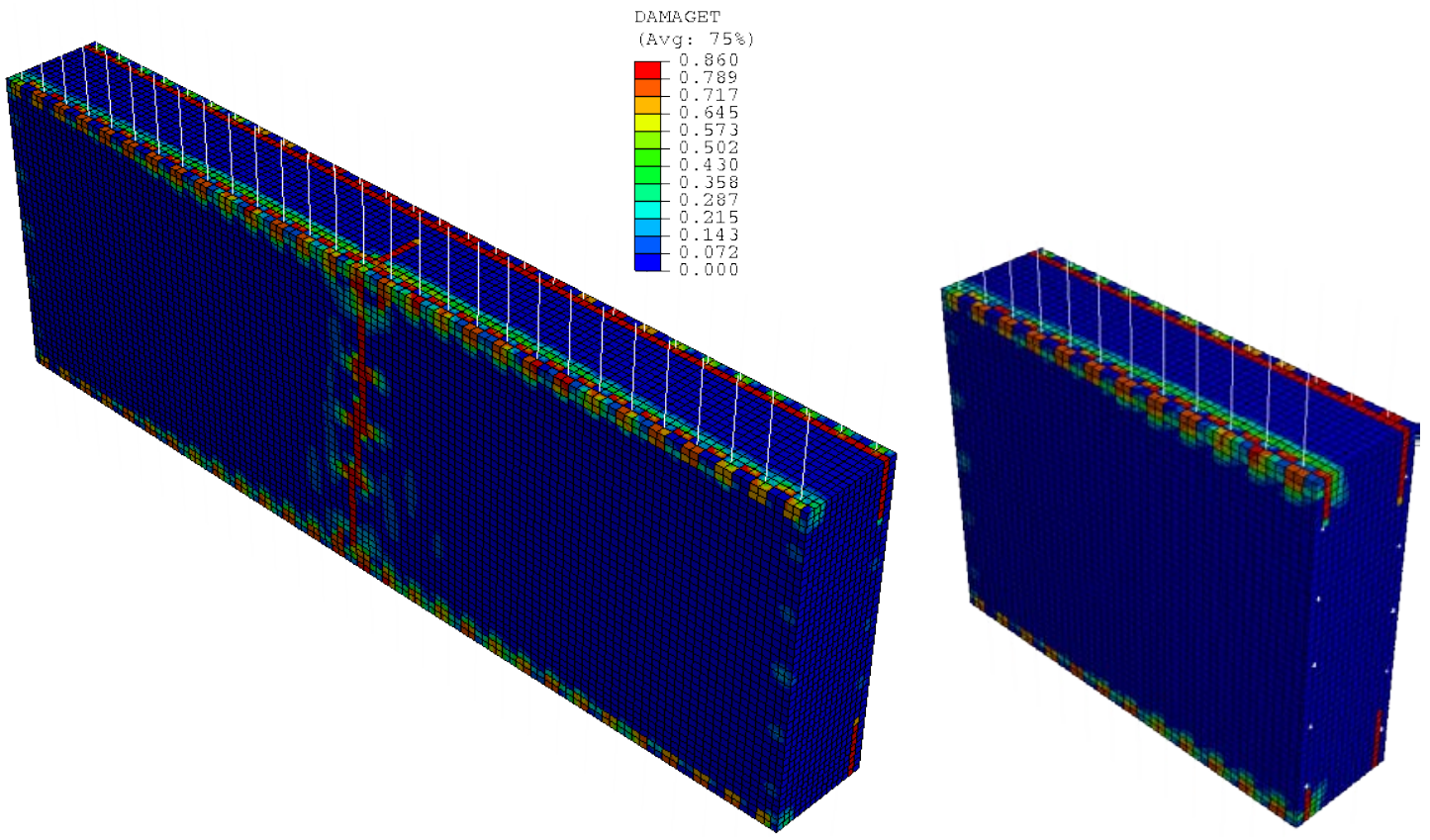

Entry dimension: $8 \mathrm{ft}$ x $24 \mathrm{ft}$, Seal thickness 32 in.

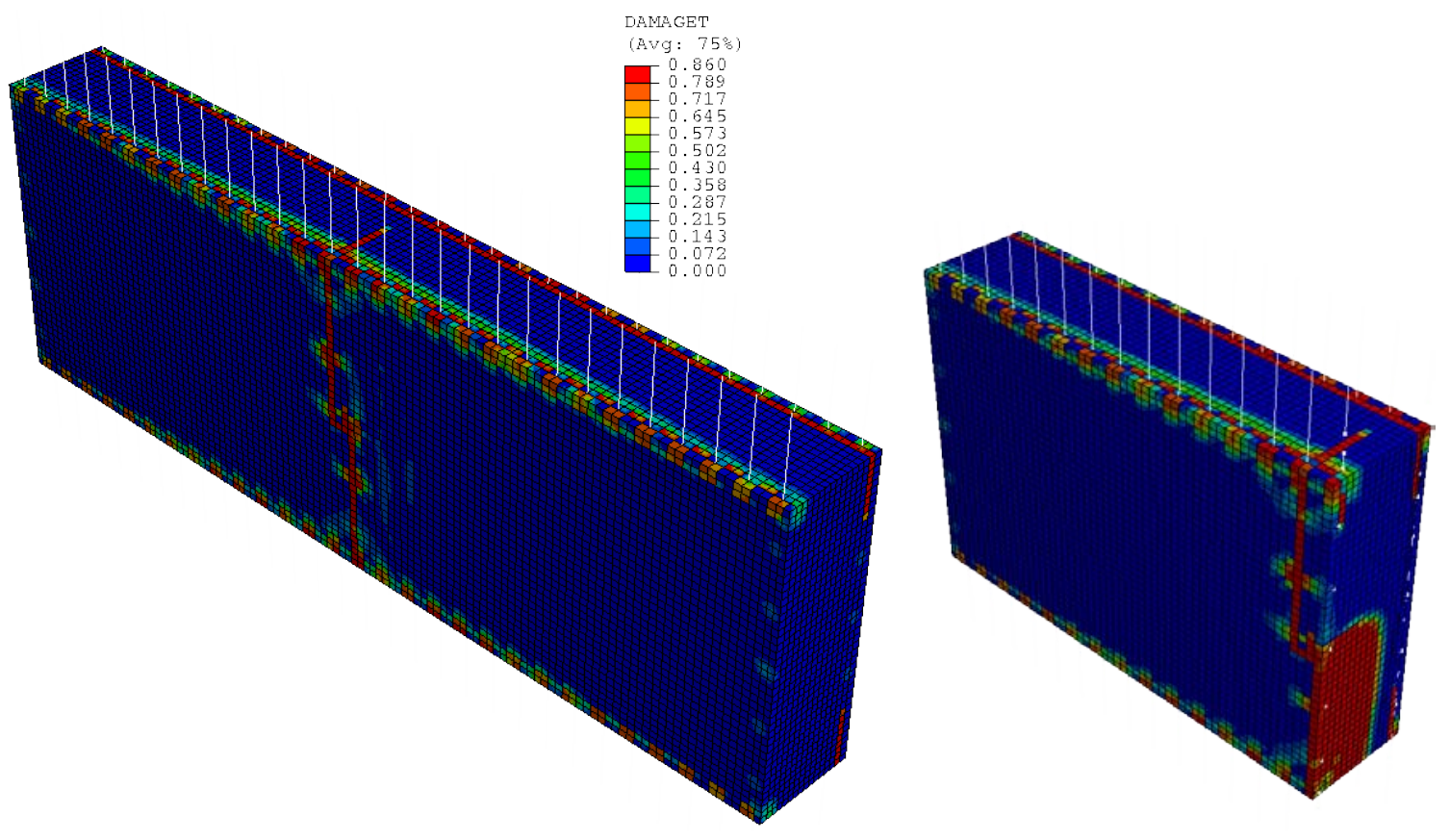

Entry dimension: $8 \mathrm{ft}$ x $24 \mathrm{ft}$, Seal thickness 34 in. 

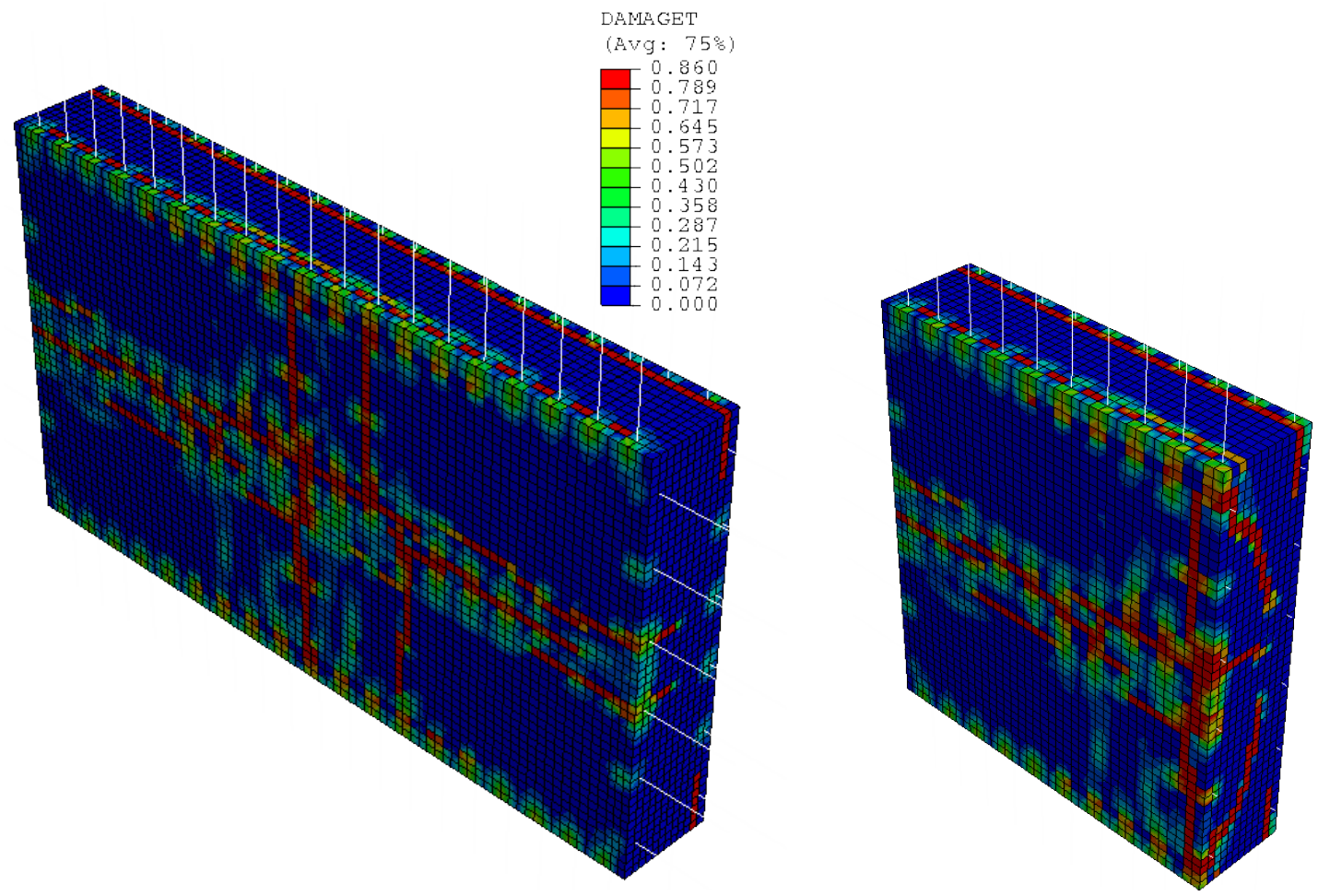

Entry dimension: 9 ft x 16 ft, Seal thickness 26 in.
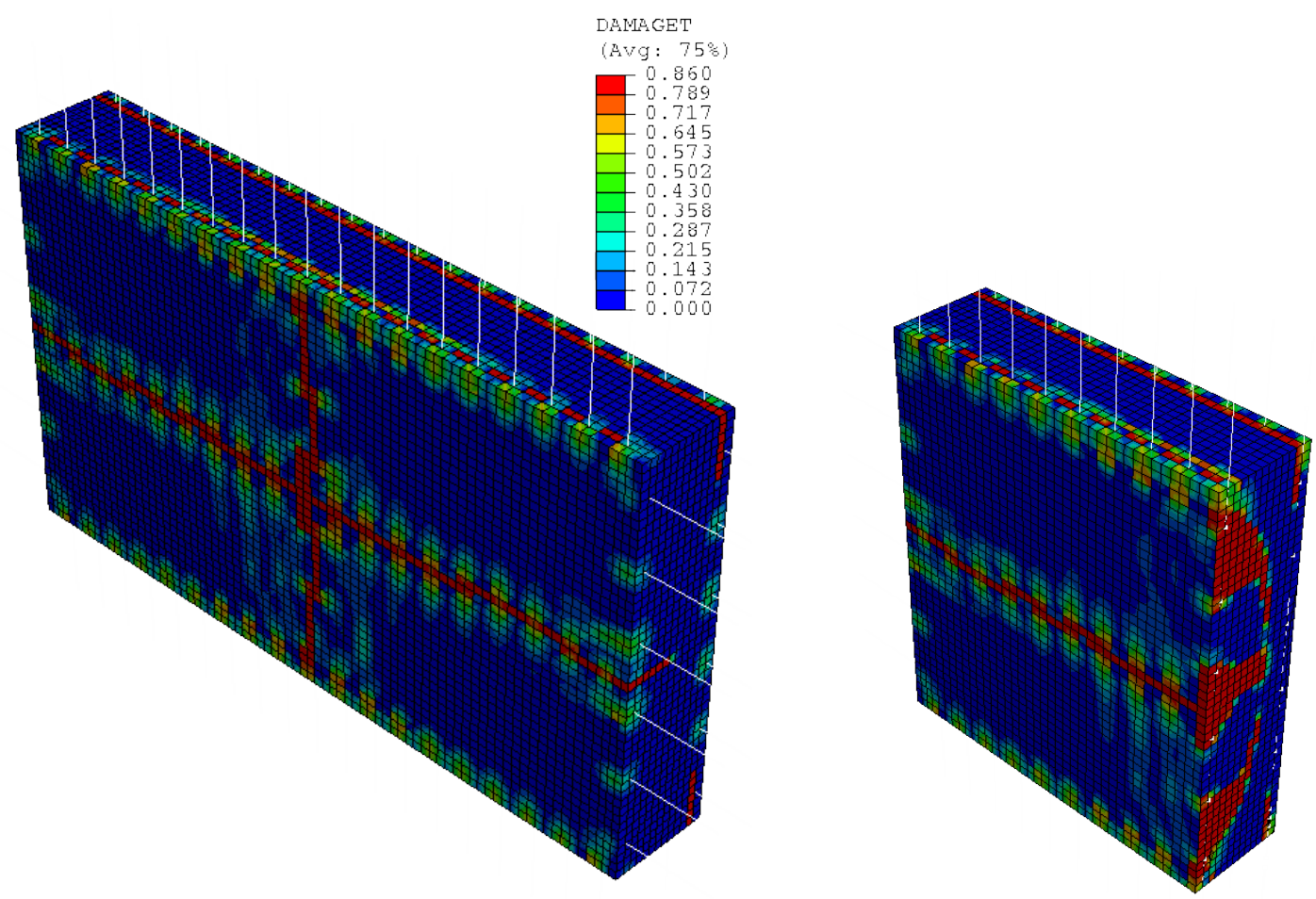

Entry dimension: $9 \mathrm{ft}$ x 16 ft, Seal thickness 28 in. 

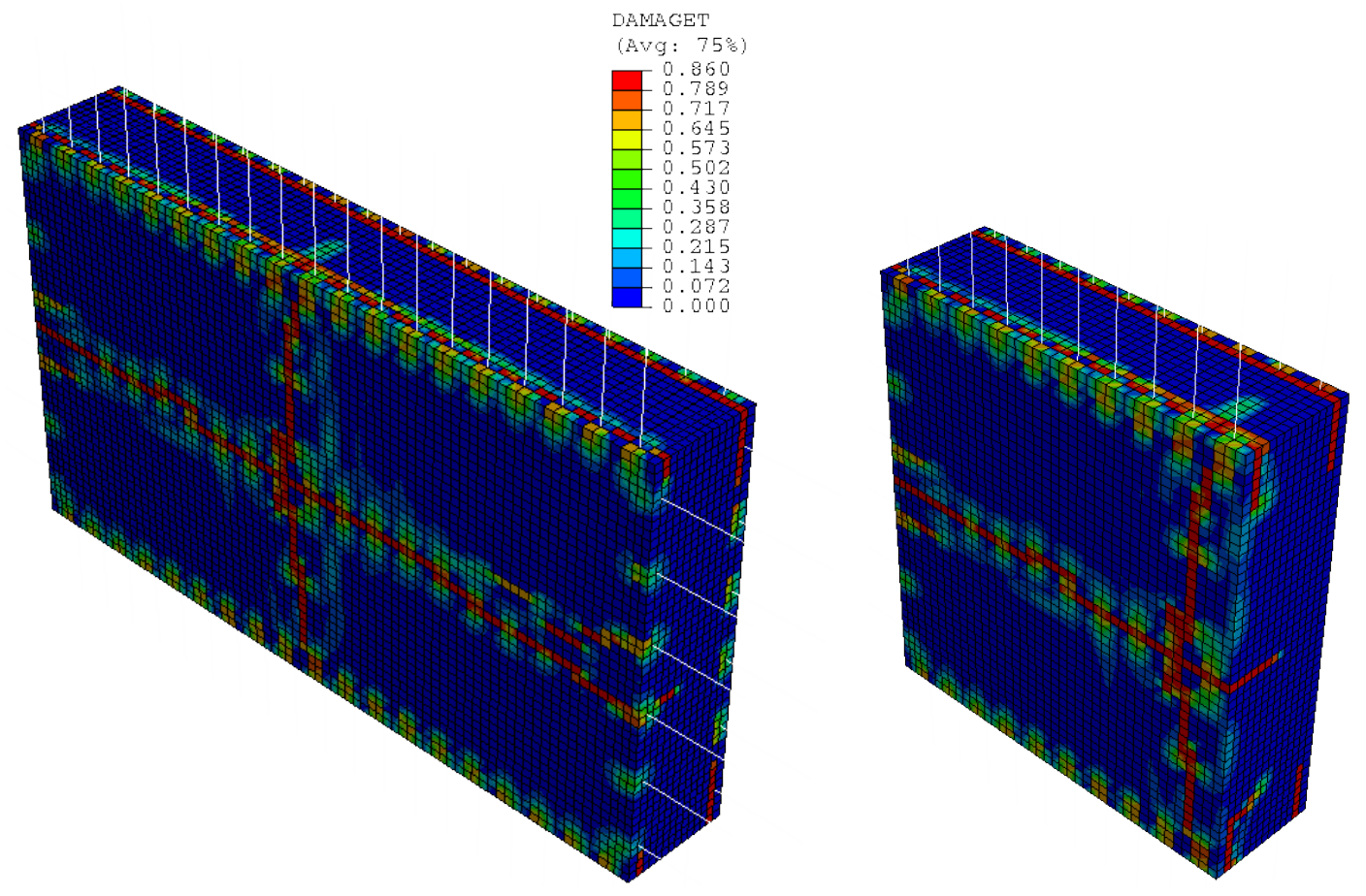

Entry dimension: $9 \mathrm{ft}$ x $16 \mathrm{ft}$, Seal thickness 30 in.
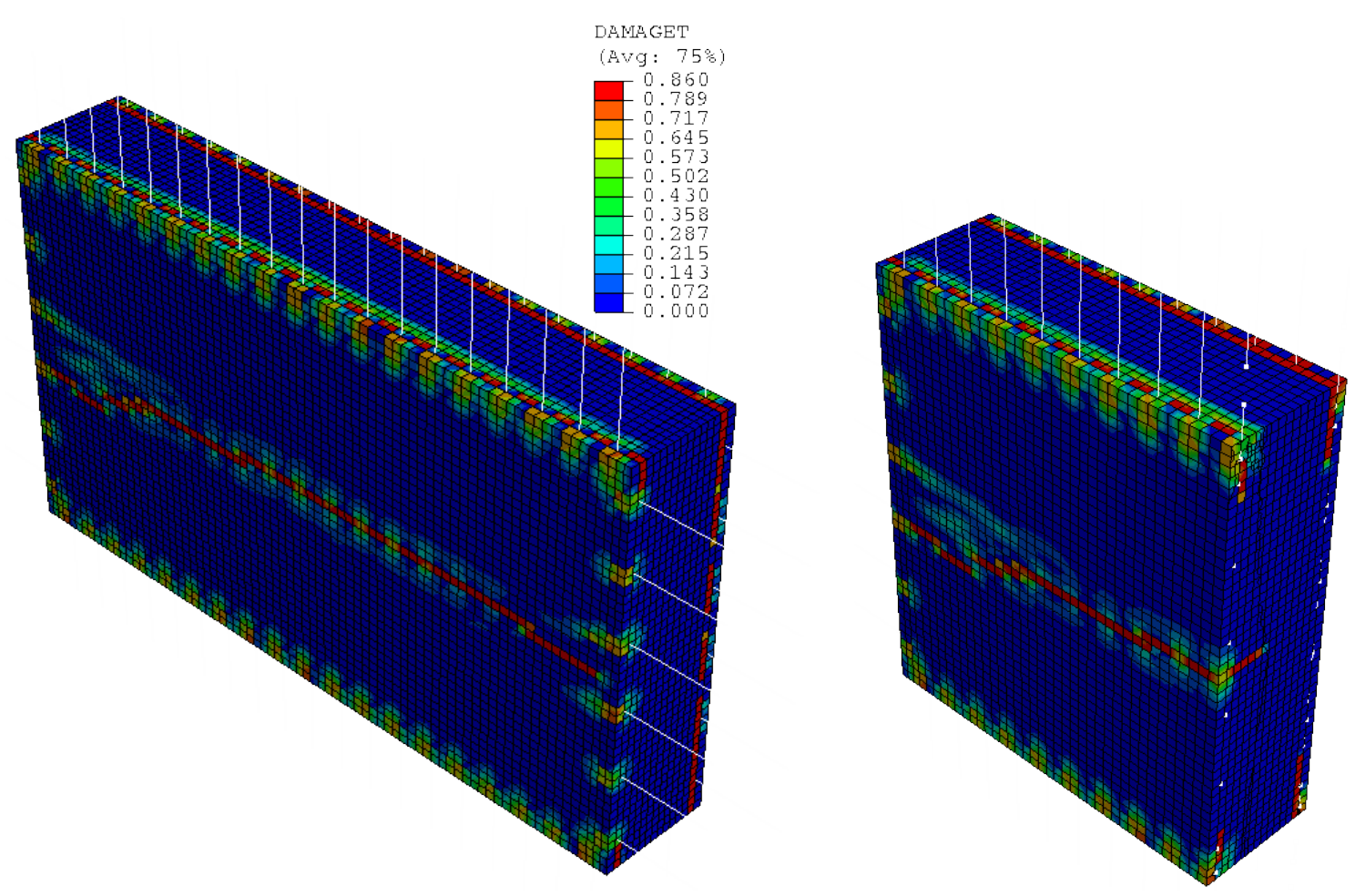

Entry dimension: $9 \mathrm{ft}$ x $16 \mathrm{ft}$, Seal thickness 32 in. 


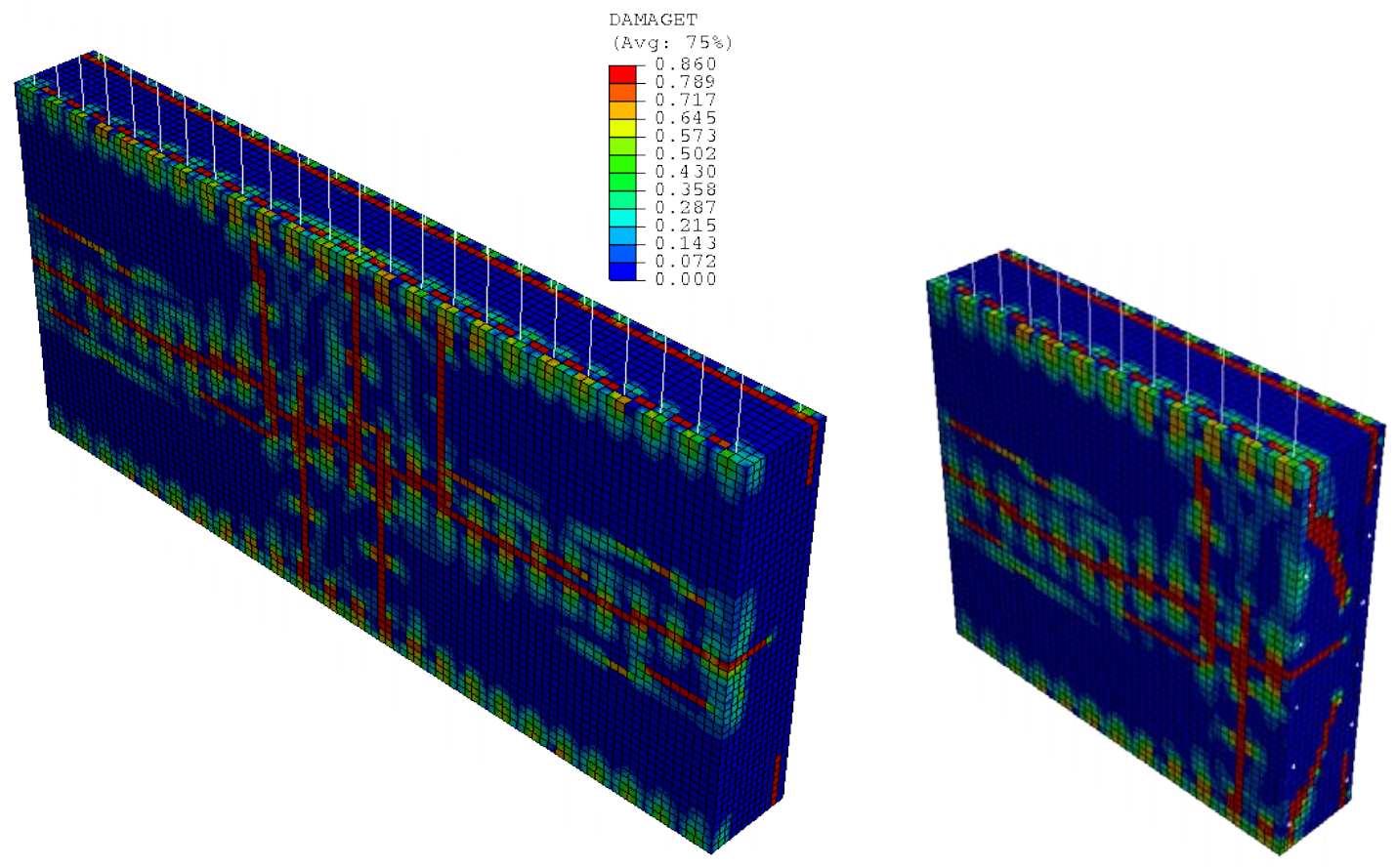

Entry dimension: $9 \mathrm{ft}$ x $20 \mathrm{ft}$, Seal thickness 26 in.
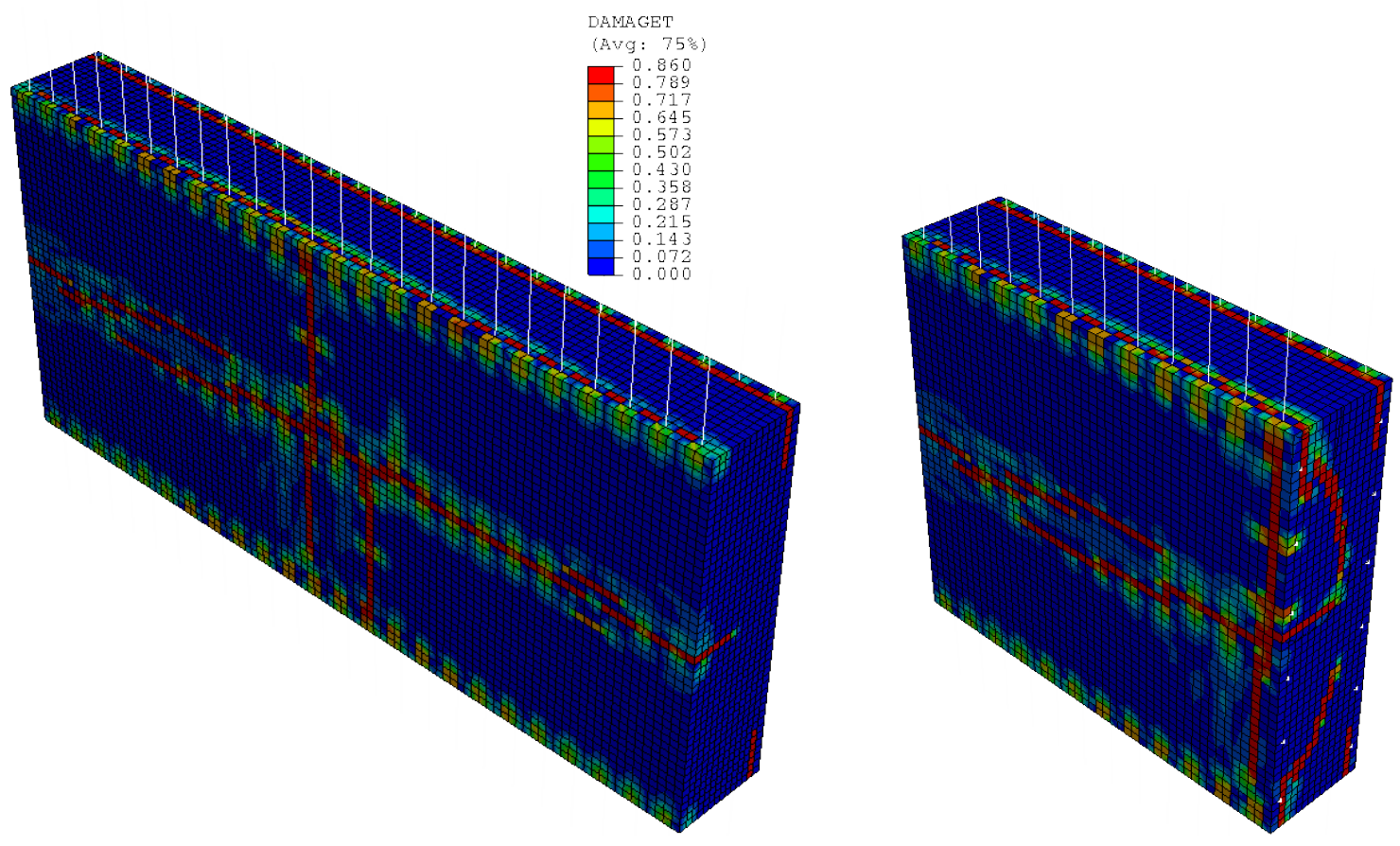

Entry dimension: 9 ft x 20 ft, Seal thickness 30 in. 

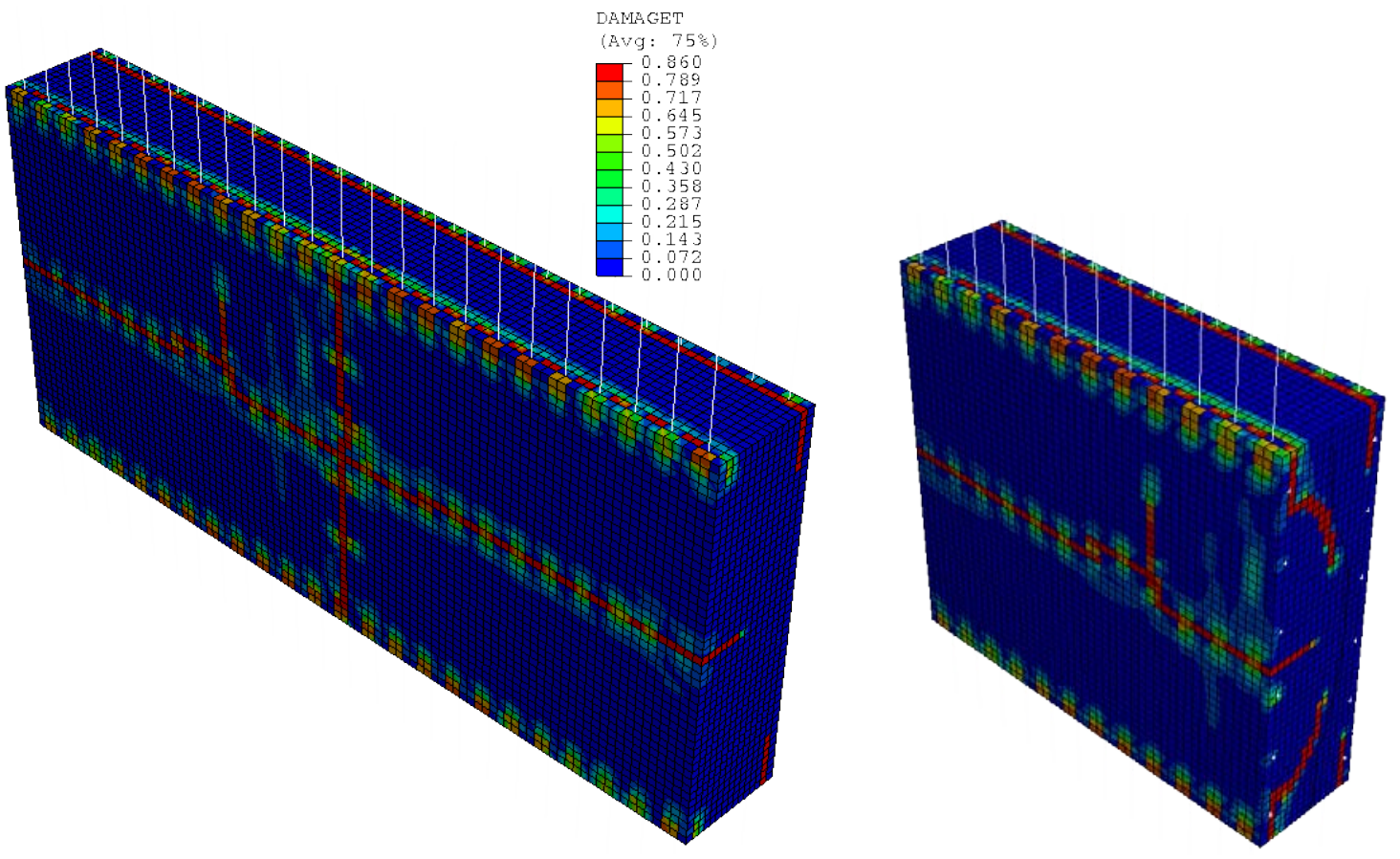

Entry dimension: $9 \mathrm{ft}$ x $20 \mathrm{ft}$, Seal thickness 32 in.
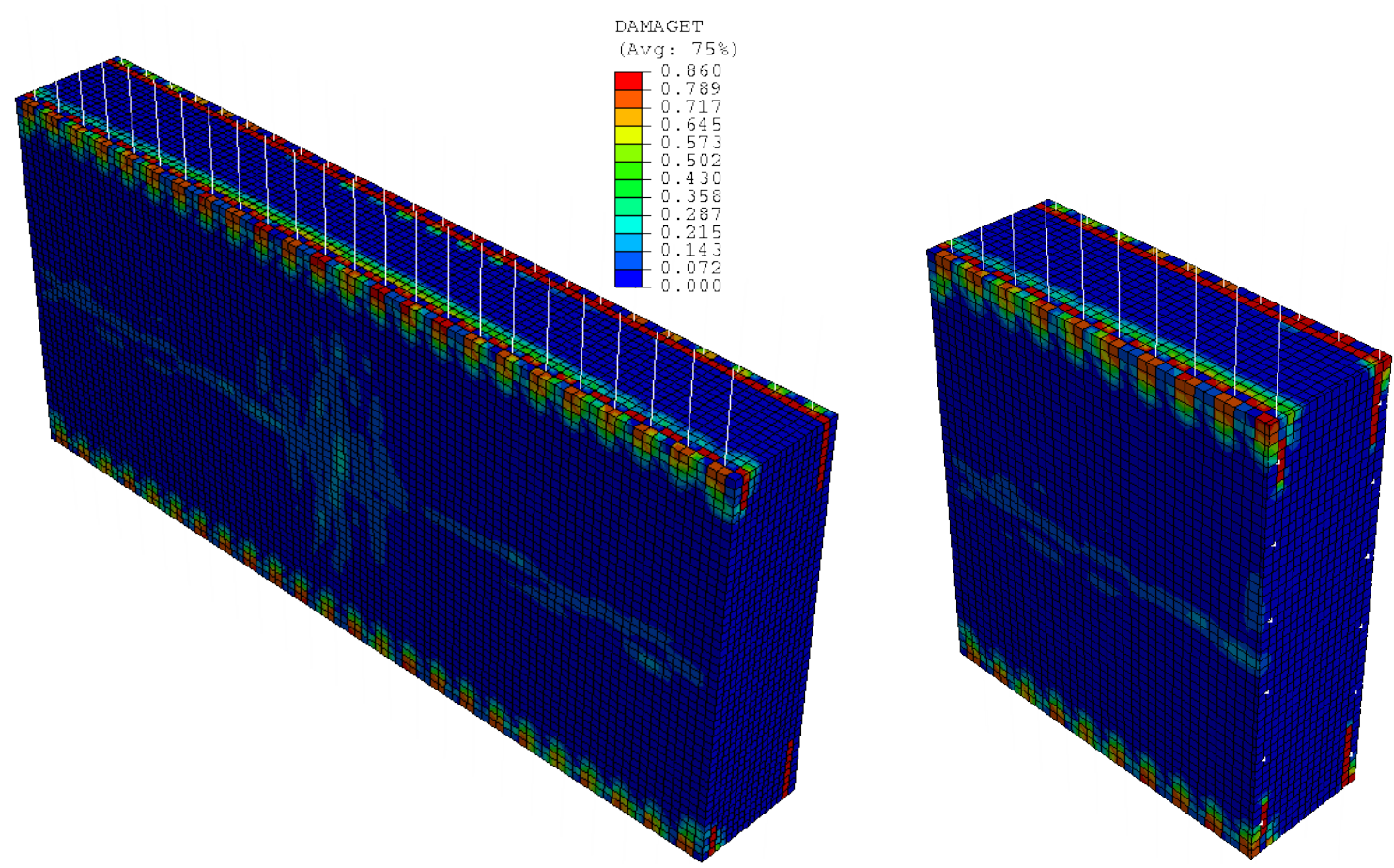

Entry dimension: $9 \mathrm{ft}$ x $20 \mathrm{ft}$, Seal thickness 34 in. 

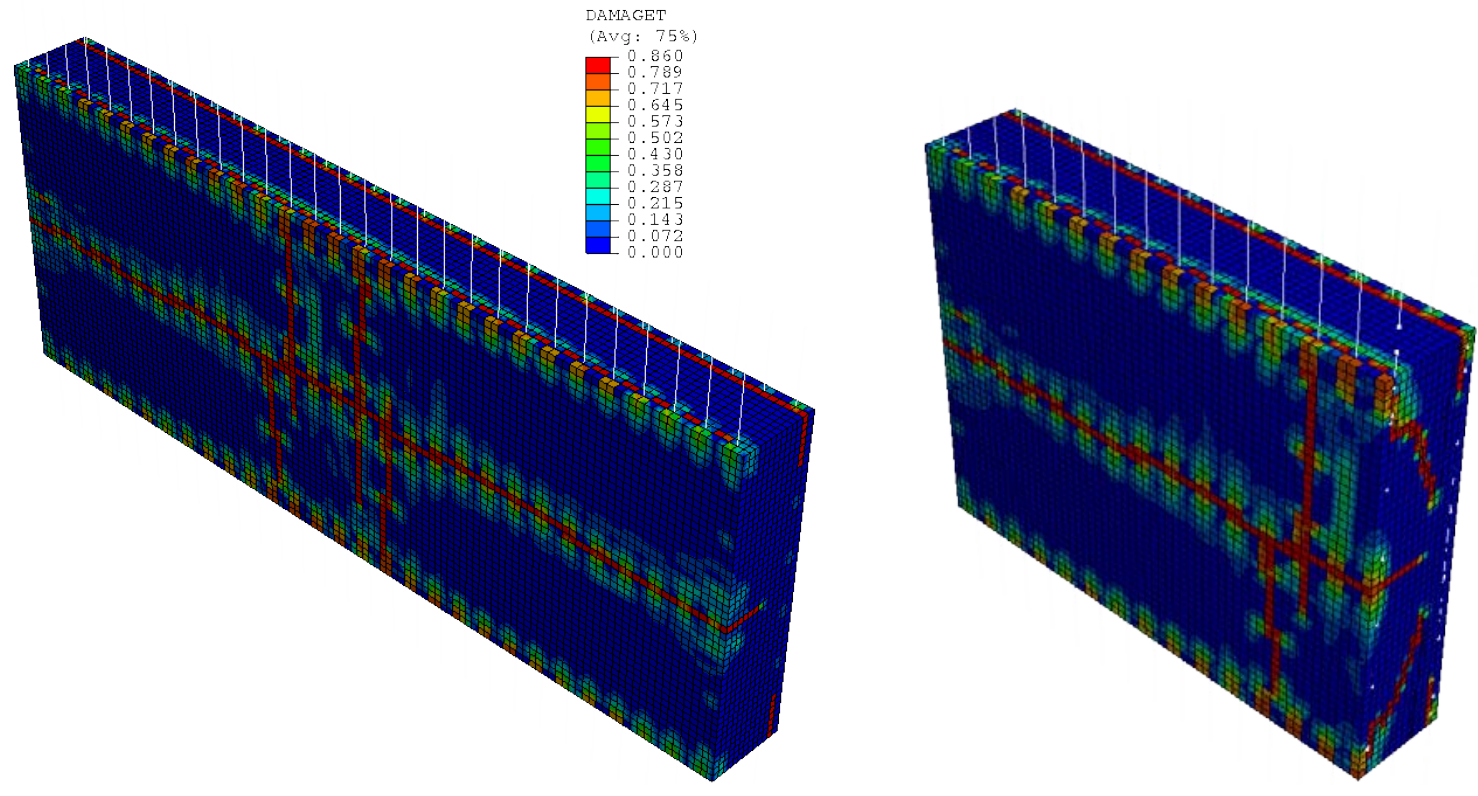

Entry dimension: 9 ft x 24 ft, Seal thickness 28 in.
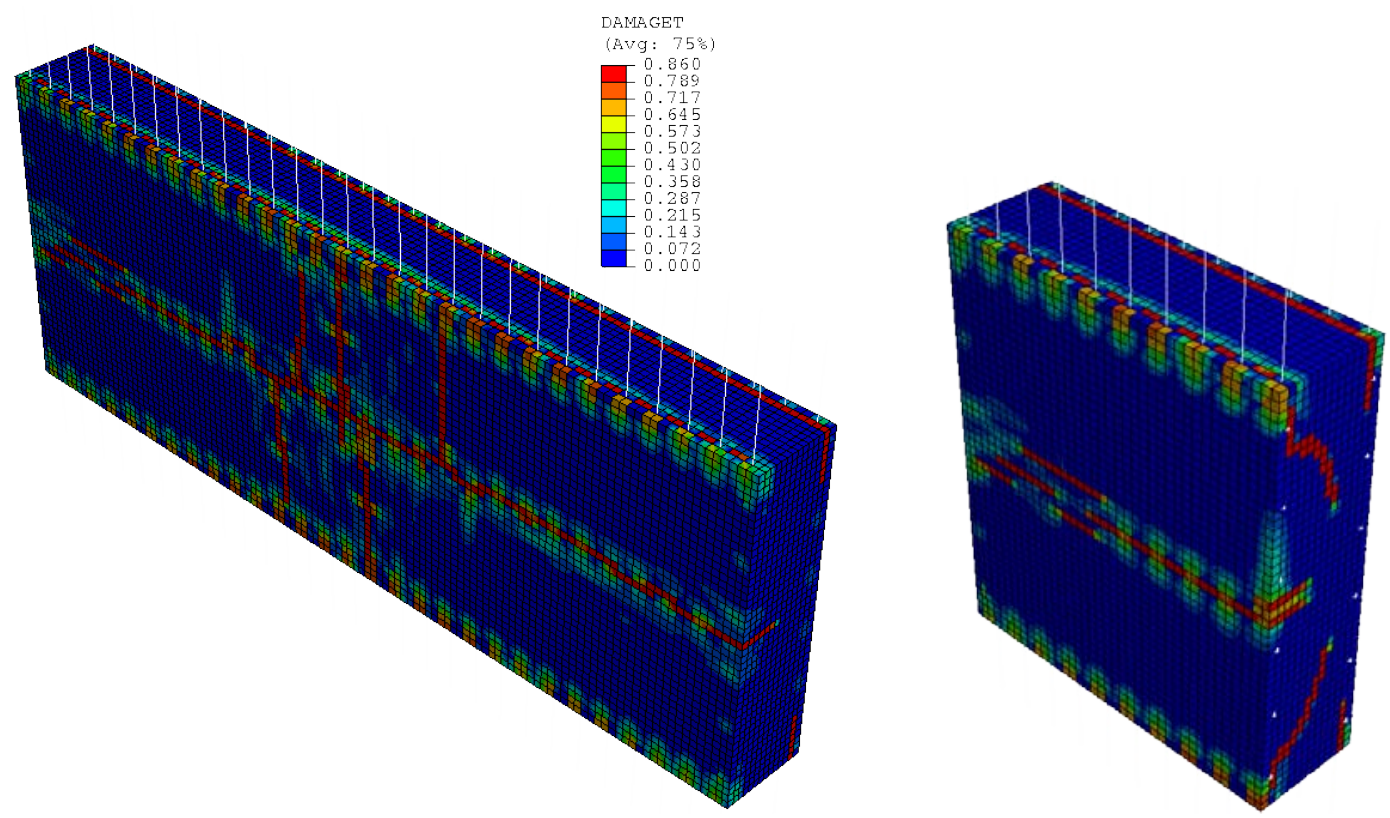

Entry dimension: $9 \mathrm{ft}$ x $24 \mathrm{ft}$, Seal thickness 30 in. 

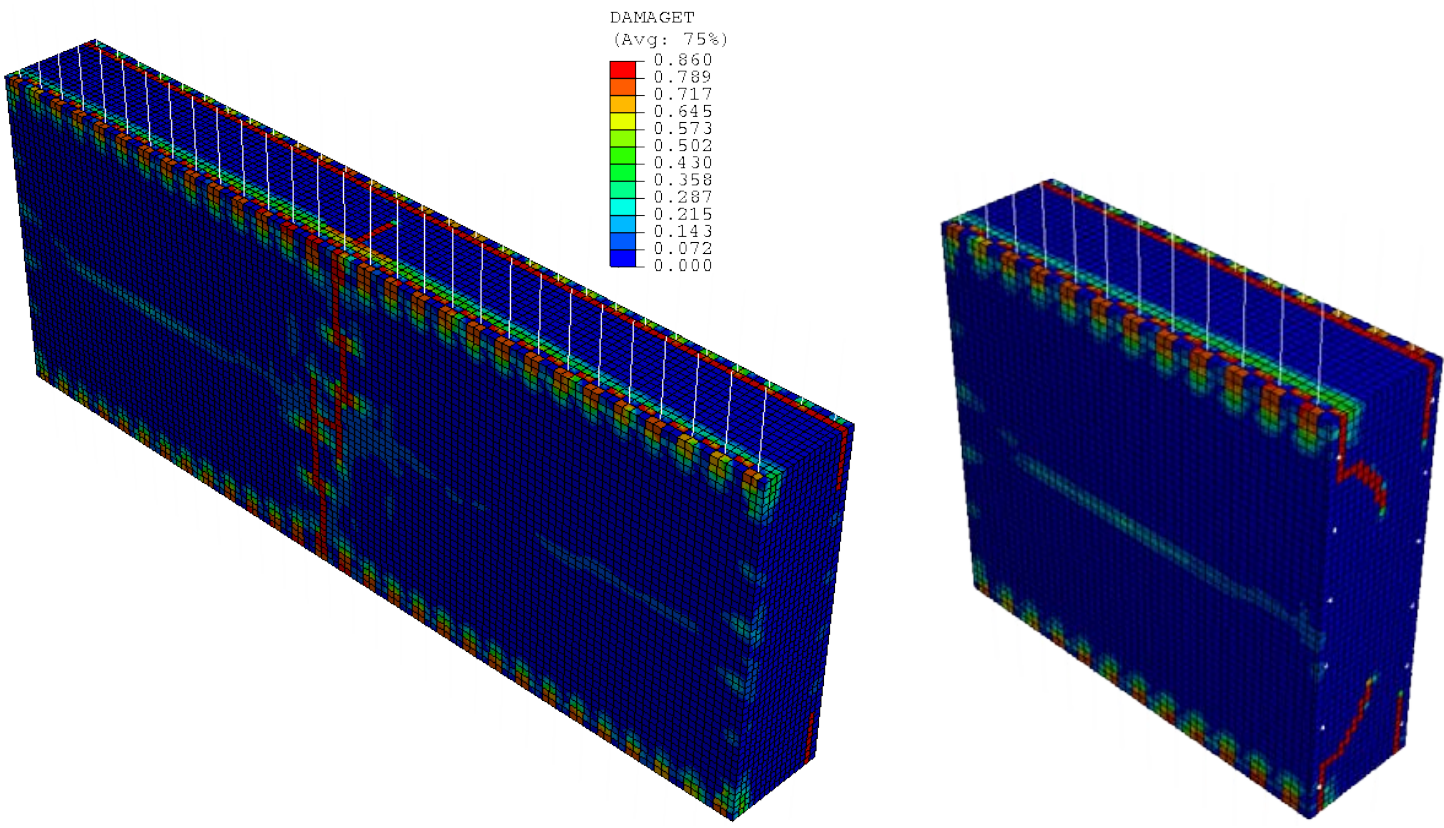

Entry dimension: $9 \mathrm{ft}$ x $24 \mathrm{ft}$, Seal thickness 34 in.
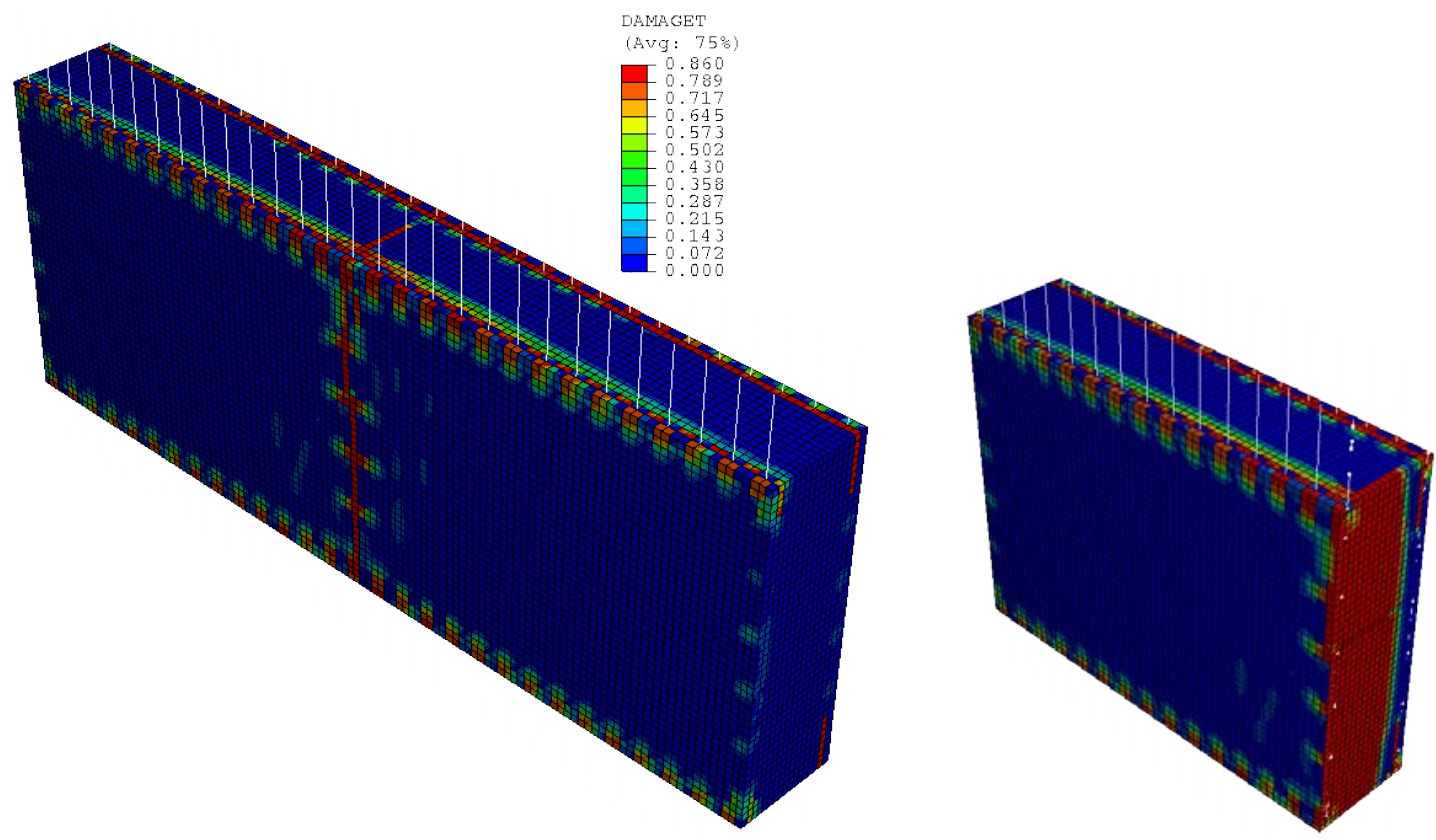

Entry dimension: $9 \mathrm{ft}$ x $24 \mathrm{ft}$, Seal thickness 36 in. 

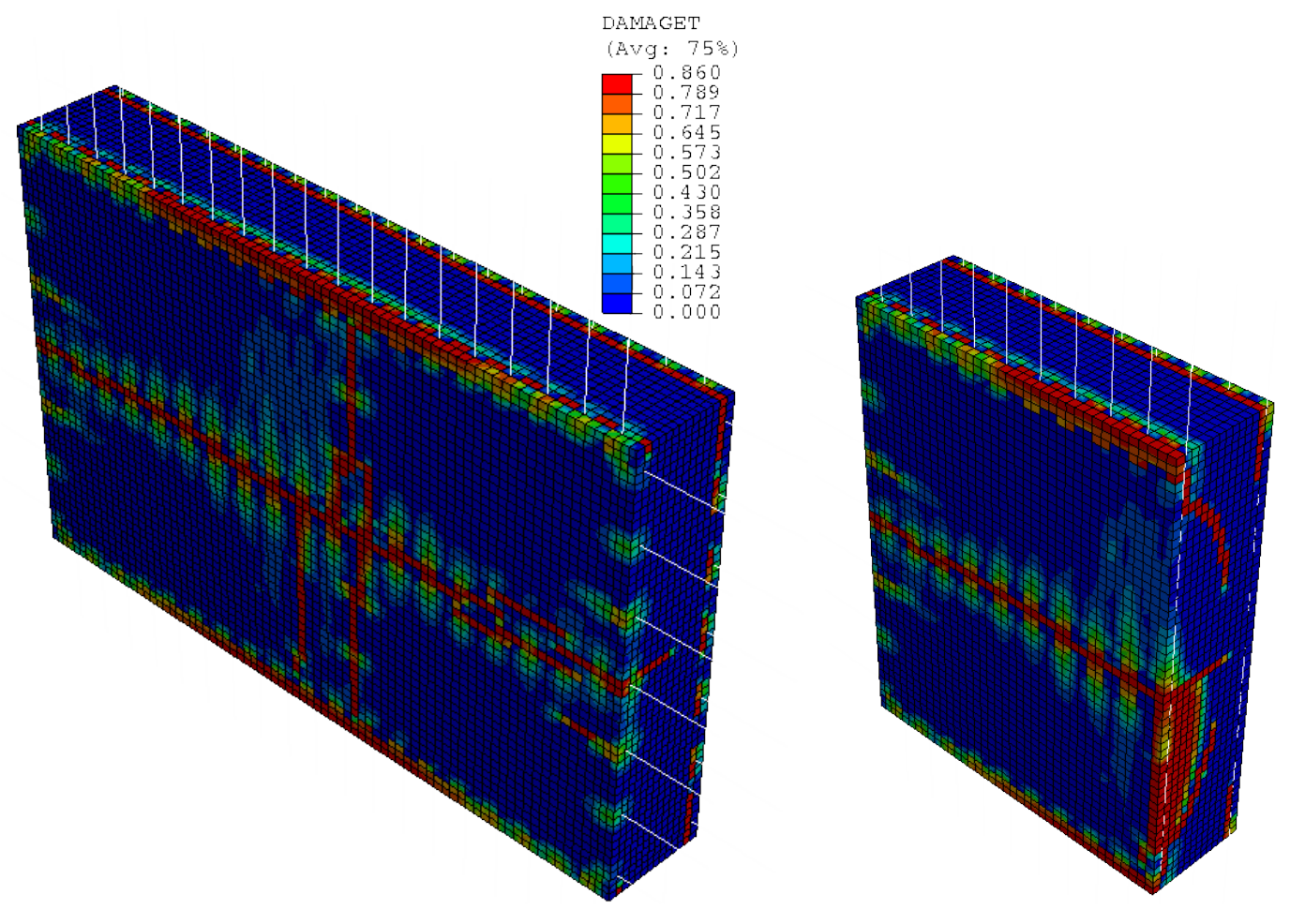

Entry dimension: $10 \mathrm{ft}$ x $16 \mathrm{ft}$, Seal thickness 30 in.
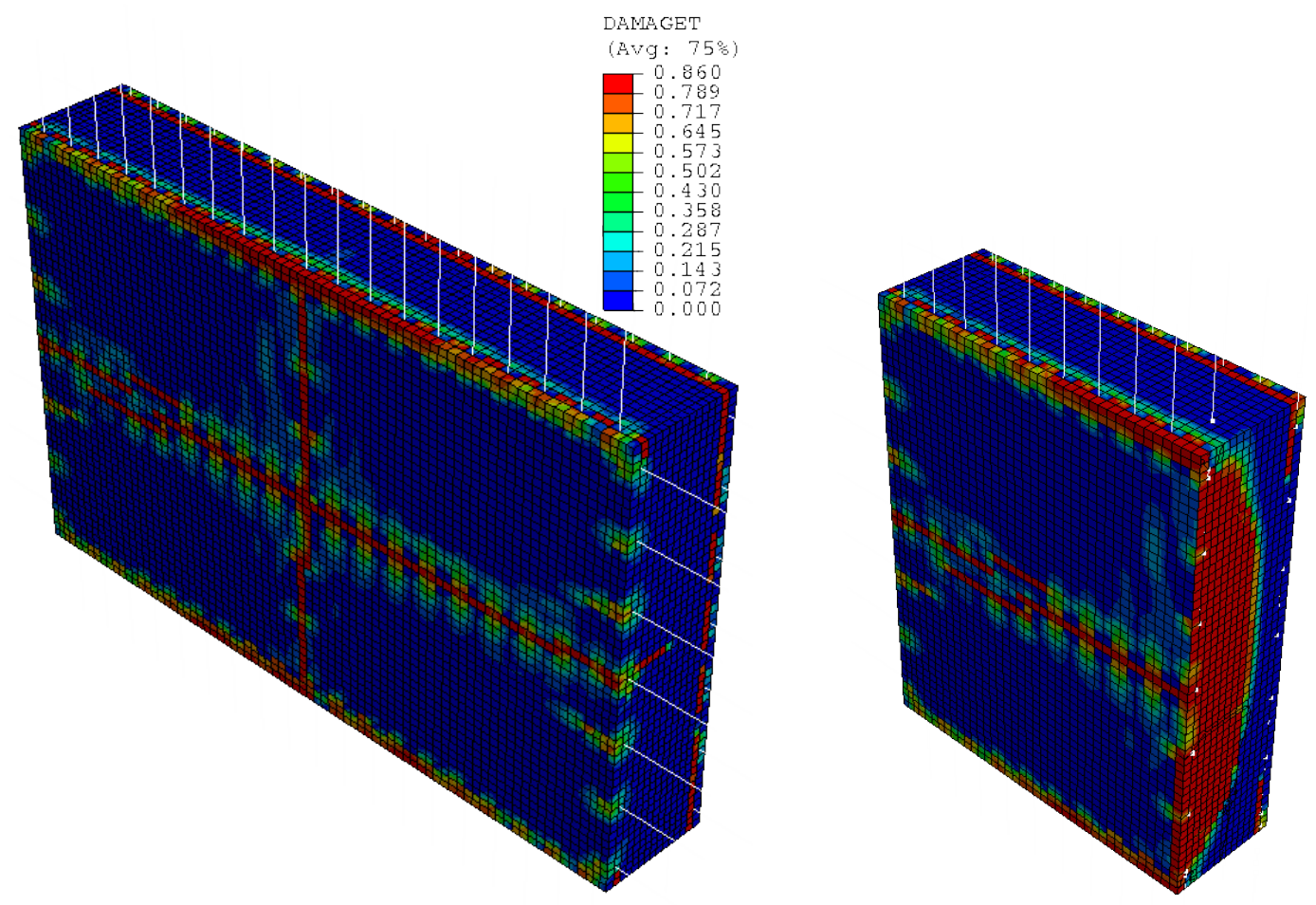

Entry dimension: $10 \mathrm{ft}$ x $16 \mathrm{ft}$, Seal thickness 32 in. 

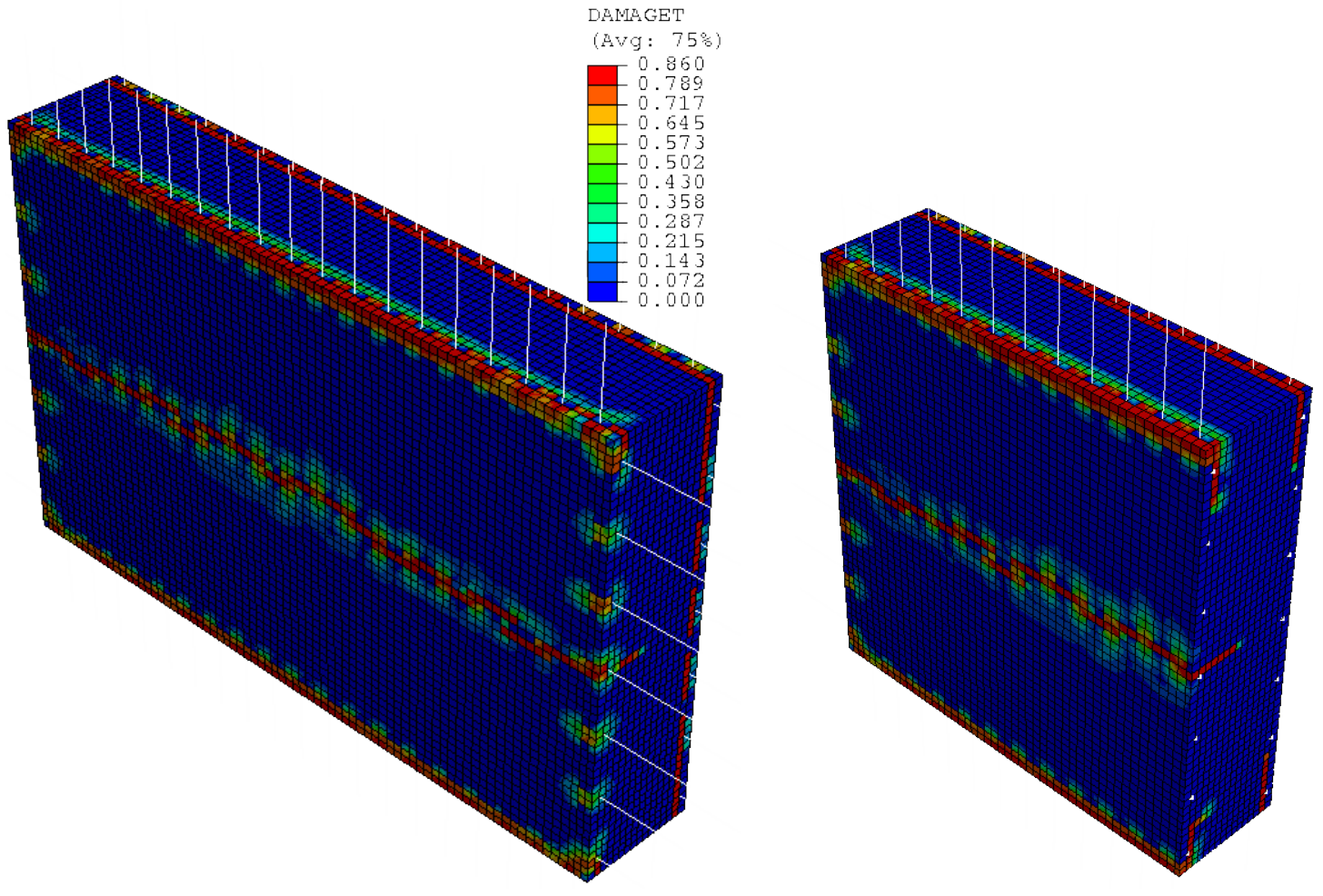

Entry dimension: $10 \mathrm{ft}$ x $16 \mathrm{ft}$, Seal thickness 34 in.
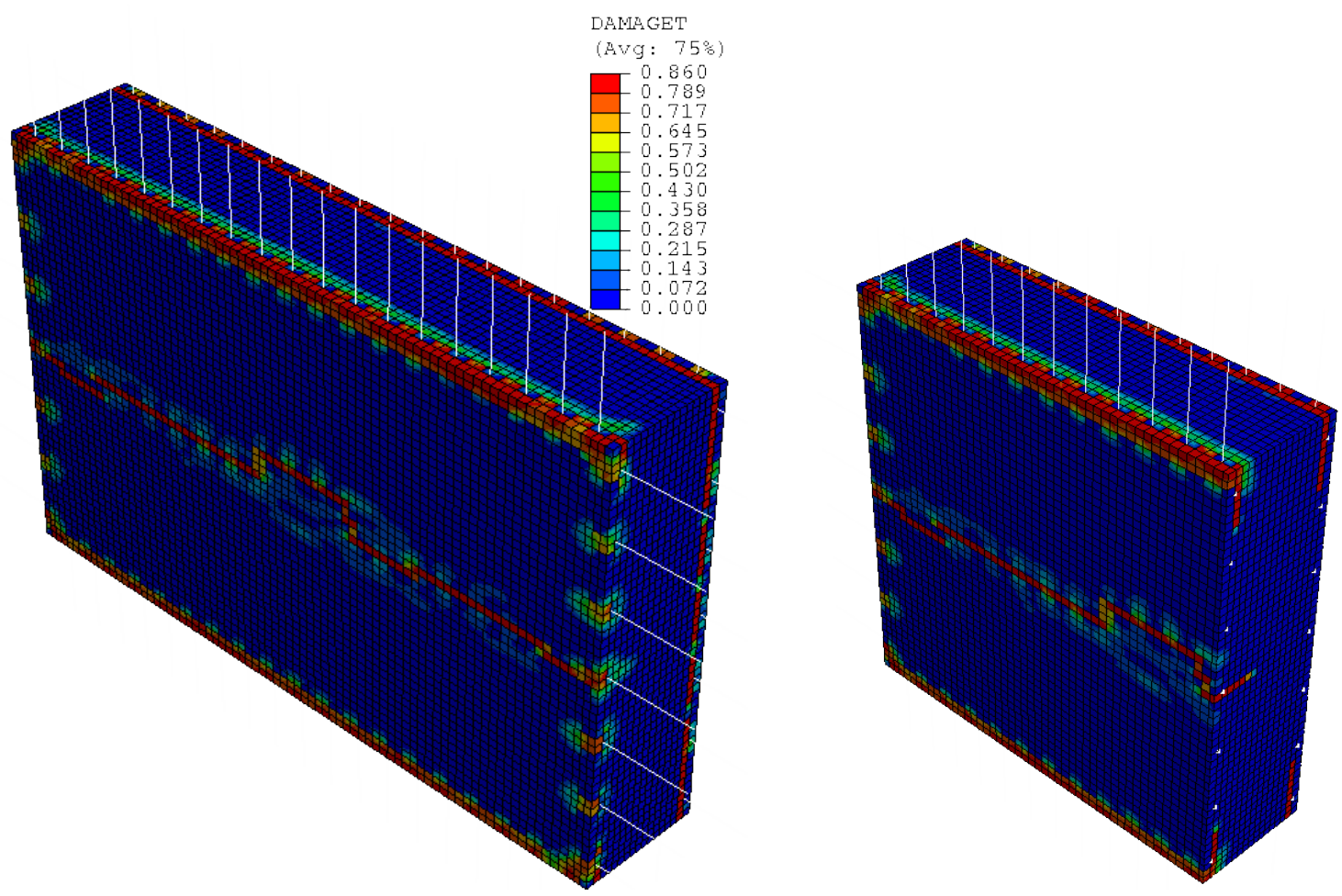

Entry dimension: $10 \mathrm{ft}$ x $16 \mathrm{ft}$, Seal thickness 36 in. 

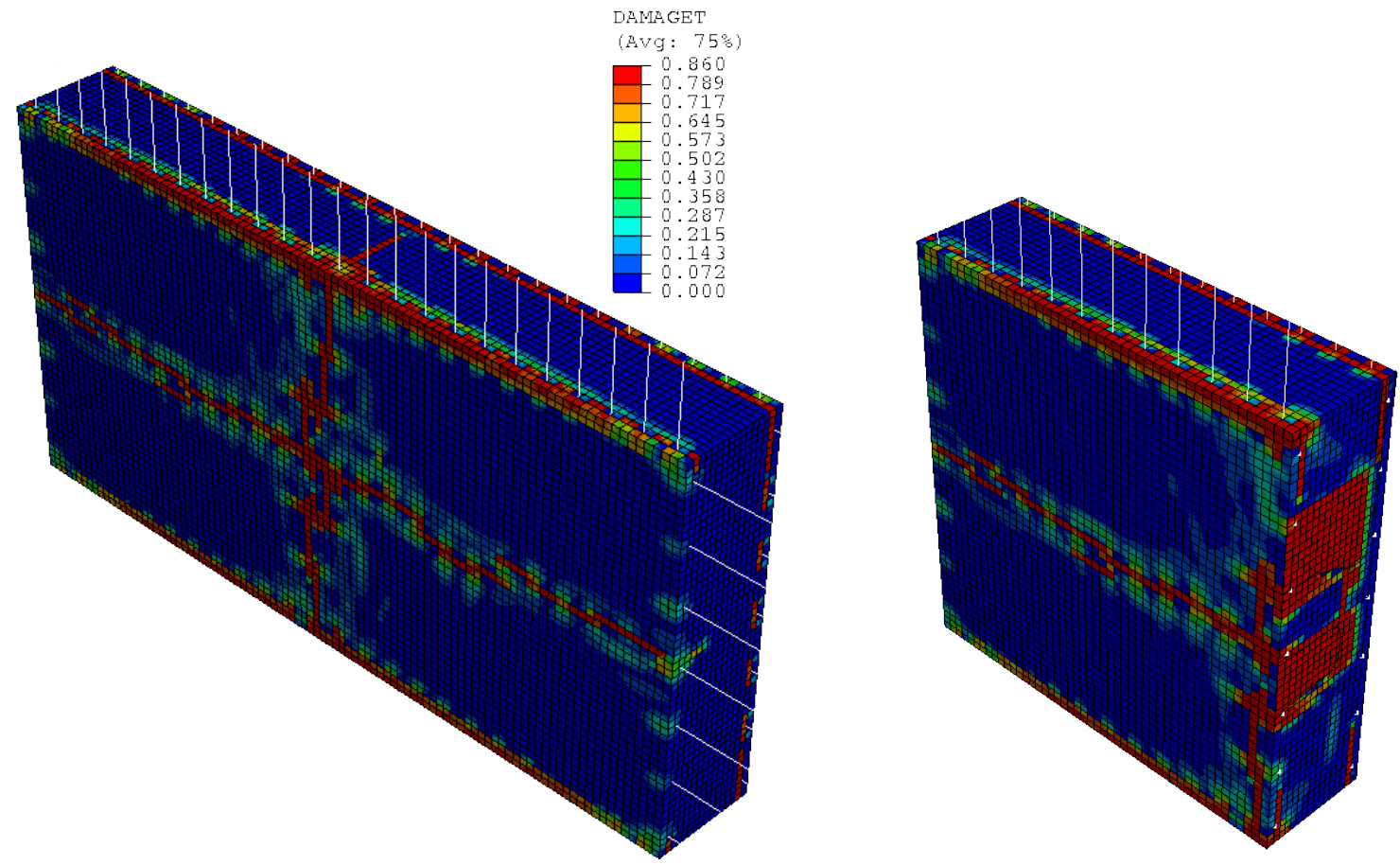

Entry dimension: $10 \mathrm{ft}$ x $20 \mathrm{ft}$, Seal thickness 34 in.
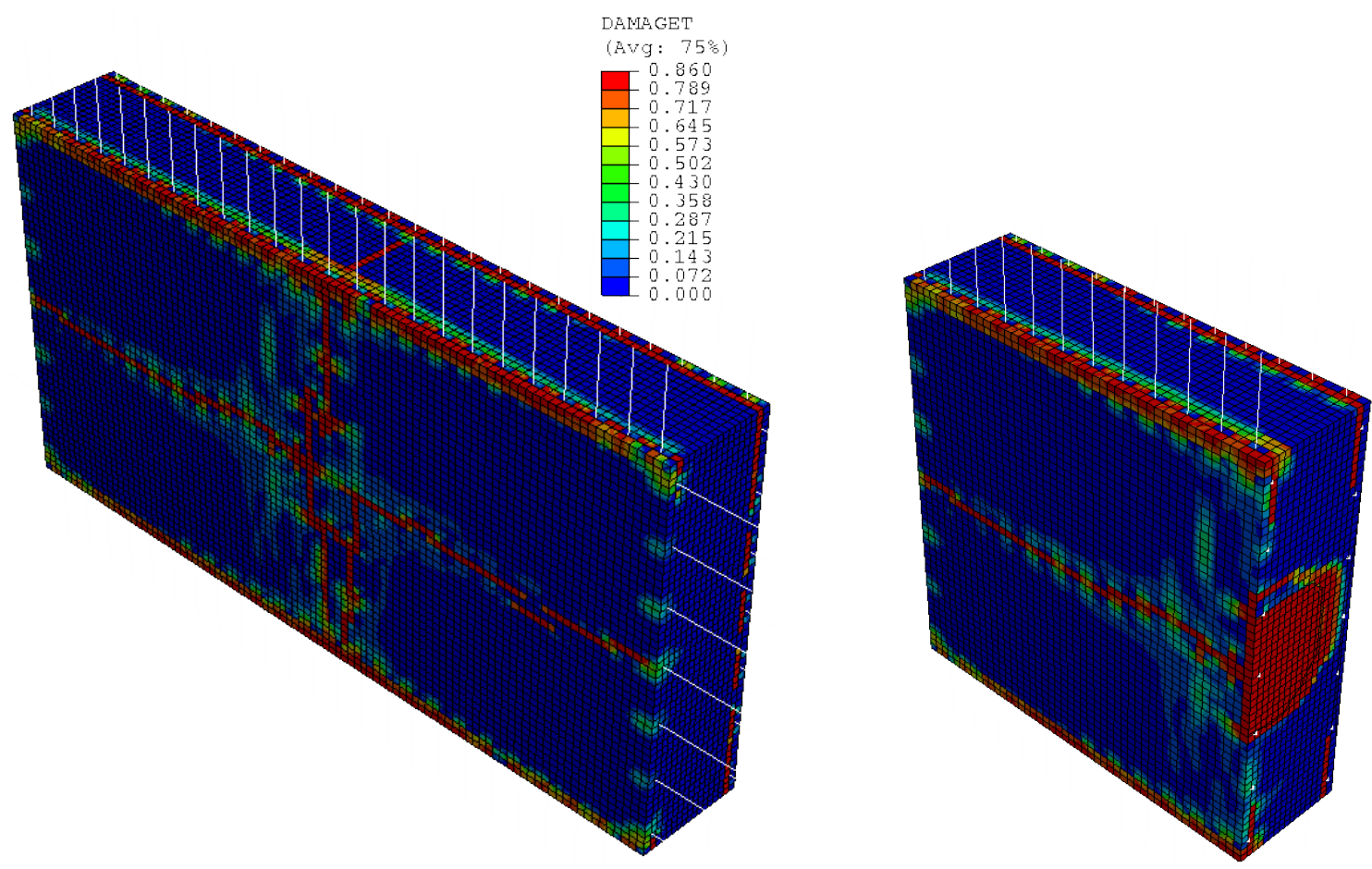

Entry dimension: $10 \mathrm{ft}$ x $20 \mathrm{ft}$, Seal thickness 36 in. 

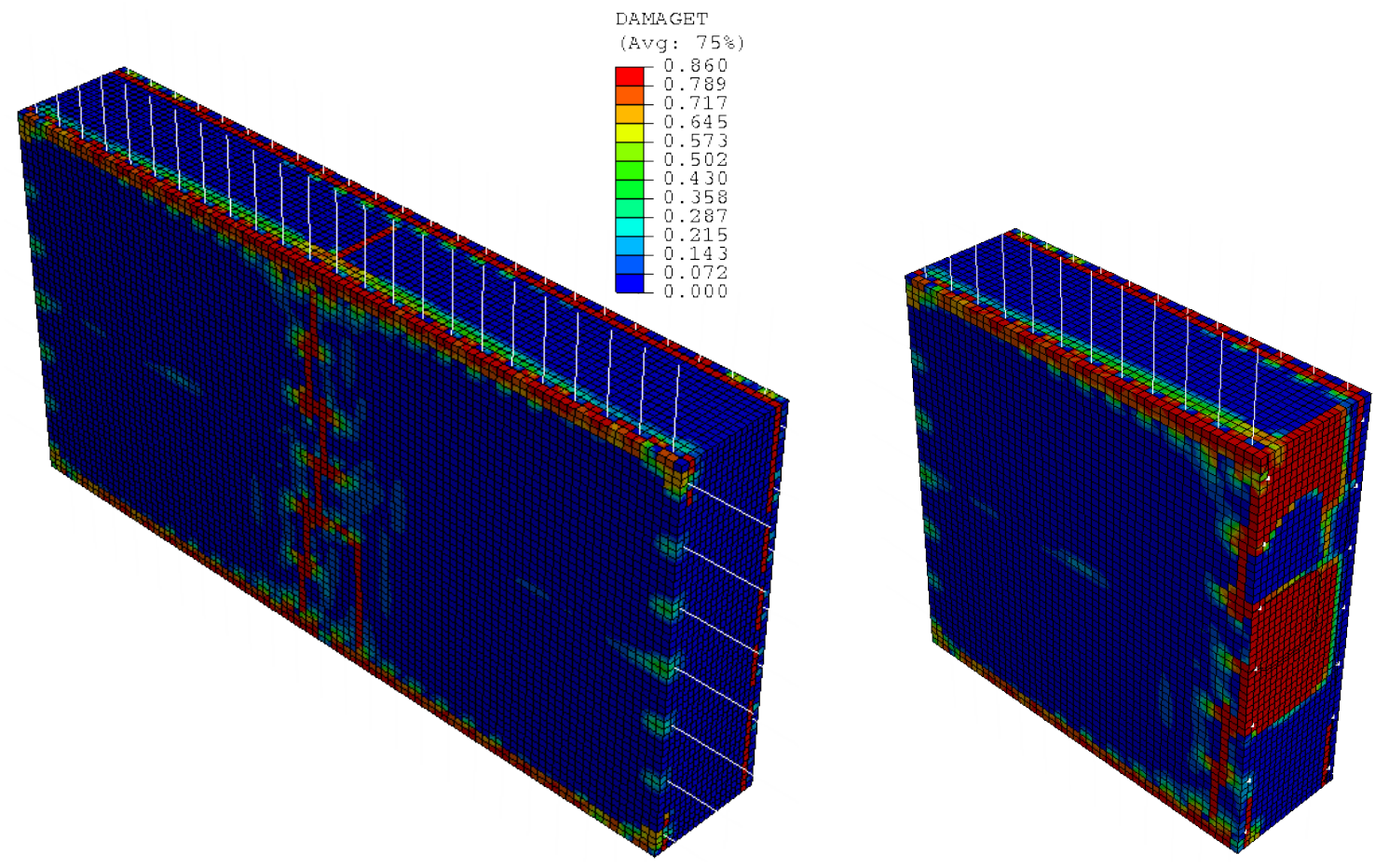

Entry dimension: $10 \mathrm{ft}$ x $20 \mathrm{ft}$, Seal thickness 38 in.
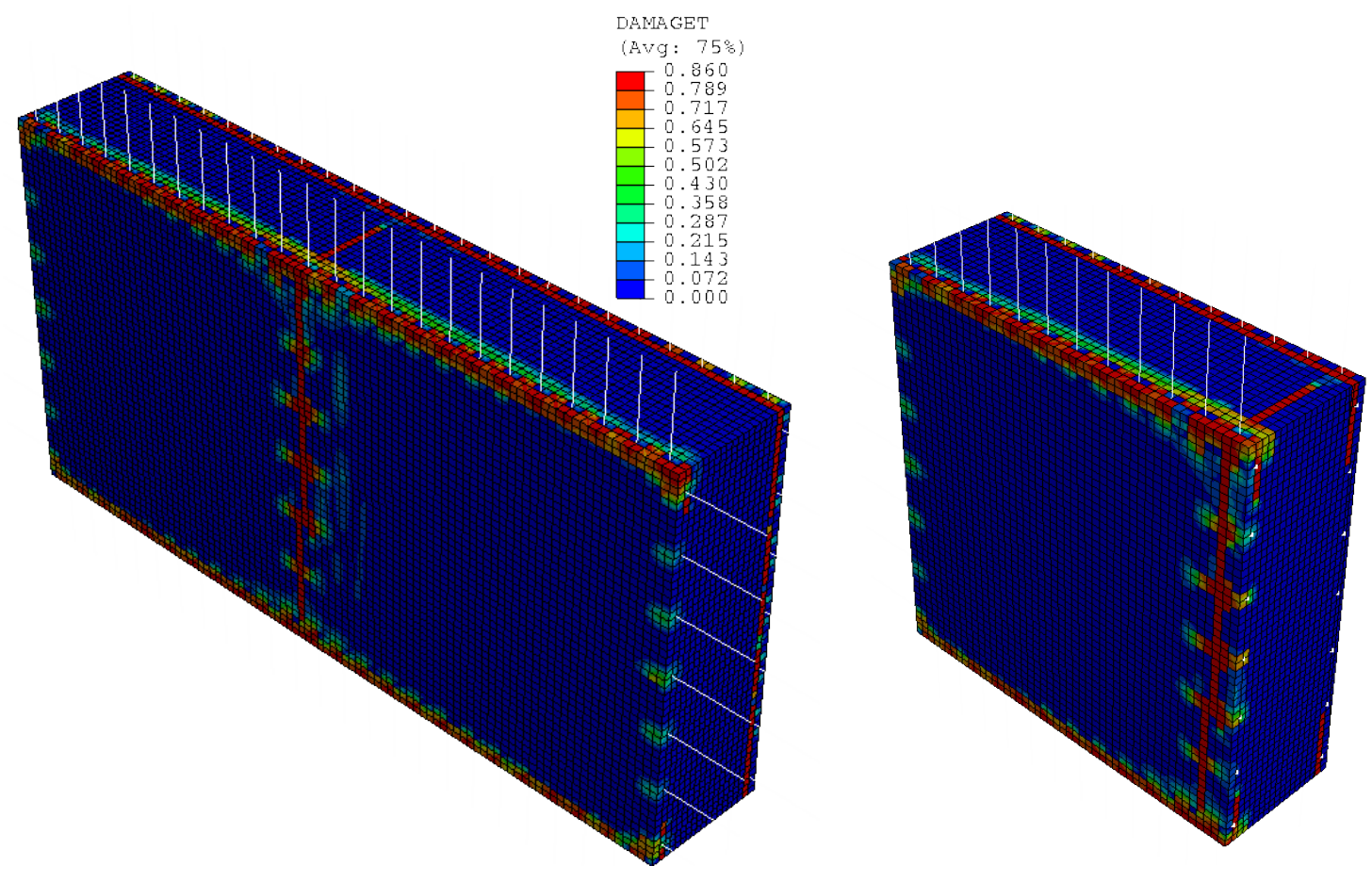

Entry dimension: $10 \mathrm{ft}$ x $20 \mathrm{ft}$, Seal thickness 40 in. 


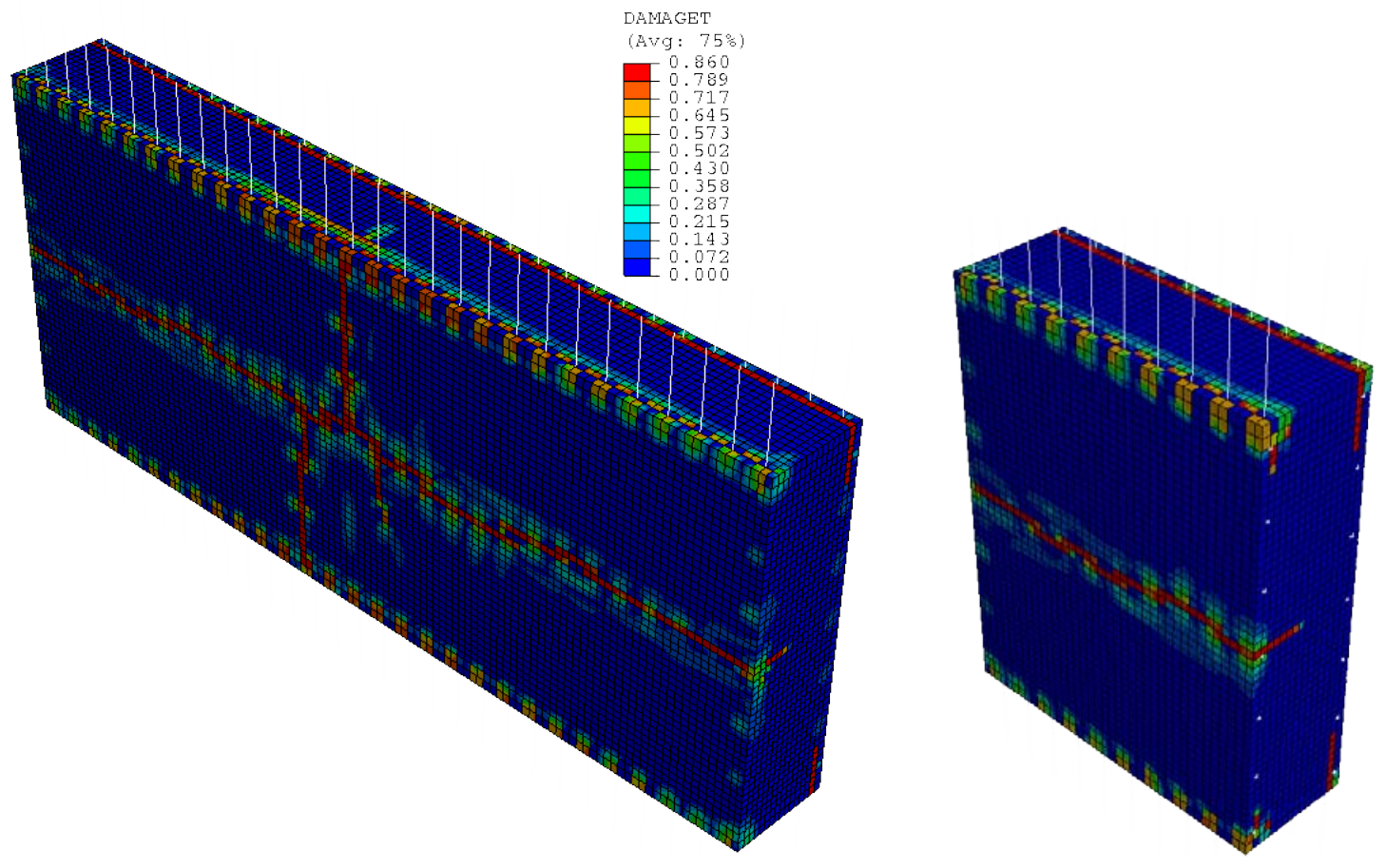

Entry dimension: $10 \mathrm{ft}$ x $24 \mathrm{ft}$, Seal thickness 34 in.

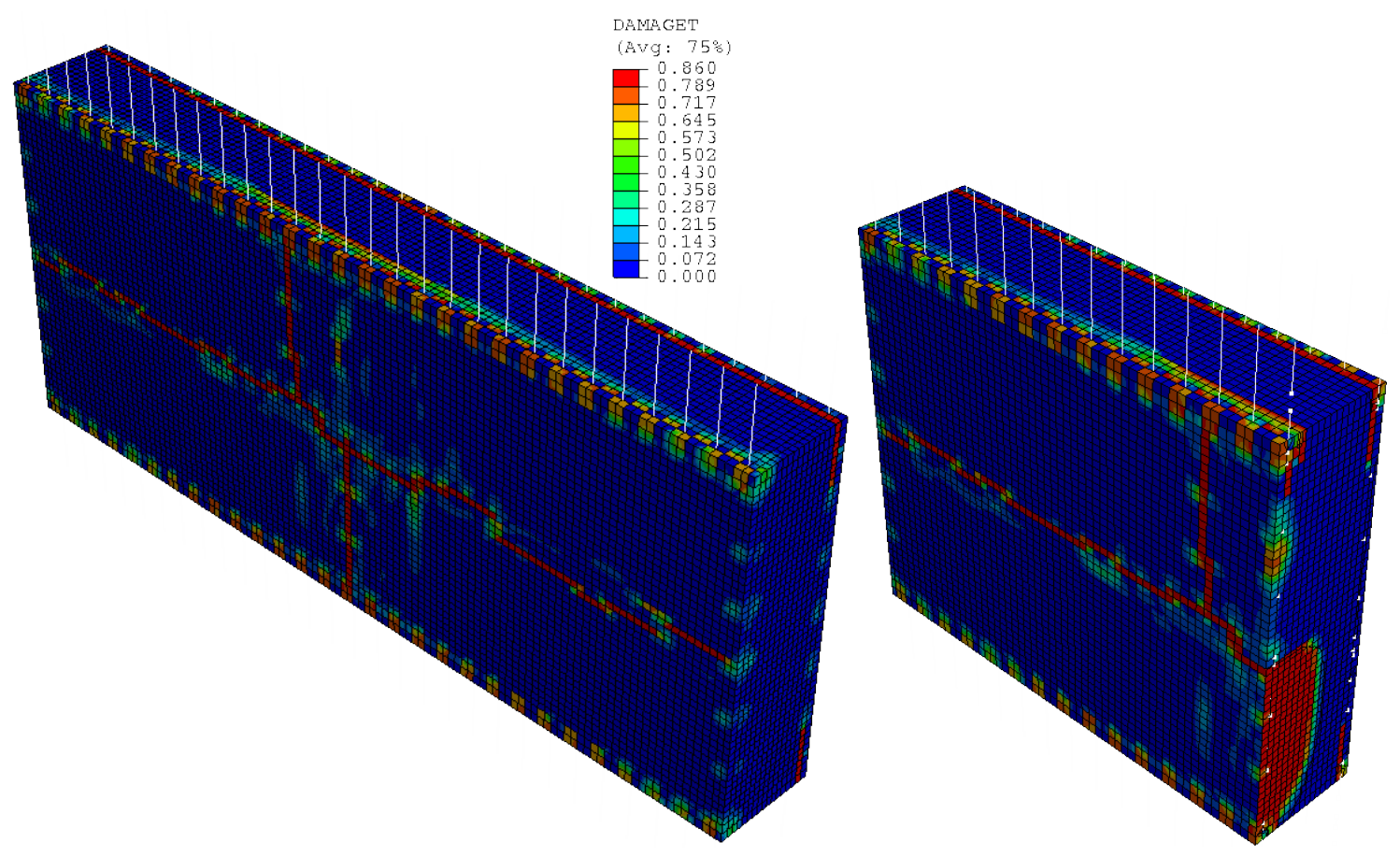

Entry dimension: $10 \mathrm{ft}$ x $24 \mathrm{ft}$, Seal thickness 36 in. 


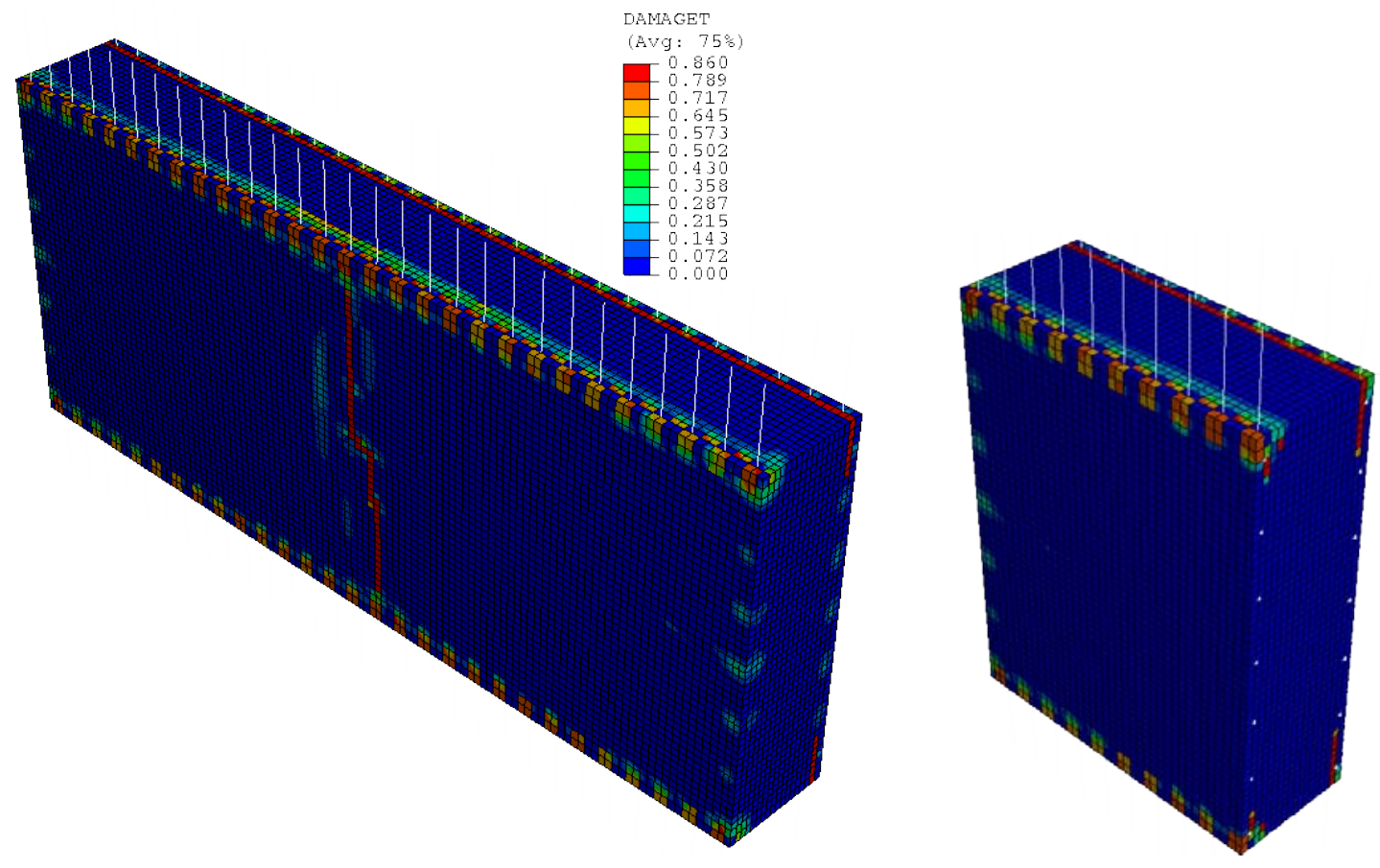

Entry dimension: $10 \mathrm{ft}$ x $24 \mathrm{ft}$, Seal thickness 38 in.

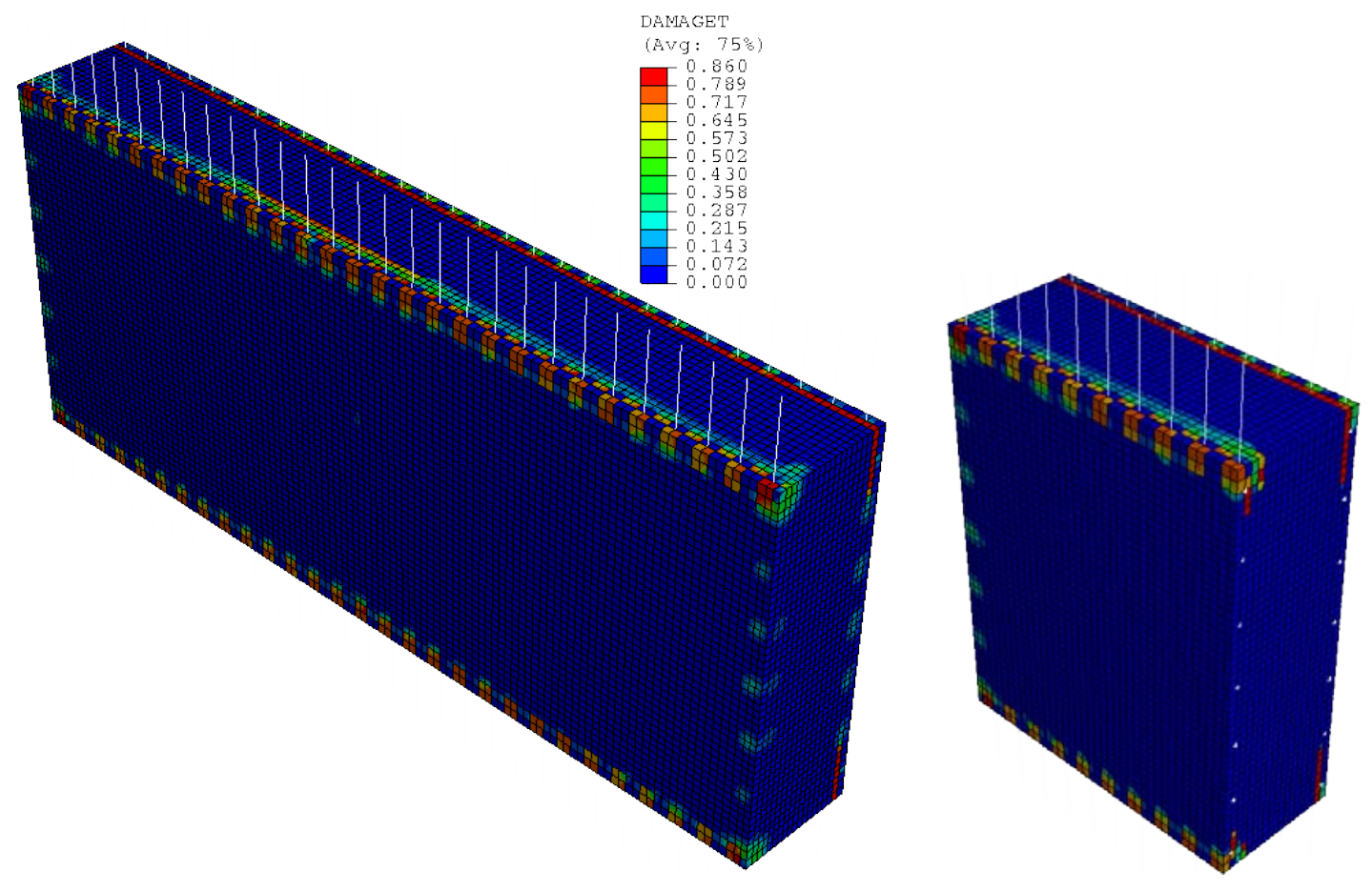

Entry dimension: $10 \mathrm{ft}$ x $24 \mathrm{ft}$, Seal thickness $40 \mathrm{in}$. 

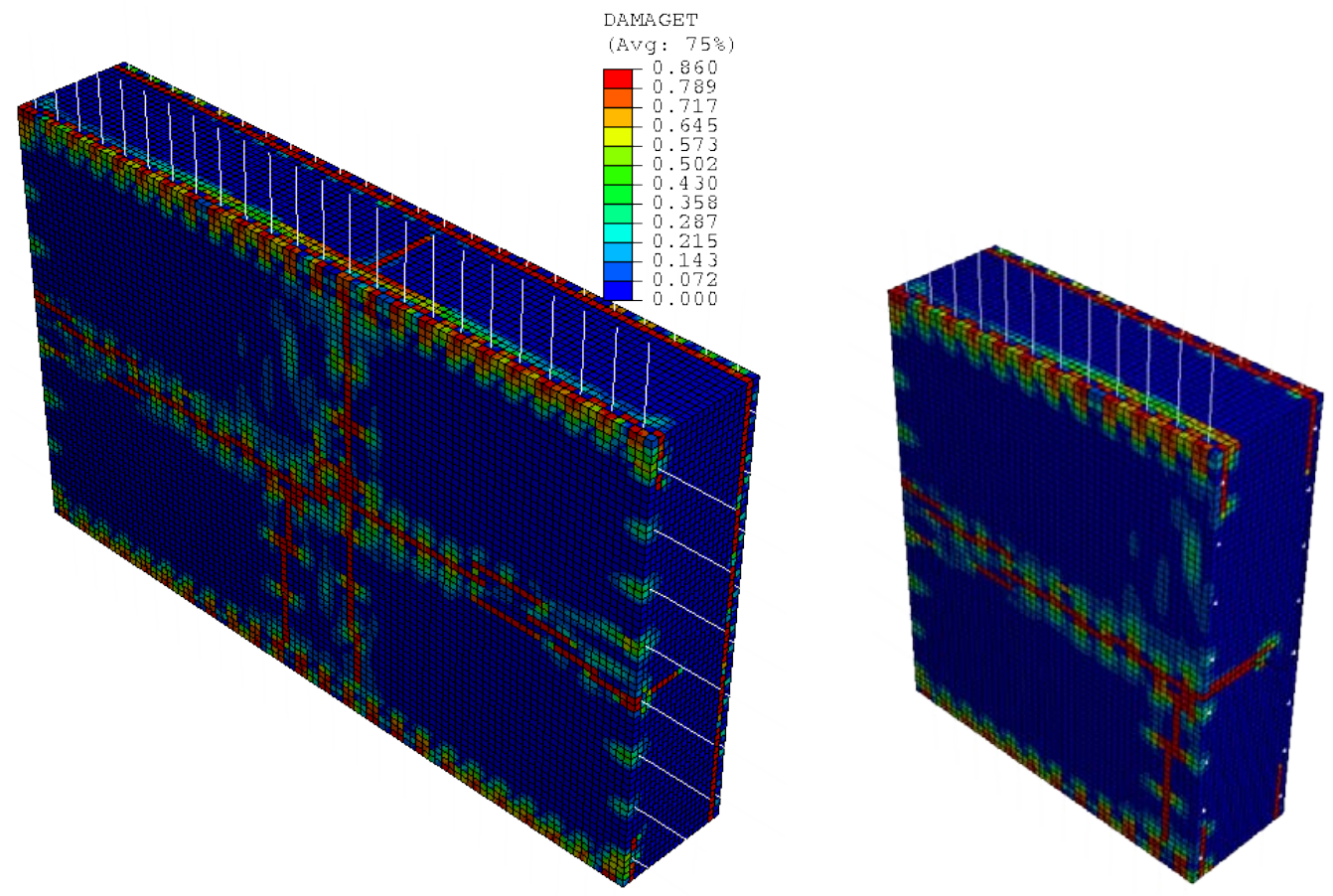

Entry dimension: $12 \mathrm{ft}$ x $20 \mathrm{ft}$, Seal thickness 40 in.
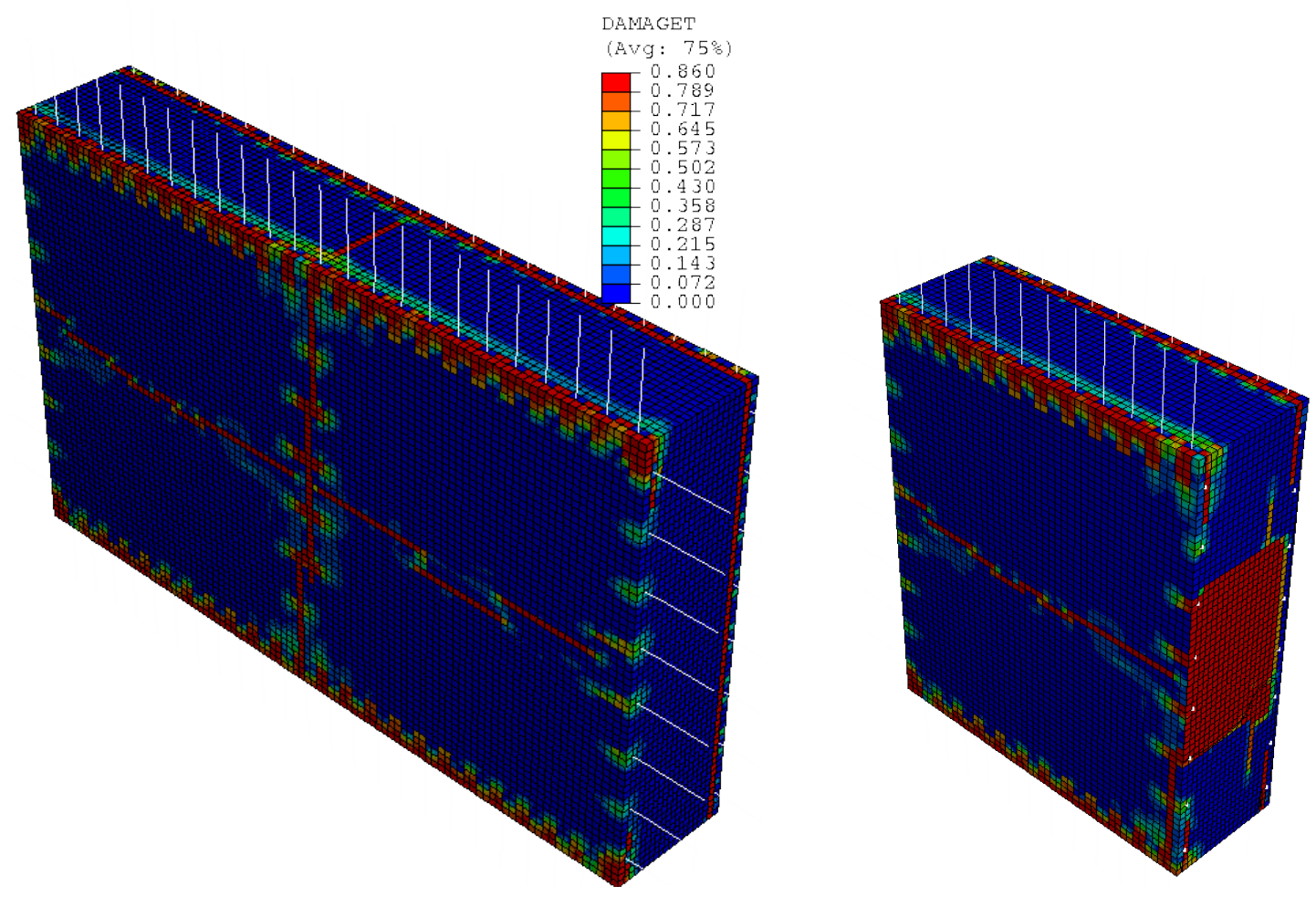

Entry dimension: $12 \mathrm{ft}$ x $20 \mathrm{ft}$, Seal thickness 42 in. 

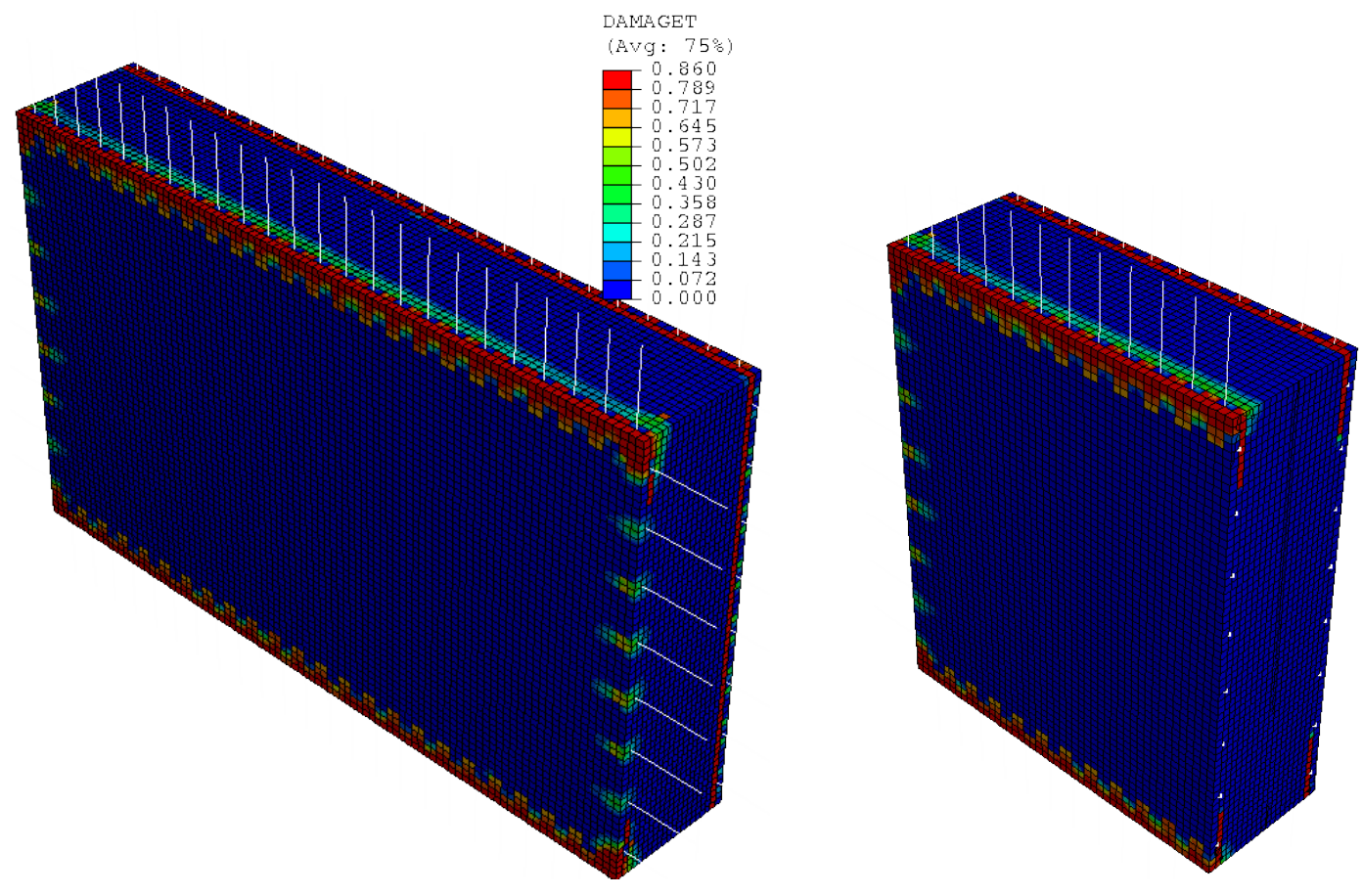

Entry dimension: $12 \mathrm{ft}$ x $20 \mathrm{ft}$, Seal thickness 44 in.
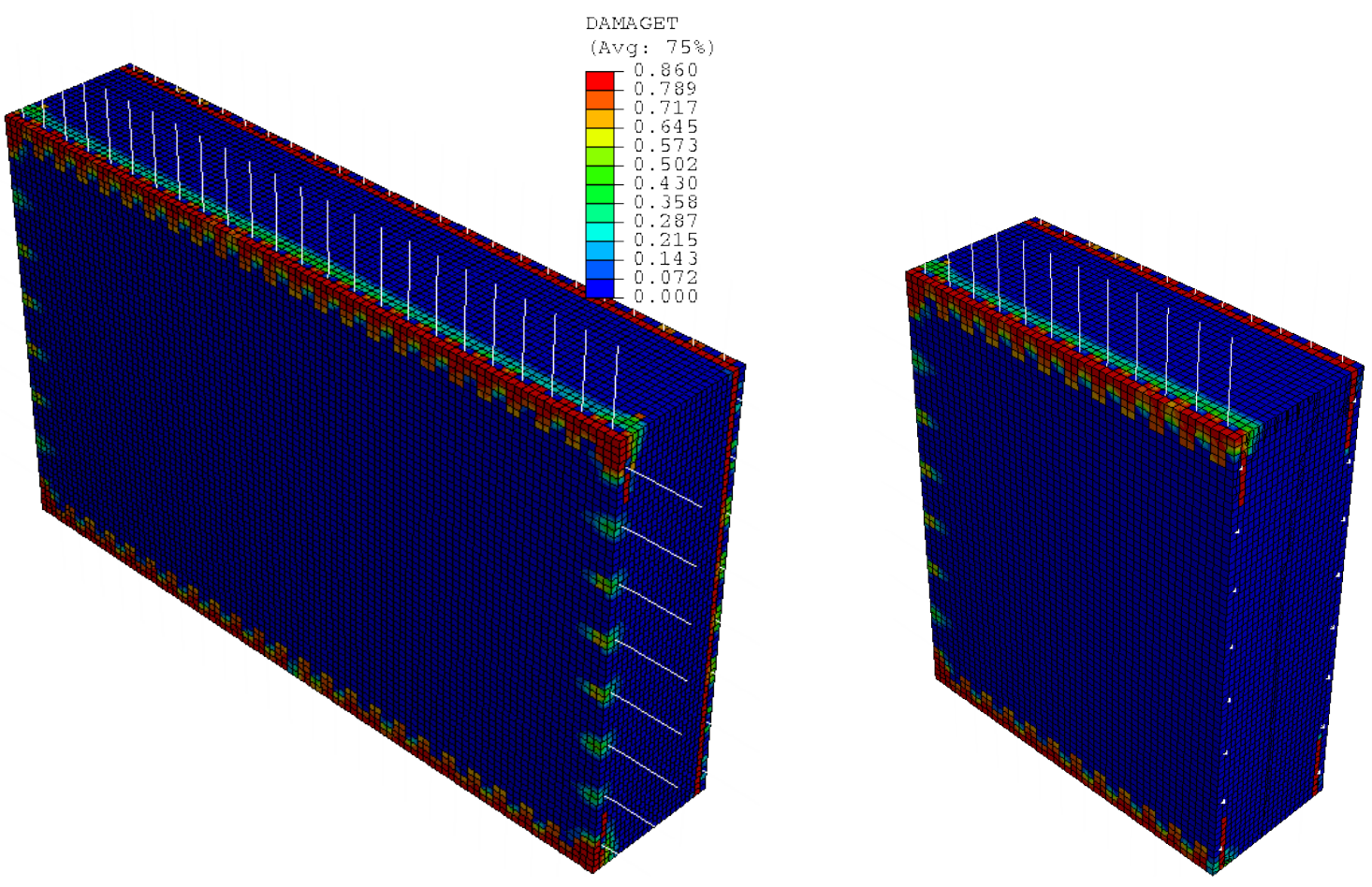

Entry dimension: $12 \mathrm{ft}$ x $20 \mathrm{ft}$, Seal thickness 48 in. 

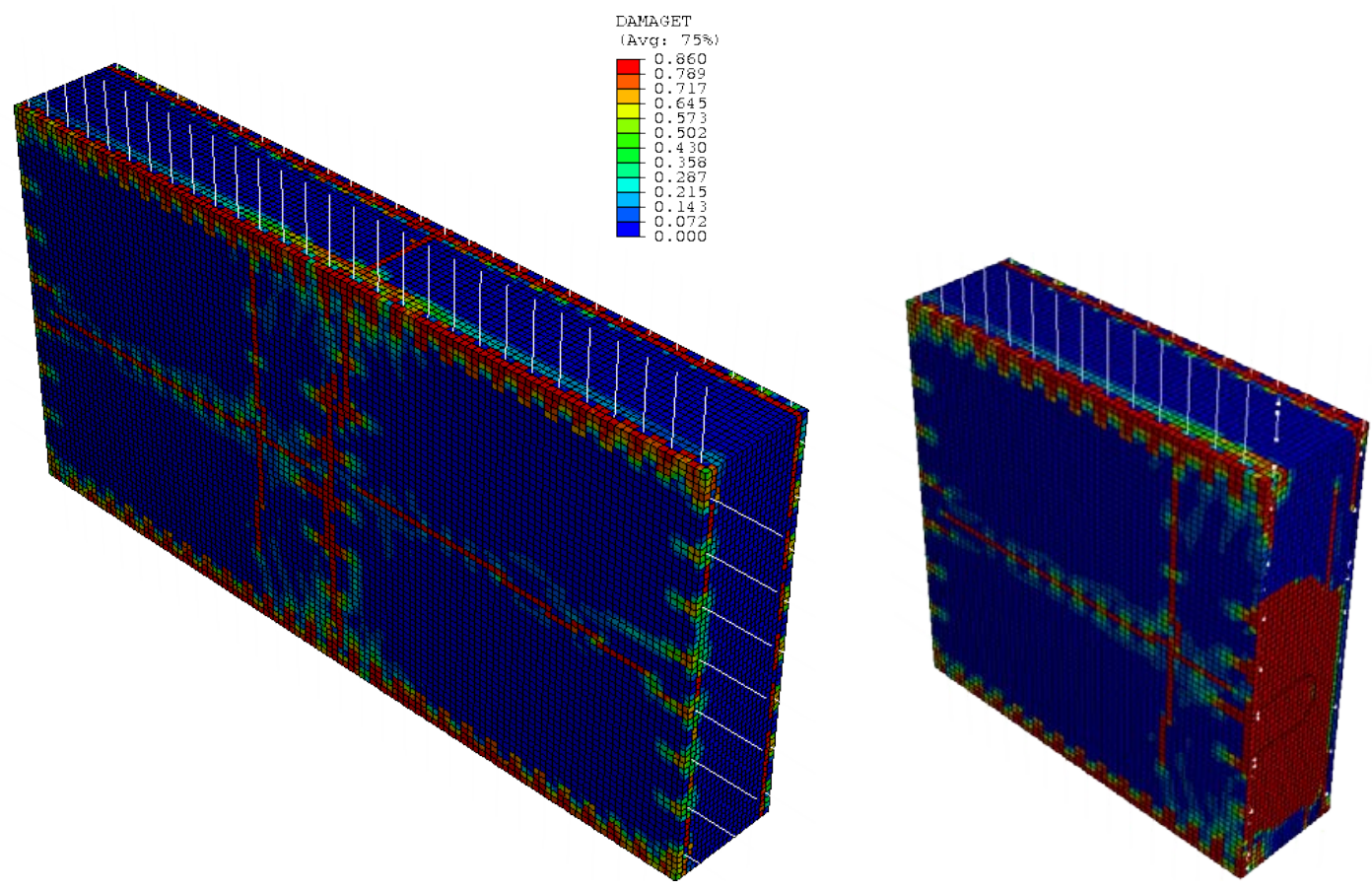

Entry dimension: $12 \mathrm{ft}$ x $24 \mathrm{ft}$, Seal thickness 42 in.
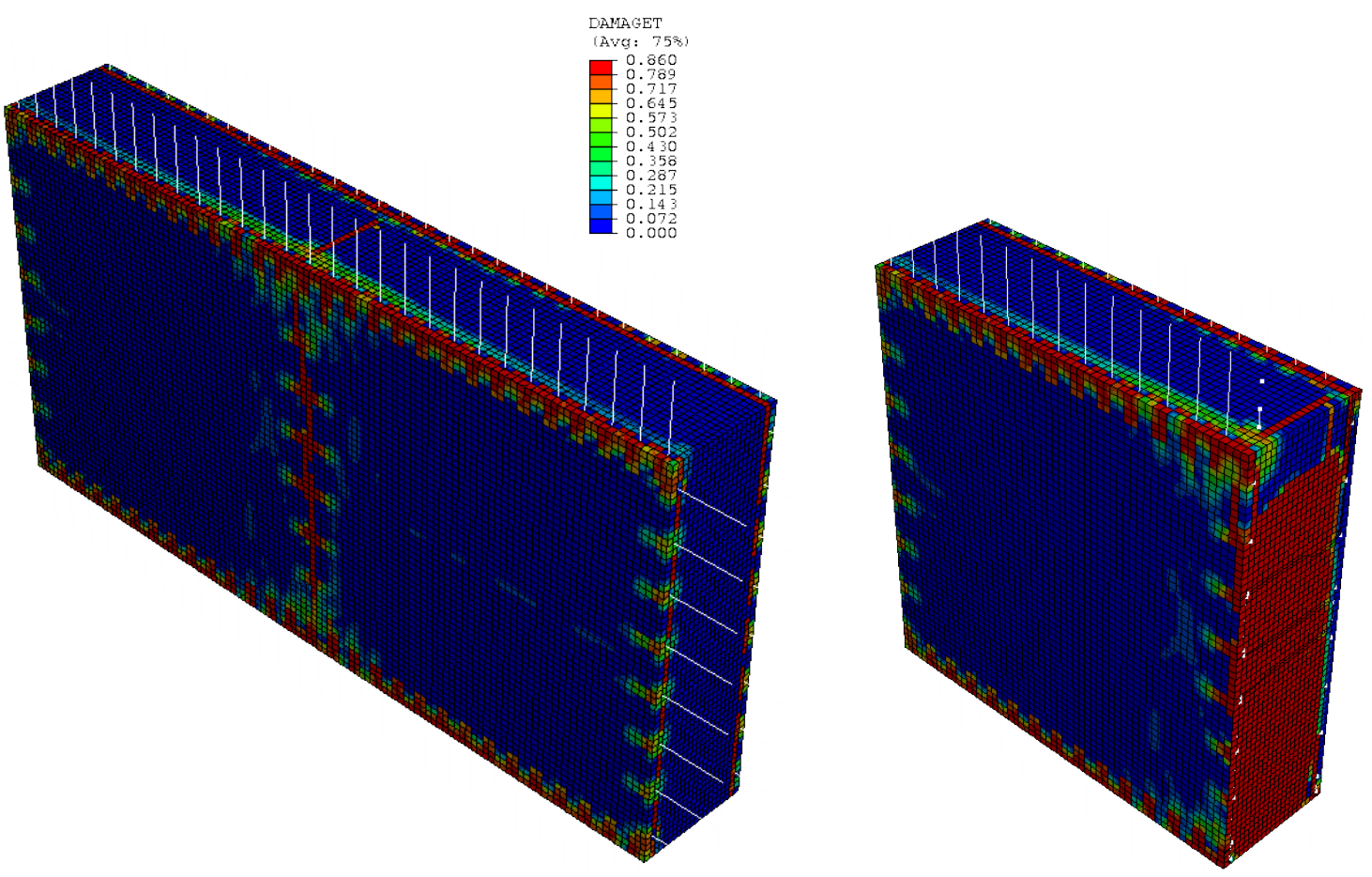

Entry dimension: $12 \mathrm{ft}$ x $24 \mathrm{ft}$, Seal thickness 44 in. 


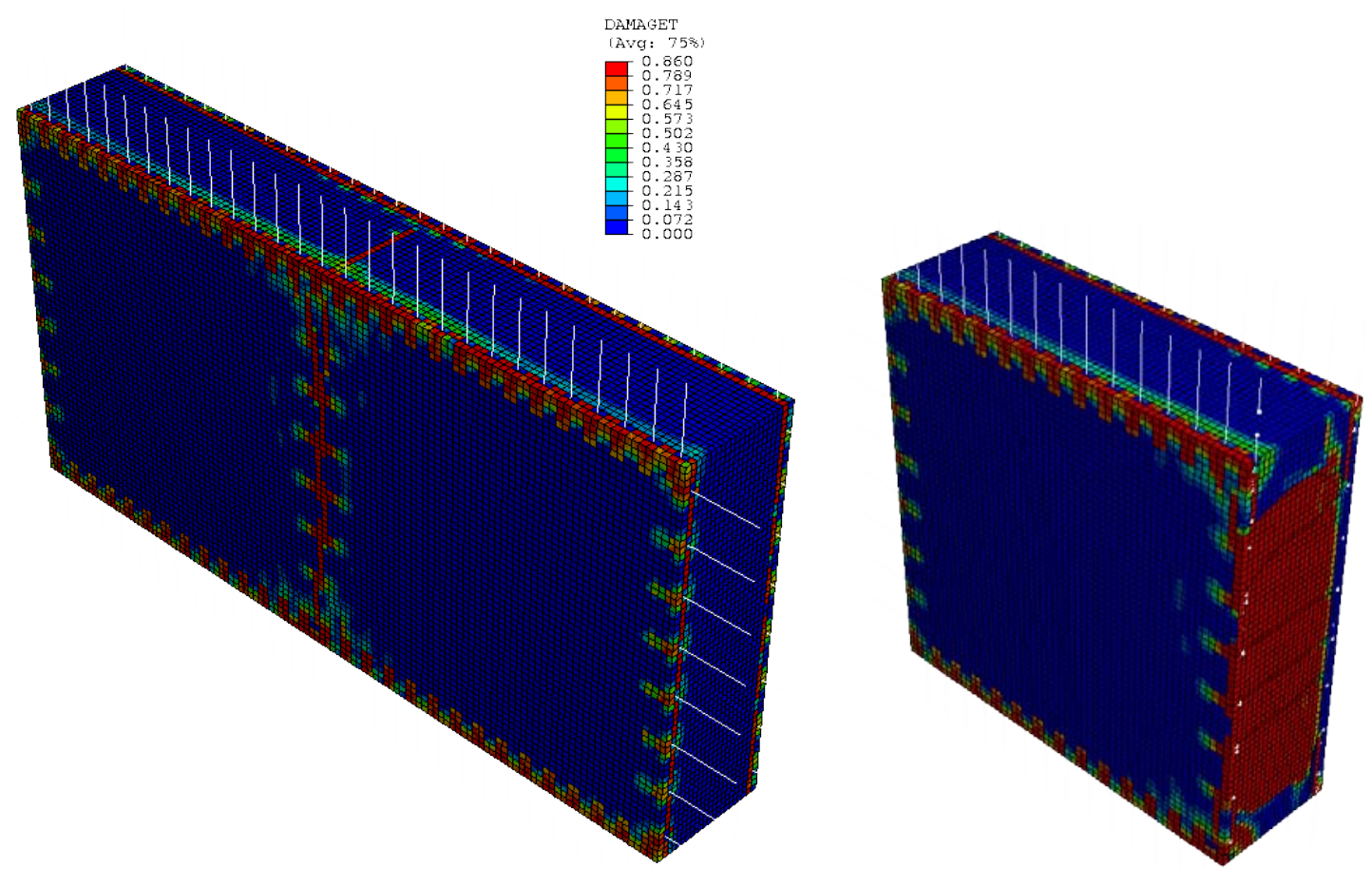

Entry dimension: $12 \mathrm{ft}$ x $24 \mathrm{ft}$, Seal thickness 46 in.

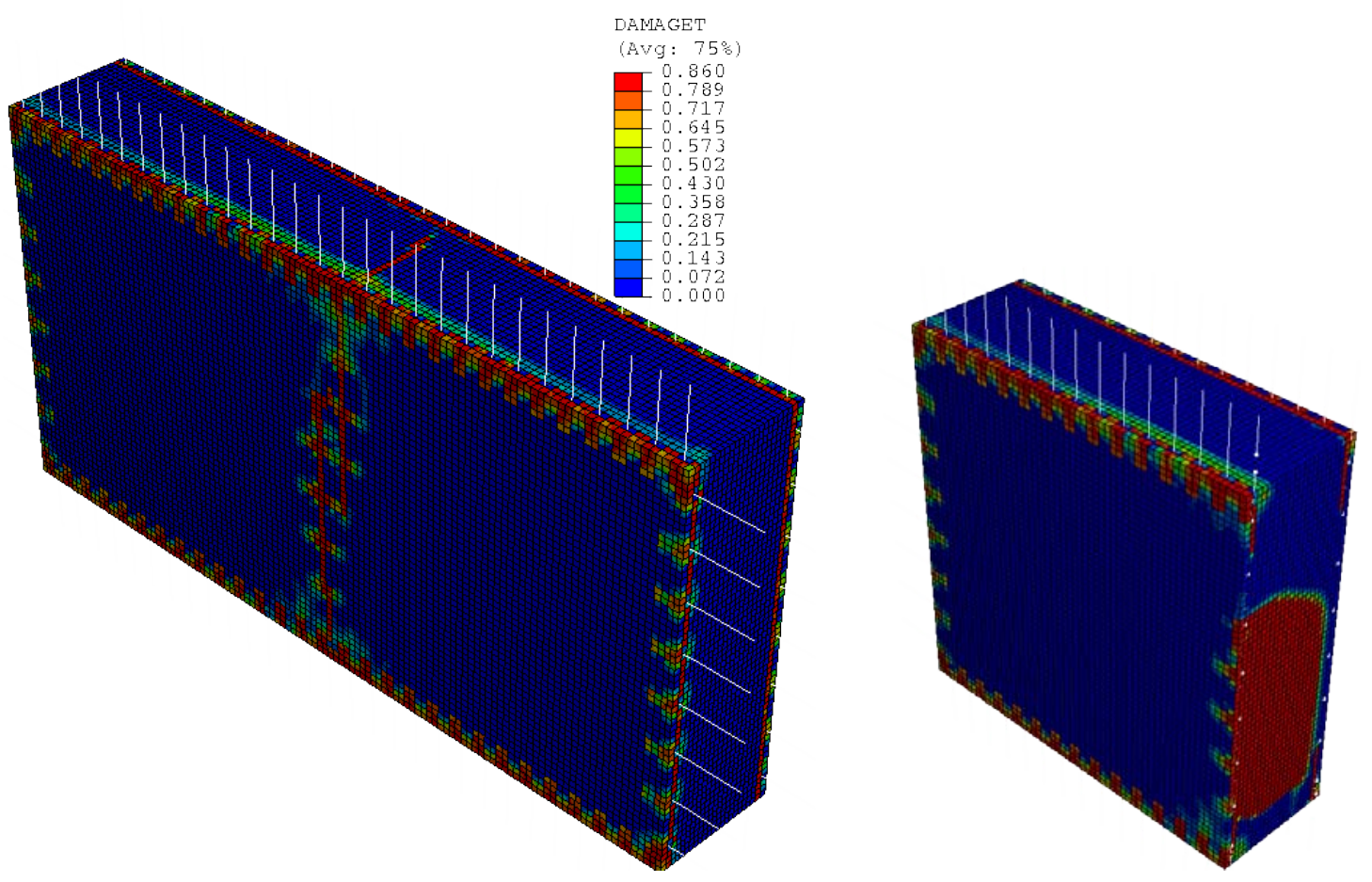

Entry dimension: $12 \mathrm{ft}$ x $24 \mathrm{ft}$, Seal thickness 48 in. 


\section{APPENDIX II}

History of lateral displacements in the seals (Outby_M) for different entry dimensions 


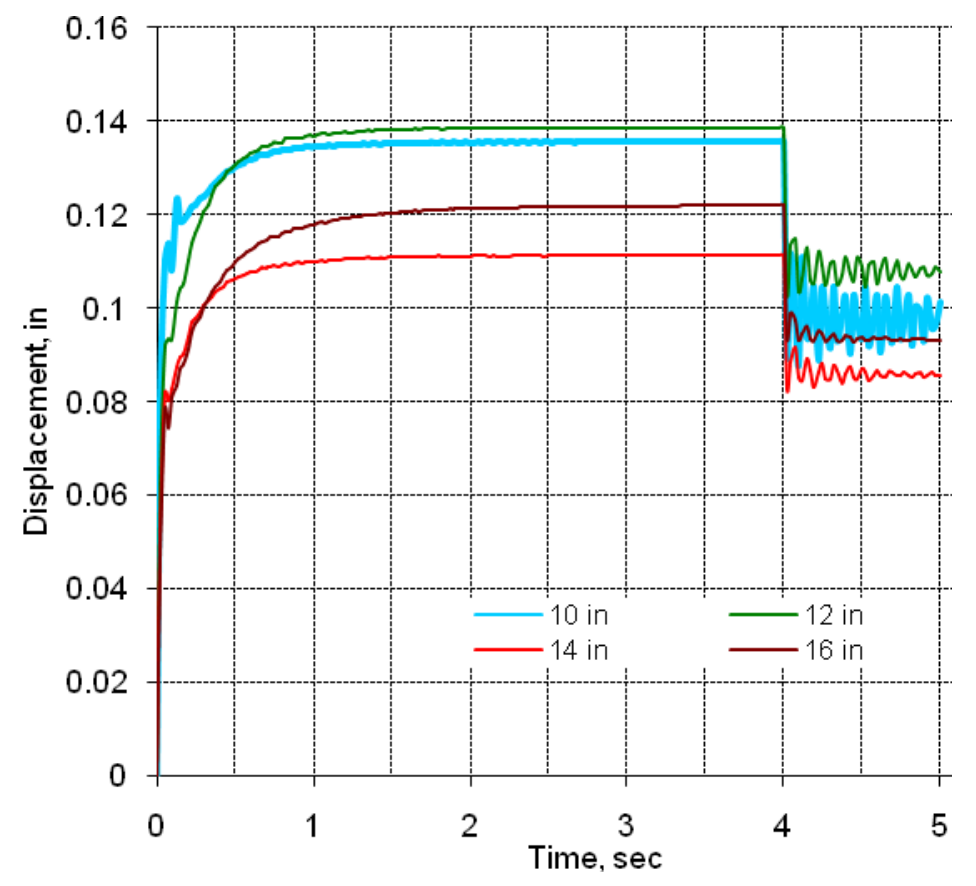

Lateral displacement history, entry dimension: $4 \mathrm{ft}$ x $16 \mathrm{ft}$

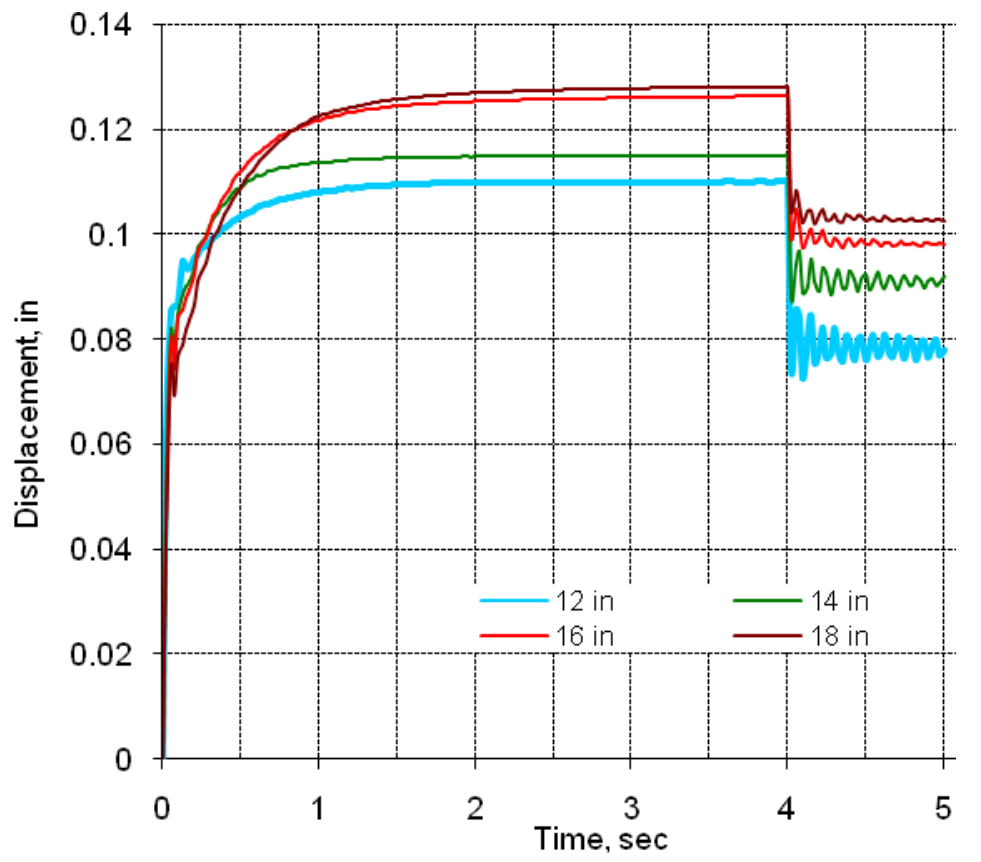

Lateral displacement history, entry dimension: $4 \mathrm{ft}$ x $20 \mathrm{ft}$ 


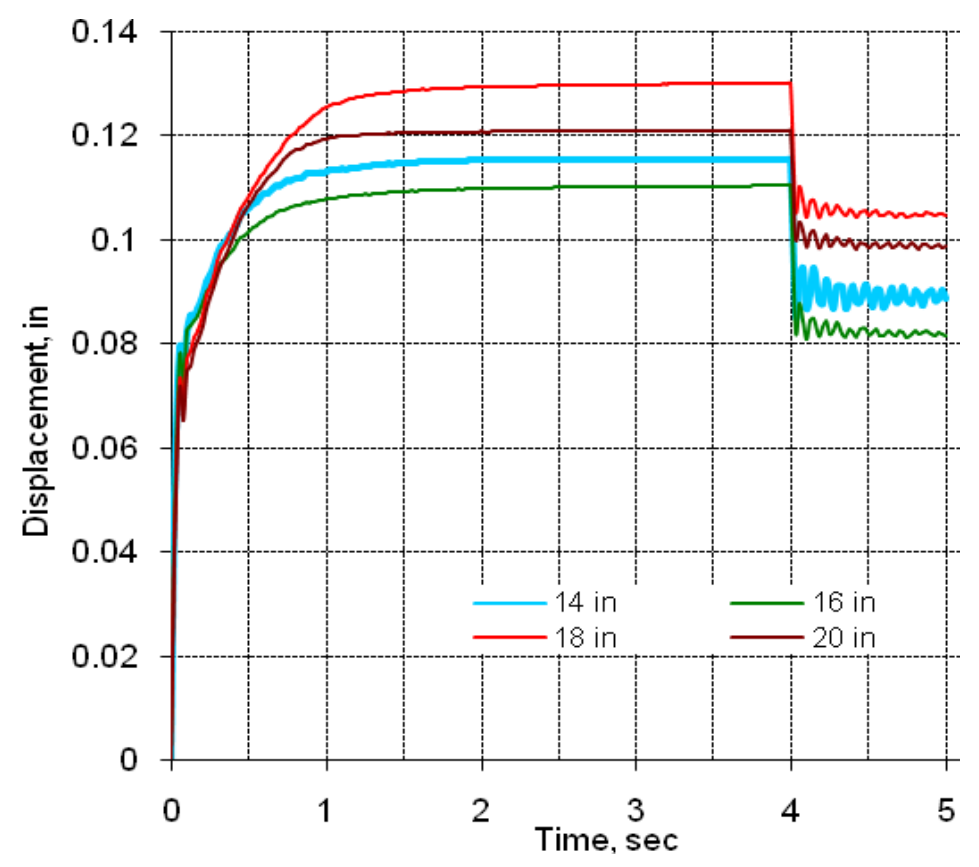

Lateral displacement history, entry dimension: $4 \mathrm{ft}$ x $24 \mathrm{ft}$

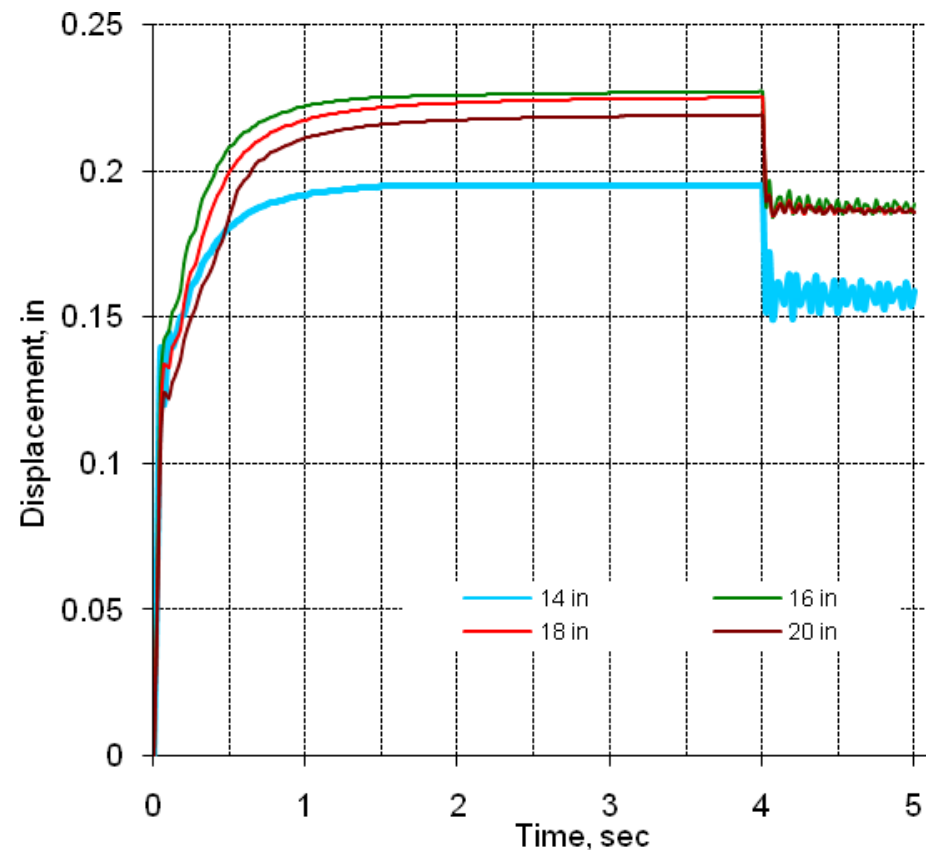

Lateral displacement history, entry dimension: $5 \mathrm{ft}$ x $16 \mathrm{ft}$ 


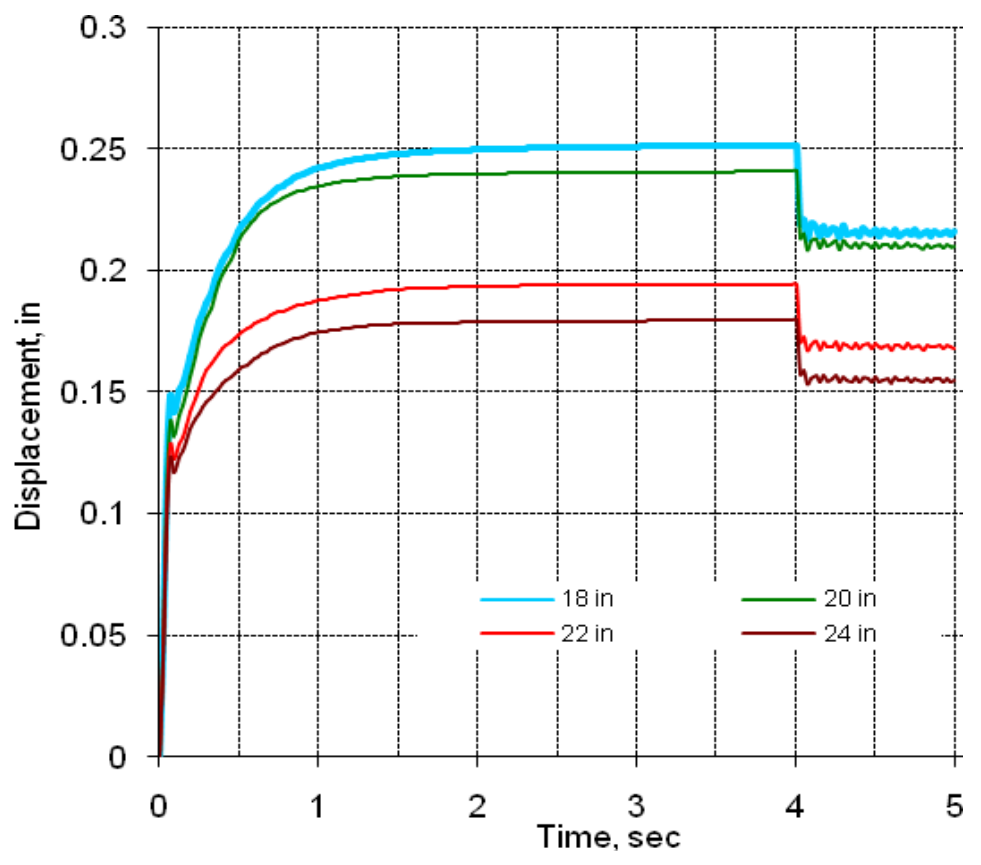

Lateral displacement history, entry dimension: $5 \mathrm{ft}$ x $20 \mathrm{ft}$

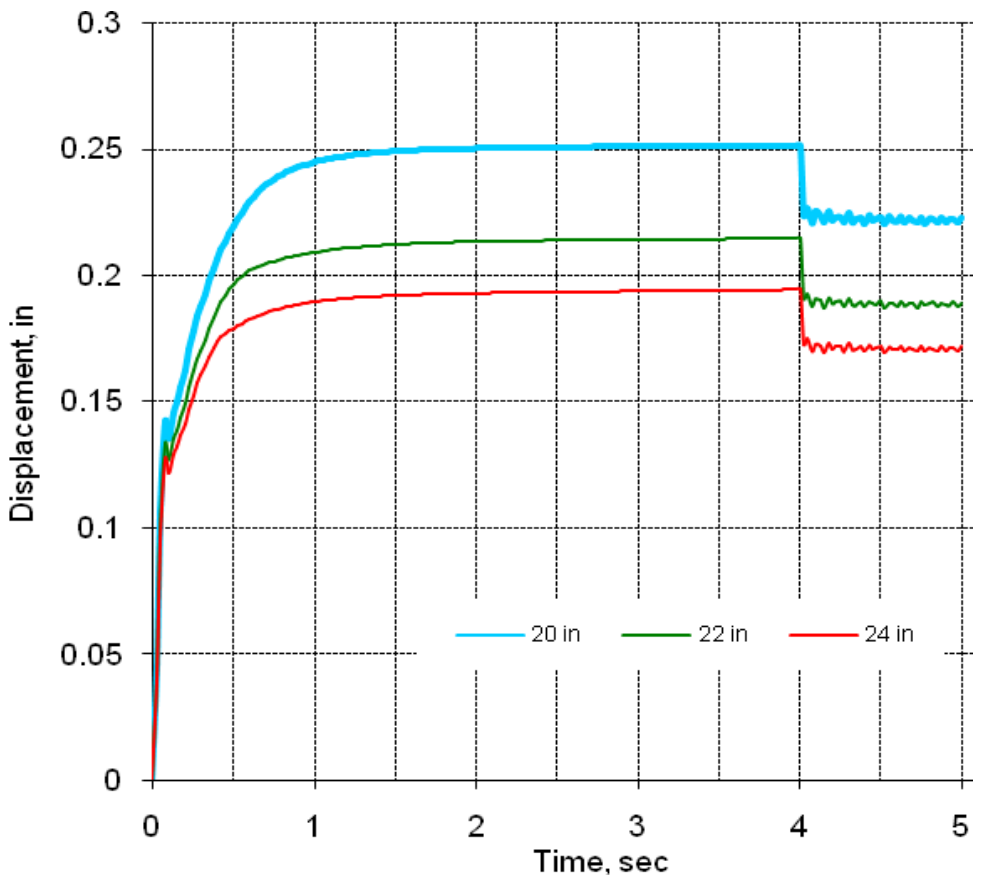

Lateral displacement history, entry dimension: $5 \mathrm{ft}$ x $24 \mathrm{ft}$ 


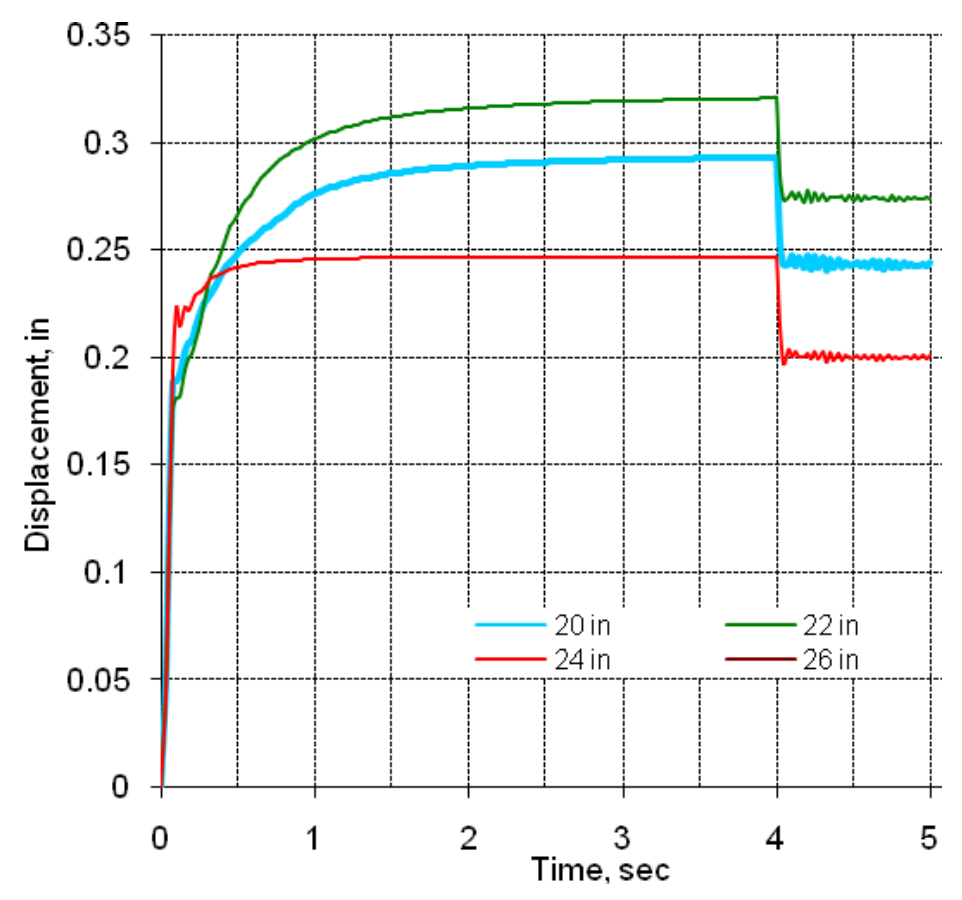

Lateral displacement history, entry dimension: $6 \mathrm{ft}$ x $16 \mathrm{ft}$

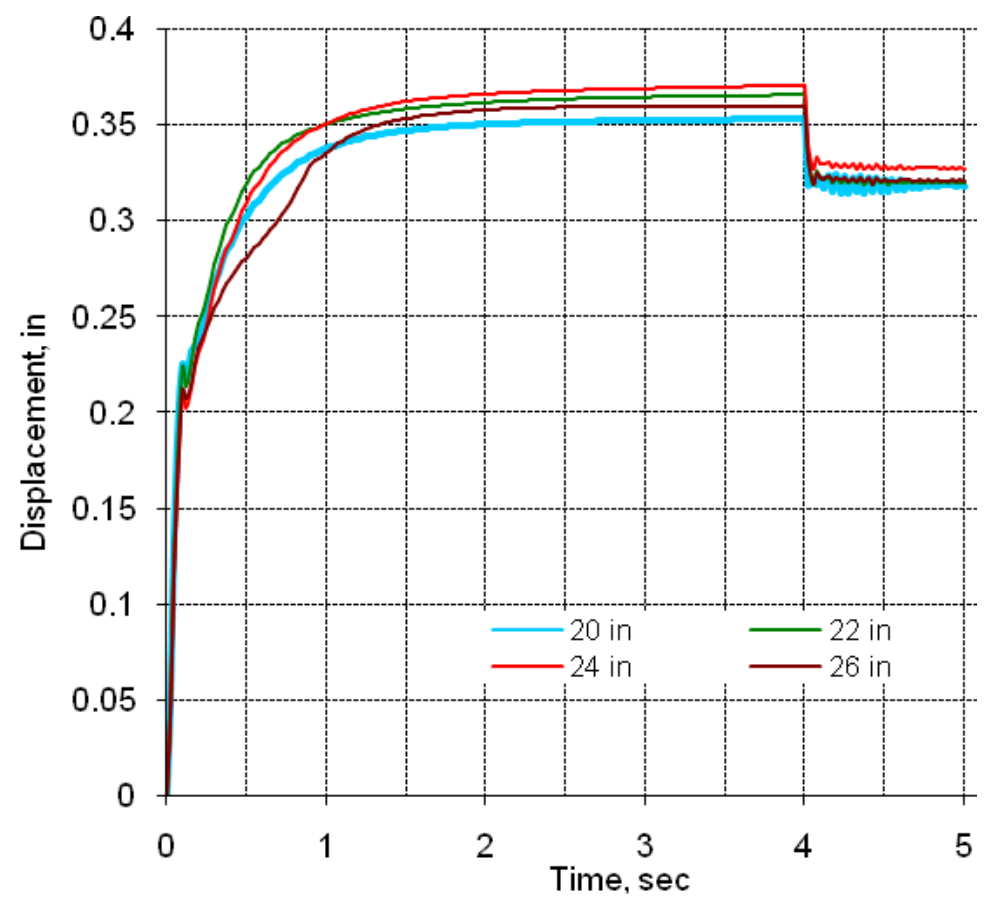

Lateral displacement history, entry dimension: $6 \mathrm{ft}$ x $24 \mathrm{ft}$ 


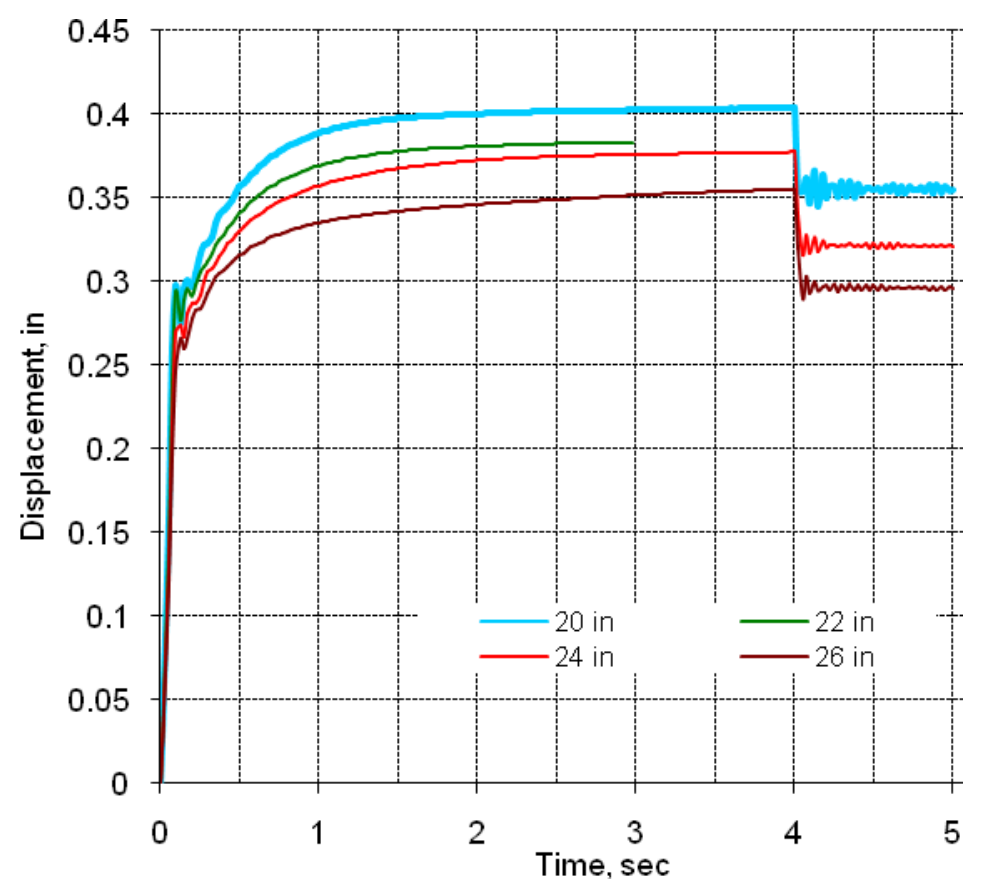

Lateral displacement history, entry dimension: $7 \mathrm{ft}$ x $16 \mathrm{ft}$

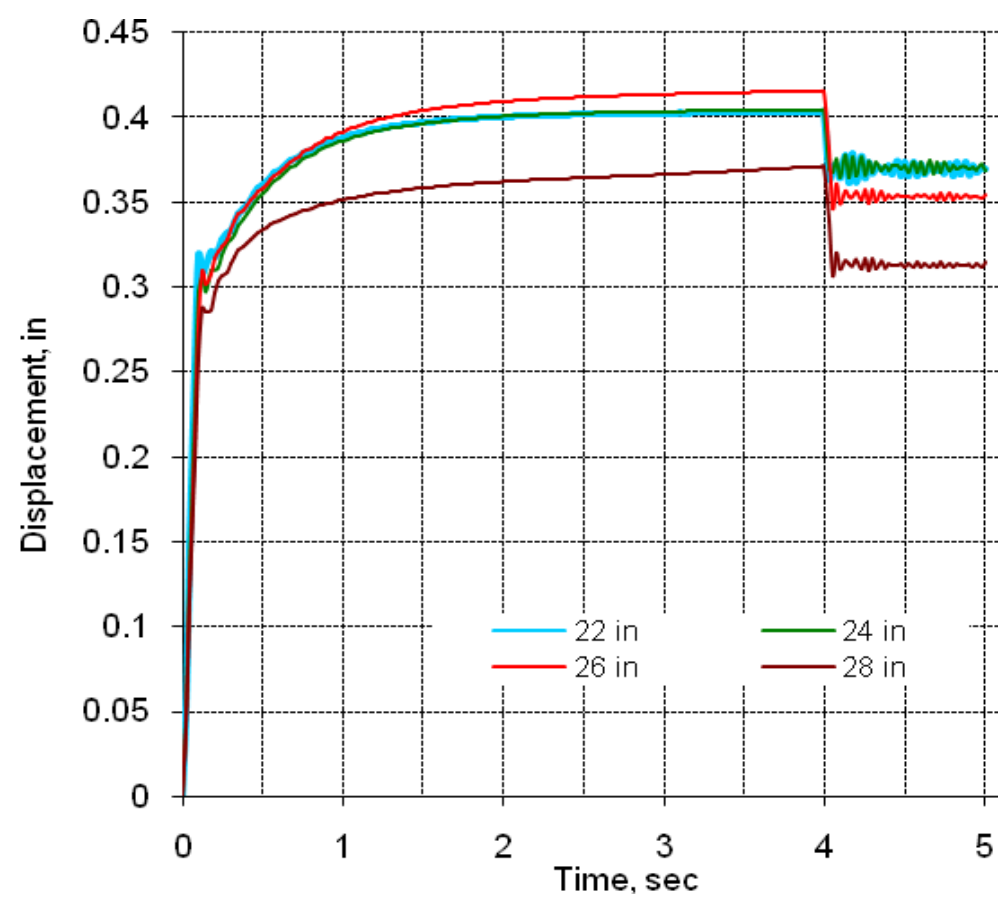

Lateral displacement history, entry dimension: $7 \mathrm{ft}$ x $20 \mathrm{ft}$ 


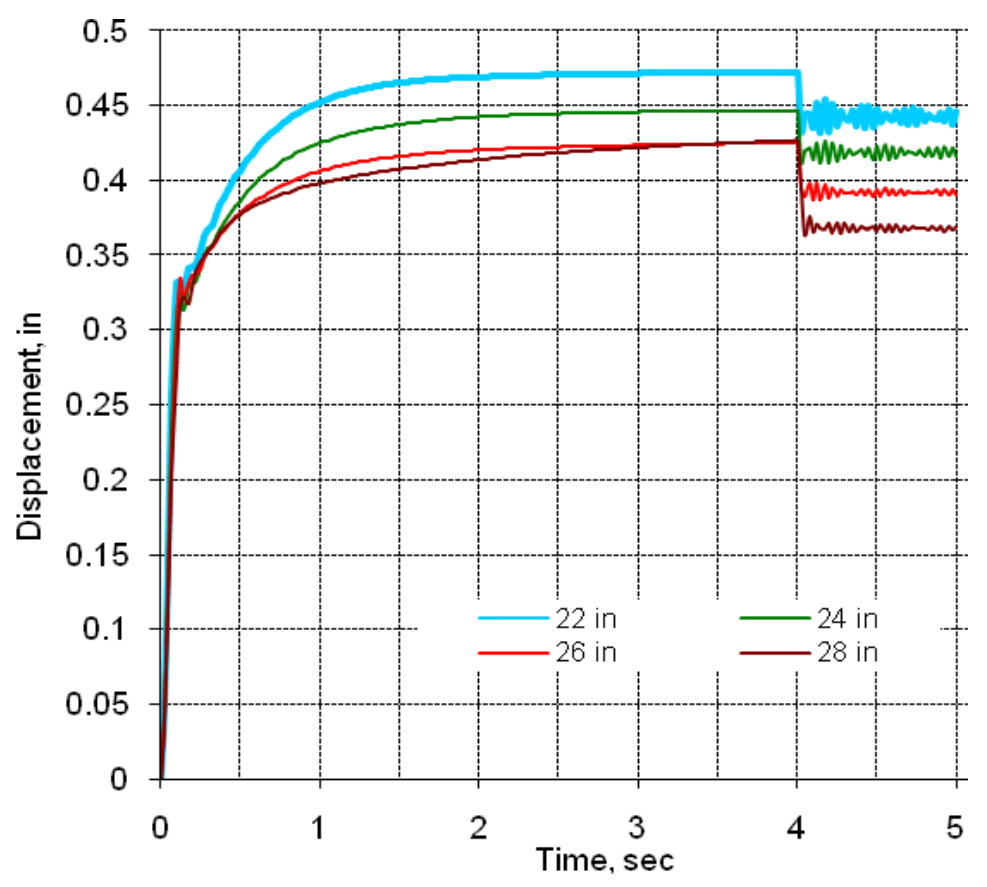

Lateral displacement history, entry dimension: $7 \mathrm{ft}$ x $24 \mathrm{ft}$

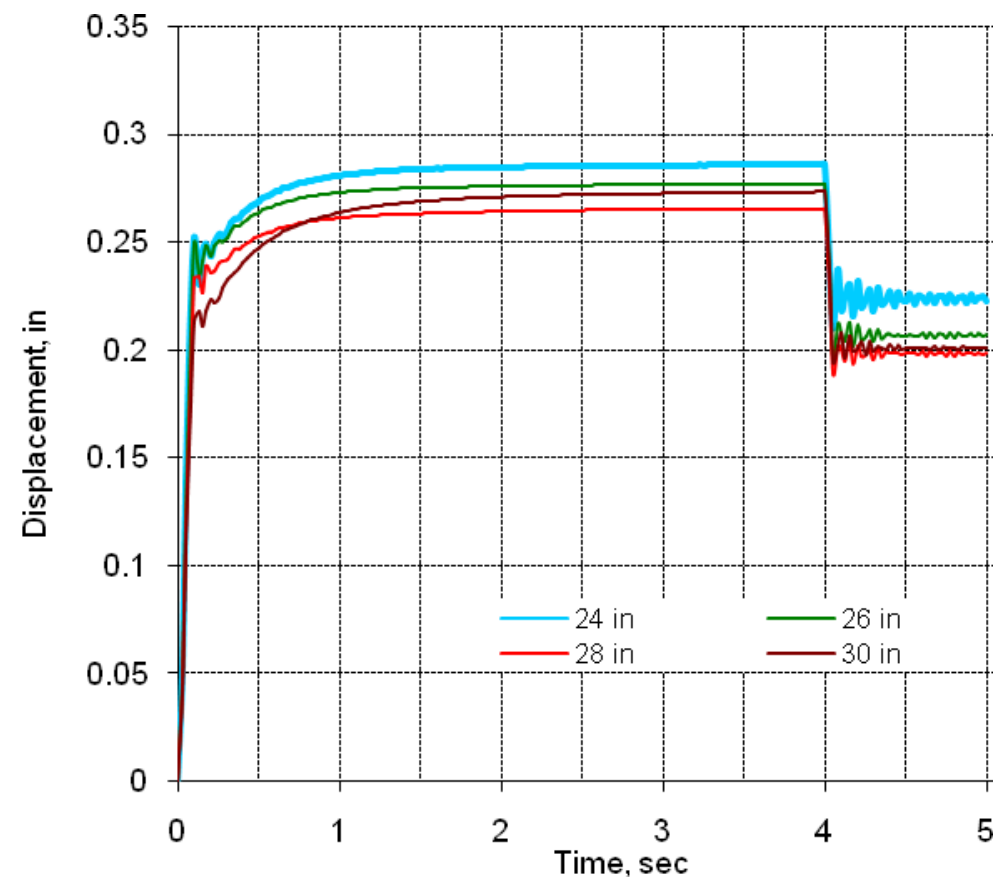

Lateral displacement history, entry dimension: $8 \mathrm{ft}$ x $16 \mathrm{ft}$ 


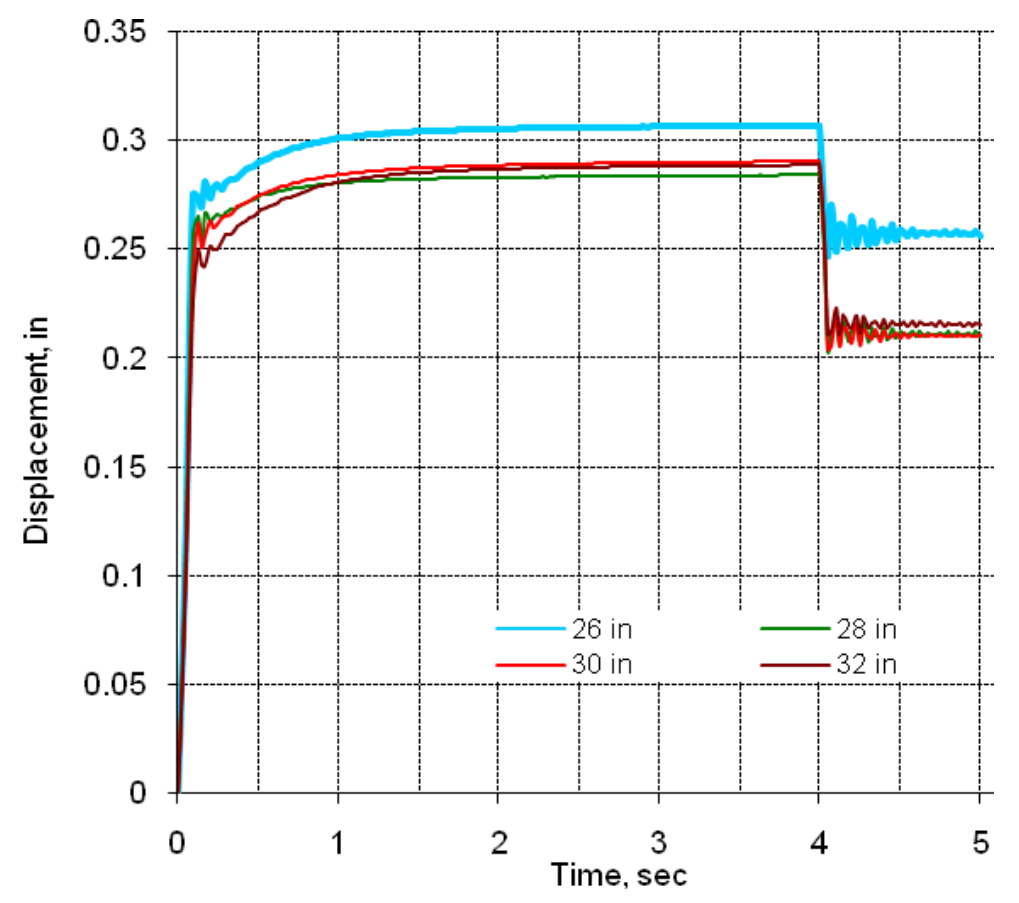

Lateral displacement history, entry dimension: $8 \mathrm{ft}$ x $20 \mathrm{ft}$

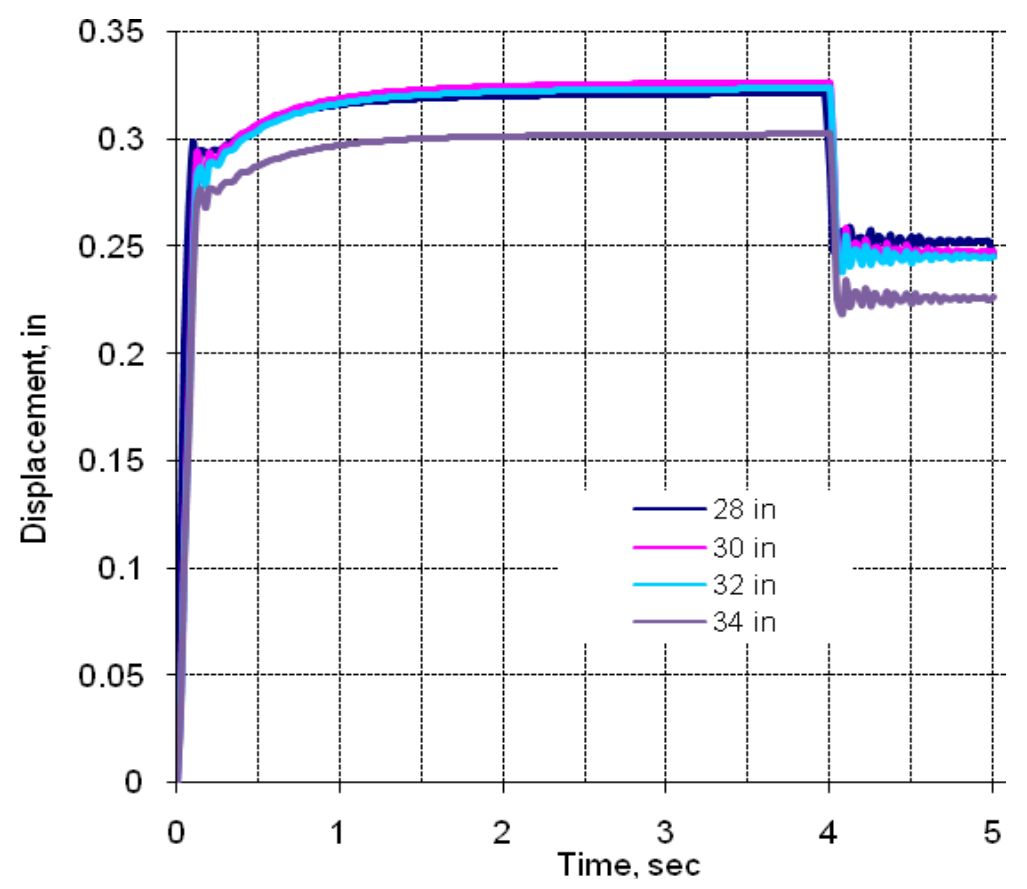

Lateral displacement history, entry dimension: $8 \mathrm{ft}$ x $24 \mathrm{ft}$ 


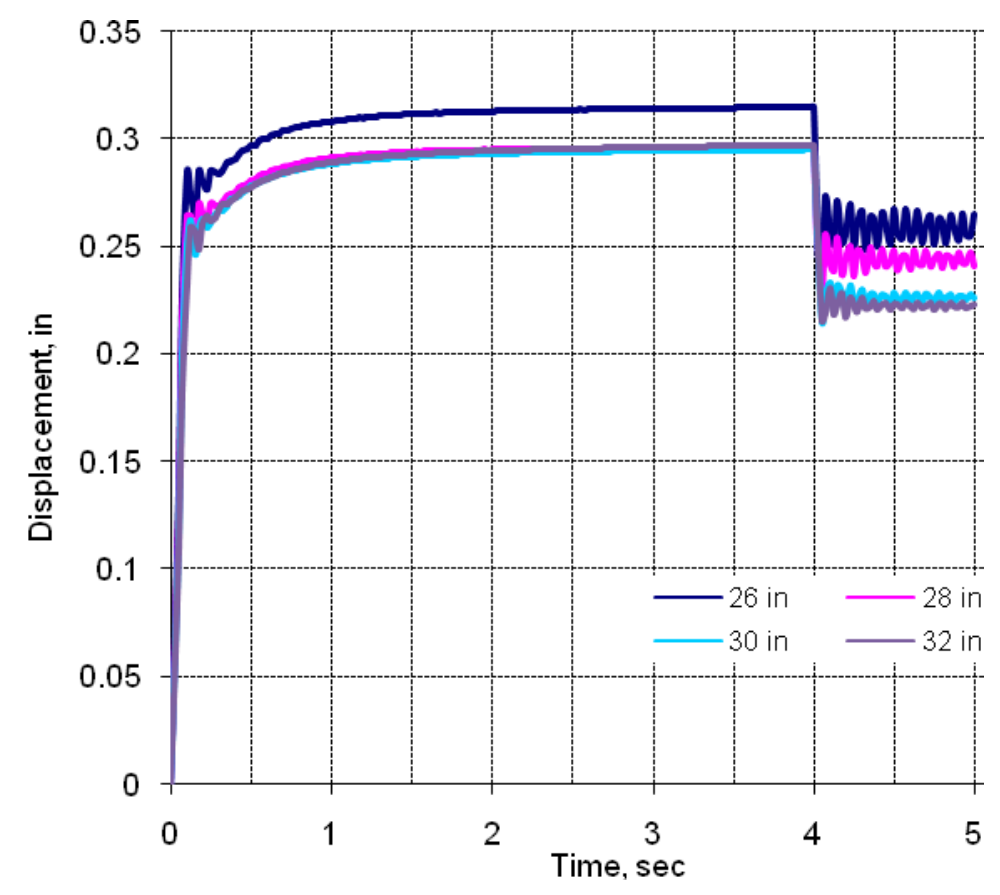

Lateral displacement history, entry dimension: $9 \mathrm{ft}$ x $16 \mathrm{ft}$

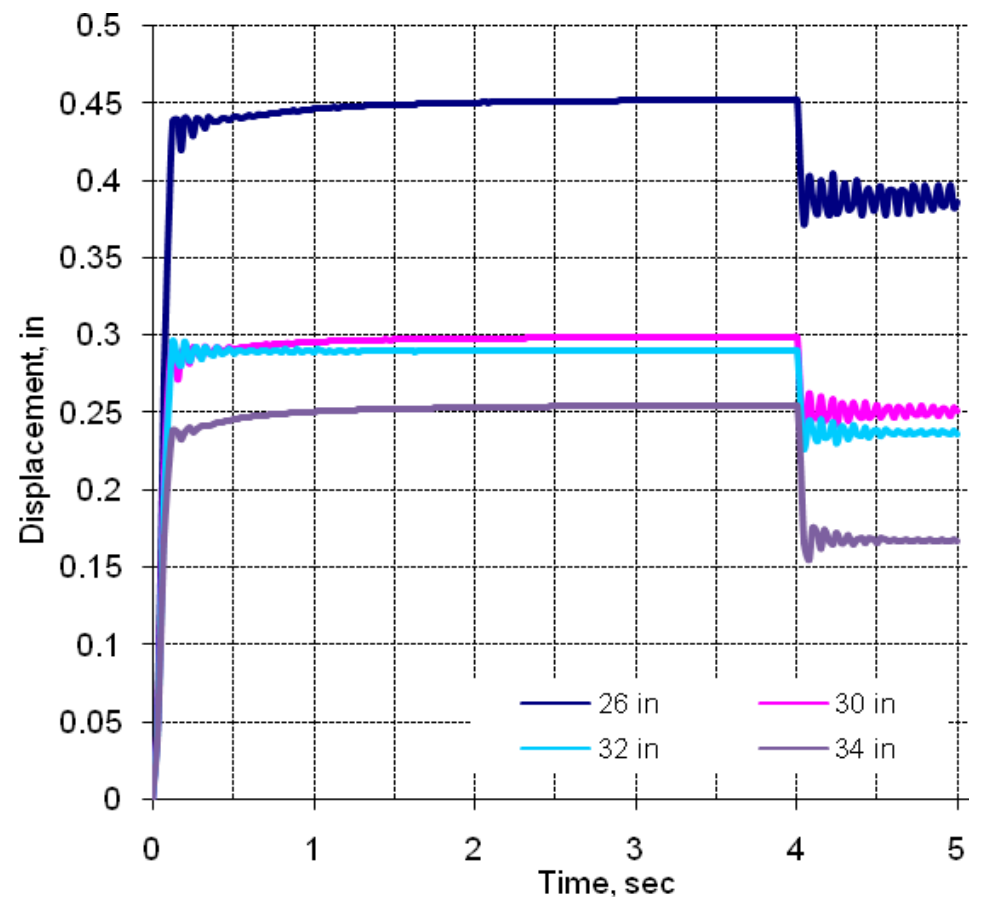

Lateral displacement history, entry dimension: $9 \mathrm{ft}$ x $20 \mathrm{ft}$ 


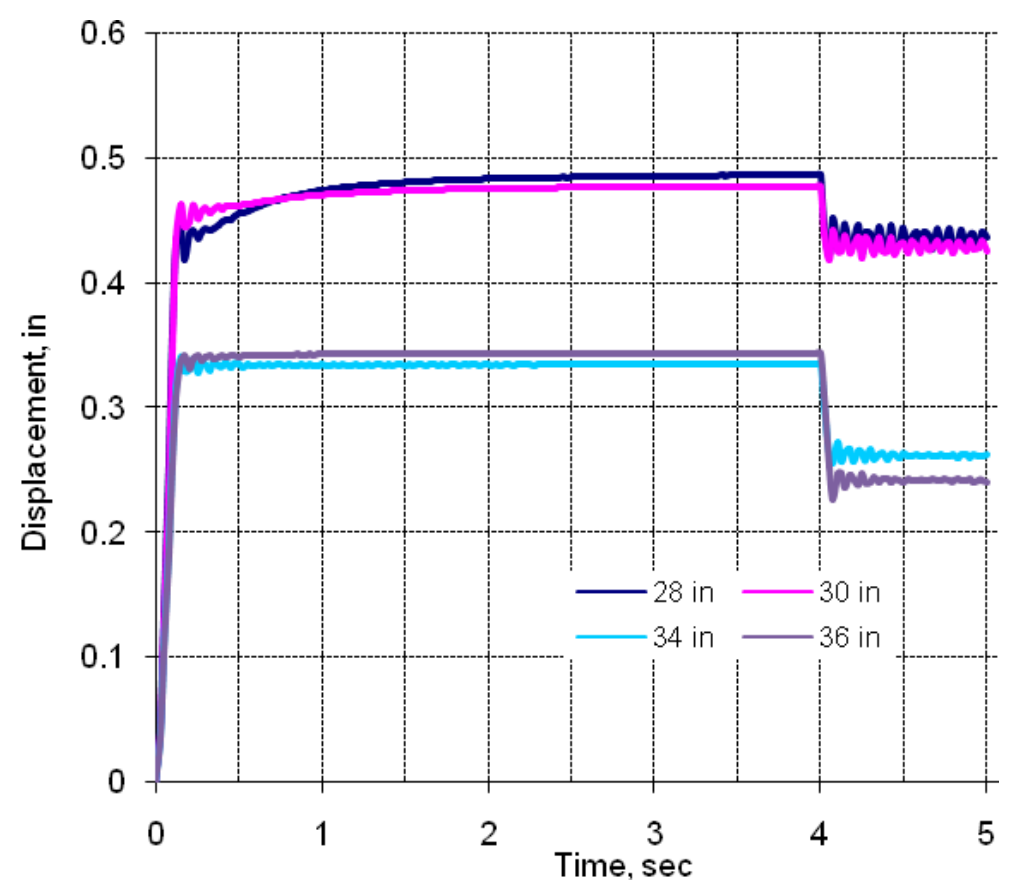

Lateral displacement history, entry dimension: $9 \mathrm{ft}$ x $24 \mathrm{ft}$

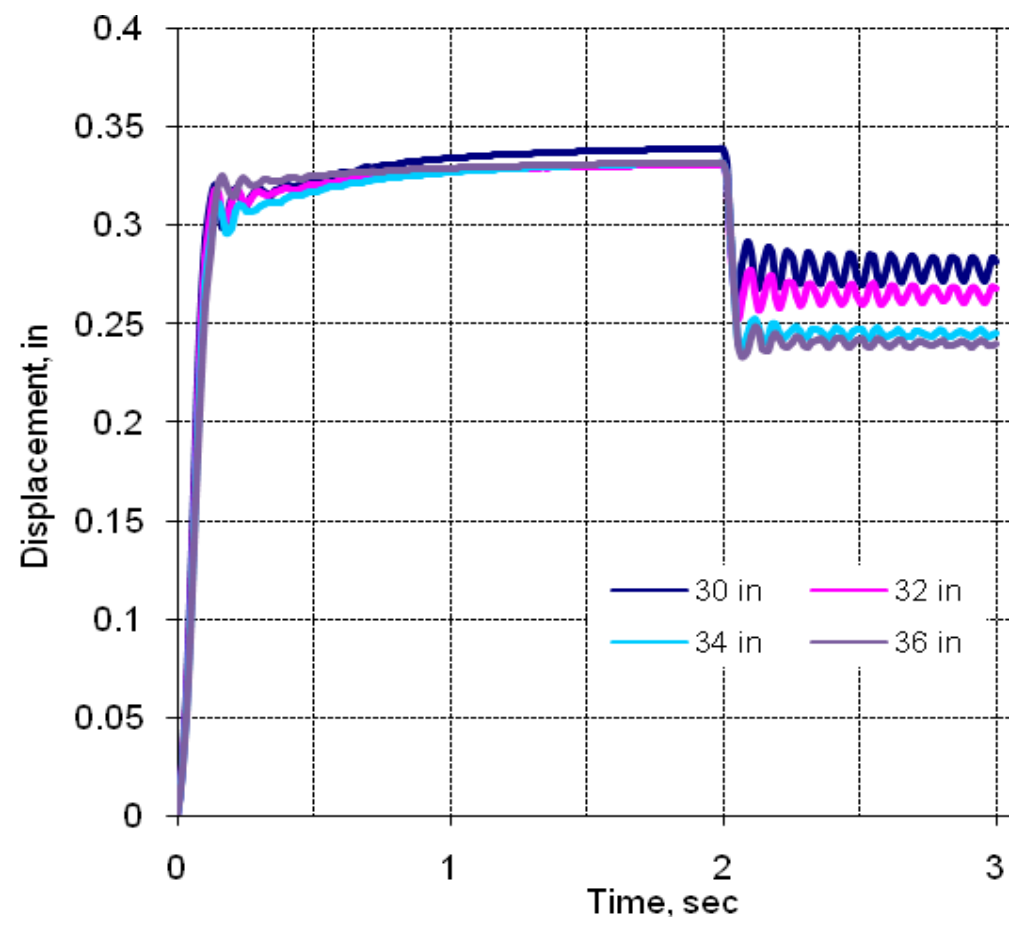

Lateral displacement history, entry dimension: $10 \mathrm{ft}$ x $16 \mathrm{ft}$ 


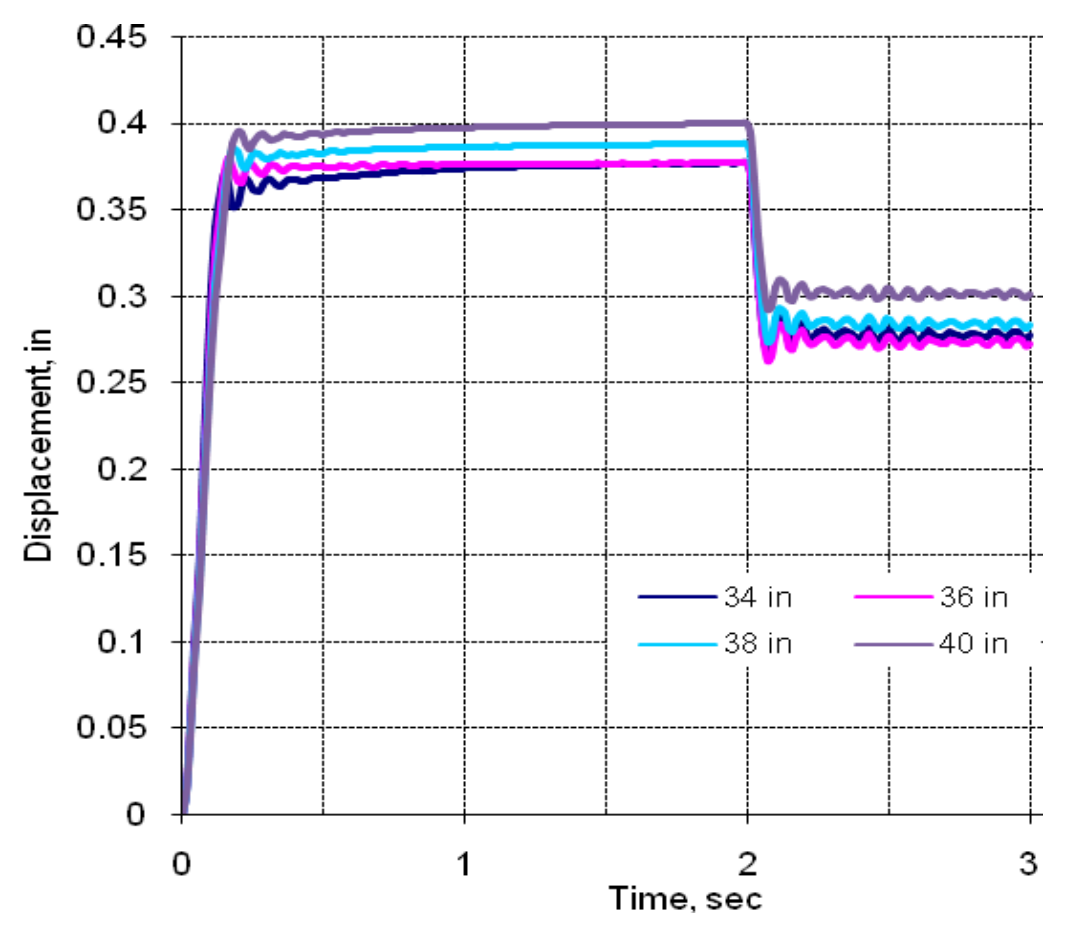

Lateral displacement history, entry dimension: $10 \mathrm{ft}$ x $20 \mathrm{ft}$

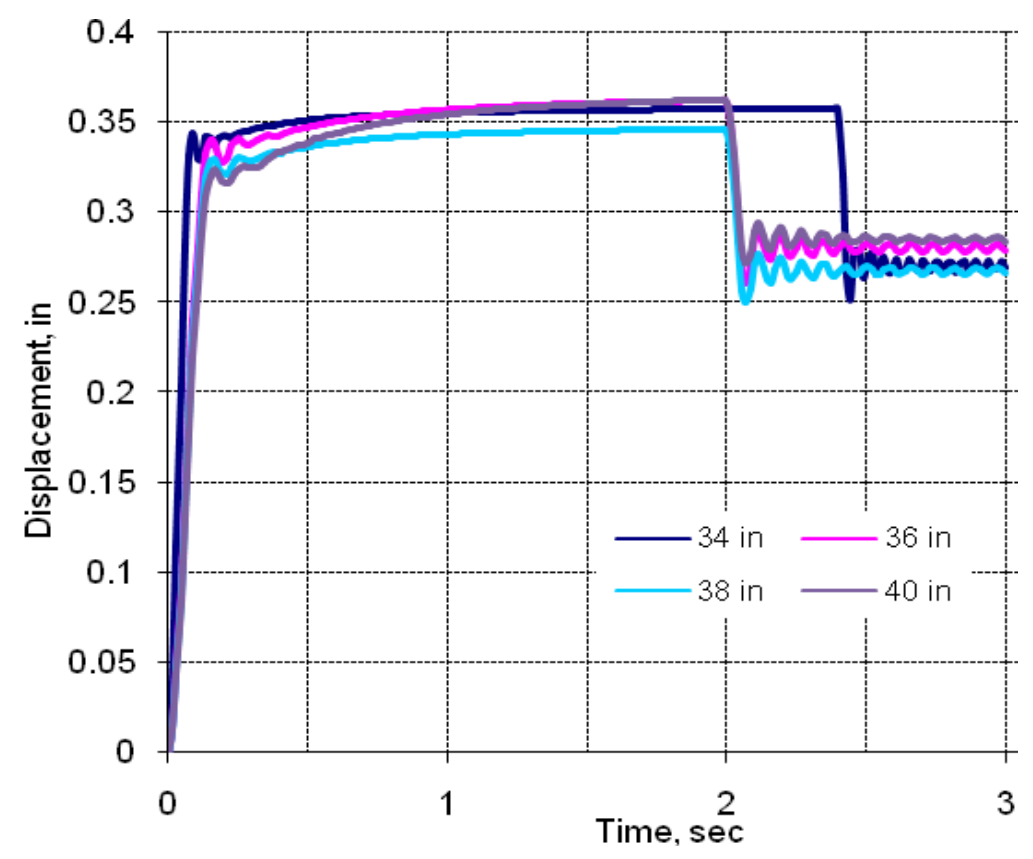

Lateral displacement history, entry dimension: $10 \mathrm{ft}$ x $24 \mathrm{ft}$ 


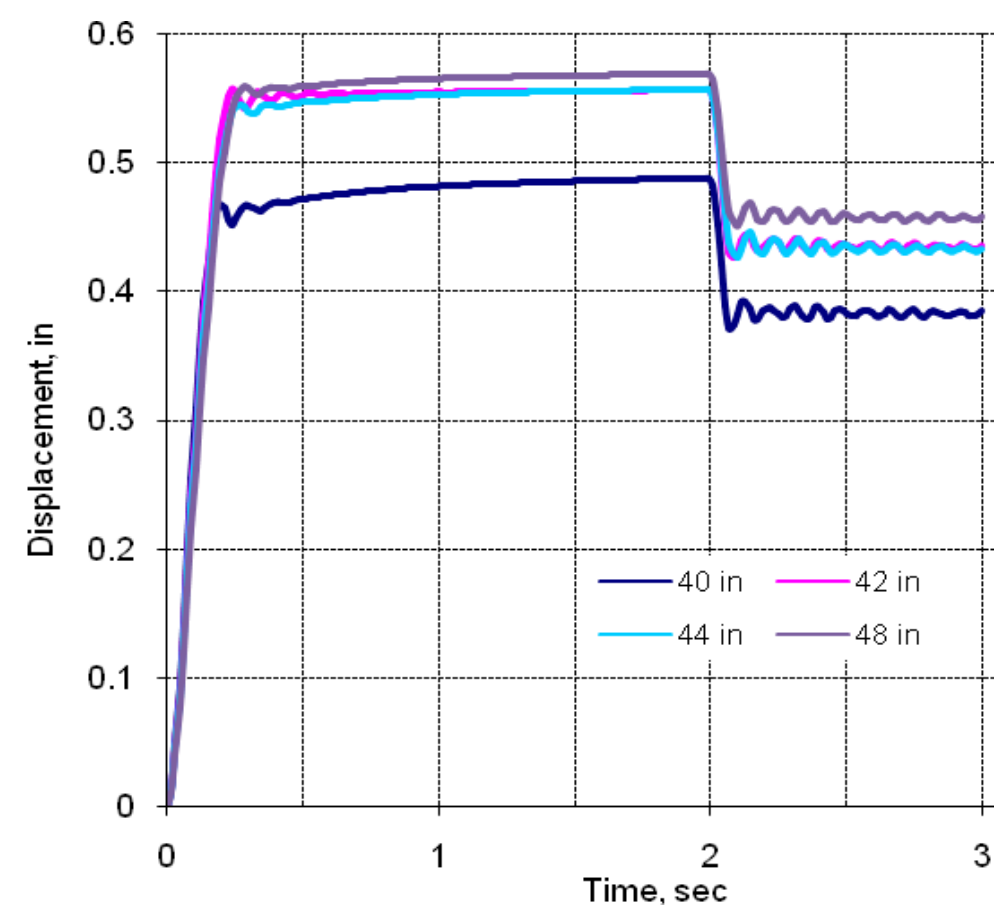

Lateral displacement history, entry dimension: $12 \mathrm{ft}$ x $20 \mathrm{ft}$

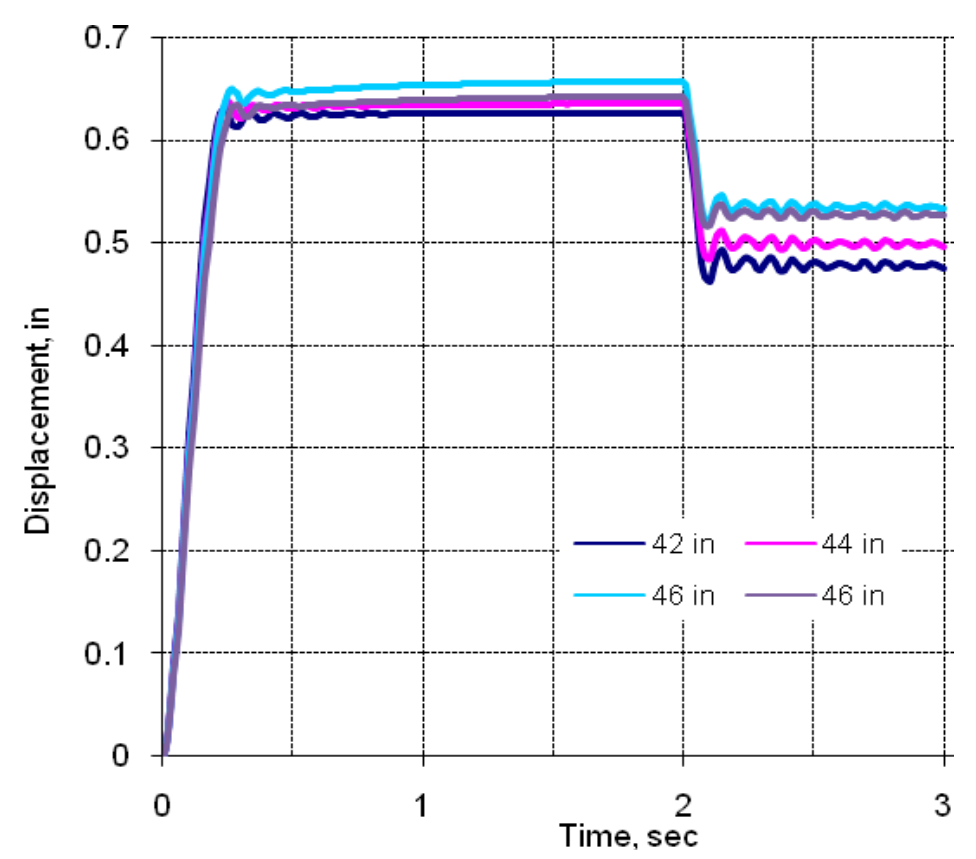

Lateral displacement history, entry dimension: $12 \mathrm{ft}$ x $24 \mathrm{ft}$ 


\section{APPENDIX III}

Damage contours (vertical mid sections) and history of lateral displacements recorded in 6’x20'x24” seal for different levels of roof-to-floor convergence. 

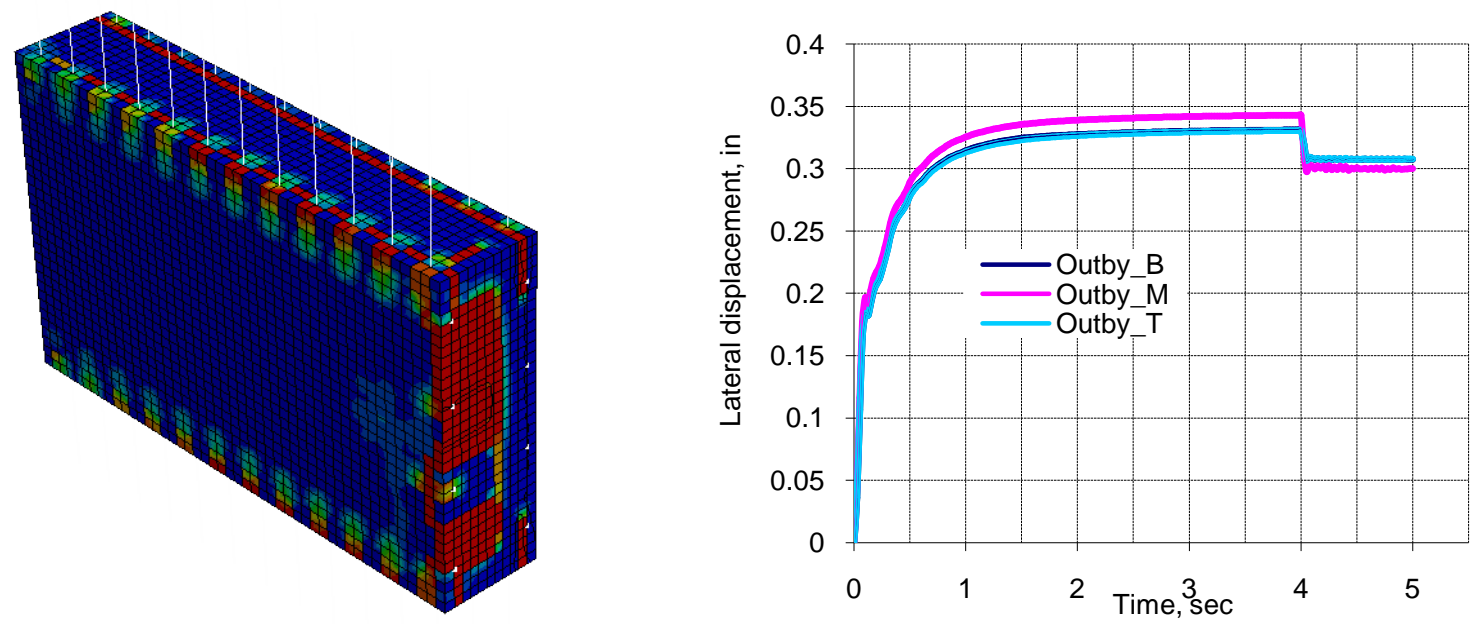

Convergence $0.0 \mathrm{in}$.
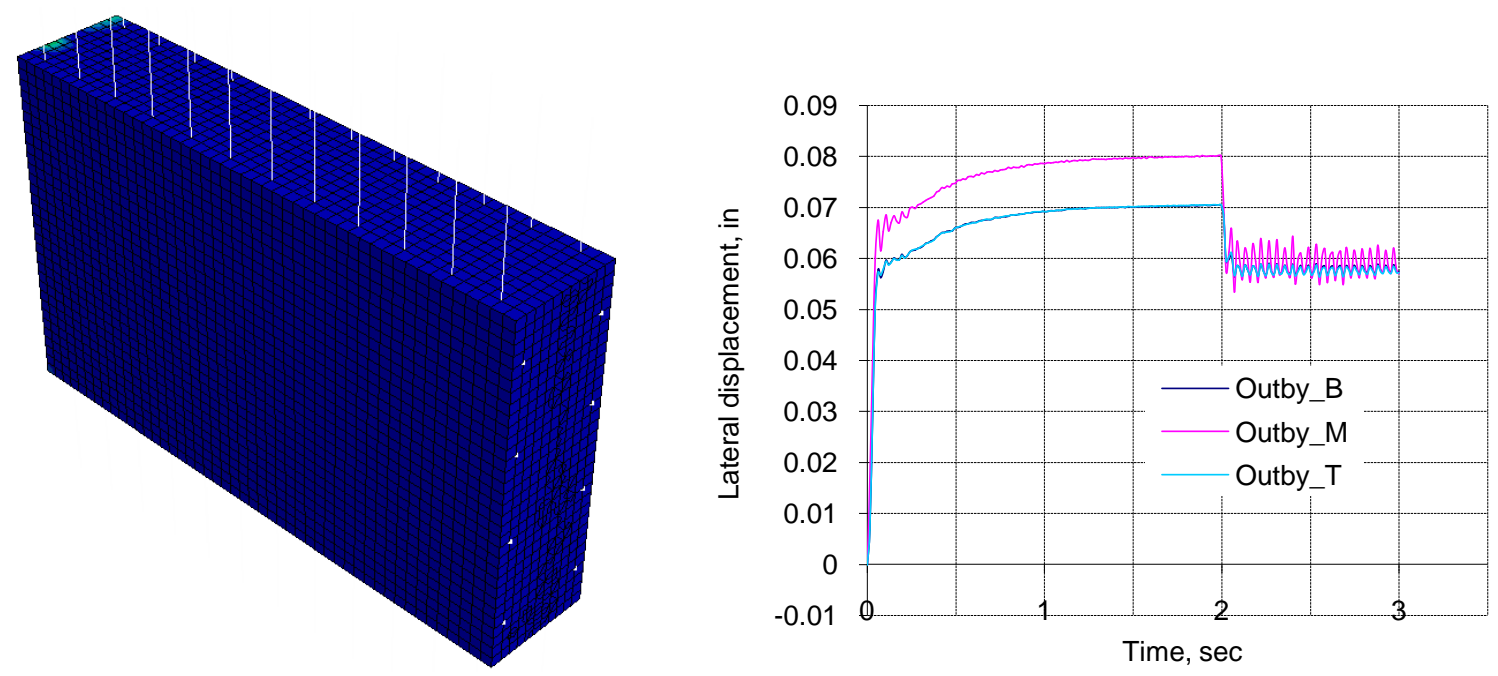

Convergence 0.0023 in.
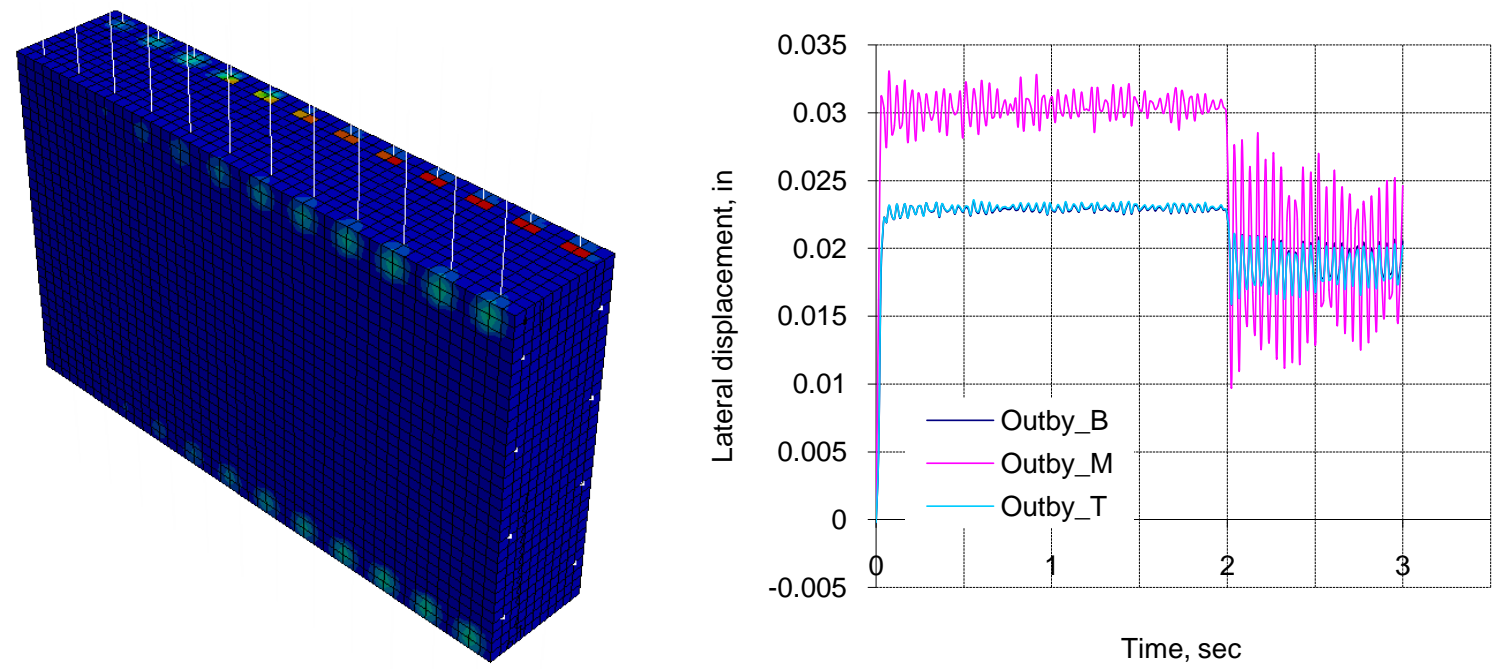

Time, sec

Convergence 0.0047 in. 

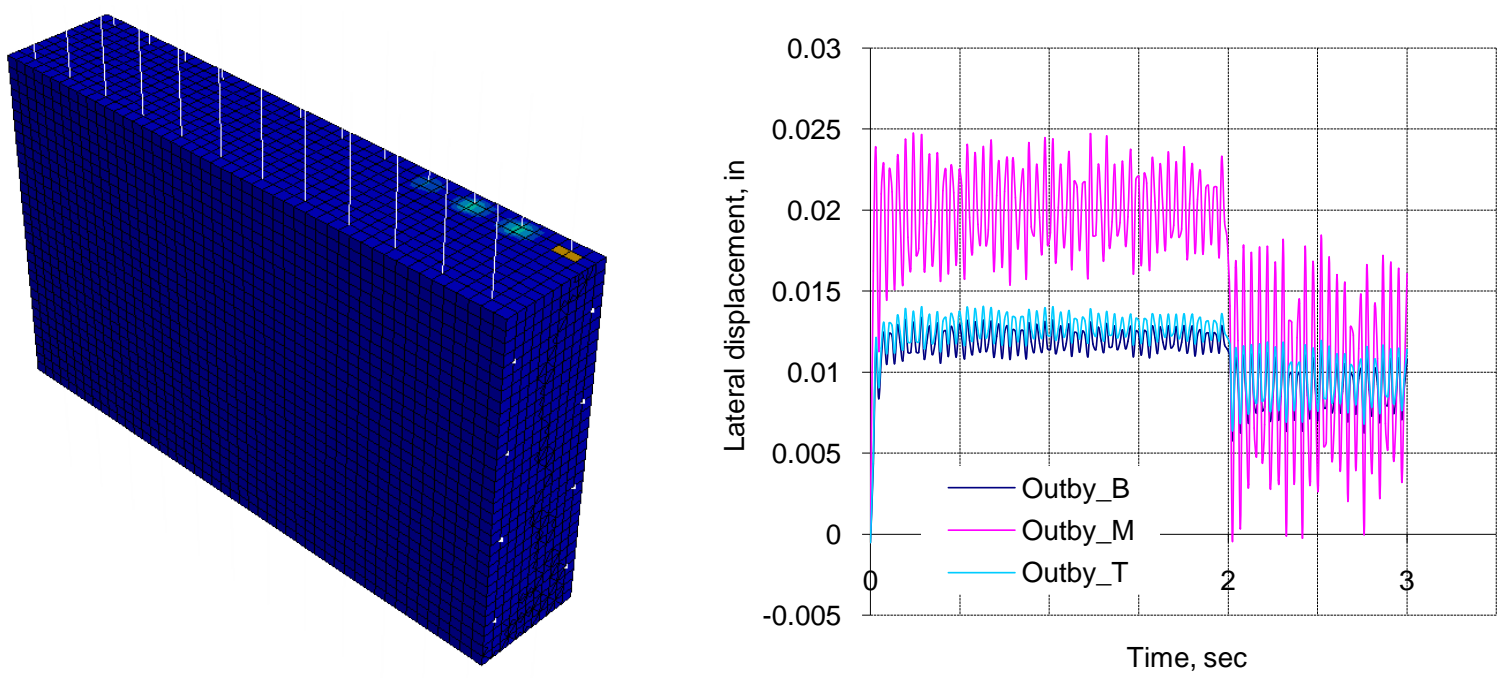

Convergence 0.0093 in.
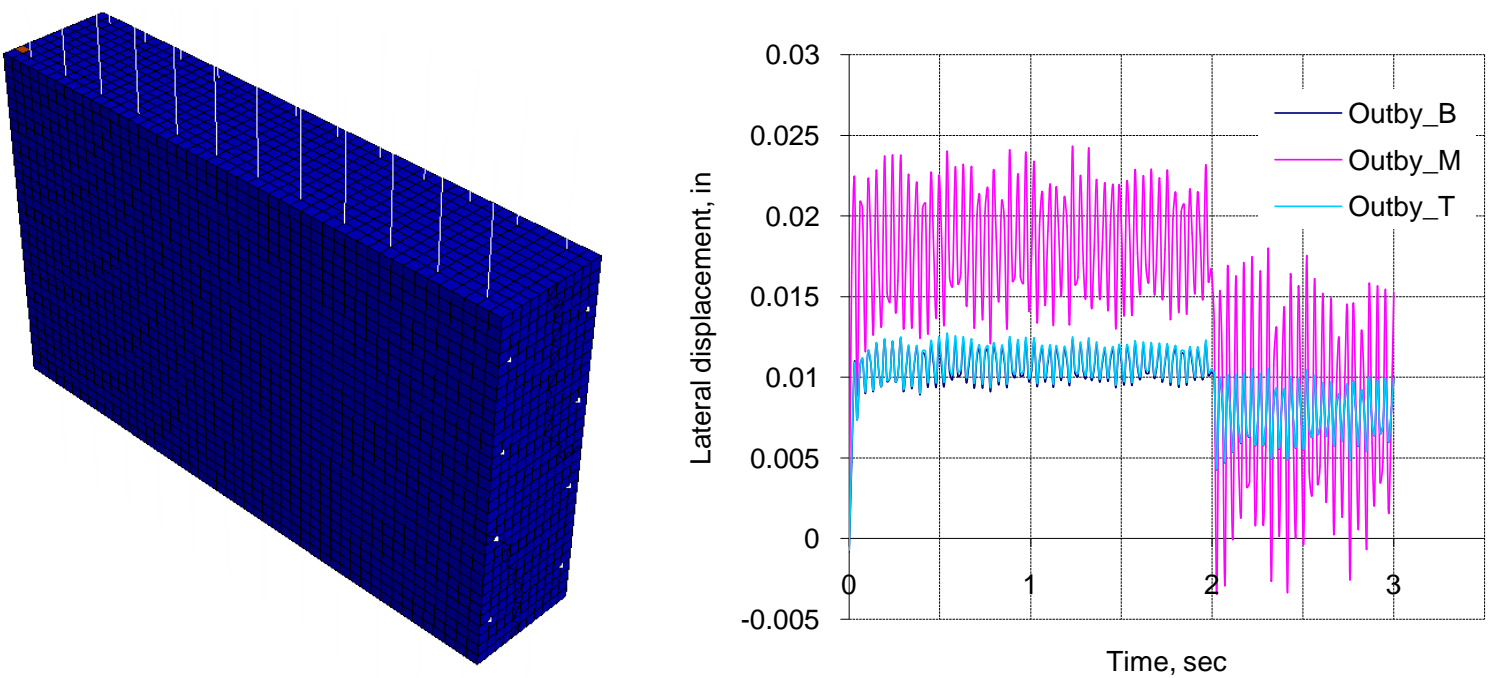

Convergence 0.0140 in.
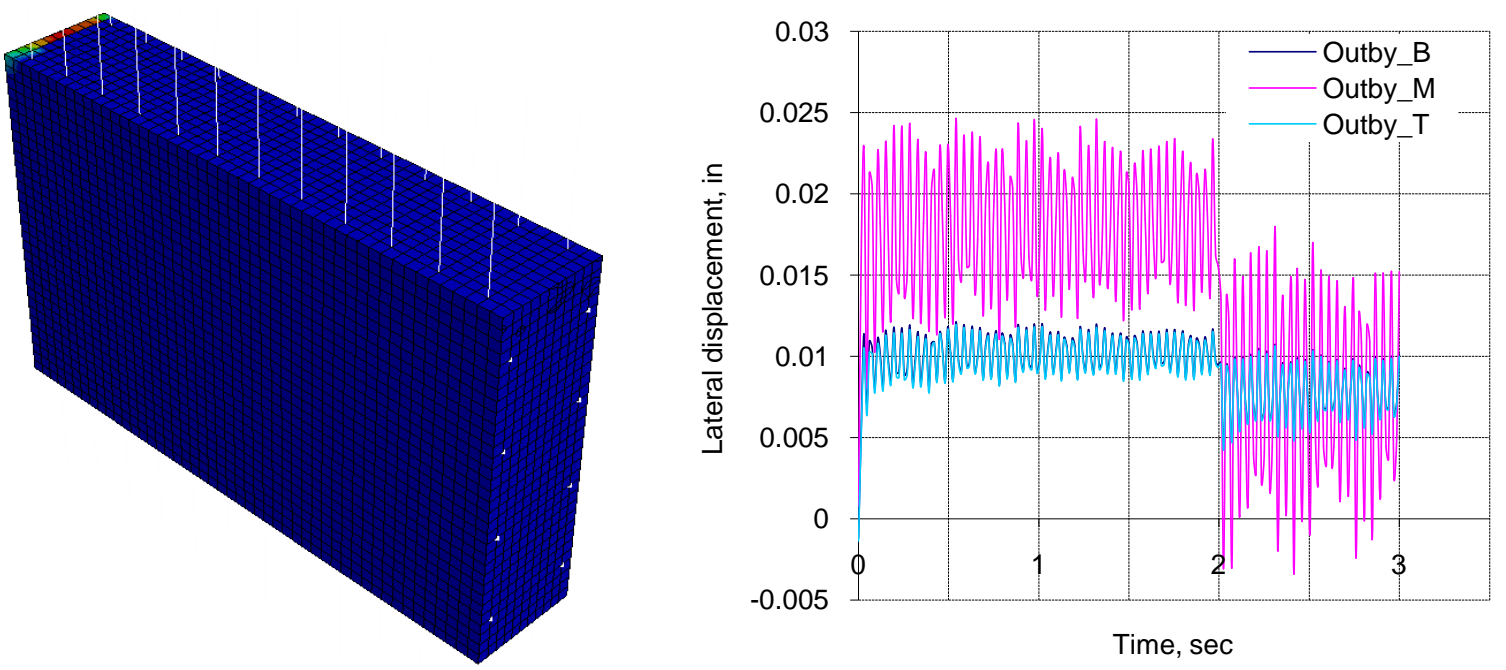

Convergence 0.0235 in. 

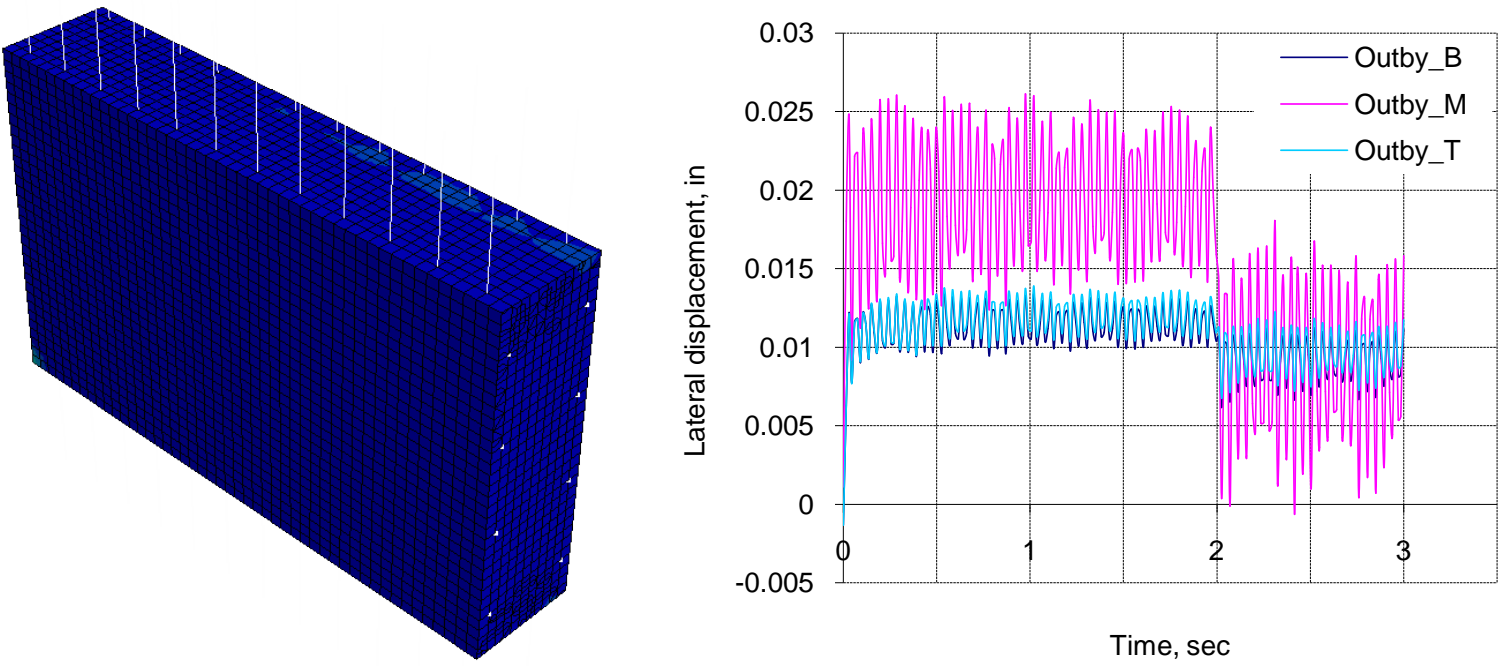

Time, sec

Convergence 0.0345 in.
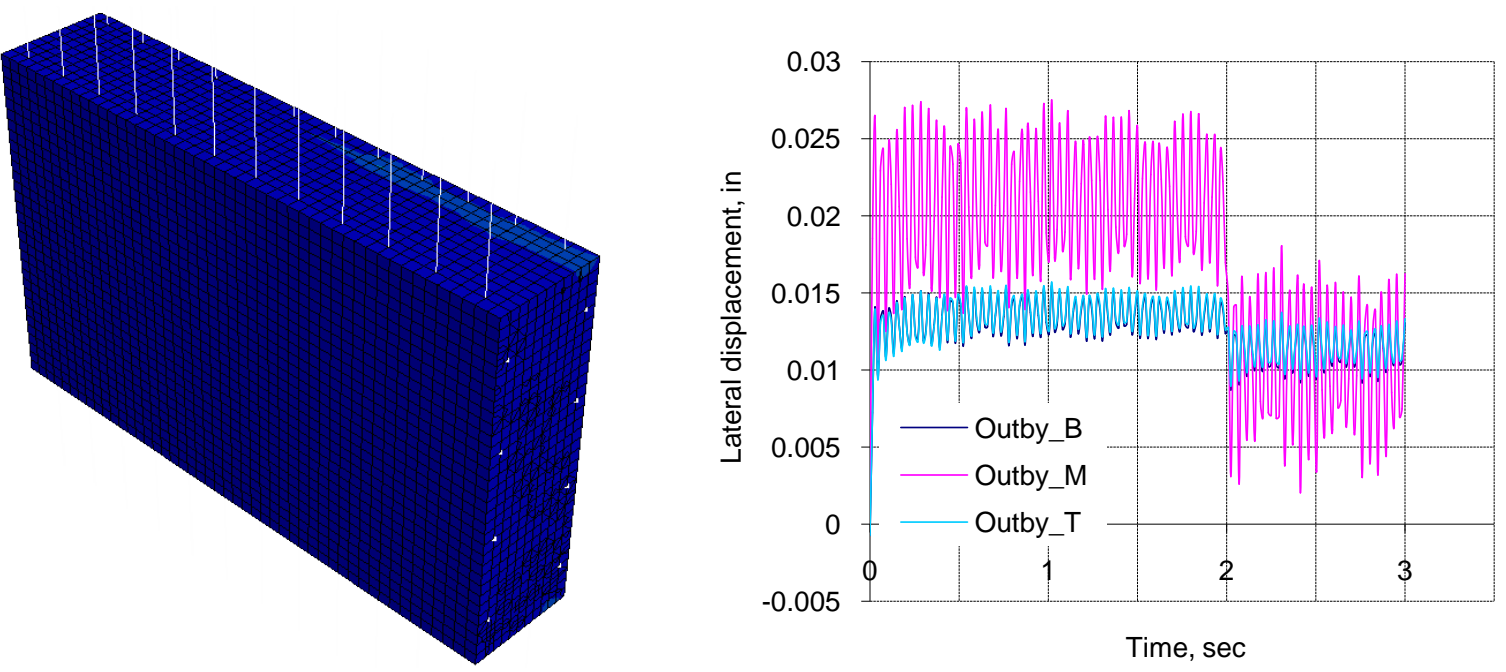

Convergence 0.0440 in.
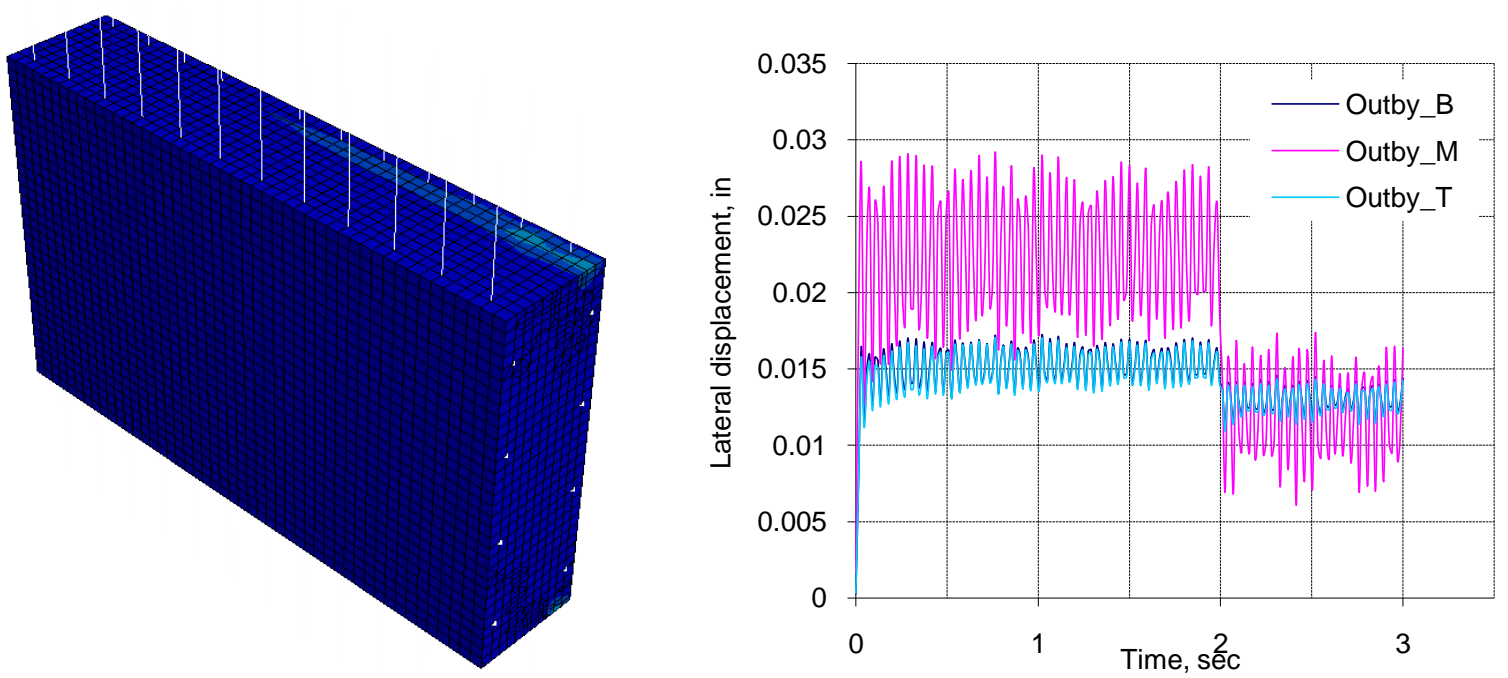

Convergence 0.0528 in. 

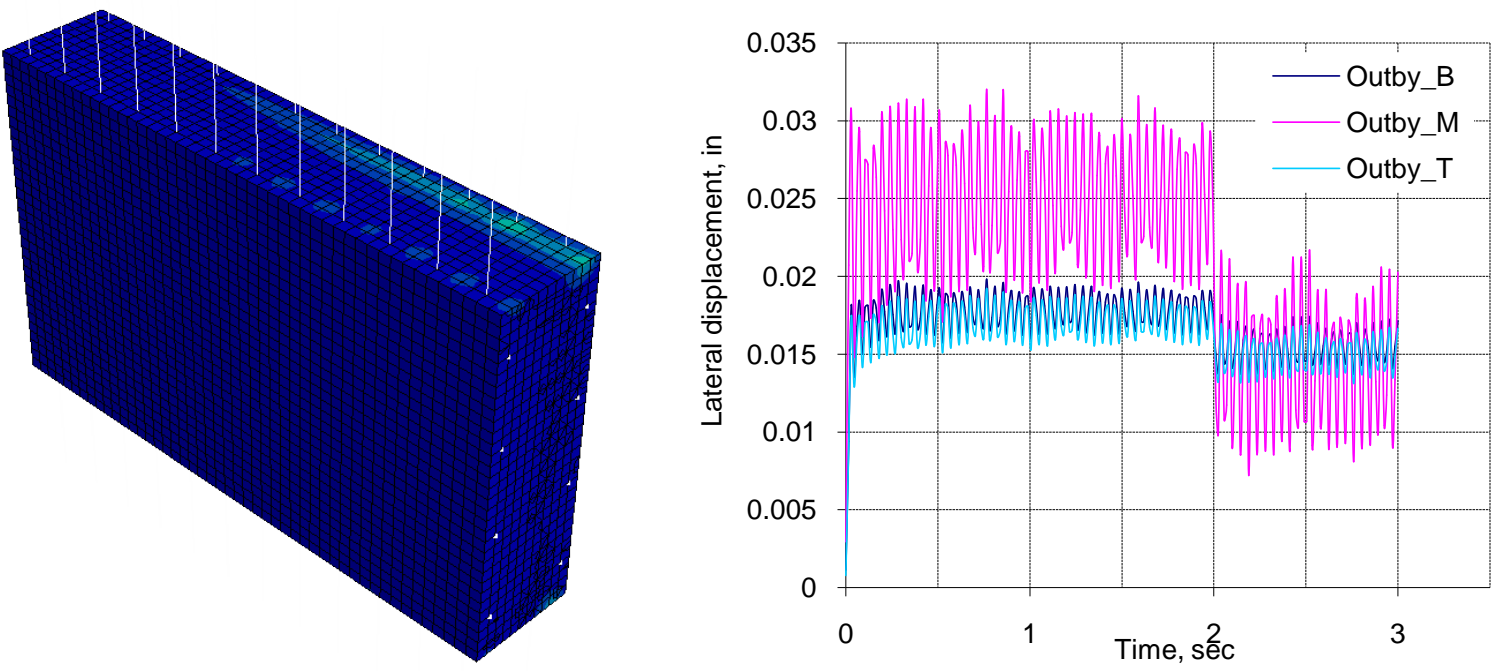

Convergence 0.0629 in.
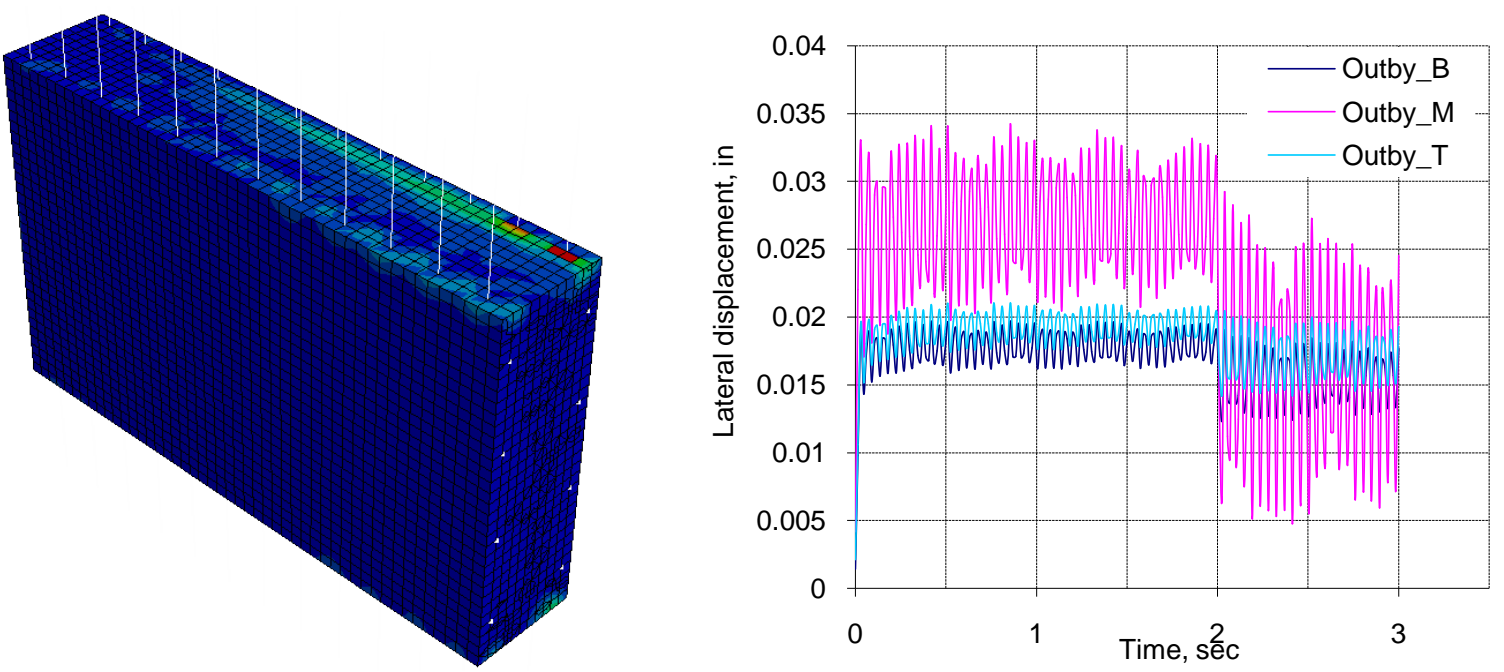

Convergence 0.0728 in.
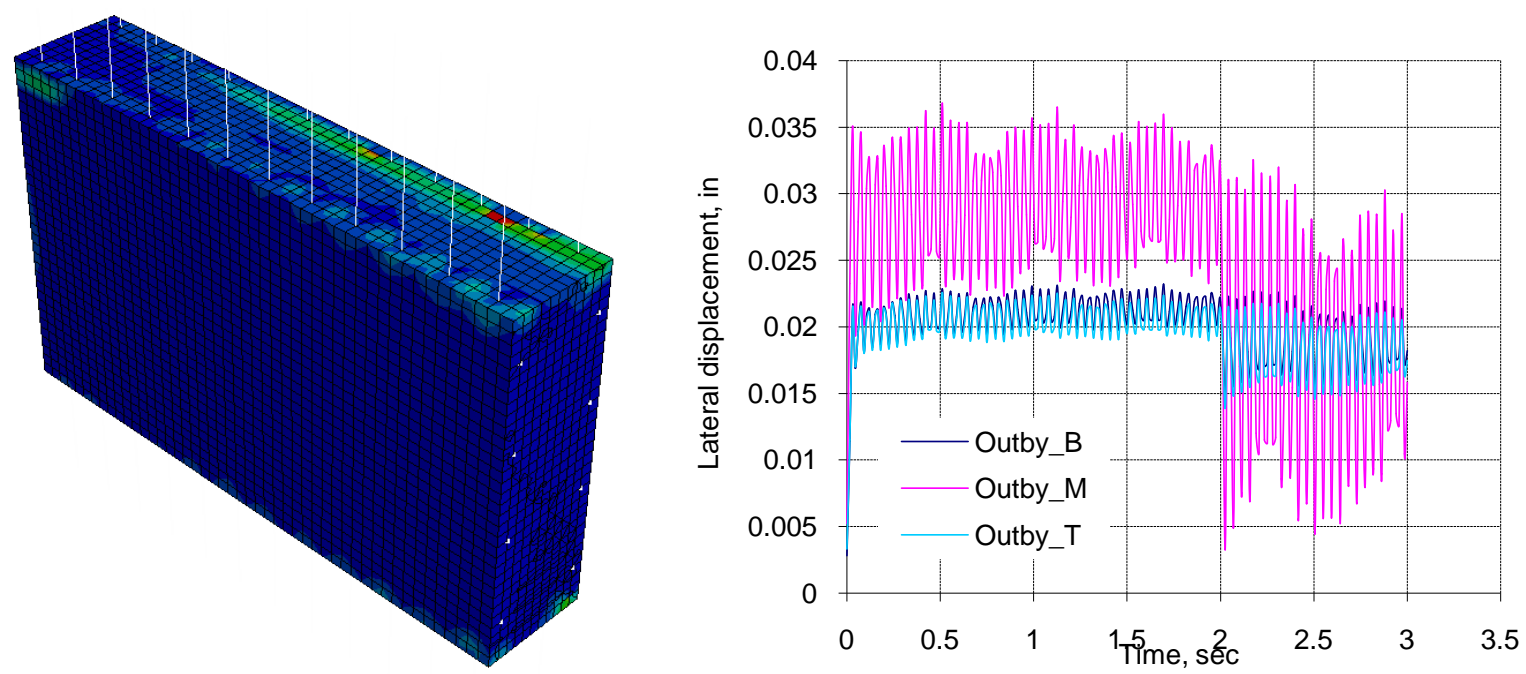

Convergence 0.0827 in. 

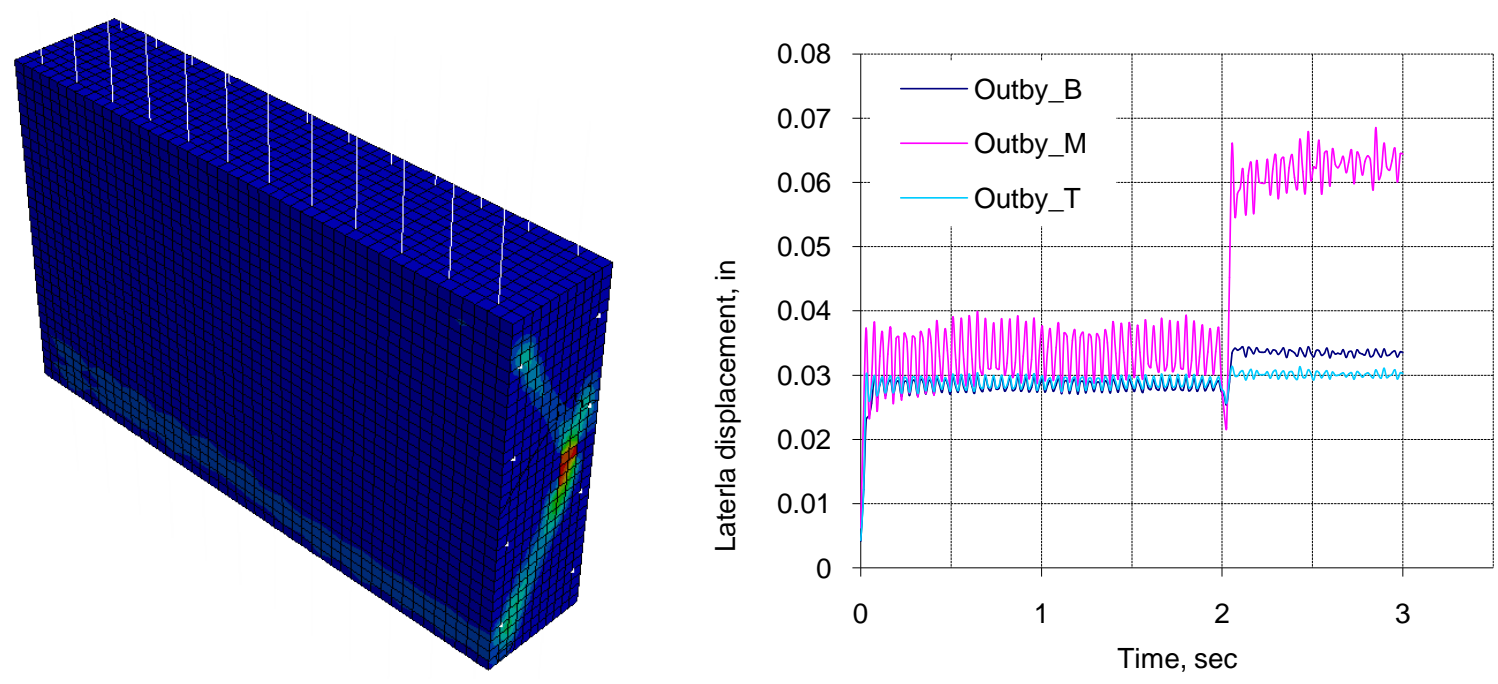

Convergence 0.0929 in.
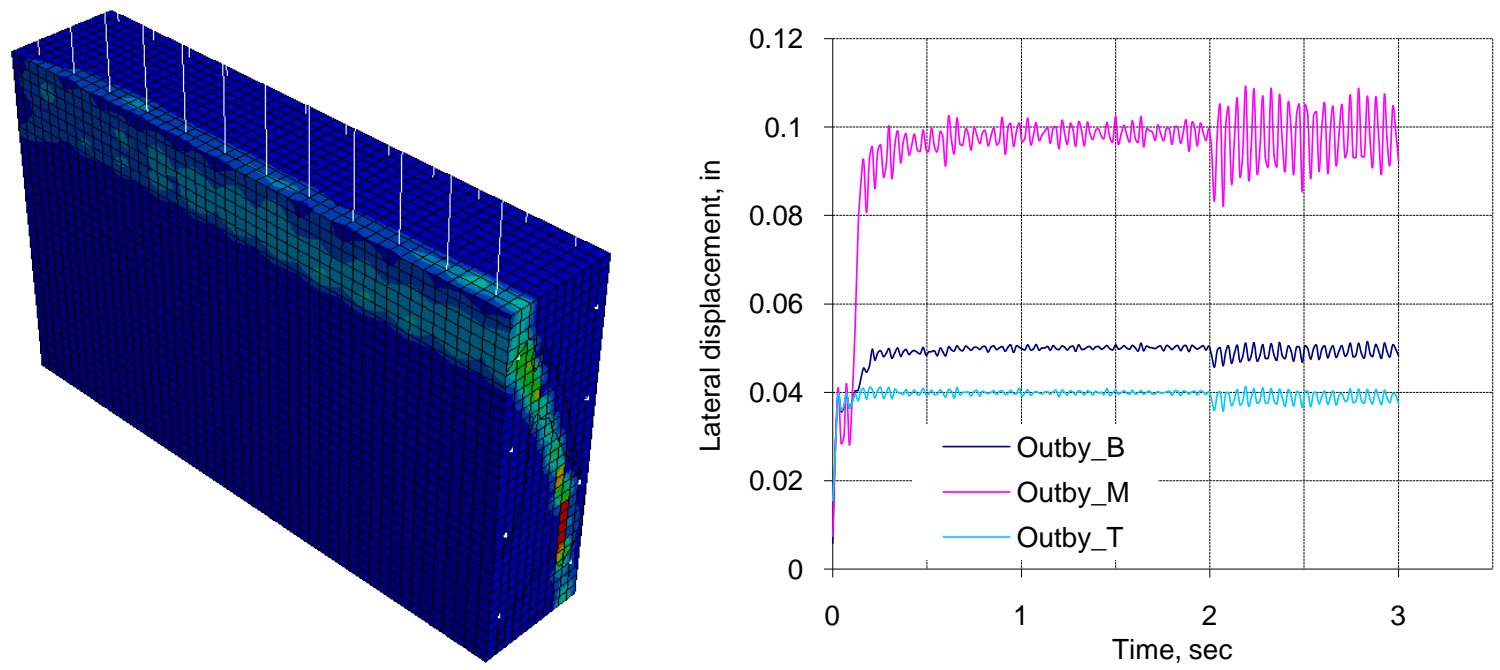

Convergence 0.1040 in.
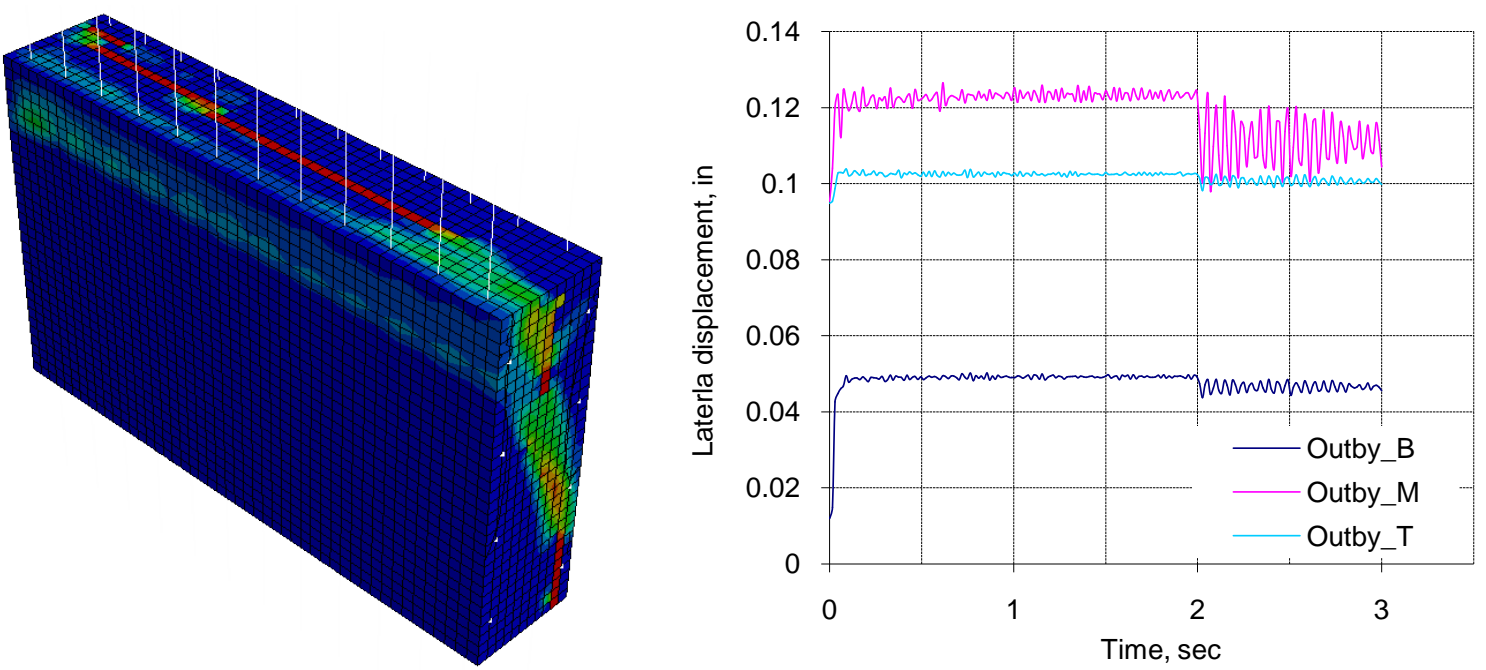

Convergence 0.1825 in. 


\section{APPENDIX IV}

Plot of the lateral displacements measured at the center of the seal on the outby side (Outby_M) vs. time and convergence for different entry dimensions 


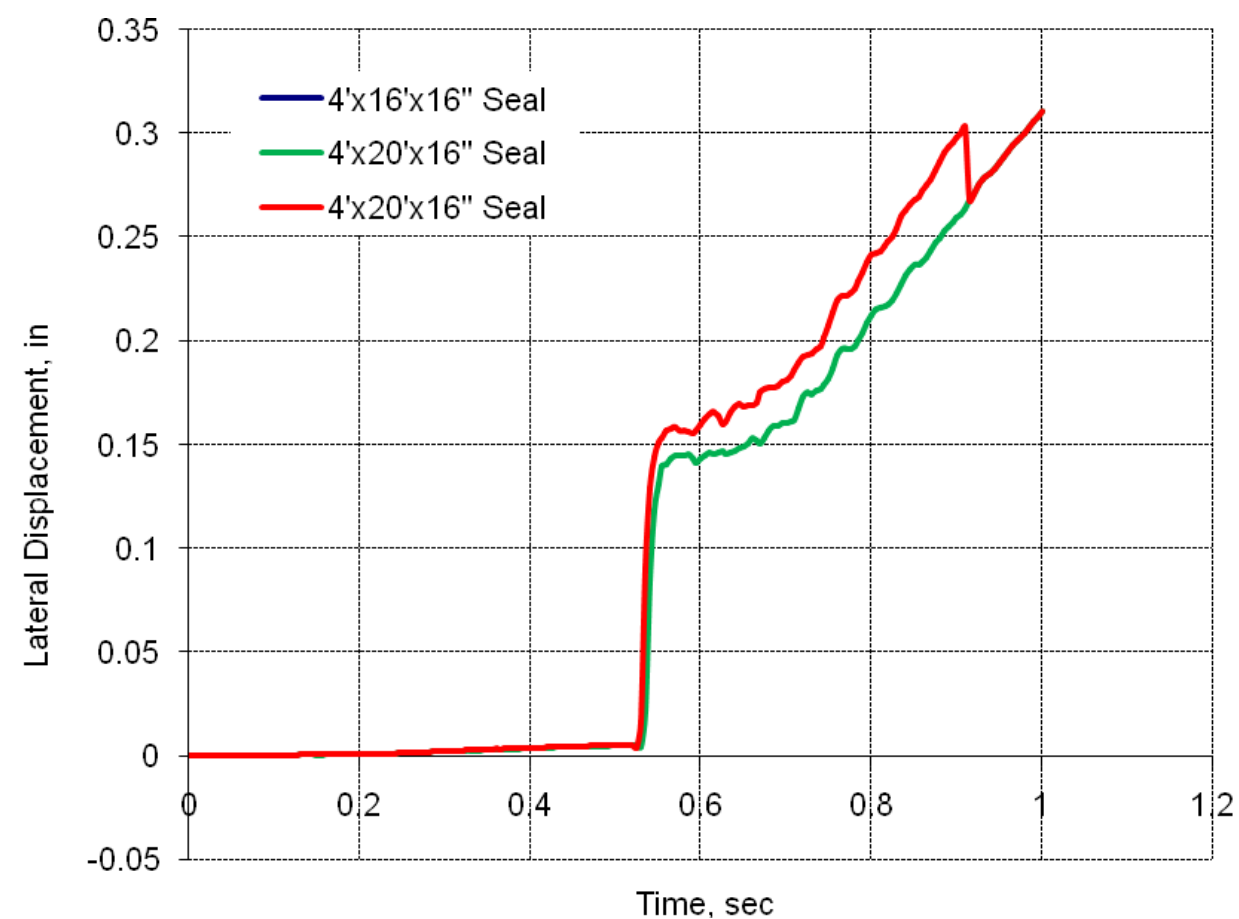

Entry height $4 \mathrm{ft}$, Lateral displacement vs. Time

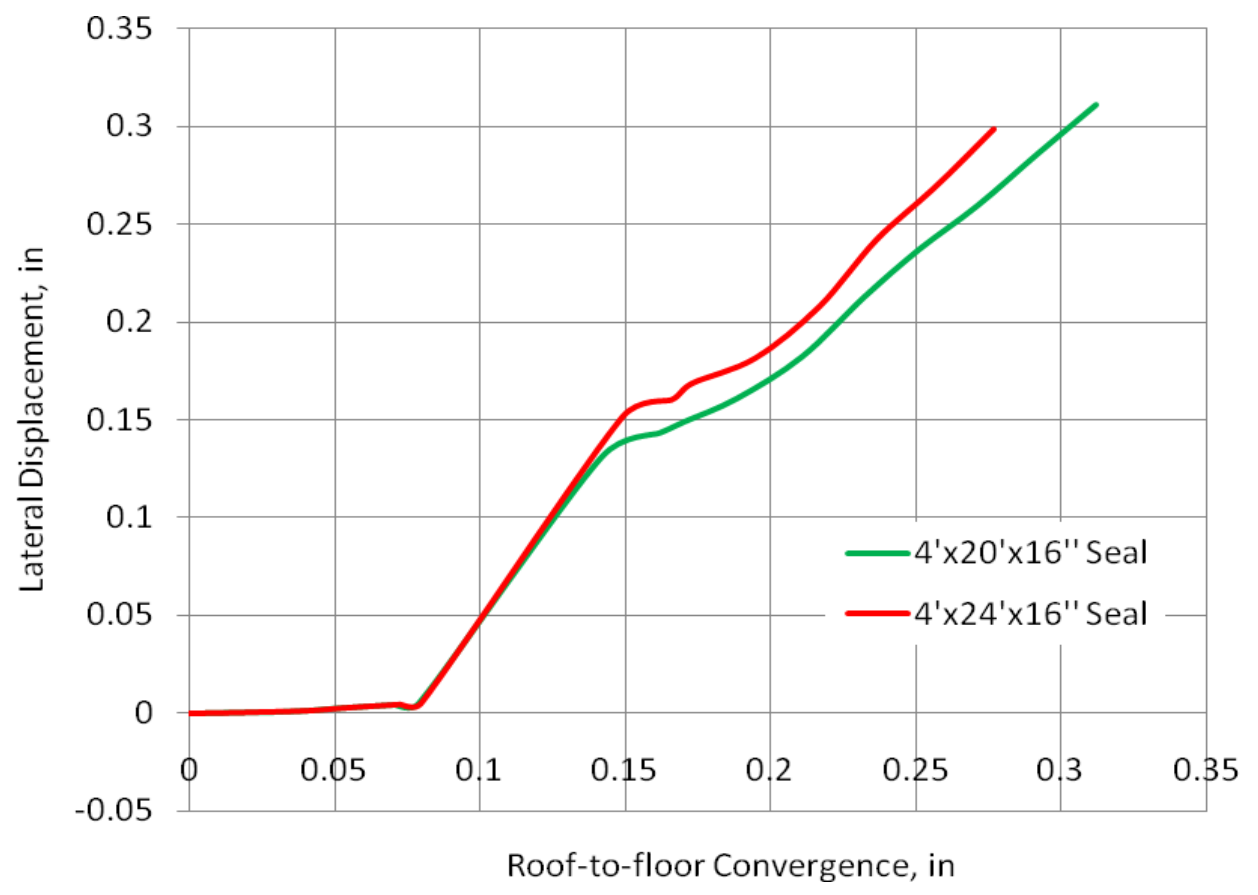

Entry height $4 \mathrm{ft}$, Lateral displacement vs. Convergence 


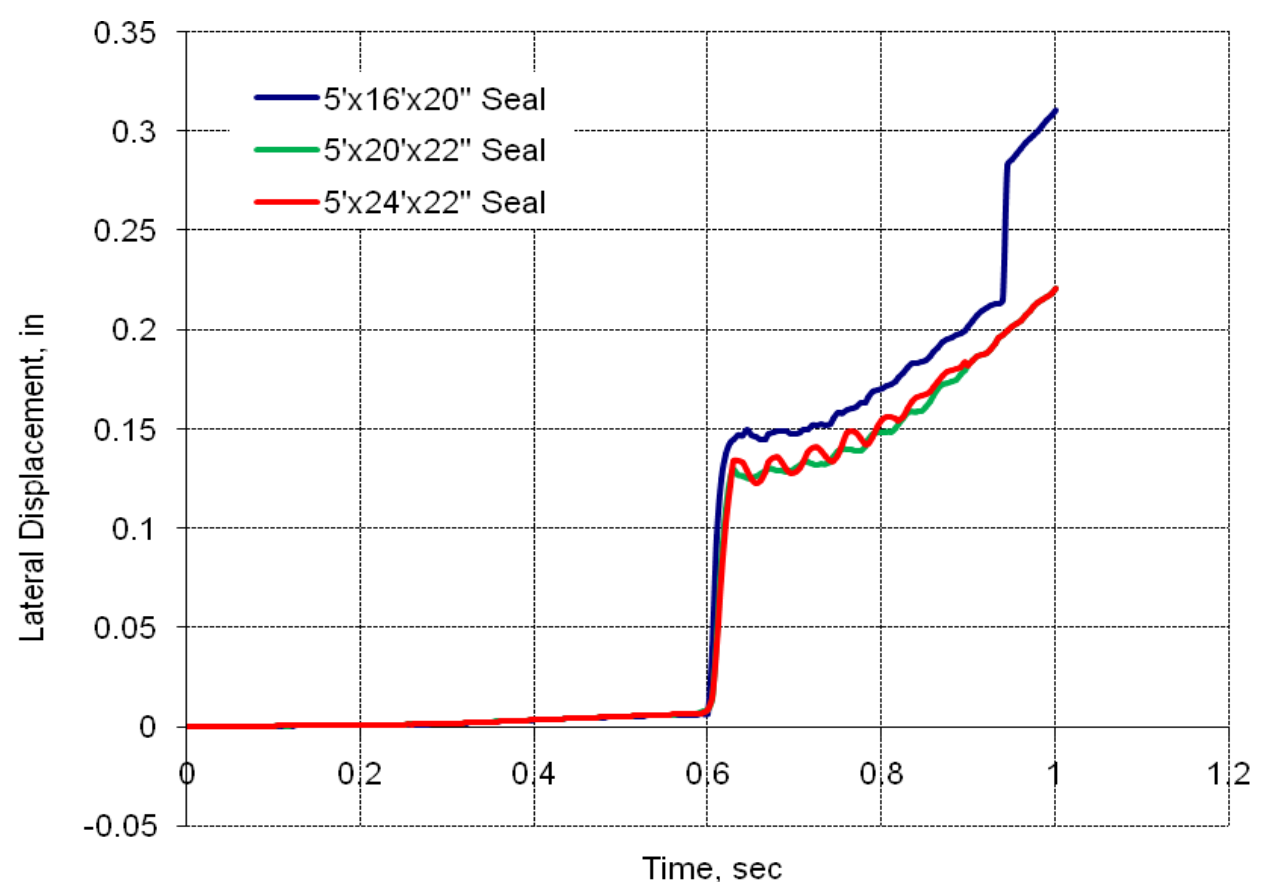

Entry height $5 \mathrm{ft}$, Lateral displacement vs. Time

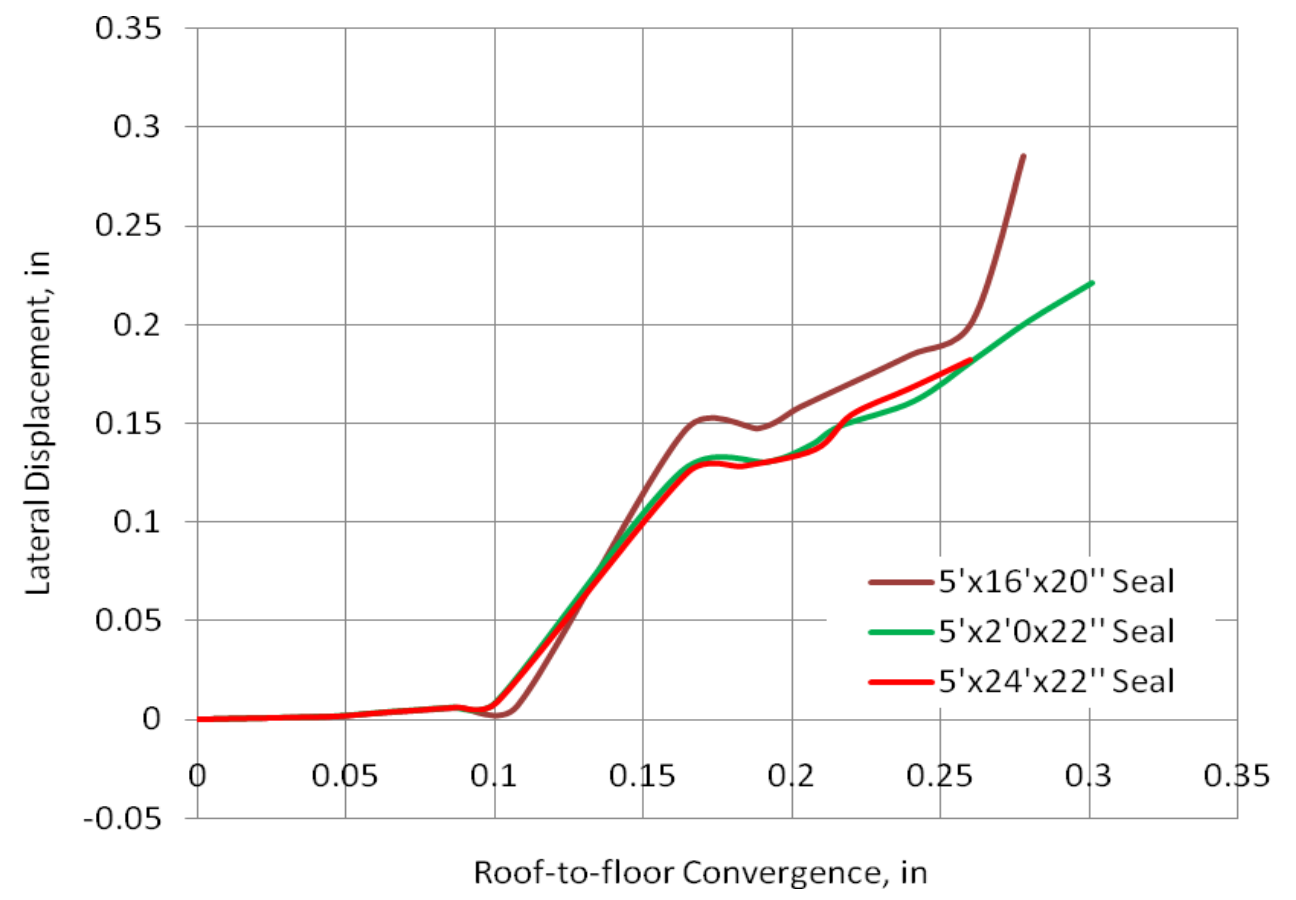

Entry height $5 \mathrm{ft}$, Lateral displacement vs. Convergence 


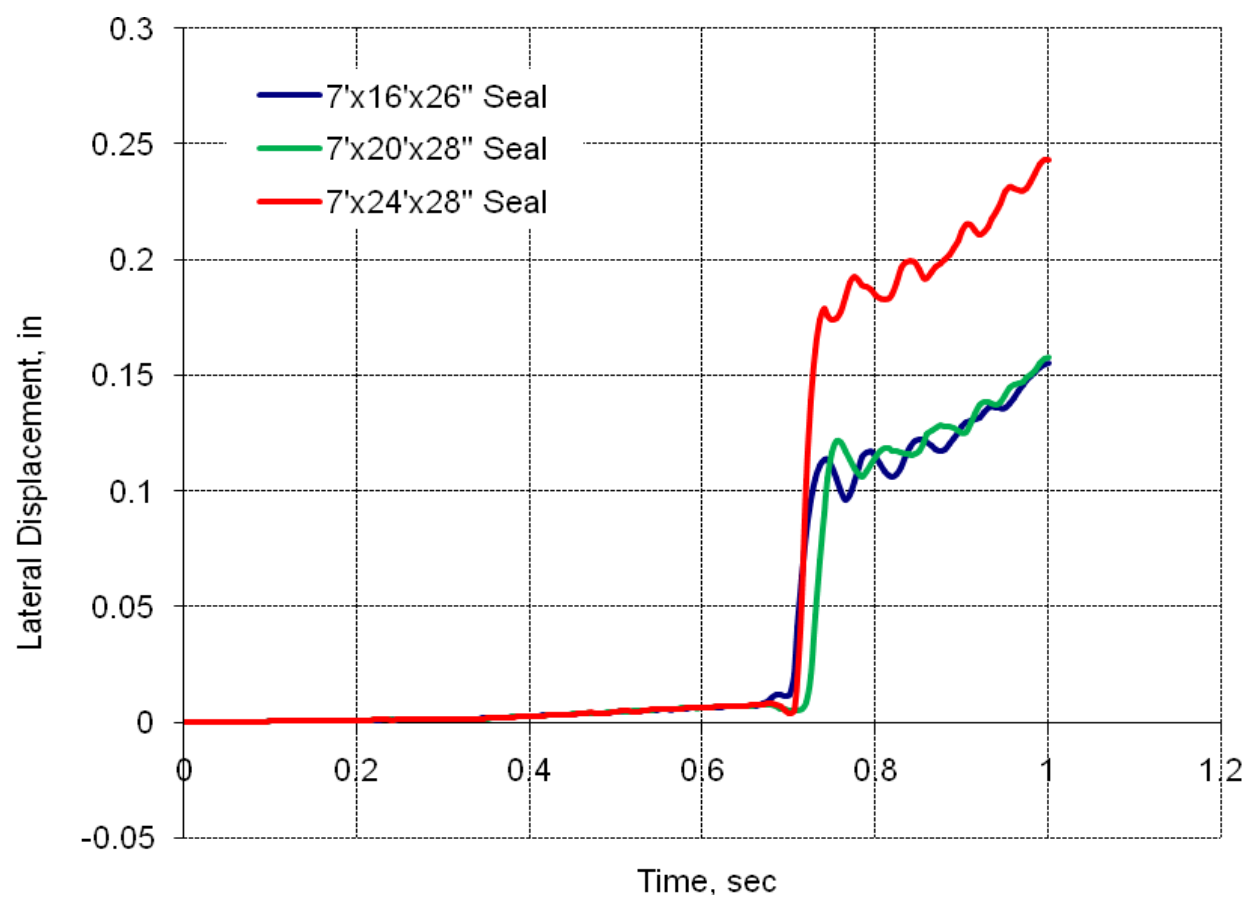

Entry height $7 \mathrm{ft}$, Lateral displacement vs. Time

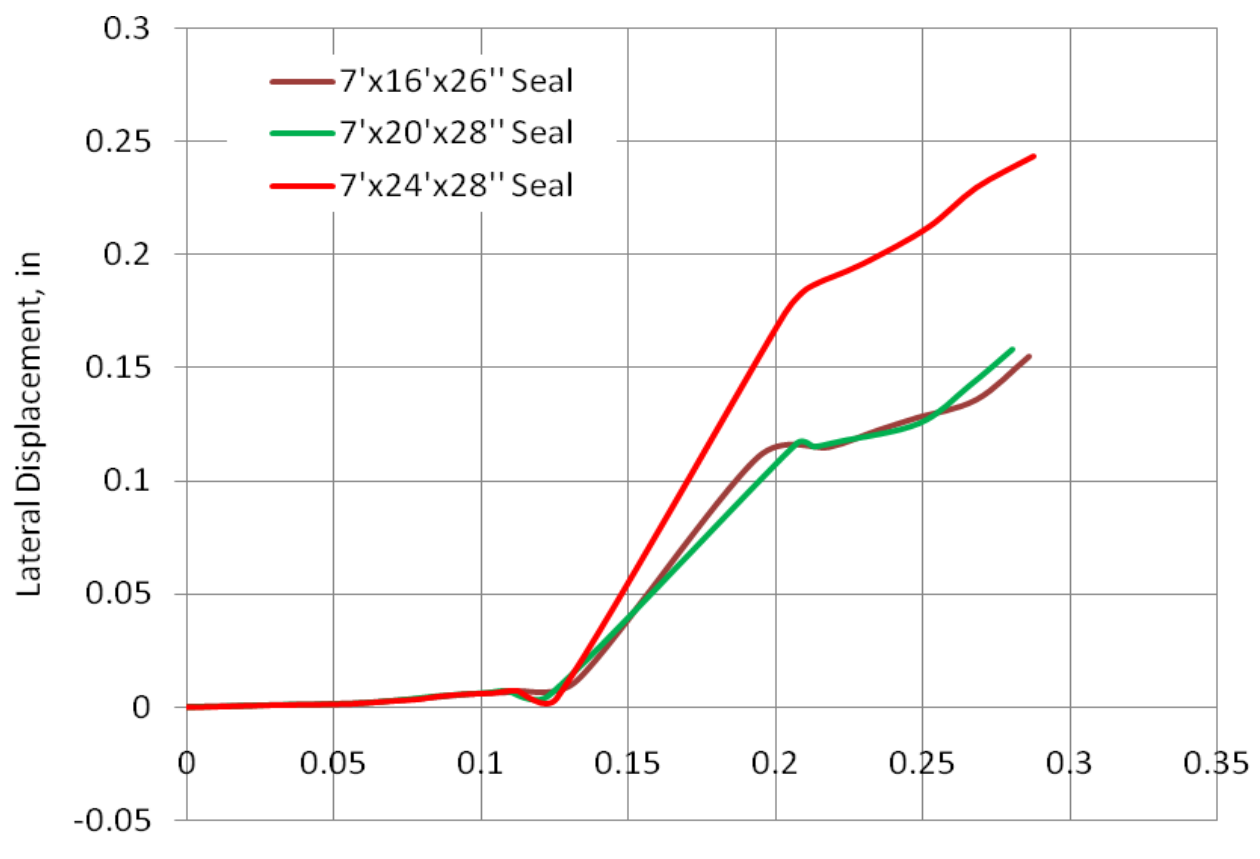

Roof-to-floor Convergence, in

Entry height $7 \mathrm{ft}$, Lateral displacement vs. Convergence 


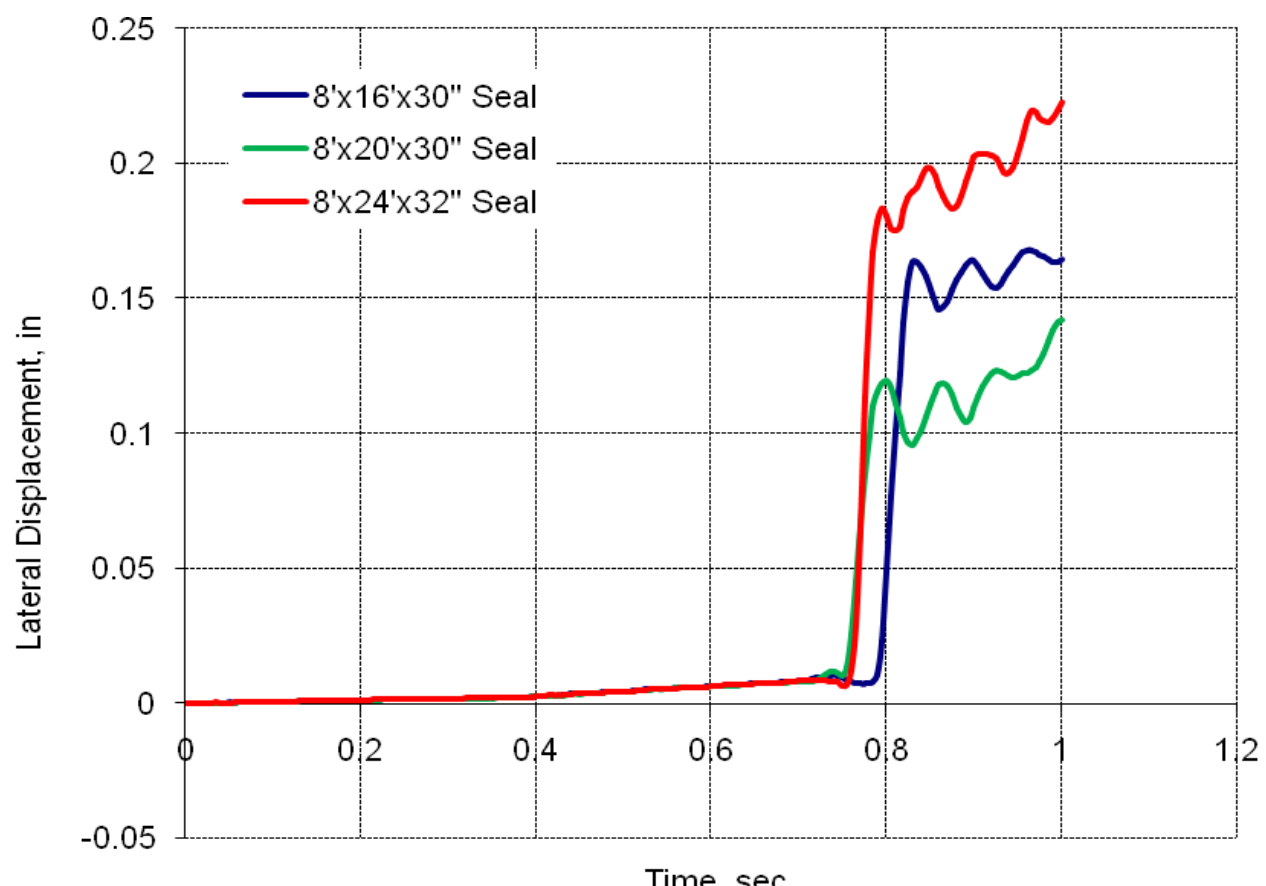

Time, sec

Entry height $8 \mathrm{ft}$, Lateral displacement vs. Time

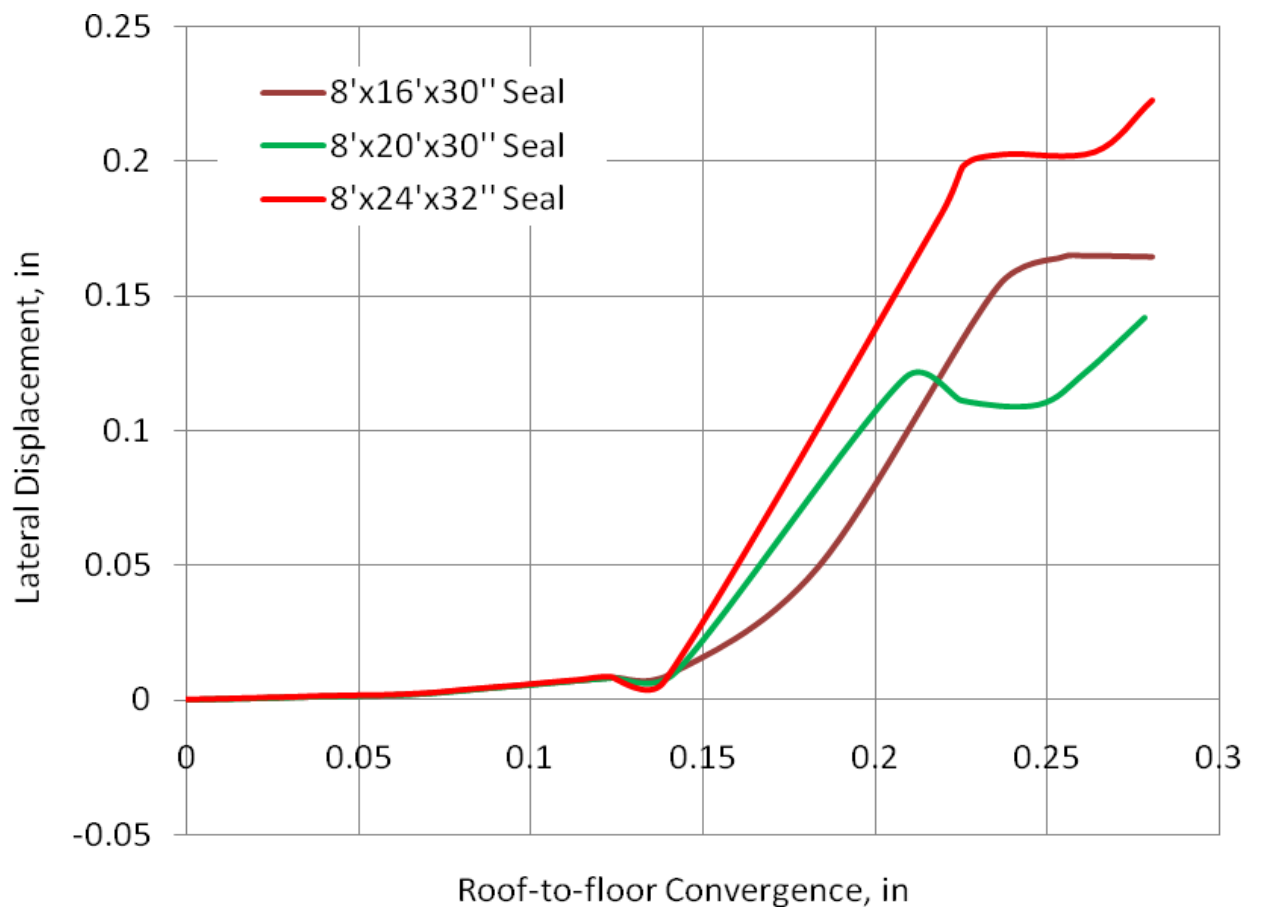

Entry height $8 \mathrm{ft}$, Lateral displacement vs. Convergence 


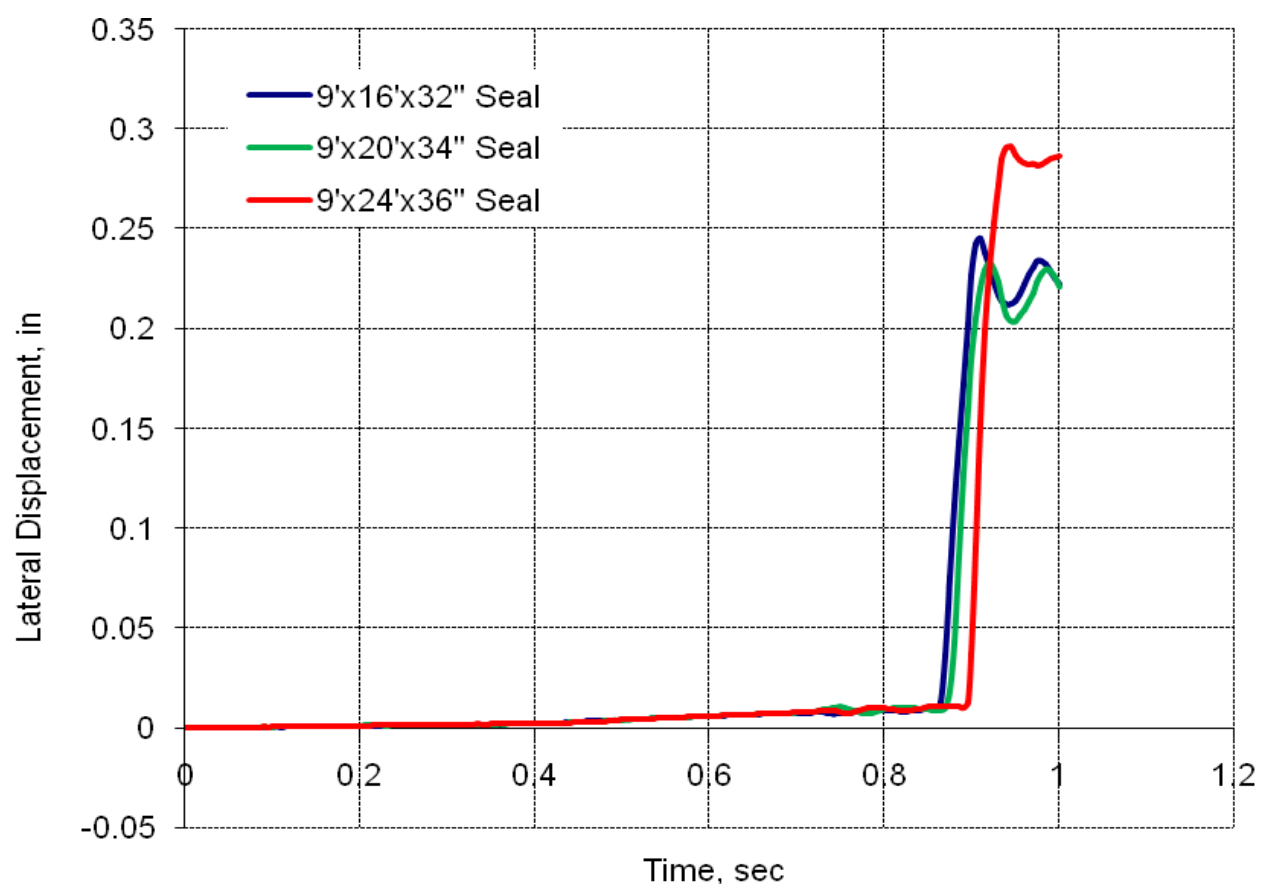

Entry height $9 \mathrm{ft}$, Lateral displacement vs. Time

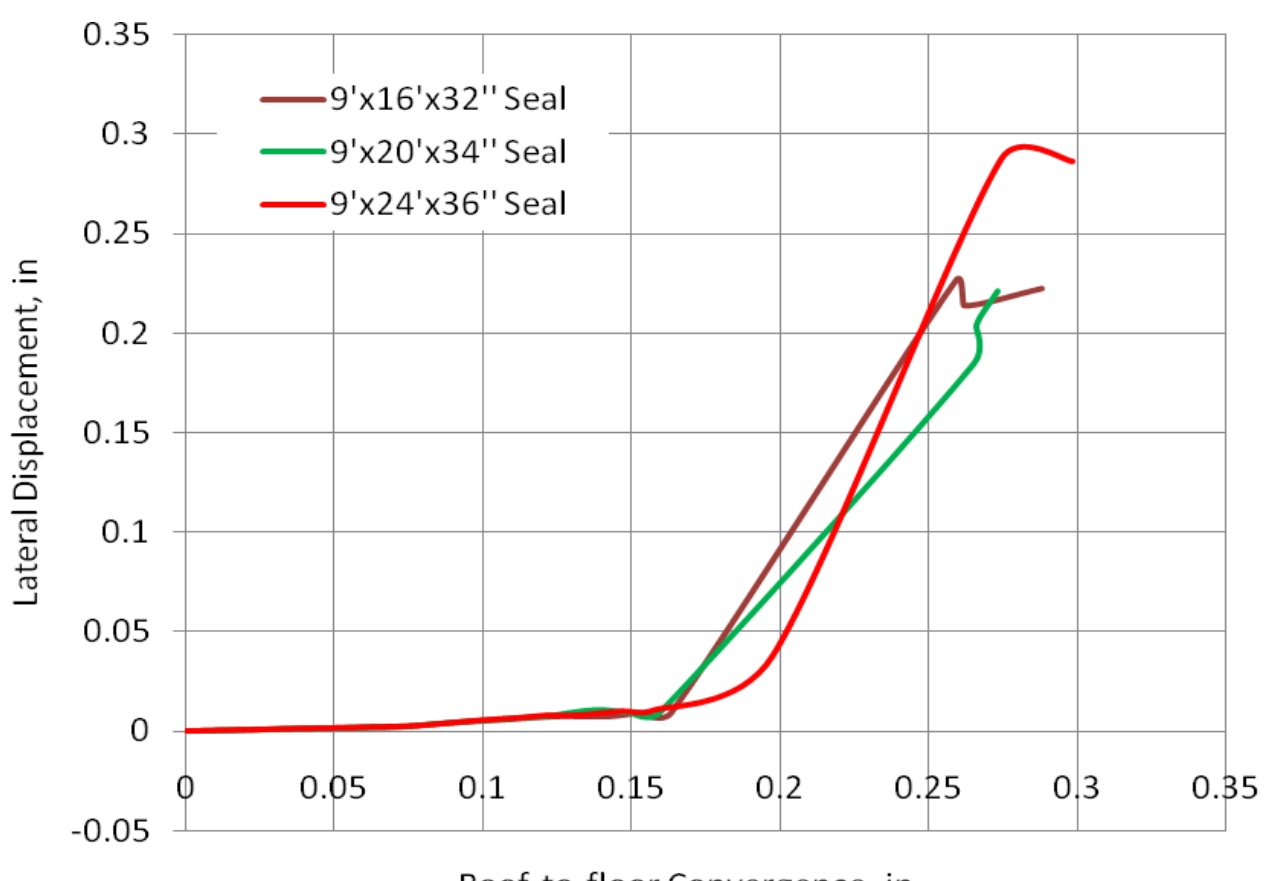

Roof-to-floor Convergence, in

Entry height $9 \mathrm{ft}$, Lateral displacement vs. Convergence 


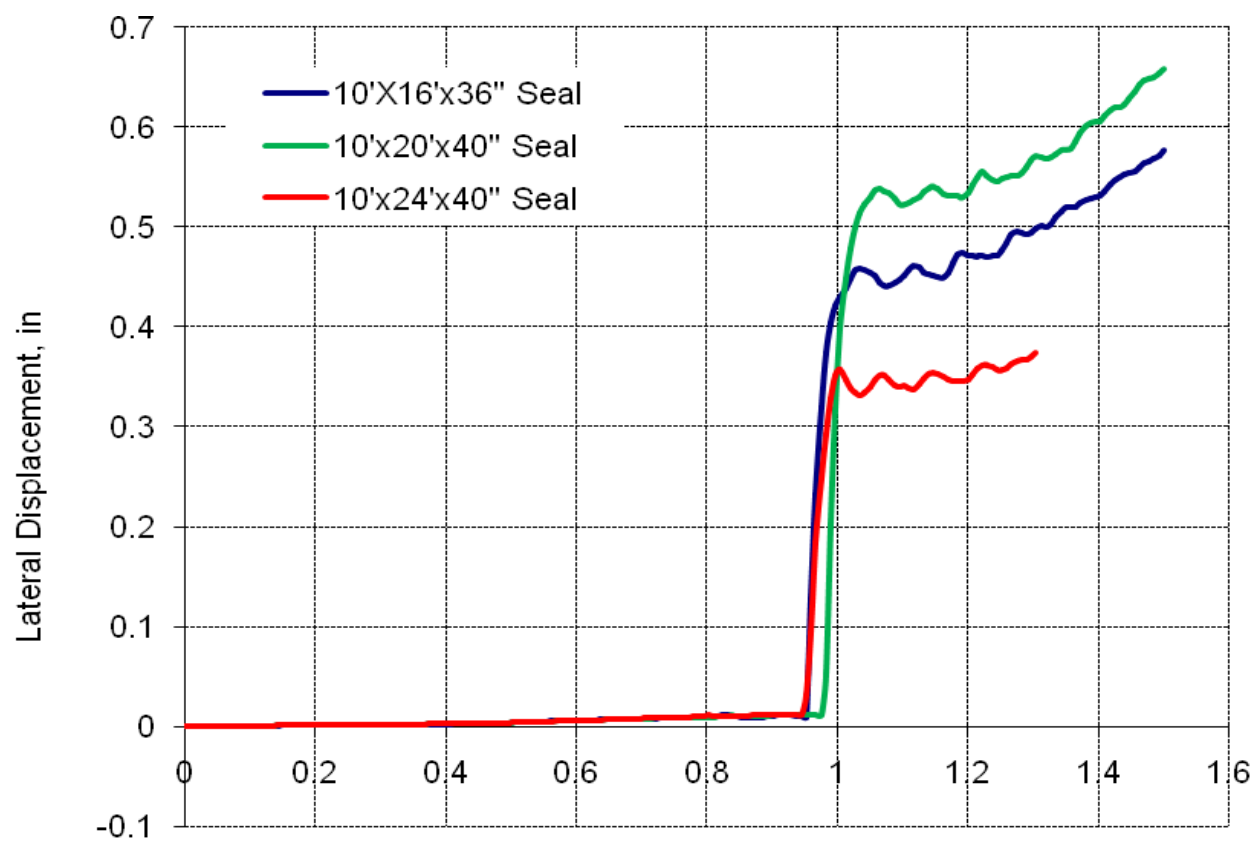

Time, sec

Entry height $10 \mathrm{ft}$, Lateral displacement vs. Time

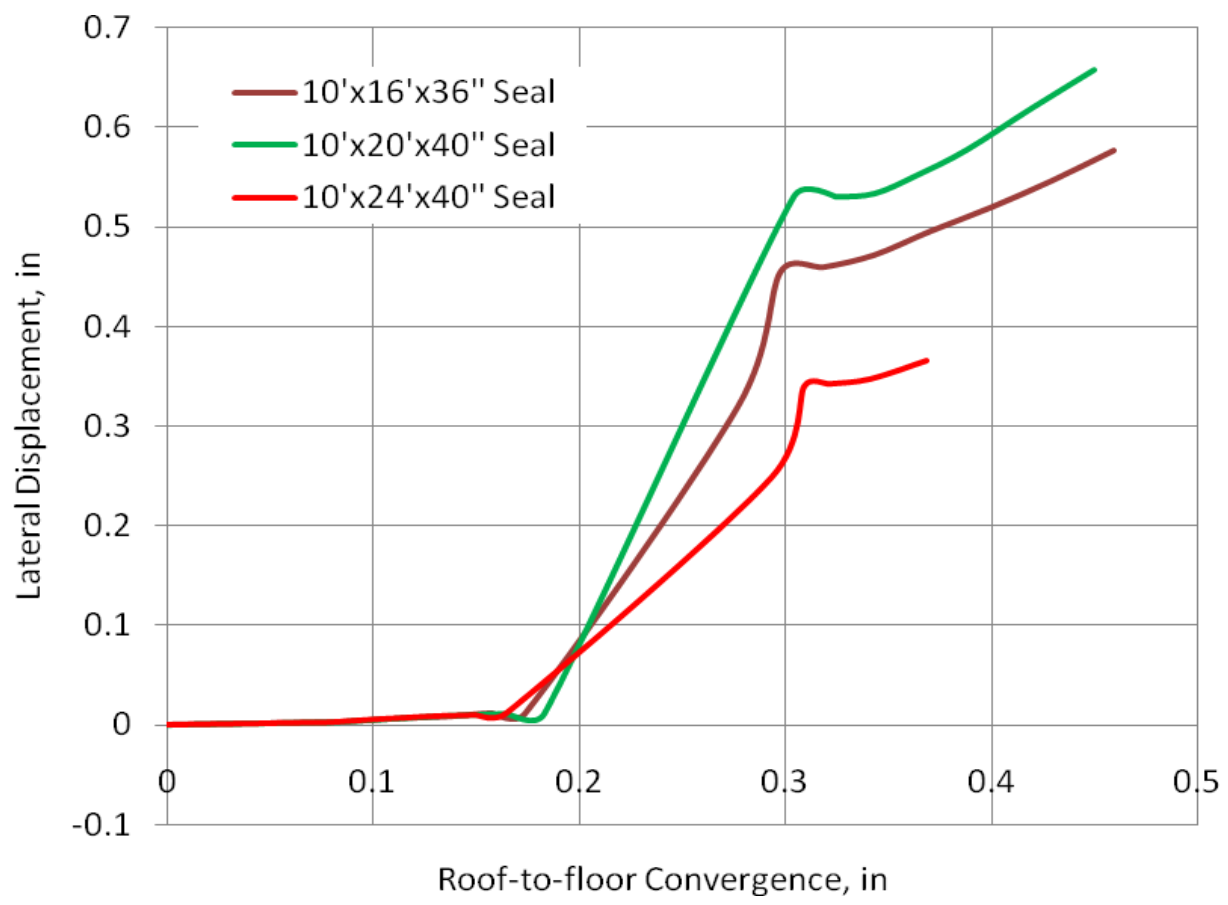

Entry height $10 \mathrm{ft}$, Lateral displacement vs. Convergence 


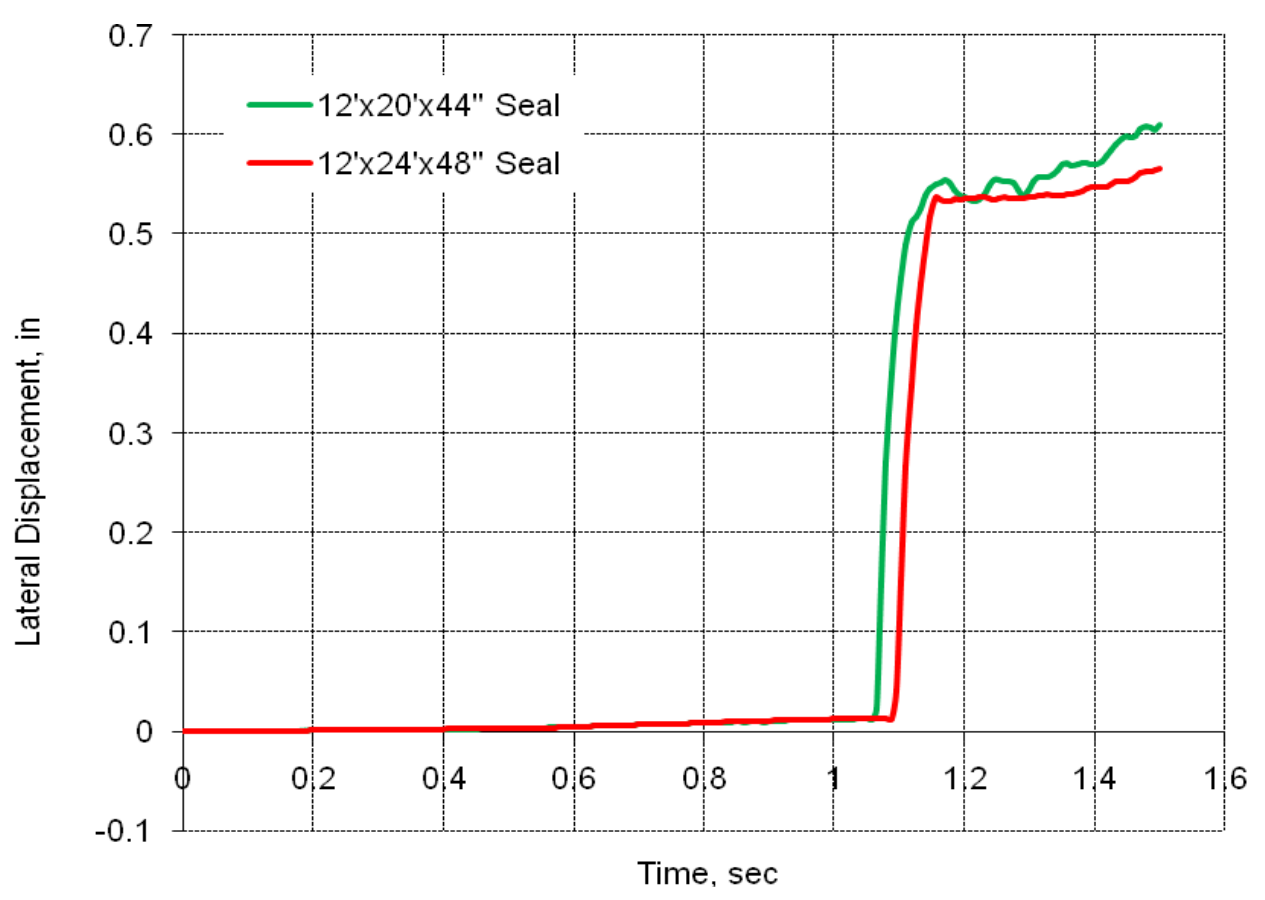

Entry height 12 ft, Lateral displacement vs. Time

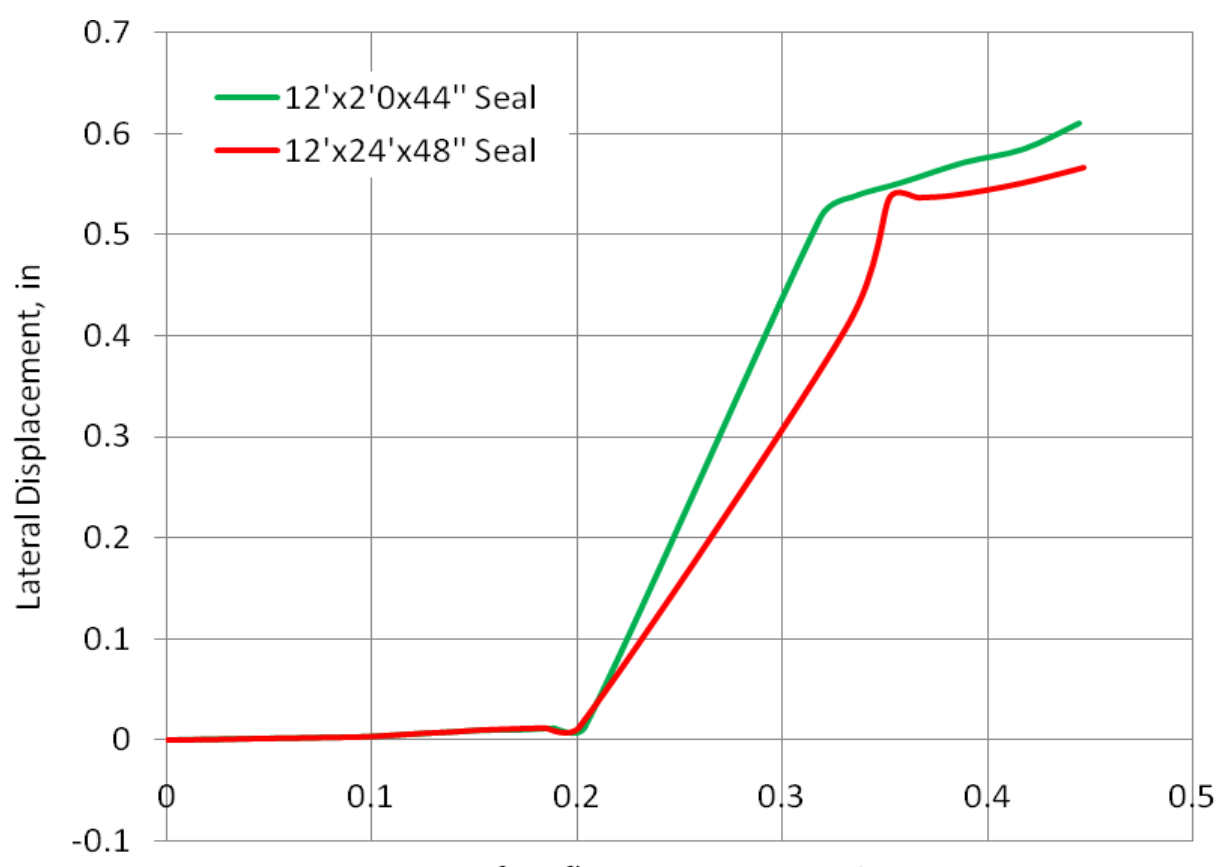

Roof-to-floor Convergence, in

Entry height $12 \mathrm{ft}$, Lateral displacement vs. Convergence 